\title{
Experimental and Computational Studies on Ruthenium- and Manganese-Catalyzed C-H and C-C Activation
}

\author{
Dissertation \\ for the award of the degree \\ "Doctor rerum naturalium" \\ of the Georg-August-University Göttingen

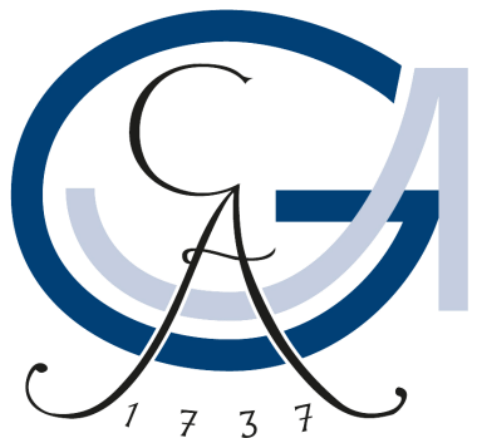

within the doctoral program of chemistry

of the Georg-August-University School of Science (GAUSS)

submitted by

Torben Rogge

from Holzminden

Göttingen, 2019 



\section{Thesis Committee}

Prof. Dr. Lutz Ackermann, Institute of Organic and Biomolecular Chemistry

Prof. Dr. Konrad Koszinowski, Institute of Organic and Biomolecular Chemistry

\section{Members of the Examination Board}

Reviewer: Prof. Dr. Lutz Ackermann, Institute of Organic and Biomolecular Chemistry

Second Reviewer: Prof. Dr. Konrad Koszinowski, Institute of Organic and Biomolecular Chemistry

\section{Further Members of the Examination Board}

Prof. Dr. Manuel Alcarazo, Institute of Organic and Biomolecular Chemistry

Prof. Dr. Ricardo Mata, Institute of Physical Chemistry

Prof. Dr. Dietmar Stalke, Institute of Inorganic Chemistry

Dr. Michael John, Institute of Organic and Biomolecular Chemistry

Date of the Oral Examination: 30.10.2019 



\section{Acknowledgement}

Zuallererst gilt mein großer Dank meinem Doktorvater Professor Dr. Lutz Ackermann für die Möglichkeit die vorliegende Arbeit in seinem Arbeitskreis anzufertigen und für zahllose hilfreiche Ratschläge und Diskussionen. Des Weiteren bin ich sehr dankbar, dass ich unter exzellenten Bedingungen an verschiedensten interessanten Projekten forschen durfte.

Professor Dr. Konrad Koszinowski danke ich für die Übernahme des Zweitgutachtens. Ebenso gilt mein Dank den weiteren Mitgliedern der Prüfungskommision Professor Dr. Manuel Alcarazo, Professor Dr. Ricardo Mata, Professor Dr. Dietmar Stalke und Dr. Michael John.

Bei Dr. Eric Clot möchte ich mich für eine schöne und produktive Zeit während meines Aufenthaltes in Montpellier bedanken.

Besonderer Dank gilt den Mitgliedern unserer DFT-Gruppe, Dr. João Oliveira, Dr. Rositha Kuniyil und Dr. Lianrui $\mathrm{Hu}$, für unzählige Diskussionen und das gemeinsame Lösen von technischen Fragestellungen.

Natürlich danke ich allen aktuellen und ehemaligen Mitgliedern des Arbeitskreises für eine großartige Arbeitsatmosphäre. Herzlicher Dank gilt inbesondere Dr. Marc Moselage für viele Ratschläge, Ideen und diverse Unternehmungen und Dr. Joachim Loup für viel Spaß während zahlreicher Konferenzen und SPP-Meetings. Weiterhin danke ich Ralf Steinbock und Julia Struwe für zahllose interessante Diskussionen und sehr viel gute Laune.

Nicht unerwähnt bleiben sollen Stefan Beußhausen und Karsten Rauch, die mit ihrer technischen Expertise immer zur Verfügung standen und für viele Probleme schnelle Lösungen gefunden haben.

Außerdem danke ich Dr. João Oliveira, Dr. Rositha Kuniyil, Valentin Müller, Julia Struwe, Nikolaos Kaplaneris und Korkit Korvorapun für das schnelle und gründliche Korrekturlesen dieser Arbeit.

Der NMR-Abteilung unter Leitung von Dr. Michael John und der Zentralen Analytik unter der Leitung von Dr. Holm Frauendorf danke ich für die zuverlässige Messung von teilweise schwierigen Proben.

Zuletzt gilt mein großer Dank meiner Familie und meinen Freunden für eine großartige Unterstüzung während des Studiums und der Promotion. 



\section{Contents}

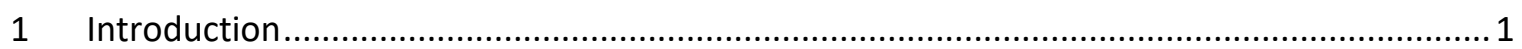

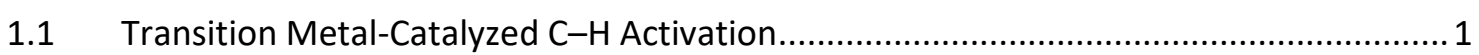

1.2 Ruthenium-Catalyzed ortho-Selective C-H Alkylation ............................................... 5

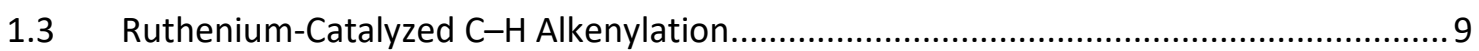

1.4 Direct C-H Arylation under Ruthenium Catalysis.......................................................... 13

1.5 Ruthenium-Catalyzed Decarboxylative C-H Activation ............................................... 18

1.6 meta-Selective C-H Activation under Ruthenium Catalysis ......................................... 20

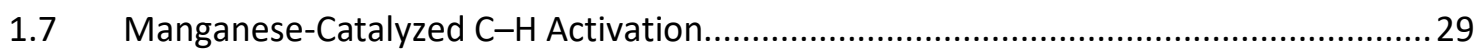

1.8 C-C Activation by Transition Metal Catalysis ................................................................. 31

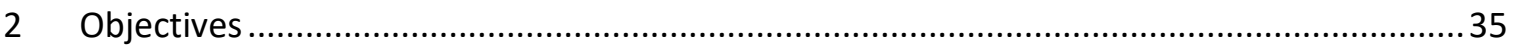

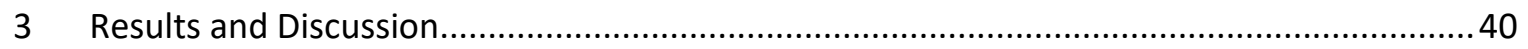

3.1 Ruthenium-Catalyzed meta-Selective C-H Bromination.............................................. 40

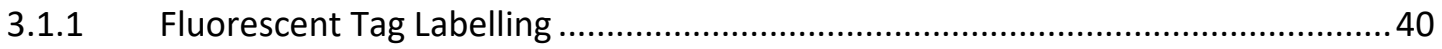

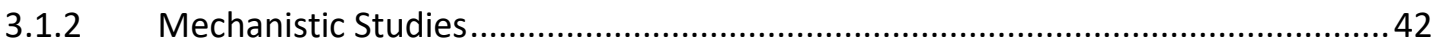

3.2 Ruthenium-Catalyzed meta-C-H Alkylation of Ketimines ............................................. 44

3.2.1 Scope of the meta-Selective C-H Alkylation ...................................................... 45

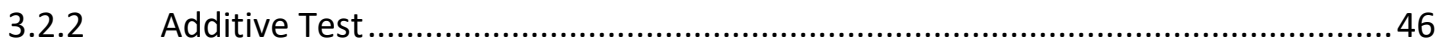

3.2.3 One-pot two-fold C-H Activation .................................................................... 48

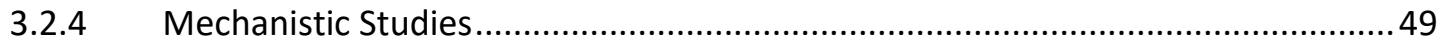

3.3 Ruthenium-Catalyzed meta-C-H Alkylation of Phenylpyridines ................................... 53

3.4 Selectivity Prediction for meta-C-H Functionalization.................................................... 55

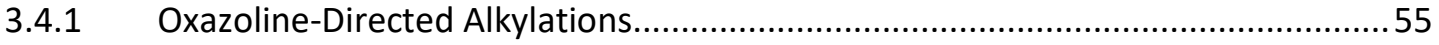

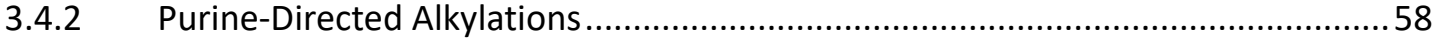

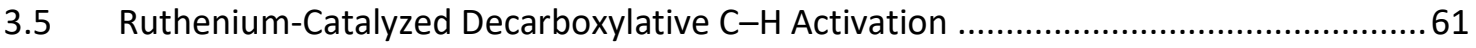

3.5.1 Alkenylations of Benzoic Acids with Alkynes........................................................ 62

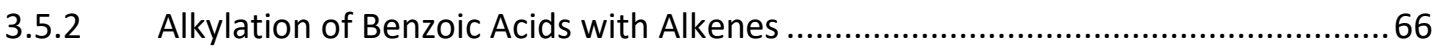

3.6 Ruthenium-Catalyzed C-H Alkenylation of Aryl Acetamides ....................................... 72

3.7 Ruthenium-Catalyzed Thiocarbonyl-Directed Ferrocene C-H Arylation.......................... 79

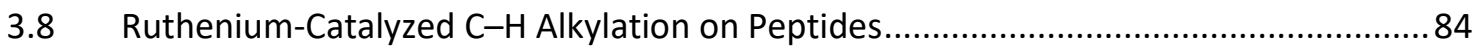

3.9 Ruthenium-Catalyzed Oxidative C-H/C-H Activation ................................................. 90

3.9.1 Studies on Substrate Control and Solvent Evaluation.......................................... 91

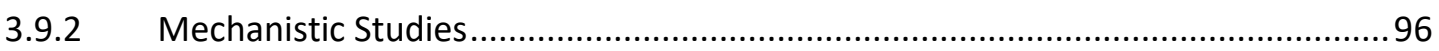

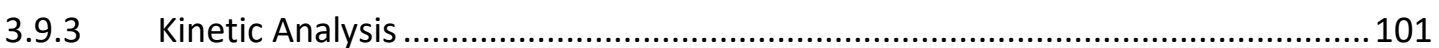


3.9.4 Computational Studies. 105

3.10 Manganese-Catalyzed C-H Allylation on Peptides ..................................................... 110

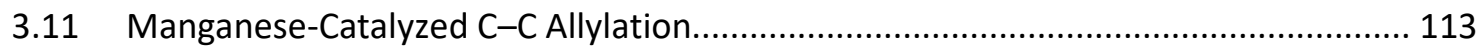

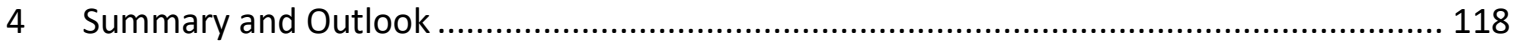

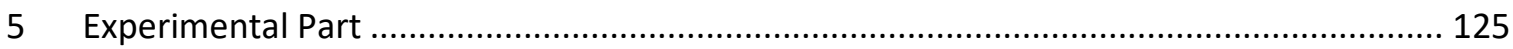

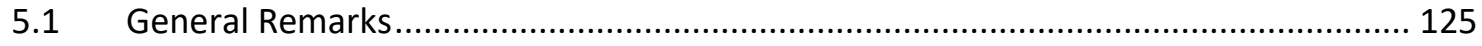

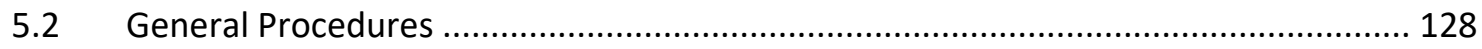

5.2.1 General Procedure A: Ruthenium-Catalyzed meta-Alkylation of Ketimines 151128

5.2.2 General Procedure B: Ruthenium-Catalyzed Oxidative C-H/C-H Activation ...... 129

5.3 Experimental Procedures and Analytical Data........................................................... 129

5.3.1 Ruthenium-Catalyzed meta-Selective C-H Bromination .................................... 129

5.3.1.1 Synthesis of Fluorescent-Labelled Compounds ............................................. 129

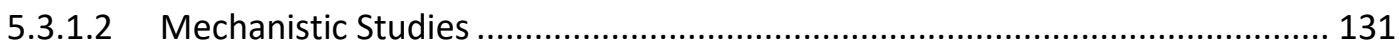

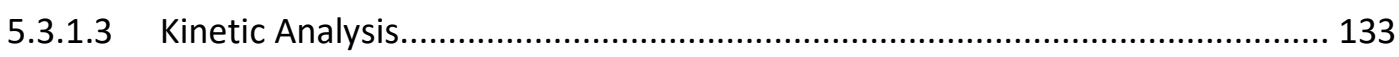

5.3.2 Ruthenium-Catalyzed meta-C-H Alkylation of Ketimines .................................. 134

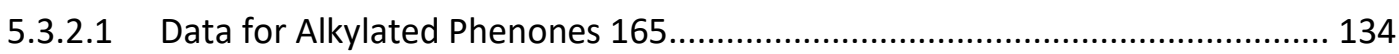

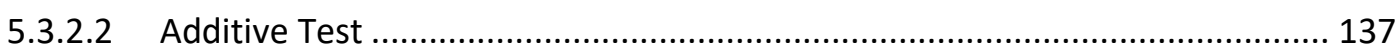

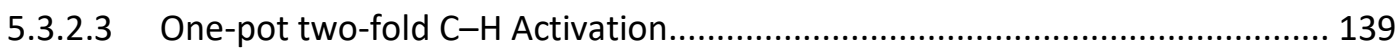

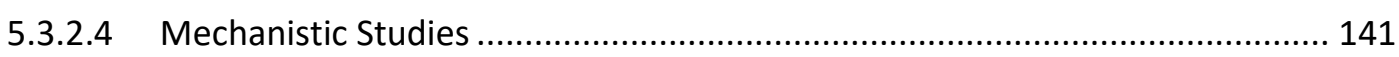

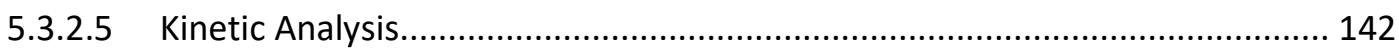

5.3.3 Ruthenium-Catalyzed meta-C-H Alkylation of Phenylpyridines.......................... 144

5.3.4 Ruthenium-Catalyzed Decarboxylative C-H Activation ...................................... 145

5.3.5 Ruthenium-Catalyzed C-H Alkenylation of Aryl Acetamides.............................. 146

5.3.6 Ruthenium-Catalyzed Oxidative C-H/C-H Activation........................................ 147

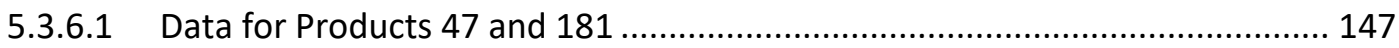

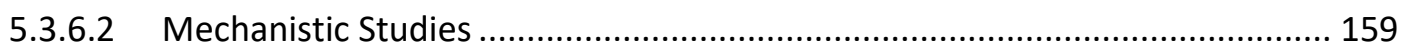

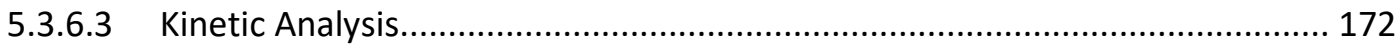

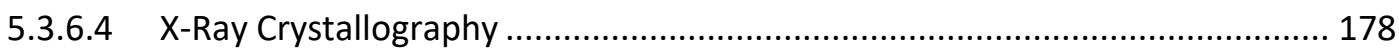

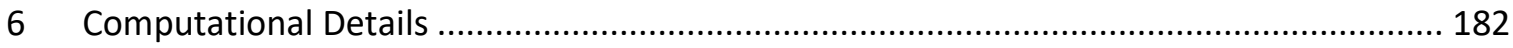

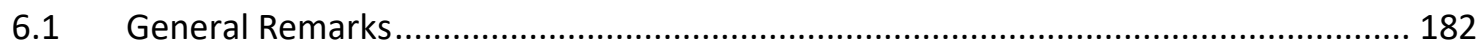

6.2 Selectivity Prediction for meta-C-H Functionalization ............................................. 182

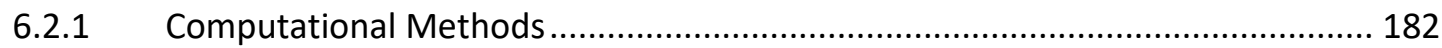

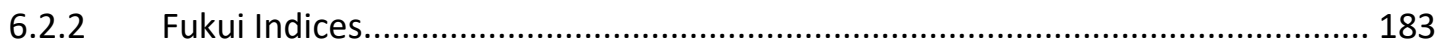

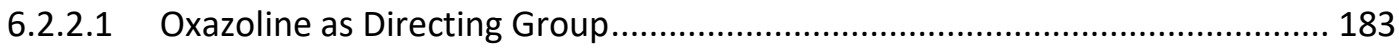

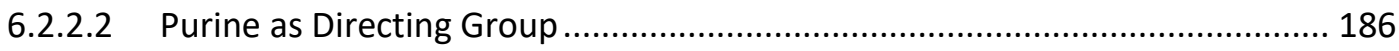

6.3 Ruthenium-Catalyzed Decarboxylative C-H Activation ............................................ 190 


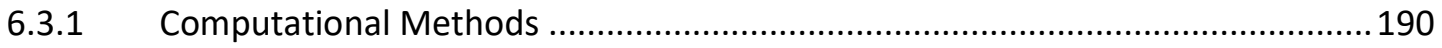

6.3.2 Relative Energies in Various Solvents............................................................ 191

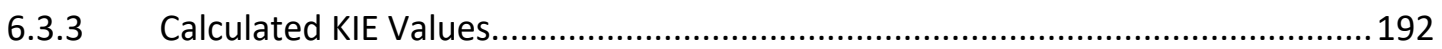

6.3.4 Electronic Energies and Correction Values...................................................... 193

6.4 Ruthenium-Catalyzed C-H Alkenylation of Aryl Acetamides .....................................196

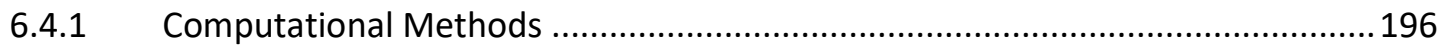

6.4.2 Electronic Energies and Correction Values.......................................................197

6.5 Ruthenium-Catalyzed Thiocarbonyl-Directed Ferrocene C-H Arylation.......................199

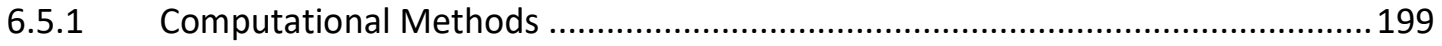

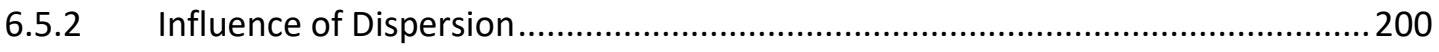

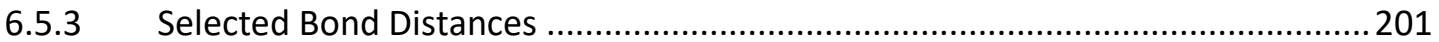

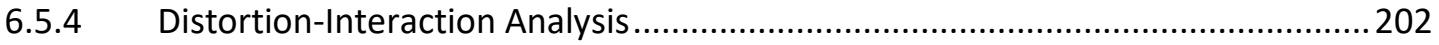

6.5.5 Electronic Energies and Correction Values...........................................................202

6.6 Ruthenium-Catalyzed C-H Alkylation on Peptides....................................................203

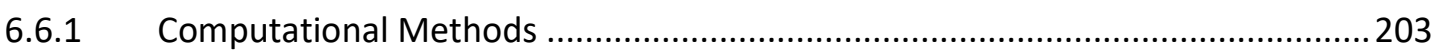

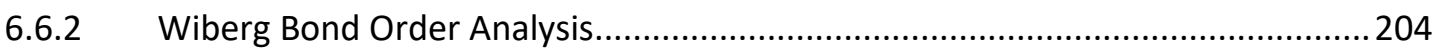

6.6.3 Electronic Energies and Correction Values.........................................................205

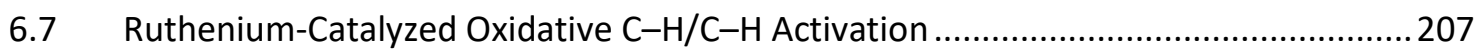

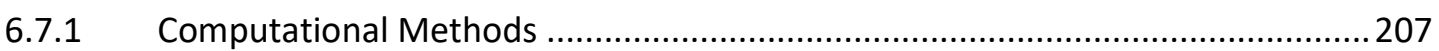

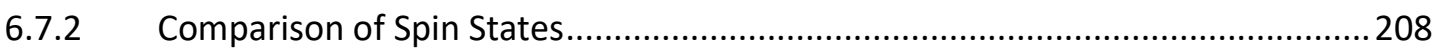

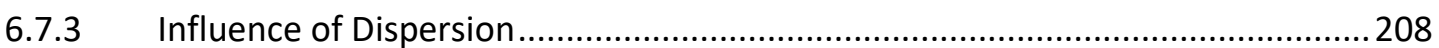

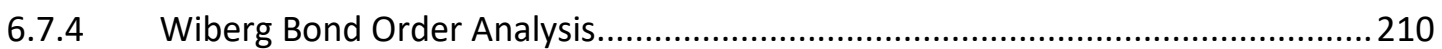

6.7.5 Electronic Energies and Correction Values......................................................210

6.8 Manganese-Catalyzed C-H Allylation on Peptides.....................................................212

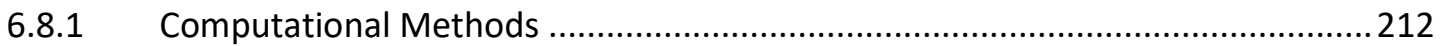

6.8.2 Electronic Energies and Correction Values..........................................................213

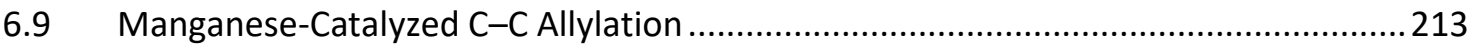

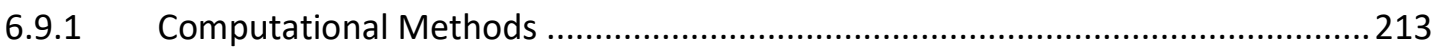

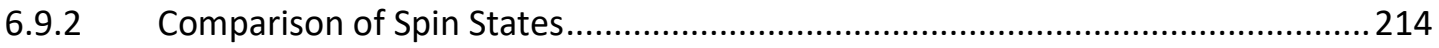

6.9.3 Electronic Energies and Correction Values......................................................215

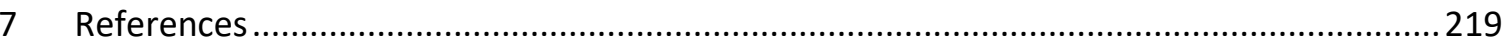

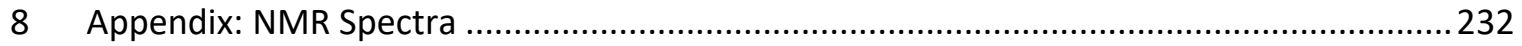




\section{List of Abbreviations}

\begin{tabular}{|c|c|}
\hline Ad & 1-Adamantyl \\
\hline Alk & Alkyl \\
\hline AMLA & Ambiphilic Metal Ligand Activation \\
\hline $\operatorname{Ar}$ & Aryl \\
\hline atm. & Atmosphere \\
\hline BIES & Base-assisted Internal Electrophilic Substitution \\
\hline BINAP & 2,2'-Bis(diphenylphosphino)-1,1'-binaphthyl \\
\hline $\mathrm{Bn}$ & Benzyl \\
\hline Boc & tert-Butyloxycarbonyl \\
\hline $\mathrm{Bu}$ & Butyl \\
\hline cat. & Catalytic \\
\hline Cat. & Catalyst \\
\hline CMD & Concerted Metalation-Deprotonation \\
\hline cod & Cyclooctadiene \\
\hline COSMO & Conductor-like Screening Model \\
\hline $\mathrm{Cp}$ & Cyclopentadienyl \\
\hline $\mathrm{Cp} *$ & Pentamethylcyclopentadienyl \\
\hline DCE & 1,2-Dichloroethane \\
\hline decomp. & Decomposition \\
\hline DFT & Density Functional Theory \\
\hline DG & Directing Group \\
\hline DMA & $N, N$-Dimethylacetamide \\
\hline DME & 1,2-Dimethoxyethane \\
\hline DMF & $\mathrm{N}, \mathrm{N}$-Dimethylformamide \\
\hline DMSO & Dimethylsulfoxide \\
\hline $\mathrm{El}$ & Electron-Ionization \\
\hline EPR & Electron Paramagnetic Resonance \\
\hline ESI & Electrospray-Ionization \\
\hline Et & Ethyl \\
\hline
\end{tabular}




\begin{tabular}{|c|c|}
\hline EWG & Electron-withdrawing Group \\
\hline FG & Functional Group \\
\hline GC & Gas Chromatography \\
\hline GGA & Generalized Gradient Approximation \\
\hline GPC & Gel Permeation Chromatography \\
\hline GVL & -Valerolactone \\
\hline Hept & Heptyl \\
\hline Het & Heteroatom \\
\hline Hex & Hexyl \\
\hline HPLC & High Performance Liquid Chromatography \\
\hline HRMS & High Resolution Mass Spectrometry \\
\hline IEFPCM & Integral Equation Formalism Polarizable Continuum Model \\
\hline IR & Infrared \\
\hline IRC & Intrinsic Reaction Coordinate \\
\hline KIE & Kinetic Isotope Effect \\
\hline $\mathrm{L}$ & Ligand \\
\hline LG & Leaving Group \\
\hline M & Metal \\
\hline m.p. & Melting Point \\
\hline $\mathrm{MBH}$ & Morita-Baylis-Hillman \\
\hline Me & Methyl \\
\hline Mes & Mesityl \\
\hline MS & Mass Spectrometry \\
\hline NAO & Natural Atomic Orbital \\
\hline NBO & Natural Bond Orbital \\
\hline NBS & $N$-Bromosuccinimide \\
\hline $\mathrm{NHC}$ & $\mathrm{N}$-Heterocyclic Carbene \\
\hline NMP & N-Methyl-2-pyrrolidone \\
\hline NMR & Nuclear Magnetic Resonance \\
\hline norm. & Normalized \\
\hline
\end{tabular}


Oct

PCM

$\mathrm{Ph}$

Piv

PMP

$\operatorname{Pr}$

py

pym

$\mathrm{R}$

SCF

SET

SMD

$t-\mathrm{Am}$

TEMPO

Tf

TFE

THF

TLC

TM

TMP

$\mathrm{Tp}$

TPGS

$x$
Octyl

Polarizable Continuum Model

Phenyl

Pivaloyl

4-Methoxyphenyl

Propyl

Pyridyl

Pyrimidyl

Rest

Self-consistent Field

Single-Electron Transfer

Solvent Model Based on Solute Electron Density

tert-Amyl (2-Methylbut-2-yl)

(2,2,6,6-Tetramethylpiperidin-1-yl)oxyl

Triflyl

2,2,2-Trifluoroethanol

Tetrahydrofuran

Thin-Layer Chromatography

Transition Metal

3,4,5-Trimethoxyphenyl

Trispyrazolylborate

DL- $\alpha$-Tocopherol methoxypolyethylene glycol succinate

(Pseudo-)halide 


\section{Introduction}

In consideration of a decreasing availability of non-renewable resources along with a heightened awareness for environmental aspects, the development of sustainable synthetic methods is currently a major goal of chemists. Therefore, novel, safer and environmentally-benign procedures for the synthesis of compounds with applications in pharmaceutical and agrochemistry, functional materials, and a plethora of other areas continue to be of great interest. Catalysis represents one important technique for the minimization of the environmental footprint as was already recognized by Anastas and Warner in their 12 Principles of Green Chemistry. ${ }^{[1]}$ Furthermore, the application of catalytic instead of stoichiometric transformations inherently reduces the amount of waste, which was declared as another principle.

Catalysis does not only offer advantages in terms of ecological aspects, but also economic benefits can be gained. Indeed, employing selective catalytic transformations usually allows for robust and broadly applicable syntheses of compounds of interest, such as drugs and functional materials, along with a minimized formation of side-products under mild reaction conditions, thereby resulting in a cost-effective synthetic strategy.

\subsection{Transition Metal-Catalyzed C-H Activation}

The development of novel strategies for the selective and efficient construction of $\mathrm{C}-\mathrm{C}$ and $\mathrm{C}-\mathrm{Het}$ bonds continues to be in high demand. Especially the functionalization of arenes is of key importance in organic synthesis, due to the ubiquitous occurrence of decorated arenes in natural products and bioactive molecules, among others. ${ }^{[2]}$

Although classical methods for the synthesis of substituted arene moieties are well-known for many years, these methods often suffer from significant drawbacks, including harsh reaction conditions and the necessity for stoichiometric reagents. A major breakthrough was achieved in the 1970s and 1980s with the development of palladium-catalyzed cross-coupling reactions. Kumada-Corriu ${ }^{[3]}$ Negishi, ${ }^{[4]}$ Stille, ${ }^{[5]}$ Suzuki-Miyaura, ${ }^{[6]}$ and Hiyama ${ }^{[7]}$ cross-coupling reactions provide access to arylated, alkylated and alkenylated compounds, while alkenyl- and alkynylsubstituents can be introduced via Mizoroki-Heck, ${ }^{[8]}$ and Sonogashira-Hagihara ${ }^{[9]}$ reactions, respectively. Since these reactions have undoubtedly vastly expanded the toolbox of organic synthesis and found numerous applications in academia as well as in industry, ${ }^{[10]}$ the contributions 
of R. F. Heck, E.-i. Negishi, and A. Suzuki were recognized with the Nobel Prize in Chemistry in 2010. ${ }^{[11]}$

Despite these undisputable advances, cross-coupling reactions still poses a number of significant drawbacks. Generally, these transformations do not only require the use of organic (pseudo-)halides as starting materials, but also rely on highly reactive, toxic and difficult to handle organometallic compounds, e.g. $\mathrm{RMgX}, \mathrm{RZnX}$ or $\mathrm{RSi}(\mathrm{Alk})_{3}$, as nucleophiles. In addition, the synthesis of organometallic reagents usually involves tedious multi-step procedures (Scheme 1). Furthermore, stoichiometric amounts of environmentally problematic metal-waste are generated in the cross-coupling process. In contrast, the selective functionalization of $\mathrm{C}-\mathrm{H}$ bonds under transition metal catalysis has gained enormous momentum over the last decades as an efficient and sustainable alternative. ${ }^{[12]}$ In case of direct $\mathrm{C}-\mathrm{H}$ functionalization, the organometallic reagent is replaced by a simple $\mathrm{C}-\mathrm{H}$ bond, which reacts with an organic (pseudo-)halide, thereby avoiding the need for prefunctionalization and greatly improving the step- and atom-economy ${ }^{[13]}$ of this process. Additionally, the formation of $\mathrm{C}-\mathrm{C}$ bonds can be realized by the activation of two $\mathrm{C}-\mathrm{H}$ bonds within a dehydrogenative transformation. Although formally $\mathrm{H}_{2}$ is generated as the sole byproduct, the oxidative nature of the $\mathrm{C}-\mathrm{H} / \mathrm{C}-\mathrm{H}$ activation manifold requires the use of an oxidant in stoichiometric amounts.

(a) cross-coupling

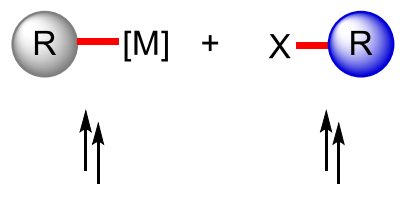

(b) direct $\mathrm{C}-\mathrm{H}$ functionalization

(c) oxidative $\mathrm{C}-\mathrm{H} / \mathrm{C}-\mathrm{H}$ activation

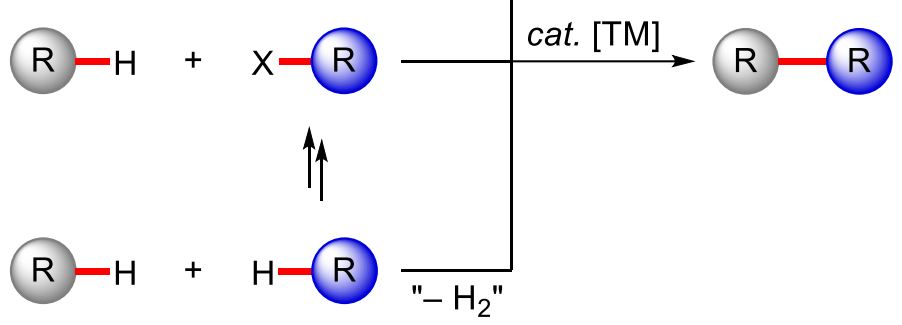

Scheme 1: Comparison of classical cross-coupling reactions with direct $\mathrm{C}-\mathrm{H}$ functionalization and oxidative $\mathrm{C}-\mathrm{H} / \mathrm{C}-\mathrm{H}$ activation.

Excluding outer-sphere/radical-type mechanisms, ${ }^{[14]}$ the key $\mathrm{C}-\mathrm{H}$ bond activation step of these transformations can occur through five distinct mechanistic pathways, which are governed by the electronic properties and the coordination environment of the metal center. ${ }^{[15]}$ 
(a) oxidative addition

$\mathrm{L}_{n} \mathrm{M}+\mathrm{R}-\mathrm{H} \rightleftharpoons \mathrm{L}_{n} \mathrm{M} \underset{\mathrm{R}}{\stackrel{\mathrm{H}}{-1}} \longrightarrow\left[\mathrm{L}_{n} \mathrm{M}^{-} \begin{array}{c}-\mathrm{H}_{1} \\ \frac{1}{\mathrm{R}}\end{array}\right]^{\ddagger} \longrightarrow \mathrm{L}_{n} \mathrm{M}_{\mathrm{R}}^{-\mathrm{H}^{\prime}}$

(b) $\sigma$-bond metathesis

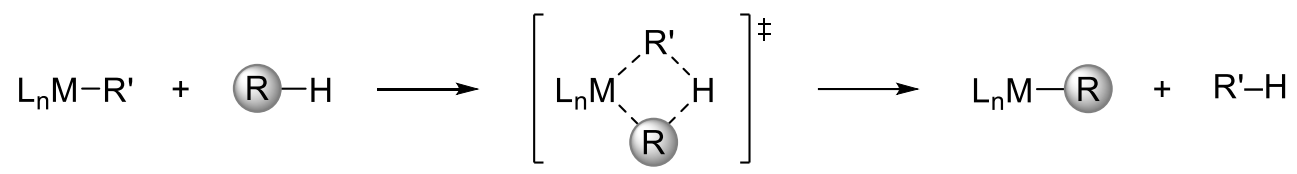

(c) 1,2-addition

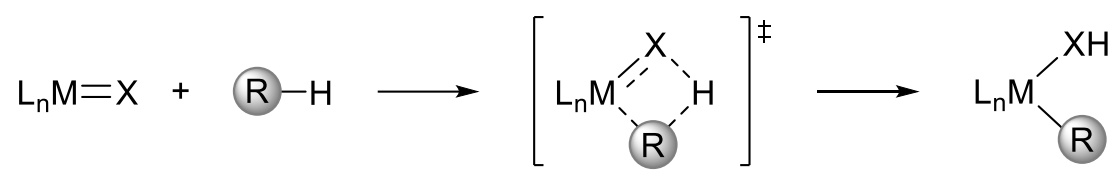

(d) electrophilic substitution

$\mathrm{L}_{n} \stackrel{\oplus}{M}-\mathrm{X}+\mathrm{R}-\mathrm{H} \longrightarrow \mathrm{L}_{\mathrm{n}} \mathrm{M}_{\mathrm{R}_{\oplus}^{\prime}}^{\mathrm{X}} \longrightarrow \stackrel{\oplus}{\longrightarrow} \longrightarrow \mathrm{L}_{n} \mathrm{M}-\mathrm{R}+\mathrm{X}-\mathrm{H}$

(e) base-assisted metalation<smiles>[R1]OC([R])=O</smiles>

Scheme 2: Mechanistic pathways for $\mathrm{C}-\mathrm{H}$ activation.

The oxidative addition of a $\mathrm{C}-\mathrm{H}$ bond to a metal-complex is usually observed for electron-rich, coordinatively unsaturated late transition metals. The corresponding transition state is often preceded by the formation of a $\sigma$-complex, which is stabilized by an agostic interaction of the $\mathrm{C}-\mathrm{H}$ bond with the metal center (Scheme 2a). $\sigma$-Bond metathesis involves the concerted cleavage of two $\sigma$-bonds and formation of two new $\sigma$-bonds without any change in oxidation state of the metal center and is the prevalent pathway for early transition metals, especially in a $d^{0}$ configuration, as well as lanthanides and actinides (Scheme 2b). With complexes bearing a metalligand multiple bond, e.g. alkylidene or imido ligands, or a formally anionic ligand with significant $\pi$-donation $\mathrm{C}-\mathrm{H}$ activation can occur via 1,2-addition of the $\mathrm{C}-\mathrm{H}$ bond onto the $\mathrm{M}=\mathrm{X}$ bond. This formal $[2 \pi+2 \sigma]$ process is mostly observed for early transition metals (Scheme $2 \mathrm{c}$ ). For late transition metals or post-transition metals, typically in higher oxidation states, $\mathrm{C}-\mathrm{H}$ activation can 
proceed via electrophilic substitution. Within this mechanistic pathway, electrophilic attack of the metal center on the carbon atom takes place, resulting in the substitution of one proton by the metal (Scheme 2d). The base-assisted metalation ${ }^{[16]}$ is observed for complexes bearing carboxylate or carbonate ligands and is closely related to the electrophilic substitution mechanism, but exhibits significant mechanistic differences. Within this mechanistic manifold, the $\mathrm{C}-\mathrm{H}$ cleavage occurs simultaneously to the formation of a new $\mathrm{R}-\mathrm{M}$ bond and a transfer of the proton to the coordinated base (Scheme 2e).

Depending on the exact transition state structure and the involved accumulation of partial charges, ${ }^{[17]}$ the base-assisted metalation pathway can be further categorized. For a deprotonative transition state, the term concerted metalation-deprotonation (CMD) was coined by Fagnou/Gorelsky (Scheme 3). ${ }^{[18]}$ The same mechanism, although explicitly including an agostic interaction between the $\mathrm{C}-\mathrm{H}$ bond and the metal center, was also described by Macgregor/Davies and named ambiphilic metal ligand activation (AMLA). ${ }^{[15 c, 19]}$ Due to the deprotonative nature of this pathway, a preferential activation of electron-deficient substrates is observed through kinetic $\mathrm{C}-\mathrm{H}$ acidity control. In contrast, the base-assisted internal electrophilic substitution (BIES) was introduced by Ackermann for the preferred activation of electron-rich substrates and proceeds in a electrophilic substitution-type pathway. ${ }^{[20]}$

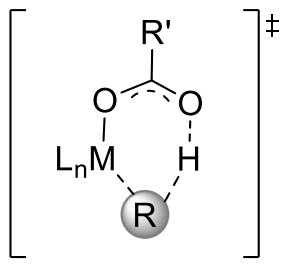

$C M D$

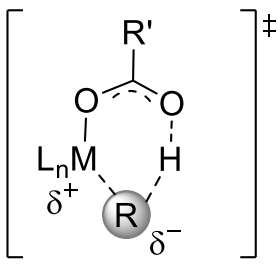

BIES

Scheme 3: Comparison of transition state structures in base-assisted metalation.

Due to the omnipresence of $\mathrm{C}-\mathrm{H}$ bonds in organic molecules and their often comparable acidities and bond dissociation energies, selectivity control is one of the major challenges in $\mathrm{C}-\mathrm{H}$ activation chemistry. ${ }^{[21]}$ By exploiting the inherently higher acidities and lower bond dissociation energies of certain $\mathrm{C}-\mathrm{H}$ bonds in heterocyclic compounds, ${ }^{[22]}$ a selective activation of specific heteroaromatic $\mathrm{C}-\mathrm{H}$ bonds can be achieved (electronic bias, Figure 1a). The introduction of sterically demanding substituents in the substrate can prevent access to adjacent $\mathrm{C}-\mathrm{H}$ bonds, thereby enforcing an activation of the desired, less hindered $\mathrm{C}-\mathrm{H}$ bond (steric bias, Figure $1 \mathrm{~b}$ ). Unfortunately, the use 
of an electronic or steric bias intrinsically limits the number of viable substrates. A more general approach is the use a of heteroatom-containing, Lewis-basic directing group (DG), which coordinates the metal complex and brings it in close proximity to the desired $\mathrm{C}-\mathrm{H}$ bond (Figure 1c). ${ }^{[23]}$ Over the years, a large number of directing groups, such as amides and $\mathrm{N}$-heterocycles, were explored for a variety of substrate classes, allowing for example the ortho-selective activation of arenes. Furthermore, in many cases the directing group can be removed after the transformation (removable or traceless directing group) or transformed into other valuable functional groups (transformable directing group). ${ }^{[24]}$ Recently, the use of transient directing groups, which are reversibly installed and removed during the catalytic $\mathrm{C}-\mathrm{H}$ activation, has gained considerable interest. ${ }^{[25]}$

(a) electronic bias

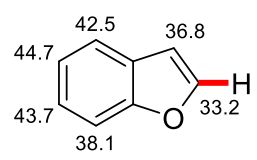

$\mathrm{pK}_{\mathrm{a}}$ values (b) steric bias<smiles>[R]c1cccc([R])c1</smiles>

(c) directing group<smiles>Cc1ccccc1[18O]c1ccccc1-c1ccccc1</smiles>

Figure 1: Selectivity-control in $\mathrm{C}-\mathrm{H}$ bond activation.

\subsection{Ruthenium-Catalyzed ortho-Selective C-H Alkylation}

During the last decades, transition metal-catalyzed $\mathrm{C}-\mathrm{H}$ activation chemistry has witnessed an enormous development and a multitude of transformations was achieved by means of $4 d$ and $5 d$ metal catalysis. In this context, ruthenium-catalysis has proven to be an efficient alternative to costly palladium-, rhodium-, platinum- or iridium-based catalysts ${ }^{[26]}$ and, consequently, a plethora of methods for ruthenium-catalyzed $\mathrm{C}-\mathrm{H}$ activation were disclosed. ${ }^{[27]}$

The first $\mathrm{C}-\mathrm{H}$ activation reaction employing ruthenium complexes was already reported in 1965 by Chatt, disclosing the stoichiometric $\mathrm{C}-\mathrm{H}$ activation of sodium naphthalene (2) by oxidative addition to an in situ generated ruthenium(0)-phosphine complex, thus resulting in the formation of ruthenium(II) species 3 (Scheme 4). ${ }^{[28]}$ 


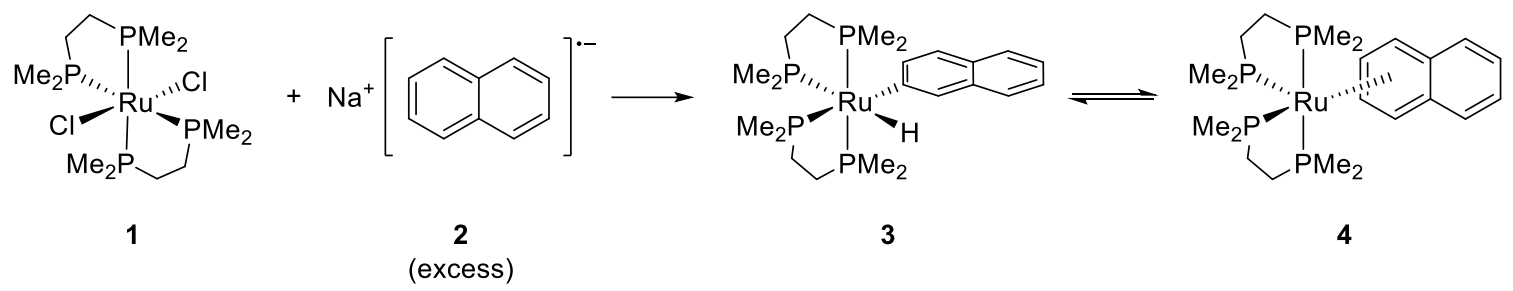

Scheme 4: Stoichiometric C-H activation of sodium naphthalene (2).

More than 20 years later, Lewis/Smith reported the ruthenium-catalyzed C-H alkylation of phenol (5) with ethene (6a) utilizing phosphites as a transient directing group, thereby representing the first example of $\mathrm{C}-\mathrm{H}$ activation under ruthenium catalysis (Scheme 5). ${ }^{\left[{ }^{[2]}\right.}$ Nevertheless, the reaction required the use of harsh conditions, led to the formation of mono- and dialkylated products and was limited to phenol and ethene as the substrates.

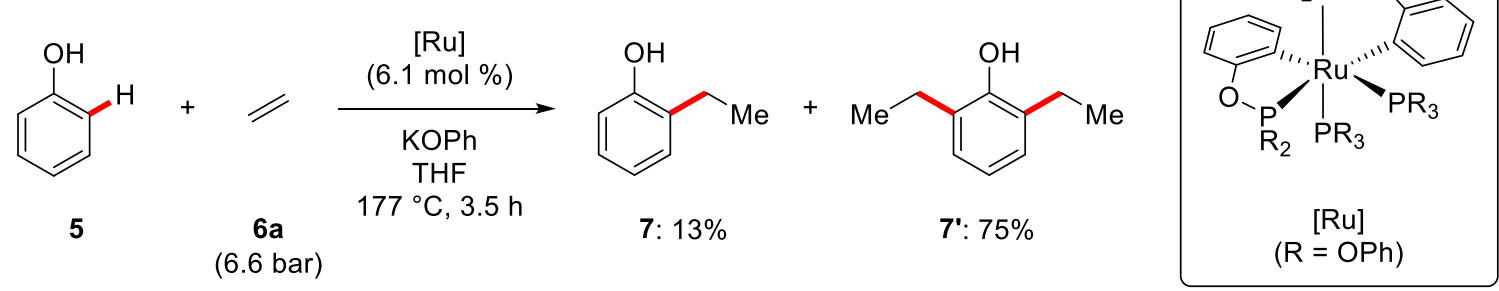

Scheme 5: Catalytic C-H alkylation of phenol (5) with ethene (6a).

In 1993, Murai achieved the ortho-selective C-H alkylation of aromatic ketones 8 with alkenes $\mathbf{6}$, employing $\left[\mathrm{RuH}_{2}(\mathrm{CO})\left(\mathrm{PPh}_{3}\right)_{3}\right]$ as the catalyst precourser (Scheme 6). ${ }^{[30]} \mathrm{A}$ variety of decorated ketones and alkenes were smoothly transformed into the alkylated products $\mathbf{9}$, therefore, representing the first broadly applicable method for $\mathrm{C}-\mathrm{H}$ alkylation in general. Although no mechanistic experiments were reported, the authors proposed the formation of the fivemembered ruthenacycle 10 by chelation-assisted oxidative addition, followed by insertion of the alkene and subsequent reductive elimination. 


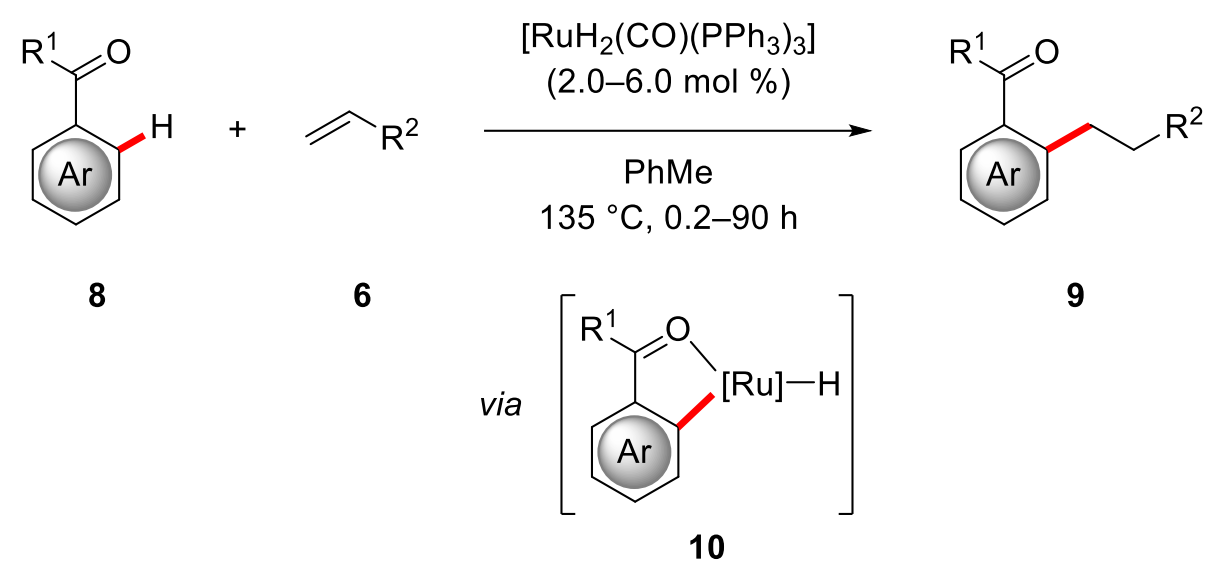

Scheme 6: Ruthenium-catalyzed C-H alkylation of ketones 8.

Later on, the group of Gunnoe employed a ruthenium-trispyrazolylborate (Tp) catalyst for the undirected hydroarylation of ethene (6a) and propene with benzene (11). ${ }^{[31]}$ In a subsequent study, thiophene as well as furan were also shown to be viable substrates in the undirected hydroarylation manifold (Scheme 7). ${ }^{[32]}$<smiles>c1ccccc1</smiles>

11

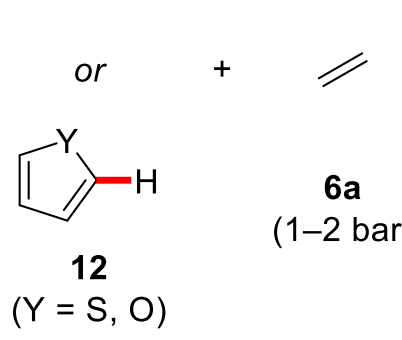

\section{$[\mathrm{Ru}(\mathrm{Tp})(\mathrm{NCMe})(\mathrm{CO}) \mathrm{R}]$}

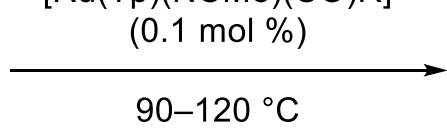

$\mathrm{R}=\mathrm{Me}$, Heteroaryl<smiles>CCc1ccccc1</smiles>

13<smiles></smiles>

14 $(\mathrm{Y}=\mathrm{S}, \mathrm{O})$

Scheme 7: Undirected hydroarylation of ethene (6a) under ruthenium catalysis.

In a pioneering study, Ackermann reported the ruthenium-catalyzed direct $\mathrm{C}-\mathrm{H}$ alkylation of arenes 15 with electrophilic primary and secondary alkyl halides 16 (Scheme 8). ${ }^{[33]}$ Optimal results were obtained with bulky $\mathrm{AdCO}_{2} \mathrm{H}(\mathbf{1 7})$ as the additive and the transformation proved applicable to a number of different substrates, including synthetically useful imines. 


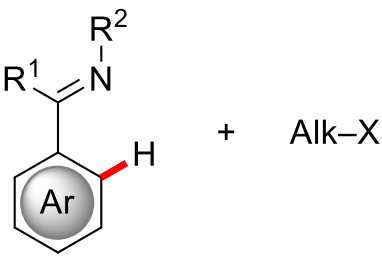

15

16

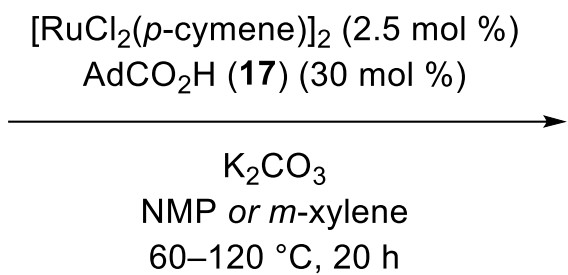

$\left(\right.$ Alk $\left.=1^{\circ}, 2^{\circ}\right)$

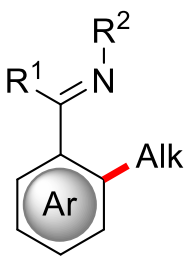

18

Scheme 8: Direct C-H alkylations with alkyl halides 16.

In a later publication, the group of Ackermann performed a series of mechanistic studies to gain insight into the catalyst's mode of action. ${ }^{[34]}$ Based on these results, the following catalytic cycle was proposed (Scheme 9): Starting from ruthenium(II)-carboxylate complex 19, coordination of the directing group and reversible $\mathrm{C}-\mathrm{H}$ ruthenation gives rise to ruthenacycle $\mathbf{2 1}$. Afterwards, oxidative addition of alkyl halide $\mathbf{1 6}$ generates ruthenium(IV) intermediate $\mathbf{2 2}$, which then undergoes reductive elimination to deliver the $\mathrm{C}-\mathrm{H}$ alkylated product $\mathbf{1 8}$.

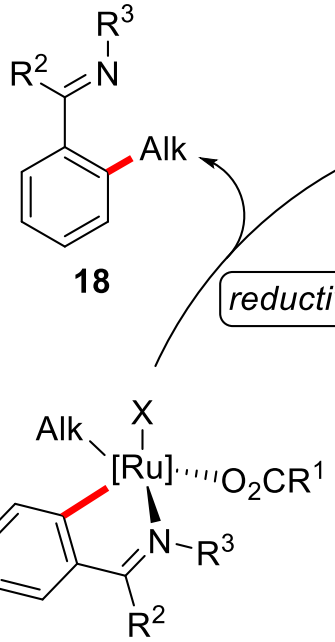

22

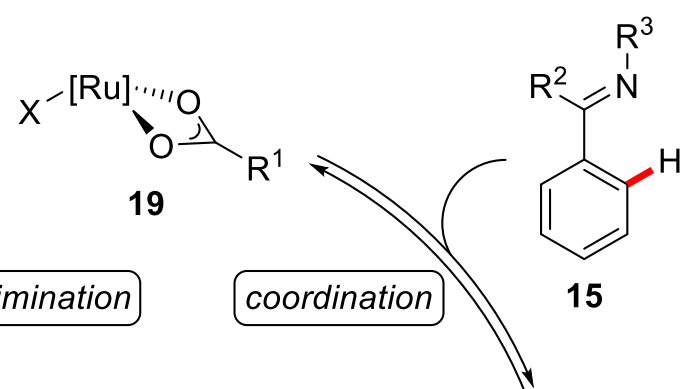

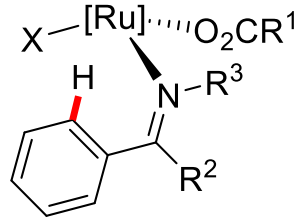

20

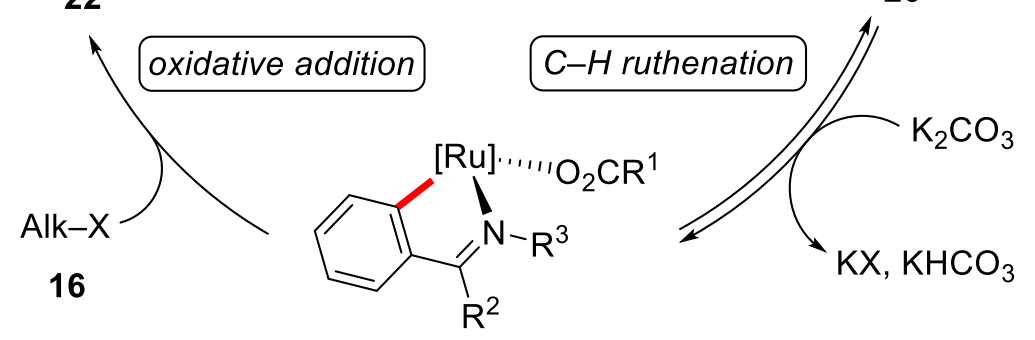

21

Scheme 9: Proposed catalytic cycle for C-H alkylations with alkyl halides $\mathbf{1 6 .}$ 
In 2014, a procedure for ruthenium-catalyzed $\mathrm{C}-\mathrm{H}$ alkylations of $\mathrm{C}\left(\mathrm{sp}^{3}\right)-\mathrm{H}$ bonds was reported for the first time by Ackermann. ${ }^{[35]} \mathrm{A}$ catalytic system consisting of $\left[\mathrm{RuCl}_{2}\left(\mathrm{PPh}_{3}\right)_{3}\right]$ together with catalytic amounts of BINAP (24) and AgOTf facilitated the mono-alkylation of $\mathrm{N}$-pyridylpyrrolidines 23 with various olefins 6 (Scheme 10).

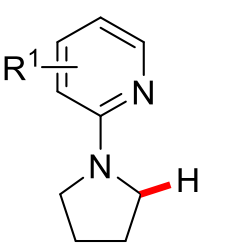

23

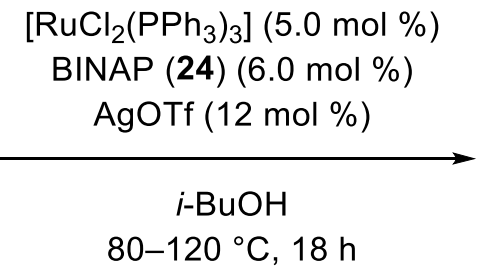

6

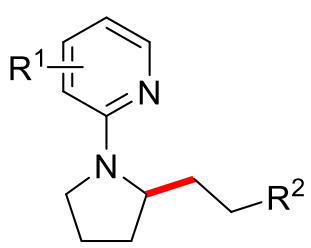

25

Scheme 10: $\mathrm{C}\left(\mathrm{sp}^{3}\right)-\mathrm{H}$ alkylations of pyrrolidines 23.

\subsection{Ruthenium-Catalyzed C-H Alkenylation}

The synthesis of alkenylated compounds via $\mathrm{C}-\mathrm{H}$ activation under ruthenium catalysis was pioneered by Milstein, who developed a method for dehydrogenative $\mathrm{C}-\mathrm{H}$ alkenylations of simple arenes $\mathbf{2 6}$ with acrylates $\mathbf{2 7}$ (Scheme 11). ${ }^{[36]}$ The reaction was conducted under a high pressure of $\mathrm{O}_{2}$, which acts as the terminal oxidant, and $\mathrm{CO}$, and requires high temperatures. Interestingly, comparable catalytic performances were reported with a number of different ruthenium(II) and ruthenium(III) complexes.

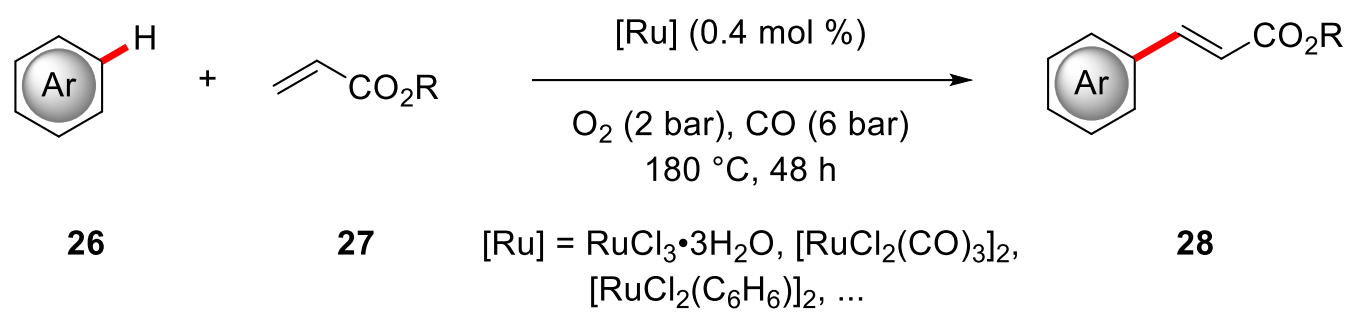

Scheme 11: Oxidative $\mathrm{C}-\mathrm{H}$ alkenylations of arenes $\mathbf{2 6}$ with acrylates $\mathbf{2 7}$.

Over the years, the contribution of Milstein inspired many research groups and led to the development of numerous ruthenium-catalyzed oxidative $\mathrm{C}-\mathrm{H}$ alkenylations. ${ }^{[24]}$ In a notable example by Satoh/Miura heterocyclic carboxylic acids $\mathbf{2 9}$ were efficiently converted to the 
corresponding alkenylated products 30 using $\mathrm{Cu}(\mathrm{OAc})_{2}$ as the oxidant (Scheme 12$) \cdot{ }^{[37]}$ In contrast to previous reports for palladium catalysis, ${ }^{[38]}$ the formation of any decarboxylated products was not observed.<smiles>O=C(O)c1[Y]c2ccccc2c1</smiles>

29 $(\mathrm{Y}=\mathrm{O}, \mathrm{S}, \mathrm{NMe})$
$\left[\mathrm{RuCl}_{2}(p \text {-cymene })\right]_{2}$ $(2.0 \mathrm{~mol} \%)$

$\mathrm{Cu}(\mathrm{OAc})_{2} \cdot \mathrm{H}_{2} \mathrm{O}$

LiOAC

DMF, $80^{\circ} \mathrm{C}, 6 \mathrm{~h}$

Scheme 12: Oxidative alkenylation of heterocyclic carboxylic acids 29.

Furthermore, in an independent study by Ackermann $\mathrm{C}-\mathrm{H}$ alkenylations of benzoic acids $\mathbf{3 1}$ with activated alkenes 32 were realized in water as reaction medium (Scheme 13). ${ }^{[39]}$ Notably, phthalides 33 were obtained in an ortho- $\mathrm{C}-\mathrm{H}$ alkenylation/oxa-Michael regime. Afterwards, this methodology was further improved by employing molecular oxygen as the terminal oxidant ${ }^{[40]}$ and by the use of biomass-derived $\gamma$-valerolactone $(G V L)$ as the reaction medium of choice. ${ }^{[41]}$

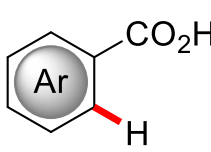

31

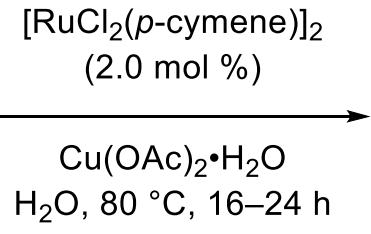

32

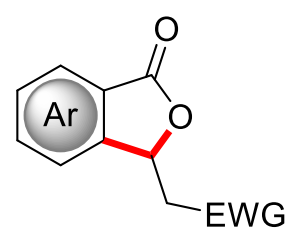

33

Scheme 13: Synthesis of phthalides 33 under ruthenium catalysis.

In 2011, Ackermann presented the synthesis of isoquinolones 36 via ruthenium-catalyzed oxidative annulation of benzamides 34 with aryl- or alkyl-substituted alkynes 35 (Scheme 14). ${ }^{[42]}$ The best results were obtained with $\mathrm{Cu}(\mathrm{OAc})_{2}$ as the oxidant and protic $t$-AmOH as the reaction medium. 


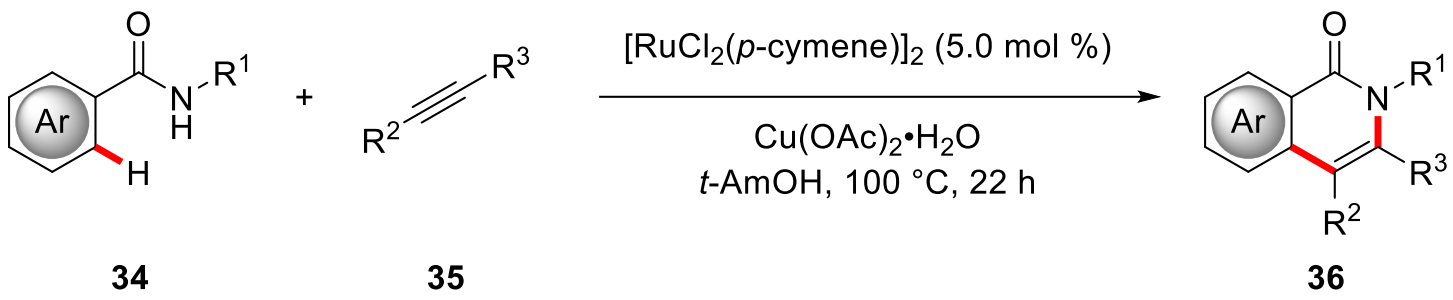

Scheme 14: Oxidative annulation for the synthesis of isoquinolones 36.

The groups of Ackermann (Scheme 15), ${ }^{[43]}$ and Jeganmohan ${ }^{[44]}$ independently reported an oxidative annulation approach for the construction of isocumarin-scaffolds, employing benzoic acids $\mathbf{3 1}$ and internal alkynes $\mathbf{3 5}$ as the substrates and an in situ generated cationic $[\mathrm{Ru}(\mathrm{OAc})(p \text {-cymene })]^{+}$species as the catalyst.

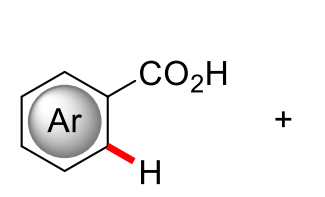

31

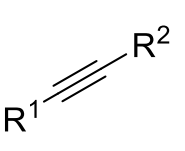

35

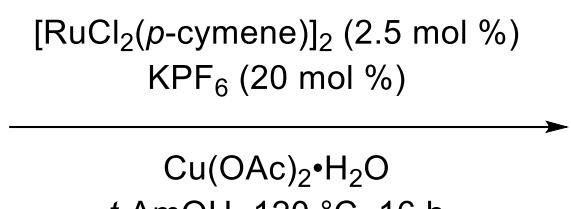

$t$-AmOH, $120^{\circ} \mathrm{C}, 16 \mathrm{~h}$

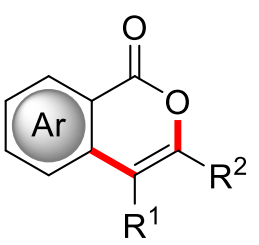

37

Scheme 15: Oxidative annulation for the synthesis of isocumarins 37.

Both authors proposed the reaction to commence with formation of cationic ruthenium complex 38, which facilitates the base-assisted ortho-metalation of substrate 31a (Scheme 16). Then, migratory insertion occurs to generate the seven-membered ruthenacycle 40. Ensuing reductive elimination and reoxidation of ruthenium(0) to ruthenium(II) by copper(II) leads to formation of isocumarin $\mathbf{3 7}$ and regenerates the catalytically active complex $\mathbf{3 8 .}$ 


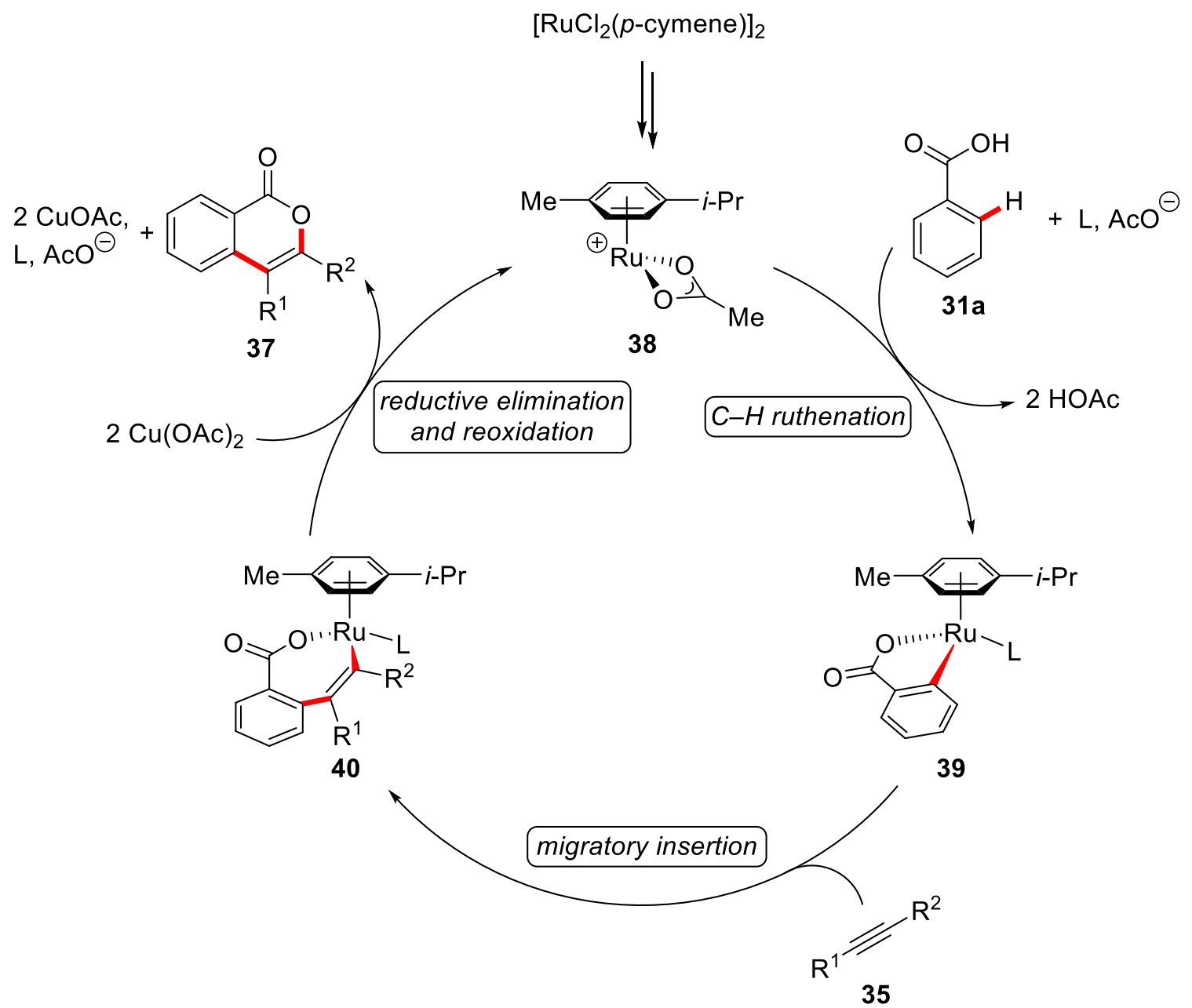

Scheme 16: Proposed catalytic cycle for oxidative annulations of benzoic acids $\mathbf{3 1}$.

Ruthenium-catalyzed $\mathrm{C}-\mathrm{H}$ alkenylations with weakly coordinating substrates via the formation of a six-membered ruthenacycles was first explored by Ackermann in the reaction of anilides $\mathbf{4 1}$ and carbamates $\mathbf{4 3}$ with acrylates $\mathbf{2 7}$ (Scheme 17). ${ }^{[45]}$ It should be noted that afterwards comparable studies were reported by Li/Wang. ${ }^{[46]}$ Shortly after, Jeganmohan disclosed the alkenylation of aryl acetates using a similar catalytic system. ${ }^{[47]}$ 
(a) Ackermann (2012)<smiles>[R]OC=CC=[O+]</smiles>

41

27

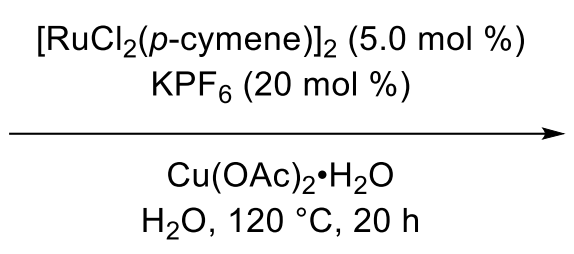<smiles>[R]OC=Cc1ccccc1NC([R])=O</smiles>

42

(b) Ackermann (2012)

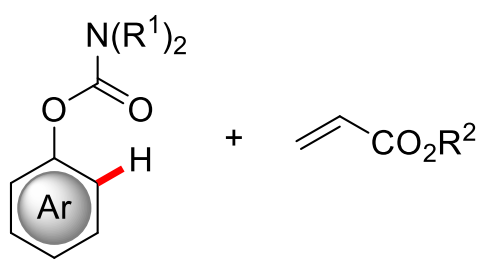

43

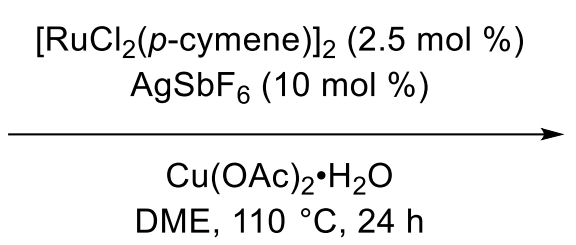

DME, $110^{\circ} \mathrm{C}, 24 \mathrm{~h}$

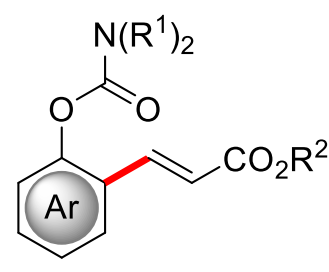

44

Scheme 17: Weak $\mathrm{O}$-coordination for ruthenium-catalyzed $\mathrm{C}-\mathrm{H}$ alkenylations.

\subsection{Direct $\mathrm{C}-\mathrm{H}$ Arylation under Ruthenium Catalysis}

An early contribution in direct $\mathrm{C}-\mathrm{H}$ arylation under ruthenium catalysis was reported by $\mathrm{Oi} /$ Inoue in 2001. ${ }^{[48]}$ By employing a ruthenium(II)-arene complex along with catalytic amounts of $\mathrm{PPh}_{3}$, phenylpyiridines 45 were successfully reacted with aryl bromides $\mathbf{4 6}$, thus delivering the desired ortho-arylated compounds (Scheme 18). Notably, when meta-substituted arenes were subjected to the reaction conditions, the reaction exclusively took place in the sterically less-hindered orthoposition.

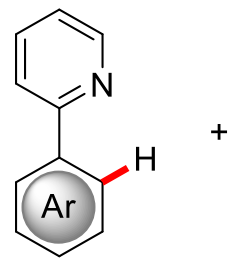

45

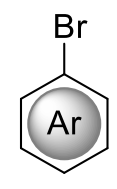

46

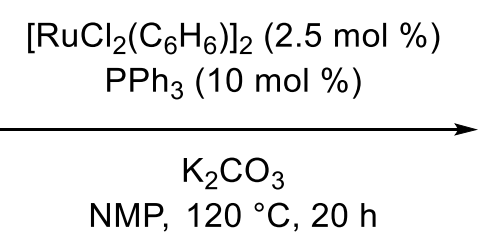

NMP, $120^{\circ} \mathrm{C}, 20 \mathrm{~h}$

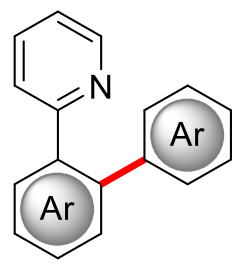

47

Scheme 18: Ruthenium(II)-catalyzed C-H arylation of phenylpyridines 45.

For the ruthenium-catalyzed $\mathrm{C}-\mathrm{H}$ arylation the proposed catalytic cycle commences with oxidative addition of aryl bromide 46 to ruthenium(II) species 48 (Scheme 19). Afterwards, zwitterionic 
ruthenacycle $\mathbf{5 0}$ is formed and subsequently undergoes elimination of $\mathrm{HBr}$. Reductive elimination from intermediate $\mathbf{5 1}$ leads to the formation of the new $\mathrm{C}-\mathrm{C}$ bond and regenerates the catalytically active ruthenium(II) complex.

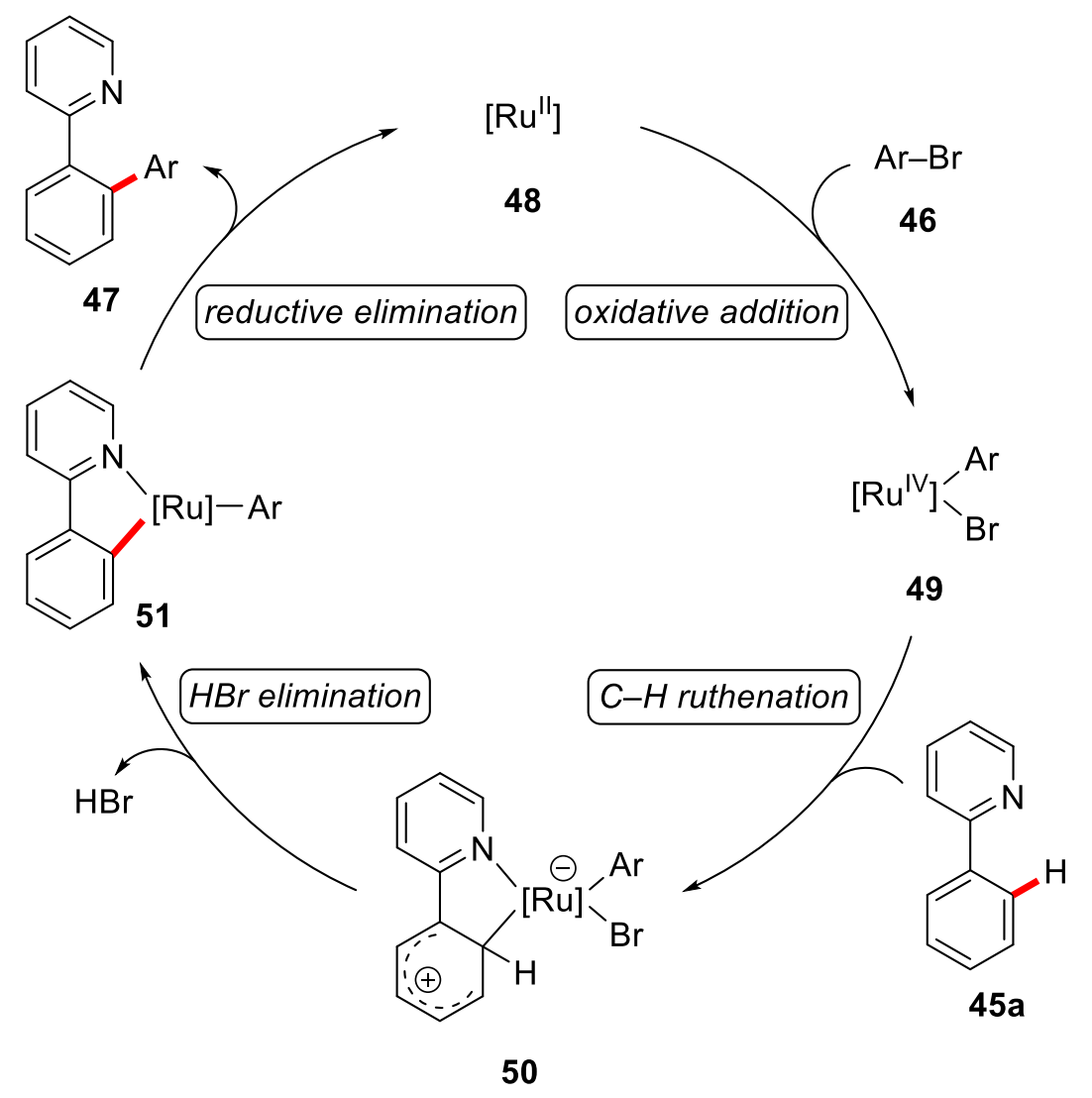

Scheme 19: Proposed catalytic cycle for $\mathrm{C}-\mathrm{H}$ arylations under ruthenium catalysis.

Unfortunately, a later study revealed a lack of reproducibility of these results due to a strong beneficial effect of solvent impurities on the reaction outcome. ${ }^{[49]}$

In 2007, Ackermann disclosed the chelation-assisted C-H arylation of alkenes and arenes with aryl halides 46, 54 using simple $\mathrm{RuCl}_{3}$ as catalyst, which represents a rare example of ruthenium(III)catalyzed $\mathrm{C}-\mathrm{H}$ activation (Scheme 20 ). ${ }^{[50]}$ 
<smiles>[O]c1ccccc1</smiles>

$45,52-53$

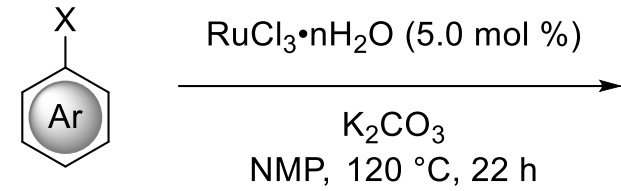

46, 54<smiles>Oc1ccccc1-c1ccccc1</smiles>

47, 55-56

$$
\mathrm{DG}=\mathrm{N}_{\mathrm{N}}
$$

Scheme 20: Ruthenium(III)-catalyzed C-H arylation of alkenes and arenes 45, 52-53.

A breakthrough in direct $\mathrm{C}-\mathrm{H}$ arylation was achieved in 2008, when the group of Ackermann introduced carboxylic acids as additives in ruthenium catalysis. ${ }^{[51]}$ Sterically demanding $\mathrm{Mes} \mathrm{CO}_{2} \mathrm{H}$ (58) outperformed previously employed NHC and phosphine ligands and facilitated the $\mathrm{C}-\mathrm{H}$ arylation of aryl pyridines $\mathbf{4 5}$, oxazolines $\mathbf{5 2}$, pyrazoles $\mathbf{5 3}$, and triazoles $\mathbf{5 7}$ in a robust manner (Scheme 21). The authors proposed the $\mathrm{C}-\mathrm{H}$ activation event to occur via a base-assisted metalation process, involving a cyclic, six-membered transition state structure.

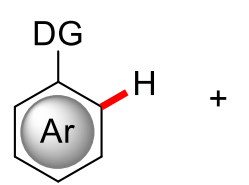

$45,52-53,57$

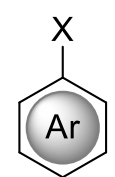

46, 54

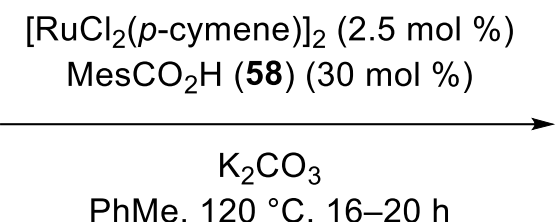

PhMe, $120^{\circ} \mathrm{C}, 16-20 \mathrm{~h}$

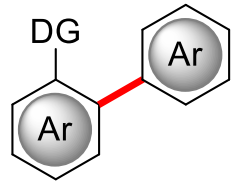

47, 55-56, 59

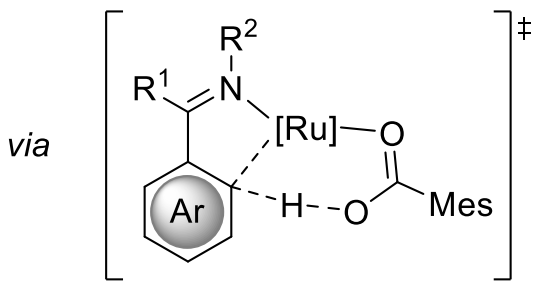

60

Scheme 21: Ruthenium-catalyzed $\mathrm{C}-\mathrm{H}$ arylations with carboxylic acid additives and representative transition state structure 60.

In a subsequent contribution, the synthesis of ruthenium-carboxylate complex $\left[\mathrm{Ru}\left(\mathrm{O}_{2} \mathrm{CMes}\right)_{2}(p\right.$-cymene $\left.)\right](61)$ was reported and the complex was shown to exhibit excellent 
performance in direct $\mathrm{C}-\mathrm{H}$ arylations. ${ }^{[52]}$ Furthermore, the reaction was proposed to proceed via a reversible, chelation-assisted $\mathrm{C}-\mathrm{H}$ activation in a base-assisted metalation process (Scheme 22). Oxidative addition of $\mathrm{Ar}-\mathrm{X}$ to $\mathbf{2 1}$ generates ruthenium(IV) intermediate $\mathbf{6 2}$ and ensuing reductive elimination leads to formation of arylated product 63.<smiles>[R]N=C([R])c1ccccc1[Al]</smiles>

63

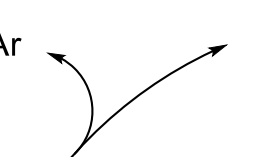

reductive elimination

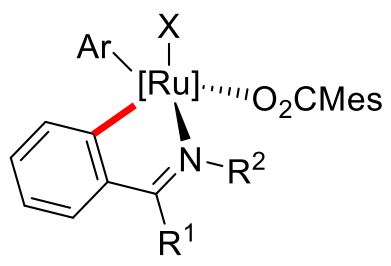

62<smiles>[R]N=C([R])c1ccccc1</smiles>

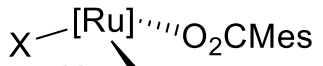

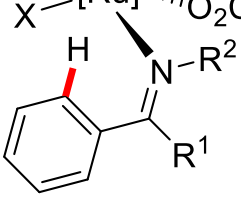

20

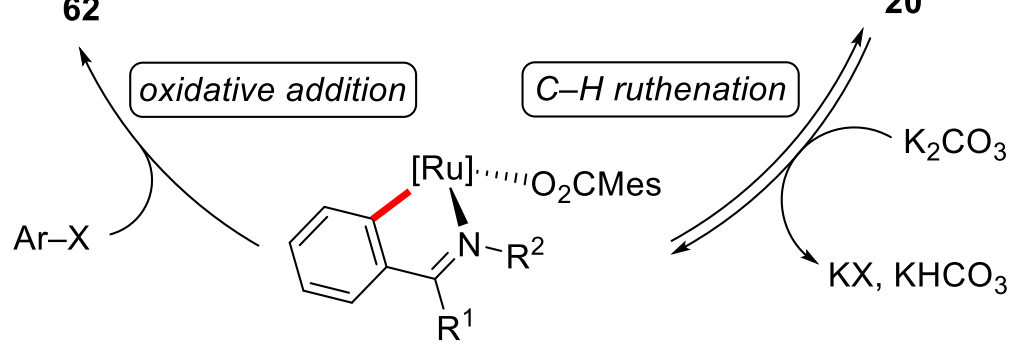

21

Scheme 22: Proposed catalytic cycle for ruthenium-carboxylate-catalyzed $\mathrm{C}-\mathrm{H}$ arylations.

A method for the synthesis of biaryl motifs in a dehydrogenative $\mathrm{C}-\mathrm{H} / \mathrm{C}-\mathrm{H}$ activation process under ruthenium catalysis was disclosed in a contribution by Oi/Inoue. ${ }^{[53]}$ In this transformation, allylic acetate $\mathbf{6 7}$ acted as the stoichiometric oxidant and enabled the homocoupling with various heterocyclic directing group decorated arenes 52-53, 64-66 (Scheme 23). 
<smiles>C=C(C)COC(C)=O</smiles>

67

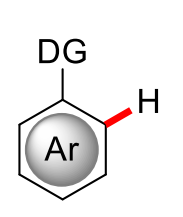

$52-53,64-66$
$\left[\mathrm{RuCl}_{2}(\mathrm{cod})\right]_{\mathrm{n}}(5.0 \mathrm{~mol} \%)$

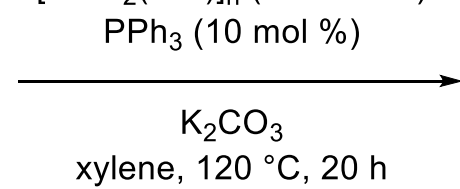

xylene, $120^{\circ} \mathrm{C}, 20 \mathrm{~h}$

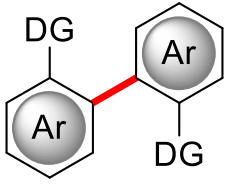

68-72

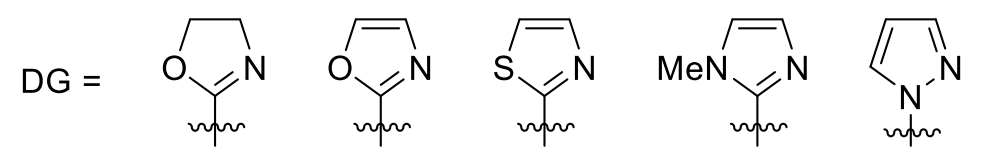

Scheme 23: Dehydrogenative $\mathrm{C}-\mathrm{H} / \mathrm{C}-\mathrm{H}$ activation with allyl acetate 67 as oxidant.

The $\mathrm{C}-\mathrm{H}$ arylation of fluoroarenes $\mathbf{7 3}$ with aryl halides $\mathbf{4 6}$ was presented in 2016 by Larrosa, ${ }^{[54]}$ again by carboxylate assistance, as introduced by Ackermann in $2008 .^{[51]}$ A catalytic system consisting of cationic $\left[\mathrm{Ru}(\mathrm{NCt}-\mathrm{Bu})_{6}\right]\left[\mathrm{BF}_{4}\right]_{2}$ as catalyst in combination with catalytic amounts of benzoate and pivalate as ligands and base proved crucial for achieving high conversions (Scheme 24).

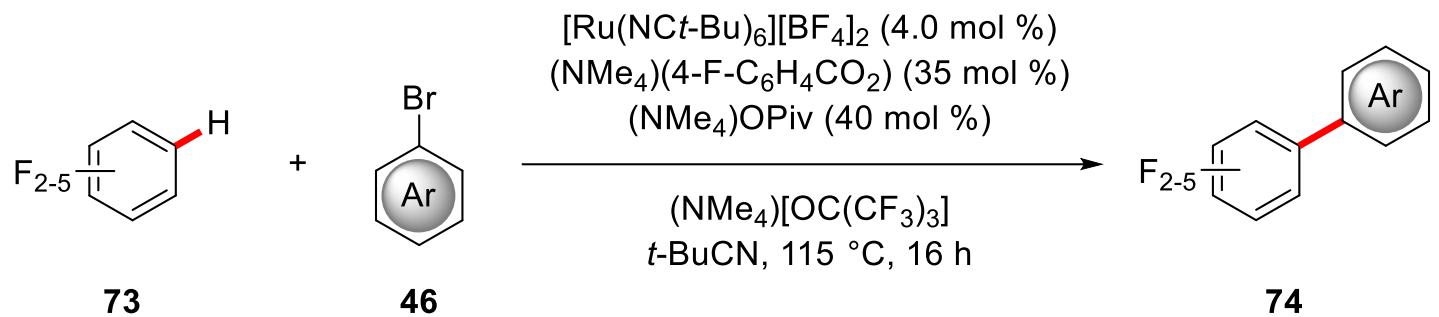

Scheme 24: C-H Arylation of fluoroarenes 73.

Recently, a cyclometalated ruthenium(II)-nitrile complex was successfully employed as catalyst in the chelation-assisted C-H arylation with aryl (pseudo-)halides 46, 54 by the group of Larrosa (Scheme 25). ${ }^{[55]}$ The reaction was performed on heteroaryl-substituted arenes 15 , some of which were coupled to pharmaceuticals and natural products. 
<smiles>[R]N=C([R])c1ccccc1</smiles>

15

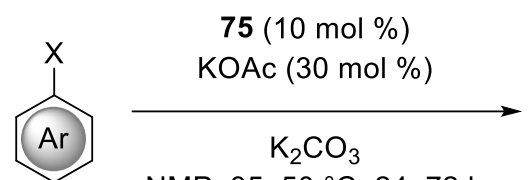

NMP, $35-50{ }^{\circ} \mathrm{C}, 24-72 \mathrm{~h}$

46,54

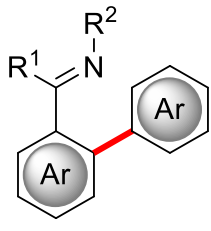

63

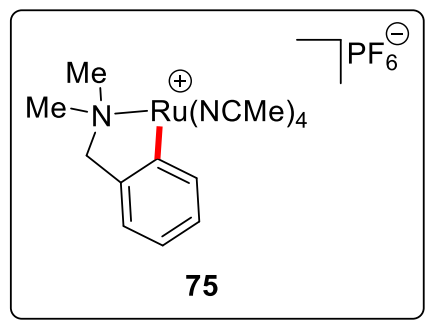

Scheme 25: $\mathrm{C}-\mathrm{H}$ arylations with cyclometalated complex 75 as catalyst.

\subsection{Ruthenium-Catalyzed Decarboxylative C-H Activation}

Throughout the years, carboxylic acids have been recognized as versatile traceless directing groups in a $\mathrm{C}-\mathrm{H}$ functionalization/decarboxylation manifold. ${ }^{[56]}$ While numerous palladium-, rhodium-, and iridium-catalyzed transformations are well-established, the use of stoichiometric amounts of copper or silver is often required to facilitate a decarboxylative process, thereby compromising the sustainability of the $\mathrm{C}-\mathrm{H}$ activation approach.

The first example of domino $\mathrm{C}-\mathrm{H}$ activation/decarboxylation under ruthenium(II) catalysis was reported by $L i$ in 2015 for the amidation of benzoic acids $\mathbf{3 1}$ with isocyanates $\mathbf{7 6}$ (Scheme 26). ${ }^{[57]}$ It should be noted that the reaction proceeded in the absence of any transition metal apart from the employed ruthenium catalyst and delivered $\mathbf{3 4}$ in high yield.

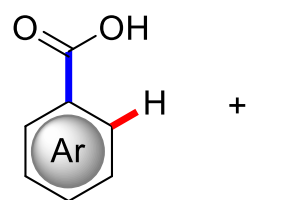

31<smiles>O=C=N[Al]</smiles>

76

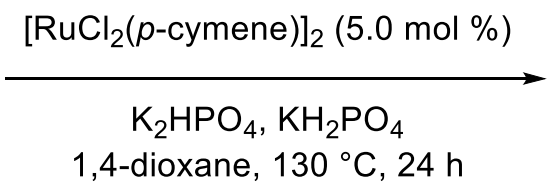

1,4-dioxane, $130{ }^{\circ} \mathrm{C}, 24 \mathrm{~h}$<smiles>O=C(N[Al])c1ccccc1</smiles>

34

Scheme 26: Decarboxylative amidations with isocyanates 76.

In the same year, $\alpha$-keto carboxylic acids $\mathbf{7 7}$ were shown to efficiently undergo $\mathrm{C}-\mathrm{H}$ alkenylation/decarboxylation with internal alkynes 35 (Scheme 27). ${ }^{[58]}$ Incorporation of oxygen from air and oxidative annulation leads to the formation of isocumarins 37 . Unfortunately, the use of stoichiometric amounts of copper(II) salts proved necessary. 


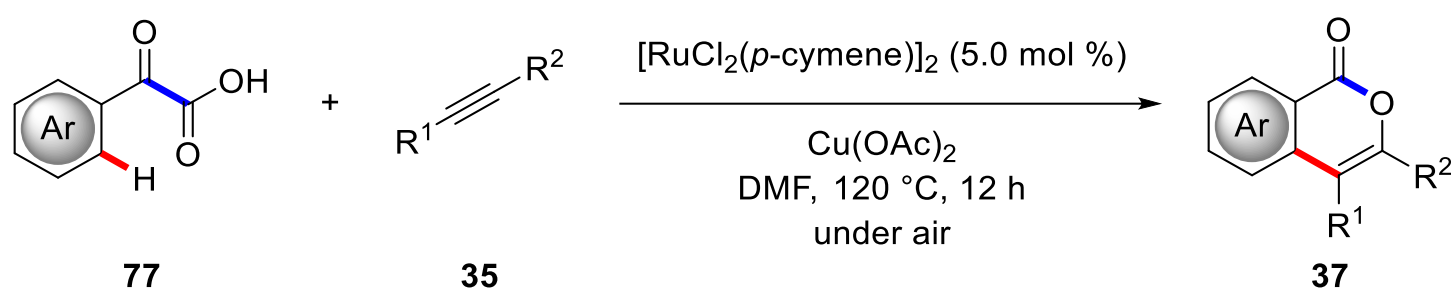

Scheme 27: Decarboxylation and oxidative annulations of $\alpha$-keto acids 77 .

Thereafter, the groups of Ackermann, ${ }^{[59]}$ Gooßen, ${ }^{[60]}$ and Zhao/Hartwig ${ }^{[61]}$ independently disclosed the decarboxylative $\mathrm{C}-\mathrm{H}$ alkenylation of benzoic acids $\mathbf{3 1}$ with alkynes $\mathbf{3 5}$ (Scheme 28). Opposed to the report by Gooßen, who opted for a ruthenium-dichloro complex in combination with a carbonate base, Ackermann, and Zhao/Hartwig employed well-defined ruthenium-carboxylate catalysts in the absence of additional base.

(a) Ackermann (2016)<smiles>O=C(O)c1ccccc1</smiles>

31<smiles>[R]C#[R]</smiles>

35

$$
\frac{\begin{array}{c}
{\left[\mathrm{Ru}\left(\mathrm{O}_{2} \mathrm{CMes}\right)_{2}(p \text {-cymene })\right](61)} \\
(10 \mathrm{~mol} \%)
\end{array}}{\mathrm{PhMe}, 100^{\circ} \mathrm{C}, 24 \mathrm{~h}}
$$

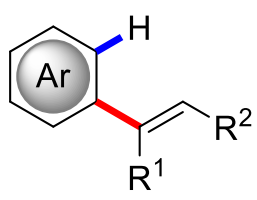

78

(b) Gooßen (2016)<smiles>O=C(O)c1ccccc1</smiles>

31<smiles>[R]C#[R]</smiles>

35

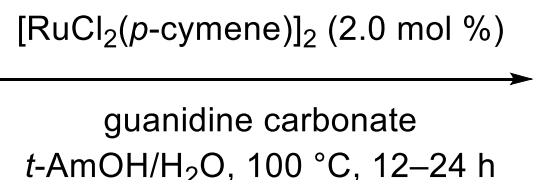

$t-\mathrm{AmOH} / \mathrm{H}_{2} \mathrm{O}, 100{ }^{\circ} \mathrm{C}, 12-24 \mathrm{~h}$<smiles>[R]C=C([R])c1ccccc1</smiles>

78

(c) Zhao/Hartwig (2016)<smiles>O=C(O)c1ccccc1</smiles>

31<smiles>[R]C#[R]</smiles>

35

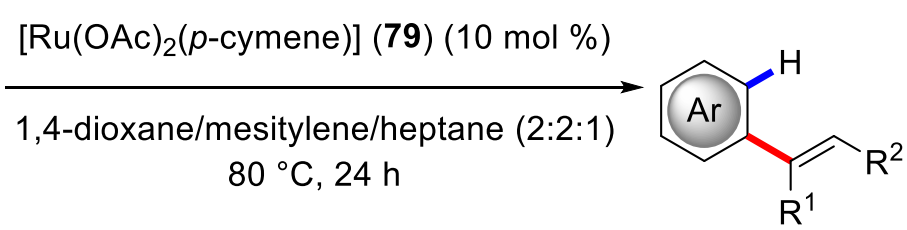

78

Scheme 28: $\mathrm{C}-\mathrm{H}$ alkenylations/decarboxylations of benzoic acids $\mathbf{3 1}$. 
Additionally, a method for domino $\mathrm{C}-\mathrm{H}$ alkenylation/decarboxylation reactions of benzoic acids 80 with acrylates 27 was explored by Ackermann (Scheme 29). ${ }^{[59]}$ The choice of $\mathrm{V}_{2} \mathrm{O}_{5}$ as the oxidant and the introduction of an ether-substituent in the ortho-position proved beneficial for obtaining high conversions in the oxidative $\mathrm{C}-\mathrm{H}$ alkenylation process.

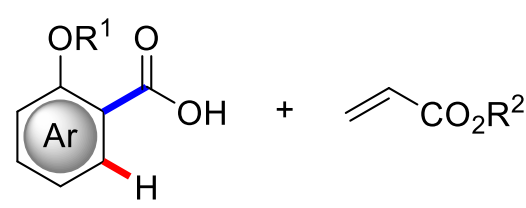

80

27

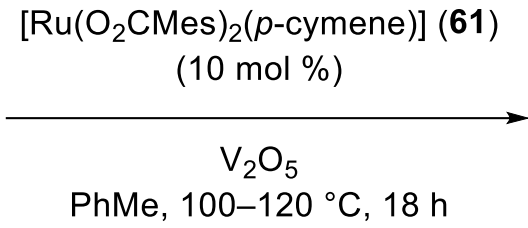

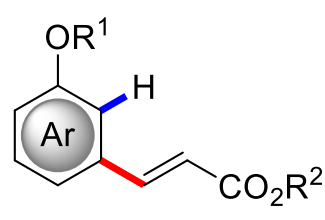

81

Scheme 29: Domino C-H alkenylations/decarboxylations with acrylates 27.

The use of indole carboxylic acids $\mathbf{8 2}$, a privileged structural motif that easily undergoes decarboxylation, in an intramolecular $\mathrm{C}-\mathrm{H}$ alkenylation/decarboxylation reaction for the synthesis of tetrahydropyridoindoles $\mathbf{8 3}$ bearing an exocyclic double bond was recently described with environmentally benign oxygen as the sole oxidant (Scheme 30). ${ }^{[62]}$

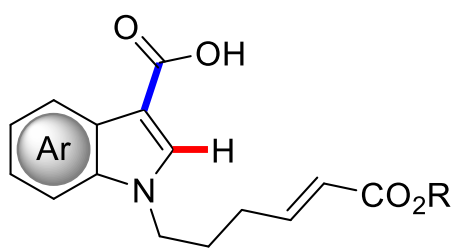

82

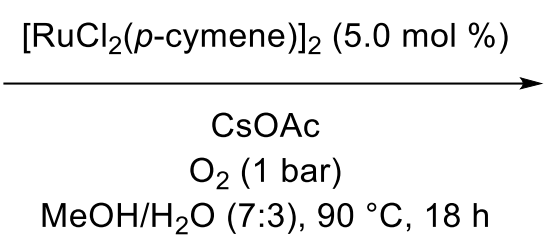

$\mathrm{MeOH} / \mathrm{H}_{2} \mathrm{O}(7: 3), 90{ }^{\circ} \mathrm{C}, 18 \mathrm{~h}$

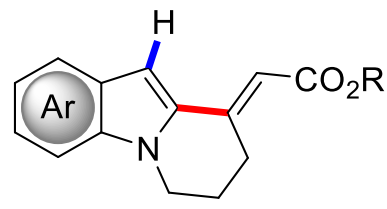

83

Scheme 30: Intramolecular C-H alkenylations/decarboxylations of indole carboxylic acids $\mathbf{8 2}$.

\section{6 meta-Selective C-H Activation under Ruthenium Catalysis}

The control of selectivity continues to be one of the major challenges in $\mathrm{C}-\mathrm{H}$ activation chemistry (vide supra). In contrast to a plethora of reports on ortho-selective $\mathrm{C}-\mathrm{H}$ activations of arenes, methods for the selective activation of $\mathrm{C}-\mathrm{H}$ bonds in the meta-position continue to be scarce. ${ }^{[63]}$ In the last decade, mainly six different approaches for meta-selective $\mathrm{C}-\mathrm{H}$ activation were established. The use of substrates bearing bulky substituents can prevent the activation of $\mathrm{C}-\mathrm{H}$ 
bonds in neighboring positions, resulting in a reaction at a non-hindered meta-position (Figure 2a). So far, this strategy is limited to iridium-catalyzed borylation reactions. ${ }^{[64]}$ By employing traceless directing groups, such as carboxylic acids, formal meta-selective $\mathrm{C}-\mathrm{H}$ activations can be achieved (Figure 2b). However, introduction of a substituent in the ortho-position with respect to the directing group is required. The installation of a template in the substrate can lead to a coordination of the catalyst, ${ }^{[65]}$ thereby bringing it into close proximity to the desired $\mathrm{C}-\mathrm{H}$ bond in meta- or para-position (Figure 2c). ${ }^{[66]}$ The installation and subsequent removal of the template requires additional synthetic operations and constitutes a major drawback of this method. In an elegant approach Kuninobu/Kanai developed a reversible hydrogen bonding linker, allowing for $\mathrm{C}-\mathrm{H}$ borylations to occur in the meta-position (Figure 2d). ${ }^{[67]}$ Unfortunately, hydrogen bonding linkers are so far limited to iridium catalysis and are not broadly applicable. Reminiscent of the Catellani reaction, ${ }^{[68]}$ norbornene can be employed as a transient meditator to obtain metafunctionalized compounds via a palladium-catalyzed ortho/ortho activation manifold (Figure 2e). ${ }^{[69]}$ Furthermore, the formation of cyclometalated ruthenium complexes by chelation-assisted ortho- $\mathrm{C}-\mathrm{H}$ metalation strongly increases the electron density at the para-position with respect to ruthenium, ${ }^{[70]}$ thus acting as an ortho/para-directing substituent and enabling functionalizations at a remote $\mathrm{C}-\mathrm{H}$ bond (Figure $2 \mathrm{f}) .{ }^{[71]}$

(a) steric control<smiles></smiles>

(b) traceless directing group<smiles>[R]c1cccc(C=O)c1[R]</smiles>

(e) transient mediator<smiles>CC1(C)CCC1c1c([18O])cccc1[TeH]</smiles>

(c) template-assisted

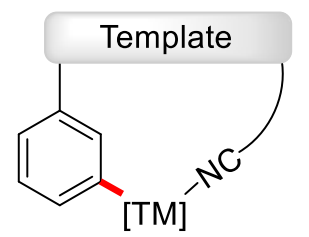

(f) remote $\sigma$-activation<smiles></smiles>

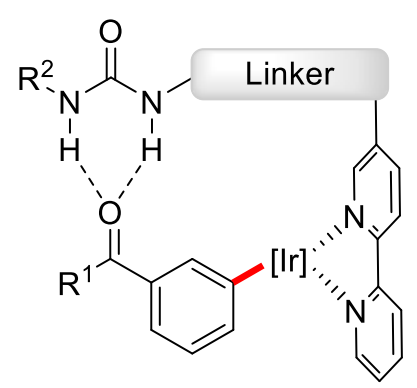

Figure 2: Strategies for meta-selective $\mathrm{C}-\mathrm{H}$ activation. 
The first example of chelation-assisted remote $\mathrm{C}-\mathrm{H}$ functionalization ${ }^{[72]}$ was reported by van Koten in 1994 for the stoichiometric reaction of complex 84 (Scheme 31). ${ }^{[73]}$ Along with homocoupled complex 85 , small amounts of chlorinated product 86 were obtained.

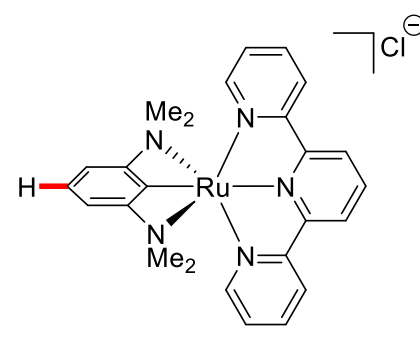

84
1) $\mathrm{CuCl}_{2}$ $\mathrm{MeOH}, 25^{\circ} \mathrm{C}, 17 \mathrm{~h}$ 2) $\mathrm{NH}_{4} \mathrm{PF}_{6}$ $\mathrm{H}_{2} \mathrm{O}$

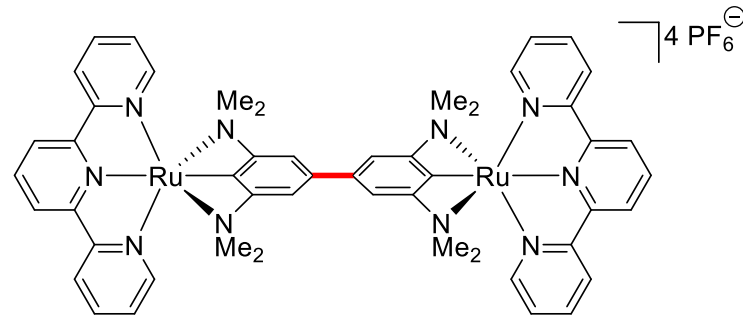

85: $60 \%$

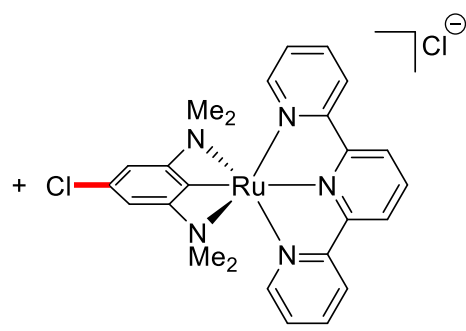

86: $<10 \%$

Scheme 31: Stoichiometric remote $\mathrm{C}-\mathrm{C}$ bond formation.

In 1998, the group of Coudret discovered the meta-selective $\mathrm{C}-\mathrm{H}$ bromination and iodination of cyclometalated phenylpyridine complexe 87 under mild conditions. ${ }^{[74]}$ Thereafter, Roper/Wright accomplished the remote, iron-catalyzed bromination of related ruthenium complexes (Scheme 32)..$^{[75]}$ 
(a) Coupret (1998)

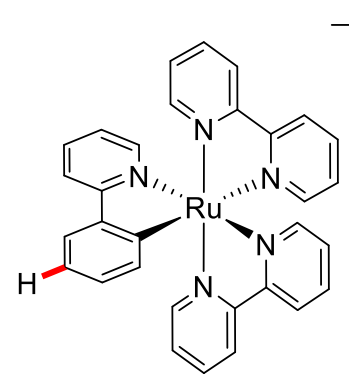

87

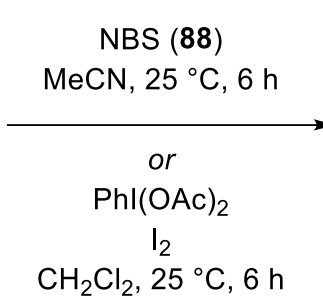

$\mathrm{CH}_{2} \mathrm{Cl}_{2}, 25^{\circ} \mathrm{C}, 6 \mathrm{~h}$

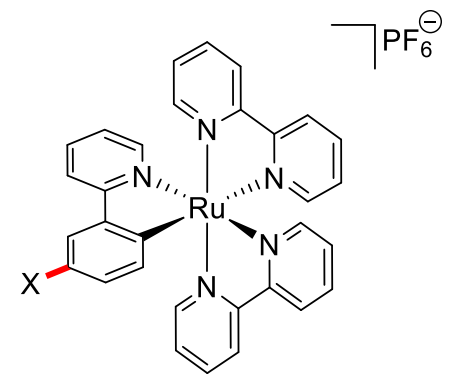

89a: $95 \%(X=B r)$ 89b: $50 \%(X=1)$

(b) Roper/Wright (1999)<smiles></smiles>

90

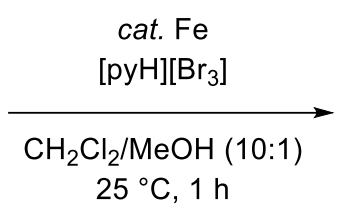

$\mathrm{Br}$<smiles></smiles>

91: $69 \%$

Scheme 32: Remote $\mathrm{C}-\mathrm{H}$ halogenations of cyclometalated complexes.

Catalytic remote $\mathrm{C}-\mathrm{H}$ functionalizations via ortho-metalation were first disclosed in a pioneering contribution by Ackermann in 2011. ${ }^{[34]}$ Phenylpyridine 45b was reacted with primary alkyl halide 92 to deliver meta-alkylated arene $\mathbf{9 3}$, albeit in very low yield, together with $\mathbf{9 3}$ ' as the major product (Scheme 33).<smiles>COc1ccc(-c2ccccn2)cc1</smiles>

45b 92
$\left[\mathrm{RuCl}_{2}(p \text {-cymene })\right]_{2}(2.5 \mathrm{~mol} \%)$ $\mathrm{MesCO}_{2} \mathrm{H}(58)(30 \mathrm{~mol} \%)$ $\mathrm{K}_{2} \mathrm{CO}_{3}$ $\mathrm{H}_{2} \mathrm{O}, 100^{\circ} \mathrm{C}, 20 \mathrm{~h}$<smiles>COc1ccc(-c2ccccn2)cc1OC#N</smiles>

93: $7 \%$<smiles>COc1ccc(-c2ccccn2)c(C=CC(=O)O)c1</smiles>

93': $45 \%$

Scheme 33: Ruthenium catalysis for meta-C-H alkylation with $n$-hexyl bromide (92).

A protocol for meta-selective sulfonations of phenylpyridines $\mathbf{4 5}$ under ruthenium catalysis was presented by Frost in the same year (Scheme 34). ${ }^{[76]}$ When the well-defined ruthenacycle 96 was subjected to the reaction conditions, a quantitative formation of 95 was observed. The authors 
attributed this observation to the strongly activating, ortho/para-directing properties of the Ru-C bond, ${ }^{[70]}$ thereby enabling an electrophilic substitution $\mathrm{S}_{\mathrm{E}} \mathrm{Ar}$ process at the remote position.<smiles>c1ccc(-c2ccccn2)cc1</smiles>

45<smiles>O=S(=O)(Cl)c1ccccc1</smiles>

94

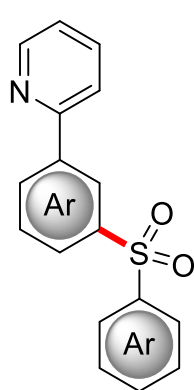

95

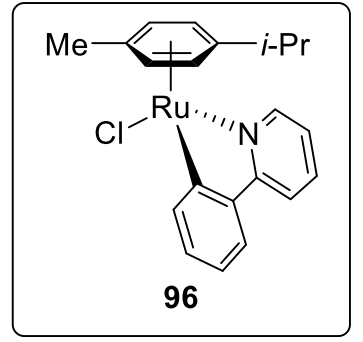

Scheme 34: meta-C-H Sulfonations of phenylpyridines 45 with sulforyl chlroides 94.

In continuation of their previous study, the group of Ackermann explored the pyridyl- and azoledirected meta-C-H alkylation with secondary alkyl halides 97 (Scheme 35). ${ }^{[77]}$ For this transformation, a reversible $\mathrm{C}-\mathrm{H}$ ruthenation and a subsequent alkylation was proposed, which was later on investigated in more detail (vide infra). Here, it was shown that TEMPO inhibits the reaction, while enantiomerically enriched alkyl halides racemize.

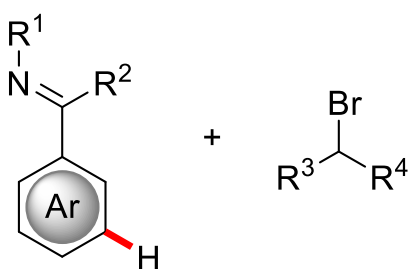

15

97

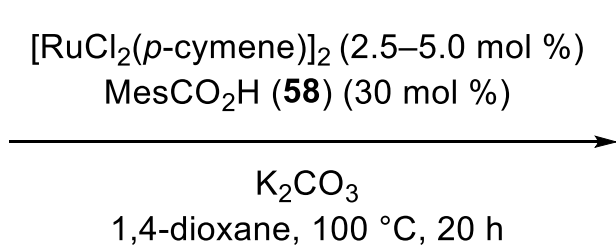

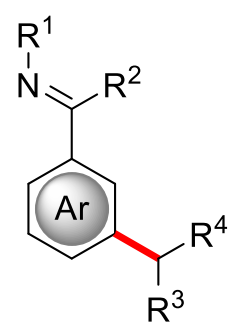

98

Scheme 35: Remote meta-C-H alkylations with secondary alkyl halides 97.

In 2015, Ackermann, ${ }^{[78]}$ and Frost ${ }^{[79]}$ almost simultaneously presented protocols for rutheniumcatalyzed tertiary $\mathrm{C}-\mathrm{H}$ alkylations, occurring exclusively in the meta-position (Scheme 36). In addition to heterocyclic directing groups, Ackermann's method was also applicable to removable pyrimidyl anilines. 
(a) Ackermann (2015)<smiles>O=[Ge]c1ccccc1</smiles>

15,99<smiles>[R]C([R])Br</smiles>

100
$\left[\mathrm{RuCl}_{2}(p \text {-cymene })\right]_{2}(2.5-5.0 \mathrm{~mol} \%)$ Piv-Val-OH (30 mol \%)

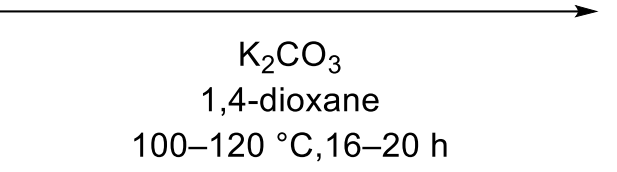

$\mathrm{DG}=$ heteroaryl, 2-pym-NH

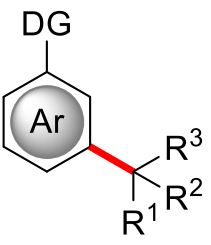

101,102

(b) Frost (2015)<smiles>c1ccc(-c2ccccn2)cc1</smiles>

45<smiles>[R]C([R])([R])[18F]</smiles>

100,103 $(\mathrm{X}=\mathrm{Br}, \mathrm{Cl})$
$\left[\operatorname{RuCl}_{2}(p \text {-cymene })\right]_{2}(5.0 \mathrm{~mol} \%)$ KOAc $(50 \mathrm{~mol} \%)$

$\mathrm{K}_{2} \mathrm{CO}_{3}$ or $\mathrm{KOAc}$

1,4-dioxane, $120^{\circ} \mathrm{C}, 15 \mathrm{~h}$

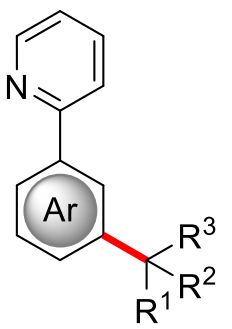

104

Scheme 36: meta-C-H alkylations with tertiary alkyl halides 100, 103.

Both contributions provided strong evidence for a radical pathway rather than an electrophilic one as was already earlier indicated by Ackermann. ${ }^{[77]}$ The following catalytic cycle was proposed by Ackermann (Scheme 37): ${ }^{[78]}$ Starting from ruthenium(II) complex 105, reversible ortho-C-H metalation generates intermediate 106. Subsequent radical addition of $\mathbf{1 0 7}$, which is formed via single-electron transfer to alkyl halide 100,103 , occurs at the para-position with respect to the ruthenium. Afterwards, rearomatization and hydrogen-atom abstraction leads to the formation of 109. Finally, proto-demetalation delivers the alkylated compound $\mathbf{1 0 4}$ and regenerates the active catalyst. Notably, Frost presented a very similar, albeit less detailed mechanistic proposal. ${ }^{[79]}$ 


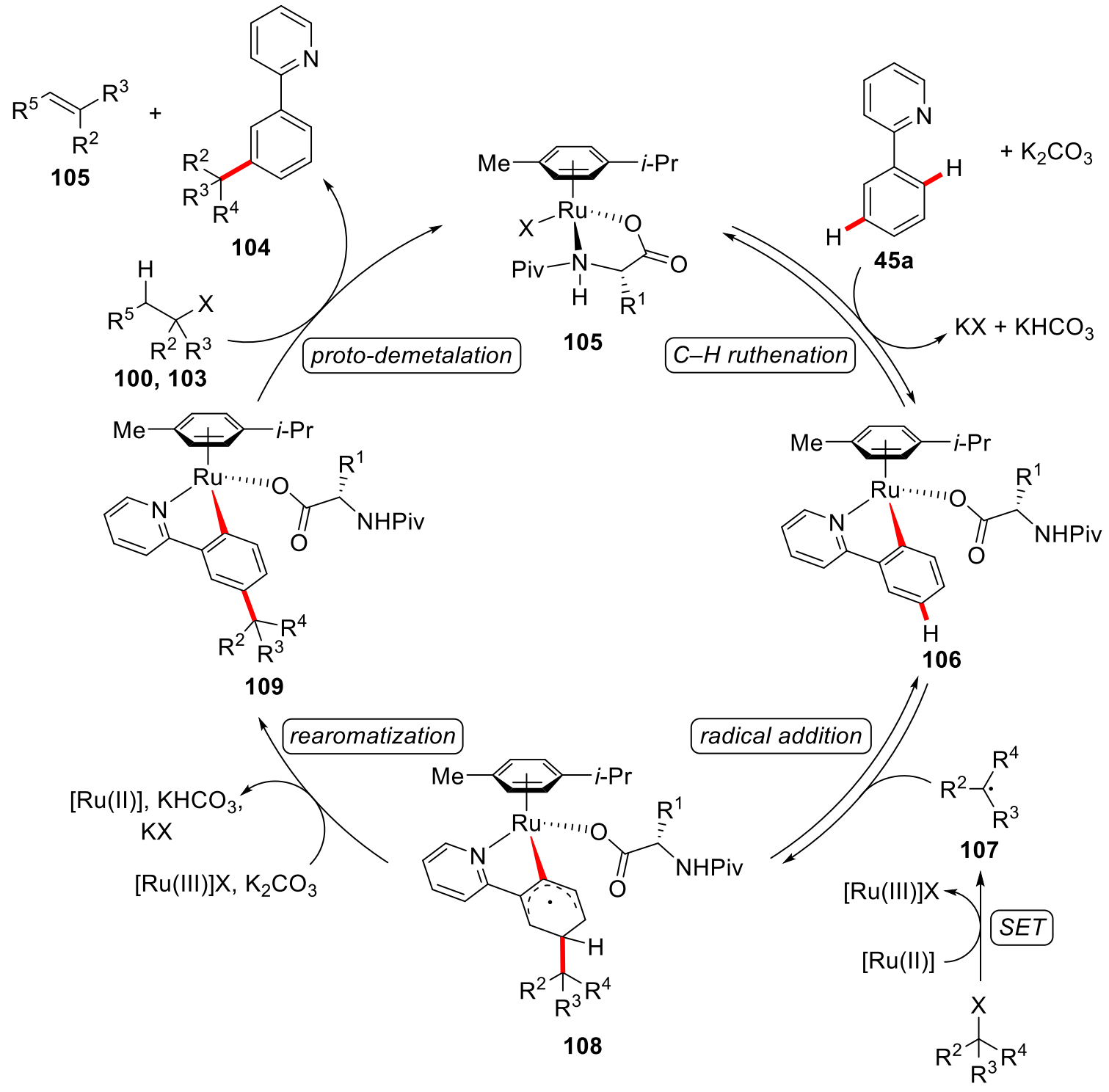

100,103

Scheme 37: Proposed catalytic cycle for remote $\mathrm{C}-\mathrm{H}$ alkylations via ortho-ruthenation.

Thereafter, the transformable/removable directing group approach for meta- $\mathrm{C}-\mathrm{H}$ alkylation was expanded to the use of diazobenzenes $110^{[80]}$ and phenoxypyridines $112^{[81]}$ by the groups of $L i / Y a n g$, and $L i$, thus providing access to substituted anilines and phenols after removal of the directing groups (Scheme 38). 
(a) Li/Yang (2017)

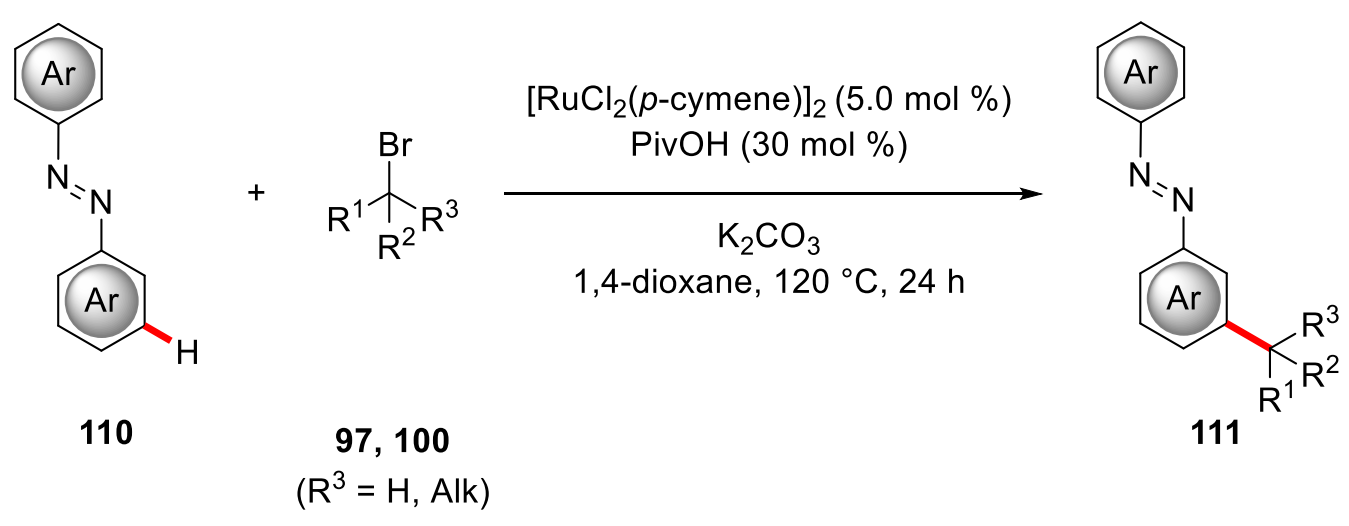

(b) $L i(2017)$

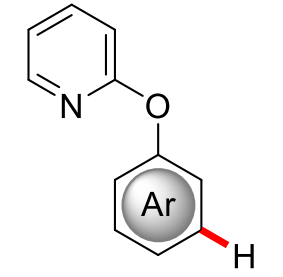

112<smiles>[R]C([R])Br</smiles>

97,100

$\left(R^{3}=H\right.$, Alk $)$
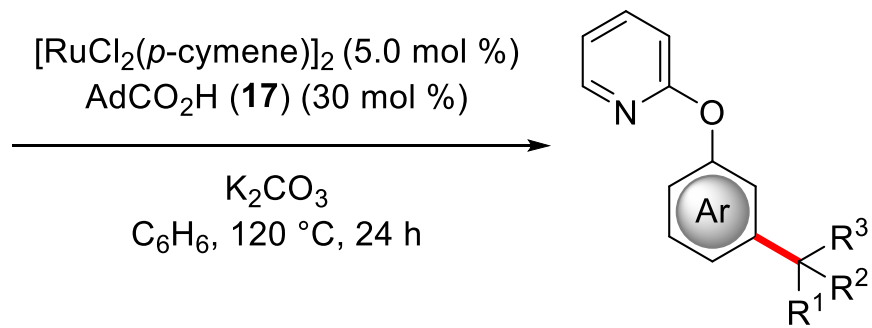

113

Scheme 38: Remote C-H alkylations of diazobenzenes 110 and phenoxypyridines 112 .

Very recently, a breakthrough in meta-C-H alkylations was reported independently by the groups of Ackermann, ${ }^{[82]}$ and Greaney ${ }^{[83]}$ Photochemical generation of the alkyl radical species allowed for a significant decrease in the reaction temperature from $120^{\circ} \mathrm{C}$ to ambient temperature (Scheme 39). Although considerably milder reaction conditions were employed and no additional photocatalyst was required, the use of powerful blue LEDs proved to be necessary. 
(a) Ackermann (2019)<smiles>[R]1cccnc1-c1ccccc1</smiles>

45<smiles>[R]C([R])([R])Br</smiles>

97, 100 $\left(\mathrm{R}^{4}=\mathrm{H}, \mathrm{Alk}\right)$
$\left[\mathrm{RuCl}_{2}(p \text {-cymene })\right]_{2}(5.0 \mathrm{~mol} \%)$

$\left(\mathrm{C}_{6} \mathrm{H}_{5} \mathrm{O}\right)_{2} \mathrm{P}(\mathrm{O}) \mathrm{OH}(30 \mathrm{~mol} \%)$

$$
\mathrm{K}_{2} \mathrm{CO}_{3}
$$

1,4-dioxane, $25^{\circ} \mathrm{C}, 24 \mathrm{~h}$, blue LEDs

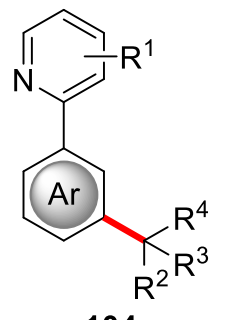

104

(b) Greaney (2019)<smiles>[R]c1cccnc1-c1ccccc1</smiles><smiles>[R]C([R])(I)I</smiles>

45

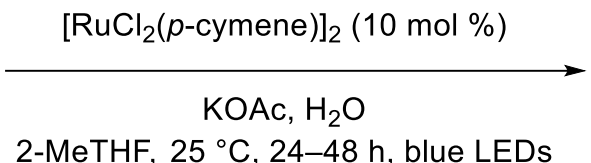

2-MeTHF, $25^{\circ} \mathrm{C}, 24-48 \mathrm{~h}$, blue LEDs

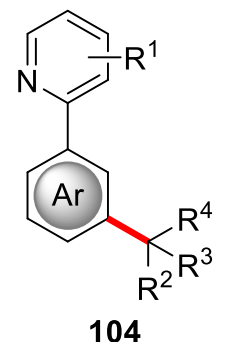

Scheme 39: Photochemical remote $\mathrm{C}-\mathrm{H}$ alkylations of phenylpyridines 45.

Greaney $^{[84]}$ and Huang ${ }^{[85]}$ simultaneously disclosed the ruthenium-catalyzed meta-selective bromination of phenylpyridines $\mathbf{4 5}$ under ruthenium catalysis (Scheme $\mathbf{4 0}$ ). The obtained products 116 were afterwards employed in cross-coupling reactions to access a variety of compounds.

(a) Greaney (2015)<smiles>[R]c1cccnc1-c1ccccc1</smiles>

45

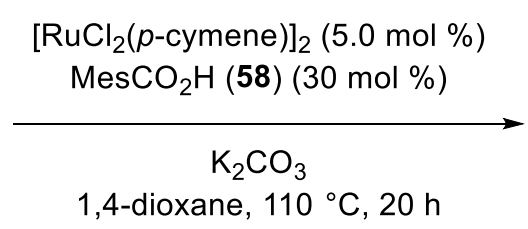

115

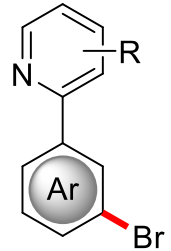

116

(b) Huang (2015)<smiles>[R]c1cccnc1-c1ccccc1</smiles>

45
NBS

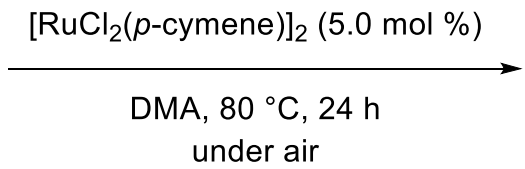

88

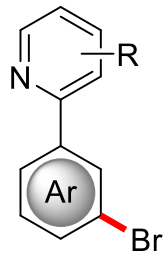

116

Scheme 40: meta-C-H brominations of phenylpyridines 45. 


\subsection{Manganese-Catalyzed C-H Activation}

While $\mathrm{C}-\mathrm{H}$ activation chemistry with $4 \mathrm{~d}$ or $5 \mathrm{~d}$ transition metal catalysts is well-established for numerous transformations and a multitude of compound classes, a number of drawbacks is associated with the use of $4 \mathrm{~d}$ - and $5 \mathrm{~d}$-transition metals. Compared to inexpensive $3 \mathrm{~d}$ transition metals, ${ }^{[86]}$ precious $4 \mathrm{~d}$ and $5 \mathrm{~d}$ transition metals exhibit a higher toxicity ${ }^{[87]}$ and a significantly lower natural abundance. ${ }^{[88]}$ With these aspects in mind, it is hardly surprising, that the application of base metal catalysts for sustainable $\mathrm{C}-\mathrm{H}$ activation has gained enormous momentum throughout the last decade. ${ }^{[12 b]}$ Especially manganese catalysis has emerged as a powerful tool for the construction of $\mathrm{C}-\mathrm{C}$ bonds via a $\mathrm{C}-\mathrm{H}$ activation strategy and was successfully employed in various transformations. ${ }^{[89]}$

In a seminal contribution, Bruce/Stone reported the synthesis of cyclometalated manganese complexes through a reaction of azobenzene (110a) with manganese(I) or manganese(0)-carbonyl complexes (Scheme 41). ${ }^{\left[{ }^{[0]}\right]}$ Thereafter, several ortho-manganated compounds were synthesized and investigated in stoichiometric transformations. ${ }^{[1]}$<smiles>c1ccc(/N=N/c2ccccc2)cc1</smiles>

$110 \mathrm{a}$
$\left[\mathrm{Mn}_{2}(\mathrm{CO})_{10}\right](117)$

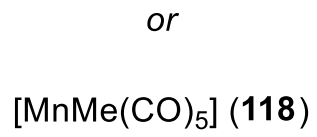

light petroleum $100-120^{\circ} \mathrm{C}, 3-92 \mathrm{~h}$<smiles>O=C([O-])n1c(-c2ccccc2)nc2ccccc21</smiles>

119

Scheme 41: Synthesis of managanacycle 119.

In 2007, Kuninobu/Takai presented the first example of manganese-catalyzed C-H activation operating through an organometallic mode of action. ${ }^{[92]}$ In the presence of $\left[\mathrm{MnBr}(\mathrm{CO})_{5}\right]$ as catalyst phenylimidazole 66a was reacted with aldehyde 120 and silane 121 to deliver silylether 122 (Scheme 42). The presence of silane $\mathbf{1 2 1}$ was required to achieve catalytic turnover, since only trace amounts of the corresponding alcohol were observed in the absence of $\mathbf{1 2 1}$. 
<smiles>[R]C(=O)[CH+]c1ccccc1-c1nccn1C</smiles>

Scheme 42: Manganese-catalyzed C-H activation of phenylimidazole 66a.

The group of Wang disclosed the $\mathrm{C}-\mathrm{H}$ alkenylation of phenylpyridines $\mathbf{4 5}$ with terminal alkynes 123 under manganese catalysis (Scheme 43 ). ${ }^{[93]}$ Key to success was the use of catalytic amounts of $\mathrm{Cy}_{2} \mathrm{NH}$ as additive, since only trace amounts of the desired product were obtained, when the additive was omitted. Based on computational studies, the authors proposed the formation of a manganese-alkynyl complex and $\mathrm{C}-\mathrm{H}$ activation via a ligand-to-ligand hydrogen transfer

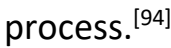

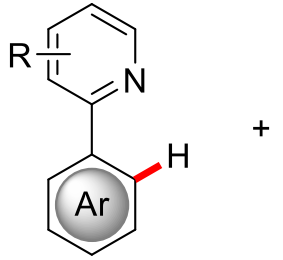

45

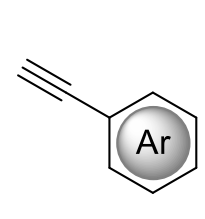

123

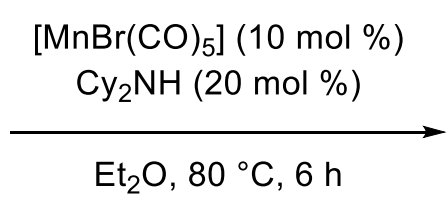

$\mathrm{Et}_{2} \mathrm{O}, 80^{\circ} \mathrm{C}, 6 \mathrm{~h}$

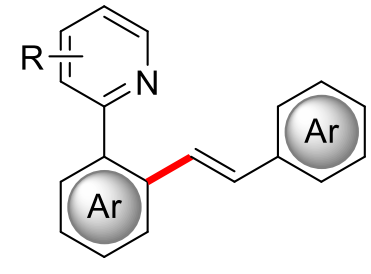

124

Scheme 43: Manganese-catalyzed C-H alkenylations with terminal alkynes 123.

The use of bromoalkynes $\mathbf{1 2 6}$ for the manganese-catalyzed $\mathrm{C}-\mathrm{H}$ alkynylation of indoles $\mathbf{1 2 5}$ containing a pyridyl or pyrimidyl directing group was reported by Ackermann (Scheme 44). ${ }^{[95]}$ It is notable that the developed method was not only applicable to indoles, but could also be applied to tryptophan and small peptides. 


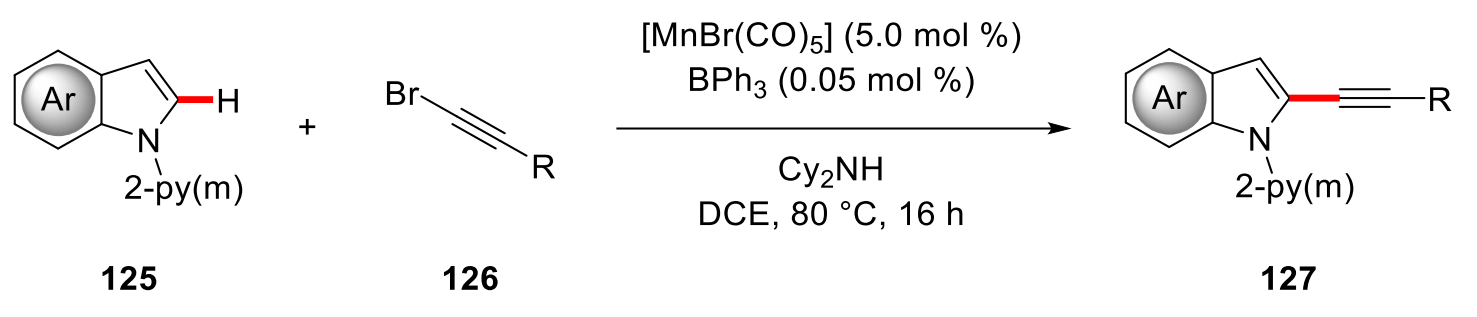

Scheme 44: Manganese-catalyzed C-H alkynylations of indoles 125.

\subsection{C-C Activation by Transition Metal Catalysis}

Despite a plethora of methods for selective $\mathrm{C}-\mathrm{H}$ bond activations, strategies for the activation of equally ubiquitous $\mathrm{C}-\mathrm{C}$ bonds via an organometallic mode of action continue to be less explored. ${ }^{[96]}$ Due to the thermodynamic and kinetic stability of $\mathrm{C}-\mathrm{C}$ bonds, the selective activation of $\mathrm{C}-\mathrm{C}$ bonds in the presence of other $\sigma$-bonds represents a major challenge. With bond dissociation energies of $85-100 \mathrm{kcal} \mathrm{mol}^{-1} \mathrm{C}-\mathrm{C} \sigma$-bonds can be considered comparatively stable and inert. ${ }^{[97]}$ In contrast, the cleavage of a strong $\mathrm{C}-\mathrm{C}$ bond and the formation of a much weaker $\mathrm{M}-\mathrm{C}$ bond is usually energetically unfavorable, since bond dissociation energies for M-Alkyl bonds are typically in the range of $35-50 \mathrm{kcal} \mathrm{mol}^{-1}{ }^{-198]}$ Furthermore, the activation of one $\mathrm{C}-\mathrm{C}$ bond of the substrate and the subsequent formation of a new $\mathrm{C}-\mathrm{C}$ bond in the desired product often does not constitute a considerable change in energy, thus no large thermodynamic driving force can be exploited to enable the desired transformation. Another issue is the kinetic stability of $\mathrm{C}-\mathrm{C}$ bonds, which is caused by the pronounced directional character of $\mathrm{C}-\mathrm{C} \sigma$-bonds. ${ }^{\left[{ }^{[6 d]}\right.}$ An efficient overlap between the bonding $\mathrm{C}-\mathrm{C} \sigma$-orbital and a metal-centered $\mathrm{d}$-orbital requires an energy-demanding distortion of the $\mathrm{C}-\mathrm{C} \sigma$-orbital (Figure 3a). The interaction of a d-orbital with the antibonding $\sigma^{*}$ orbital is also challenging, due to the high energy of the $\sigma^{*}$-orbital (Figure $3 \mathrm{~b}$ ).

(a) interaction with $\mathrm{C}-\mathrm{C} \sigma$-orbital

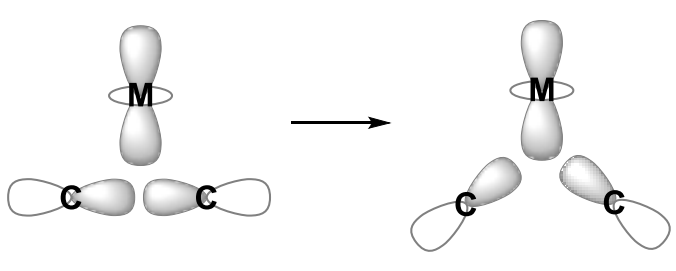

(b) interaction with $C-C \sigma^{*}$-orbital

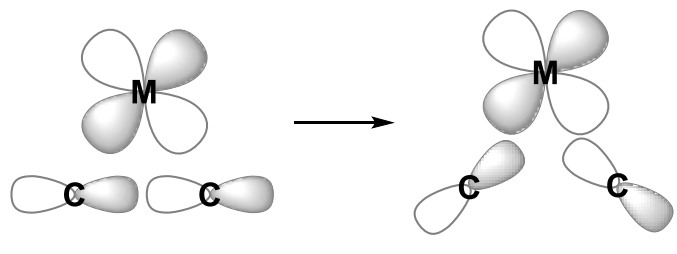

Figure 3: Orbital interactions for $\mathrm{C}-\mathrm{C}$ bond activation. 
Nevertheless, a number of protocols for selective $\mathrm{C}-\mathrm{C}$ bond activations was developed throughout the years by utilizing various strategies to overcome these inherent challenges. One approach, which was first applied by Tipper in the stoichiometric reaction of cyclopropane (128) with a platinum complex to form four-membered metalacycle $130,{ }^{[99]}$ is the use of highly strained ring systems to provide a thermodynamic driving force (Scheme 45). ${ }^{[100]}$ Later on, the opening of strained rings was utilized in a number of catalytic $\mathrm{C}-\mathrm{C}$ activation reactions. ${ }^{[966]}$

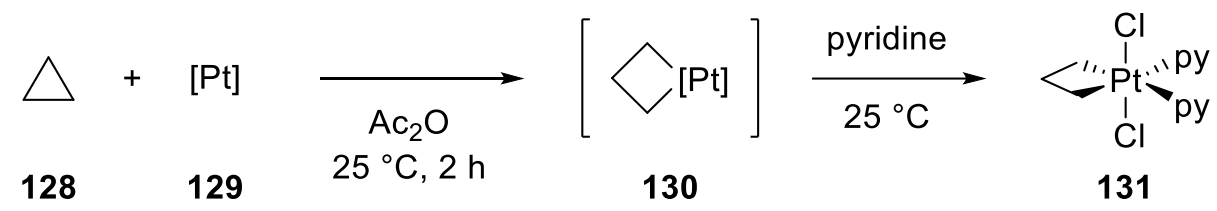

Scheme 45: Stoichiometric reaction of cyclopropane (128) with platinum complex 129.

By combining sustainable transition metal-catalyzed $\mathrm{C}-\mathrm{H}$ activation methodologies with $\mathrm{C}-\mathrm{C}$ activation reactions, highly versatile transformations can be achieved. In this context, Fürstner reported the intramolecular cycloisomerization of substrates $\mathbf{1 3 2}$ bearing an alkylidenecyclopropane motif under rhodium catalysis to deliver entropically favored cycloheptens 133 (Scheme 46). ${ }^{[101]}$<smiles>[R]/C(=C\c1ccccn1)C([R])C=C1CC1</smiles>

132

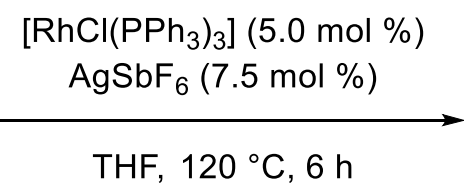

THF, $120^{\circ} \mathrm{C}, 6 \mathrm{~h}$<smiles>[R]C1C=CCCC(=Cc2ccccn2)C1[R]</smiles>

133

Scheme 46: Rhodium-catalyzed C-H/C-C activations of alkylidenecyclopropanes 132.

Ackermann reported the ruthenium-catalyzed intermolecular $\mathrm{C}-\mathrm{H} / \mathrm{C}-\mathrm{C}$ activation of phenylpyridines 45 with methylencyclopropane 134 (Scheme 47). ${ }^{[102]}$ While geminal diphenylsubstituted substrate $\mathbf{1 3 4}$ led to a complete opening of the cyclopropane ring, a conservation of the cyclopropane was observed for other substitution patterns. ${ }^{[103]}$ 
<smiles>[R]c1ccccc1-c1ccccn1</smiles>

45

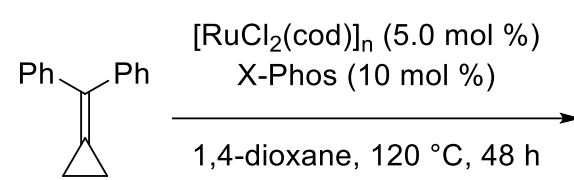

134<smiles>[R]c1cccc(CC(=C)C(c2ccccc2)c2ccccn2)c1-c1ccccc1</smiles>

135<smiles>[R]c1cccc(C/C(C)=C(\c2ccccc2)c2ccccn2)c1-c1ccccc1</smiles>

135'

Scheme 47: Ruthenium-catalyzed C-H/C-C activation with methylenecyclopropane 134.

The group of Huang/Li/Wang disclosed the synthesis of allylated arenes via a chelation-assisted, rhodium-catalyzed $\mathrm{C}-\mathrm{H} / \mathrm{C}-\mathrm{C}$ activation approach with vinylcyclopropanes 136 (Scheme 48). ${ }^{[104]}$ The $E$-configured product was obtained predominantly with $E / Z$ ratios of more than 7:1. Thereafter, a similar reaction, albeit employing a less expensive cobalt catalyst, was developed by Ackermann in 2016. It is noteworthy that, in contrast to previous reports, the thermodynamically less stable $Z$-isomer was observed as the major product. ${ }^{[105]}$ In addition, manganese complexes were also found to be competent catalysts for this $\mathrm{C}-\mathrm{H} / \mathrm{C}-\mathrm{C}$ activation reaction, again leading to a prevalent formation of the $E$-isomer. ${ }^{[106]}$

(a) Huang/Li/Wang (2015)<smiles>CONC(=O)c1ccccc1</smiles>

34<smiles>C=CC1CC1(C#N)C#N</smiles>

136

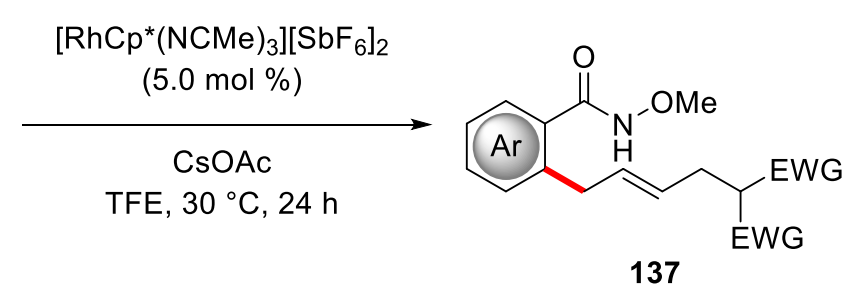

137

(b) Ackermann (2016)

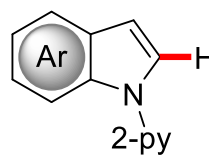

125<smiles>C=CC1CC1(C#N)C#N</smiles>

136

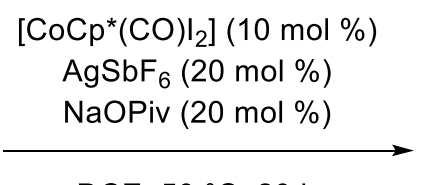

DCE, $50^{\circ} \mathrm{C}, 20 \mathrm{~h}$

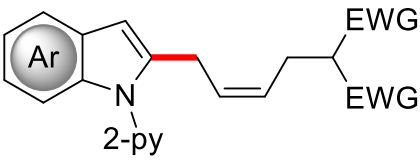

(Z)-138

(c) Ackermann (2017)

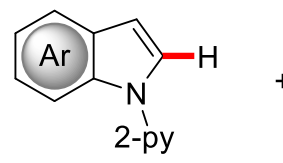

125

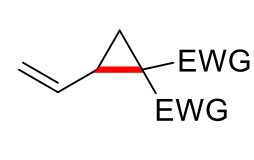

136

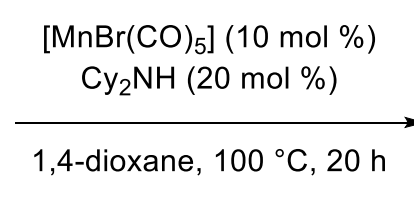

(

1,4-dioxane, $100{ }^{\circ} \mathrm{C}, 20 \mathrm{~h}$

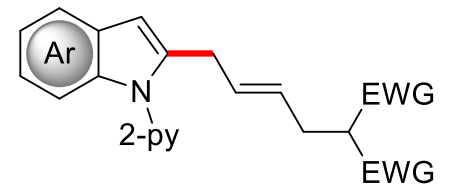

(E)-138

Scheme 48: Transition metal-catalyzed C-H/C-C activations with vinylcyclopropanes 136. 
Over the years, the cleavage of $\mathrm{C}-\mathrm{C}$ bonds in $\alpha$-position to a coordinating functional group via a B-carbon elimination process and the subsequent installation of a new $\mathrm{C}-\mathrm{C}$ bond was wellestablished for various functional groups, including nitriles, carboxylic acids, aldehydes, and ketones. ${ }^{[96 d, 96 f]}$ A C $-C$ activation strategy for the formation of biaryls $\mathbf{1 4 0}$ was first applied to benzylic alcohols 139 by Miura in 2001 (Scheme 49). ${ }^{[107]}$ The reaction was proposed to occur via b-carbon elimination, leading to the stoichiometric formation of ketone $\mathbf{1 4 1}$ as byproduct.

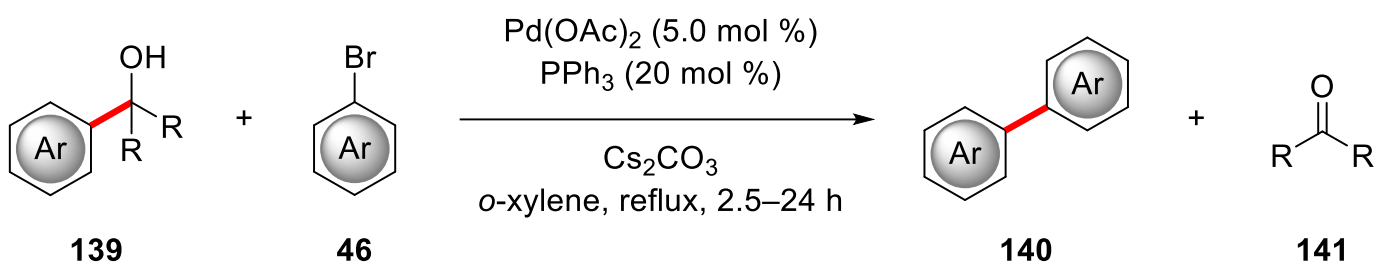

Scheme 49: Synthesis of biaryls 140 by C-C arylation of benzylic alcohols 139.

Afterwards, structurally related secondary benzylic alcohols $\mathbf{1 4 2}$ were successfully employed in a chelation-assisted C-C alkenylation reaction under rhodium catalysis by the group of Shi (Scheme 50). ${ }^{[108]}$ In contrast to the previous report by Miura, the introduction of a pyridyl substituent as directing group proved necessary to deliver the alkenylated compounds 143 . Thereafter, Morandi reported the cobalt-catalyzed $\mathrm{C}-\mathrm{C}$ cyanation and allylation employing the same substrate. ${ }^{[109]}$

(a) Shi (2011)

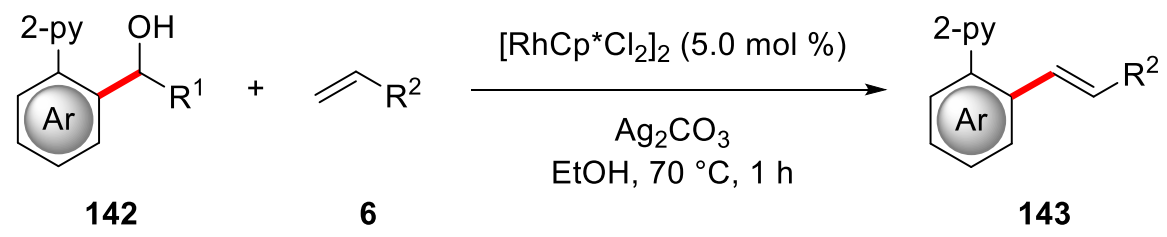

(b) Morandi (2015)

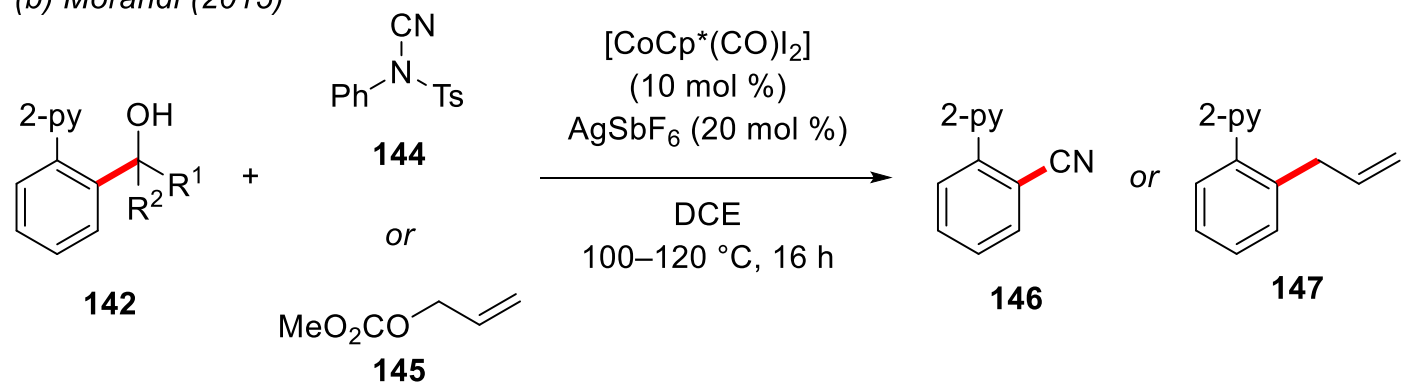

Scheme 50: C-C alkenylations, cyanations, and allylations of benzylic alcohols 142. 


\section{Objectives}

During the last years, transition metal-catalyzed $\mathrm{C}-\mathrm{H}$ activation has emerged as a powerful method for the selective construction of $\mathrm{C}-\mathrm{C}$ and $\mathrm{C}-\mathrm{Het}$ bonds and has greatly expanded the toolbox of synthetic chemistry. ${ }^{[12,21,25]}$ Ruthenium catalyst were recognized as a potent alternative to costly palladium or rhodium catalysts and have enabled a number of unique transformations, especially in terms of remote $\sigma$-activation. ${ }^{[27,71]}$ However, a detailed mechanistic understanding of these transformations is often lacking and thus impedes the improvement of established catalytic systems as well as the rational design of novel synthetic protocols. Therefore, the main objective of this thesis was directed towards detailed mechanistic investigations of various $\mathrm{C}-\mathrm{H}$ and $\mathrm{C}-\mathrm{C}$ activation processes by means of experiment and computation.

Protocols for ruthenium-catalyzed meta-selective $\mathrm{C}-\mathrm{H}$ activations are frequently restricted to strongly coordinating, nitrogen-containing heterocycles as directing groups, thereby limiting the applicability towards biologically relevant structures (vide supra). With this in mind, a method for the meta- $\mathrm{C}-\mathrm{H}$ bromination of bioactive purines should be investigated and used as a platform for further diversifications (Scheme 51).

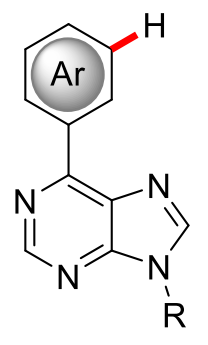

148

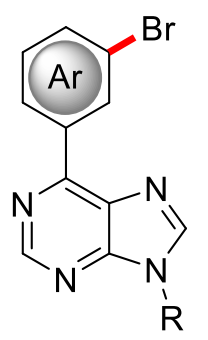

149

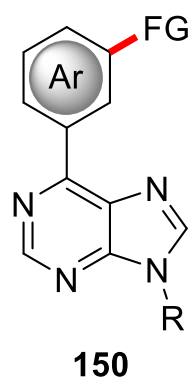

150

Scheme 51: meta-C-H bromination of purines 148 under ruthenium catalysis.

Furthermore, based on the ruthenium-catalyzed meta- $\mathrm{C}-\mathrm{H}$ alkylation strategies developed by Ackermann, ${ }^{[77,78]}$ the application of ketimines as easily transformable directing groups in metaselective $\mathrm{C}-\mathrm{H}$ alkylations should be explored. In addition to the development of a novel synthetic protocol, detailed mechanistic investigations should provide valuable insights into the catalyst's mode of action (Scheme 52). 


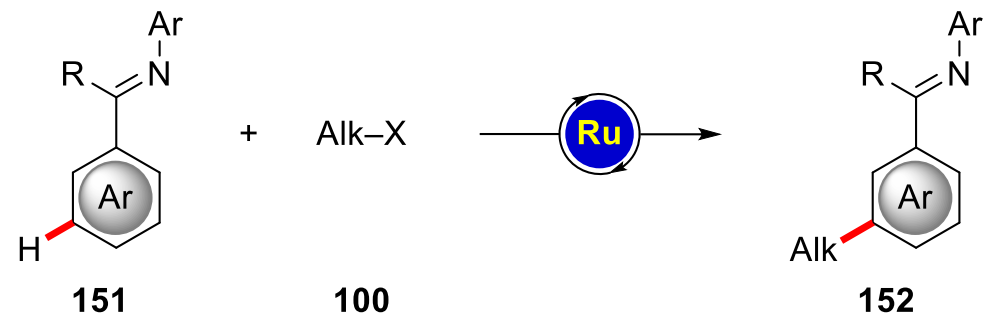

Scheme 52: Ruthenium catalysis for remote $\mathrm{C}-\mathrm{H}$ alkylation of ketimines 151.

In the context of remote $\mathrm{C}-\mathrm{H}$ activations, the prediction of ortho/meta-selectivities by means of computational chemistry could contribute to a deeper understanding of the reaction mechanism and to the identification of potential key intermediates. To this end, various conceivable cyclometalated complexes with different substrates and coordination environments should be evaluated and compared to experimental observations.

The use of easily accessible carboxylic acids as traceless directing groups in transition metalcatalyzed $\mathrm{C}-\mathrm{H}$ activation holds enormous potential. ${ }^{[56]}$ So far, detailed insights into the reaction mechanism of decarboxylative $\mathrm{C}-\mathrm{H}$ activations under ruthenium catalysis remained scarce and should prove instrumental to the development of novel transformations. Especially the competition between decarboxylative and annulative processes is worth investigating (Scheme $53)$.

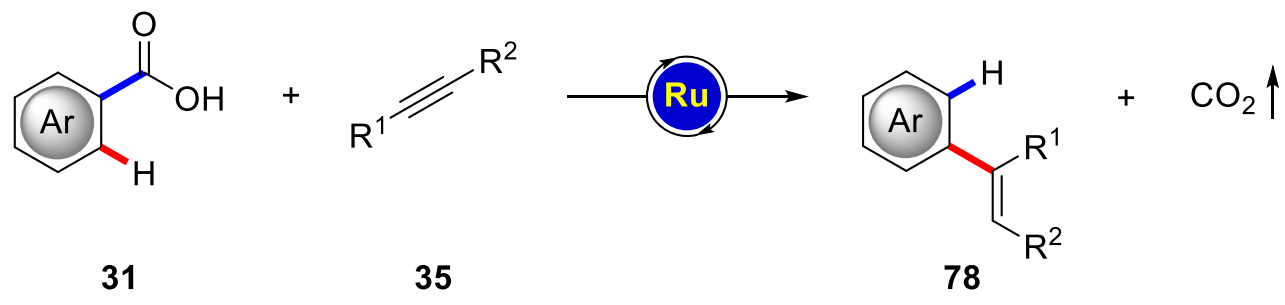

Scheme 53: Decarboxylative $\mathrm{C}-\mathrm{H}$ activation of benzoic acids $\mathbf{3 1}$ under ruthenium catalysis.

The $\mathrm{C}-\mathrm{H}$ activation of weakly coordinating aryl acetamides $\mathbf{1 5 3}$ was previously achieved by palladium catalysis, but was thus far not explored with less costly ruthenium catalysts. ${ }^{[110,111]}$ Due to a presumed formation of an unusual and challenging six-membered ruthenacycle, the utilization of these substrates in ruthenium-catalyzed $\mathrm{C}-\mathrm{H}$ activation should be experimentally studied and a comparison with the corresponding, more commonly occuring five-membered metalacycle conducted (Scheme 54). 


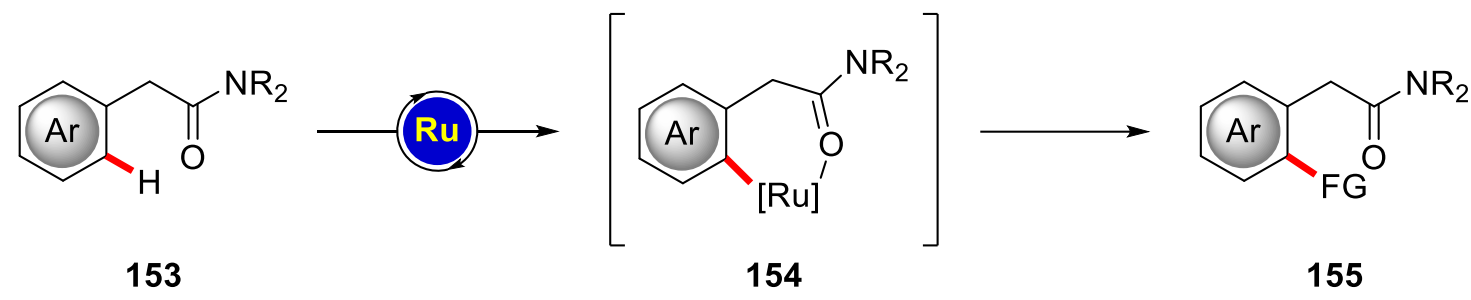

Scheme 54: Ruthenium-catalyzed distal C-H activation of aryl acetamides 153.

Furthermore, the development of sustainable protocols for the diversification of ferrocenes via a $\mathrm{C}-\mathrm{H}$ activation approach is highly desirable due to the application of substituted ferrocenes as inter alia ligands ${ }^{[112]}$ and bioactive molecules. ${ }^{[113]}$ Different weakly coordinating directing groups for direct $\mathrm{C}-\mathrm{H}$ arylations of ferrocenes under ruthenium catalysis should be investigated with respect to the $\mathrm{C}-\mathrm{H}$ ruthenation step and the stability of the generated metalacycle (Scheme 55).

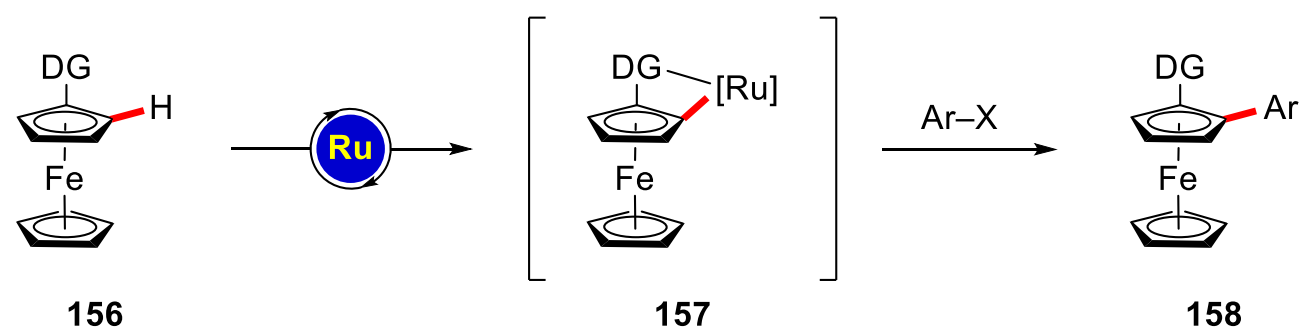

Scheme 55: $\mathrm{C}-\mathrm{H}$ arylation of ferrocenes 156 with ruthenium catalysts.

During the last years, transition metal-catalyzed $\mathrm{C}-\mathrm{H}$ activation was recognized as a convenient strategy for the last-stage diversification of peptides and amino acids. ${ }^{[114]}$ Computational studies on the hydroarylation with indoles $\mathbf{1 2 5}$ as a model substrate for tryptophan should be conducted to gain insight into the catalytic pathway. In addition, an analysis of the ligand influences on the energy profile could lead to the identification of more efficient catalysts (Scheme 56).

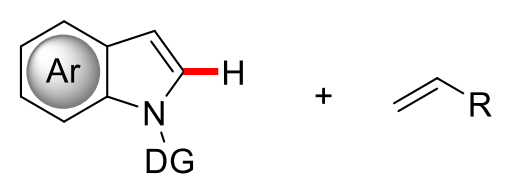

125

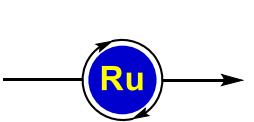

6

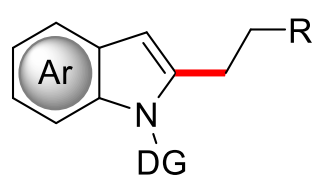

159

Scheme 56: Hydroarylation with indoles 125 under ruthenium catalysis. 
In an earlier report on ruthenium-catalyzed $\mathrm{C}-\mathrm{H}$ arylations with aryl halides, the group of Ackermann observed a competing oxidative $\mathrm{C}-\mathrm{H} / \mathrm{C}-\mathrm{H}$ activation process, in which the aryl halide acts as the oxidant. ${ }^{[115]}$ However, no explanation concerning this change in mechanism was presented at that time and the selectivity-controlling parameters remained unclear. An in-depth study on the rate- and selectivity-controlling factors as well as the catalyst's mode of action should be performed and should prove invaluable, not only to the understanding of oxidative $\mathrm{C}-\mathrm{H} / \mathrm{C}-\mathrm{H}$ activations with ruthenium catalysts, but also in providing new insights into well-established $\mathrm{C}-\mathrm{H}$ arylation processes (Scheme 57).

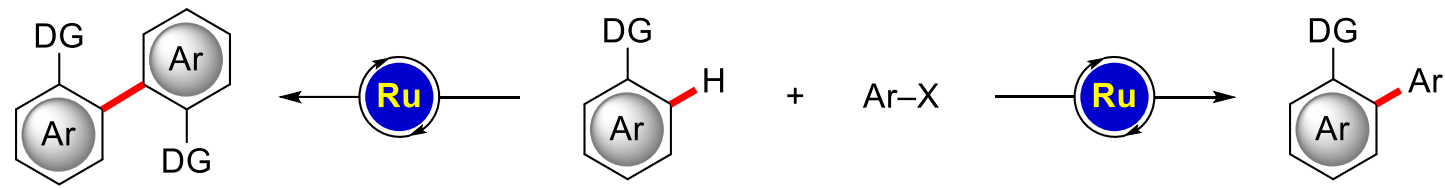

Scheme 57: Ruthenium-catalyzed $\mathrm{C}-\mathrm{H} / \mathrm{C}-\mathrm{H}$ activation and $\mathrm{C}-\mathrm{H}$ arylation.

Throughout the last years, a trend towards the use of earth-abundant, inexpensive ${ }^{[86]}$ base metal catalysts for $\mathrm{C}-\mathrm{H}$ activation could be witnessed (Figure 4). In that regard, the potential of manganese catalysis for the late-stage diversification of tryptophan-containing peptides was revealed in a previous report on $\mathrm{C}-\mathrm{H}$ alkynylation (vide supra). ${ }^{[95]}$ Consequently, computational investigation of the key elementary steps of a related manganese-catalyzed $\mathrm{C}-\mathrm{H}$ allylation of tryptophan $\mathbf{1 6 0}$ should contribute to a deeper understanding of the turnover-limiting steps of the reaction mechanism (Scheme 58).

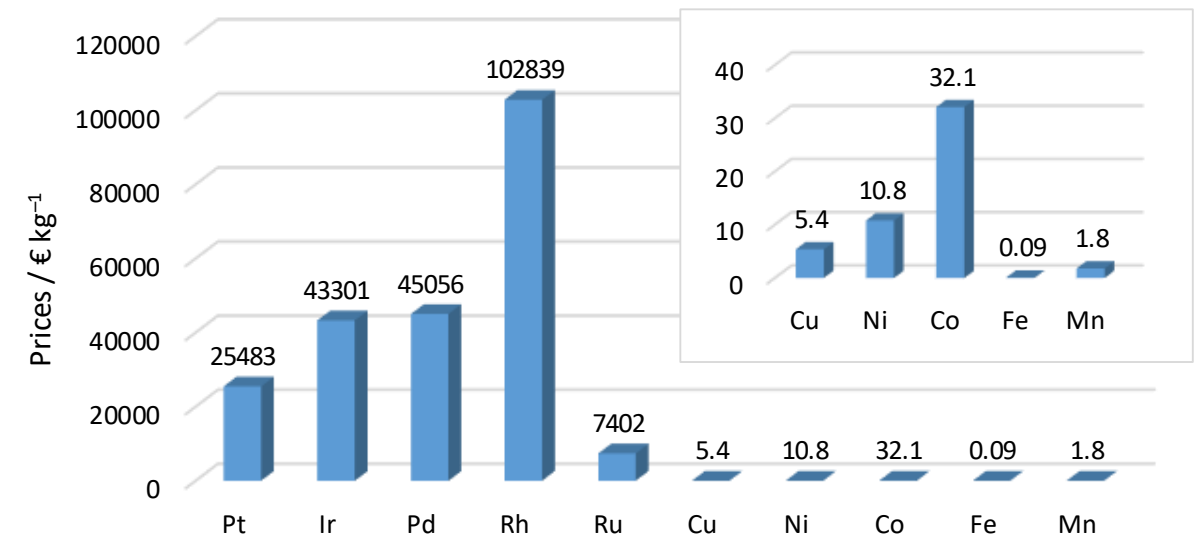

Figure 4: Prices of commonly employed metals in $€$ per kg. 
<smiles>[R1]NC([R])Cc1c(CC([R])C([R])=O)c2ccccc2n1[O-]</smiles>

160<smiles>[R]C(=C)C([R])[Ge]</smiles>

Mn<smiles>[R]C=C([R])Cc1c(CC(N[R1])C([R])=O)c2ccccc2n1[O+]</smiles>

162

Scheme 58: Manganese-catalyzed C-H allylation of tryptophan 160.

Through transition metal-catalyzed $\mathrm{C}-\mathrm{C}$ activation strategies a number of $\mathrm{C}-\mathrm{C}$ and $\mathrm{C}-\mathrm{Het}$ bond formations can be achieved, which cannot be realized by other methods. ${ }^{[96]}$ The use of benzylic alcohols 142 as substrates in the context of manganese-catalyzed C-C allylations with cyclic carbonates and carbamates should be explored. In addition to the user-friendly access to synthetically useful allylated arenes, detailed studies of the manganese-catalyzed C-C activation process could provide novel insights into the fundamental differences of $\mathrm{C}-\mathrm{C}$ and $\mathrm{C}-\mathrm{H}$ activation reactions (Scheme 59).

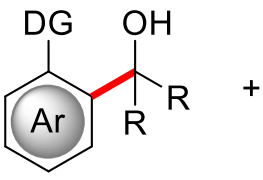

142<smiles>C=CC1C[Y]2C(=O)OC21</smiles>

163 $(Y=O, N R)$

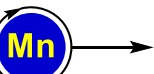<smiles>[Y]C/C=C/Cc1ccccc1[2H]</smiles>

164

$(\mathrm{Y}=\mathrm{O}, \mathrm{NR})$

Scheme 59: $C-C$ allylation of benzylic alcohols 142 under manganese catalysis. 


\section{Results and Discussion}

\subsection{Ruthenium-Catalyzed meta-Selective C-H Bromination}

Despite a multitude of protocols for directing group-enabled ortho-selective $\mathrm{C}-\mathrm{H}$ activation, procedures for the selective functionalization of remote $\mathrm{C}-\mathrm{H}$ bonds are considerably less explored and are often limited to biologically less relevant phenylpyridine as the substrate (vide supra).

Purines are important structural motifs in biology and biomolecular chemistry, while unnatural nucleosides are employed as anticancer or antiviral agents in drugs or as biological probes. ${ }^{[16]}$ Therefore, procedures allowing for the diversification of purine-based molecules are highly desirable and could lead to the discovery of novel, biologically active compounds.

To this end, Dr. S. Warratz and Dr. D. J. Burns in the Ackermann group developed a strategy for the meta-selective $\mathrm{C}-\mathrm{H}$ bromination of arylated purines $\mathbf{1 4 8}$ under ruthenium catalysis (Scheme 60). ${ }^{[117]}$ Excellent catalytic performance was observed with inexpensive $\mathrm{RuCl}_{3} \cdot 3 \mathrm{H}_{2} \mathrm{O}$ as catalyst and, remarkably, also heterogeneous $\mathrm{Ru} @ \mathrm{SiO}_{2}$ proved to be a viable and recyclable catalyst for this transformation.

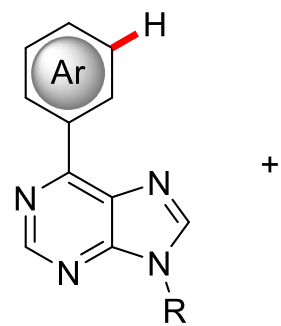

148

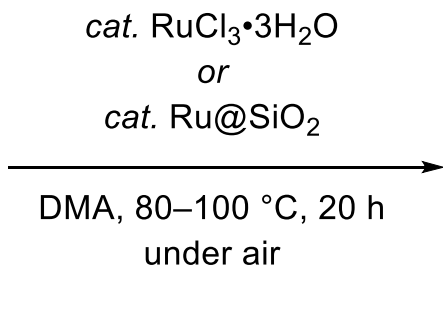

88

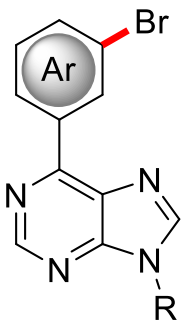

149

Scheme 60: Optimized reaction conditions for the meta-selective $\mathrm{C}-\mathrm{H}$ bromination of purines

148.

\subsubsection{Fluorescent Tag Labelling}

To demonstrate the synthetic utility of the meta-selective $\mathrm{C}-\mathrm{H}$ bromination strategy, a pyrene motif was introduced as a fluorescent tag into the purine base via a palladium-catalyzed Sonogashira-Hagihara cross-coupling reaction, delivering alkynylated compound $150 \mathrm{~b}$ in excellent yield (Scheme 61). ${ }^{[118]}$ 


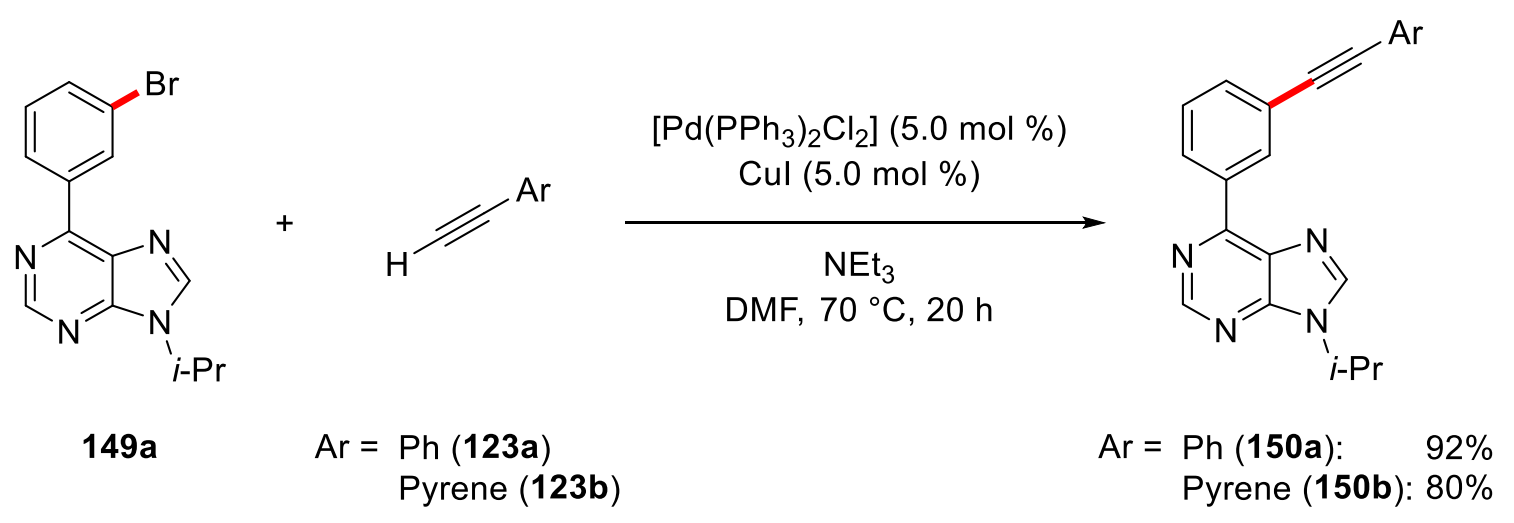

Scheme 61: Fluorescent tag labelling of brominated purine 149a.

The pyrene-labelled compound 150b exhibited very good fluorescence properties with emission maxima at 402 and $423 \mathrm{~nm}$ at excitation wavelengths of 295 or $360 \mathrm{~nm}$, which corresponds to a Stokes shift of up to $128 \mathrm{~nm}$. In contrast, compound 150a, substituted with a simple phenyl moiety, only showed neglectable emission intensities (Figure 5).

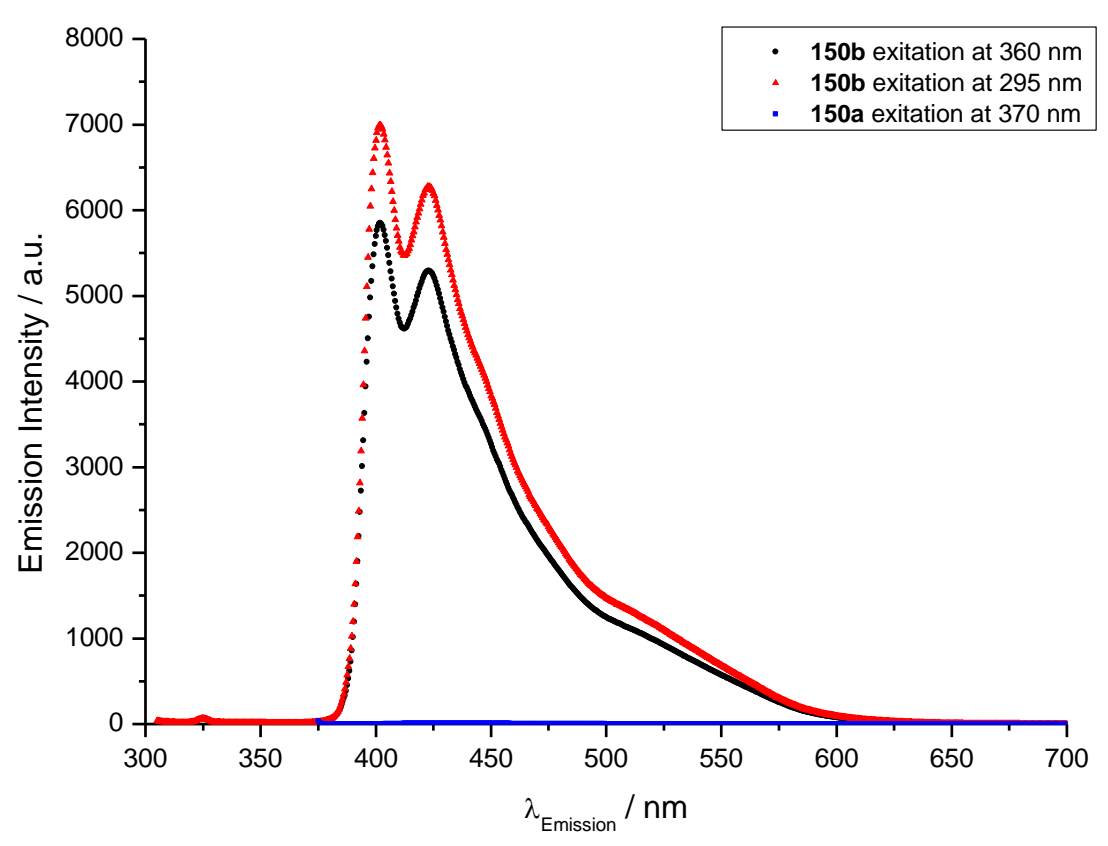

Figure 5: Fluorescence spectra of 150a and 150b. 


\subsubsection{Mechanistic Studies}

To gain insight into the catalyst's mode of action, mechanistic investigations were performed. When the reaction was performed in the presence of isotopically labelled $\mathrm{D}_{2} \mathrm{O}$ as cosolvent, a significant $\mathrm{H} / \mathrm{D}$ exchange was not observed in the product 149a or in the reisolated substrate 148a, which is indicative of a irreversible $\mathrm{C}-\mathrm{H}$ activation step (Scheme 62).

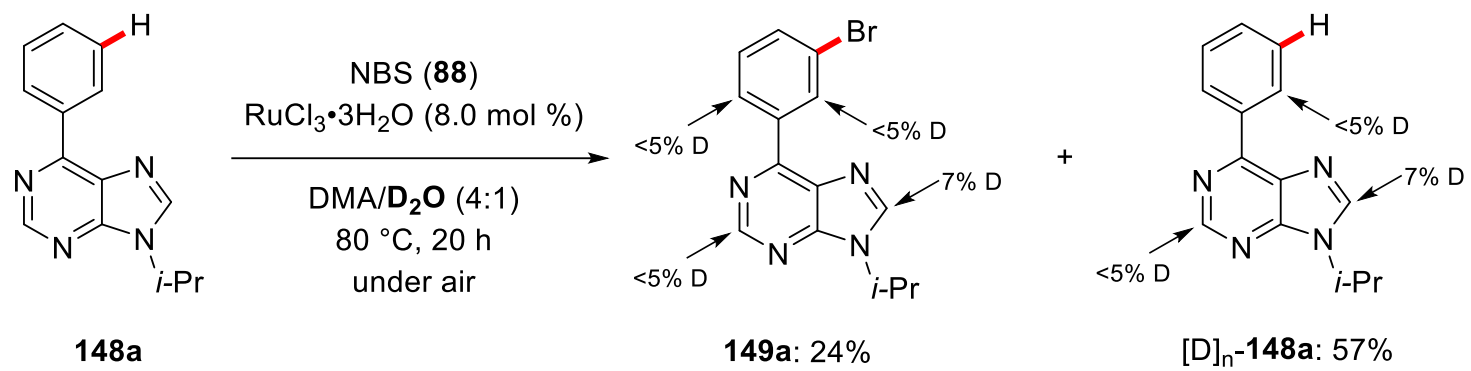

Scheme 62: H/D exchange study.

Kinetic analysis of the reaction revealed saturation kinetics with respect to the concentration of $\mathrm{RuCl}_{3} \cdot 3 \mathrm{H}_{2} \mathrm{O}$ (Figure 6a). For catalyst loadings of up to $8 \mathrm{~mol} \%$ a reaction order of 1 was determined, while at higher concentrations an independence of the rate towards the concentration was observed. This observation can be rationalized by a limited solubility of $\mathrm{RuCl}_{3} \cdot 3 \mathrm{H}_{2} \mathrm{O}$ in DMA, which limits the actual concentration in solution. Furthermore, the observed rate was found to be independent of the phenylpurine 148a concentration, suggesting that the substrate is not involved in any kinetically relevant elementary step during the catalysis (Figure $6 b)$. 


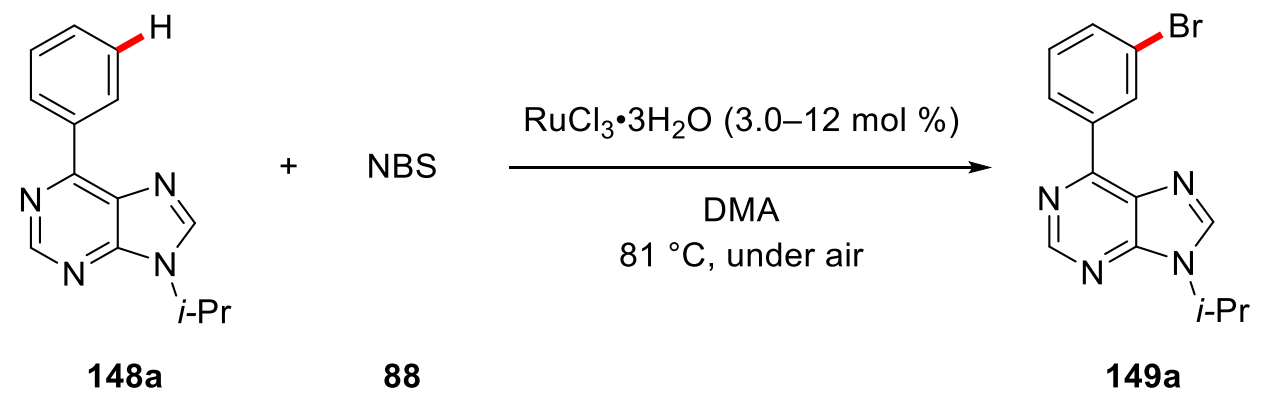

(a) Order in $\mathrm{RuCl}_{3} \cdot 3 \mathrm{H}_{2} \mathrm{O}$

(b) Order in purine $\mathbf{1 4 8 a}$
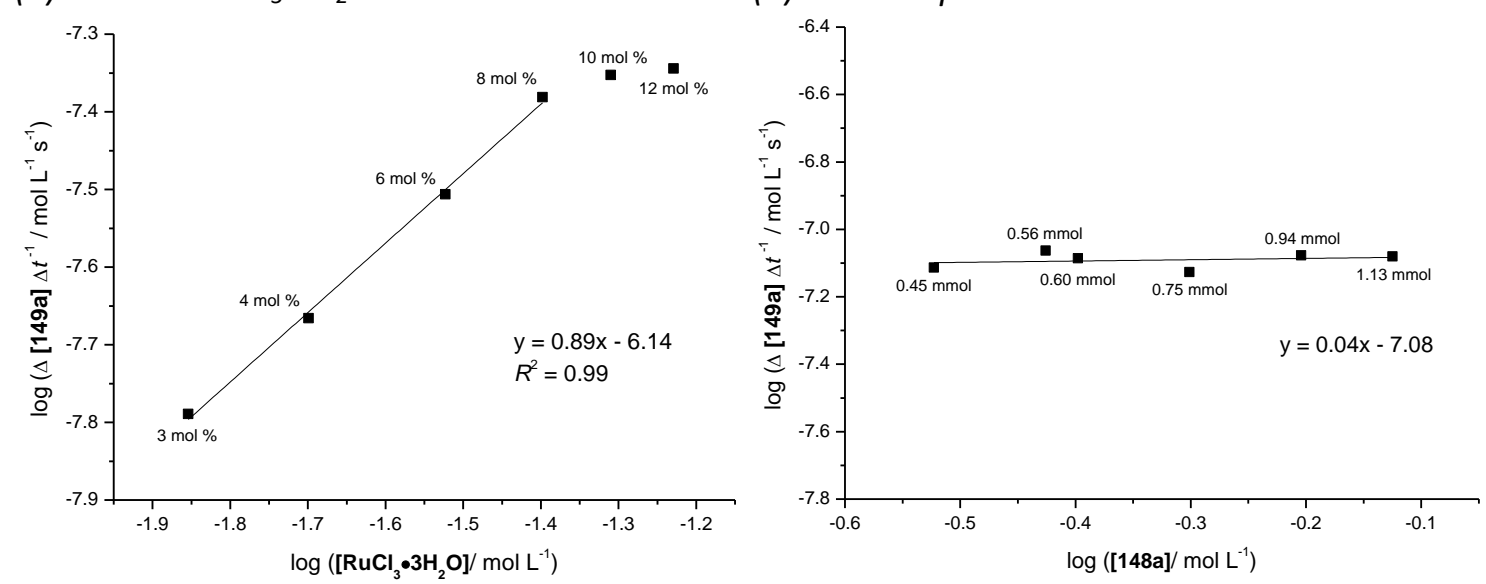

Figure 6: Reaction order with respect to the (a) $\mathrm{RuCl}_{3} \cdot 3 \mathrm{H}_{2} \mathrm{O}$ and (b) purine 148a concentration.

To test if the independence towards the substrate concentration is a unique behavior of phenylpurines 148 , phenylpyridine (45a) was studied as well. As expected, the concentration of phenylpyridine (45a) was also not kinetically relevant (Figure 7). Based on these results it can be assumed, that the substrate is involved in a reversible process - most likely a coordination of the substrate to ruthenium - taking place before the turnover-limiting step. 


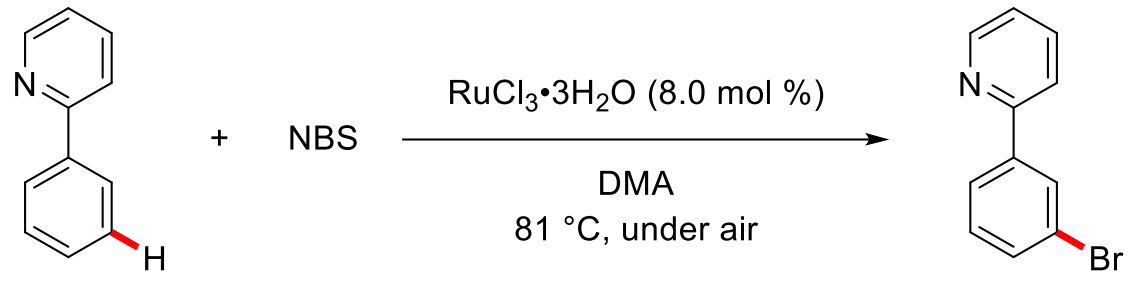

45a

88

$116 a$

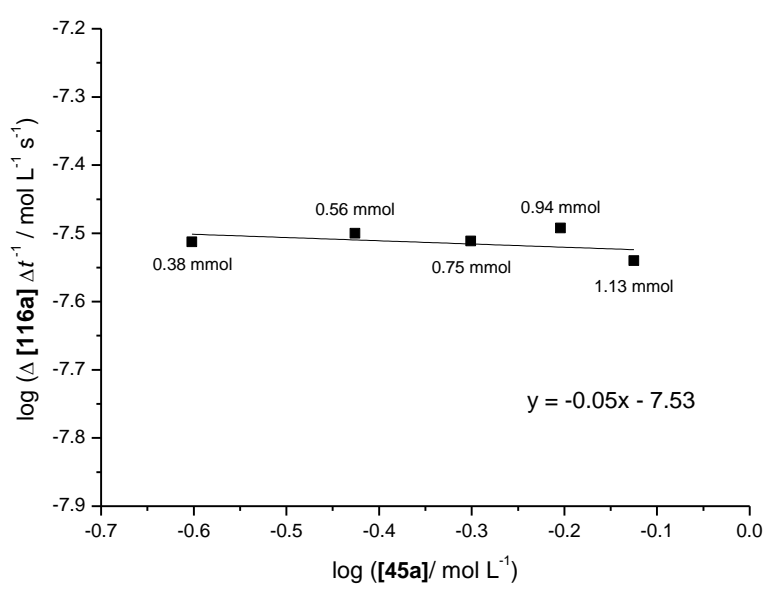

Figure 7: Reaction order with respect to phenylpyridine 45a concentration.

\subsection{Ruthenium-Catalyzed meta-C-H Alkylation of Ketimines}

During the last years, an increasing number of protocols for remote $\mathrm{C}-\mathrm{H}$ functionalization has been developed and various transition metal catalysts could be successfully employed (vide supra). Nevertheless, many protocols are only applicable to a single class of substrates and cannot be readily adapted to the syntheses of different target molecules. Furthermore, meta-selective transformations under ruthenium catalysis were so far limited to strongly coordinating, nitrogencontaining heterocycles, such as pyridines and pyrimidines, as directing groups. ${ }^{[11]}$ These heterocycles are usually difficult to modify and their removal often requires harsh conditions, which represents a major drawback of the otherwise elegant strategies.

The use of ketimines as directing groups constitutes an ideal choice as these compounds can be easily hydrolyzed to yield synthetically useful ketones or directly converted into numerous valuable functional groups. ${ }^{[119]}$

meta-Alkylated arenes are a structural motif, that can be found in a number of drug molecules, natural products, and crop protection agents (Scheme 63). ${ }^{[120]}$ Therefore, the development of novel, sustainable protocols for the introduction of alkyl-substituents in positions, which are not accessible via classical synthetic approaches, is highly desirable. 
<smiles>CC(=O)c1ccc2c(c1)C1CCCC1C(c1cc3c(cc1Br)OCO3)N2</smiles>

GPR30 specific ligand<smiles>CC(C(=O)O)c1cccc(C(=O)c2ccccc2)c1</smiles>

Ketoprofen analgesic, anti-inflammatory drug

Scheme 63: Representative meta-alkylated phenones in pharmaceuticals.

K. Korvorapun, Dr. J. Li, and Dr. S. De Sarkar in the Ackermann group optimized the reaction conditions for the ruthenium-catalyzed remote $\mathrm{C}-\mathrm{H}$ alkylations of ketimines $\mathbf{1 5 1}$ with optimal results being achieved with an in situ formed ruthenium-bisadamantylcarboxylate complex as the catalyst and $\mathrm{PhCMe}_{3}$ as the solvent (Scheme 64). ${ }^{[121]}$

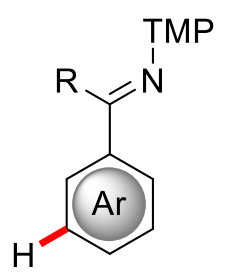

151

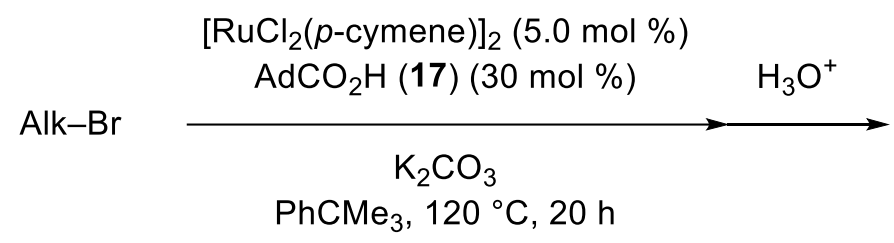

100

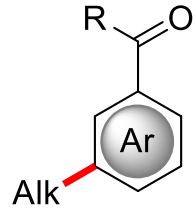

165

Scheme 64: Optimized reaction conditions for meta-selective $\mathrm{C}-\mathrm{H}$ alkylations of ketimines 151.

\subsubsection{Scope of the meta-Selective C-H Alkylation}

The versatility of the ruthenium-catalyzed remote $\mathrm{C}-\mathrm{H}$ alkylation was investigated with a number of differently substituted ketimines 151 (Scheme 65). Substituents in the para-position were generally well tolerated including a structurally complex cholesterol moiety, which delivered the desired product 165 aa in acceptable yield. In addition, dimethylamino and even thiophene motifs were well accepted in the ruthenium catalysis, highlighting the robustness of the established procedure (165ba, $165 \mathrm{bb}$ and $165 \mathrm{ca})$. 

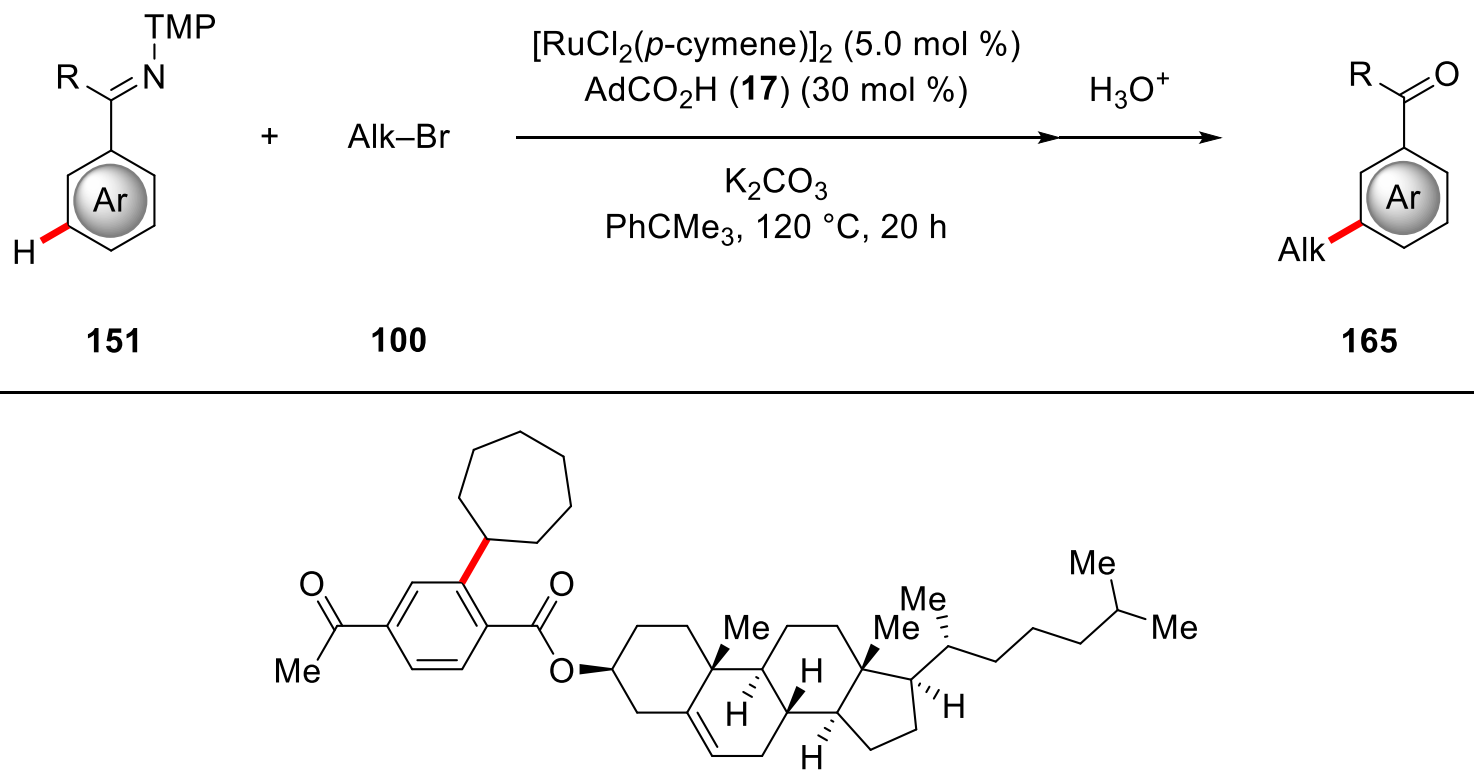

165aa: $57 \%$<smiles>CC(=O)c1ccc(OC(=O)c2ccc(N(C)C)cc2)c(C2CCCCCC2)c1</smiles>

165ba: $64 \%$<smiles>CC(=O)c1ccc(OC(=O)c2ccc(N(C)C)cc2)c(C(C)(C)C)c1</smiles>

165bb: $59 \%$<smiles>CC(=O)c1ccc(OC(=O)c2ccsc2)c(C2CCCCCC2)c1</smiles>

165ca: $34 \%$

Scheme 65: Ruthenium-catalyzed meta-C-H alkylations of ketimines.

\subsubsection{Additive Test}

To further evaluate the tolerance of the remote meta-alkylation strategy towards various functionalities, a robustness test was performed (Table 1). This additive test allows for the evaluation of functional groups, that cannot be readily incorporated into the substrate, such as amines or carbonyls. Although steric and electronic influences on the substrate are neglected in this methodology, it provides a general overview of potentially viable functional groups. Among others, ketones, alkenes, chlorides, and benzofuranes were well-tolerated (entries 2, 6, 11, and 15), whereas benzoxazole, 2 -chloroquinoline and $\mathrm{N}$-methylimidazole completely suppressed all 
reactivity (entries 18, 19, and 22). Additives containing Brønsted-basic functionalities underwent protonation during hydrolysis of the ketimine and could therefore not be detected afterwards.

Table 1: Additive test for meta-C-H alkylations.<smiles>CC(=N)c1ccc(F)cc1</smiles>

$151 d$<smiles>BrC1CCCCCC1</smiles>

$100 \mathrm{a}$
1) $\left[\mathrm{RuCl}_{2}(p \text {-cymene })\right]_{2}(5.0 \mathrm{~mol} \%)$ $\mathrm{AdCO}_{2} \mathrm{H}(17)(30 \mathrm{~mol} \%)$ Additive (1.0 equiv)

$\mathrm{K}_{2} \mathrm{CO}_{3}$

$\mathrm{PhCMe}_{3}, 120^{\circ} \mathrm{C}, 20 \mathrm{~h}$

2) $\mathrm{HCl}(2 \mathrm{~N}), 23^{\circ} \mathrm{C}, 3 \mathrm{~h}$

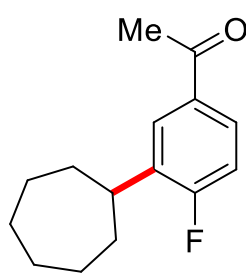

165da

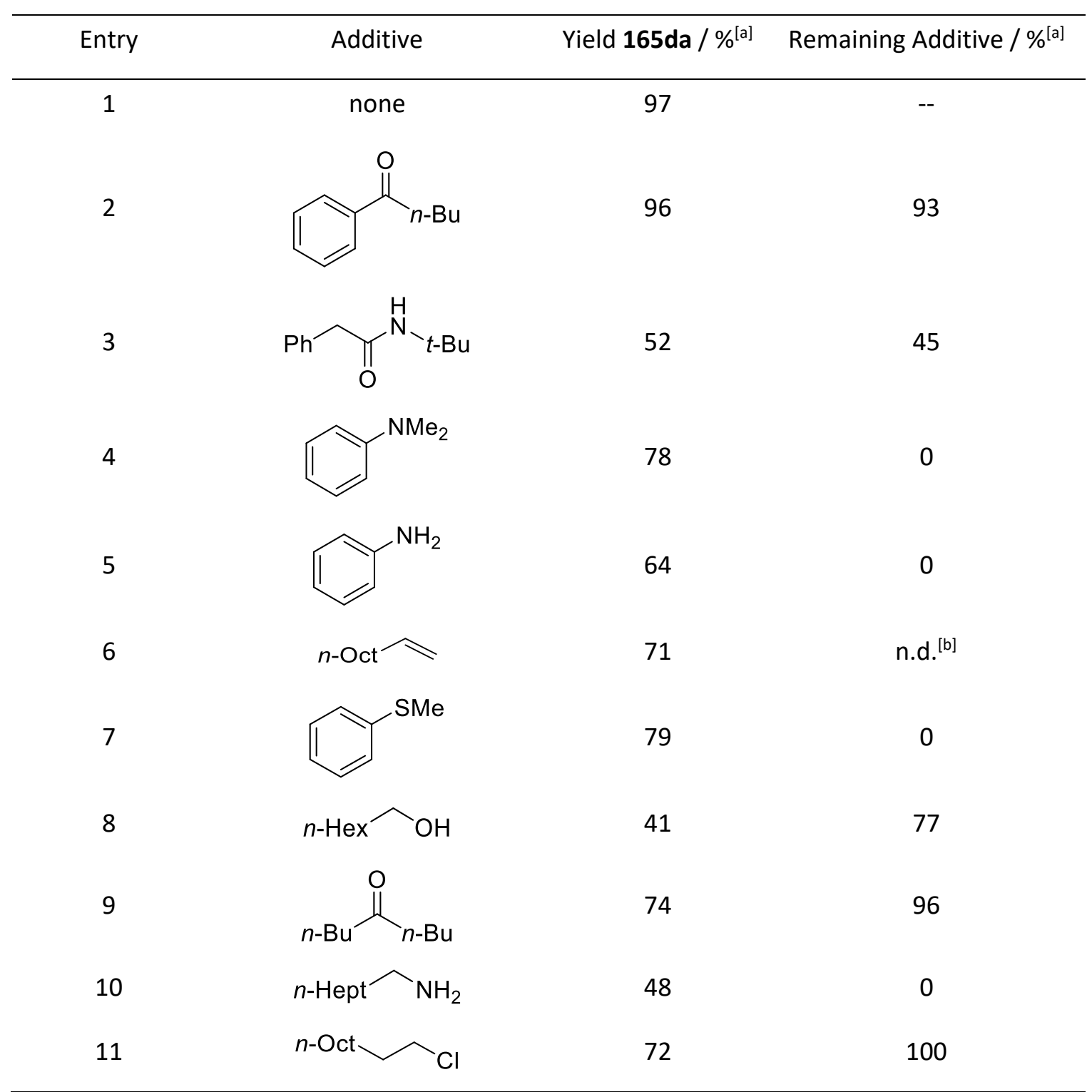


12<smiles>O=Cc1ccccc1</smiles>

13<smiles>c1ccncc1</smiles>

14<smiles>Cc1ccccn1</smiles>

15<smiles>c1ccc2occc2c1</smiles>

16<smiles>c1ccc2[nH]ccc2c1</smiles>

17

18

19<smiles>c1ccc2ncccc2c1</smiles><smiles>Clc1ccc2ccccc2n1</smiles>

38

n.d. ${ }^{[b]}$

0

91

41

0

0

88

0

[a] Determined by GC analysis with $n$-dodecane as the internal standard. [b] Not detected due to overlap with the solvent signal.

\subsubsection{One-pot two-fold C-H Activation}

The catalyst was also active for ortho-selective $\mathrm{C}-\mathrm{H}$ arylations and alkylations, allowing for unprecedented sequential two-fold meta/ortho-C-H activations (Scheme 66). Operationally simple addition of aryl or primary alkyl bromide provided access to densely substituted arenes $166 \mathrm{a}$ and $166 \mathrm{~b}$ with perfect levels of regioselectivity in high yields of $69 \%$ and $56 \%$, respectively. These results showcase the stability of the in situ formed ruthenium catalyst, which retains its activity even after longer reaction times at elevated temperatures. 
<smiles>CC(=N[18F])c1ccc(F)cc1</smiles>

$151 d$<smiles>CC1(Br)CCCCC1</smiles>

$100 \mathrm{c}$

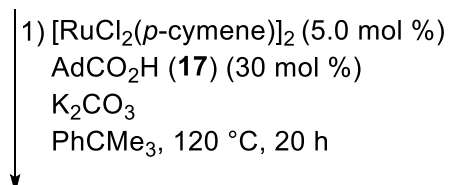

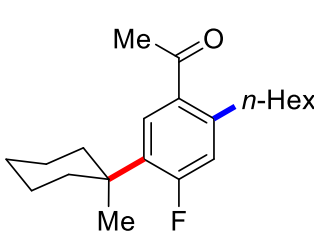

166b: $56 \%$

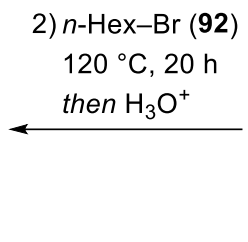

$120^{\circ} \mathrm{C}, 20 \mathrm{~h}$

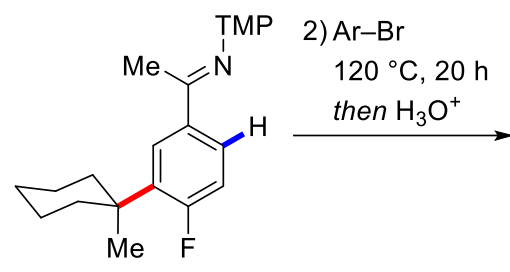

$152 d c$

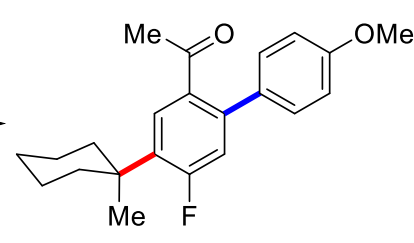

166a: $69 \%$

Scheme 66: Sequential one-pot two-fold C-H activation.

\subsubsection{Mechanistic Studies}

Earlier studies on ruthenium-catalyzed meta-C-H alkylations of phenylpyridines provided evidence for the formation of an alkyl radical species. ${ }^{[78]}$ Consequently, the involvement of alkyl radicals in the alkylation of ketimines was probed by the addition of the radical scavenger TEMPO, which completely suppressed product formation and resulted in the formation of an TEMPO-alkyl adduct. When enantiomerically enriched alkyl bromide (S)-100d was subjected to the reaction conditions, racemization of the stereogenic center in product $165 \mathrm{ed}$ was observed, thereby rendering the formation of an alkyl radical highly probable (Scheme 67). 
<smiles>CC(=NN)c1ccc2ccccc2c1</smiles>

$151 e$<smiles>CC(Br)[18O][Na]</smiles>

(S)-100d

$(84 \%$ ee $)$

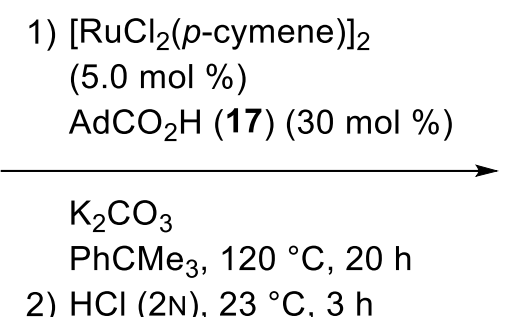

2) $\mathrm{HCl}(2 \mathrm{~N}), 23^{\circ} \mathrm{C}, 3 \mathrm{~h}$<smiles>CC(=O)c1cc([C@H](C)[14CH3])c2ccccc2c1</smiles>

rac-165ed: $78 \%$

Scheme 67: Reaction with enantiomerically enriched alkyl bromide 100d.

To gain further insights into the nature of the active catalyst, a series of kinetic investigations with well-defined complex $\left[\mathrm{Ru}\left(\mathrm{O}_{2} \mathrm{CAd}\right)_{2}(p\right.$-cymene)] (167) was performed. Variation of the catalyst loading in the range of $2.5-10 \mathrm{~mol} \%$, which corresponds to concentrations of $6.3-25 \mathrm{mmol} \mathrm{L}^{-1}$, resulted in a reaction order of 1 with respect to the $\left[\mathrm{Ru}\left(\mathrm{O}_{2} \mathrm{CAd}\right)_{2}(p\right.$-cymene)] (167) concentration (Figure 8).<smiles>CC(=N[Na])c1ccc(F)cc1</smiles>

$151 d$
$\left[\mathrm{Ru}\left(\mathrm{O}_{2} \mathrm{CAd}\right)_{2}(p\right.$-cymene $\left.)\right](167)$<smiles>CC1(Br)CCCC1</smiles>

$100 \mathrm{c}$

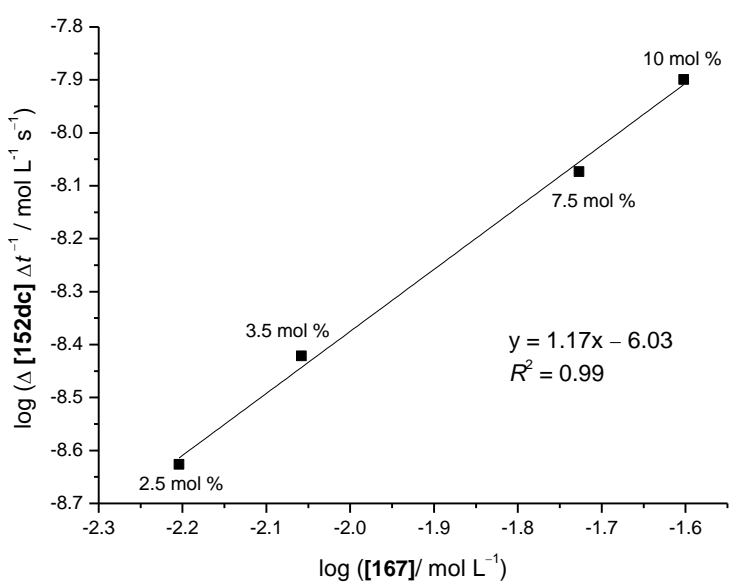

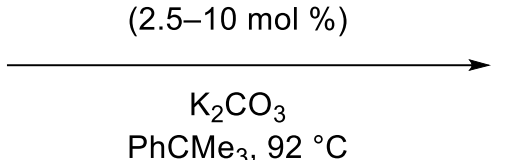

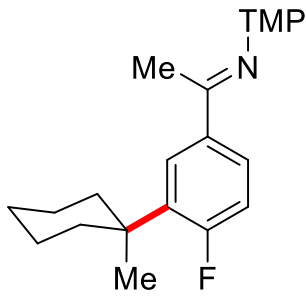

$152 \mathrm{dc}$

Figure 8: Reaction order with respect to the $\left[\mathrm{Ru}\left(\mathrm{O}_{2} \mathrm{CAd}\right)_{2}(p\right.$-cymene)] (167) concentration. 
A first order dependence of the rate with respect to the concentration of $\mathbf{1 5 1 d}$ was determined, while a more complex behavior was observed, when the concentration of alkyl bromide 100c was altered (Figure 9). Here, first an increase of the reaction rate with increasing concentrations was observed. In contrast, the rate was found to decrease at higher concentrations, leading to the assumption, that bromide $\mathbf{1 0 0 c}$ is either facilitating catalyst deactivation or the formation of a resting state. It should be noted that the measurements were performed with relatively high concentrations of $100 \mathrm{c}$ in the range of $0.25-1.13 \mathrm{~mol} \mathrm{~L}^{-1}$, where a limited solubility could effect the theoretical concentration and thereby cause the observed behaviour.<smiles>CC(=N)c1ccc(F)c(C)c1</smiles>

$151 d$<smiles>CC1(Br)CCCCC1</smiles>

$\mathrm{Br}$
$\left[\mathrm{Ru}\left(\mathrm{O}_{2} \mathrm{CAd}\right)_{2}(p\right.$-cymene $\left.)\right]$ $(7.5 \mathrm{~mol} \%)$

$$
\mathrm{K}_{2} \mathrm{CO}_{3}
$$

$\mathrm{PhCMe}_{3}, 92^{\circ} \mathrm{C}$
(167)<smiles>[Y6]N=C(C)c1ccc(F)c(C2(C)CCCCC2)c1</smiles>

$152 d c$ (a) Order in ketimine 151d

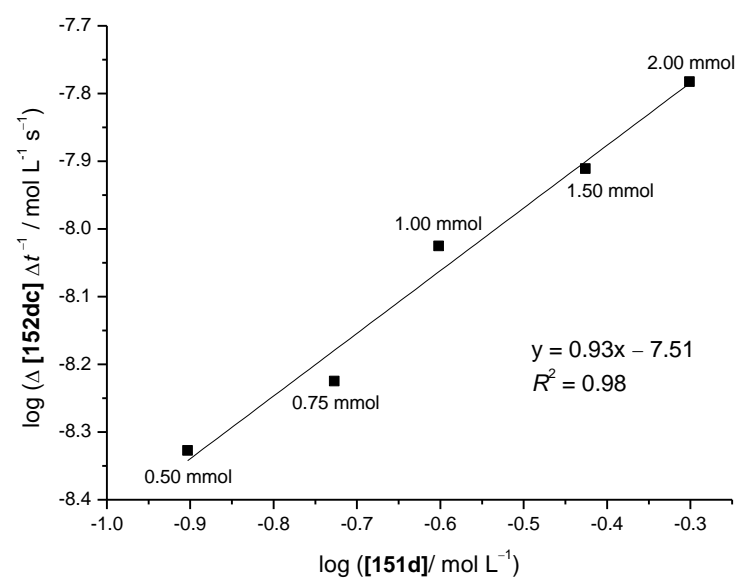

(b) Order in alkyl bromide $100 \mathrm{c}$

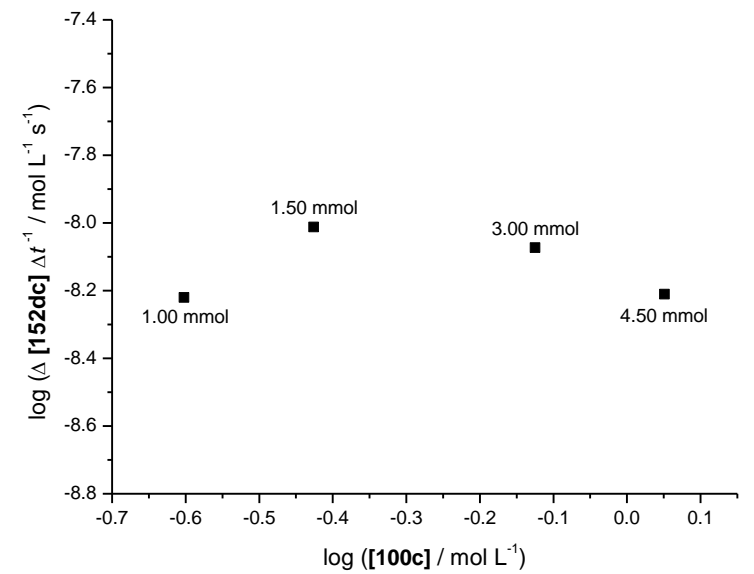

Figure 9: Reaction order with respect to the concentration of (a) ketimine 151d and (b) alkyl bromide 100c.

Additionally, the temperature dependence of the reaction rate was studied and the obtained rates were evaluated using the Arrhenius equation. A linearized plot resulted in values for the activation energy $E_{\mathrm{A}}$ of $24 \mathrm{kcal} \mathrm{mol}^{-1}$ (Figure 10 ). 
<smiles>CC(=N[18F])c1ccc(F)cc1</smiles>

$151 d$<smiles>CC1(Br)CCCCC1</smiles>

$\left[\mathrm{Ru}\left(\mathrm{O}_{2} \mathrm{CAd}\right)_{2}(p\right.$-cymene $\left.)\right]$

$(7.5 \mathrm{~mol} \%)$

$\mathrm{Br}$

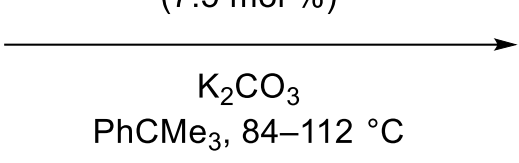

$100 \mathrm{c}$

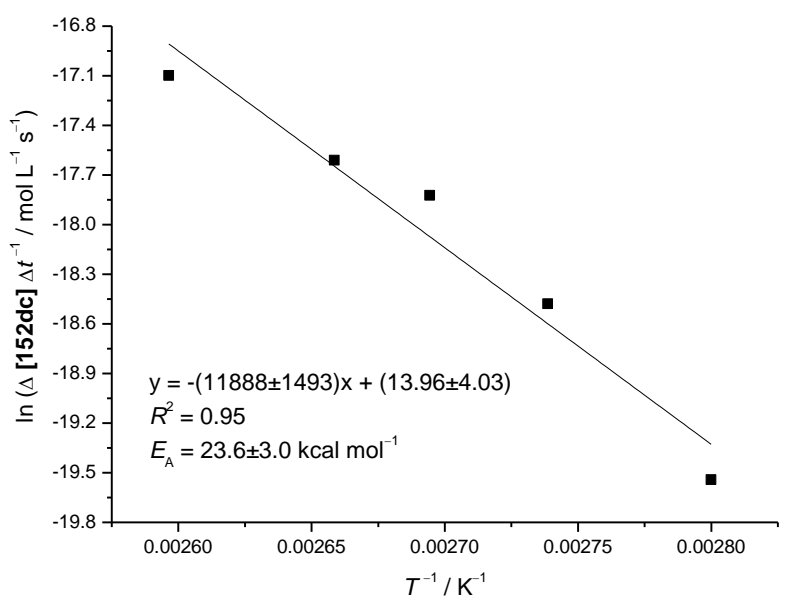<smiles>CC(=N[18F])c1ccc(F)c(C2(C)CCCC2)c1</smiles>

$152 d c$

Figure 10: Arrhenius plot analysis of the meta-alkylation of ketimine 151d.

Based on the results of the mechanistic studies and previous reports (vide supra), a plausible catalytic cycle commences with carboxylate-assisted ortho- $\mathrm{C}-\mathrm{H}$ bond activation to generate fivemembered ruthenacycle 169 (Scheme 68). Afterwards, homolytic $\mathrm{C}-\mathrm{Br}$ bond cleavage leads to the formation of alkyl radical species 107 and ruthenium(III) intermediate 171. Ruthenium acts as a strongly ortho- and para-directing substituent on the arene ${ }^{[70]}$ and, due to steric congestion in ortho-position, facilitates selective attack of $\mathbf{1 0 7}$ in the para-position with respect to the C-Ru bond. Cleavage of the $\mathrm{C}-\mathrm{H}$ bond results in the rearomatization of the arene, while the reduction of ruthenium(III) to ruthenium(II) formally generates $\mathrm{HBr}$, which is trapped by the base. Protodemetalation liberates the final product and regenerates the catalytically active complex 168. 


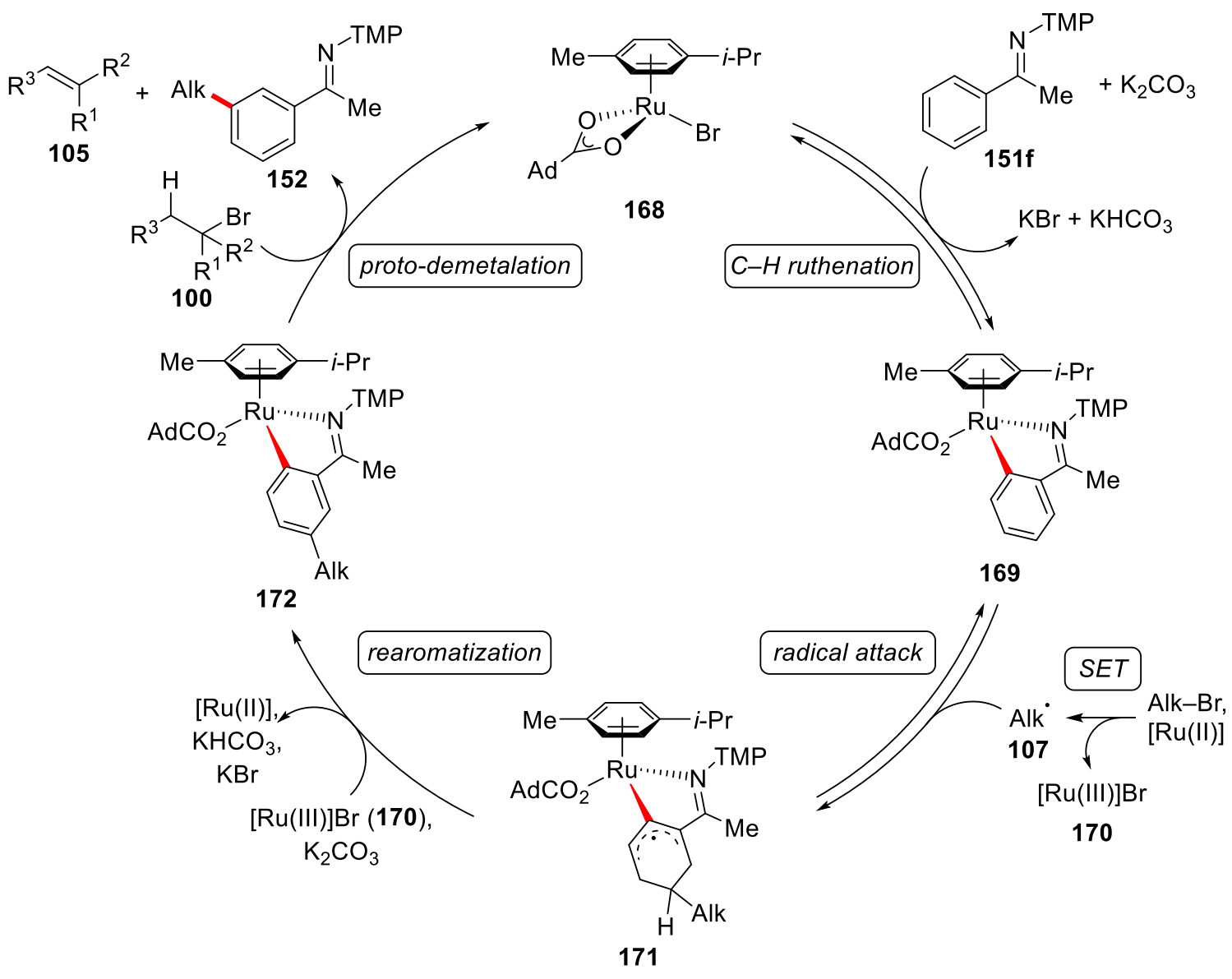

Scheme 68: Plausible catalytic cycle for ruthenium-catalyzed meta-C-H alkylations of ketimines

151.

\subsection{Ruthenium-Catalyzed meta-C-H Alkylation of Phenylpyridines}

In a previous study by Ackermann, meta-selective $\mathrm{C}-\mathrm{H}$ alkylations of 2-phenylpyridines were achieved using an in situ generated catalyst derived from of $\left[\mathrm{RuCl}_{2}(p \text {-cymene })\right]_{2}$ and monoprotected amino acid Piv-Val-OH (vide supra). ${ }^{[78]}$ Kinetic investigations revealed a first order dependence of the reaction rate on the concentration of $\left[\mathrm{RuCl}_{2}(p-c y m e n e)\right]_{2}$ as well as the concentration of 2-phenylpyridine.

To investigate a possible bimetallic pathway involving two ruthenium center, further studies were required. Hence, kinetic studies were performed with well-defined $\left[\mathrm{Ru}\left(\mathrm{O}_{2} \mathrm{CMes}\right)_{2}(p\right.$-cymene)] (61) complex, which was already shown to be a competent catalyst for meta-C-H functionalizations. ${ }^{[77]}$ Variation of the catalyst concentration resulted in a first order rate-dependence, which is evidence for a monometallic mechanism. Therefore, the involvement of a second ruthenium complex in a kinetically relevant elementary step appears to be unlikely (Figure 11). 
<smiles>c1ccc(-c2ccccn2)cc1</smiles>

$45 a$<smiles>CC1(Br)CCCCC1</smiles>

$\mathrm{Br}$$$
\text { (1) }
$$$$
\left[\mathrm{Ru}\left(\mathrm{O}_{2} \mathrm{CMes}\right)_{2}(p \text {-cymene })\right](\mathbf{6 1})
$$$$
\text { (2.5-13 } \mathrm{mol} \%)
$$$$
\mathrm{K}_{2} \mathrm{CO}_{3}
$$

1,4-dioxane, $92{ }^{\circ} \mathrm{C}$

$100 c$

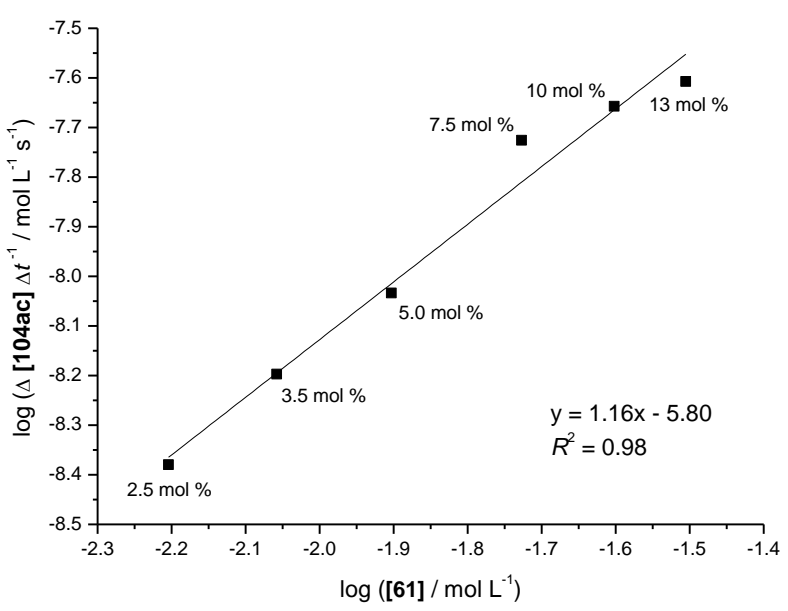

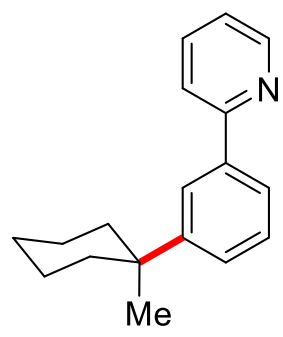

104ac

Figure 11: Reaction order with respect to the $\left[\mathrm{Ru}\left(\mathrm{O}_{2} \mathrm{CMes}\right)_{2}(p\right.$-cymene)] (61) concentration.

Furthermore, an Arrhenius plot analysis was performed to determine the activation energy of the reaction from experimentally derived temperature-dependent rates (Figure 12). For the activation energy $E_{\mathrm{A}}$ a value of $20 \mathrm{kcal} \mathrm{mol}^{-1}$ was derived, which is in good agreement with the results obtained for the meta-alkylation of ketimines (vide supra). 

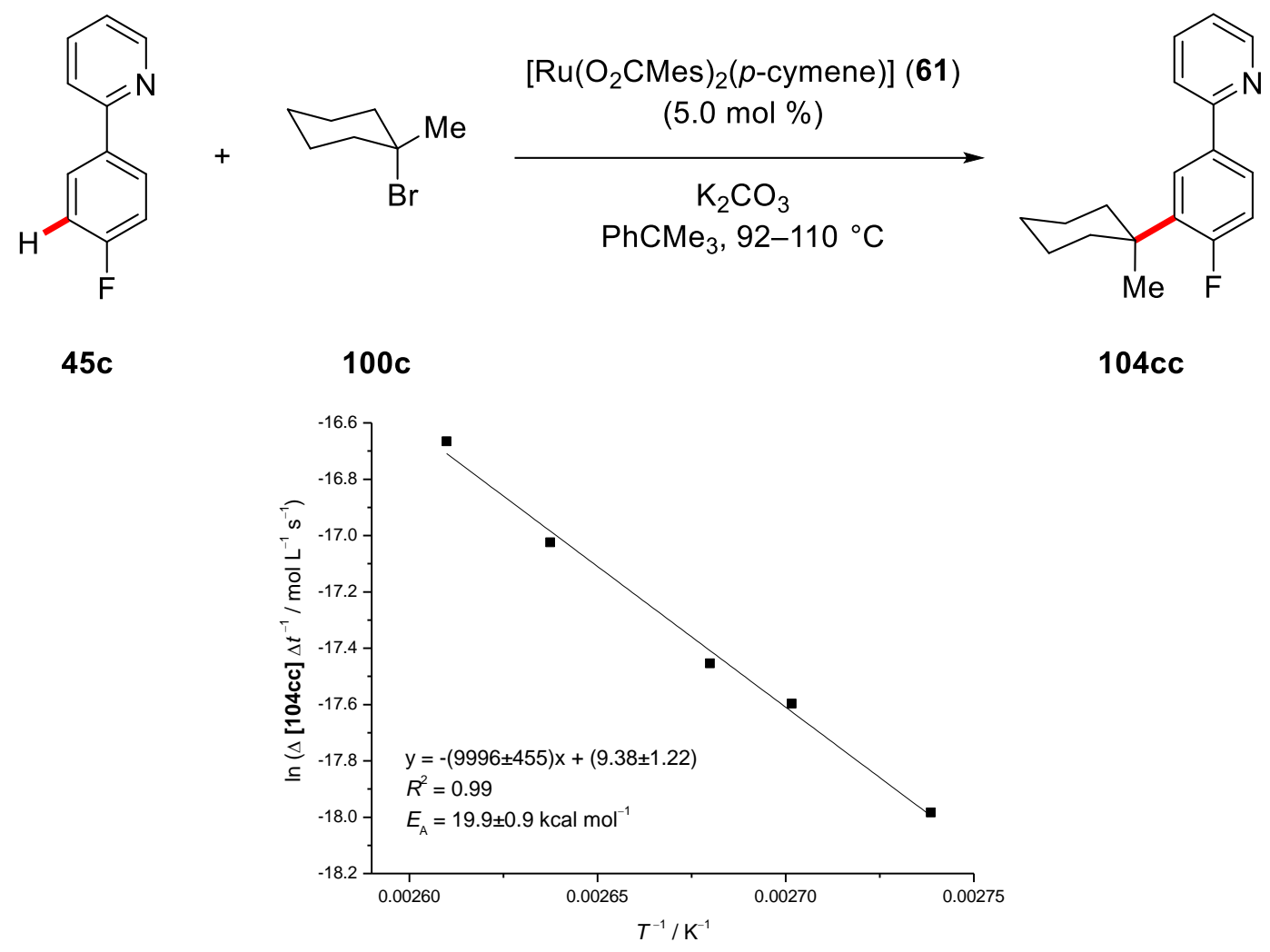

Figure 12: Arrhenius plot analysis for the meta-C-H alkylation of phenylpyridine 45c.

\subsection{Selectivity Prediction for meta-C-H Functionalization}

In contrast to the rapid development of procedures for meta-selective $\mathrm{C}-\mathrm{H}$ activation reactions in ruthenium catalysis during the last years by a number of research groups (see Section 1.6), a reliable method for the prediction and rationalization of experimentally observed selectivities has proven elusive. Nonetheless, the rationalization of selectivities by means of computational studies would offer enormous benefits for the identification of viable substrates and complexes for metaor para-C-H functionalizations. One method for computationally predicting selectivities is the Fukui function and its corresponding indices, as recently employed by Ritter for palladiumcatalyzed $\mathrm{C}-\mathrm{H}$ activations ${ }^{[122]}$ and Frost for ruthenium catalysis. ${ }^{[123]}$

\subsubsection{Oxazoline-Directed Alkylations}

Based on the results obtained for meta-selective $\mathrm{C}-\mathrm{H}$ alkylations of ketimines, $K$. Korvorapun and N. Kaplaneris in the Ackermann group developed a strategy for oxazoline-directed meta-C-H alkylations with $\alpha$-bromo esters 173 using a $\left[\mathrm{Ru}\left(\mathrm{O}_{2} \mathrm{CR}\right)_{2}(p\right.$-cymene $\left.)\right] / \mathrm{PPh}_{3}$ catalyst, which exclusively yielded meta-functionalized product 174 (Scheme 69). ${ }^{[124]}$ 


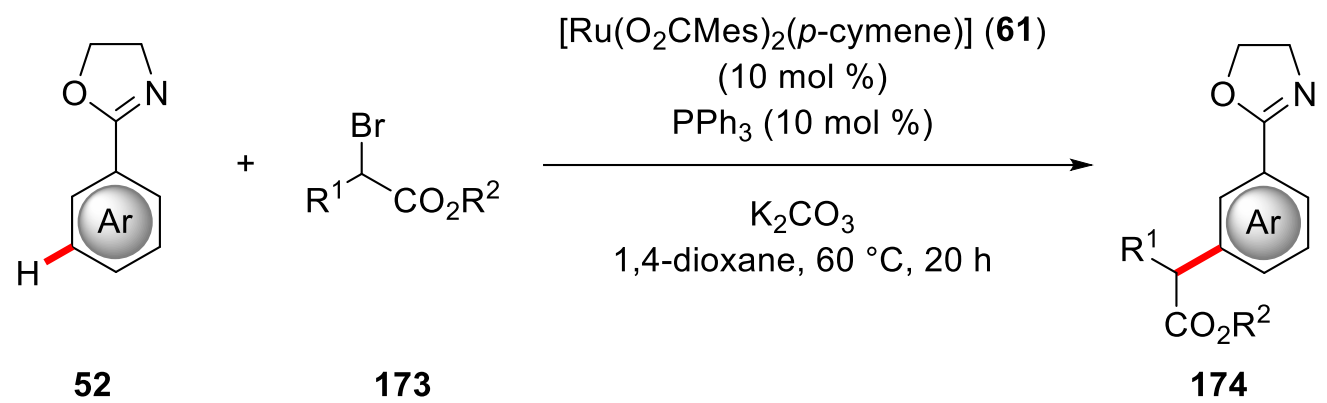

Scheme 69: Optimized reaction conditions for oxazoline-assisted meta-C-H alkylations.

To investigate the ortho/meta/para-selectivities, various cyclometalated ruthenium(II) and ruthenium(III) complexes, which are likely candidates under the reaction conditions, were explored by means of DFT calculations. Geometry optimizations were performed at the TPSSD3(BJ)/def2-TZVP level of theory, ${ }^{[125,126,127]}$ while Fukui indices were based on NBO charges obtained at the B3LYP-D3(BJ)/def2-TZVP level of theory ${ }^{[128]}$ (for full details see Section 6.2). Nucleophilicity Fukui indices, which designate the most favorable position for an electrophilic attack, predict the reaction to occur in para-position with respect to the C-Ru bond in all studied complexes (Figure 13). Nevertheless, the formation of a carbocation through a heterolytic $\mathrm{C}-\mathrm{Br}$ bond cleavage in the alkyl bromide can be safely excluded due to experimental mechanistic findings, including spin trapping EPR investigations, and isolation of a TEMPO-alkyl adduct. 
(a) Ruthenium(II)

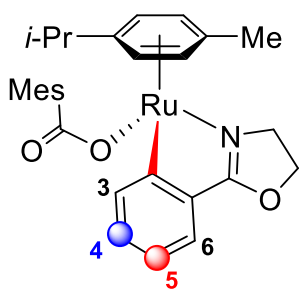

4.A

$\mathrm{C} 5 / \mathrm{C} 4=2.61$
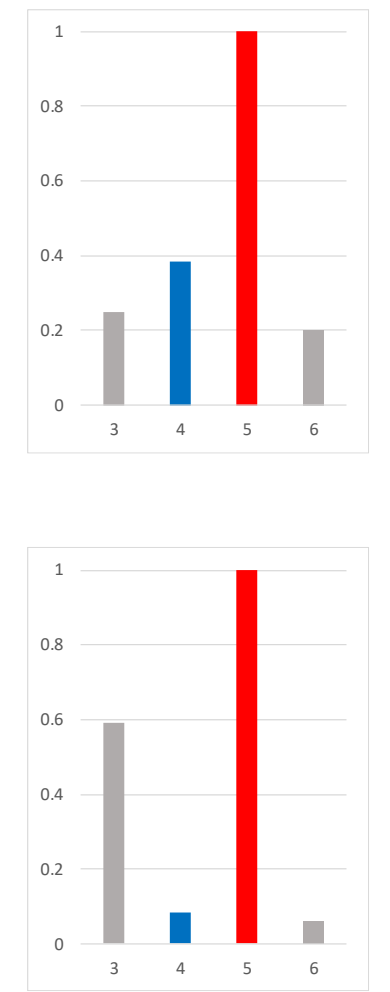

4.B

C5/C4 = 11.9

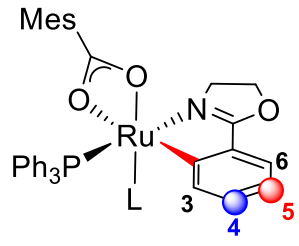

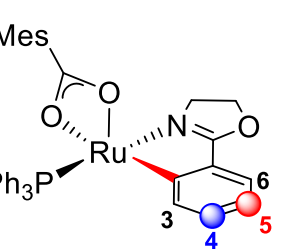

4.C

$\mathrm{C} 5 / \mathrm{C} 4=11.0$

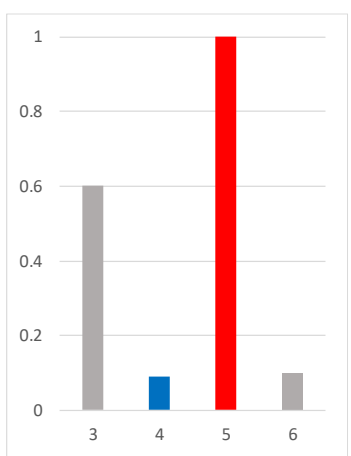

(b) Ruthenium(III)

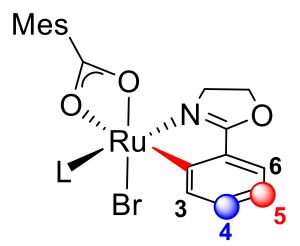

4.D

C5/C4 $=5.91$

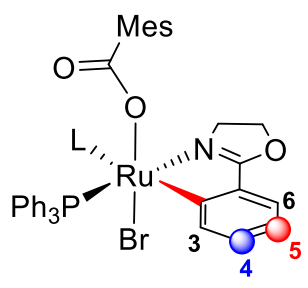

4.E

$\mathrm{C} 5 / \mathrm{C} 4=7.97$

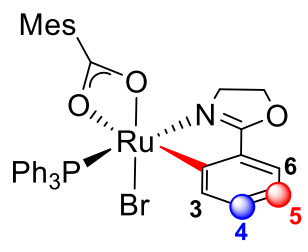

4.F

$\mathrm{C} 5 / \mathrm{C} 4=21.2$
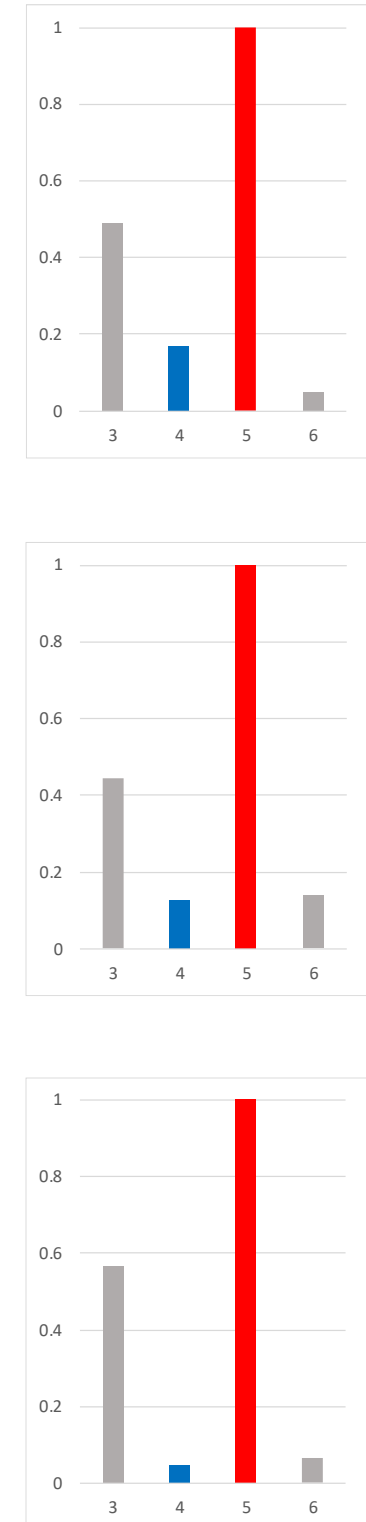

Figure 13: Relative nucleophilicity Fukui indices for cyclometalated complexes with oxazolines. $L=1,4-d i o x a n e$.

In contrast, the calculation of radical Fukui indices revealed significant differences between the studied complexes. Complex 4.A, featuring a $\eta^{6}$-coordinated $p$-cymene ligand, as well as complex 4.B exhibited the highest reactivity at the carbon atom in the para-position with respect to the directing group, which is opposed to the experimentally observed selectivity (Figure 14). Even though for ruthenium(II) complex 4.C the reaction was predicted to occur at the correct position, a C5/C4 ratio of only 2.7 was obtained, indicating the formation of a mixture of products. Furthermore, 4.C is a coordinatively unsaturated complex, that is presumable not stable under the reaction conditions. Increased C5/C4 ratios were found for ruthenium(III) complexes 4.D-4.F, 
which is in agreement with a homolytic $\mathrm{C}-\mathrm{Br}$ bond cleavage in a SET fashion leading to an oxidation of ruthenium(II) to ruthenium(III).

(a) Ruthenium(II)<smiles>CC(=O)OP(C1=C(C2=C(c3cccc(C)c3)OCCN2C)OCC1)c1cc(C)ccc1C(C)C</smiles>

4.A

$\mathrm{C} 5 / \mathrm{C} 4=0.43$

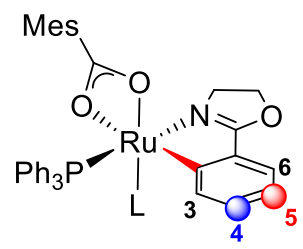

4.B

$\mathrm{C} 5 / \mathrm{C} 4=0.88$

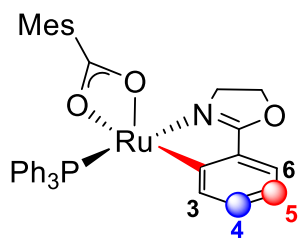

4.C

$\mathrm{C} 5 / \mathrm{C} 4=2.70$

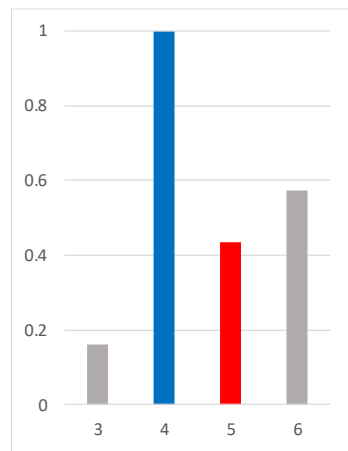

(b) Ruthenium(III)

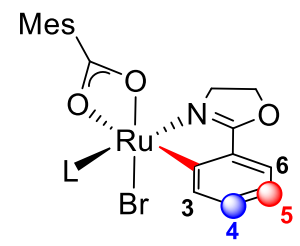

4.D

$\mathrm{C} 5 / \mathrm{C} 4=3.45$

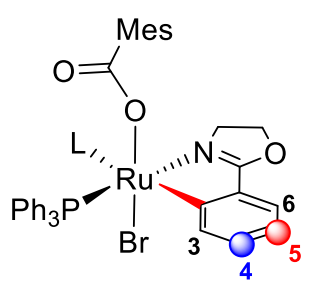

4.E

$\mathrm{C} 5 / \mathrm{C} 4=5.41$

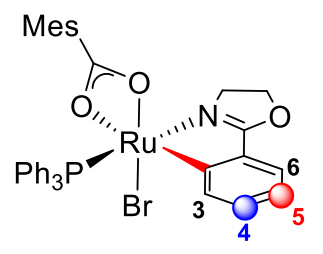

4.F

$\mathrm{C} 5 / \mathrm{C} 4=8.40$
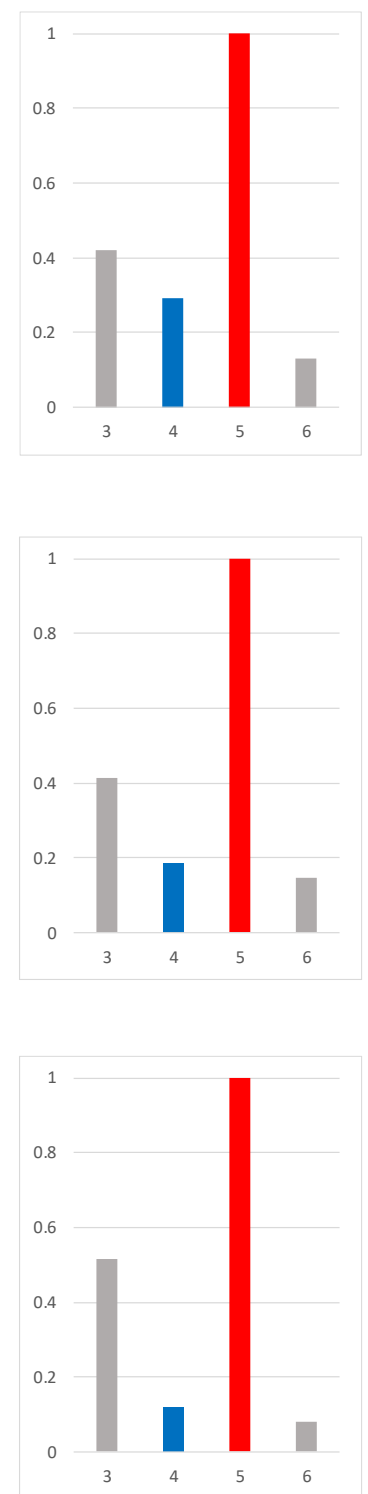

Figure 14: Relative radical Fukui indices for cyclometalated complexes with oxazolines.

$$
L=1,4 \text {-dioxane. }
$$

\subsubsection{Purine-Directed Alkylations}

In continuation of the studies on ruthenium-catalyzed meta-selective alkylations of oxazolines, $F$. Fumagalli and Dr. S. Warratz in the Ackermann group explored the purine-directed meta-C-H alkylation of purines 148 with various alkyl halides 100 under ruthenium catalysis (Scheme 70). ${ }^{[129]}$ 
The efficacy of the arene-ligand-free complex $\left[\mathrm{Ru}(\mathrm{OAc})_{2}\left(\mathrm{PPh}_{3}\right)_{2}\right](\mathbf{1 7 5})$ was shown by efficiently catalyzing the desired transformation. Additionally, the catalyst showed an improved performance compared to typically employed $\left[\mathrm{Ru}\left(\mathrm{O}_{2} \mathrm{CR}\right)_{2}(p\right.$-cymene $\left.)\right]$ catalysts.<smiles>[R]n1cnc2c(-c3ccccc3)ncnc21</smiles>

148<smiles>[R]C([R])Br</smiles>

100

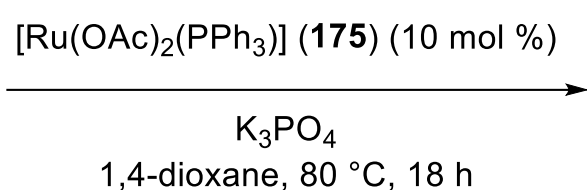

1,4-dioxane, $80^{\circ} \mathrm{C}, 18 \mathrm{~h}$<smiles>[R]C([R])c1cccc(-c2ncnc3c2ncn3[R1])c1</smiles>

176

Scheme 70: Optimized reaction conditions for purine-assisted meta-C-H alkylations.

Subsequently, this catalyst was investigated by means of DFT calculations. Structures of cyclometalated complexes were optimized at the TPSS-D3(BJ)/def2-TZVP level of theory ${ }^{[125,126,127]}$ and NBO charges for the assessment of Fukui indices were calculated at the B3LYP-D3(BJ)/def2TZVP level of theory ${ }^{[128]}$ (for full details see Section 6.2). Nucleophilicity Fukui indices revealed a preferential reactivity at the $\mathrm{C} 5$ position, that is the para-position with respect to the $\mathrm{C}-\mathrm{Ru}$ bond, and indicate very high C5/C4 ratios of more than 20:1 (Figure 15). Although, significant values were also obtained for the C3 position, which would also lead to an overall meta-selective functionalization of the substrate, an attack at this position can be disregarded due to steric congestion. In line with the experimental mechanistic studies previously performed for the aryl oxazolines, EPR experiments and reactions in the presence of radical scavengers again strongly suggested the formation of an alkyl radical. 
(a) Ruthenium(II)
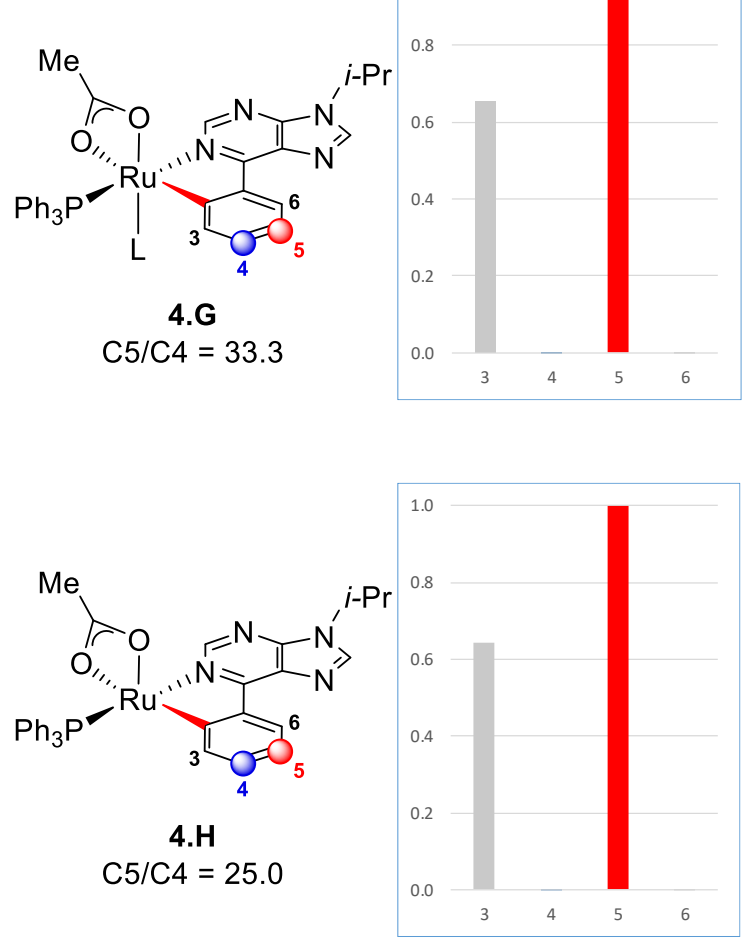

(b) Ruthenium(III)<smiles></smiles>

4.I

$\mathrm{C} 5 / \mathrm{C} 4=33.3$
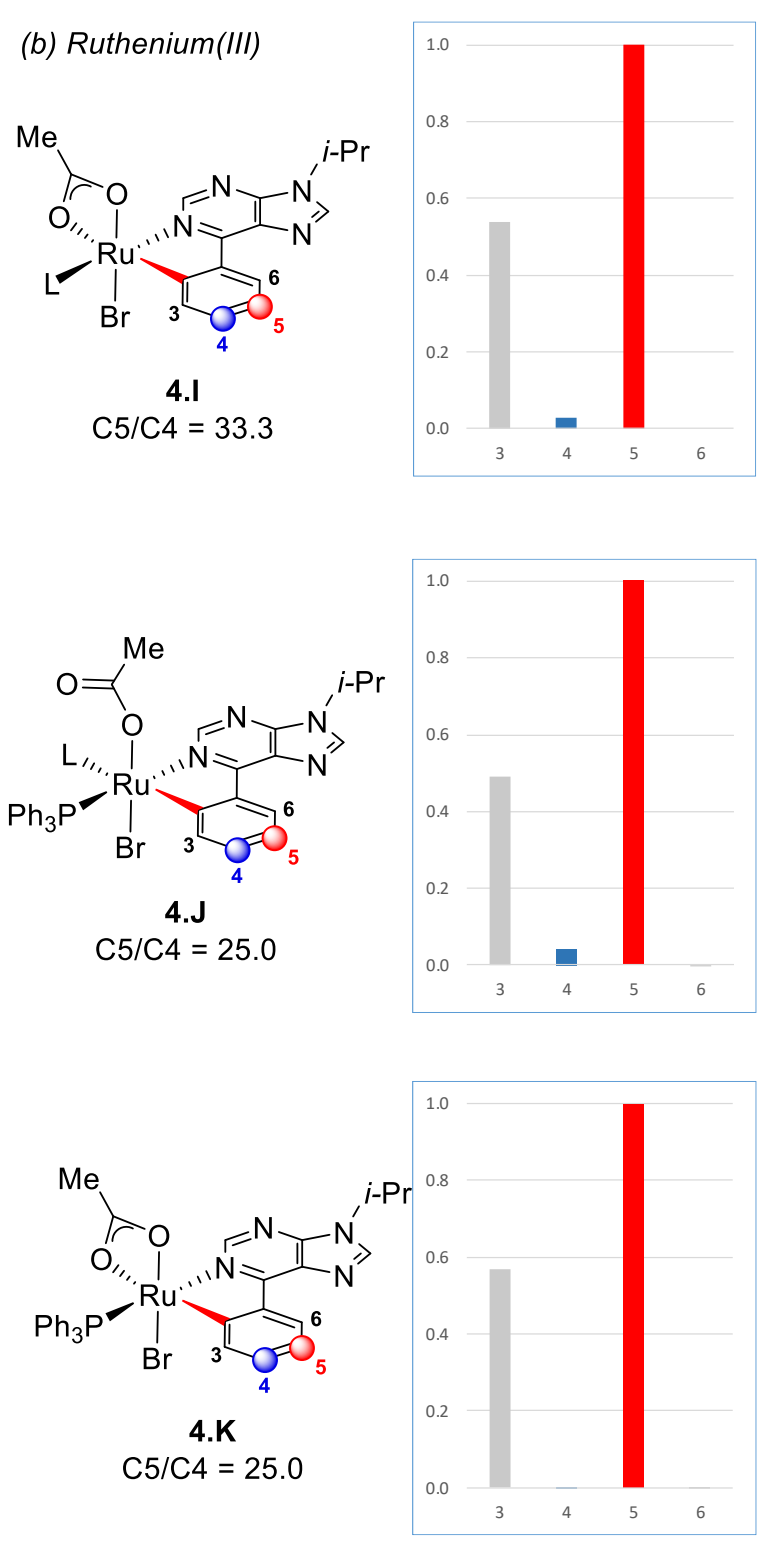

Figure 15: Relative nucleophilicity Fukui indices for cyclometalated complexes with purines.

$$
\mathrm{L}=1 \text {,4-dioxane. }
$$

Fukui indices for radical reactivity predicted a higher reactivity at the C4 position for all investigated complexes in comparison to the nucleophilicity indices. Furthermore, in complex 4.G reaction at the C4-position is determined to be even more likely than at the experimentally observed C5 position (Figure 16). It is noteworthy that in $\mathbf{4 . G}$ the highest value was calculated for the 6-position of the purine directing group, where no reaction can possibly occur. Ruthenium(III) complexes 4.I-4.K exhibited high C5/C4 ratios, with the highest value obtained for complex 4.K, which contains a phosphine as well as a $\kappa^{2}$-coordinated acetate ligand. 
(a) Ruthenium(II)
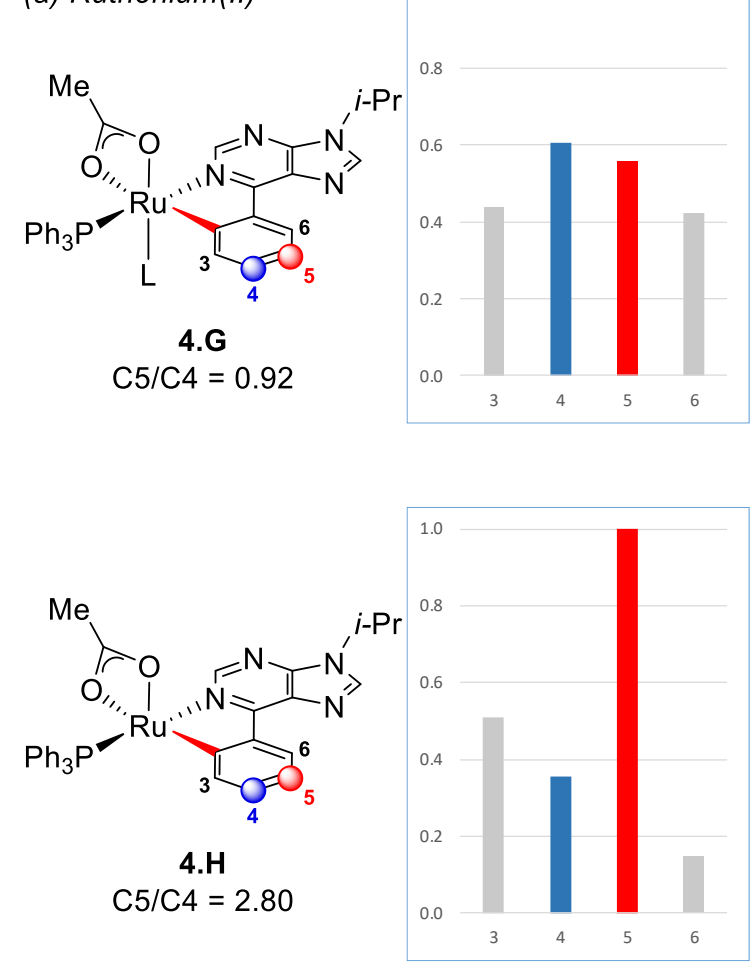

(b) Ruthenium(III)

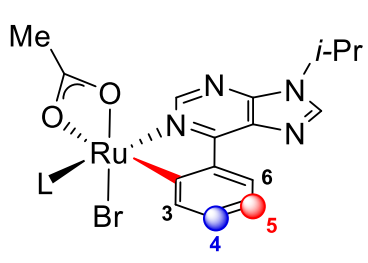

4.I

$\mathrm{C} 5 / \mathrm{C} 4=7.02$

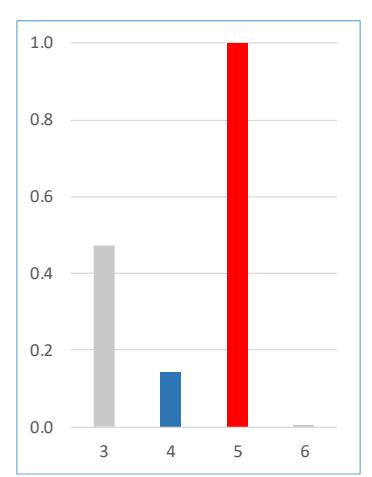

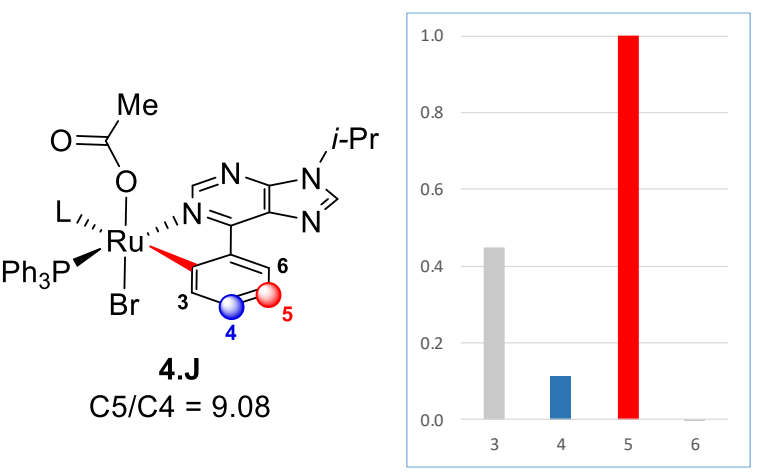

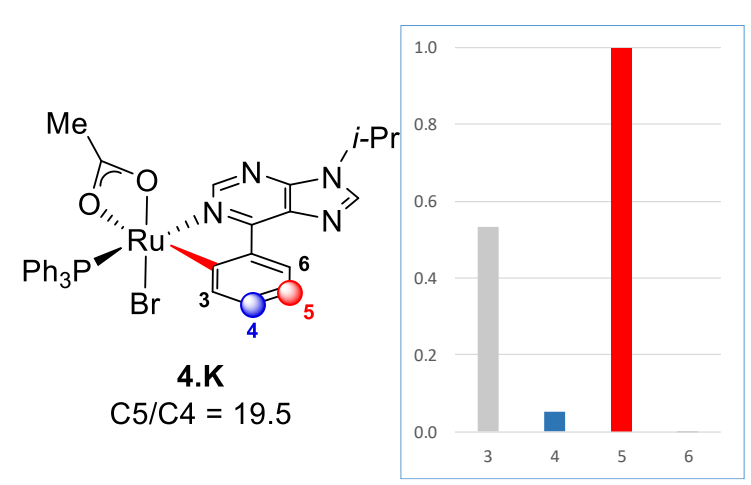

Figure 16: Relative radical Fukui indices for cyclometalated complexes with purines.

$$
L=1,4 \text {-dioxane. }
$$

\subsection{Ruthenium-Catalyzed Decarboxylative C-H Activation}

One mayor drawback in the use of directing groups for chelation-assisted $\mathrm{C}-\mathrm{H}$ bond activation is the fact, that a removal of the directing group usually requires further synthetic operations, thus compromising the overall step- and atom-economy. In contrast, carboxylic acid directing groups can be removed in a traceless fashion during the $\mathrm{C}-\mathrm{H}$ activation (vide supra). Although decarboxylative $\mathrm{C}-\mathrm{H}$ activations under ruthenium-catalysis were previously reported, detailed studies on the catalyst's mode of action remained scarce (Scheme 71$){ }^{[59,130]}$ 


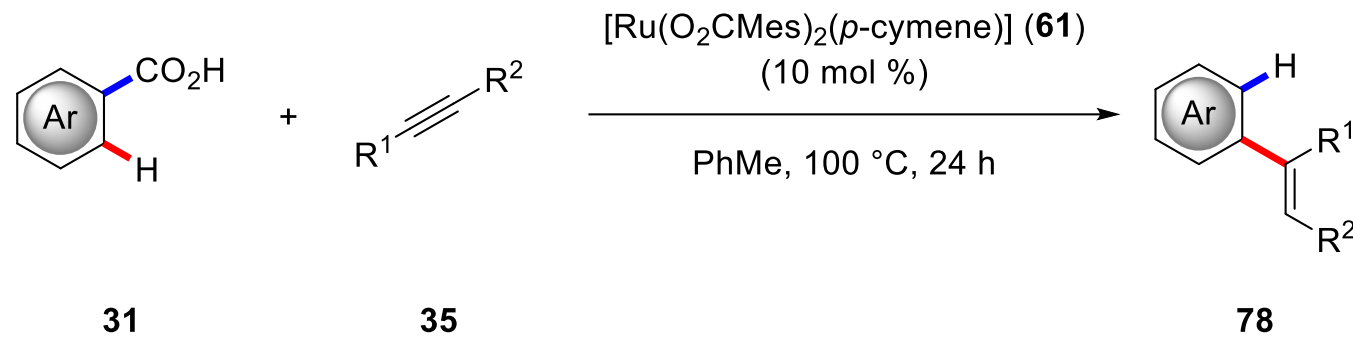

Scheme 71: Optimized reaction conditions for ruthenium-catalyzed decarboxylative $\mathrm{C}-\mathrm{H}$ alkenylations.

Despite an increasing number of protocols for decarboxylative $\mathrm{C}-\mathrm{H}$ activations under ruthenium catalysis (see Section 1.5), these procedures are often limited to acrylates or alkynes as the reagents. In this context, synthetically useful maleimides $\mathbf{1 7 7}$ were identified as viable substrates within the versatile hydroarylation/decarboxylation manifold by Dr. N. Y. P. Kumar ${ }^{[131]}$ in the Ackermann group and provide access to arylated succinimides, ${ }^{[132]}$ which find applications as anticancer and anticonvulsant agents. ${ }^{[133]}$ Optimal results were obtained in DCE as the solvent of choice and $\left[\mathrm{Ru}\left(\mathrm{O}_{2} \mathrm{CMes}\right)_{2}(p\right.$-cymene) $](\mathbf{6 1})$ as the catalyst (Scheme 72$)$.

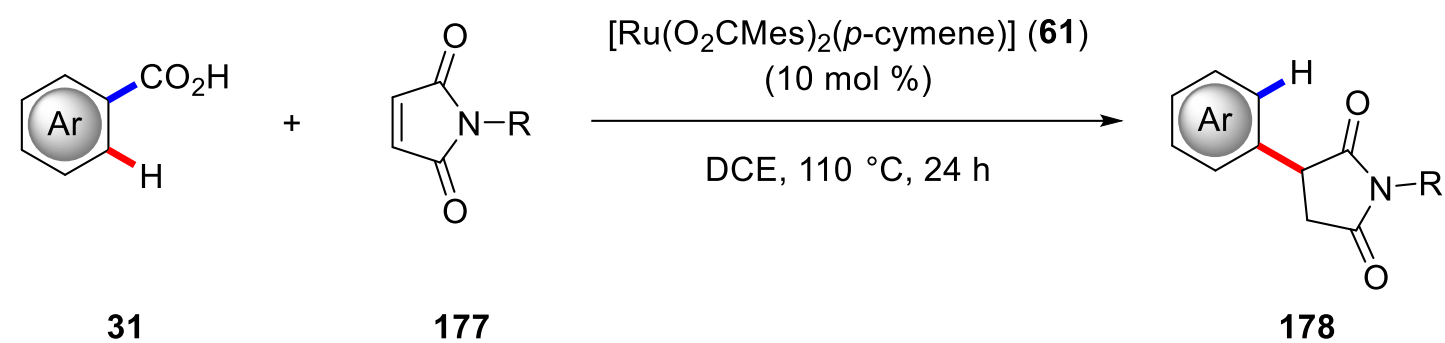

Scheme 72: Optimized reaction conditions for ruthenium-catalyzed decarboxylative $\mathrm{C}-\mathrm{H}$ alkylations with maleimides 177.

\subsubsection{Alkenylations of Benzoic Acids with Alkynes}

The mechanism of the ruthenium-catalyzed alkenylation of benzoic acid (31a) with diphenylacetylene (35a) was studied by means of DFT calculations. Geometry optimizations were performed at the PBE0/def2-SVP level of theory ${ }^{[127,134]}$ and energies were refined through single point calculations at the PBEO-D3(BJ) /def2-QZVP*+SMD level[126, 135] (for full details see Section 6.3). The PBEO hybrid functional was selected due to an excellent performance in a benchmark 
study on transition metal complexes and a good performance in the GMTKN55 benchmark by Grimme, ${ }^{[136]}$ while the def2-QZVP* basis set provides sufficient accuracy at manageable computational cost.

As a first step, ligand exchange on the complex $\left[\mathrm{Ru}\left(\mathrm{O}_{2} \mathrm{CMes}\right)_{2}(p\right.$-cymene)] (61) with benzoic acid (31a) leads to the formation of $\left[\mathrm{Ru}\left(\mathrm{O}_{2} \mathrm{CPh}\right)_{2}(p\right.$-cymene) $)$ (5.A), which is the catalytically active species (Figure 17). Afterwards, agostic complex 5.B is formed with an energy barrier of $19.6 \mathrm{kcal} \mathrm{mol}^{-1}$ and subsequently undergoes concerted $\mathrm{C}-\mathrm{H}$ cleavage and $\mathrm{C}-\mathrm{Ru}$ formation via transition state TS5.2 to form five-membered ruthenacycle intermediate 5.C. In intermediate 5.B the C-Ru distance was found to be $2.44 \AA$, which is $0.25 \AA$ larger than the sum of the covalent radii $(2.19 \AA),{ }^{[137]}$ which therefore indicates that the C-Ru bond is not yet formed. In contrast, a C-Ru distance of $2.05 \AA$ was observed in 5.C. Exchange of the coordinated benzoic acid with alkyne 35a generates complex 5.D and turnover-limiting migratory insertion of 35a into the C-Ru bond forms seven-membered ruthenacycle 5.E. Surprisingly, intermediate 5.E was calculated to be $9.9 \mathrm{kcal} \mathrm{mol}^{-1}$ more stable than intermediate 5.D, despite the unfavorable ring size. Then, the key decarboxylation step takes place via concerted $\mathrm{C}-\mathrm{C}$ bond cleavage/C-Ru bond formation in transition state TS5.4 (Figure 18). Two-fold proto-demetalation with two molecules of benzoic acid leads to the formation of the final product $\mathbf{5 . K}$ and regenerates the catalytically active complex 5.A. The first proto-demetalation was revealed to proceed via formation of agostic intermediate 5.H, whereas no agostic intermediate was located for the second protodemetalation process. Compared to 5.I, intermediate 5.J is energetically less favorable by $9.4 \mathrm{kcal} \mathrm{mol}^{-1}$ due to considerable steric crowding. In total, the reaction is exergonic with a Gibbs free energy difference of $-19.0 \mathrm{kcal} \mathrm{mol}^{-1}$. 


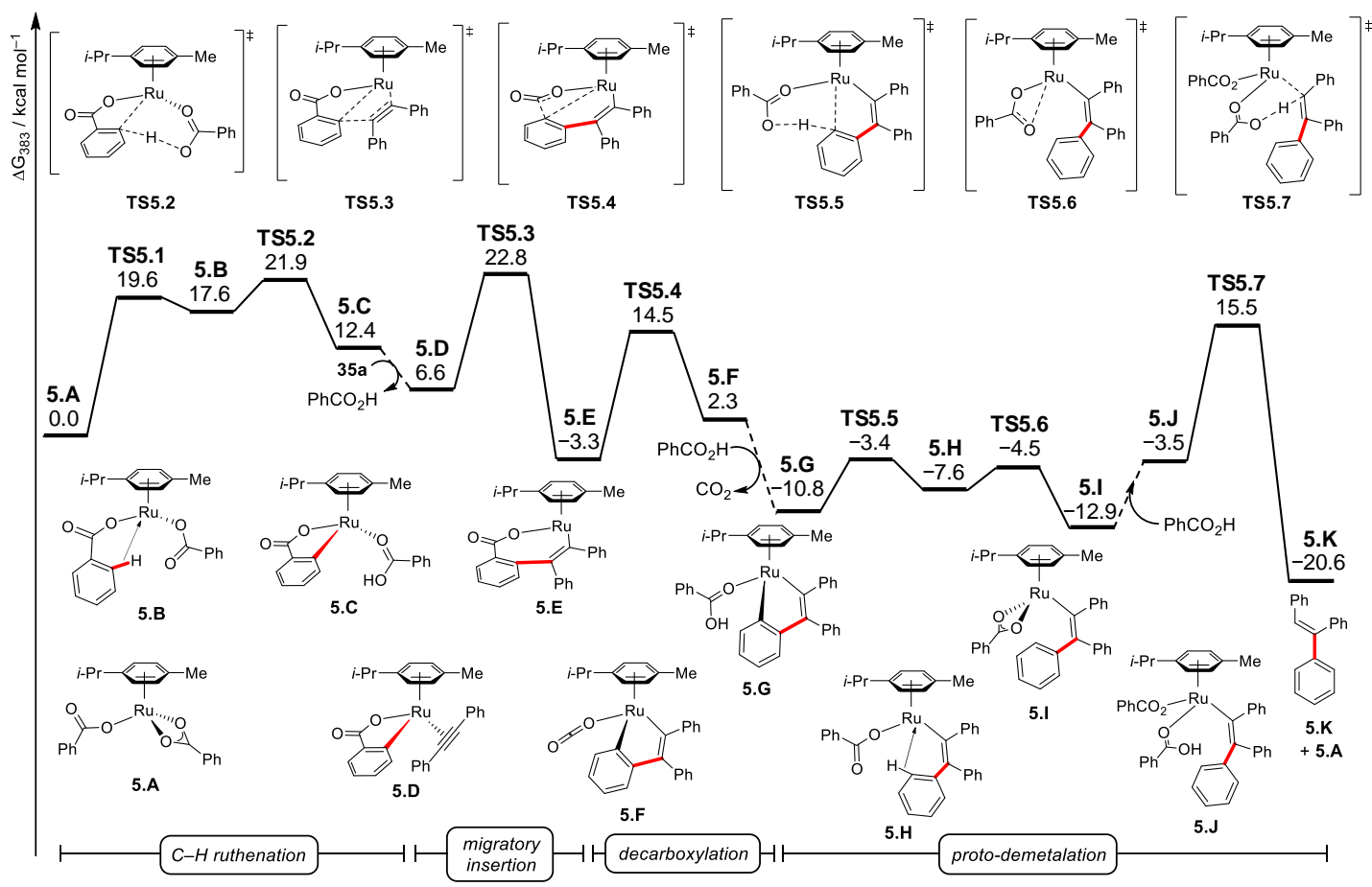

Figure 17: Relative Gibbs free energy profile for the reaction of benzoic acid (31a) with alkyne 35a at the PBEO-D3(BJ)/def2-QZVP*+SMD(PhMe) level of theory.

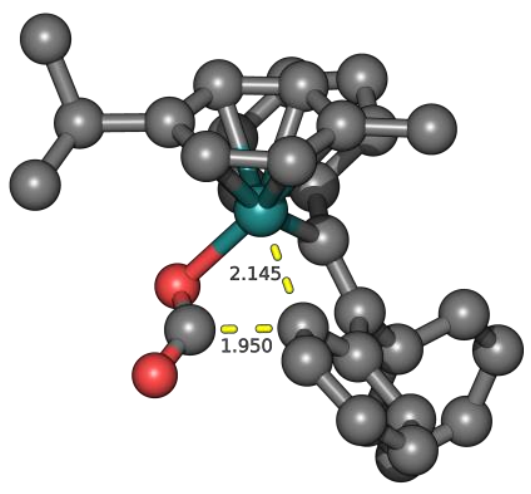

Figure 18: Structure of decarboxylation transition state TS5.4. Distances are given in $\AA$ and hydrogen atoms are omitted for clarity.

In addition, an evaluation of DCE, TFE, and water as representative polar and apolar solvents within the framework of the SMD/IEFPCM model was conducted. $\mathrm{C}-\mathrm{H}$ ruthenation and migratory insertion was found to be energetically feasible in polar solvents with an energy difference of $9.1 \mathrm{kcal} \mathrm{mol}^{-1}$ for TS5.1 in PhMe and water (Figure 19). In contrast, the energies of the transition states and intermediates of the two proto-demetalation steps increased, when polar solvents were used in the calculations. It is noteworthy that, while in toluene the turnover-limiting step 
was represented by the migratory insertion, in TFE or water the decarboxylation event became turnover-limiting.

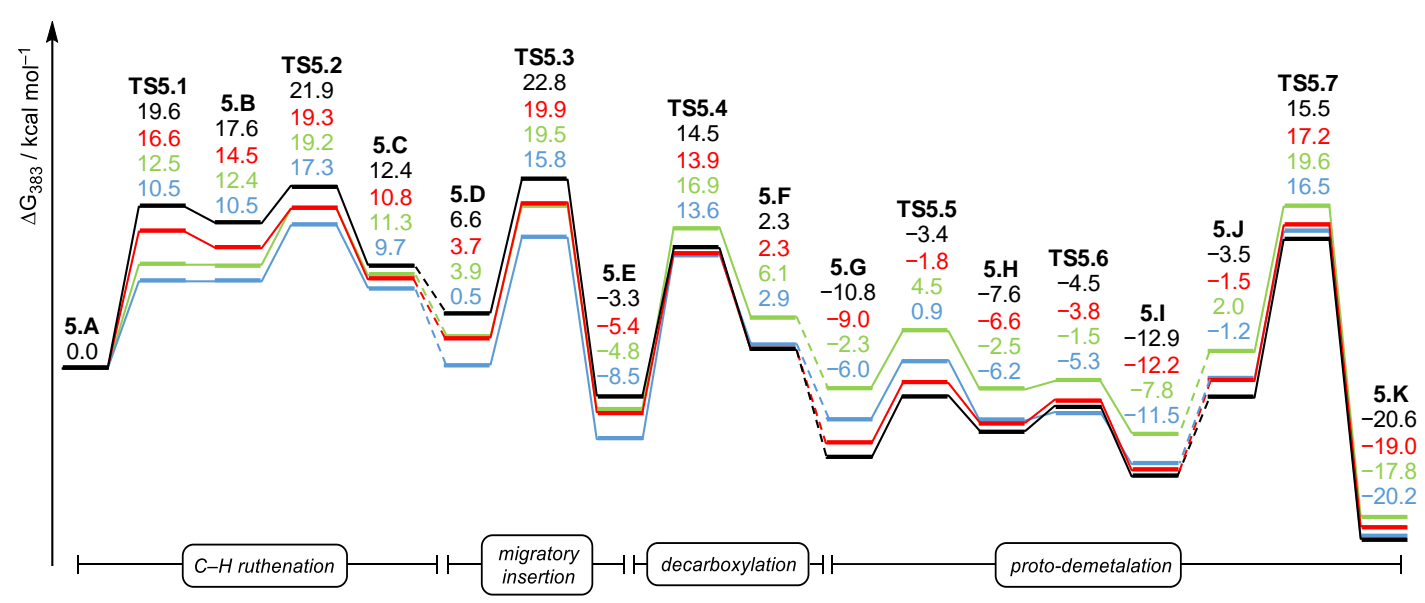

Figure 19: Relative Gibbs free energy profile in PhMe (black line), DCE (red), TFE (green), and water (blue) for the reaction of benzoic acid (31a) with alkyne 35a.

Furthermore, a significant stabilization of transition states and intermediates of the reaction of benzoic acid (31a) with alkyne 35a by dispersion forces was revealed by comparison of single point calculations with and without Grimme's D3(BJ) correction (Figure 20). Especially for the structures of the proto-demetalation steps a notable influence of weak dispersive interactions was observed with stabilizations of up to $25.1 \mathrm{kcal} \mathrm{mol}^{-1}$ for TS5.7.

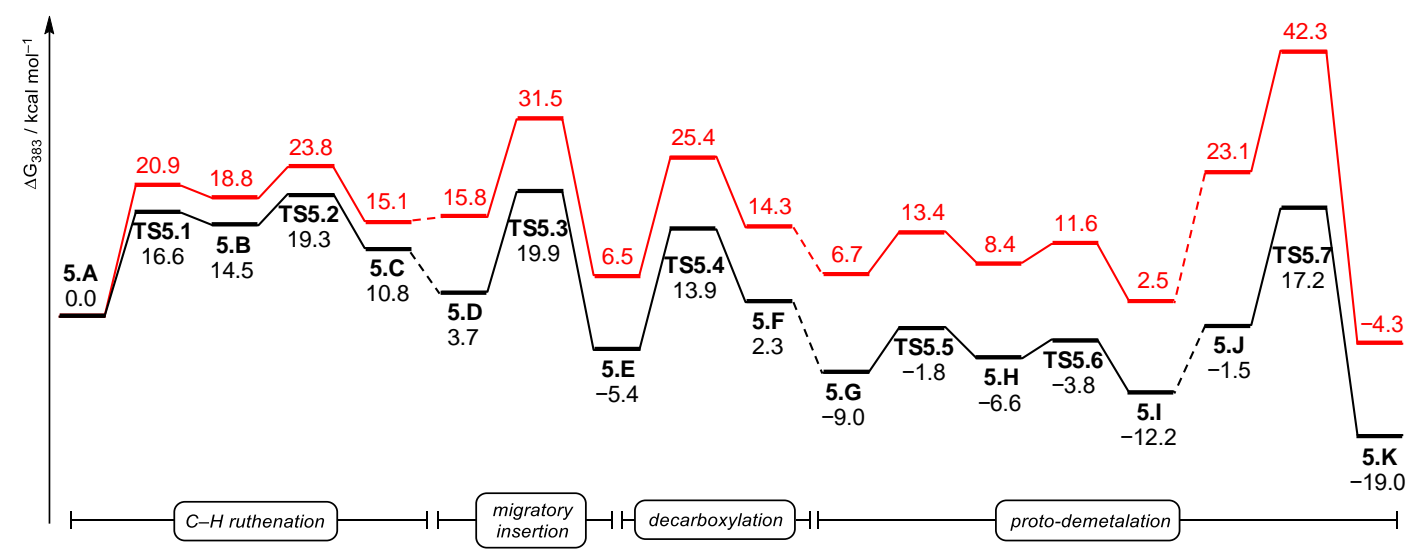

Figure 20: Relative Gibbs free energy profile in DCE with D3(BJ) (black line) and without dispersion correction (red). 
Following the migratory insertion, reductive elimination can occur as a competing pathway to form isochromene-derivative $37 \mathrm{aa}$ in an overall [4+2] annulation reaction (vide supra). A comparison of the energies of TS5.4 and TS5.8 in toluene resulted in an energy difference $\Delta \Delta \mathrm{G}^{\ddagger}$ of $5.0 \mathrm{kcal} \mathrm{mol}^{-1}$ in favor of the decarboxylation regime (Figure 21). This value decreases with an increase in solvent polarity and in TFE or water the difference is neglectable with a $\Delta \Delta \mathrm{G}^{\ddagger}$ value of only $0.2 \mathrm{kcal} \mathrm{mol}^{-1}$ and $0.1 \mathrm{kcal} \mathrm{mol}^{-1}$, respectively. Independent of the solvent, intermediate $\mathbf{5 . F}$, which is formed in the decarboxylation process, was calculated to be energetically less favorable than ruthenium(0) complex $5 . \mathrm{L}$ by $19.7-22.2 \mathrm{kcal} \mathrm{mol}^{-1}$. Opposed to a report by $\mathrm{Hong}^{[130]}$ these findings suggest, that the chemoselectivity of the reaction is not exclusively controlled by the energy difference of TS5.4 and TS5.8 and therefore is not solely influenced by the choice of solvent, but rather by the presence or absence of a suitable oxidant for the reoxidation of ruthenium(0) to catalytically competent ruthenium(II). If no oxidant is present in the reaction, intermediate 5.L represents a resting state as no reoxidation to ruthenium(II) can occur, while 5.F is an on-cycle intermediate.

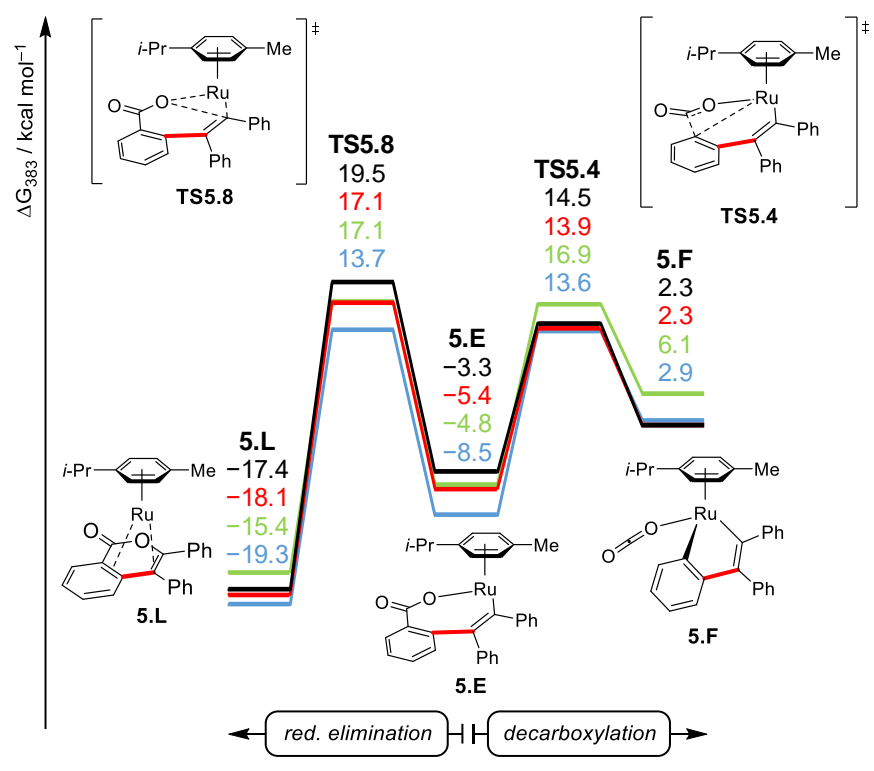

Figure 21: Comparison of reductive elimination and decarboxylation in PhMe (black line), DCE (red), TFE (green), and water (blue). Energies are given in $\mathrm{kcal} \mathrm{mol}^{-1}$ relative to 5.A.

\subsubsection{Alkylation of Benzoic Acids with Alkenes}

Concerning the reaction of benzoic acids $\mathbf{3 1}$ with maleimides $\mathbf{1 7 7}$ (Scheme 72), DFT calculations at the PBEO-D3(BJ)/def2-QZVP*+SMD(DCE)//PBE0/def2-SVP level of theory ${ }^{[126,127,134,135]}$ (for full 
details see Section 6.3) point to a reaction mechanism very similar to the reaction with alkynes 35 (Figure 22). C-H ruthenation, which is omitted due to similarity with the results presented above, is followed by coordination of maleimide $177 \mathbf{a}$, which can either occur with the amide moiety oriented away from the $p$-cymene ligand (5.D') or towards it (5.D') (Figure 23). Although geometry 5. $\mathbf{D}^{\prime \prime}$ is energetically favored by $4.9 \mathrm{kcal} \mathrm{mol}^{-1}$, the energy barrier for migratory insertion is higher by $6.2 \mathrm{kcal} \mathrm{mol}^{-1}$. Therefore, it is reasonable that the reaction proceeds via intermediate 5.D'. Seven-membered ruthenacycle intermediate $\mathbf{5 . E ^ { \prime }}$ then undergoes decarboxylation to form complex 5.F' and proto-demetalation with two molecules of benzoic acid leads to liberation of the arylated succinimide and regeneration of complex 5.A.

Compared to the reaction with alkynes 35 (Figure 17), intermediate 5.E' and 5.F' are energetically less favorable by 6.0 and $4.3 \mathrm{kcal} \mathrm{mol}^{-1}$, respectively, due to the constrained geometry dictated by the succinimide motif. It is noteworthy that intermediate $5 . J^{\prime}$ is $16.5 \mathrm{kcal} \mathrm{mol}^{-1}$ higher in energy than the corresponding intermediate 5.J, which is caused by the formation of a less favorable hydrogen bond $\left(d_{\mathrm{OH}-\mathrm{O}}=1.41 \AA\right.$ ) between the $\mathrm{OH}$ group of the coordinated benzoic acid and the ruthenium-coordinated oxygen of the benzoate ligand (Figure 24).

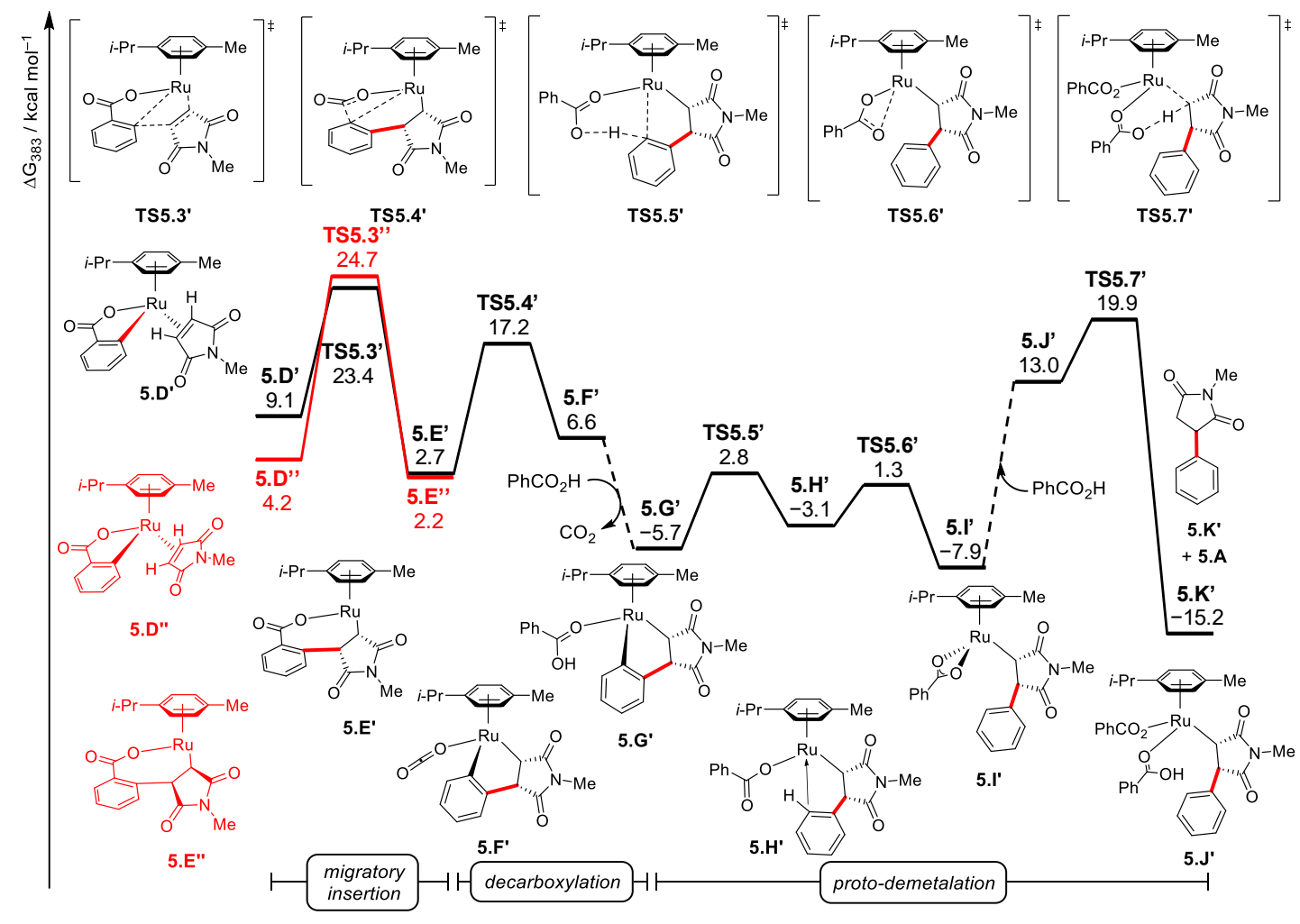

Figure 22: Relative Gibbs free energy profile for the reaction of benzoic acid (31a) with maleimide 177a at the PBE0-D3(BJ)/def2-QZVP*+SMD(PhMe) level of theory relative to 5.A. 

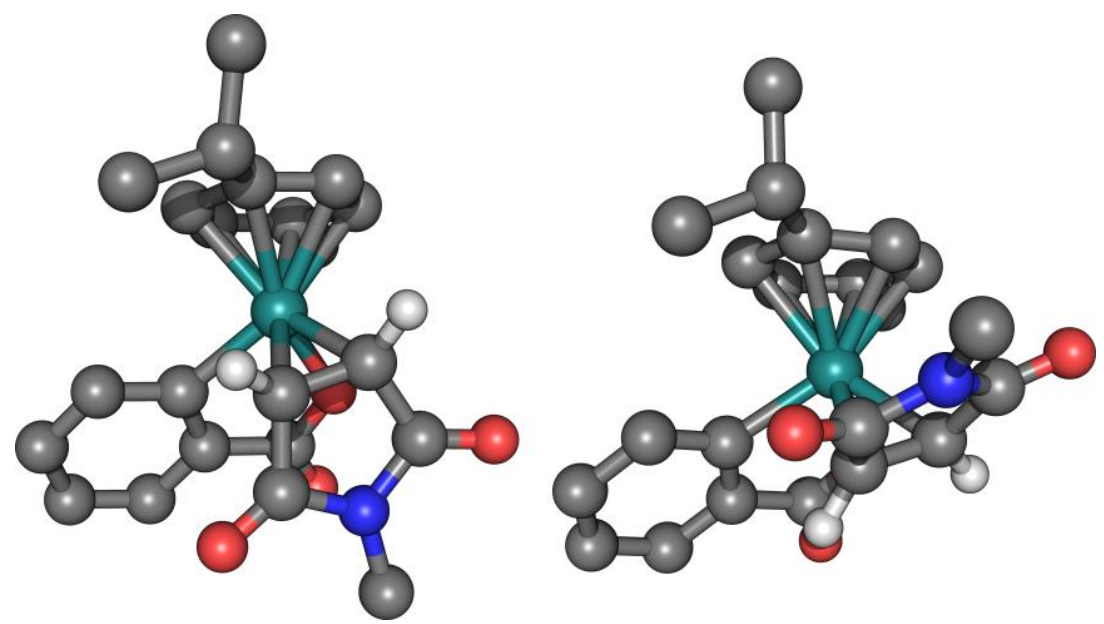

Figure 23: Structure of coordination intermediate 5.D' (left) and 5.D" (right). Non-participating hydrogen atoms are omitted for clarity.

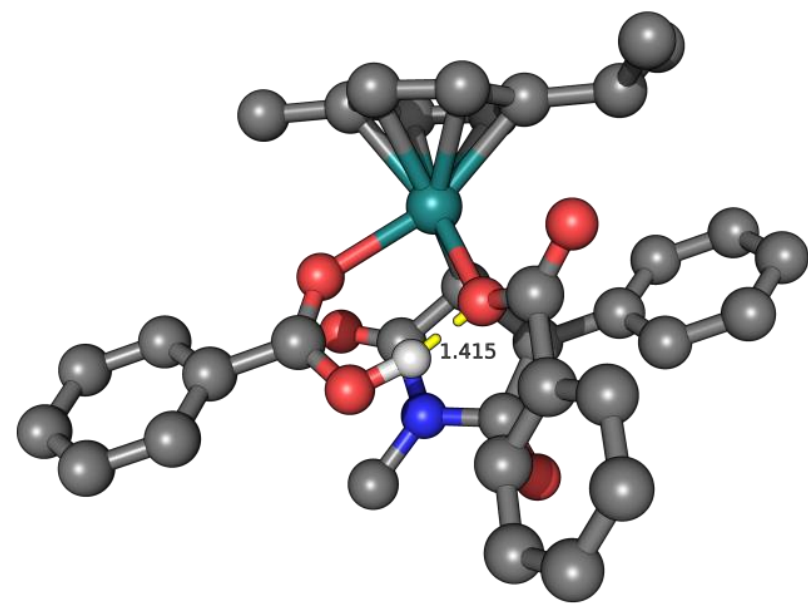

Figure 24: Structure of intermediate 5.J'. Distances are given in $\AA$ and non-participating hydrogen atoms are omitted for clarity.

Single point calculations with different solvents revealed a trend similar to the one observed for alkynes 35. Again, the energies of intermediates 5.' ' and 5.E' as well as transition state TS5.3' decreased with increasing solvent polarity, while proto-demetalation became energetically slightly less favorable (Figure 25). 


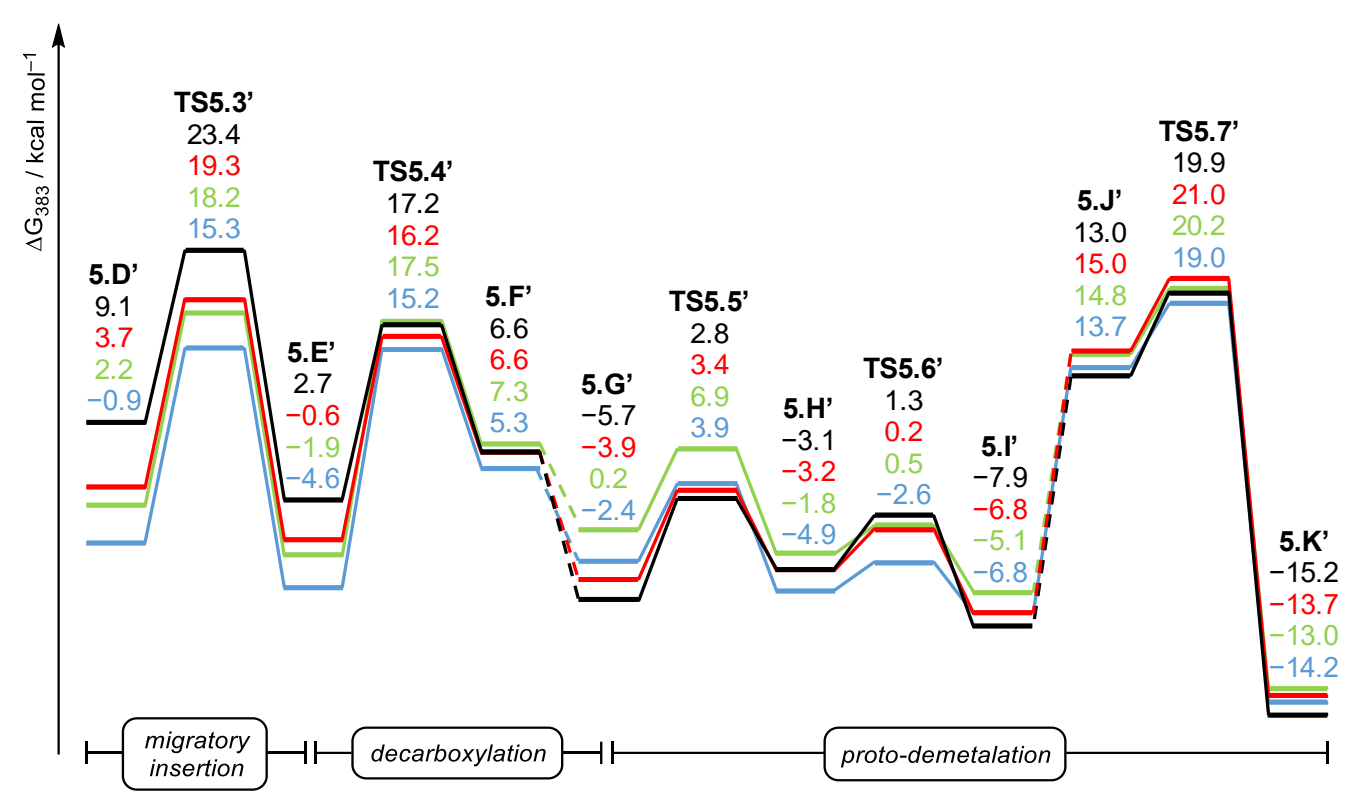

Figure 25: Relative Gibbs free energy profile in PhMe (black line), DCE (red), TFE (green), and water (blue) for the reaction of benzoic acid (31a) with maleimide 177a.

A study of the influence of dispersion forces on the mechanism was performed. In line with the previously obtained results for the reaction of alkynes 35, considerable destabilization was observed, when no dispersion correction was employed (Figure 26). A significant difference of $21.3 \mathrm{kcal} \mathrm{mol}^{-1}$ was found for intermediate $\mathbf{5 . J}$, thereby highlighting the importance of accurate dispersion corrections in computational investigations.

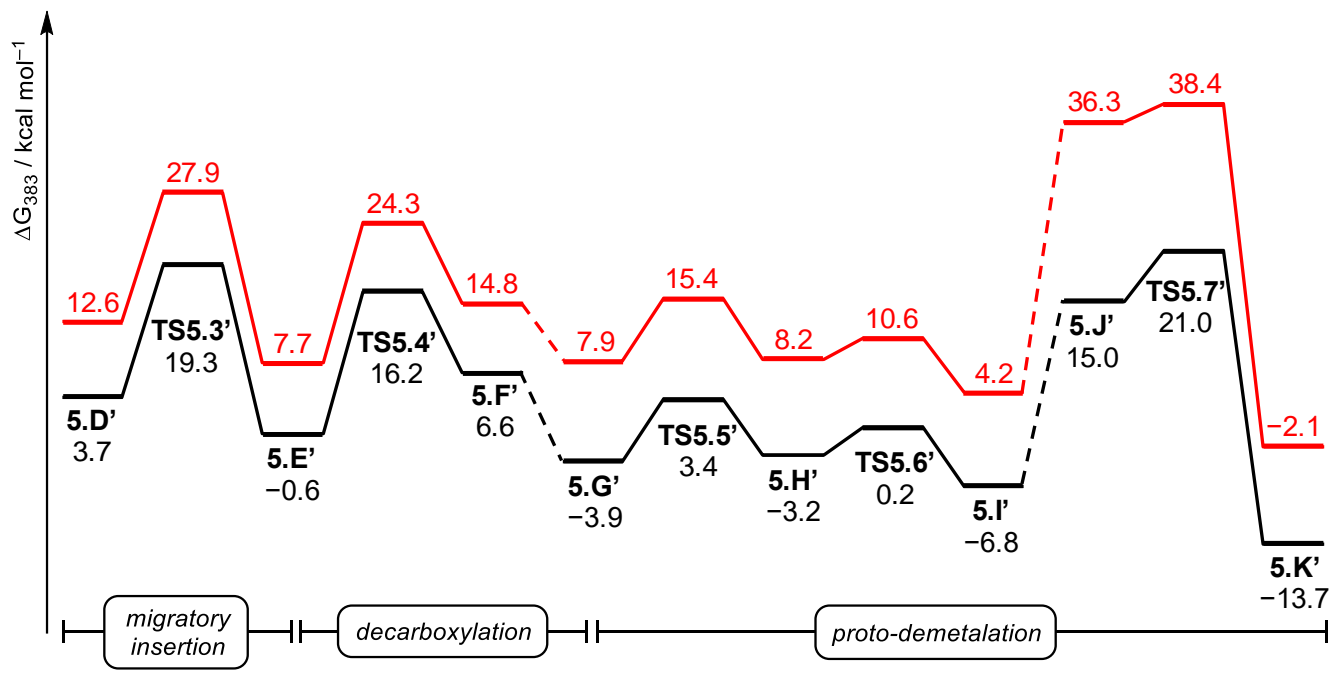

Figure 26: Relative Gibbs free energy profile in DCE with D3(BJ) (black line) and without dispersion correction (red). 
The possibility of a [4+2] cyclization as a competing reaction pathway could be completely excluded due to unrealistically high energies for the reductive elimination transition state TS5.8' and ruthenium(0) sandwich-type complex 5.L' (Figure 27). Independent of the solvent, Gibbs free energies in excess of 67 and $22 \mathrm{kcal} \mathrm{mol}^{-1}$ were determined for TS5.8' and 5.'L', respectively, which can be attributed to mainly two factors: a) cyclization via reductive elimination requires the $\mathrm{C}-\mathrm{C}$ bond between the arene and succinimide moieties to bend out of the arene-plane (approx. $22^{\circ}$

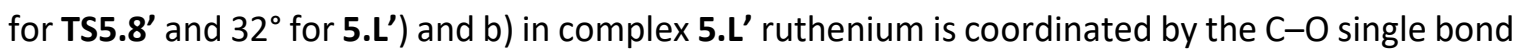
of the formed isochromanone moiety, which represents a disadvantageous, weak ligand.

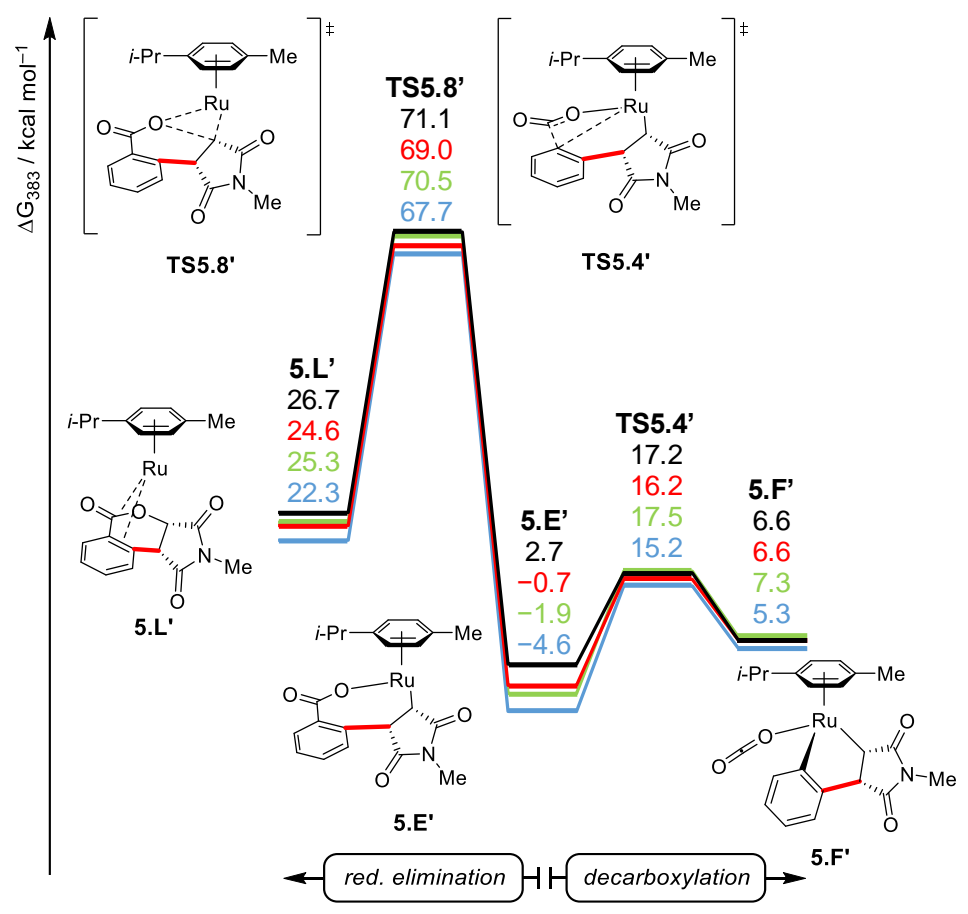

Figure 27: Comparison of reductive elimination and decarboxylation in PhMe (black line), DCE (red), TFE (green), and water (blue). Energies are given in $\mathrm{kcal} \mathrm{mol}^{-1}$ relative to 5.A.

The computationally obtained results were further confirmed by experimental mechanistic investigations. Experiments with deuterium-labelled benzoic acid 31b led to deuteriumincorporation in the former ipso-position of $\mathbf{1 7 8 b b}$ and in the succinimide-motif, indicating that the carboxylate acts indeed as the proton-acceptor during the $\mathrm{C}-\mathrm{H}$ scission and, subsequently, the corresponding acid serves as the proton-source in the proto-demetalation step (Scheme 73a). Additionally, a significant deuterium incorporation in the succinimide-motif was found in the cisposition with respect to the newly formed $\mathrm{C}-\mathrm{C}$ bond, which is in line with the calculated proto- 
demetalation step and renders an outer-sphere protonation event unlikely. The observed incorporation of deuterium in the para-position to the fluorine-substituent can be attributed to a post-transformational H/D scrambling. Initial rate measurements by in situ IR spectroscopy with substrate $\mathbf{3 1 b}$ or $[D]_{1}-\mathbf{3 1} \mathbf{b}$ resulted in a neglectable kinetic isotope effect value of $k_{H} / k_{D}=1.05$, thus pointing to a non-turnover-limiting $\mathrm{C}-\mathrm{H}$ cleavage event (Scheme 73b and Figure 28). The observed KIE value is in good agreement with a calculated value of 1.08 for the formation of agostic intermediate 5.B as obtained from the DFT calculations (see Section 6.3.3).

(a) isotopically labelled substrates<smiles>O=C(O)c1ccccc1F</smiles>

$[D]_{1}-31 b$<smiles>[2H]c1cccc(F)c1C(=O)O</smiles>

$[D]_{1}-31 b$<smiles>O=C1C=CC(=O)N1Cc1ccccc1</smiles>

$177 b$
$\left[\mathrm{Ru}\left(\mathrm{O}_{2} \mathrm{CMes}\right)_{2}(p\right.$-cymene $\left.)\right](\mathbf{6 1})$ $(10 \mathrm{~mol} \%)$

PhMe, $100^{\circ} \mathrm{C}, 24 \mathrm{~h}$<smiles>O=C1C=CC(=O)N1Cc1ccccc1</smiles>

$177 b$

$\left[\mathrm{Ru}\left(\mathrm{O}_{2} \mathrm{CMes}\right)_{2}(p\right.$-cymene $\left.)\right](\mathbf{6 1})$ $(10 \mathrm{~mol} \%)$

PhMe, $100^{\circ} \mathrm{C}, 24 \mathrm{~h}$

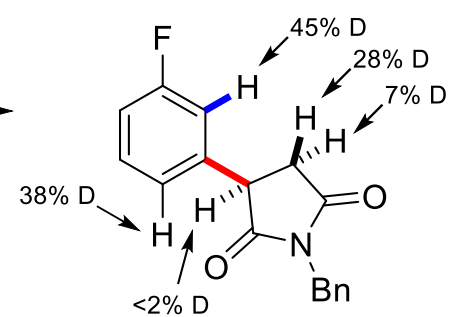

$[D]_{n}-178 b b: 62 \%$

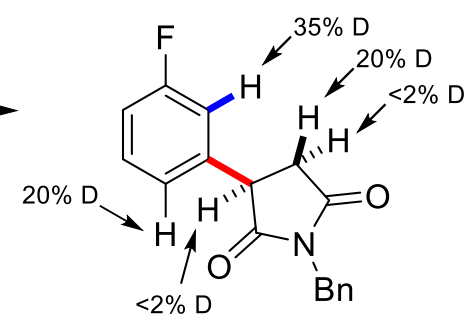

$[D]_{n}-178 b b: 56 \%$

(b) KIE study<smiles>O=C(O)c1c([18OH])cccc1F</smiles>

$\left[\mathrm{Ru}\left(\mathrm{O}_{2} \mathrm{CMes}\right)_{2}(p\right.$-cymene $\left.)\right](61)$

$(10 \mathrm{~mol} \%)$

PhMe, $110{ }^{\circ} \mathrm{C}$

$k_{H} / k_{D}=1.05$

$31 b$ or $[D]_{1}-31 b$

177b<smiles>O=C1CC(c2cccc(F)c2)C(=O)N1Cc1ccccc1</smiles>

$[D]_{n}-178 b b$

Scheme 73: (a) Reaction with isotopically labelled substrate (performed by Dr. N. Y. P. Kumar).

(b) Kinetic isotope effect study by parallel reactions. 


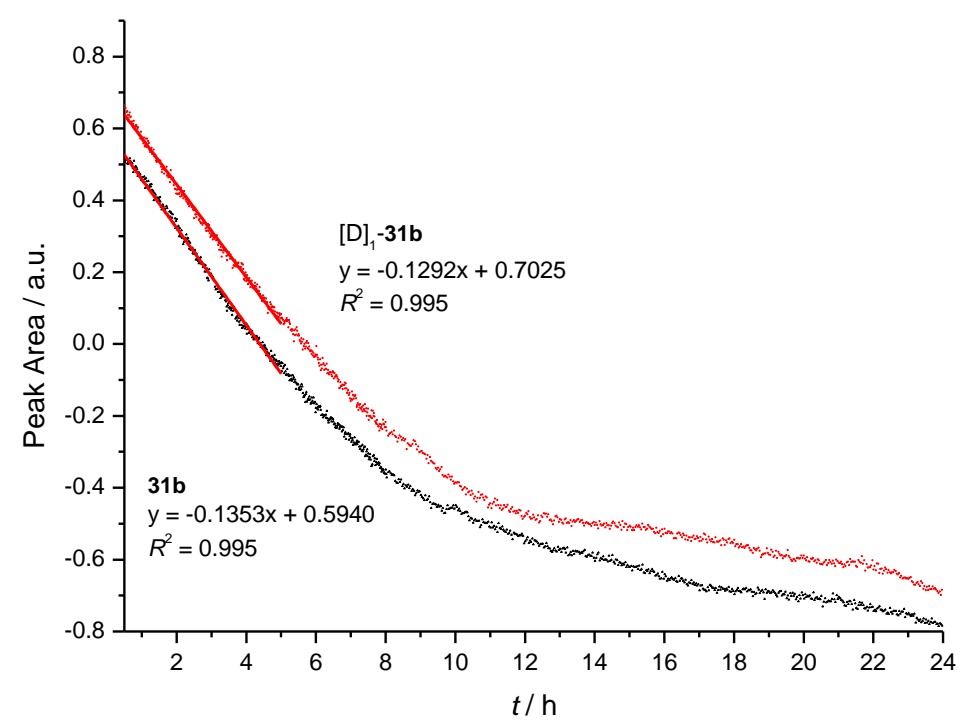

Figure 28: Kinetic isotope effect study by in situ IR spectroscopy.

\subsection{Ruthenium-Catalyzed C-H Alkenylation of Aryl Acetamides}

Aryl acetamides are an important structural motif that can be found in a number of natural products and bioactive molecules (Scheme 74). They represent for example a class of $k$-opioid agonists ${ }^{[138]}$ with applications as analgesic drugs. ${ }^{[139]}$ In addition, atenolol acts as $B$-blocker and can be used as treatment for cardiovascular diseases. ${ }^{[140]}$ Consequently, the development of novel methods for the functionalization of aryl acetamides remains highly desirable.<smiles>CC(C)C(CN1CC=CC1)N(C)C(=O)Cc1ccc(Cl)c(Cl)c1</smiles>

LPK-26 analgesic<smiles>CN(C(=O)Cc1ccc(Cl)c(Cl)c1)[C@@H]1CC[C@]2(CCCO2)C[C@@H]1N1CCCC1</smiles>

Spiradoline analgesic<smiles>CC(C)NC[C@H](O)COc1ccc(CC(N)=O)cc1</smiles>

Atenolol hypertension

Scheme 74: Selected bioactive aryl acetamides.

The application of $\mathrm{C}-\mathrm{H}$ activation strategies towards the synthesis of substituted aryl acetamides was so far limited to precious palladium catalysts with contributions by $Y u^{[110]}$ among others. ${ }^{[111]}$ In sharp contrast, the use of less expensive ruthenium catalysts for $\mathrm{C}-\mathrm{H}$ activations of aryl 
acetamides remained undisclosed, due to the challenging formation of an unfavorable sixmembered ruthenacycle through the distal weak coordination of amides.

Nevertheless, Dr. Q. Bu and Dr. V. Kotek in the Ackermann group developed the oxidative alkenylation of aryl acetamides 153 with acrylates 27, employing an in situ generated cationic ruthenium complex and a copper(II) salt as the oxidant (Scheme 75). ${ }^{[141]}$ Tertiary, secondary, and even challenging primary amides were smoothly transformed under the reaction conditions and a number of valuable functional groups was well tolerated.<smiles>[R][CH-]C=CO[R]</smiles>

153

27

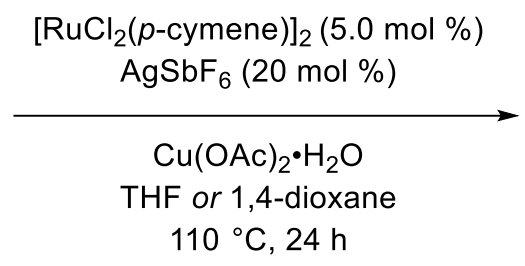

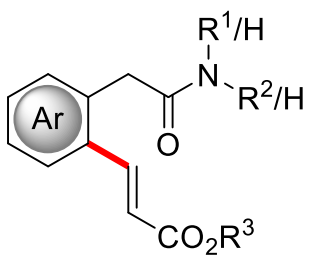

155

Scheme 75: Optimized reaction conditions for ruthenium-catalyzed $\mathrm{C}-\mathrm{H}$ alkenylations of acetamides 153.

To gain insight into the catalyst's mode of action, a series of mechanistic experiments was performed. When the reaction was conducted in the presence of isotopically labeled methanol as cosolvent, significant H/D scrambling was observed in the ortho-position of the product 155aa as well as the reisolated substrate 153a, thus indicating a facile $\mathrm{C}-\mathrm{H}$ ruthenation (Scheme $76 \mathrm{a}$ ). Furthermore, the kinetic isotope effect was determined in two parallel reactions by means of in situ IR spectroscopy and resulted in a low, non-significant KIE value of $k_{H} / k_{\mathrm{D}}=1.02$, which renders a turnover-limiting $\mathrm{C}-\mathrm{H}$ activation event unlikely (Scheme 76b). An intermolecular competition experiment between acetamide $153 \mathrm{c}$ and benzamide $34 \mathrm{a}$ led to exclusive formation of alkenylated benzamide 179ab, thereby highlighting the considerably more challenging transformation of aryl acetamide substrates (Scheme 76c). 
(a) $H / D$ exchange

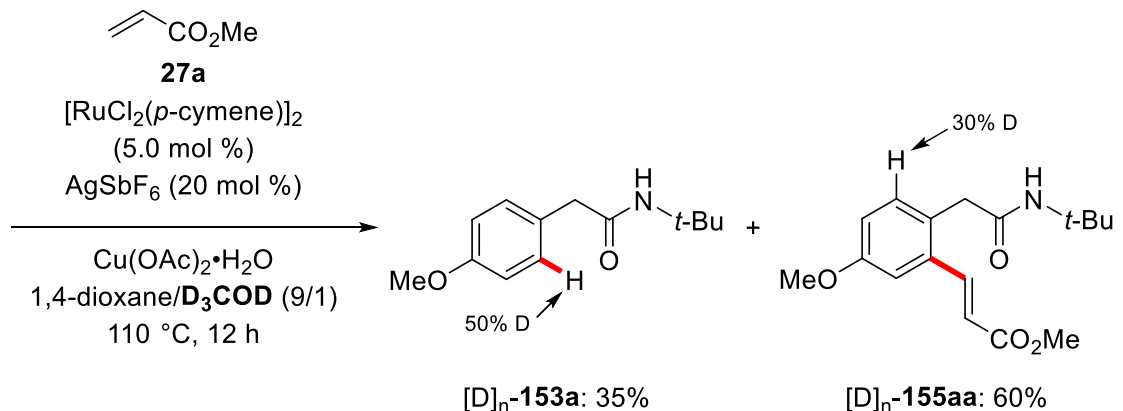

(b) KIE study

$$
\mathrm{CO}_{2} n-\mathrm{Bu}
$$

27b

$\left[\mathrm{RuCl}_{2}(p \text {-cymene })\right]_{2}$

$(5.0 \mathrm{~mol} \%)$

$\mathrm{D}_{5} / \mathrm{H}_{5} \frac{\overbrace{L}^{1}}{\mathrm{O}_{\mathrm{O}}^{\mathrm{N}}-\mathrm{Bu}}$

$\mathrm{AgSbF}_{6}(20 \mathrm{~mol} \%)$

$\mathrm{Cu}(\mathrm{OAc})_{2} \cdot \mathrm{H}_{2} \mathrm{O}$

1,4-dioxane, $100^{\circ} \mathrm{C}$

$153 b$ or $[D]_{5}-153 b$

$k_{\mathrm{H}} / k_{\mathrm{D}}=1.02$

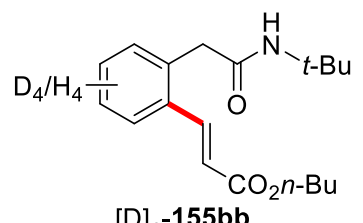

$[D]_{n}-155 b b$ (c) intermolecular competition

$\widehat{C O}_{27 b} \mathrm{CO}_{2} \mathrm{Bu}$

$\left[\mathrm{RuCl}_{2}(p \text {-cymene })\right]_{2}$

$(5.0 \mathrm{~mol} \%)$

$\overbrace{\mathrm{O}}^{\mathrm{NH}_{2}}+$<smiles>NC(=O)c1ccccc1</smiles>

$\mathrm{AgSbF}_{6}(20 \mathrm{~mol} \%)$

$\mathrm{Cu}(\mathrm{OAc})_{2} \cdot \mathrm{H}_{2} \mathrm{O}$

1,4-dioxane, $110^{\circ} \mathrm{C}$

$34 a$

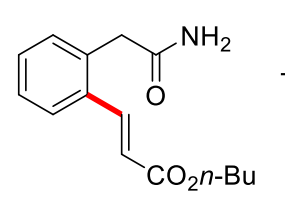

153cb: traces

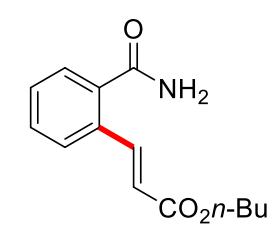

179ab: $39 \%$

Scheme 76: (a) H/D exchange experiment (performed by Dr. Q. Bu). (b) Kinetic isotope effect study by parallel reactions. (c) Intermolecular competition reaction (performed by Dr. Q. Bu).

Additionally, the mechanism of the ruthenium-catalyzed oxidative $\mathrm{C}-\mathrm{H}$ alkenylation was studied by means of DFT calculations. Geometry optimizations and frequency calculations were performed with the TPSS meta-GGA functional ${ }^{[125]}$ in combination with the Karlsruhe def2-TZVP basis set ${ }^{[127]}$ and $\mathrm{D} 3(\mathrm{BJ})$ correction. ${ }^{[126]}$ For the single point calculations, the B3LYP hybrid functional ${ }^{[128]}$ with def2-TZVP basis set, D3(BJ) correction and COSMO solvation model ${ }^{[142]}$ was employed (for full details see Section 6.4).

The experimental studies revealed that the presence of a silver salt containing a weakly coordinating anion, ${ }^{[143]}$ such as hexafluoroantimonate or tetrafluoroborate, was required to achieve conversion to the desired product. Furthermore, no reaction was observed, when $\mathrm{Cu}(\mathrm{OAc})_{2}$ was replaced by other copper(II) salts or by other metal-based oxidants, thus leading to 
the assumption that a cationic $[\mathrm{Ru}(\mathrm{OAc})(p \text {-cymene })]^{+}$complex is formed in situ. Based on this hypothesis, the computational investigations were started with cationic, $\mathrm{O}$-coordinated complex 6.A and the weakly coordinating anion was omitted in all calculations for the sake of simplicity (Figure 29). Coordination through the deprotonated amide nitrogen can be reasonably excluded based on the fact, that tertiary amides as well as substrates bearing bulky $\mathrm{N}$-substituents also furnished the desired products in high yields. Decoordination of one oxygen of the $\kappa^{2}$-coordinated acetate ligand with an energy barrier of $11.8 \mathrm{kcal} \mathrm{mol}^{-1}$ generates five-coordinated intermediate 6.B, which undergoes concerted $\mathrm{C}-\mathrm{H}$ cleavage/C-Ru formation to form six-membered ruthenacycle 6.C. Afterwards, acetic acid is replaced by acrylate $\mathbf{2 7 a}$ to generate intermediates 6.D. Turnover-limiting migratory insertion of the alkene into the Ru-C bond generates eightmembered ruthenacycle intermediate $6 . \mathrm{E}$ with an energy barrier of $18.2 \mathrm{kcal} \mathrm{mol}^{-1}$. Finally, formation of agostic complex 6 .F followed by 6 -hydride elimination leads to the formation of product-coordinated complex 6.G.

Coordination of the alkene can also occur with the ester substituent facing away from the p-cymene ligand as shown in complex 6.' $\mathbf{D}^{\prime}$. Although intermediate 6.' $\mathbf{D}^{\prime}$ and transition state TS6.3' are energetically favorable compared to 6.D and TS6.3 with energy differences of $6.2 \mathrm{kcal} \mathrm{mol}^{-1}$ for the transition state, subsequent 6 -hydride elimination requires considerably more energy, since TS6.4' was found to be $8.9 \mathrm{kcal} \mathrm{mol}^{-1}$ higher in energy than TS6.4. These results are in agreement with calculations by McMullin/Williams/Frost on a related catalytic system. ${ }^{[144]}$ Additionally, 6.G' features a Z-configured double bond, which is experimentally not observed. The two possible coordination geometries with the ester-substituent in proximal position with respect to the phenyl ring were disregarded, since these geometries would lead to the formation of the experimentally not observed branched product. 


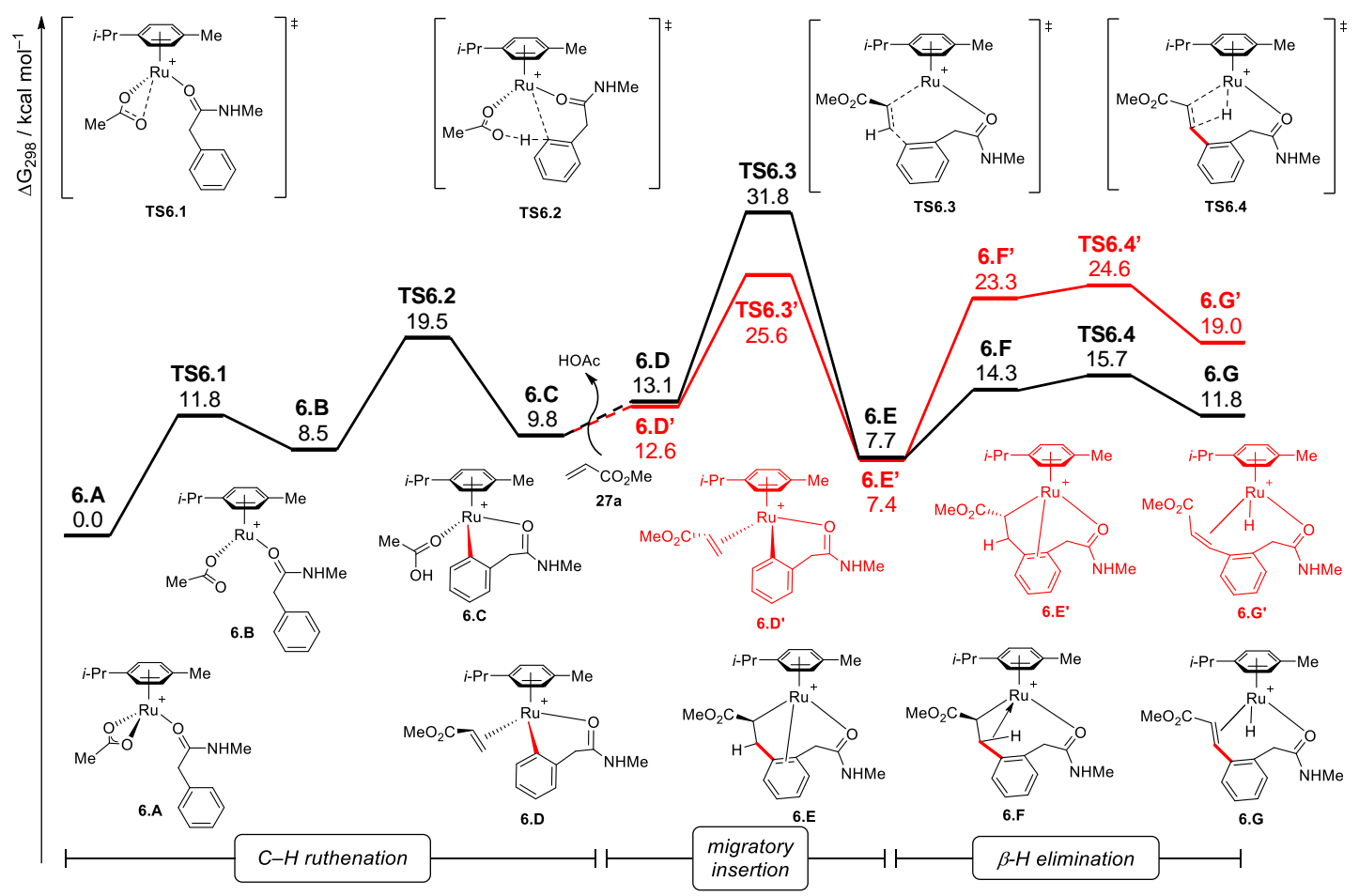

Figure 29: Relative Gibbs free energy profile for the reaction of amide 153d with acrylate $\mathbf{2 7 a}$.

A Mayer bond order analysis was employed to investigate the $\mathrm{C}-\mathrm{H}$ cleavage/Ru-C formation step in greater detail (Table 2). For the $\mathrm{C}-\mathrm{H}$ bond, the bond order decreases from 0.87 in intermediate 6.B over 0.38 in TS6.2 to a value of 0.11 in intermediate 6.C. At the same time the bond order of the $\mathrm{O}-\mathrm{H}$ bond increases from a neglectable value of $<0.10$ over 0.39 to a final value of 0.77 , which is in line with the observed $\mathrm{C}-\mathrm{H}$ distances. Here, the $\mathrm{C}-\mathrm{H}$ distance was found to increase from a value of $1.08 \AA$ in complex 6.B to $1.34 \AA \AA$ in TS6.2 (Figure 30) and, finally, to $1.96 \AA$ in metallacycle 6.C. Additionally, the Ru-C bond order was calculated to increase from 0.28 in intermediate 6.B to 0.72 in cyclometalated complex 6.C. The nonzero value in complex 6.B can be explained by a weak coordination of ruthenium to the $\pi$-system of the substrate with a distance of $d_{\text {Ru-C }}=2.53 \AA$, which is $0.34 \AA$ larger than the sum of the covalent radii $(2.19 \AA) . .^{[137]}$

Table 2: Bond order analysis for the $\mathrm{C}-\mathrm{H}$ ruthenation step.

\begin{tabular}{cccc}
\hline Bond & 6.B & TS6.2 & 6.C \\
\hline C-H & 0.8700 & 0.3754 & 0.1064 \\
Ru-C & 0.2767 & 0.4471 & 0.7177 \\
$\mathrm{O}-\mathrm{H}$ & $<0.10$ & 0.3938 & 0.7676 \\
\hline
\end{tabular}




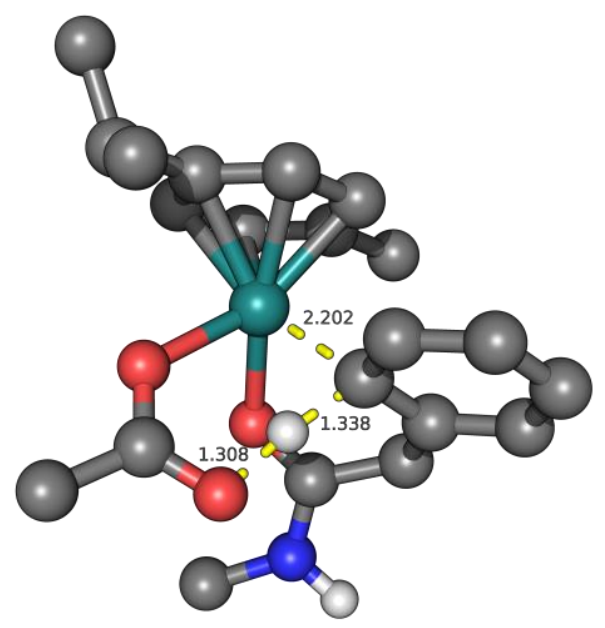

Figure 30: Structure of transition state TS6.2. Distances are given in $\AA$ and non-participating hydrogen atoms are omitted for clarity.

A comparison with the corresponding benzamide substrate revealed the $\mathrm{C}-\mathrm{H}$ cleavage transition state TS6.2 $2^{5}$ to be energetically favorable by $2.0 \mathrm{kcal} \mathrm{mol}^{-1}$ and the five-membered ruthencycle analogue $6 . \mathrm{C}^{5}$ to be stabilized by $6.1 \mathrm{kcal} \mathrm{mol}^{-1}$ (Figure 31). This stabilization is caused by a more favorable planar geometry of $6 . C^{5}$ as compared to the boat-like geometry of six-membered metallacycle 6.C (Figure 32). Furthermore, these findings are congruent with the results obtained by intermolecular competition experiments.

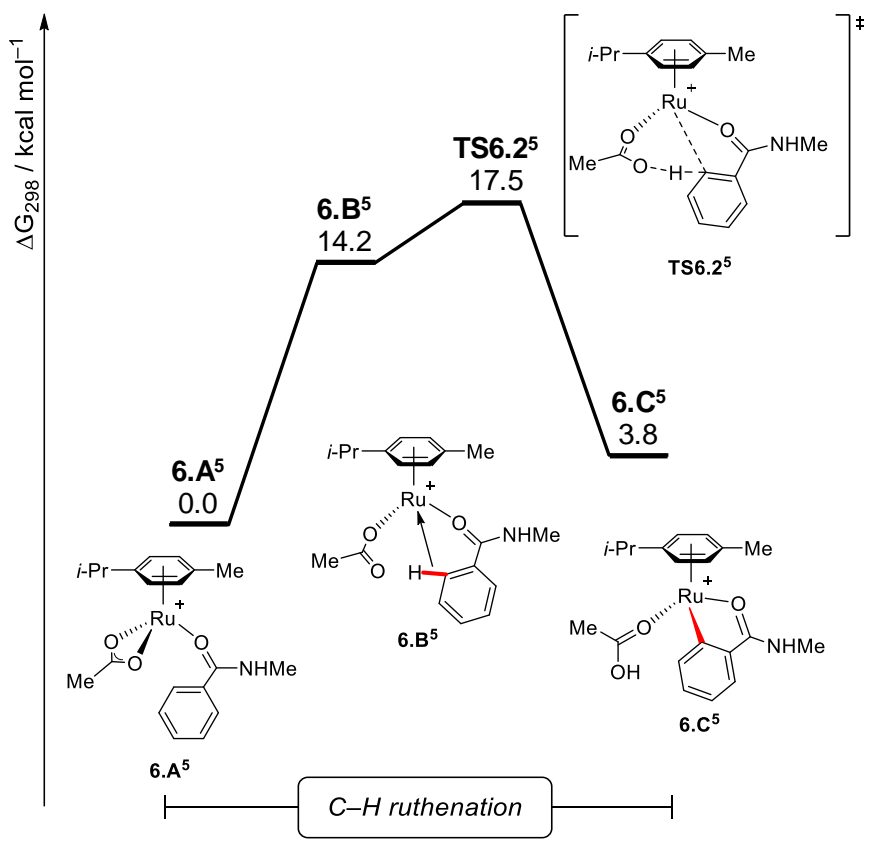

Figure 31: Relative Gibbs free energy profile for the $\mathrm{C}-\mathrm{H}$ activation of benzamide 34b. 

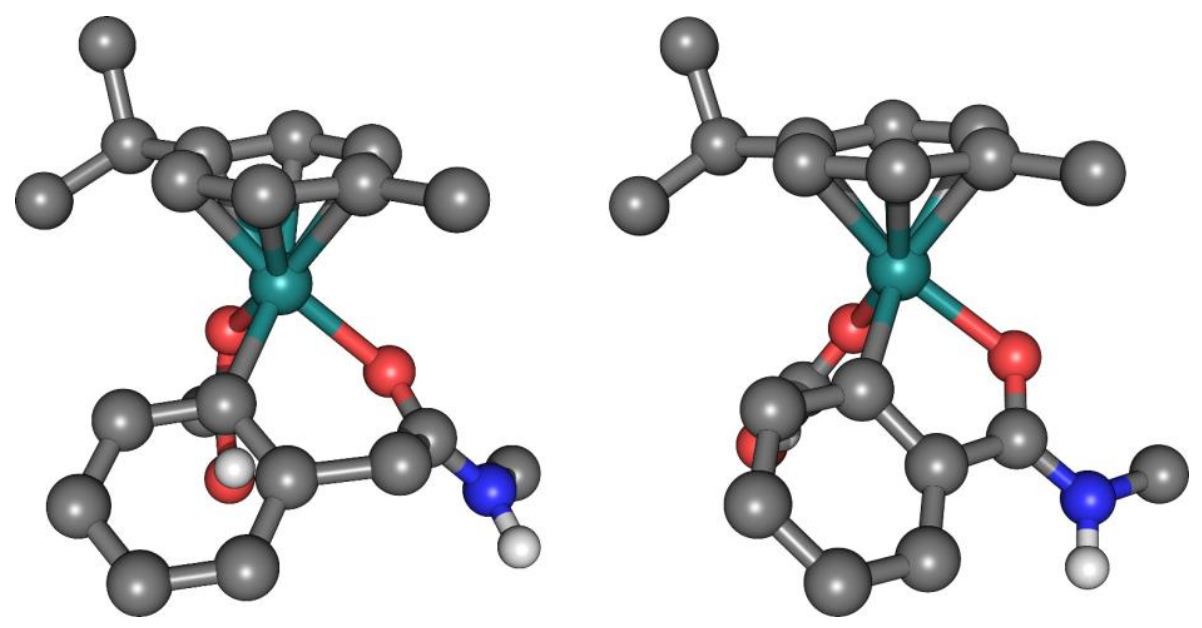

Figure 32: Structure of cyclometalated complex 6.C (left) and 6..$^{5}$ (right). Non-participating hydrogen atoms are omitted for clarity.

The influence of dispersion effects on the Gibbs free energy profile was investigated by removing the D3 correction energies from the single point energies. As expected, omission of dispersion contributions led to a considerable destabilization of intermediates as well as transition states with energy differences of at least $3.7 \mathrm{kcal} \mathrm{mol}^{-1}$ (Figure 33). Especially eight-membered ruthenacycle 6.E was found to be vastly stabilized through dispersion effects by $10.6 \mathrm{kcal} \mathrm{mol}^{-1}$, highlighting the importance of weak non-covalent interactions in catalysis.

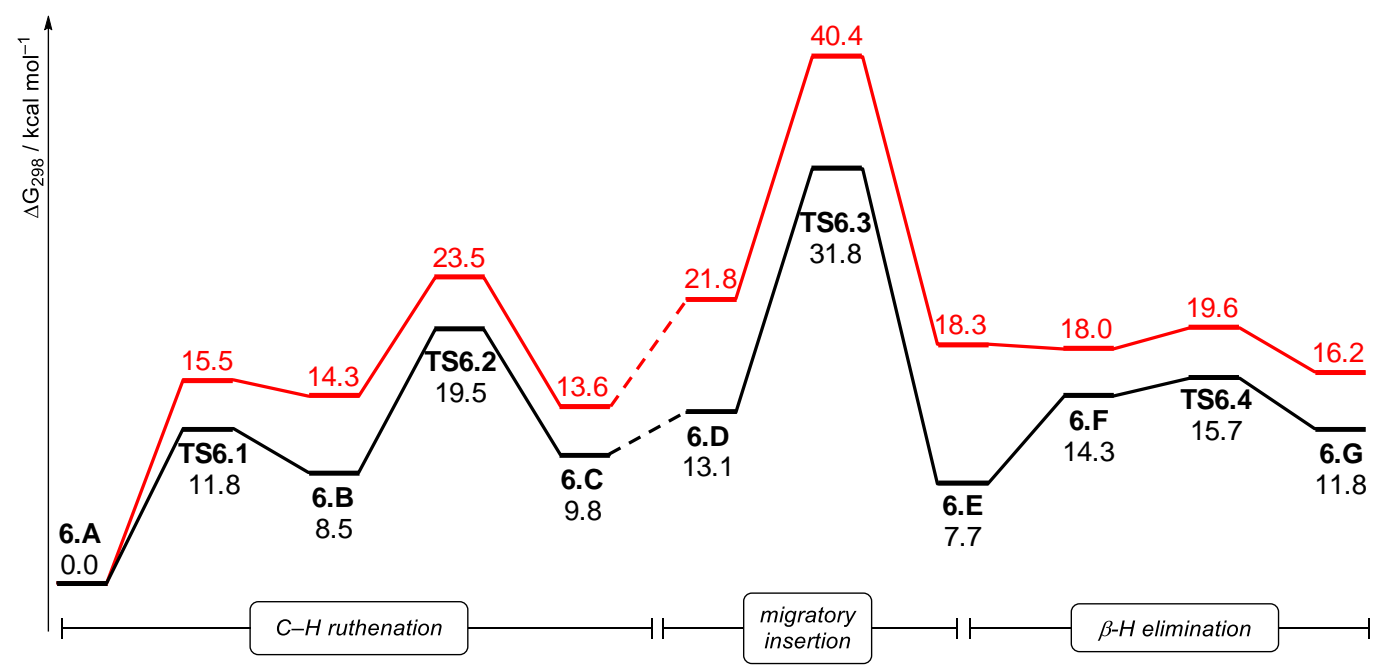

Figure 33: Relative Gibbs free energy profile with D3(BJ) (black line) and without dispersion correction (red). 
The calculated energies at the B3LYP-D3(BJ)/def2-TZVP+COSMO level of theory were further evaluated with a number of commonly employed functionals. Hence, single point calculations were performed using the PBE0 hybrid GGA functional ${ }^{[134]}$ and the PW6B95 hybrid-meta-GGA functional[145] (Figure 34). Energies obtained with Truhlar's PW6B95 functional were overall in good agreement with the B3LYP results, which is in line with a comparable performance of these functionals in various benchmark studies. ${ }^{[136,146]}$ In contrast, calculations at the PBEO level resulted in comparatively more stable intermediates 6.D-6.G and transition states TS6.3 and TS6.4, whereas only relatively minor changes in the relative Gibbs free energies for the $\mathrm{C}-\mathrm{H}$ ruthenation step were observed.

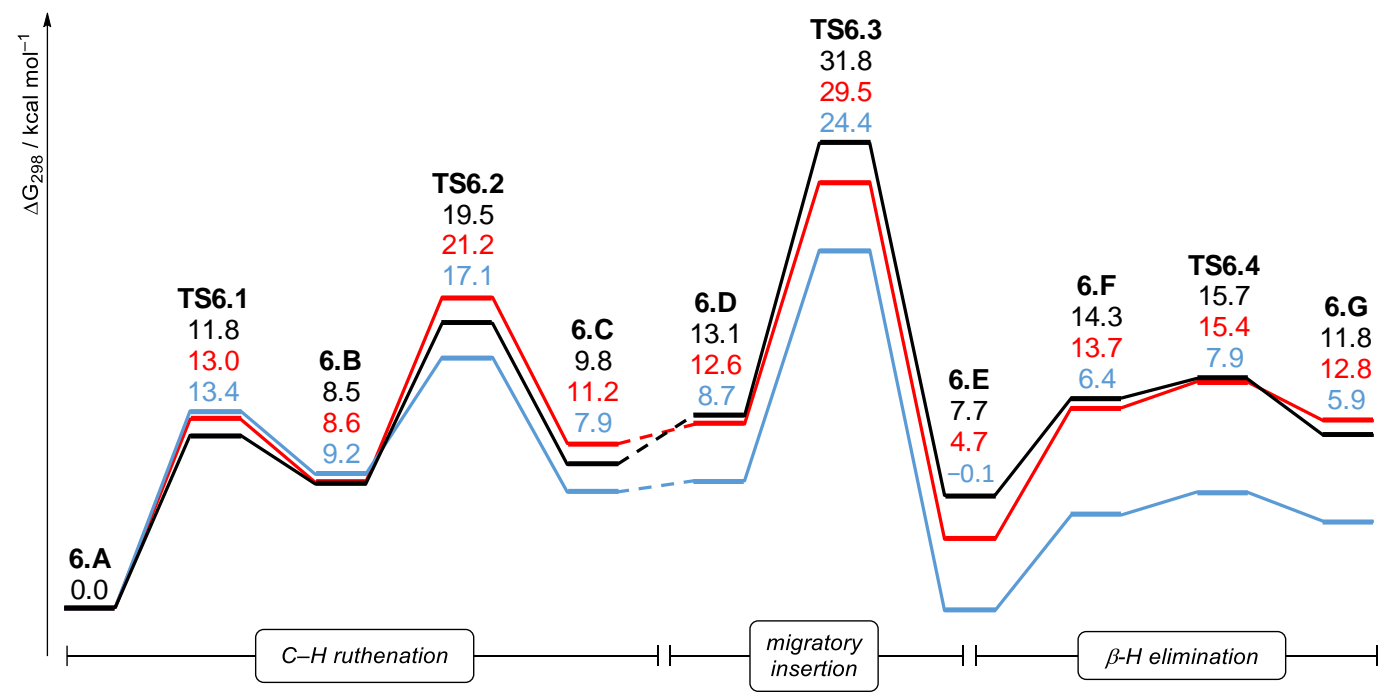

Figure 34: Relative Gibbs free energy profile at the B3LYP (black line), PW6B95 (red), and PBE0 (blue) level of theory.

\subsection{Ruthenium-Catalyzed Thiocarbonyl-Directed Ferrocene C-H Arylation}

Substituted ferrocenes constitute an important class of compounds with numerous applications in organocatalysis and transition metal catalysis. ${ }^{[112]}$ Additionally, bioactivity studies revealed promising antimalarial and anticancer properties of functionalized ferrocenes (Scheme 77). ${ }^{[113]}$ Therefore, novel methods for the efficient functionalization of ferrocenes continue to be in high demand. 


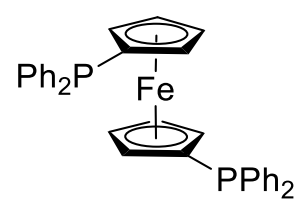

dppf

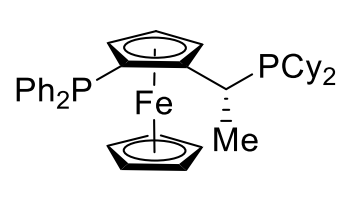

JosiPhos<smiles>CN(C)CCc1ccccc1CNc1ccnc2cc(Cl)ccc12</smiles>

Ferroquine antimalarial

Scheme 77: Selected ferrocene-containing ligands and drugs.

Despite the undisputable advances in catalyzed $\mathrm{C}-\mathrm{H}$ activation towards the development of environmentally-benign synthetic methods, these reactions are usually conducted in environmentally problematic, non-recyclable organic solvents, thus compromising the overall sustainability of the $\mathrm{C}-\mathrm{H}$ activation methodology. ${ }^{[147]}$ While water would at first glance offer an alternative as a non-toxic and non-flammable ubiquitous reaction medium, the limited solubility of commonly employed catalysts and organic compounds usually leads to an impaired reaction outcome.

With this aspect in mind, Dr. S. R. Yetra in the Ackermann group observed that the use of micelleforming surfactant TPGS-750M allowed for the ruthenium-catalyzed C-H arylation of ferrocenes 156 to occur with high efficacy in water (Scheme 78). ${ }^{[148]}$ Ruthenium(II)-biscarboxylate catalysts facilitated the thiocarbonyl-directed direct $\mathrm{C}-\mathrm{H}$ arylation, delivering the desired monofunctionalized products 158 in good to excellent yields. Interestingly, replacement of the thiocarbonyl directing group with simple ketones resulted in a complete shutdown of the reaction under otherwise identical conditions.

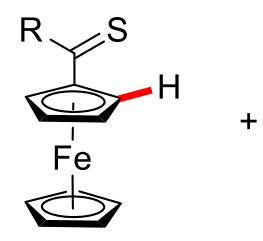

156

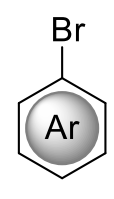

46

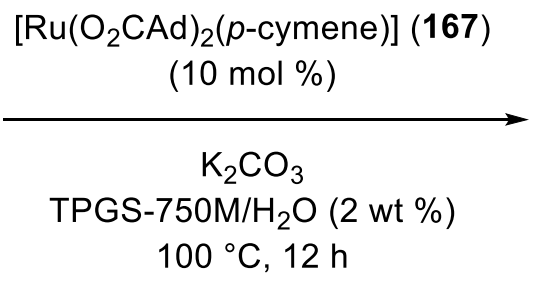

$100{ }^{\circ} \mathrm{C}, 12 \mathrm{~h}$

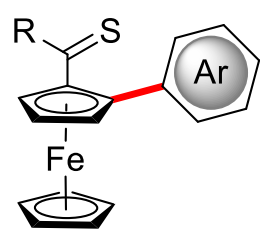

158

Scheme 78: Optimized reaction conditions for ruthenium-catalyzed $\mathrm{C}-\mathrm{H}$ arylations of ferrocenes 156. 
Intrigued by the vastly different behavior of thiocarbonyls and ketones, the key $\mathrm{C}-\mathrm{H}$ activation step was studied computationally by means of DFT calculations. Geometry optimization and vibrational frequency calculations were performed at the TPSS-D3(BJ)/def2-TZVP meta-GGA level of theory. ${ }^{[125,126,127]}$ In the single point calculations, Truhlar's PW6B95 hybrid-meta-GGA functional ${ }^{[145]}$ was employed in combination with D3(BJ) dispersion correction and def2-TZVP basis set, while solvent effects were accounted for through the use of the COSMO solvation model ${ }^{[142]}$ with a dielectric constant corresponding to toluene (for full details see Section 6.5). The use of toluene as reaction medium led to comparable results and, therefore, toluene was chosen as the solvent in the calculations for the sake of simplicity. Furthermore, the adamantyl carboxylate ligands were replaced by acetate, due to a similar performance in the reaction.

Starting from adduct complex 7.A, which is formed by coordination of 156 a to ruthenium and dissociation of one acetate ligand, $\mathrm{C}-\mathrm{H}$ activation proceeds via formation of agostic complex 7.B with an energy barrier of $10.9 \mathrm{kcal} \mathrm{mol}^{-1}$ (Figure 35). Afterwards, concerted C-H cleavage/Ru-C formation in TS7.2 generates cyclometalated intermediate 7.C with an overall barrier of $14.8 \mathrm{kcal} \mathrm{mol}^{-1}$, which is in good agreement with studies on comparable ruthenium-catalyzed reactions (vide supra). In all calculated structures, the $\mathrm{Cp}$-rings of the ferrocene-moiety adopt an eclipsed rather than a staggered configuration, ${ }^{[149]}$ and the $\mathrm{Cp}$-rings are noticeable tilted towards each other in cyclometalated intermediate 7.C (Figure 36). In stark contrast, replacing sulfur in complex 7.A with oxygen led to a significant destabilization by $8.6 \mathrm{kcal} \mathrm{mol}^{-1}$. Consequently, the relative Gibbs free energies of the later intermediates and transition states increased by 10.7$13.0 \mathrm{kcal} \mathrm{mol}^{-1}$ compared to the respective sulfur analogues along with higher energy barriers of 13.0 and $19.2 \mathrm{kcal} \mathrm{mol}^{-1}$. Calculations of the corresponding selenium analogues revealed these structures to be slightly more stable than the initial sulfur complexes with energy differences of 0.2-3.1 kcal mol-1. Nevertheless, the energy barriers for the formation of agostic intermediate 7.B and cyclometalated complex 7.C are 12.6 and $15.8 \mathrm{kcal} \mathrm{mol}^{-1}$, respectively, which represents a small increase compared to thiocarbonyl as the directing group. 


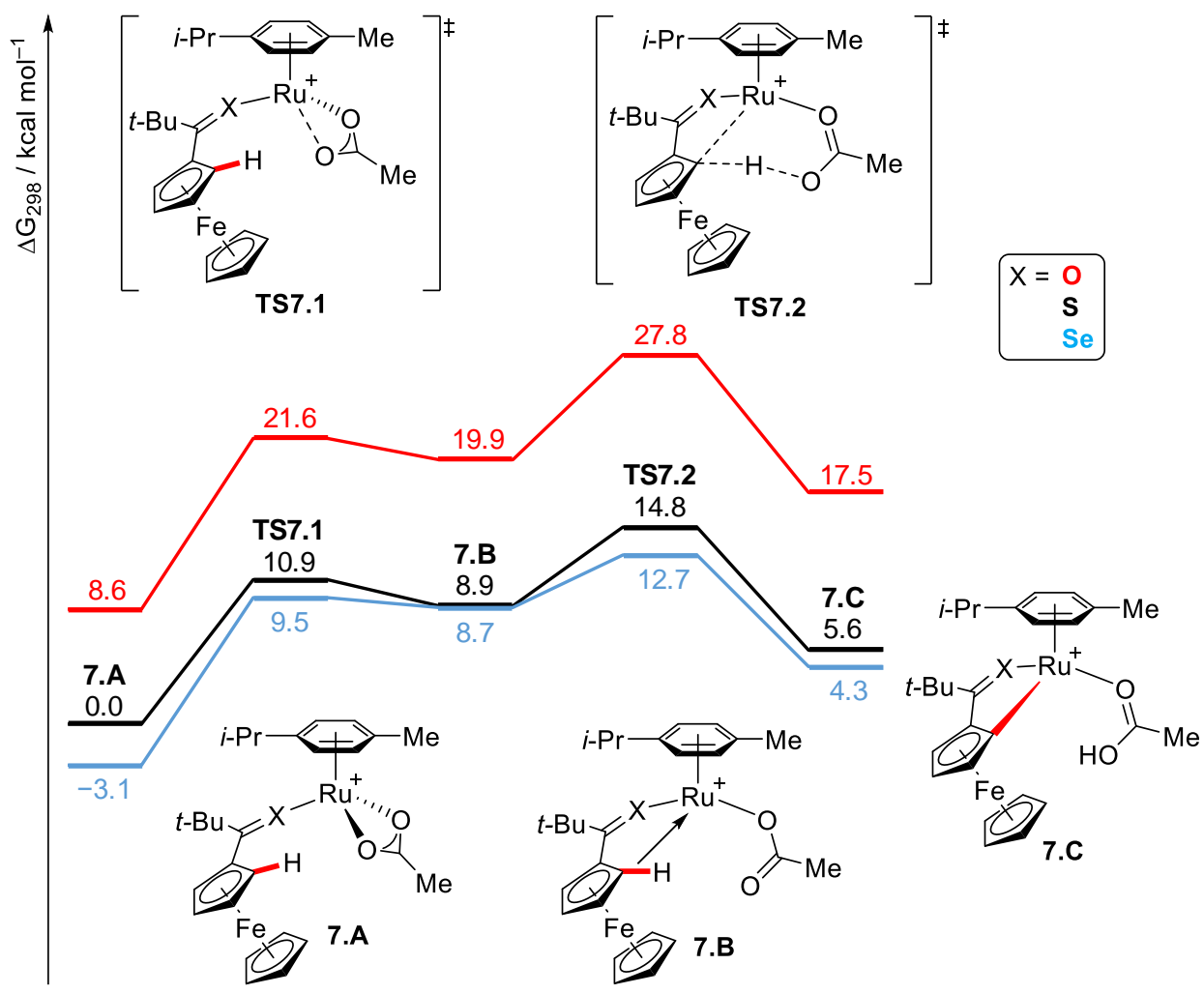

Figure 35: Relative Gibbs free energy profile for the $\mathrm{C}-\mathrm{H}$ activation of ferrocene 156a with thioketone (black line), ketone (red), and selenoketone (blue) directing group.

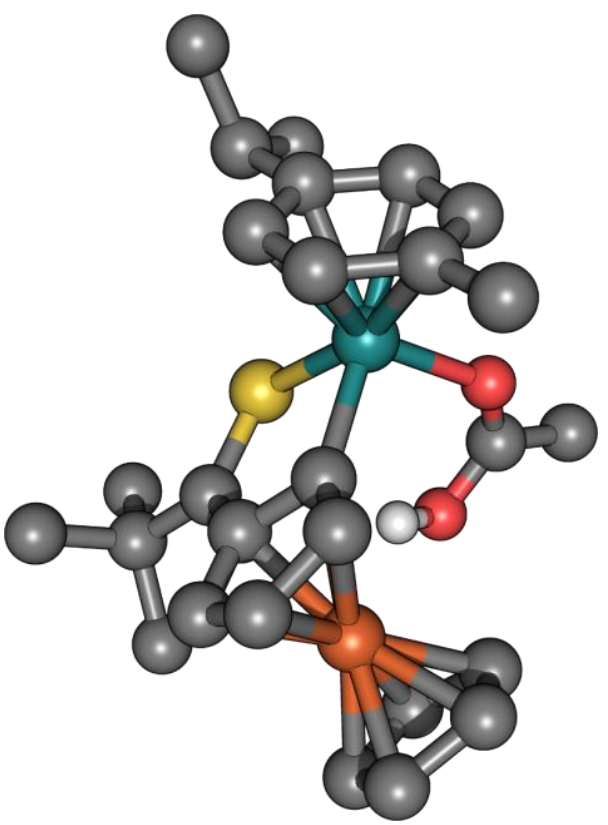

Figure 36: Structure of cyclometalated complex 7.C $(X=S)$. Non-participating hydrogen atoms are omitted for clarity. 
Although the increasing size of the chalcogen atoms (van-der-Waals radii: $1.52 \AA$ for oxygen, $1.80 \AA$ for sulfur, and $1.90 \AA$ for selenium ${ }^{[150]}$ ) and the consequently greater $\mathrm{X}-\mathrm{Ru}$ and $\mathrm{X}-\mathrm{C}$ bond lengths should reduce the steric repulsion within the complex and also the ring-strain in cyclometalated intermediate 7.C (for selected bond lengths see Section 6.5.3), this effect does not rationalize the already considerable energy differences in intermediate 7.A. To this end, a distortion-interaction analysis ${ }^{[151]}$ was performed for transition state TS7.1 to quantify differences in the complex geometries (Figure 37). The structures were separated into a substrate and a $[\mathrm{Ru}(\mathrm{OAc})(p \text {-cymene })]^{+}$fragment and the energies of the fragments were compared to the freely optimized structures. Notably, the distortion energy is almost identical for all structures with differences of less than $1.0 \mathrm{kcal} \mathrm{mol}^{-1}$, thereby substantiating the suspected marginal geometric influences on the observed energy differences. In contrast, the interaction energies showed more pronounced differences with larger stabilizations for the higher chalcogens. With respect to the corresponding intermediates 7.A, the interaction energy decreased by $3.1 \mathrm{kcal} \mathrm{mol}^{-1}$ and $1.3 \mathrm{kcal} \mathrm{mol}^{-1}$, when the ketone was compared to the thioketone and selenoketone, respectively.

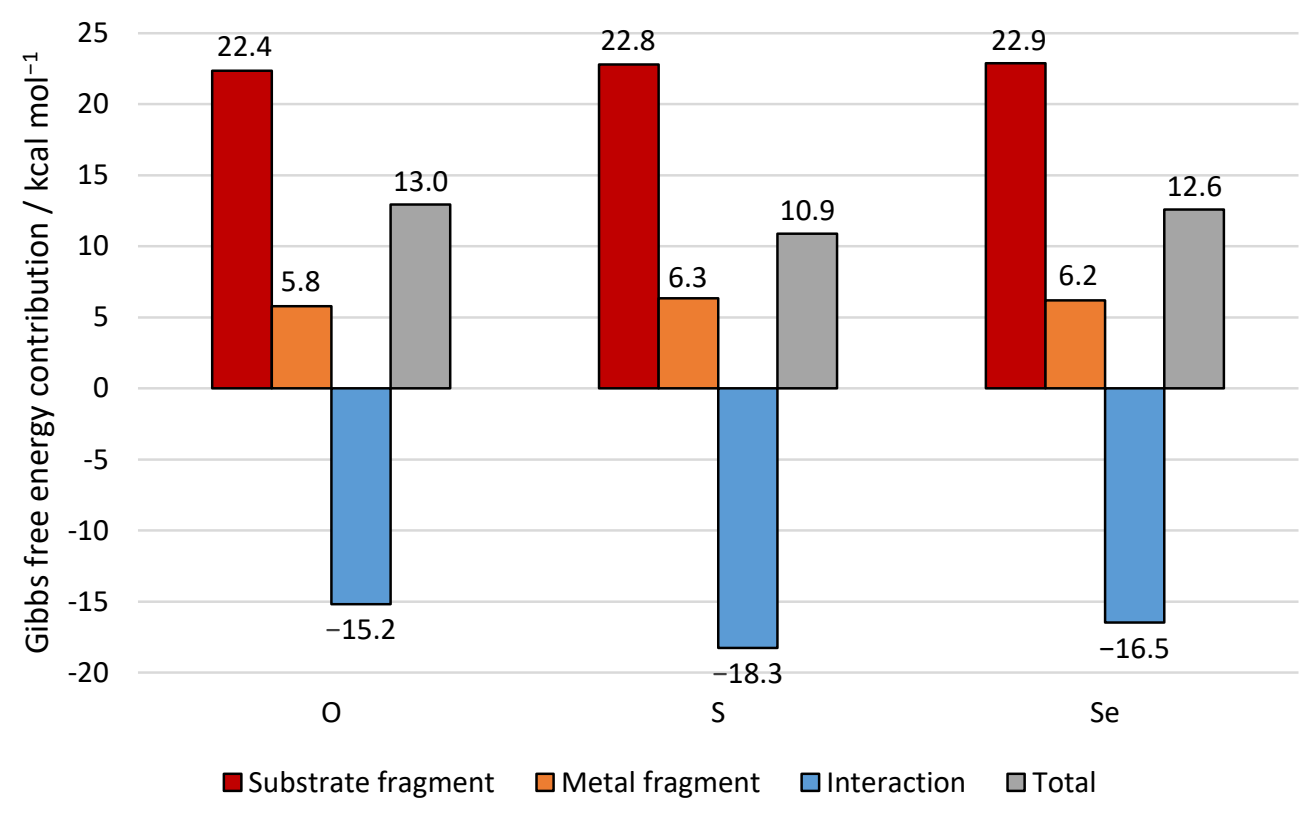

Figure 37: Distortion-interaction analysis for transition state TS7.1 with distortion energies for the substrate (red column) and the metal fragment (orange), interaction energies (blue), and total energies (grey). Negative values correspond to stabilizing contributions. 
Along with an increase in size the polarizability drastically increases for higher chalcogens (in a.u.: 5.3 for oxygen, 19.4 for sulfur, and 28.9 for selenium ${ }^{[152]}$ ), which might result in stronger attractive London dispersion interactions within the complexes. A comparison of energies calculated with and without Grimme's D3 correction revealed a largely neglectable influence with differences of less than $2.0 \mathrm{kcal} \mathrm{mol}^{-1}$ for all structures (Figure 38). As expected, the largest influence was observed for structures containing highly polarizable selenoketone as the directing group.

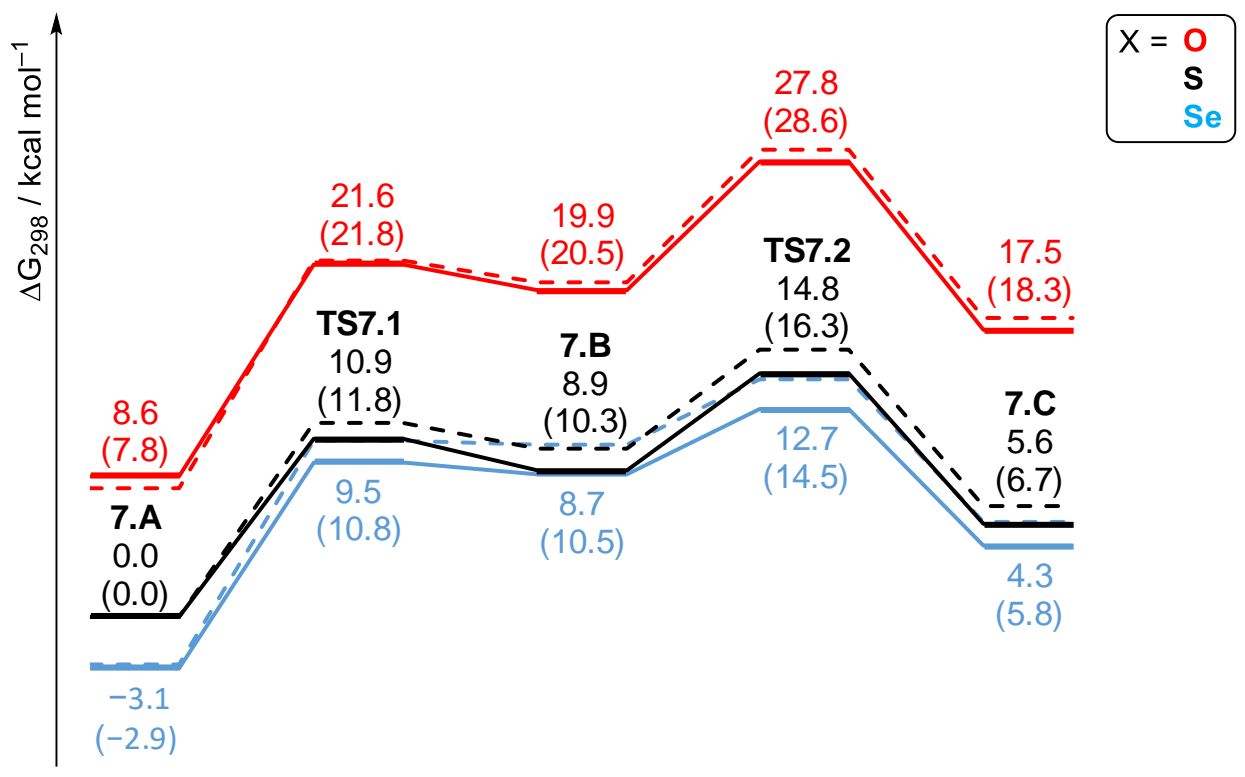

Figure 38: Relative Gibbs free energy profile for $\mathrm{C}-\mathrm{H}$ ruthenation with thioketone (black line), ketone (red), and selenoketone (blue) directing group with (solid lines) and without dispersion correction (dashed lines).

\subsection{Ruthenium-Catalyzed C-H Alkylation on Peptides}

During the last decade non-natural amino acids and peptides were recognized as an important scaffold for pharmaceutical applications and medicinal chemistry. ${ }^{[153]}$ Consequently, novel methods for the late-stage diversification of peptides and amino acids are highly sought after. While peptide diversification so far largely relies on classical approaches or cross-coupling reactions employing precious palladium-catalysts, drawbacks in terms of atom- and step-economy remained (vide supra). ${ }^{[154]}$ In contrast, $\mathrm{C}-\mathrm{H}$ activation strategies offer considerable economical as well as ecological advantages for the syntheses of substituted peptides with palladium- and ruthenium-catalyzed transformations reported by a number of research groups. ${ }^{[114]}$ 
Out of the natural occurring amino acids, diversification of tryptophan offers great potential due to a low natural occurrence of only $1-2 \%$ in peptides, ${ }^{[155]}$ hence minimizing potential regioselectivity issues, and a user-friendly installation of directing groups for chelation-assisted C$\mathrm{H}$ activation via indole $\mathrm{N}$-substitution.

With these aspects in mind, Dr. A. Schischko and N. Kaplaneris in the Ackermann group achieved ruthenium-catalyzed $\mathrm{C}-\mathrm{H}$ alkylations of tryptophans $\mathbf{1 6 0}$ with acrylates and maleimides, among others (Scheme 79). ${ }^{[156]}$ Optimal results were obtained in acetic acid as the reaction medium and commercially available $\left[\mathrm{RuCl}_{2}(p \text {-cymene })\right]_{2}$ as the catalyst. The reaction was not only applicable to tryptophans, but also to small peptides, and even peptide ligations could be realized. It is noteworthy that peptides on resin delivered the desired product likewise, thus allowing for userfriendly purification procedures.

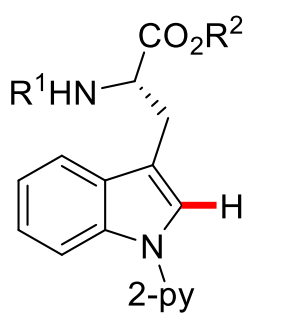

160

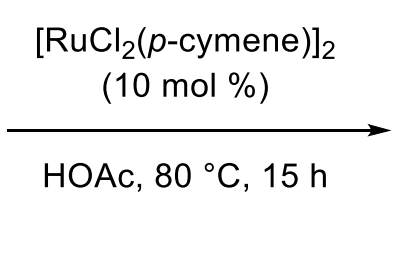

27

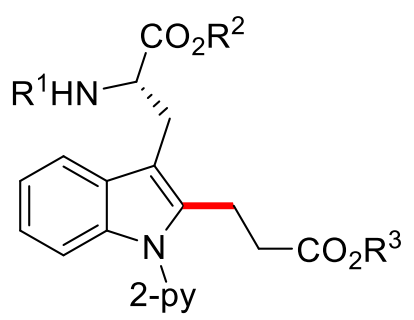

180

Scheme 79: Optimized reaction conditions for ruthenium-catalyzed $\mathrm{C}-\mathrm{H}$ alkylations of tryptophans 160 with acrylates 27.

To gain further insight into the catalyst's mode of action, the reaction mechanism was explored by DFT calculations. Geometry optimizations were conducted at the PBEO-D3(BJ)/def2-SVP level of theory ${ }^{[126,127,134]}$ and single point calculations were performed at the PBEO-D3(BJ)/def2-QZVP* $+\mathrm{SMD}\left(\mathrm{HOAC}\right.$ ) level of theory ${ }^{[127,135]}$ (for full details see Section 6.6). For the sake of simplicity and a reduction of the computational cost, tryptophan was replaced by $N$-pyridyl indole (125a) in the calculations.

Due to the use of acetic acid as reaction medium, $\left[\operatorname{RuCl}_{2}(p \text {-cymene })\right]_{2}$ likely undergoes saltmetathesis/ligand exchange with the solvent to generate biscarboxylate complex $\left[\mathrm{Ru}(\mathrm{OAc})_{2}(p\right.$-cymene)] (79). Subsequently, decoordination of one acetate ligand and coordination of 125a generates mono-cationic intermediate 8.A (Scheme 80). Although this process was calculated to be endergonic by $13.8 \mathrm{kcal} \mathrm{mol}^{-1}$, it involves the formation of cationic complex 8.A 
and an anionic acetate. Formation of solvent-separated or contact ion-pairs, which unfortunately cannot be accurately described within the framework of continuum solvation models, will likely occur in polar proctic solvents, such as acetic acid, and should stabilize the charged species, thereby reducing the relative energy.

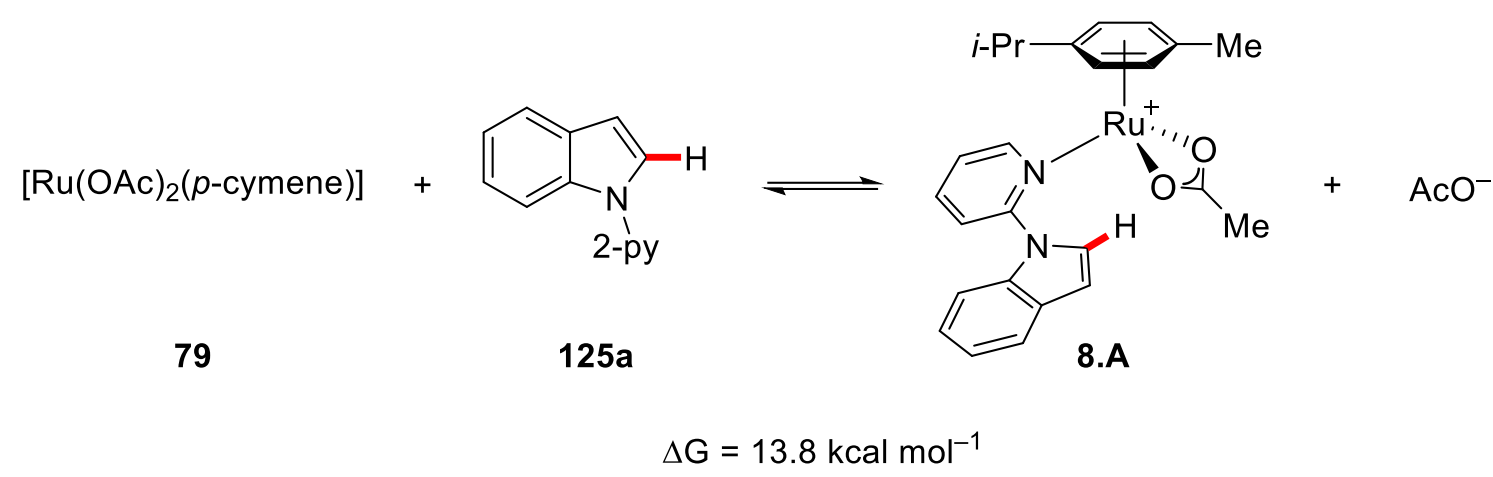

Scheme 80: Formation of mono-cationic intermediate 8.A.

Starting from intermediate 8.A, formation of agostic complex 8.B occurs via transition state TS8.1 with an energy barrier of $10.7 \mathrm{kcal} \mathrm{mol}^{-1}$ (Figure 39). Afterwards, five-membered ruthenacycle 8.C is formed (Figure 40), which then undergoes ligand exchange to generate intermediate 8.D. Unfortunately, a transition state for the formation of intermediate 8.C could not be located at this level of theory (vide infra). Migratory insertion of the coordinated alkene into the Ru-C bond with an energy barrier of $13.1 \mathrm{kcal} \mathrm{mol}^{-1}$ leads to the formation of seven-membered ruthenacycle 8.E. Coordination of acetic acid facilitates turnover-limiting proto-demetalation via TS8.4 with a barrier of $24.7 \mathrm{kcal} \mathrm{mol}^{-1}$ (Figure 41) and generates agostic complex 8.G. Thereafter, $\kappa^{2}-K^{1}$ coordination shift of the acetate ligand results in the formation of final intermediate $\mathbf{8 . H}$. Overall the reaction was found to be exergonic by $-12.8 \mathrm{kcal} \mathrm{mol}^{-1}$. 


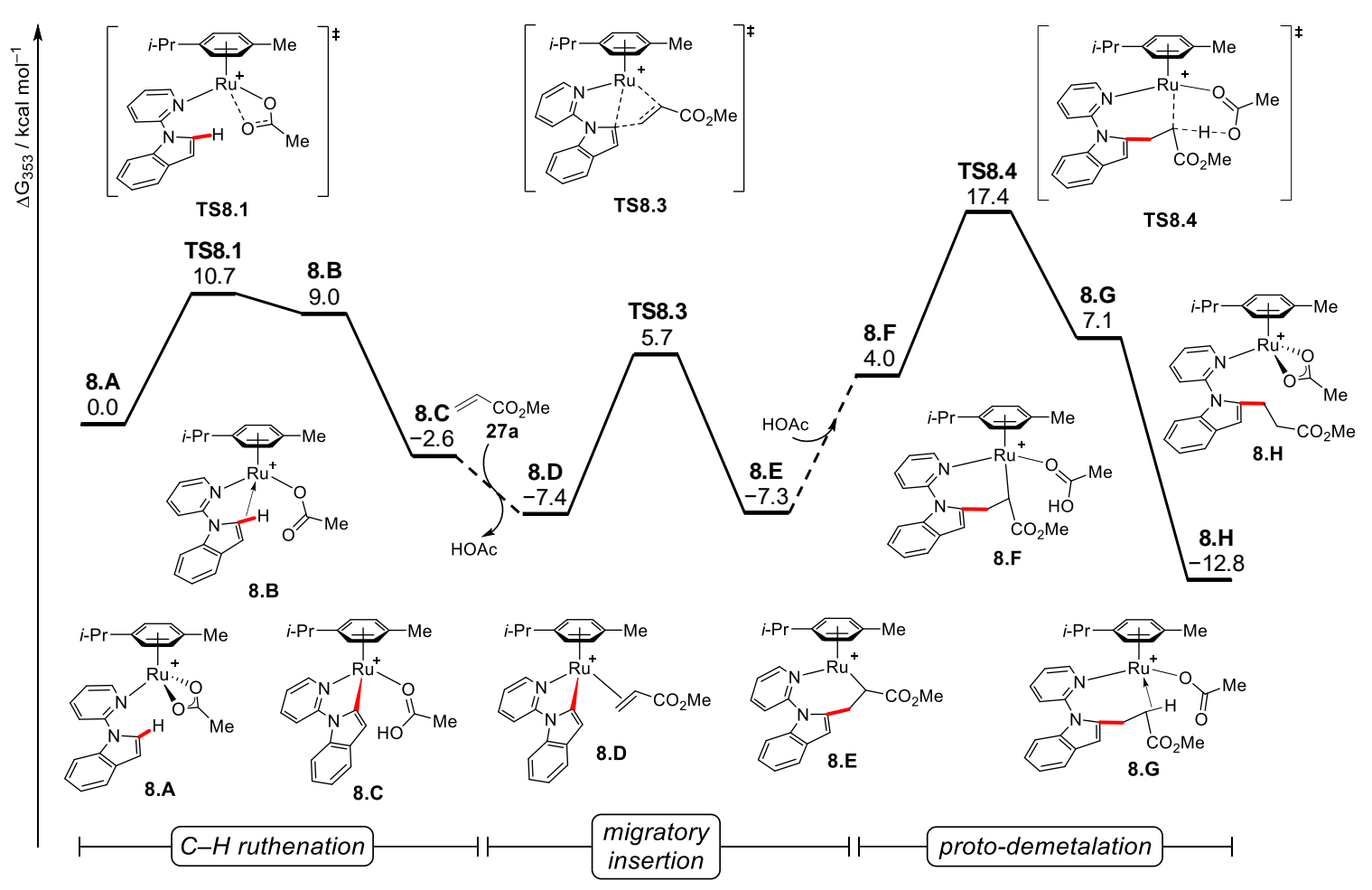

Figure 39: Relative Gibbs free energy profile for the reaction of indole 125a with acrylate 27a.

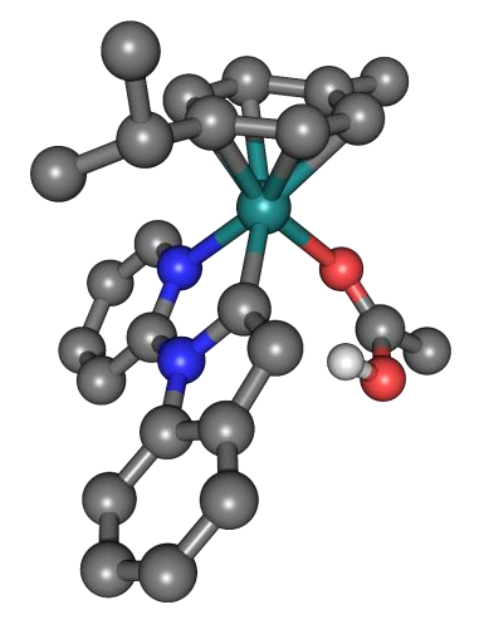

Figure 40: Structure of cyclometalated complex 8.C. Non-participating hydrogen atoms are omitted for clarity. 


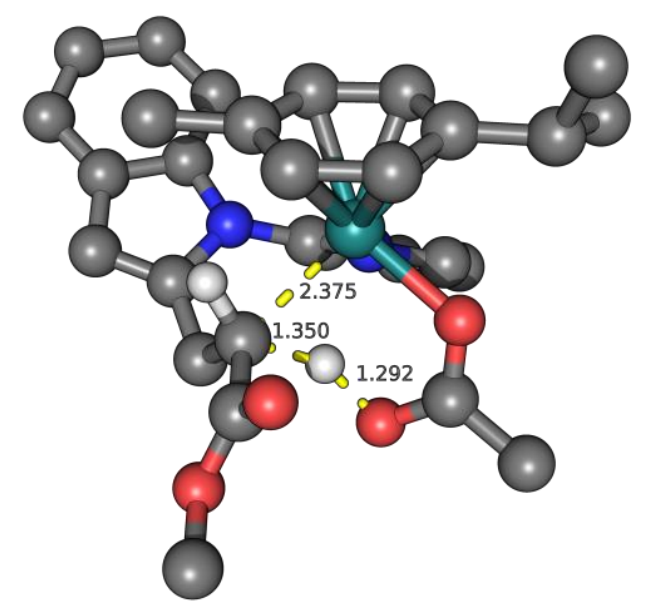

Figure 41: Structure of key transition state TS8.4. Distances are given in $\AA$ and non-participating hydrogen atoms are omitted for clarity.

Furthermore, the influence of the $\eta^{6}$-coordinated arene ligand on the energy profile of the reaction was investigated by replacing $p$-cymene with sterically more demanding $t$-butylbenzene or unsubstituted benzene (Figure 42). Complexes with benzene as well as $t$-butylbenzene were destabilized compared to the respective $p$-cymene ligand-containing complexes, due to an increased steric demand of $t$-butylbenzene and a decreased ring-electron density of benzene. The $t$-butylbenzene derivatives of transition state TS8.3 and intermediate 8.G represent the only exceptions and were found to be slightly more stable by $0.8 \mathrm{kcal} \mathrm{mol}^{-1}$ and $0.3 \mathrm{kcal} \mathrm{mol}^{-1}$, respectively. For the unencumbered and less electron-rich benzene ligand, a considerable destabilization of 2.7-5.6 kcal mol${ }^{-1}$ was observed for all intermediate and transition states. 


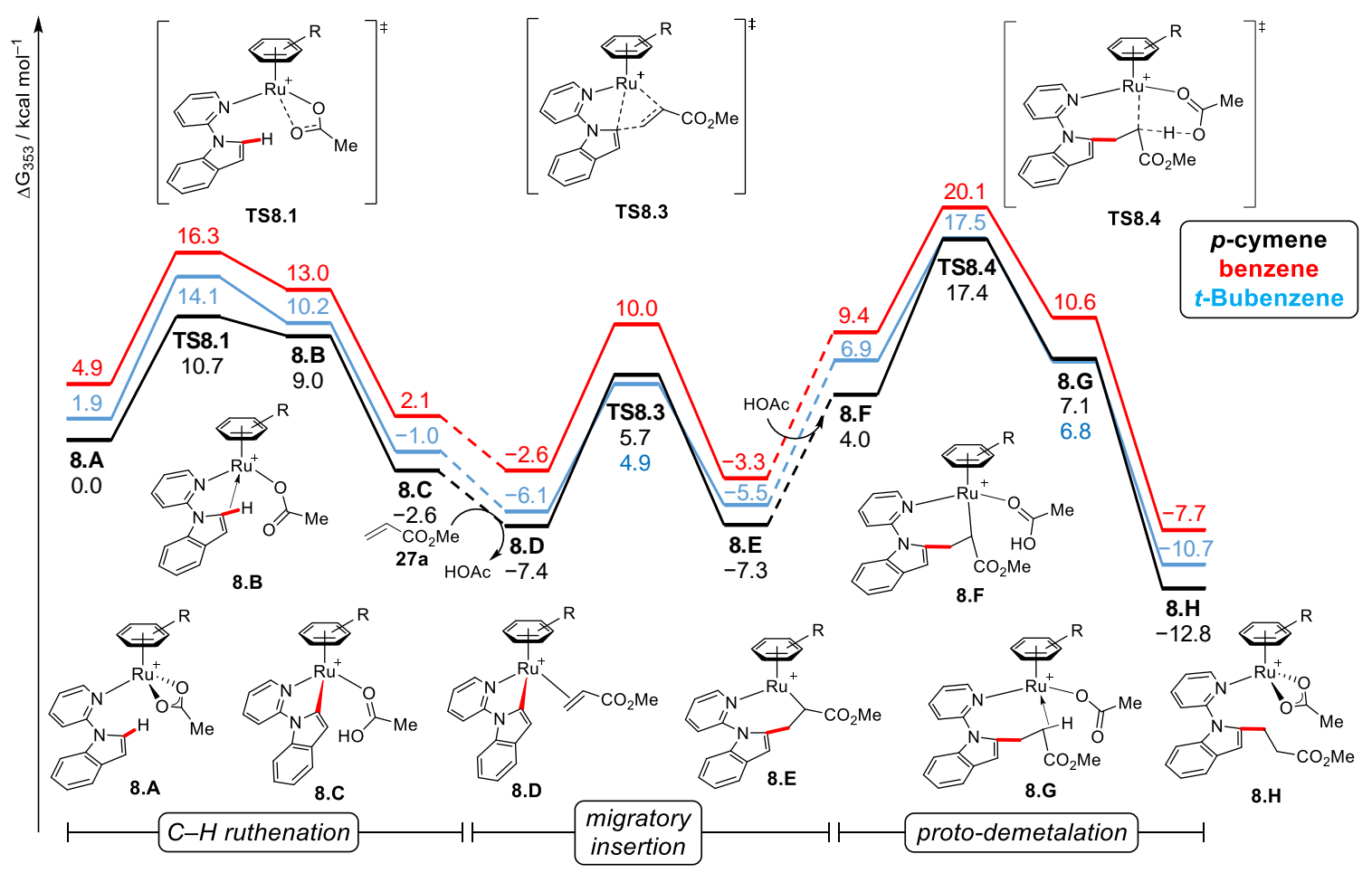

Figure 42: Relative Gibbs free energy profile for $\eta^{6}$-coordinated $p$-cymene (black line), $t$-butylbenzene (blue), and benzene (red).

To verify that the proto-demetalation event is the turnover-limiting step of the reaction, a number of different functionals and basis sets were tested in an attempt to locate the $\mathrm{C}-\mathrm{H}$ ruthenation transition state. By employing the M06 hybrid functional ${ }^{[157]}$ from the Minnesota group of functionals an appropriate transition state was successfully identified (for full details see Section 6.6). Calculations at the PW6B95-D3(BJ)/def2-QZVP*+SMD(HOAC)//M06-D3/def2-SVP level of theory ${ }^{[145]}$ resulted in energy barriers, that are largely comparable to the results obtained with the PBEO functional (Figure 43). Indeed, the energy barrier for $\mathrm{C}-\mathrm{H}$ bond cleavage (TS8.2) was calculated to be $14.7 \mathrm{kcal} \mathrm{mol}^{-1}$, which is $10.4 \mathrm{kcal} \mathrm{mol}^{-1}$ lower than the corresponding barrier for the proto-demetalation step $\left(25.1 \mathrm{kcal} \mathrm{mol}^{-1}\right)$. Therefore, the calculations confirmed a facile and not turnover-limiting $\mathrm{C}-\mathrm{H}$ cleavage event, which is in agreement with results obtained from H/D scrambling experiments. ${ }^{[156]}$

It should be noted that the PW6B95/M06 calculations led to significantly higher relative energies for ruthenacycle 8.C and all following transition states and intermediates compared to the calculations at the PBEO level. The calculated energy differences between the two methods were in the range of 2.4-8.3 kcal mol${ }^{-1}$ with the largest difference observed for complex 8.D. 


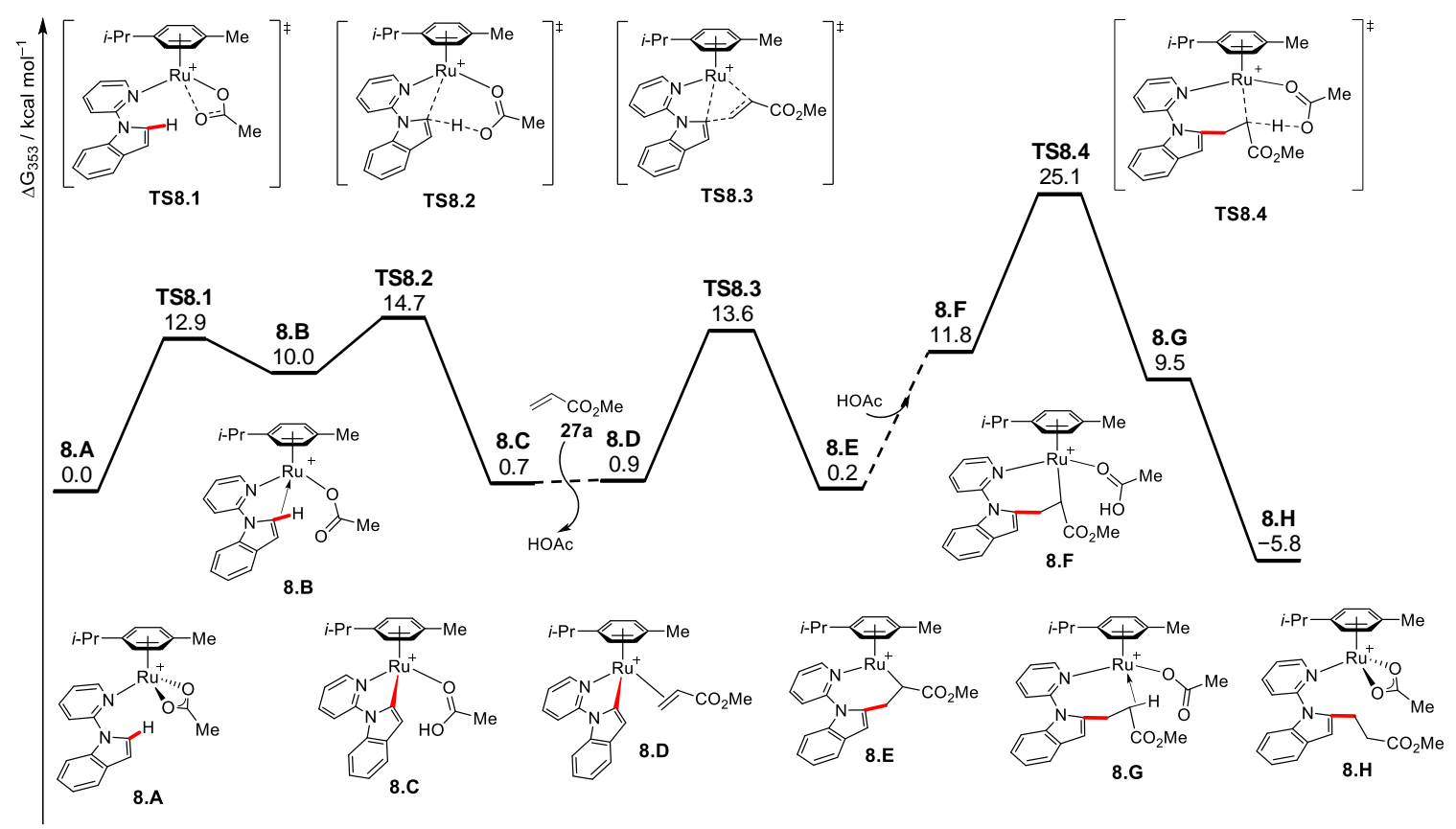

Figure 43: Relative Gibbs free energy profile at the PW6B95-D3(BJ)/def2-QZVP*+SMD(HOAc)// M06-D3/def2-SVP level of theory.

\subsection{Ruthenium-Catalyzed Oxidative $\mathrm{C}-\mathrm{H} / \mathrm{C}-\mathrm{H}$ Activation}

Although direct $\mathrm{C}-\mathrm{H}$ arylations under ruthenium catalysis have received considerable attention throughout the years and led to the development of protocols for the functionalization of numerous synthetically useful compound classes, ${ }^{[27]}$ ruthenium-catalyzed $\mathrm{C}-\mathrm{C}$ bond formations via dehydrogenative $\mathrm{C}-\mathrm{H} / \mathrm{C}-\mathrm{H}$ activations continue to be mostly limited to the use of costly metal salts as terminal oxidants. ${ }^{[158]}$ In contrast, a study by Ackermann uncovered the potential of aryl halides as oxidants under specific reaction conditions (Scheme 81). ${ }^{[115]}$
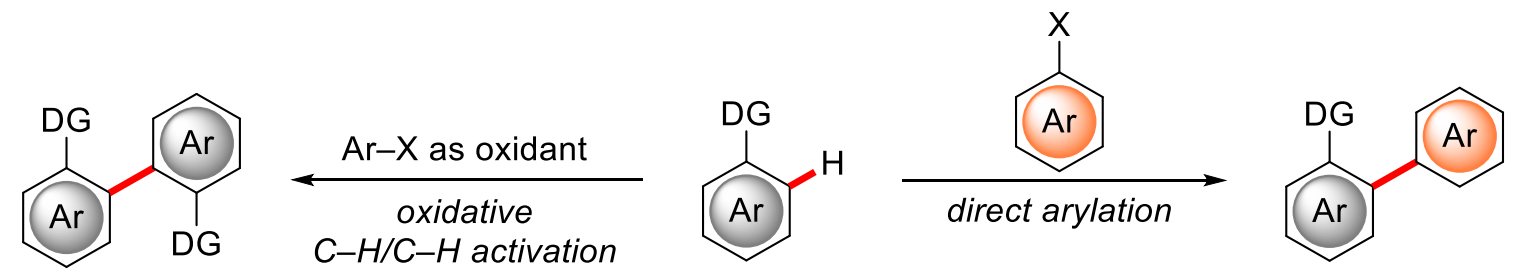

Scheme 81: Oxidative $\mathrm{C}-\mathrm{H} / \mathrm{C}-\mathrm{H}$ activation versus direct $\mathrm{C}-\mathrm{H}$ arylation. 
Thus far, a thorough mechanistic understanding of the reaction mechanism and the parameters, which control the switch in selectivity between the $\mathrm{C}-\mathrm{H}$ arylation and $\mathrm{C}-\mathrm{H} / \mathrm{C}-\mathrm{H}$ activation process, is lacking. Detailed insight into the catalyst's mode of action could lead to further improvements to both processes with regard to catalyst performance and substrate scope.

\subsubsection{Studies on Substrate Control and Solvent Evaluation}

The studies were initiated by reacting 2-(2-methylphenyl)pyridine (45d) with diversly decorated aryl halides 46, 54 in the presence of in situ generated ruthenium-biscarboxylate complexes as catalysts (Figure 44). While aryl halides devoid of ortho-substituents (46c-e) as well as 2fluorobromobenzene (46f) led to exclusive formation of the arylated product $\mathbf{4 7}$, arenes bearing a substituent in the 2-position resulted in a mixture of products. Electron-withdrawing substituents favored the $\mathrm{C}-\mathrm{H} / \mathrm{C}-\mathrm{H}$ activation process and 2-bromobenzonitrile (46k) proved optimal in facilitating the dehydrogenative pathway, delivering the desired product $181 \mathrm{~d}$ in $73 \%$ yield. Furthermore, a 2,6-disubstitution pattern did not result in any synthetically useful reaction outcome. Compared to aryl bromide $\mathbf{4 6 \mathbf { j }}$, aryl chloride $\mathbf{5 4 a}$ exhibited a reduced reactivity, whereas aryl iodides $\mathbf{5 4 b}$ and $\mathbf{5 4 c}$ led to a reaction outcome comparable to aryl bromides $\mathbf{4 6 \mathbf { j }}$ and $\mathbf{4 6 \mathbf { k }}$. 

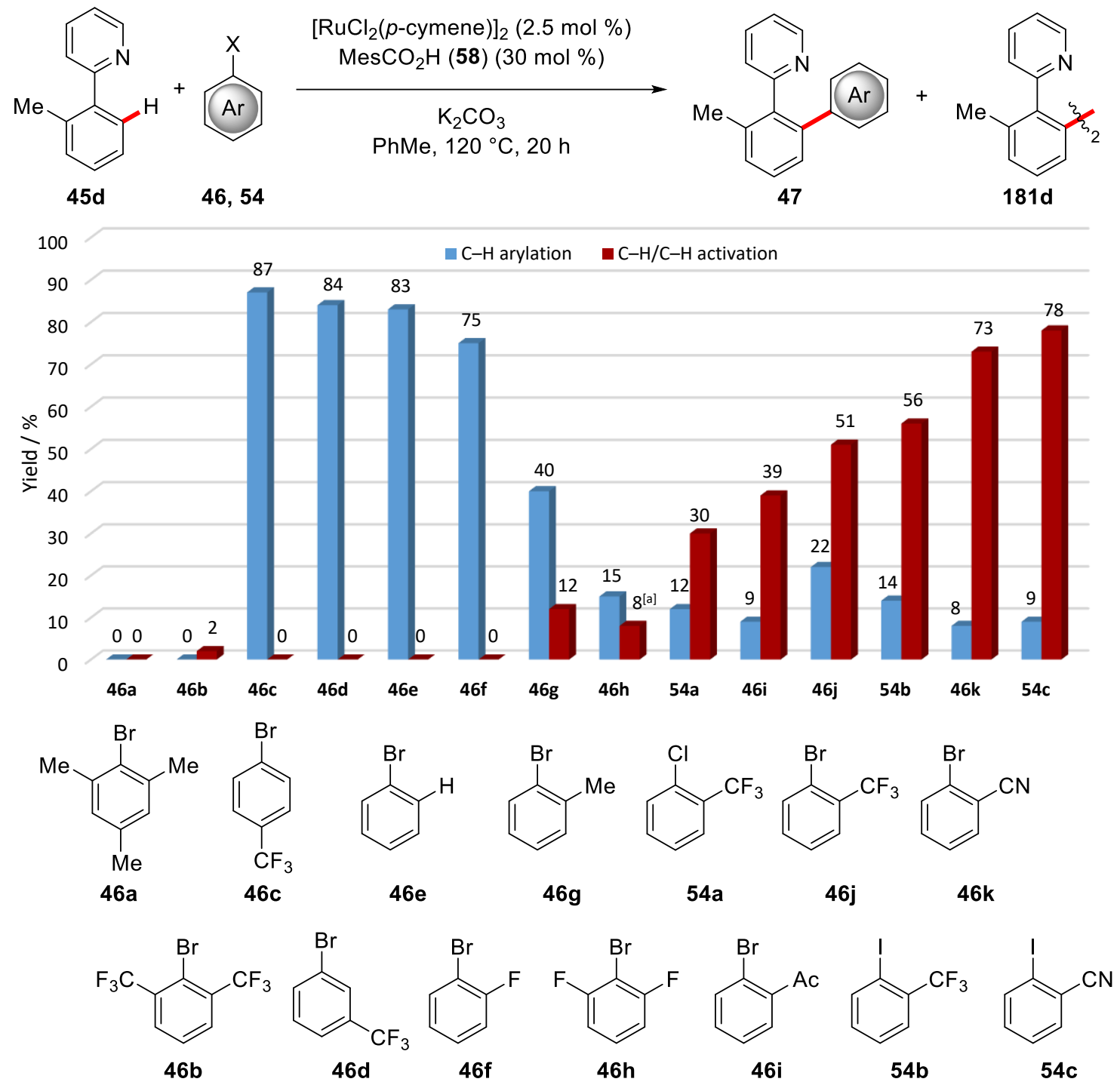

Figure 44: Influence of the aryl halide substitution pattern. [a] Determined by crude ${ }^{1} \mathrm{H}-\mathrm{NMR}$ with 4- $\left(\mathrm{MeO}_{2} \mathrm{C}\right)_{2} \mathrm{C}_{6} \mathrm{H}_{4}$ as the internal standard.

With 2-bromobenzonitrile (46k) being identified as the optimal reagent for the oxidative $\mathrm{C}-\mathrm{H}$ / $\mathrm{C}-\mathrm{H}$ activation, the influence of the phenylpyridine $\mathbf{4 5}$ substitution pattern on the reaction outcome was evaluated (Figure 45). While 2-fluoro-, and 3-alkyl-substituted arenes delivered the arylated product $\mathbf{4 7}$ in good to excellent yield, moderate amounts of $\mathbf{1 8 1}$ were obtained with 2-dimethylamino-, 2-methoxy-substituted, and unsubstituted arenes $\mathbf{4 5 i - j , ~ 4 5 a . ~ I t ~ i s ~ n o t e w o r t h y ~}$ that the introduction of a PMP group in the ortho-position resulted in the formation of minor amounts of $\mathrm{C}-\mathrm{H} / \mathrm{C}-\mathrm{H}$ activated product and high amounts of arylated product. In contrast, orthoalkylated, benzylated, and trifluoromethylated phenylpyridines $45 \mathrm{~d}, 45 \mathrm{I}-\mathrm{n}$ facilitated the formation of $\mathbf{1 8 1}$ in very good yield, hence suggesting that the selectivity is governed by steric as 
well as electronic properties. Gratifyingly, pyridylnaphthalene $45 \mathbf{k}$ also favored the $\mathrm{C}-\mathrm{H} / \mathrm{C}-\mathrm{H}$ activation process, thus allowing for the rapid construction of $\pi$-conjugated, fluorescent $2,2^{\prime}$ binaphthyl 181k in moderate yield (Figure 46). In addition, the structure of $181 \mathbf{k}$ was unambiguously determined by single crystal X-ray diffraction analysis (Figure 47).

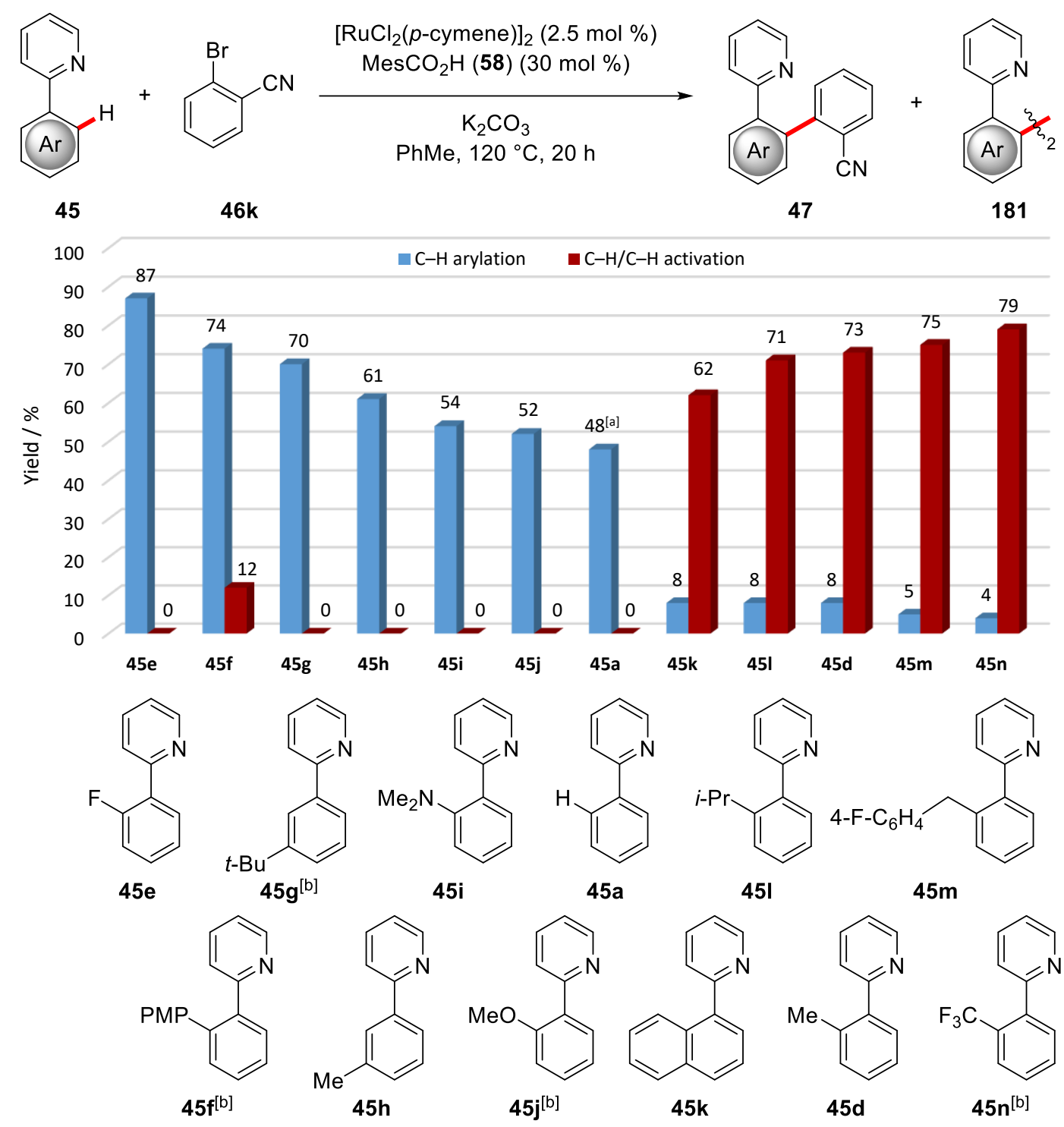

Figure 45: Influence of the phenylpyridine substitution pattern. [a] Diarylated product was obtained. [b] Performed by Dr. Y. Bourne-Branchu. 


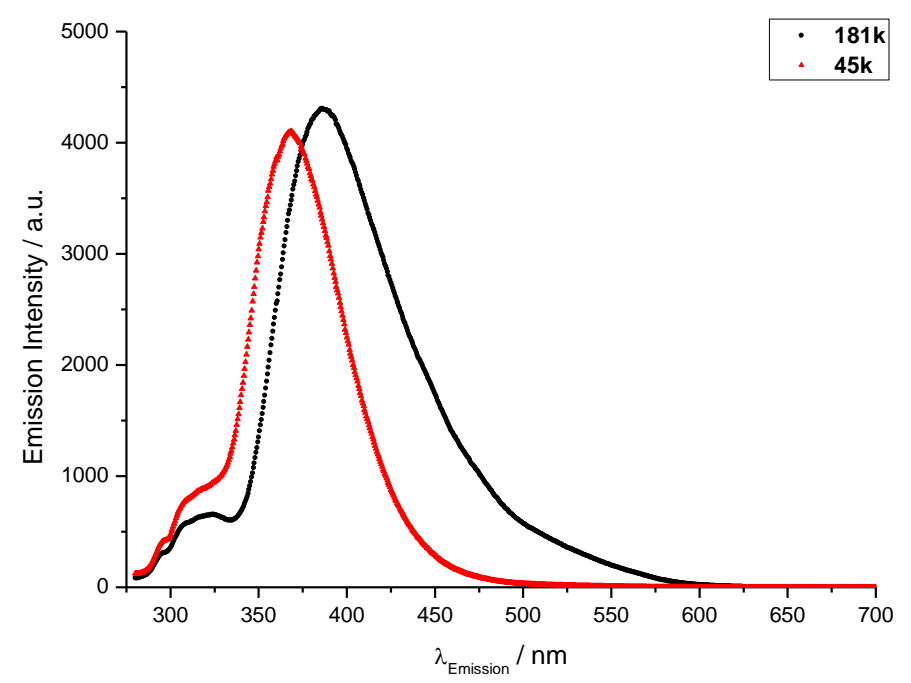

Figure 46: Fluorescence spectra of $45 \mathbf{k}$ and $181 \mathbf{k}$ with excitation at $270 \mathrm{~nm}$.

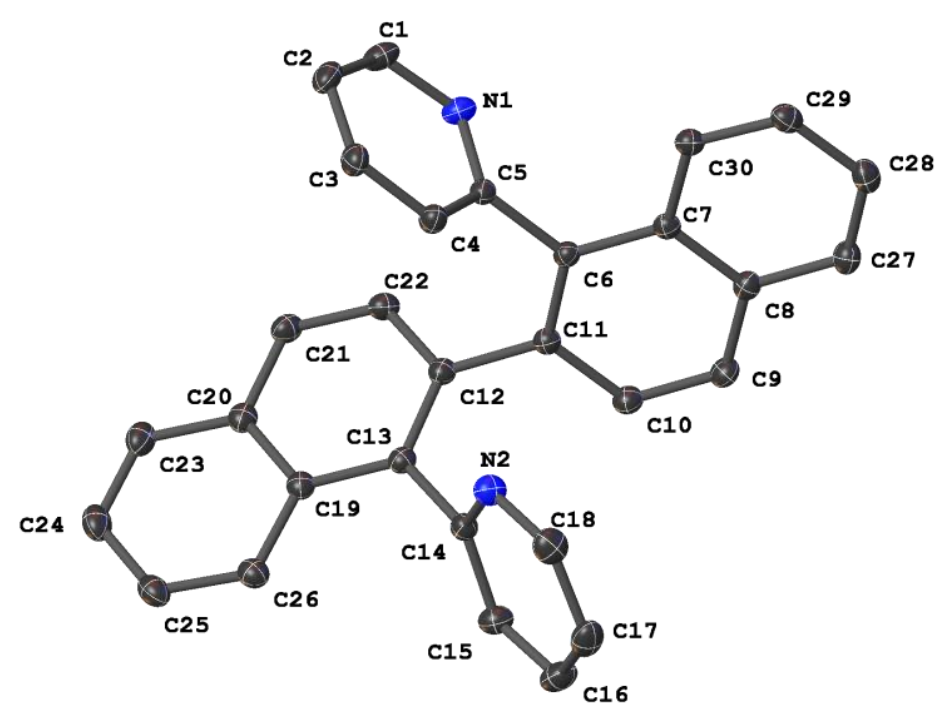

Figure 47: Crystal structure of 181k. Hydrogen-atoms are omitted for clarity.

Furthermore, various solvents were tested in the ruthenium-catalyzed direct $\mathrm{C}-\mathrm{H}$ arylation and oxidative $\mathrm{C}-\mathrm{H} / \mathrm{C}-\mathrm{H}$ activation reaction. The use of apolar 1,4-dioxane instead of toluene as the reaction medium delivered comparable amounts of arylated product $\mathbf{4 7} \mathbf{d j}$, even though a decreased $\mathrm{C}-\mathrm{H} / \mathrm{C}-\mathrm{H}$ activation efficiency was observed (Table 3, entries 1 and 2). In contrast, a

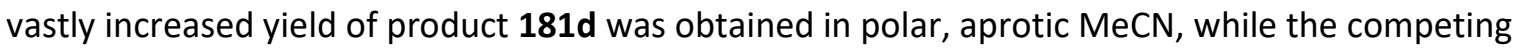
$\mathrm{C}-\mathrm{H}$ arylation pathway was almost completely suppressed (entry 3). Unfortunately, other polar solvents did not prove beneficial (entries 4-6), which indicates that MeCN serves a dual role as the 
solvent as well as a potential ligand. Furthermore, the essential role of the ruthenium catalyst and MesCO ${ }_{2} \mathrm{H}(58)$ was verified (entries 7-8), highlighting the importance of carboxylate-assistance ${ }^{[15 a]}$ for ruthenium-catalyzed $\mathrm{C}-\mathrm{H}$ activation. The use of well-defined $\left[\mathrm{Ru}\left(\mathrm{O}_{2} \mathrm{CMes}\right)_{2}(p\right.$-cymene) $(\mathbf{6 1})$ or a cylometalated complex resulted in a similar reaction outcome and did not constitute a major improvement (entry 9 and 11). Cationic complex $\left[\mathrm{Ru}(\mathrm{NCMe})_{6}\right]\left[\mathrm{SbF}_{6}\right]_{2}$ fell short in facilitating the desired transformation (entry 11).

Table 3: Influence of reaction media and catalysts. ${ }^{[a]}$<smiles>Cc1ccccc1-c1ccccn1</smiles>

45d<smiles>FC(F)(F)c1ccccc1Br</smiles>

46j

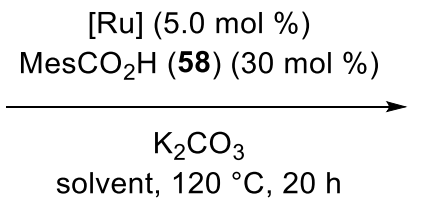

solvent, $120^{\circ} \mathrm{C}, 20 \mathrm{~h}$<smiles>Cc1cccc(-c2ccccc2C(F)(F)F)c1-c1ccccn1</smiles>

47dj<smiles>Cc1cccc(C(C)(C)C)c1-c1ccccn1</smiles>

$181 d$

\begin{tabular}{|c|c|c|c|c|}
\hline Entry & {$[\mathrm{Ru}]$} & Solvent & Yield 47dj / \% & Yield 181d / \% \\
\hline 1 & {$\left[\mathrm{RuCl}_{2}(p \text {-cymene })\right]_{2}$} & PhMe & 22 & 51 \\
\hline 2 & {$\left[\mathrm{RuCl}_{2}(p \text {-cymene })\right]_{2}$} & 1,4-dioxane & 25 & 40 \\
\hline 3 & {$\left[\mathrm{RuCl}_{2}(p \text {-cymene })\right]_{2}$} & $\mathrm{MeCN}$ & trace & 78 \\
\hline 4 & {$\left[\mathrm{RuCl}_{2}(p \text {-cymene })\right]_{2}$} & NMP & 13 & 18 \\
\hline 5 & {$\left[\mathrm{RuCl}_{2}(p \text {-cymene })\right]_{2}$} & DMSO & -- & -- \\
\hline 6 & {$\left[\mathrm{RuCl}_{2}(p \text {-cymene })\right]_{2}$} & DMF & $11^{[b]}$ & $18^{[b]}$ \\
\hline 7 & -- & PhMe & -- & -- \\
\hline $8^{[c]}$ & {$\left[\mathrm{RuCl}_{2}(p \text {-cymene })\right]_{2}$} & PhMe & 8 & 8 \\
\hline $9^{[c]}$ & {$\left[\mathrm{Ru}\left(\mathrm{O}_{2} \mathrm{CMes}\right)_{2}(p\right.$-cymene $\left.)\right](\mathbf{6 1})$} & PhMe & 24 & 57 \\
\hline 10 & {$\left[\mathrm{Ru}(\mathrm{NCMe})_{6}\right]\left[\mathrm{SbF}_{6}\right]_{2}$} & PhMe & trace & trace \\
\hline 11 & \rceil $\mathrm{PF}_{6}{ }^{-}$ & $\mathrm{PhMe}$ & 22 & 55 \\
\hline
\end{tabular}

[a] Reaction conditions: 45d (0.50 mmol), 46j $(0.75 \mathrm{mmol}),[\mathrm{Ru}](5.0 \mathrm{~mol} \%), \mathrm{MesCO}_{2} \mathrm{H}(\mathbf{5 8})$ (30 mol \%), $\mathrm{K}_{2} \mathrm{CO}_{3}(1.00 \mathrm{mmol})$, solvent $(2.0 \mathrm{~mL}), 120^{\circ} \mathrm{C}, 20 \mathrm{~h}$. Yields of isolated products are given. [b] Determined by crude ${ }^{1} \mathrm{H}-\mathrm{NMR}$ with $4-\left(\mathrm{MeO}_{2} \mathrm{C}\right)_{2} \mathrm{C}_{6} \mathrm{H}_{4}$ as the internal standard. [c] Without $\mathrm{MesCO}_{2} \mathrm{H}(\mathbf{5 8})$. 


\subsubsection{Mechanistic Studies}

Intrigued by the unusual switch between the direct $\mathrm{C}-\mathrm{H}$ arylation and dehydrogenative $\mathrm{C}-\mathrm{H} / \mathrm{C}-\mathrm{H}$ activation pathways, the reaction mechanism was further explored by experimental mechanistic studies. Kinetic isotope effect (KIE) studies with deuterated substrate $\mathbf{4 5 d}$ resulted in a KIE value of $k_{\mathrm{H}} / k_{\mathrm{D}} \approx 2.2$ and 1.8 when using 2-bromobenzonitrile (46k) and 2-bromotrifluorotoluene (46j) as the oxidant, respectively, as determined by parallel reactions (Scheme 82 and Section 5.3.6.2).<smiles>[2H]c1cccc(C)c1-c1ccccn1</smiles>

$45 d$ or $[D]_{1}-45 d$<smiles>[R]c1ccccc1Br</smiles>

46j or 46k
$\left[\mathrm{Ru}\left(\mathrm{O}_{2} \mathrm{CMes}\right)_{2}(p\right.$-cymene $\left.)\right](\mathbf{6 1})$

$(5.0 \mathrm{~mol} \%)$

$$
\mathrm{K}_{2} \mathrm{CO}_{3}
$$

$\mathrm{PhMe}, 102^{\circ} \mathrm{C}$

$\mathrm{R}=\mathrm{CN}: \quad k_{\mathrm{H}} / k_{\mathrm{D}}=2.17$

$\mathrm{R}=\mathrm{CF}_{3}: \quad k_{\mathrm{H}} / k_{\mathrm{D}}=1.76$<smiles>Cc1cccc(C)c1-c1ccccn1</smiles>

$181 d$

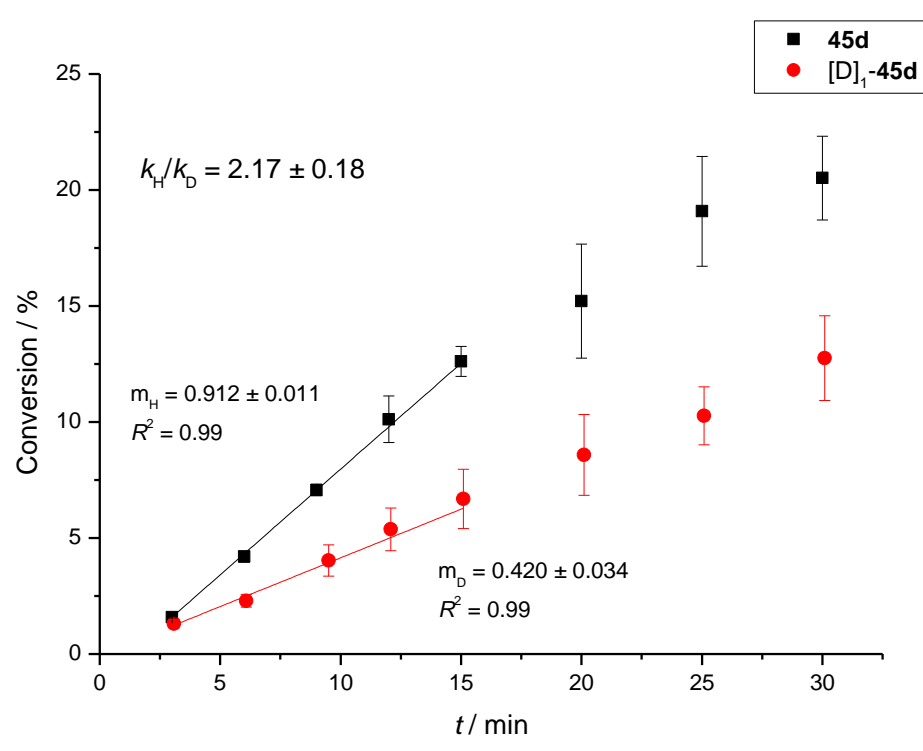

Scheme 82: Kinetic isotope effect studies by parallel reactions. The graph corresponds to the reaction with 2-bromobenzonitrile (46k).

In addition, conducting the reaction in the presence of isotopically labelled $\mathrm{D}_{2} \mathrm{O}$ as cosolvent led to nearly quantitative deuterium-incorporation in the ortho-position of reisolated substrate $\mathbf{4 5 d}$ (Scheme 83a). A minor amount of deuterium-incorporation was observed the somewhat acidic 6 -position of the pyridine directing group. When deuterated substrate $[D]_{1}-45 d$ was subjected to the reaction conditions, moderate H/D exchange was observed in the reisolated phenylpyridine, 
suggesting that the $\mathrm{MesCO}_{2} \mathrm{H}$ additive (58) or trace amounts of water in the employed base or solvent acted as the proton source (Scheme 83b).

(a) deuterium incorporation with $\mathrm{D}_{2} \mathrm{O}$ cosolvent

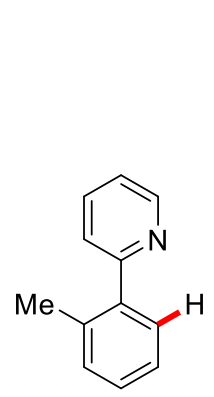

45d<smiles>N#Cc1ccccc1Br</smiles>

$\left[\mathrm{RuCl}_{2}(p \text {-cymene })\right]_{2}(2.5 \mathrm{~mol} \%)$ $\mathrm{MesCO}_{2} \mathrm{H}(58)(30 \mathrm{~mol} \%)$

$$
\mathrm{K}_{2} \mathrm{CO}_{3}
$$$$
\mathrm{PhMe} / \mathrm{D}_{2} \mathrm{O}(9: 1)
$$

$120^{\circ} \mathrm{C}, 30 \mathrm{~min}$<smiles>Cc1cccc(C)c1-c1cccc(C=[As])n1</smiles>

181d: $21 \%$<smiles>Cc1cccc(PO)c1-c1ccccn1</smiles>

$[D]_{n}-45 d: 69 \%$

(b) $H / D$ scrambling<smiles>N#Cc1c(Br)cccc1Br</smiles><smiles>Cc1cccc(OC#N)c1-c1ccccn1</smiles>

$[D]_{1}-45 d$ (1)
$\left[\mathrm{RuCl}_{2}(p \text {-cymene })\right]_{2}(2.5 \mathrm{~mol} \%)$ $\mathrm{MesCO}_{2} \mathrm{H}(58)(30 \mathrm{~mol} \%)$

$$
\mathrm{K}_{2} \mathrm{CO}_{3}
$$

$\mathrm{PhMe}, 120^{\circ} \mathrm{C}, 1 \mathrm{~h}$

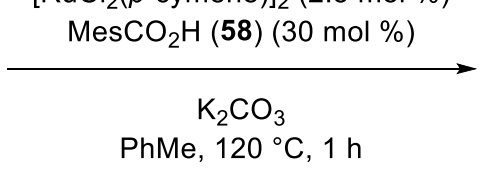

$[D]_{n}-181 d: 19 \%$

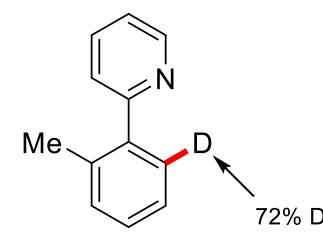

$[D]_{n}-45 d: 33 \%$

Scheme 83: H/D exchange studies.

Based on the hypothesis that the aryl halides act as the oxidant in the $\mathrm{C}-\mathrm{H} / \mathrm{C}-\mathrm{H}$ activation process, most likely via oxidative addition to ruthenium, subsequent proto-demetalation would consequently result in the generation of trifluorotoluene (182) as byproduct. Indeed, thorough analysis of the reaction mixture by GC and GC-MS revealed the presence of $74 \%$ of 182 after $20 \mathrm{~h}$, thus substantiating the hypothesized oxidative addition/proto-demetalation pathway (Scheme 84). 


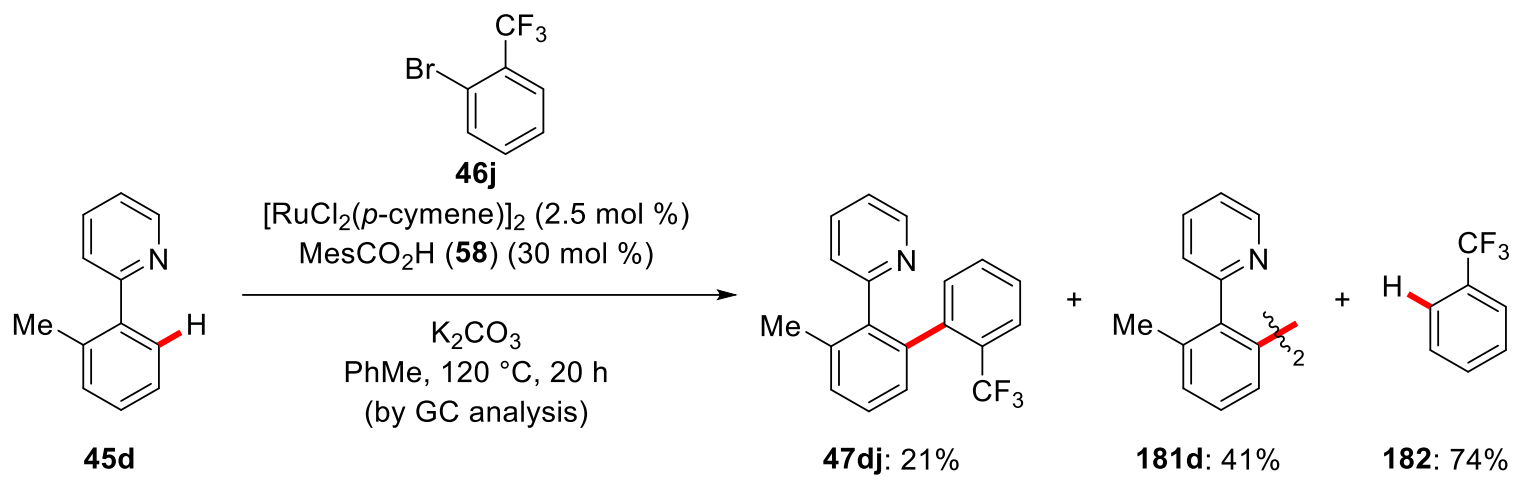

Scheme 84: Detection and quantification of trifluorotoluene (182) as byproduct.

To confirm that 45 and not $\mathrm{MesCO}_{2} \mathrm{H}(\mathbf{5 8})$ or trace amounts of water is indeed the proton-source for the proto-dehalogenation of aryl halide 46, the reaction was conducted with deuterated substrate $[D]_{1}-\mathbf{4 5 d}$ (Scheme 85 ). The formation of $[D]_{n}-183$ was confirmed by GC-MS analysis, thereby indicating that the transferred proton/deuteron originates from 45d (see Section 5.3.6.2). Unfortunately, isolation of $[D]_{n}-\mathbf{1 8 3}$ and characterization by NMR spectroscopy was not possible due to the low polarity and non-neglectable vapor pressure of $\mathbf{1 8 3}$.<smiles>[2H]c1cccc(C)c1-c1ccccn1</smiles>

$46 k$

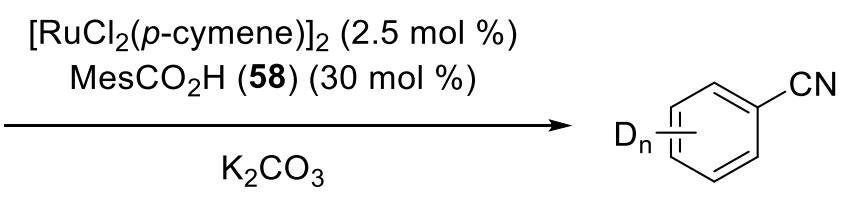

$\mathrm{PhMe}, 120^{\circ} \mathrm{C}, 20 \mathrm{~h}$ (detected by GC-MS)

Scheme 85: Proto-dehalogenation of $\mathbf{4 6} \mathbf{k}$ with deuterated phenylpyridine.

The amount of free $p$-cymene (184) was determined over the course of the reaction to investigate the possible formation of arene-ligand-free ruthenium complexes as catalytically active species. ${ }^{[54,}$ ${ }^{55,159]} \mathrm{A}$ rapid liberation of $\mathrm{p}$-cymene was observed alongside a fast formation of $\mathrm{C}-\mathrm{H} / \mathrm{C}-\mathrm{H}$ activated product $181 \mathrm{~d}$ in the reaction of $\mathbf{4 5 d}$ with $\mathbf{4 6 k}$ (Scheme 86 ). Already after a reaction time of only $3 \mathrm{~min}, 26 \%$ decoordinated $p$-cymene was detected, which increased to more than $70 \%$ within 180 min as determined by GC analysis with $n$-dodecane as the internal standard. 
<smiles></smiles>

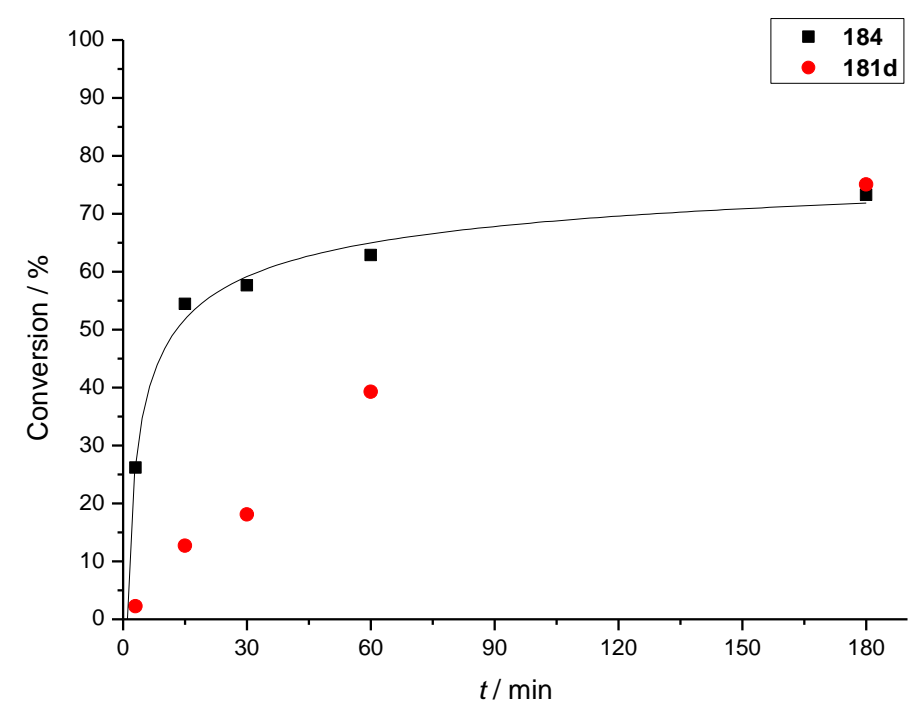

Scheme 86: Detection of free $p$-cymene (184) in the reaction of $45 \mathrm{~d}$ with $46 \mathrm{k}$ by GC analysis with $n$-dodecane as the internal standard.

The same trend, albeit at a reduced rate, was observed, when aryl halide 46j was employed in the reaction (Scheme 87). Here, an amount of $40 \%$ free $p$-cymene was determined after a reaction time of $180 \mathrm{~min}$. Due to the much slower reaction rate, the increase in $p$-cymene concentration was also significantly slower compared to the reaction with $\mathbf{4 6 k}$. 


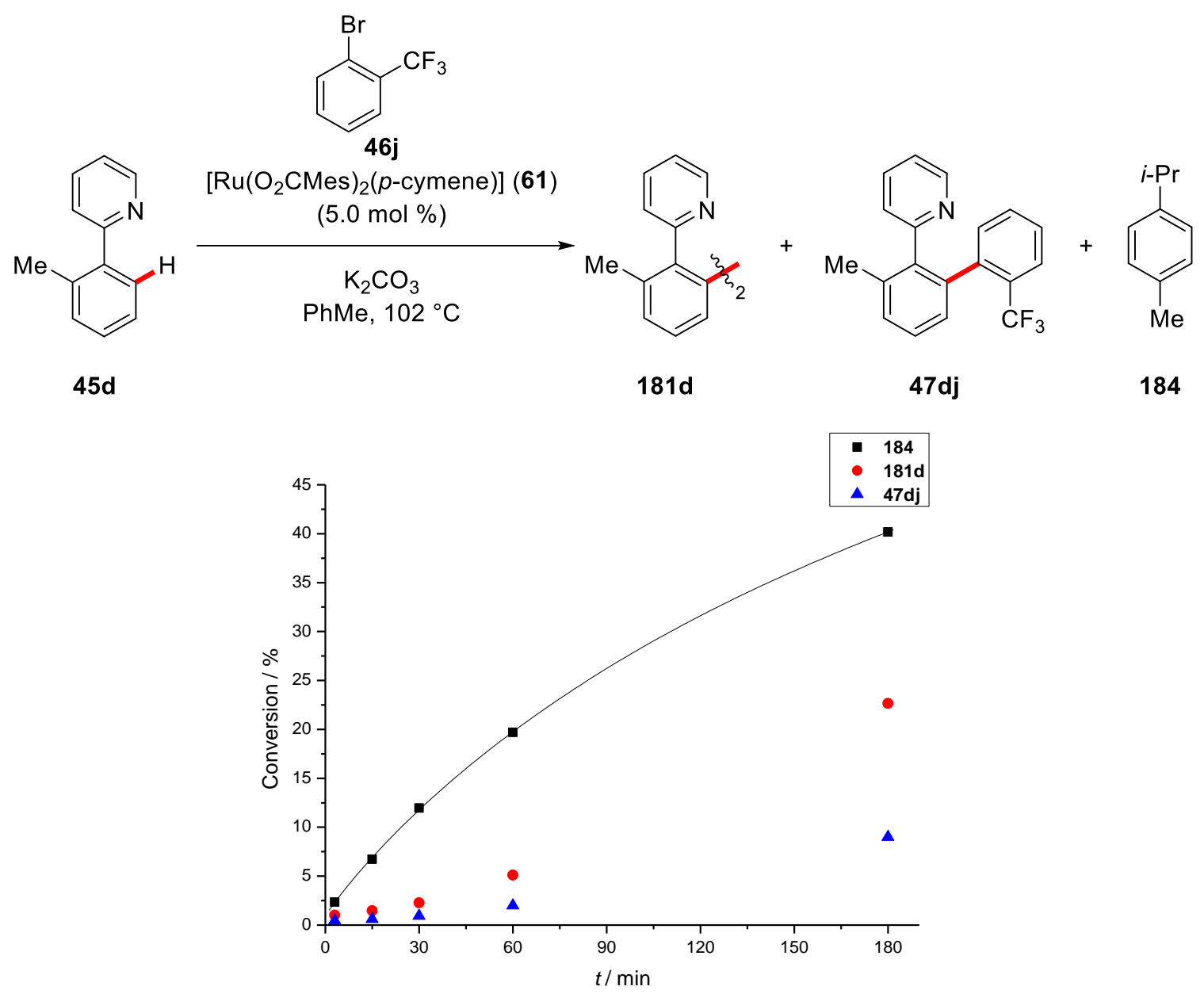

Scheme 87: Detection of free $p$-cymene (184) in the reaction of $45 \mathrm{~d}$ with $46 \mathrm{j}$ by GC analysis with $n$-dodecane as the internal standard.

Furthermore, the decoordination of $p$-cymene from ruthenium was found to be independent of the phenylpyridine substrate 45. Employing fluorine-substituted phenylpyridine 45e as the substrate, which exclusively undergoes $\mathrm{C}-\mathrm{H}$ arylation, led to the release of $45 \%$ of $p$-cymene from the ruthenium-complex within the first $180 \mathrm{~min}$, thereby indicating that an arene-ligand-free complex is the catalytically active species in the $\mathrm{C}-\mathrm{H} / \mathrm{C}-\mathrm{H}$ activation as well as the direct $\mathrm{C}-\mathrm{H}$ arylation process (Scheme 88). 


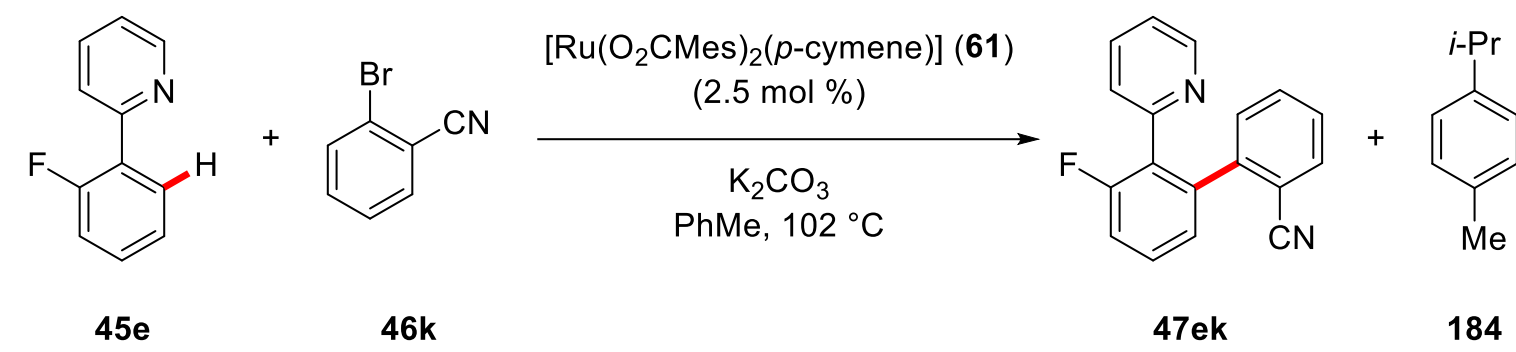

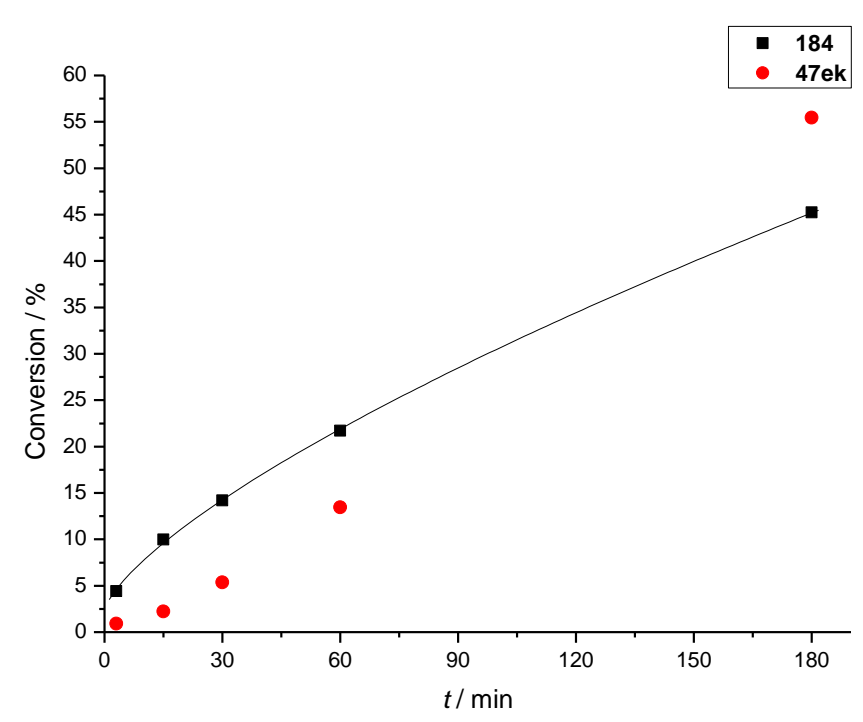

Scheme 88: Detection of free $p$-cymene (184) in the reaction of $45 \mathrm{e}$ with $46 \mathrm{k}$ by GC analysis with $n$-dodecane as the internal standard.

\subsubsection{Kinetic Analysis}

To gain further insight into the catalyst's modus operandi, the reaction kinetics were investigated by means of initial rate measurements. Measurements with different concentrations of phenylpyridine $45 \mathrm{~d}$ revealed a first order dependence of the reaction rate on the substrate concentration for the $\mathrm{C}-\mathrm{H} / \mathrm{C}-\mathrm{H}$ activation as well as the $\mathrm{C}-\mathrm{H}$ arylation process (Figure 48a). Furthermore, a reaction order smaller than 1 was determined with respect to the concentration of $\left[\mathrm{RuCl}_{2}(p \text {-cymene) }]_{2}\right.$ catalyst (Figure $\left.48 \mathrm{~b}\right)$. While the concentration of $\left[\mathrm{RuCl}_{2}(p \text {-cymene) }]_{2}\right.$ was varied in the range of 3.8-12.5 mmol L-1, the concentration of $\mathrm{MesCO}_{2} \mathrm{H}(\mathbf{5 8})$ was held constant at $75 \mathrm{mmol} \mathrm{L}{ }^{-1}$, thereby resulting in different $[\mathrm{Ru}] / \mathrm{MesCO}_{2} \mathrm{H}$ ratios, which could lead to the observed non-integer reaction order. Additionally, the reaction rate was found to be independent of the aryl halide concentration (Figure 48c). The observed similar kinetic behavior for the two competing pathways suggests the reactions to proceed via the same intermediates, with the selectivity-determining step occurring late in the catalytic cycle. 
<smiles>COc1ccccc1-c1ccccn1</smiles>

45d<smiles>FC(F)(F)c1ccccc1Br</smiles>

46j

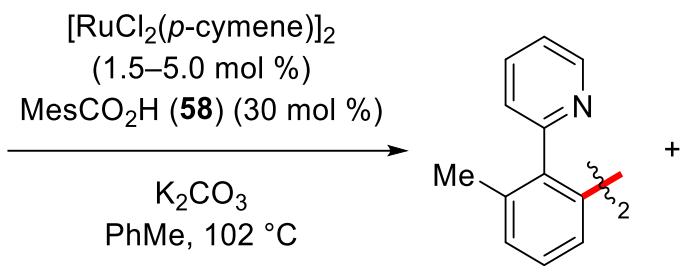

$181 d$<smiles>Cc1cccc(-c2ccccc2C(F)(F)F)c1-c1ccccn1</smiles>

$47 \mathrm{dj}$

(a) Reaction order in phenylpyridine $\mathbf{4 5 d}$
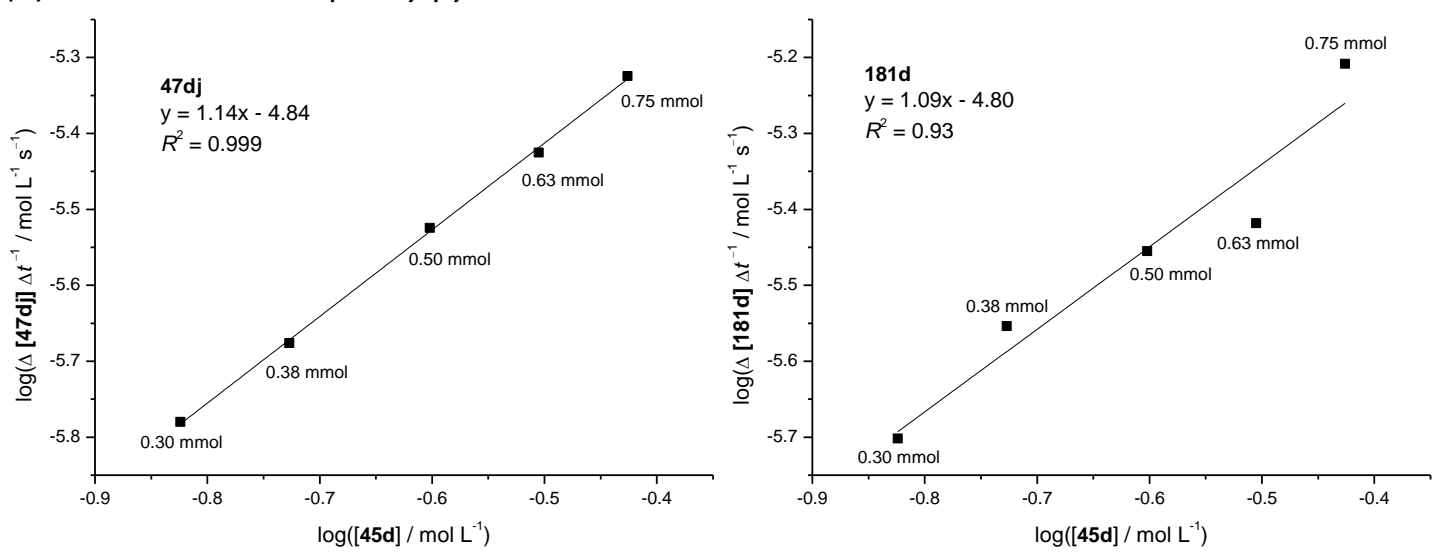

(b) Reaction order in $\left[\mathrm{RuCl}_{2}(\text { p-cymene })\right]_{2}$
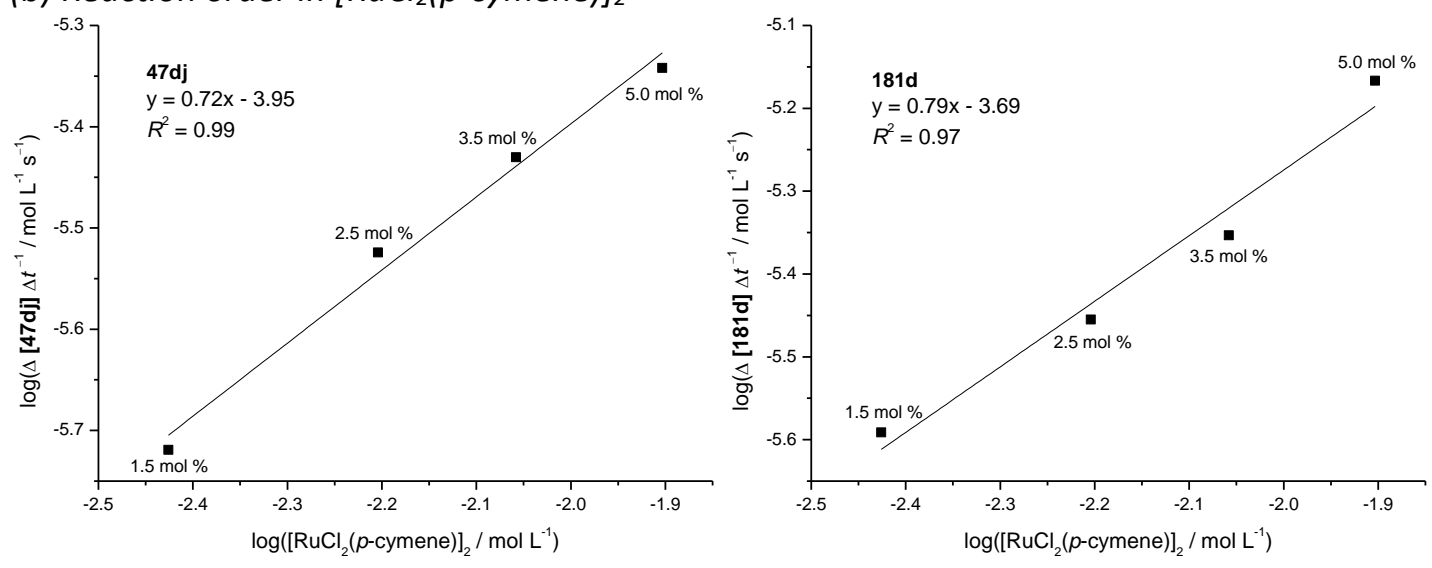

(c) Reaction order in aryl halide $\mathbf{4 6 j}$
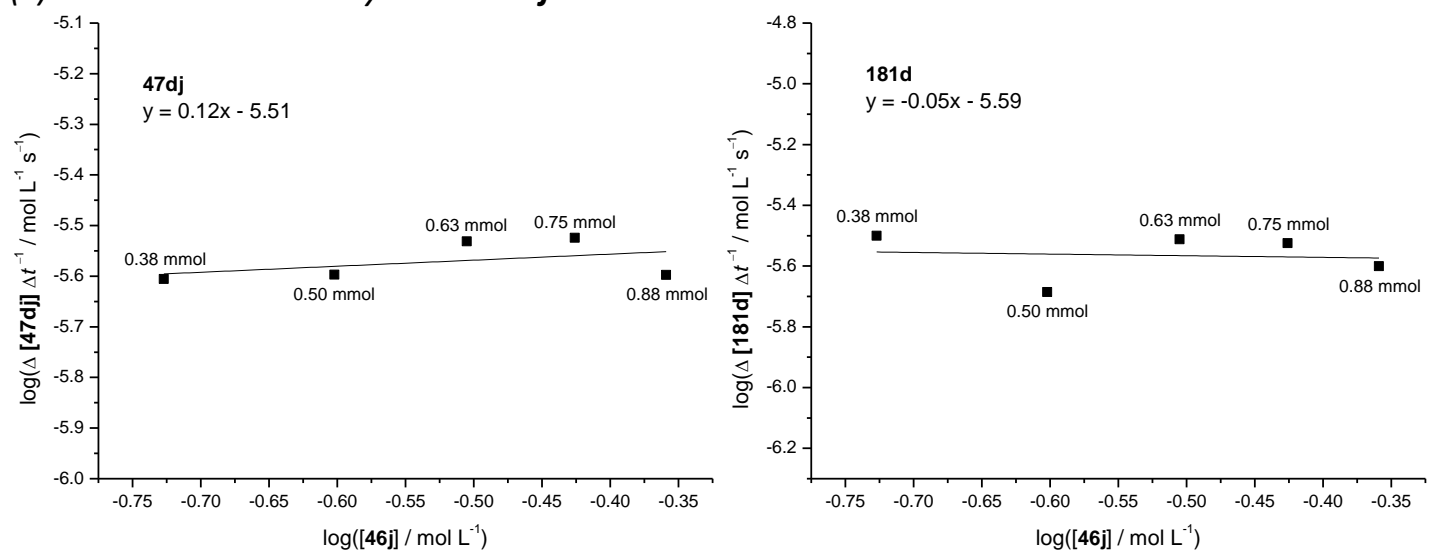

Figure 48: Kinetic analysis of the $\mathrm{C}-\mathrm{H} / \mathrm{C}-\mathrm{H}$ activation and direct $\mathrm{C}-\mathrm{H}$ arylation reactions. 
Employing well-defined $\left[\mathrm{Ru}\left(\mathrm{O}_{2} \mathrm{CMes}\right)_{2}(p\right.$-cymene $\left.)\right](61)$ as the catalyst led to an unusual reaction order of approx. 0.5 , indicating a complex rate-law, possibly due to an equilibrium between two or more catalytically competent ruthenium species (Figure 49). Additionally, by changing the $\left[\mathrm{Ru}\left(\mathrm{O}_{2} \mathrm{CMes}\right)_{2}(p\right.$-cymene) $)(\mathbf{6 1})$ concentration, the concentration of $\mathrm{MesCO}_{2} \mathrm{H}(\mathbf{5 8})$ was changed concurrently, which could influence the rate of the presumed proto-demetalation event.<smiles>COc1ccccc1-c1ccccn1</smiles>

45d<smiles>FC(F)(F)c1ccccc1Br</smiles>

46j
$\left[\mathrm{Ru}\left(\mathrm{O}_{2} \mathrm{CMes}\right)_{2}(\right.$ p-cymene $\left.)\right](\mathbf{6 1})$

(5.0-10 mol \%)

$\mathrm{K}_{2} \mathrm{CO}_{3}$ $\mathrm{PhMe}, 102^{\circ} \mathrm{C}$

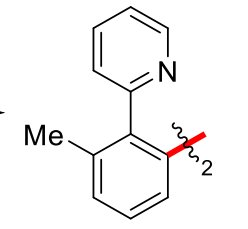

$181 d$<smiles>Cc1cccc(-c2ccccc2C(F)(F)F)c1-c1ccccn1</smiles>

47dj

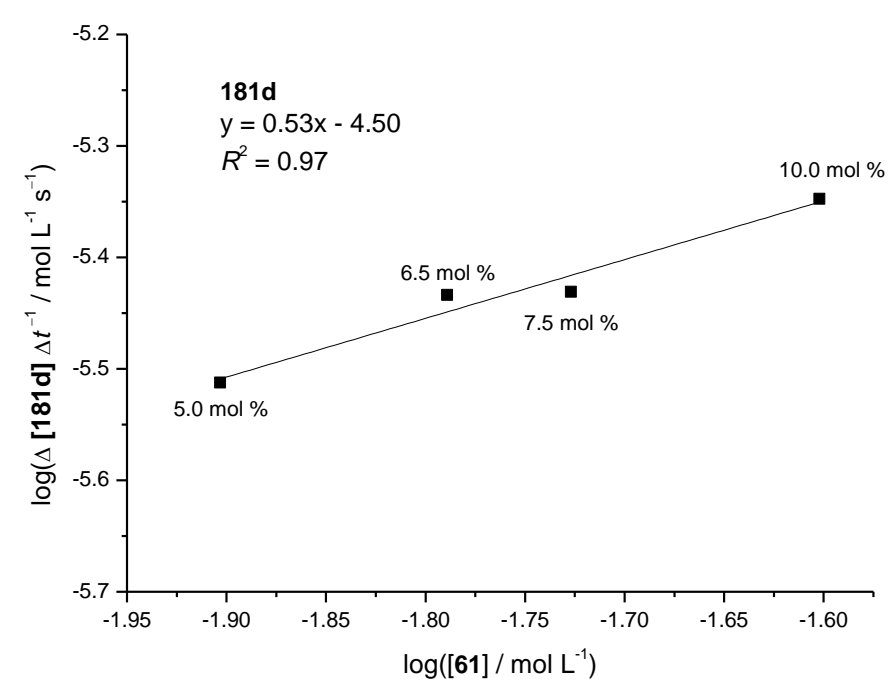

Figure 49: Reaction order in well-defined $\left[\mathrm{Ru}\left(\mathrm{O}_{2} \mathrm{CMes}\right)_{2}(p\right.$-cymene $\left.)\right](61)$.

Further studies with 2-bromobenzonitrile (46k) as the reagent revealed a much higher reaction rate compared to 2 -bromotrifluorotoluene $(\mathbf{4 6 j})$, indicating a significantly lower activation energy (Figure 50). It is noteworthy that in this reaction no induction period was observed. 


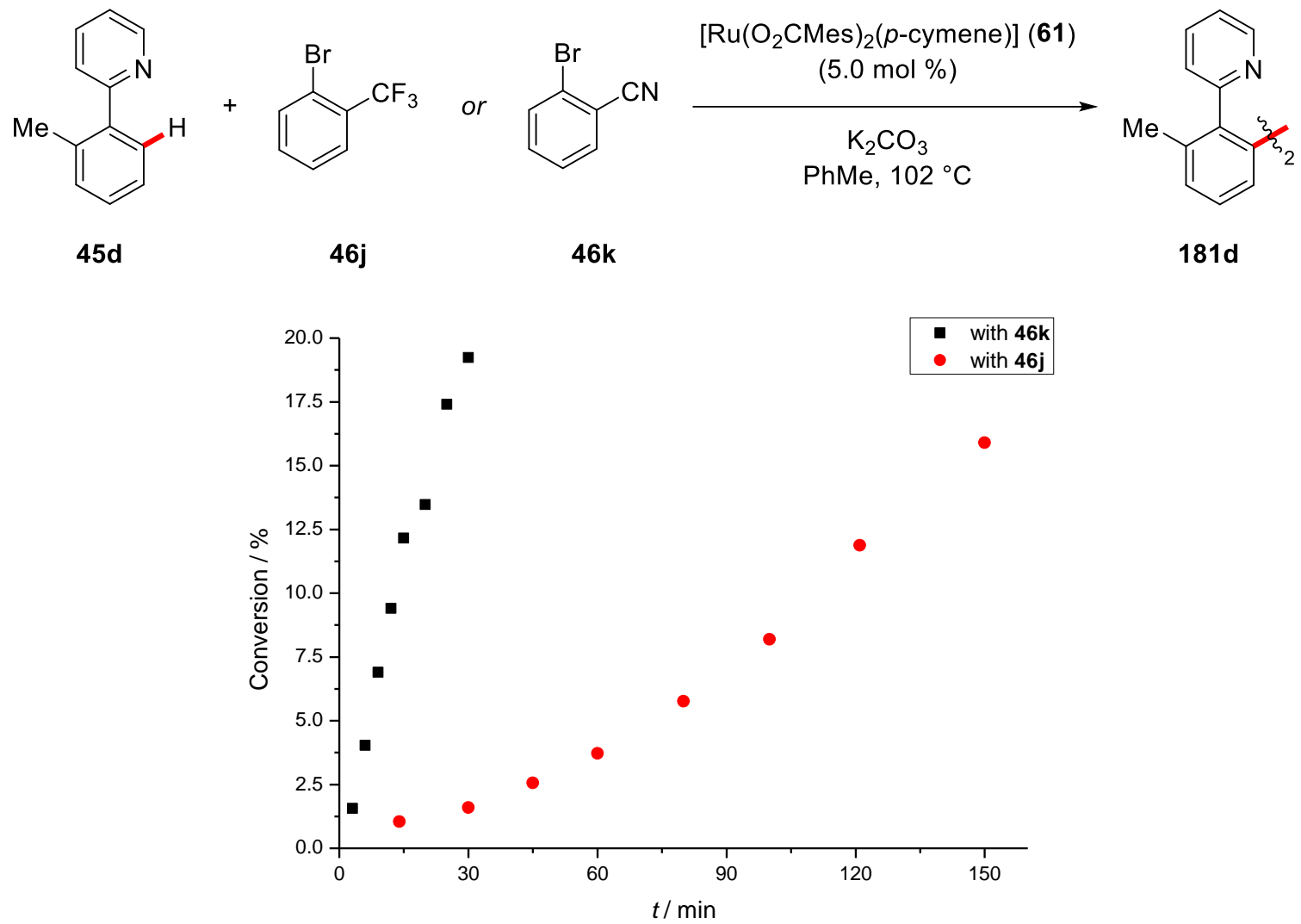

Figure 50: Comparison of aryl halides $\mathbf{4 6 j}$ and $\mathbf{4 6 k}$.

Considerable changes in the reaction orders were uncovered by detailed kinetic studies using 2-bromobenzonitrile (46k) as the aryl halide. For the $\mathrm{C}-\mathrm{H} / \mathrm{C}-\mathrm{H}$ activation process the reaction order in phenylpyridine $45 \mathrm{~d}$ was found to decrease to a value of 0.4 (Figure 51a), whereas the order with respect to the aryl halide 46k concentration increased significantly to approx. 0.7 (Figure 51c). Again, the reaction rate showed a non-integer order dependence on the concentration of $\left[\mathrm{Ru}\left(\mathrm{O}_{2} \mathrm{CMes}\right)_{2}(p\right.$-cymene)] (61) (Figure 51b). Unfortunately, the reaction order for the $\mathrm{C}-\mathrm{H}$ arylation process could not be derived due to a very slow formation of the arylated

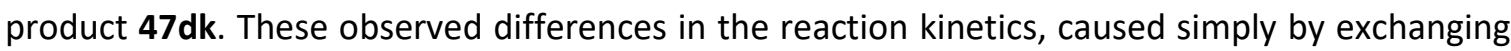
the aryl halide, indicate a distinct change in the turnover-limiting step of the reaction. In contrast to 2-bromotrifluorotoluene (46j), 2-bromobenzonitrile (46k) is able to coordinate to ruthenium through the nitrile-substituent, thereby changing the coordination environment of the catalytically active ruthenium species. In addition, DFT studies showed that the energy barrier for the oxidative addition of $\mathbf{4 6 k}$ is comparable to the energy barrier of the $\mathrm{C}-\mathrm{H}$ ruthenation step, thereby rendering both processes kinetically relevant (vide infra). 
<smiles>Cc1ccccc1-c1ccccn1</smiles>

45d<smiles>N#Cc1ccccc1Br</smiles>

$46 k$
$\left[\mathrm{Ru}\left(\mathrm{O}_{2} \mathrm{CMes}\right)_{2}(p\right.$-cymene $\left.)\right](\mathbf{6 1})$

$(2.5-10 \mathrm{~mol} \%)$

$$
\mathrm{K}_{2} \mathrm{CO}_{3}
$$

$\mathrm{PhMe}, 102{ }^{\circ} \mathrm{C}$<smiles>COc1cccc(C)c1-c1ccccn1</smiles>

$181 d$ (a) Reaction order in pheny/pyridine $\mathbf{4 5 d}$

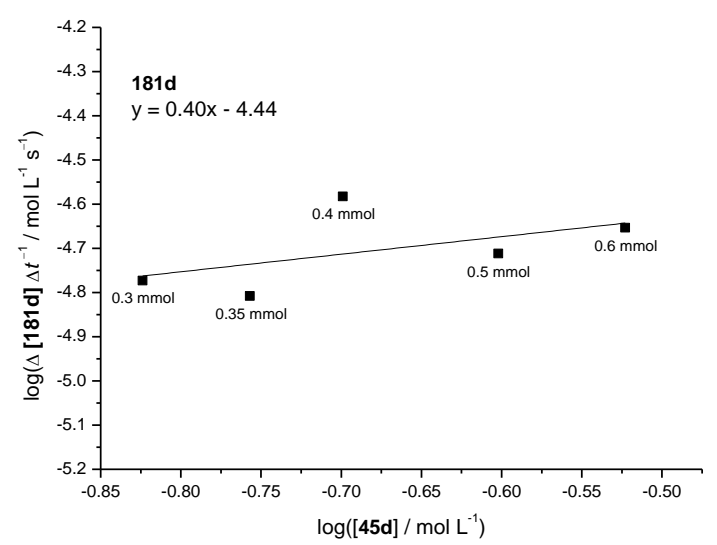

(b) Reaction order in $\left[\mathrm{Ru}\left(\mathrm{O}_{2} \mathrm{CMes}\right)_{2}(\right.$ p-cymene)] (61)

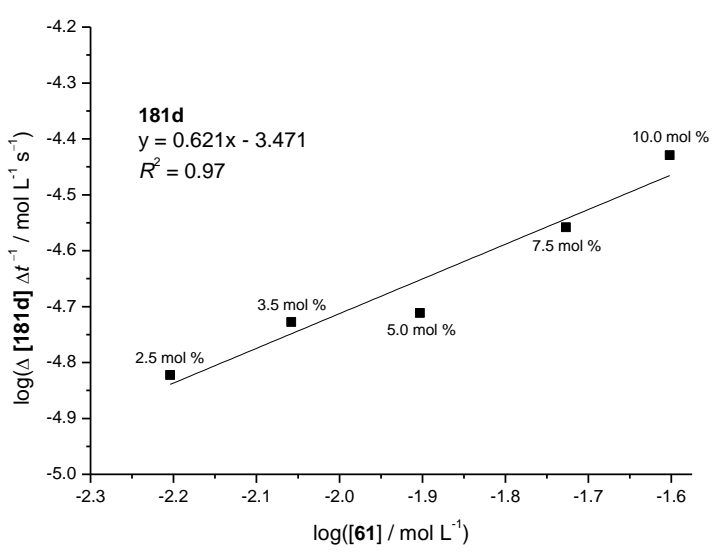

(c) Reaction order in aryl halide $\mathbf{4 6 k}$

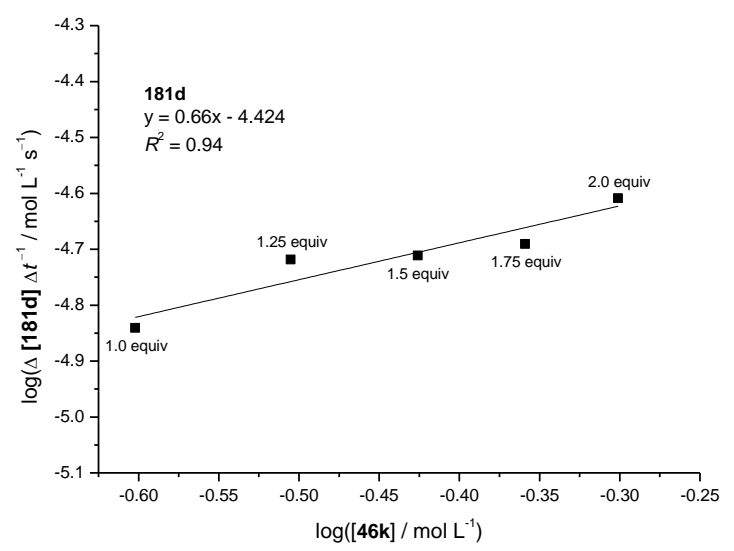

Figure 51: Kinetic analysis of the $\mathrm{C}-\mathrm{H} / \mathrm{C}-\mathrm{H}$ activation employing 2-bromobenzonitrile (46k).

\subsubsection{Computational Studies}

The transformation was additionally investigated by means of DFT calculations to gain further insight into the elemental steps of the reaction. Geometry optimizations were performed at the TPSS-D3(BJ)/def2-TZVP level of theory, ${ }^{[125,126,127]}$ while single-point calculations were conducted at the PBEO-D3(BJ)/def2-TZVP+SMD(MeCN) level ${ }^{[134,135]}$ (for full details see Section 6.7). For the sake of simplicity mesityl carboxylate was replaced by acetate within the calculations. 
Starting from complex 9.A containing two $\mathrm{N}$-coordinated phenylpyridine motifs in a transconfiguration, which was found to be $0.5 \mathrm{kcal} \mathrm{mol}^{-1}$ more stable than the corresponding cisconfigured complex (see Section 6.7.2), agostic intermediate 9.B is formed via $\kappa^{2}-k^{1}$ displacement of one acetate-ligand with an energy barrier of $10.4 \mathrm{kcal} \mathrm{mol}^{-1}$ (Figure 52). Afterwards, concerted $\mathrm{C}-\mathrm{H}$ cleavage and $\mathrm{Ru}-\mathrm{C}$ formation generates ruthenacycle 9.C. $\mathrm{C}-\mathrm{H}$ activation of the second substrate proceeds via formation of agostic intermediate 9.D with an energy barrier of $16.9 \mathrm{kcal} \mathrm{mol}^{-1}$, followed by $\mathrm{C}-\mathrm{H}$ cleavage with a low barrier of only $4.7 \mathrm{kcal} \mathrm{mol}^{-1}$. In the resulting biscyclometalated complex 9.E, the two aryl-ligands adopt a cis-configuration (Figure 53), consistent with previous reports. ${ }^{[55]}$ In the presence of a nitrile-containing compound as either the reaction medium or the aryl halide reagent, ligand exchange can occur on intermediate 9.C. Exchange of the coordinated acetic acid with acetonitrile stabilizes the complex by $11.0 \mathrm{kcal} \mathrm{mol}^{-1}$ and, furthermore, reduces the energy required for the $2^{\text {nd }} \mathrm{C}-\mathrm{H}$ activation process (Figure 52, red line).

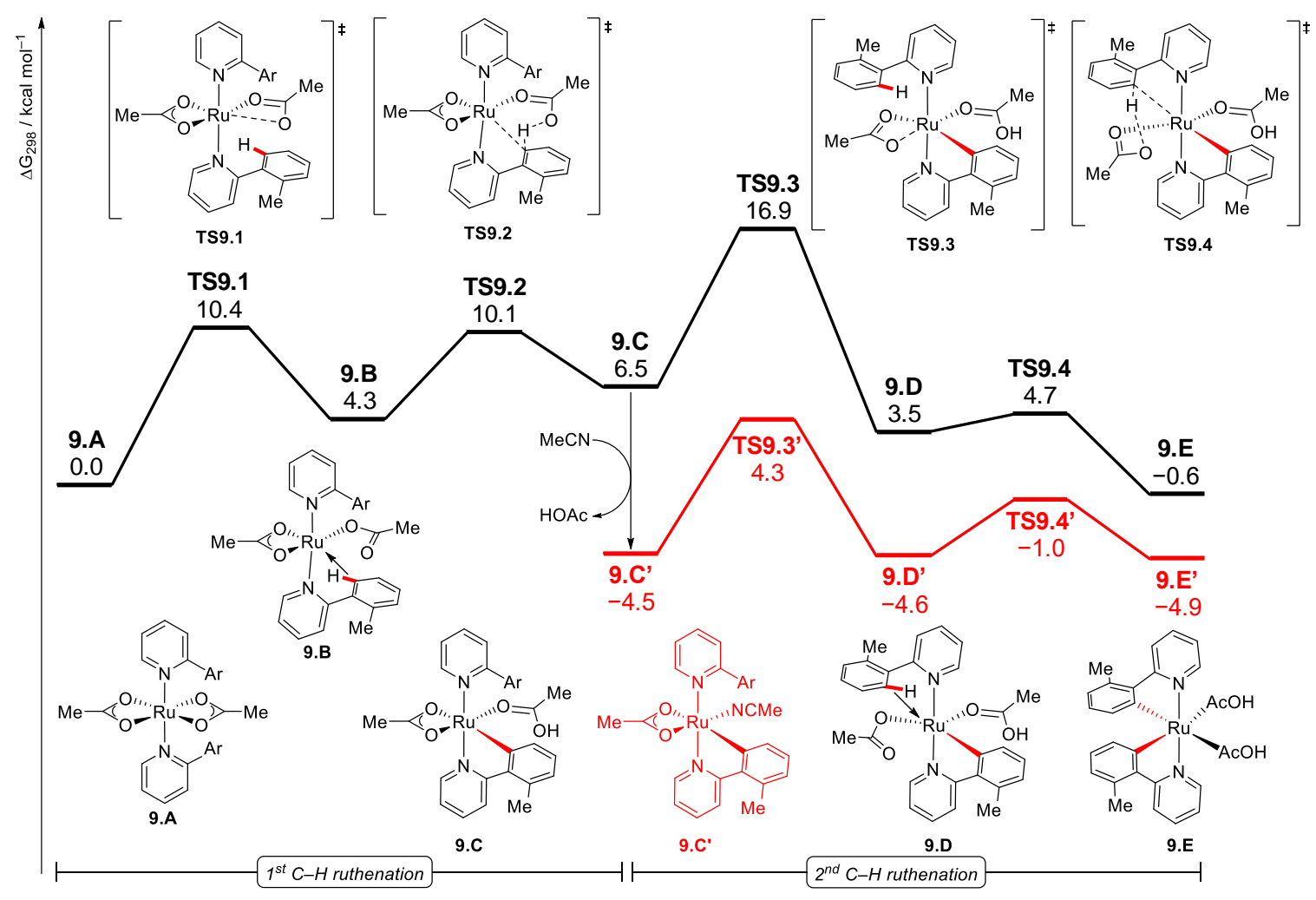

Figure 52: Relative Gibbs free energy profile for the cyclometalation of $45 \mathrm{~d}$. Ar $=0$-tolyl. 


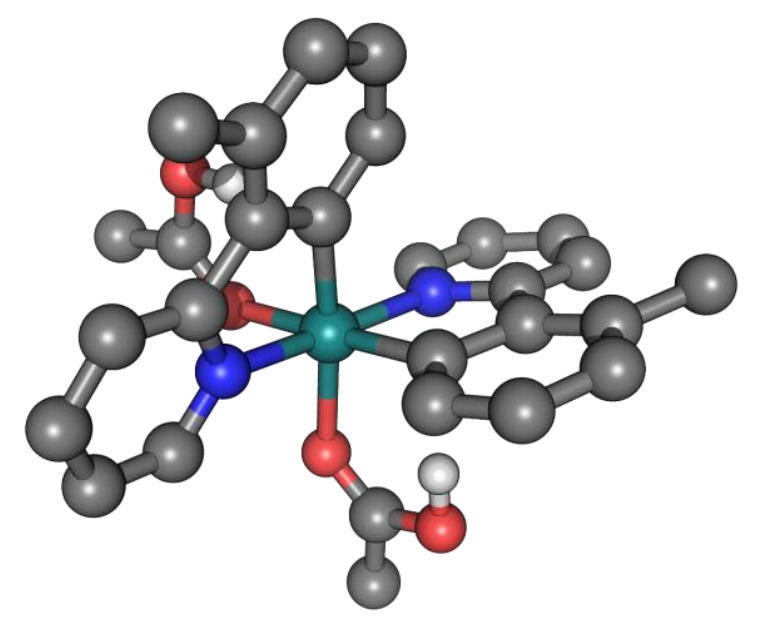

Figure 53: Structure of biscyclometalated complex 9.E. Non-participating hydrogen atoms are omitted for clarity.

A careful bond order analysis of the $\mathrm{C}-\mathrm{H}$ ruthenation steps within a More O'Ferral-Jencks plot ${ }^{[160]}$ was performed and indicated a substitutive BIES-type ${ }^{[20]}$ rather than a deprotonative CMD-type ${ }^{[18]}$ $\mathrm{C}-\mathrm{H}$ ruthenation event (Figure 54).
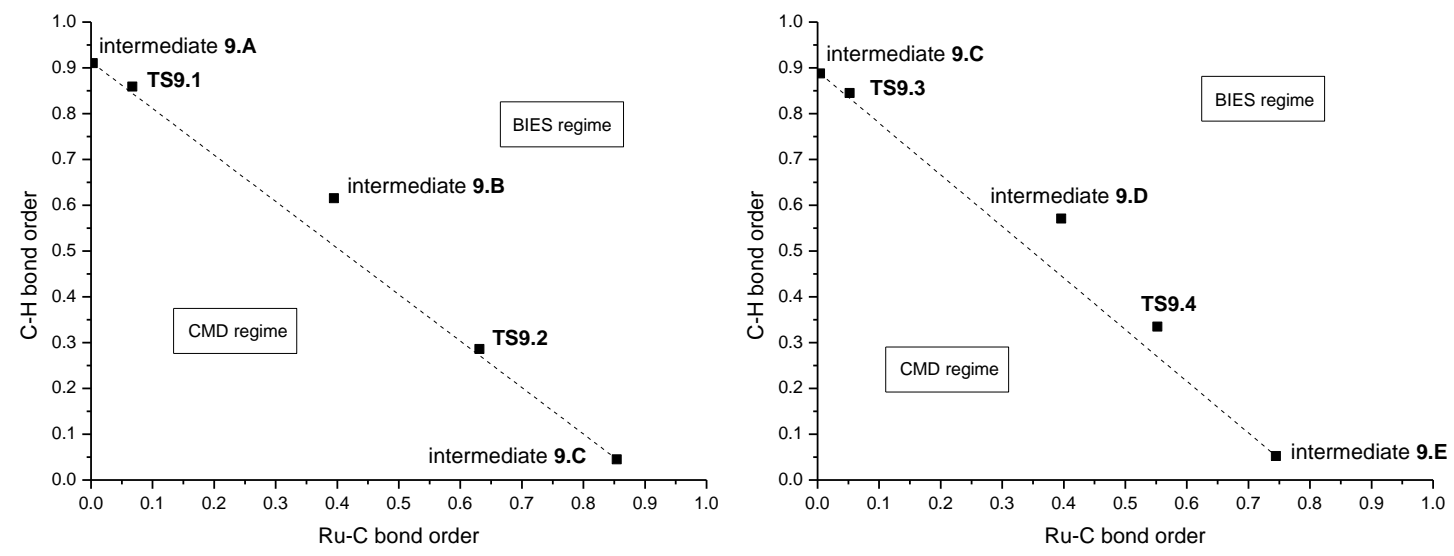

Figure 54: More $\mathrm{O}^{\prime}$ Ferral-Jencks plot for the $1^{\text {st }}$ (left) and $2^{\text {nd }}$ (right) $\mathrm{C}-\mathrm{H}$ ruthenation step.

Following the $\mathrm{C}-\mathrm{H}$ ruthenation, decoordination of acetic acid and coordination of bromobenzene

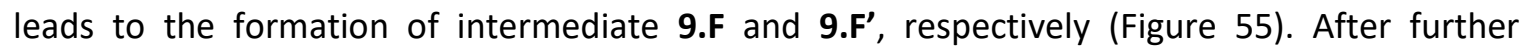
decoordination of HOAc or MeCN, five-coordinated complex 9.G undergoes turnover-limiting oxidative addition of the $\mathrm{C}-\mathrm{Br}$ bond to generate ruthenium(IV) species $\mathbf{9 .} \mathbf{H}$ via transition state TS9.5 with a relative energy of $19.8 \mathrm{kcal} \mathrm{mol}^{-1}$. It is worth mentioning that introduction of a cyano 
group in the ortho-position of the aryl bromide led to a stabilization of $\mathrm{Br}$-coordinated complex 9.G' by $3.0 \mathrm{kcal} \mathrm{mol}^{-1}$ and a subsequent decrease in the energy of oxidative addition transition state TS9.5' by $3.8 \mathrm{kcal} \mathrm{mol}^{-1}$ (Figure 55, blue line). Notably, ruthenium(IV) complexes $\mathbf{9 . H}$ and $\mathbf{9 . \mathbf { H } ^ { \prime }}$ only showed a marginal difference in stability of $0.3 \mathrm{kcal} \mathrm{mol}^{-1}$.

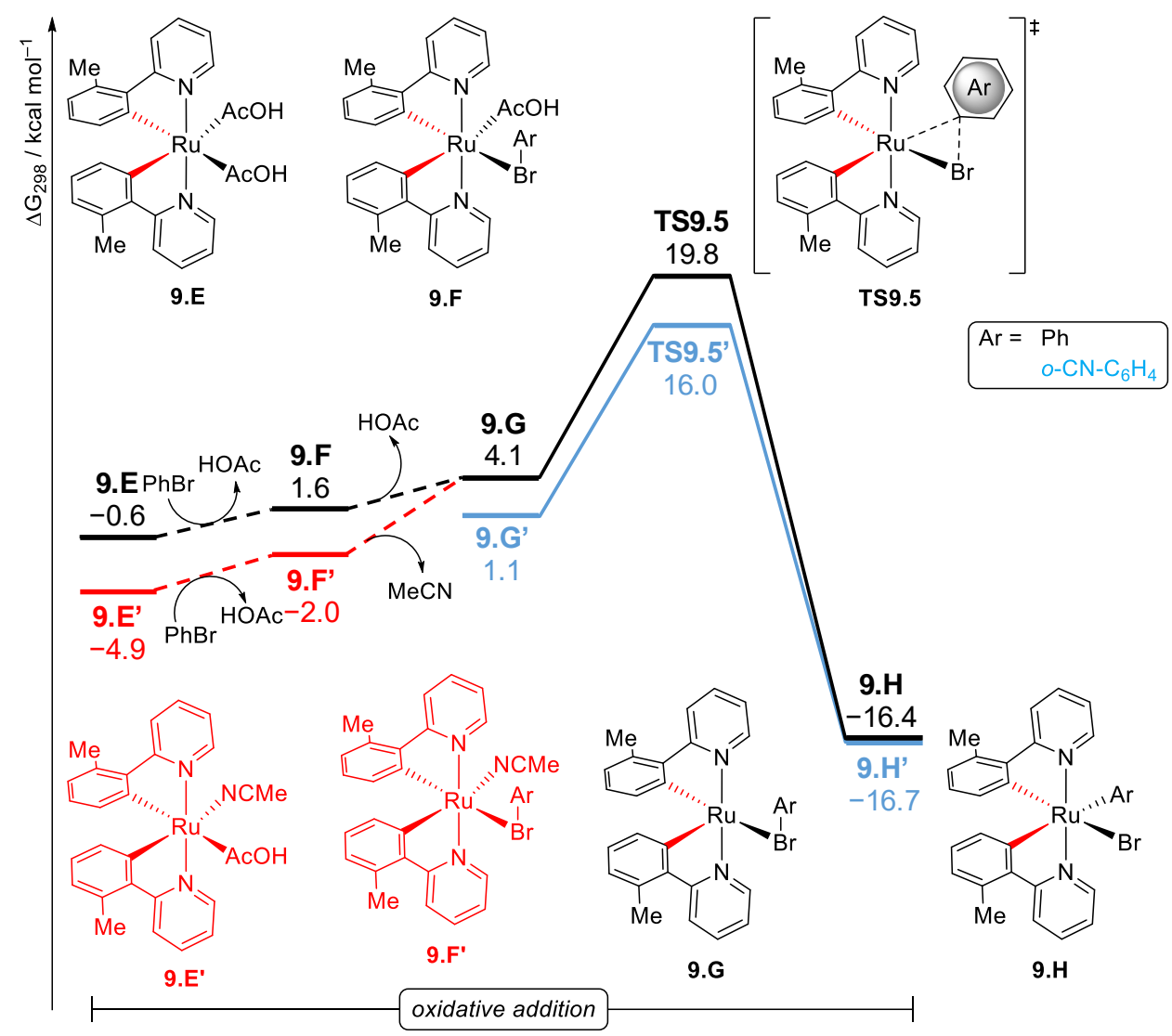

Figure 55: Relative Gibbs free energy profile for the oxidative addition of aryl bromides.

As a next step selectivity-determining reductive elimination takes place either between the aryl groups of the two phenylpyridine motifs to deliver the $\mathrm{C}-\mathrm{H} / \mathrm{C}-\mathrm{H}$ functionalized product or between an aryl group of one phenylpyridine motif and the aryl ligand originating from the aryl halide, thus furnishing the corresponding $\mathrm{C}-\mathrm{H}$ arylated compound (Figure 56). Complex 9.H containing a phenyl ligand shows a strong preference for reductive elimination via TS9.7, thereby resulting in the formation of $\mathrm{C}-\mathrm{H}$ arylated product 9.J. The difference in the energy barriers for the two competing pathways was calculated to be $\Delta \Delta \mathrm{G}^{\ddagger}{ }_{\mathrm{Ts}} \mathrm{G} . \mathrm{-Ts9.7}=3.9 \mathrm{kcal} \mathrm{mol}^{-1}$. In contrast, installation of a cyano group in the 2-position of the aryl ligand resulted in a significant stabilization of TS9.6' along with a destabilization of TS9.7', resulting in a preferential reductive elimination between the two phenylpyridine motifs, hence delivering the $\mathrm{C}-\mathrm{H} / \mathrm{C}-\mathrm{H}$ activated product $\mathbf{9 . I ^ { \prime }}$ 
(Figure 56, blue line). In this case, the energy difference between both transition states was calculated to be $\Delta \Delta \mathrm{G}^{\ddagger}{ }_{\text {TS9.6'-TS9.7 }}=-5.7 \mathrm{kcal} \mathrm{mol}^{-1}$ in favor of TS9.6. This switch in selectivity by a change in the aryl halide species is in good agreement with the experimentally obtained product distributions (vide supra). Susequent two-fold proto-demetalation of intermediate 9.1 by HOAc and coordination of two molecules of phenylpyridine $45 \mathrm{~d}$ liberates the product, generates $\mathrm{HBr}$ and $\mathrm{Ar}-\mathrm{H}$ as byproducts, and regenerates catalyst 9.A. With respect to complex 9.J, protodemetalation with one molecule of HOAc in combination with the coordination of $\mathbf{4 5 d}$ delivers product 47 and $\mathrm{HBr}$. In this case, the catalyst reenters the catalytic cycle as intermediate 9.C/9.C'.

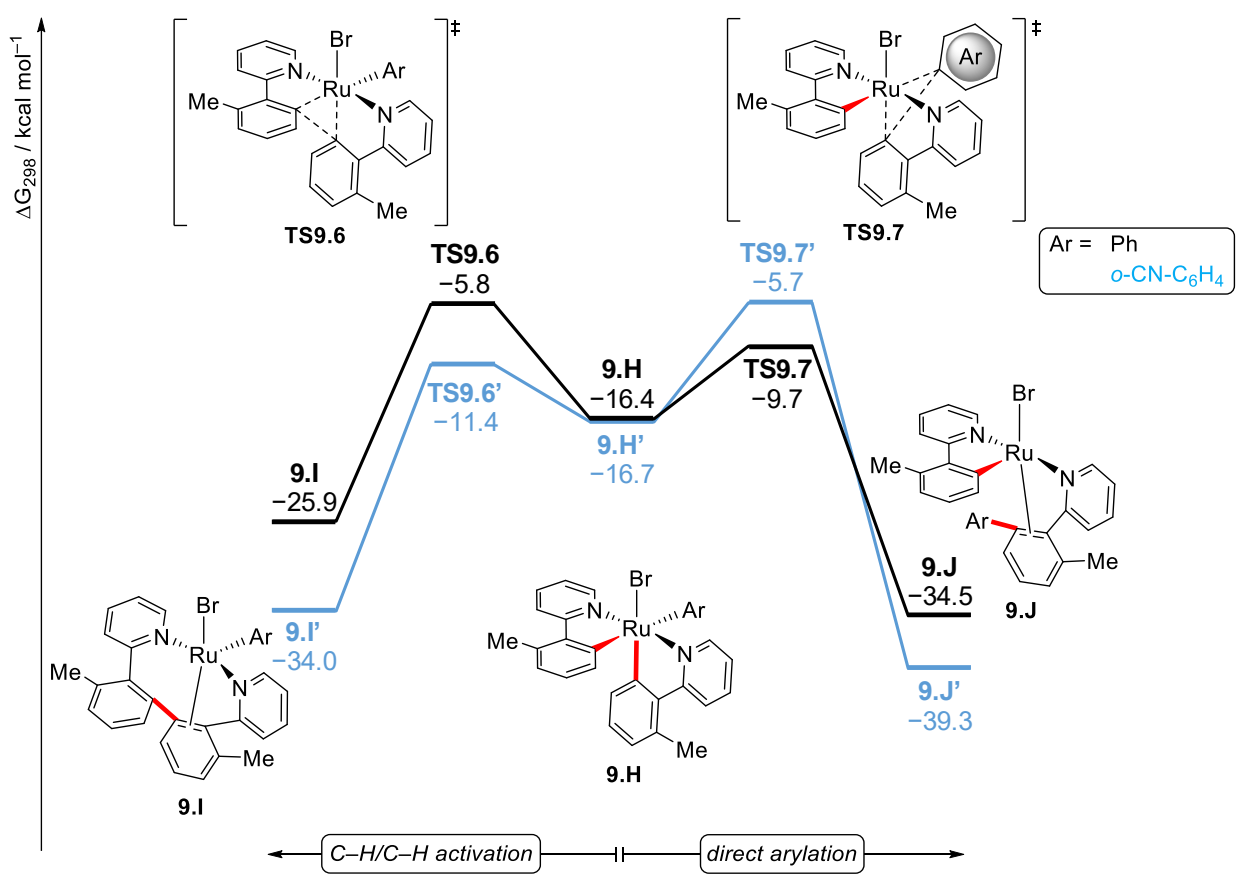

Figure 56: Relative Gibbs free energy profile for the selectivity-determining reductive elimination.

The formation of $\mathrm{C}-\mathrm{H} / \mathrm{C}-\mathrm{H}$ functionalized product $\mathbf{1 8 1 d}$ by reductive elimination from biscyclometalated complex 9.E via transition state TS9.8 exhibited an energy barrier of $48.8 \mathrm{kcal} \mathrm{mol}^{-1}$, thus rendering a ruthenium(II/0/II) manifold unlikely (Figure 57). In contrast, these findings can be better rationalized by an energetically favorable oxidation-induced reductive elimination manifold. ${ }^{[161]}$ 


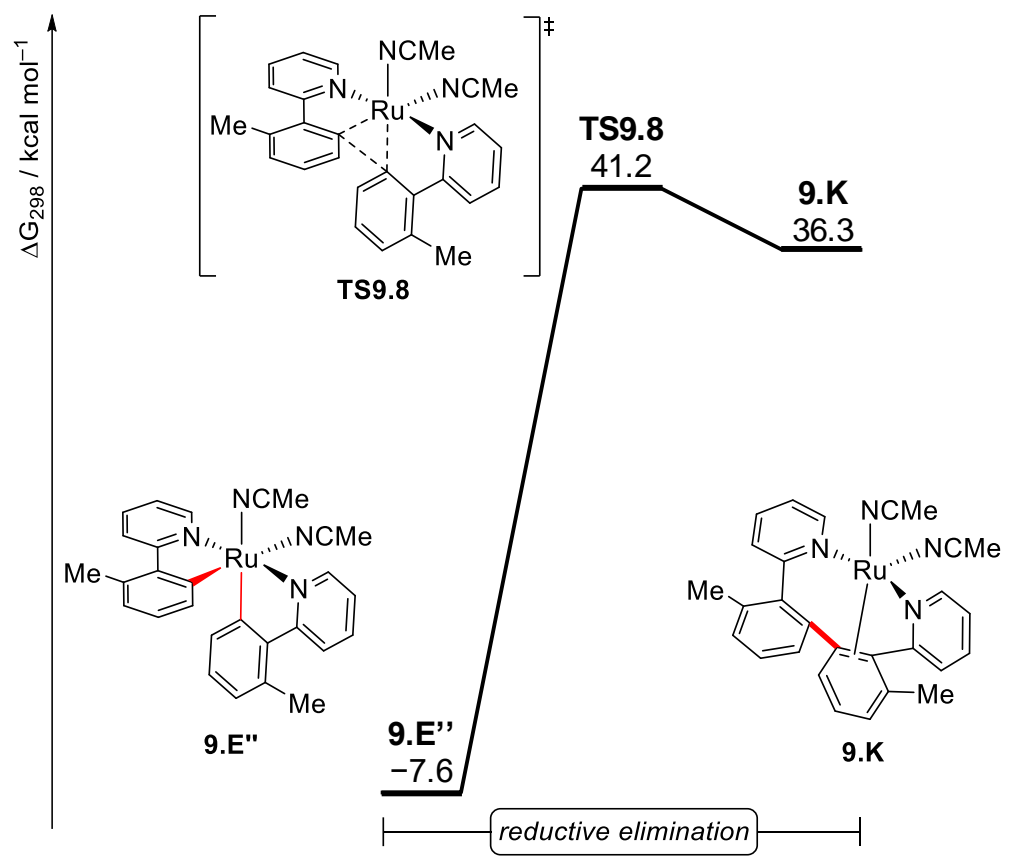

Figure 57: Relative Gibbs free energy profile for reductive elimination from ruthenium(II).

The involvement of higher spin states, namely triplet and quintet states, can be disregarded due to significantly higher energies for a number of representative ruthenium(II), ruthenium(0) as well as ruthenium(IV) intermediates (see Table 38 on page 208).

\subsection{Manganese-Catalyzed C-H Allylation on Peptides}

As already discussed above, modifications of peptides by $\mathrm{C}-\mathrm{H}$ activation strategies hold an immense potential (see Section 3.8). Despite the inherently more sustainable nature of $\mathrm{C}-\mathrm{H}$ activation approaches compared to traditional cross-coupling reactions, $\mathrm{C}-\mathrm{H}$ activation on peptides ${ }^{[114]}$ is largely limited to precious metal catalysts, whereas the use of inexpensive, less toxic $^{[87]} 3 \mathrm{~d}$ transitions metals, ${ }^{[12 b]}$ especially manganese, continues to be limited (vide supra). ${ }^{[95]}$

The introduction of an allyl substituent into organic molecules can provide a synthetic handle for a plethora of functionalizations by means of classical as well as novel methods. Especially allylic alcohols or amines provide easy access to a number of important moieties. Considering these aspects, N. Kaplaneris in the Ackermann group developed manganese-catalyzed C-H allylations of tryptophans and tryptophan-containing peptides with user-friendly Morita-Baylis-Hillman (MBH) adducts, providing access to synthetically useful $\alpha, b$-unsaturated esters 162 (Scheme 89). ${ }^{[162]}$ 
Employing $\left[\mathrm{MnBr}(\mathrm{CO})_{5}\right]$ as the catalyst of choice, a variety of diversely decorated hybrid, cyclic, and acyclic peptides could be obtained in good to excellent yields.<smiles>[R]C(=O)C([R])Cc1c(C)n([R10])c2ccccc12</smiles>

160<smiles>[R]C(O[Na])C(=O)O[Na]</smiles>

161

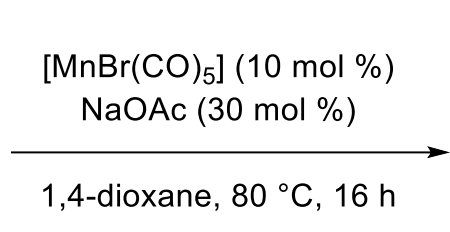<smiles>[R]C=C(Cc1c(CC([R])C([R])[R])c2ccccc2n1[R17])C(C)=O</smiles>

162

Scheme 89: Optimized reaction conditions for manganese-catalyzed $\mathrm{C}-\mathrm{H}$ allylations of tryptophans 160.

The reaction mechanism was explored in detail to gain further insights into this unprecedented transformation. To this end, DFT calculations were performed at the TPSS-D3(BJ)/def2-TZVP level of theory ${ }^{[125,126,127]}$ for geometry optimizations and PW6B95-D3(BJ)/def2-QZVP+COSMO(1,4dioxane) level of theory ${ }^{[127,142,145]}$ for single point calculations (for full details see Section 6.8).

Experimental mechanistic studies indicated a facile, reversible $\mathrm{C}-\mathrm{H}$ activation process. ${ }^{[163]}$ The $\mathrm{C}-\mathrm{H}$ activation step was therefore omitted within the computational investigations and managacycle 10.A was chosen as the starting point (Figure 58). Starting from intermediate 10.A, migratory insertion of the coordinated alkene into the $\mathrm{Mn}-\mathrm{C}$ bond takes place to generate sevenmembered manganacycle 10.B, which is $8.8 \mathrm{kcal} \mathrm{mol}^{-1}$ more stable than 10.A. Coordination of one carbonate oxygen to manganese facilitates the key C-O cleavage event via transition state TS10.2 with an energy barrier of $11.7 \mathrm{kcal} \mathrm{mol}^{-1}$. Ligand exchange with acetic acid leads to the formation of complex 10.E containing a $\kappa^{1}$-coordinated acetate ligand. It is noteworthy that TS10.2 occurs late in the $\mathrm{C}-\mathrm{O}$ cleavage step. The $\mathrm{C}-\mathrm{O}$ distance in the transition state structure is already increased by $0.53 \AA$ to a value of $2.02 \AA$ and the two geminal protons at the newly forming double bond adopt a nearly planar conformation (Figure 59). 


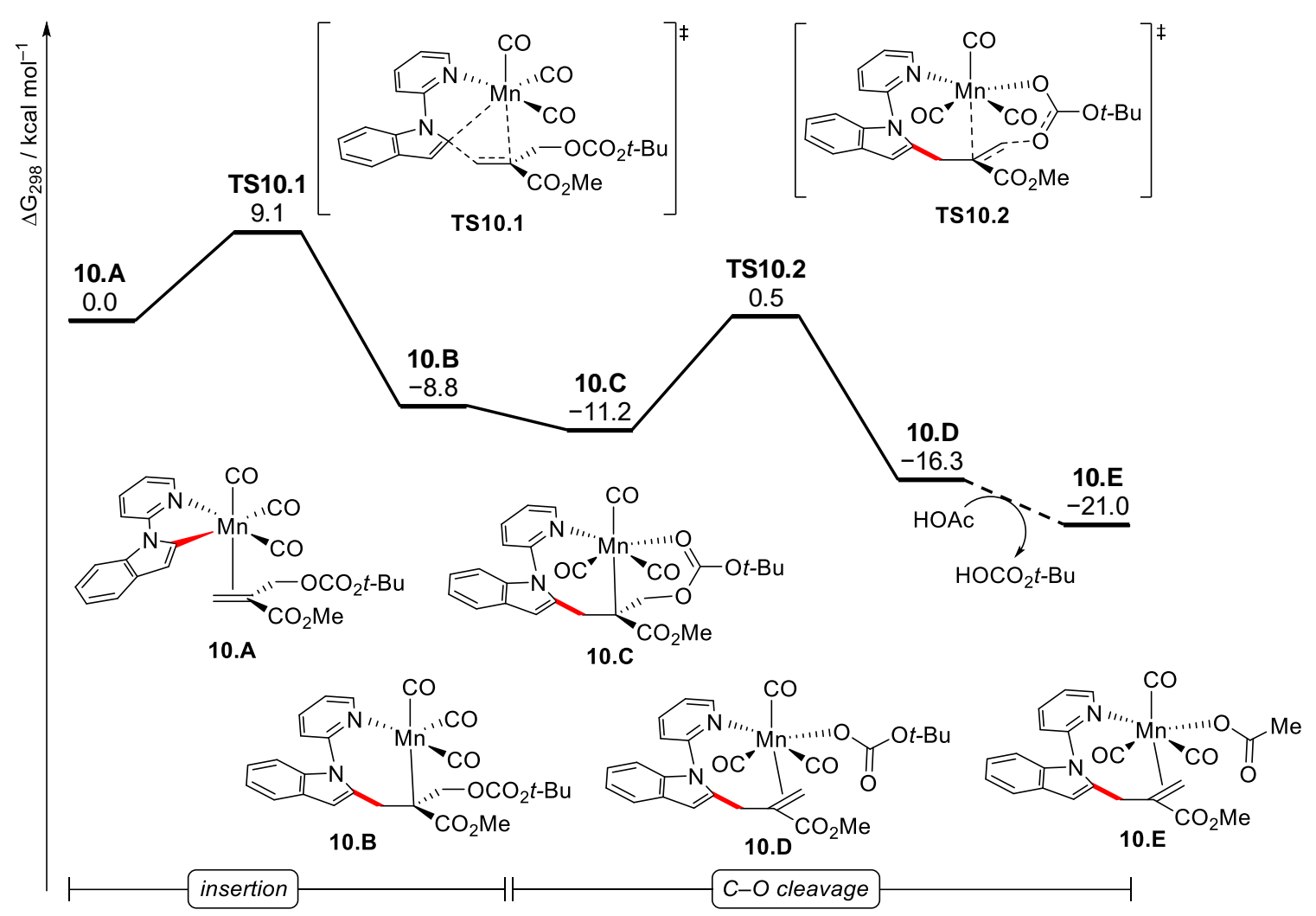

Figure 58: Relative Gibbs free energy profile for the reaction of 125a with MBH adduct 161a.

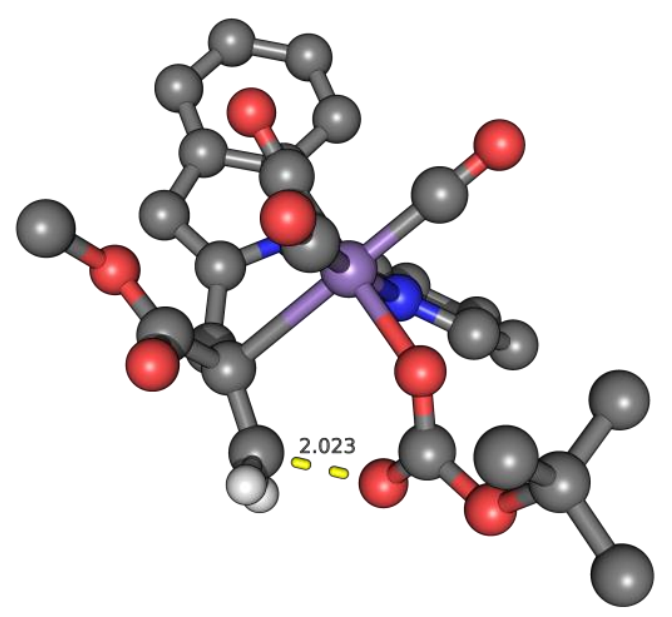

Figure 59: Structure of key transition state TS10.2. Distances are given in $\AA$ and non-participating hydrogen atoms are omitted for clarity. 


\subsection{Manganese-Catalyzed C-C Allylation}

In contrast to a vast number of reports on manganese-catalyzed $\mathrm{C}-\mathrm{H}$ activation, ${ }^{[89]} \mathrm{C}-\mathrm{C}$ activation strategies largely rely on precious transition metals such as rhodium and palladium, whereas earth-abundant and less toxic manganese catalysis remains underutilized in $\mathrm{C}-\mathrm{C}$ activation reactions. ${ }^{[96]}$ Although methods for organometallic $\mathrm{C}-\mathrm{C}$ activation require the prior installment of a suitable group in the molecule, this strategy allows for the synthesis of 1,2,3-trisubstituted arenes. In contrast, such a substitution pattern can usually not be obtained through $\mathrm{C}-\mathrm{H}$ activation reactions due to a preferred activation at the sterically less hindered C6 position of metasubstituted arenes.

It is therefore noteworthy that $H$. Wang, I. Choi, and N. Kaplaneris in the Ackermann group achieved the allylation of arenes $142 a$ by employing a manganese-catalyzed $C-C$ activation strategy with vinyldioxolanones 163 a or vinyloxazolidinones $163 \mathrm{~b}$ as substrates (Scheme 90). ${ }^{[164]}$ Commercially available $\left[\mathrm{MnBr}(\mathrm{CO})_{5}\right]$ proved to be the catalyst of choice and, in addition to commonly employed organic solvents, non-toxic, non-flammable water could be employed as the reaction medium, delivering the desired product in high yield with acetone and $\mathrm{CO}_{2}$ as the sole byproducts.

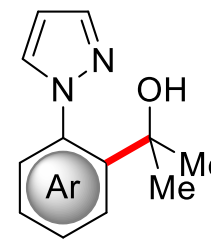

$142 a$

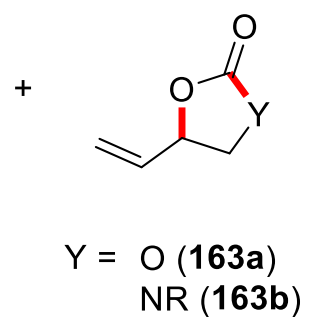

$\left[\mathrm{MnBr}(\mathrm{CO})_{5}\right](10 \mathrm{~mol} \%)$

$\mathrm{H}_{2} \mathrm{O}, 120^{\circ} \mathrm{C}, 16 \mathrm{~h}$

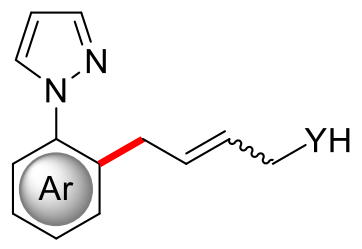

$X=O(164 a)$ NR (164b)

Scheme 90: Optimized reaction conditions for the manganese-catalyzed C-C activation.

To shed light on the reaction mechanism, DFT calculations were performed in order to investigate the manganese-catalyzed $\mathrm{C}-\mathrm{C}$ allylation. Geometry optimizations were carried out at the PBEO$\mathrm{D} 3(\mathrm{BJ}) / \mathrm{def} 2-\mathrm{SVP}+\mathrm{SMD}\left(\mathrm{H}_{2} \mathrm{O}\right)$ level of theory ${ }^{[126,127,134,135]}$ and energies were calculated at the PBEOD3(BJ)/def2-QZVP* + SMD $\left(\mathrm{H}_{2} \mathrm{O}\right)$ level ${ }^{[127]}$ (for full details see Section 6.9).

Starting from manganese-alkoxide 11.A, which is formed via salt metathesis of $\left[\mathrm{MnBr}(\mathrm{CO})_{5}\right]$ with substrate 142a, decoordination of one CO ligand leads to the formation of five-coordinated managense complex 11.B, which was also observed by mass spectrometric investigations (Figure 
60). Turnover-limiting $C-C$ cleavage with an energy barrier of $25.5 \mathrm{kcal} \mathrm{mol}^{-1}$ generates fivemembered manganacycle 11.C, which is in good agreement with experimental kinetic studies (Figure 61). Ligand exchange of the coordinated acetone with 163a is followed by migratory insertion of the alkene into the $\mathrm{Mn}-\mathrm{C}$ bond to form seven-membered complex 11.E. Coordination of dioxolanone oxygen and subsequent $\mathrm{C}-\mathrm{O}$ cleavage via $\mathrm{B}$-carbon elimination with an energy barrier of $15.3 \mathrm{kcal} \mathrm{mol}^{-1}$ leads to a ring opening and the formation of energetically stable, coordinatively saturated intermediate 11.G. Finally, decarboxylation generates alkoxide complex 11.I, which after proto-demetalation delivers the experimentally obtained compound 164a with a reaction Gibbs free energy of $-10.1 \mathrm{kcal} \mathrm{mol}^{-1}$ in total.

Under the reaction conditions $\left[\mathrm{MnBr}(\mathrm{CO})_{5}\right]$ was employed as the pre-catalyst, therefore energy values were also calculated relative to the pre-catalyst and the substrate. Salt-metathesis to generate intermediate 11.A formally involves the formation of one molecule of $\mathrm{HBr}$, which in the experiment is stabilized by the formation of $\mathrm{HBr} \cdot\left(\mathrm{H}_{2} \mathrm{O}\right)_{n}$ clusters. ${ }^{[165]}$ This stabilization can only be incompletely described by the employed gas-phase calculations within the framework of a continuum solvation model, hence resulting in considerably higher relative energies. Already the explicit introduction of a $\left(\mathrm{H}_{2} \mathrm{O}\right)_{5}$ cluster resulted in a stabilization of $\mathrm{HBr}$ by $7.2 \mathrm{kcal} \mathrm{mol}^{-1}$ and larger clusters should lead to even stronger stabilization effects. With these aspects in mind, the Gibbs free energies relative to the precatalyst need to be considered with caution.

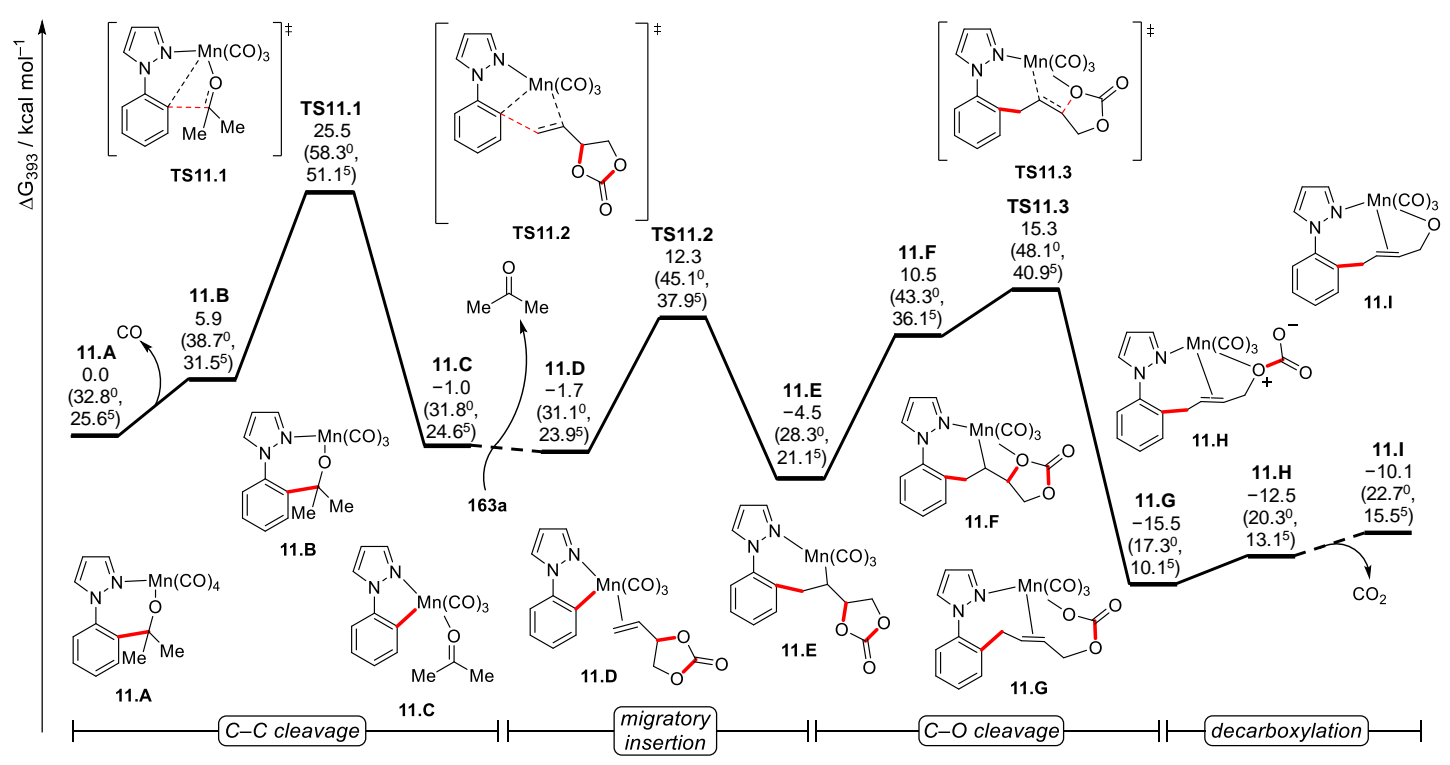

Figure 60: Relative Gibbs free energy profile for the reaction of 142a with vinyldioxolanone 163a. Values in parenthesis correspond to energies relative to $\left[\mathrm{MnBr}(\mathrm{CO})_{5}\right]+142 \mathrm{a}+\left(\mathrm{H}_{2} \mathrm{O}\right)_{n}-$ $\mathrm{HBr} \cdot\left(\mathrm{H}_{2} \mathrm{O}\right)_{n}$; superscripts correspond to the number of water molecules. 


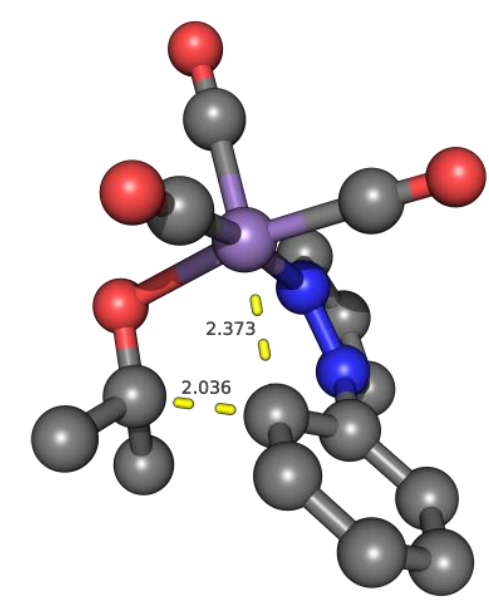

Figure 61: Structure of key transition state TS11.1. Distances are given in $\AA$ and hydrogen atoms are omitted for clarity.

Furthermore, the corresponding high-spin (quintet state) and intermediate spin (triplet state) complexes were investigated regarding the occurrence of spin-crossover (Figure 62). For almost all calculated structures the low-spin, singlet state was found to be favored, while higher spinstates were at least $10 \mathrm{kcal} \mathrm{mol}^{-1}$ less stable. Although optimization of intermediate $\mathbf{1 1 . F}$ in a triplet state led to a lower energy compared to the singlet state, decoordination of the oxygen atom was observed $\left(d_{\mathrm{Mn}-\mathrm{O}}=3.12 \AA\right)$, therefore resulting in a structure similar to complex 11.E. For the quintet state of intermediate $\mathbf{1 1 . H}$, a decoordination of the alkene and a coordination of two carbonate oxygen atoms in a $\kappa^{2}$-fashion was observed. In contrast, the quintet state of transition state TS11.3 as well as intermediate 11.G was calculated to be slightly more stable than the corresponding low-spin complexes without any change in the coordination environment, indicating a possible spin-crossover. Due to the low energy differences between singlet and quintet state $\left(\Delta \Delta \mathrm{G}=1.5\right.$ and $0.8 \mathrm{kcal} \mathrm{mol}^{-1}$, respectively), calculations at a higher level of theory are necessary to confirm a possible spin-crossover event. 


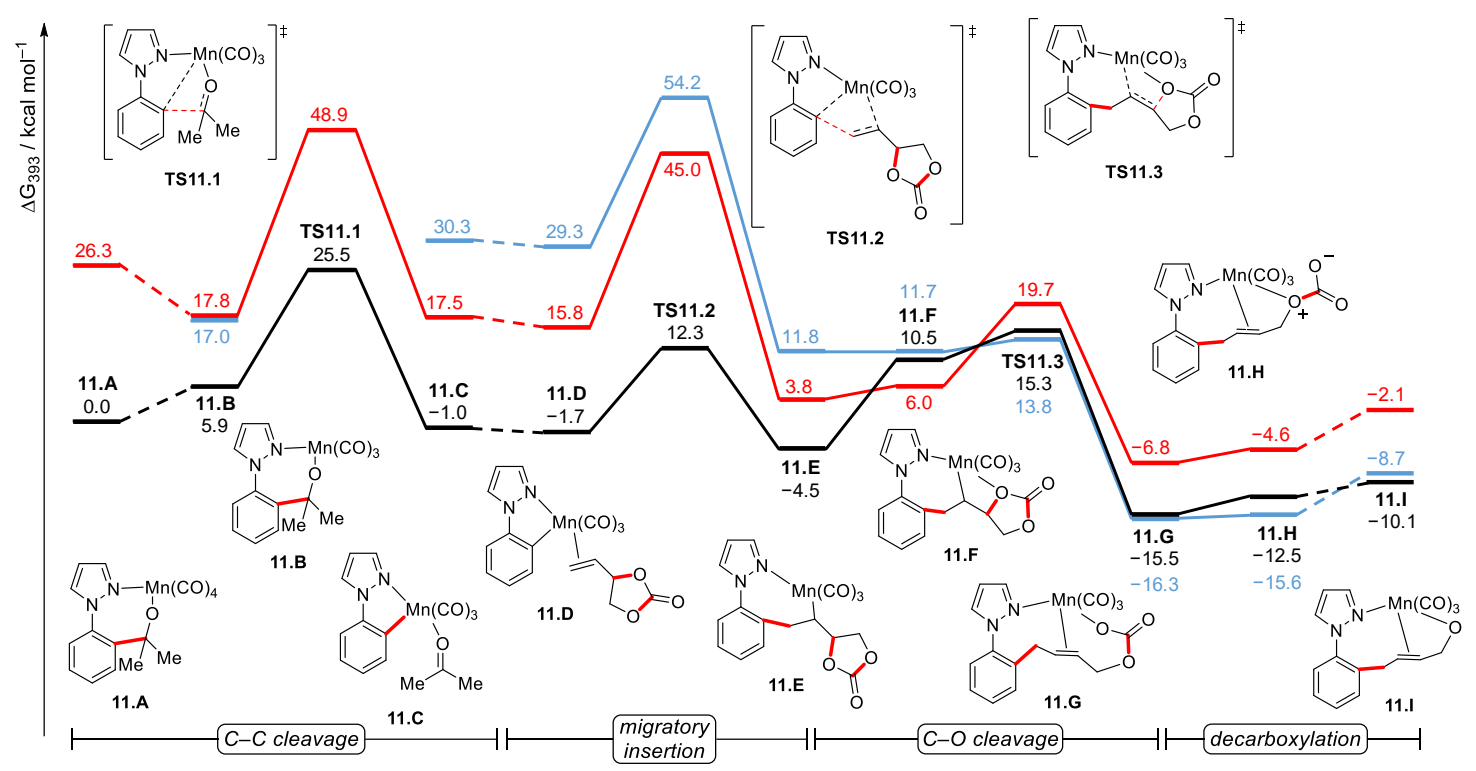

Figure 62: Relative Gibbs free energy profile for low-spin (black line), intermediate spin (red), and high-spin (blue) complexes.

Furthermore, calculations were performed without the SMD solvation model in the geometry optimizations (Figure 63). The obtained results are largely in agreement with results at the PBEO$\mathrm{D} 3(\mathrm{BJ}) /$ def2-QZVP* $+\mathrm{SMD}\left(\mathrm{H}_{2} \mathrm{O}\right) / /$ PBEO-D3(BJ)/def2-SVP+SMD $\left(\mathrm{H}_{2} \mathrm{O}\right)$ level of theory and only small energy differences of less than $2 \mathrm{kcal} \mathrm{mol}^{-1}$ were observed. It is noteworthy that a significantly larger difference was uncovered for intermediate $\mathbf{1 1 . H}$ and omitting the solvation model during optimization resulted in a destabilization by $5.7 \mathrm{kcal} \mathrm{mol}^{-1}$. Additionally, decarboxylation transition state TS11.4 could be located at this level of theory, which confirmed a facile, not turnover-limiting decarboxylation process (Figure 64).

A comparison with Gibbs free energies obtained in apolar DCE as the solvent, which was shown to be a suitable reaction medium for this transformation, resulted in a decrease of the turnoverlimiting $\mathrm{C}-\mathrm{C}$ cleavage energy barrier by $1.2 \mathrm{kcal} \mathrm{mol}^{-1}$ and a slightly more exergonic reaction Gibbs free energy of $-11.1 \mathrm{kcal} \mathrm{mol}^{-1}$. 


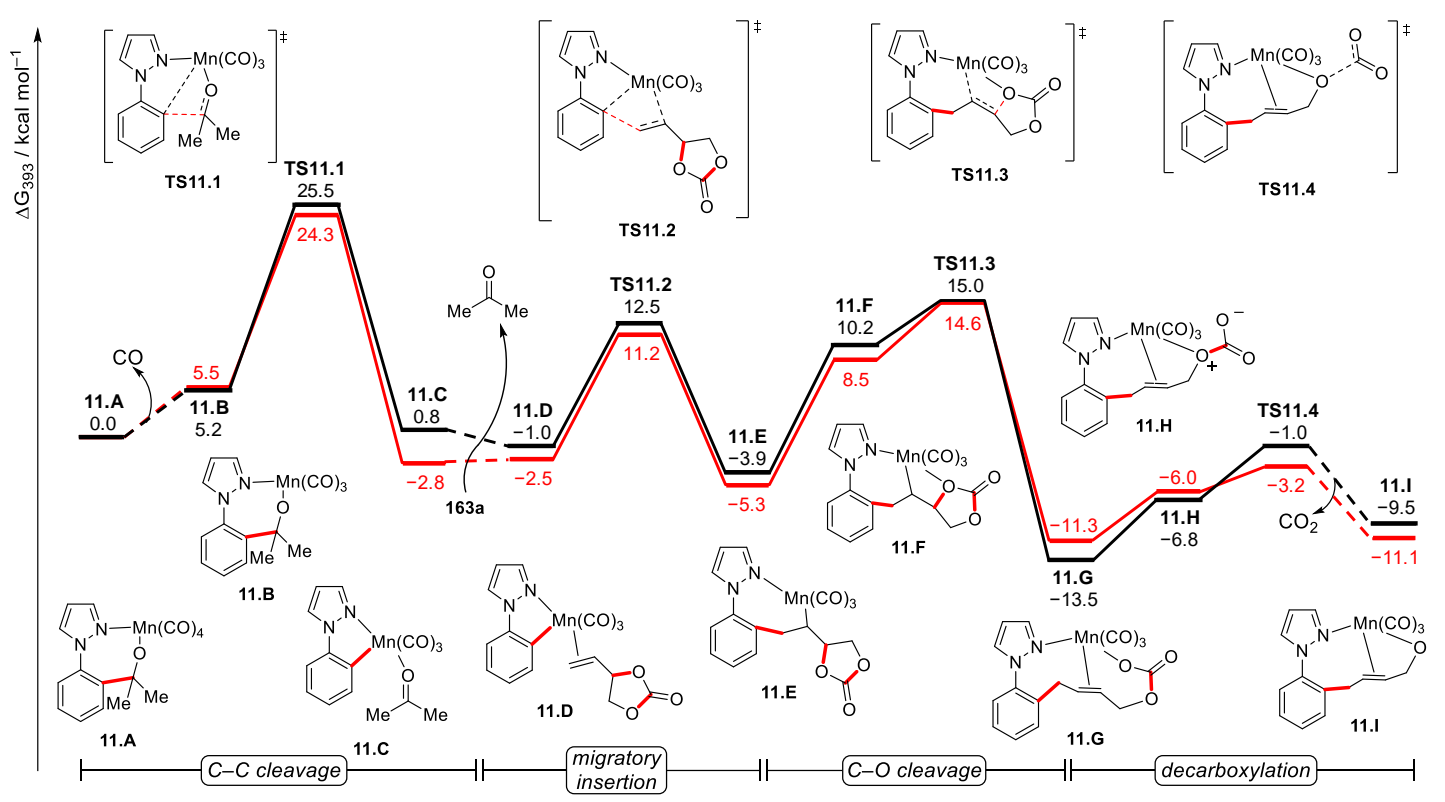

Figure 63: Relative Gibbs free energy profile for the reaction of 142a with vinyldioxolanone 163a without solvent model in the optimization in water (black line) and DCE (red).

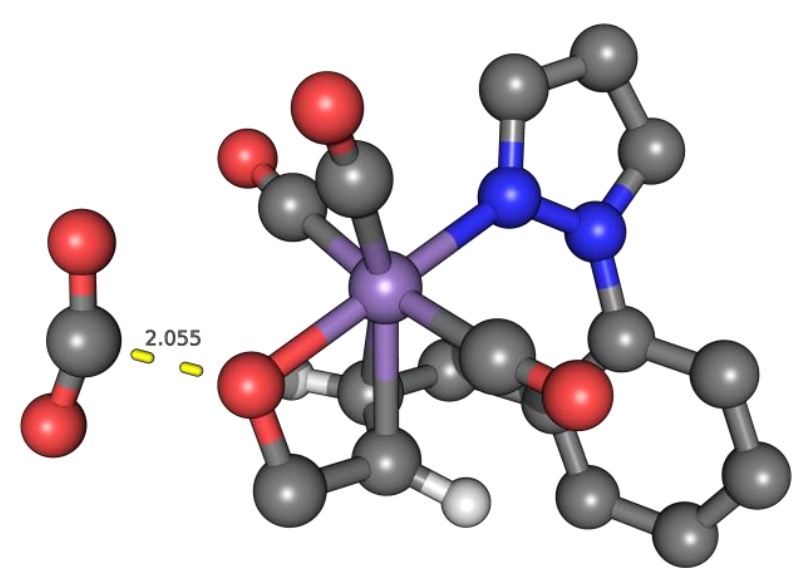

Figure 64: Structure of decarboxylation transition state TS11.4. Distances are given in Å and nonparticipating hydrogen atoms are omitted for clarity. 


\section{Summary and Outlook}

$\mathrm{C}-\mathrm{H}$ and $\mathrm{C}-\mathrm{C}$ activation chemistry holds enormous potential for the formation of $\mathrm{C}-\mathrm{C}$ and $\mathrm{C}-\mathrm{Het}$ bonds and the development of streamlined, sustainable syntheses of compounds of interest to inter alia pharmaceutical industry and material science. To further advance the field of $\mathrm{C}-\mathrm{H}$ and $\mathrm{C}-\mathrm{C}$ activation, a detailed understanding of the reaction mechanisms and the catalyst's properties is of prime importance. Therefore, a variety of transformations with different ruthenium- and manganese-based catalytic systems was investigated within this thesis.

In the first part of this thesis, a ruthenium-catalyzed meta-C-H bromination approach was applied to purines $\mathbf{1 4 8}$ for the introduction of a fluorescent pyrene motif in high yield via a subsequent Sonogashira-Hagihara reaction, thereby showcasing the potential of the established protocol for the diversification of biologically relevant structural motifs (Scheme 91). ${ }^{[117]}$ Furthermore, kinetic studies revealed a first order dependence on the catalyst concentration within a turn-over limiting $\mathrm{C}-\mathrm{H}$ activation regime.

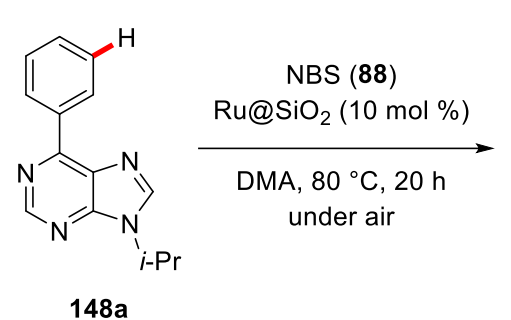

$148 a$

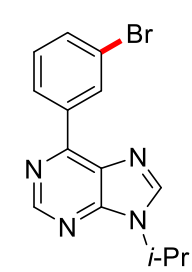

$149 \mathrm{a}$

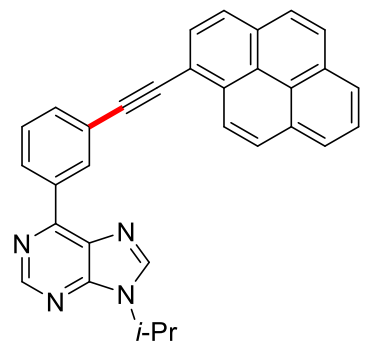

150b: $62 \%$ over two steps

Scheme 91: Fluorescent tag labelling of purines via meta-C-H bromination.

In additional studies, the developed approach could be expanded to other bioactive substrates and the installed bromine-substituent should prove invaluable as a synthetic handle for a multitude of further diversifications.

Secondly, ruthenium-catalyzed remote meta-C-H alkylations of versatile ketimines 151 with secondary and tertiary alkyl halides $\mathbf{1 0 0}$ were developed. The established method featured a broad substrate scope and high functional group tolerance including valuable heterocycles and a structurally complex cholesterol motif. In addition, this novel transformation gave rise to an unprecedented one-pot two-fold meta/ortho-C-H activation protocol for the synthesis of densely 
substituted arenes 166 in a user-friendly, operationally simple fashion (Scheme 92). ${ }^{[121]}$ Detailed mechanistic investigations provided strong support for a radical pathway and a first order rate dependence with respect to the concentration of catalyst as well as ketimine, which is consistent with results obtained for phenylpyridines as substrates.

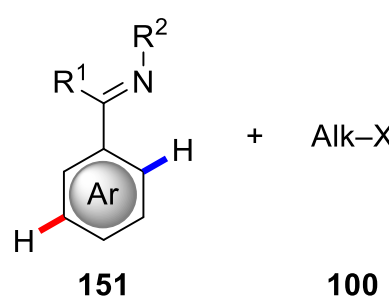

1) $\left[\mathrm{RuCl}_{2}(p \text {-cymene })\right]_{2}(5.0 \mathrm{~mol} \%)$

$\mathrm{AdCO}_{2} \mathrm{H}(\mathbf{1 7})(30 \mathrm{~mol} \%)$

$\mathrm{K}_{2} \mathrm{CO}_{3}$

$\mathrm{PhCMe}_{3}, 120^{\circ} \mathrm{C}, 20 \mathrm{~h}$

2) $R^{3}-X$

$120^{\circ} \mathrm{C}, 20 \mathrm{~h}$

then $\mathrm{H}_{3} \mathrm{O}^{+}$

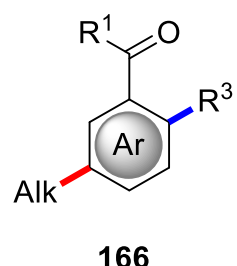

Scheme 92: One-pot meta/ortho-C-H activation of ketimines 151.

Through a combination of the ketimine-directed meta- $\mathrm{C}-\mathrm{H}$ alkylation protocol and a photochemical alkyl radical generation, a significant reduction of the reaction temperature can possibly be achieved, thereby allowing for the extension of the developed protocol towards other sensitive functional groups.

In a related project, Fukui indices were calculated to predict the preferred position of electrophilic and radical attacks on cyclometalated complexes of aryloxazolines and phenylpurines. ${ }^{[124,129]} \mathrm{High}$ meta/para-selectivities were predicted for a radical addition onto ruthenium(III) complexes, which is in good agreement with the experimentally observed exclusive formation of metafunctionalized products and additional EPR studies (Figure 65). Although the calculations suggested the formation of an arene-ligand-free complex, knowledge of the exact coordination environment is still underdeveloped, and requires additional investigations through other computational methods.

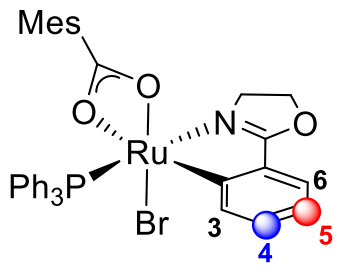

4.F

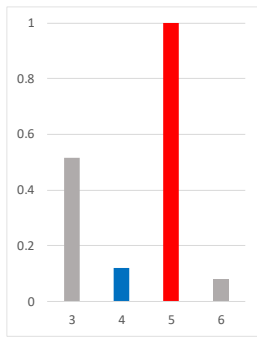

Figure 65: Fukui indices for radical addition onto ruthenium(III) species 4.F. 
In the fourth part of this thesis, the application of carboxylic acids as traceless directing groups in ruthenium-catalyzed domino $\mathrm{C}-\mathrm{H}$ alkenylation/decarboxylation reactions with alkynes $\mathbf{3 5}$ was investigated (Scheme 93). ${ }^{[132]}$ Extensive DFT studies revealed a turnover-limiting migratory insertion event and a subsequent facile decarboxylation process. Furthermore, the decarboxylation pathway was found to be preferred over a competing cyclization process. However, the energy difference was decreasing significantly with an increased polarity of the employed solvent. While a novel C-H alkylation/decarboxylation manifold with maleimides 177 occurred via a similar reaction mechanism as revealed by DFT calculations and in situ IR spectroscopic studies, a possible cyclization process was found to be energetically inaccessible.

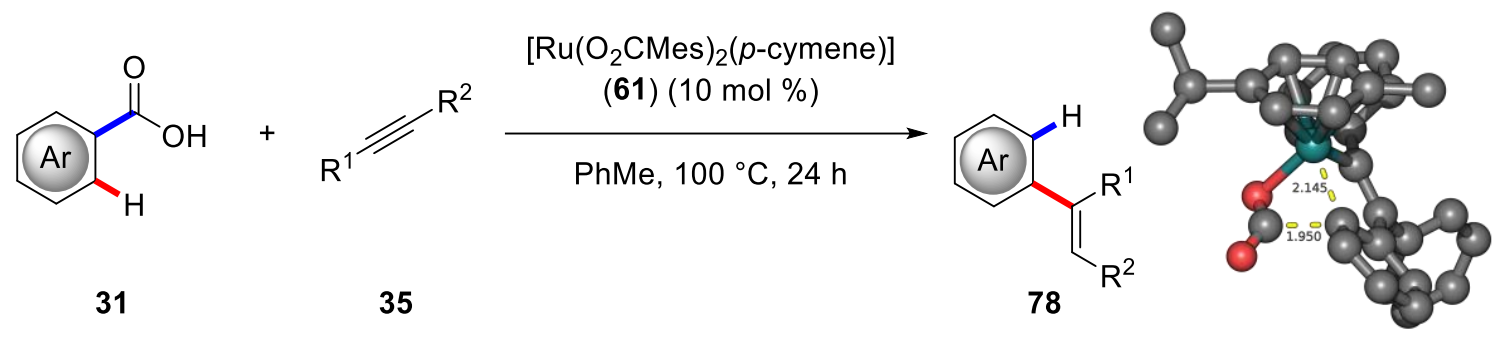

Scheme 93: Domino C-H alkenylation/decarboxylation under ruthenium catalysis.

The detailed mechanistic insights provided by this study could in the future lead to the identification of further viable substrates for decarboxylative $\mathrm{C}-\mathrm{H}$ activation reactions and to the application of this method in complex natural product synthesis. Importantly, these results could contribute to the development of unparalleled, highly desirable ruthenium-catalyzed carboxylation reactions, since these represent the microscopic reverse process with respect to decarboxylative transformations.

In addition, an unprecedented ruthenium-catalyzed oxidative $\mathrm{C}-\mathrm{H}$ alkenylation with weakly coordinating aryl acetamides $\mathbf{1 5 3}$ as substrates was explored. ${ }^{[141]}$ Detailed experimental and computational investigations provided strong support for a facile $\mathrm{C}-\mathrm{H}$ ruthenation event and the formation of an unusual six-membered ruthenacycle (Scheme 94). DFT studies indicated the migratory insertion into the $\mathrm{Ru}-\mathrm{C}$ bond to be the turnover-limiting step. Furthermore, a comparison with the $\mathrm{C}-\mathrm{H}$ ruthenation process of the corresponding benzamide analogue highlighted the challenging nature of the distal $\mathrm{C}-\mathrm{H}$ activation with aryl acetamides. 


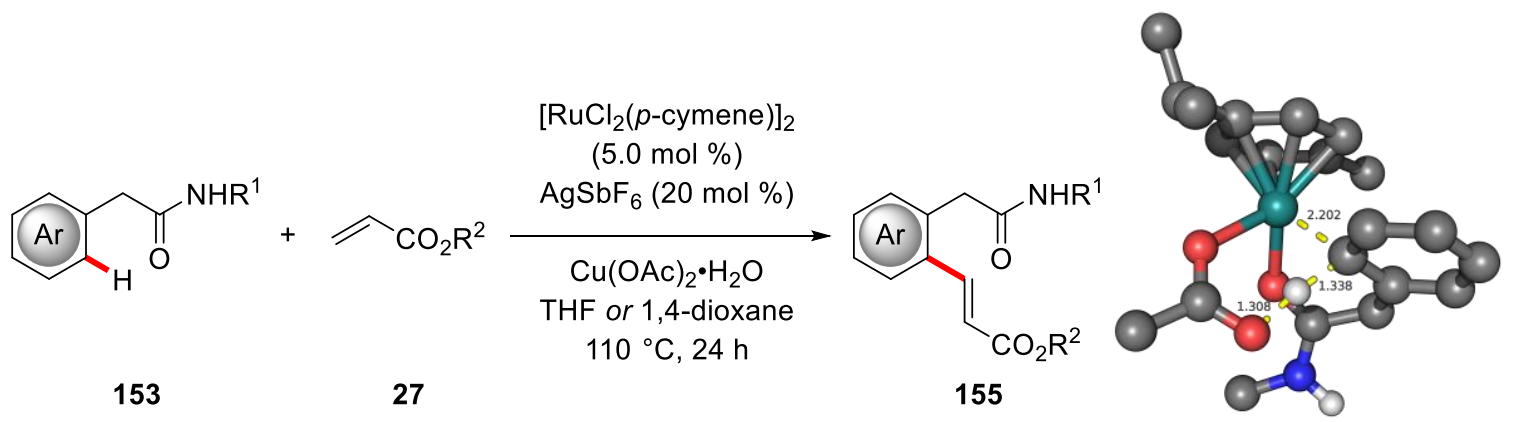

Scheme 94: Distal $\mathrm{C}-\mathrm{H}$ alkenylation of aryl acetamides 153 by weak $O$-coordination.

Since primary, secondary, and tertiary amides were viable substrates for the established $\mathrm{C}-\mathrm{H}$ alkenylation protocol, the application towards the diversification of aryl acetamide containing natural products and drugs might be worth investigating and could enable the sustainable synthesis of previously not easily accessible substitution patterns. In addition, the protocol could be extended towards various other weakly coordinating directing groups, such as esters or ketones.

The sixth project was focused on investigating fundamental differences in the chelation-assisted $\mathrm{C}-\mathrm{H}$ ruthenation of ferrocenes $\mathbf{1 5 6}$ bearing weakly coordinating ketone, thioketone or selenoketone directing groups (Scheme 95). ${ }^{[148]}$ In silico studies uncovered a considerable energy difference between the employed directing groups, with selenoketone-substituted ferrocene being thermodynamically preferred. While only small differences in destabilizing distortion energies were revealed within a distortion-interaction analysis, the stabilizing interaction energies showed larger deviations and unveiled the strongest interactions for thioketone-decorated ferrocene.
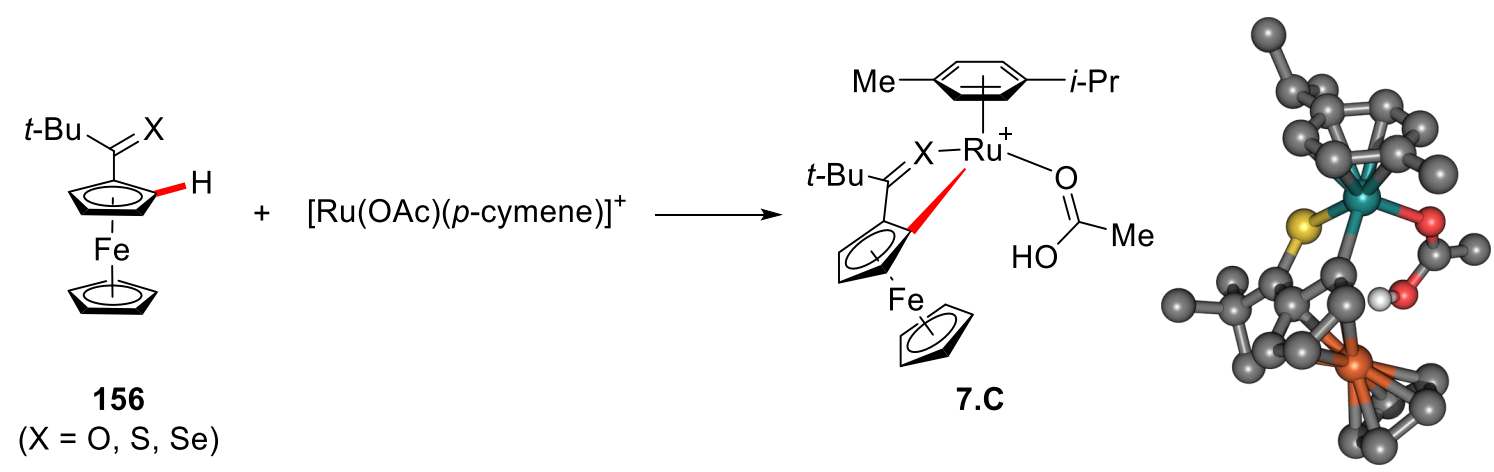

Scheme 95: Chelation-assisted C-H ruthenation of ferrocenes 156. 
By applying more sophisticated computational methods like DFT-SAPT ${ }^{[166]}$ or DLPNO coupled cluster, ${ }^{[167]}$ various energetic contributions could be further dissected and provide more insights into the different stabilizing and destabilizing effects. These further studies might prove useful for understanding the role of weak interactions in $\mathrm{C}-\mathrm{H}$ activation with ruthenium complexes, with possible extrapolations towards other transformations.

Furthermore, thorough DFT studies on ruthenium-catalyzed C-H alkylations of indoles $\mathbf{1 2 5}$ as a model substrate for tryptophan in a hydroarylation approach were conducted and revealed the reaction to occur through reversible chelation-assisted $\mathrm{C}-\mathrm{H}$ ruthenation, followed by migratory insertion and turnover-limiting proto-demetalation (Scheme 96). ${ }^{[156]}$ Additionally, a detailed evaluation of different $\eta^{6}$-coordinated arene-ligands was performed and indicated a destabilization by an increased steric demand and by a reduced $\pi$-electron density.

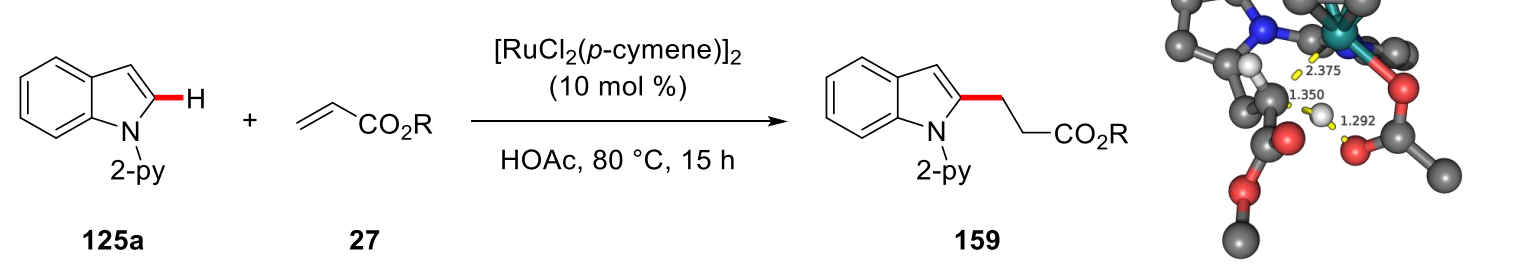

Scheme 96: Ruthenium catalysis for $\mathrm{C}-\mathrm{H}$ alkylation of indoles 125.

The comparison of different arene-ligands could contribute to the development of novel, highly active catalysts for these kind of transformations. Likewise, DFT studies for tryptophan or even small peptides instead of indole might prove highly rewarding, since these could unveil secondary interactions with the metal center, for example through interactions with the peptidic backbone. Extensive investigations of oxidative $\mathrm{C}-\mathrm{H} / \mathrm{C}-\mathrm{H}$ activations and direct $\mathrm{C}-\mathrm{H}$ arylations of phenylpyridines $\mathbf{4 5}$ under ruthenium catalysis uncovered the selectivity to be controlled by steric as well as electronic properties of both reagents (Scheme 97). ${ }^{[168]}$ The observation of a considerable decoordination of $p$-cymene from the ruthenium catalyst strongly suggested the formation of an arene-ligand-free catalytically active complex, and a kinetic analysis indicated, that both processes proceed through largely the same pathway. Unprecedented calculations provided strong support for the formation of a biscyclometalated ruthenium(II) intermediate by two-fold $\mathrm{C}-\mathrm{H}$ ruthenation. Afterwards, oxidative addition generates an energetically favorable 
ruthenium(IV) species, which then undergoes selectivity-determining reductive elimination. Notably, the preferred reductive elimination pathway, and thereby the preferentially formed product, was controlled by the nature of the aryl halide.
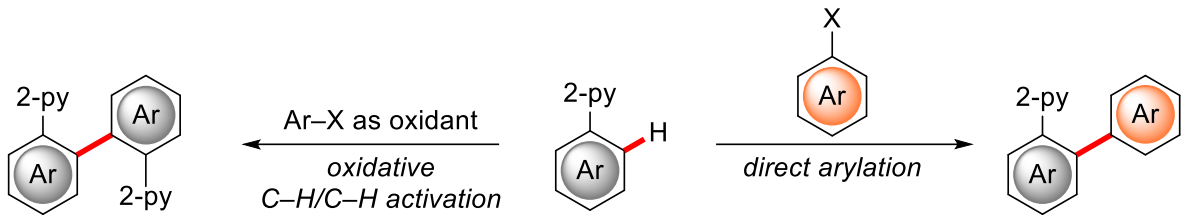

- steric and electronic control - detailed kinetic analysis and DFT studies - oxidation-induced reductive elimination - ruthenium(II/IV/II) catalytic cycle

Scheme 97: Oxidative $\mathrm{C}-\mathrm{H} / \mathrm{C}-\mathrm{H}$ activation and $\mathrm{C}-\mathrm{H}$ arylation of phenylpyridines 45.

In further studies, the viability of other substrates, such as aryloxazolines or ketimines, for oxidative $\mathrm{C}-\mathrm{H} / \mathrm{C}-\mathrm{H}$ arylations could be evaluated and should prove useful for the rapid construction of substituted, extended $\pi$-systems as ligands or functional materials. Since the current calculations were focused on the substitution pattern of the aryl halide, a subsequent investigation of the phenylpyridine substitution should be conducted to complement the mechanistic understanding. In this context, an analysis of the steric and electronic influences within a multivariate analysis ${ }^{[169]}$ might be worthwhile and could identify subtle, easily overlooked influences.

In the ninth project, the key steps of manganese-catalyzed $\mathrm{C}-\mathrm{H}$ allylations of pyridyl-substituted tryptophan 160 with MHB adducts 161 were explored by means of DFT calculations (Scheme 98). ${ }^{[162]}$ Within the computational studies, a facile migratory insertion event along with a turnoverlimiting C-O cleavage step was identified, thus delivering allylated compound $\mathbf{1 6 2 .}$

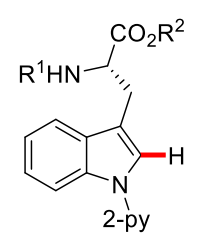

160<smiles>[R]C(OC)C(=O)OC(=O)OC</smiles>

161

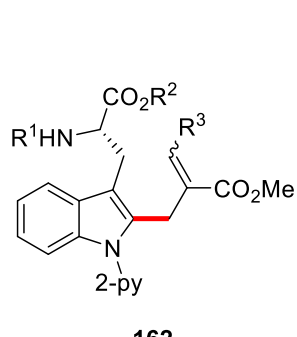

162

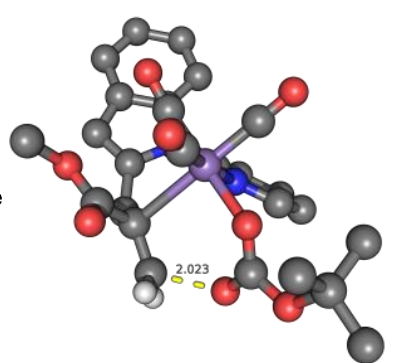

Scheme 98: Manganese-catalyzed C-H allylation of tryptophan 160. 
As already stated above, additional computational studies with the untruncated tryptophan instead of pyridylindole as a simplified model might reveal selectivity- or reactivity-influencing interactions between the metal catalyst and functional groups of the peptide side chains or backbone.

Within the last part of this thesis, a detailed investigation of unprecedented manganese-catalyzed C-C allylations with benzylic alcohols 142 was presented (Scheme 99). ${ }^{[164]}$ Computational studies on the catalyst's mode of action indicated the reaction to proceed via turnover-limiting $\mathrm{C}-\mathrm{C}$ cleavage, followed by migratory insertion into the $\mathrm{Mn}-\mathrm{C}$ bond. Thereafter, ring-opening by $\mathrm{C}-\mathrm{O}$ bond scission takes place and facile decarboxylation occurs. An examination of various spin states showed the reaction to proceed mainly on the singlet, low-spin energy surface. During the $\mathrm{C}-\mathrm{O}$ cleavage and decarboxylation step indications for a possible singlet-quintet, meaning low-spin to high-spin, spin crossover could be observed.

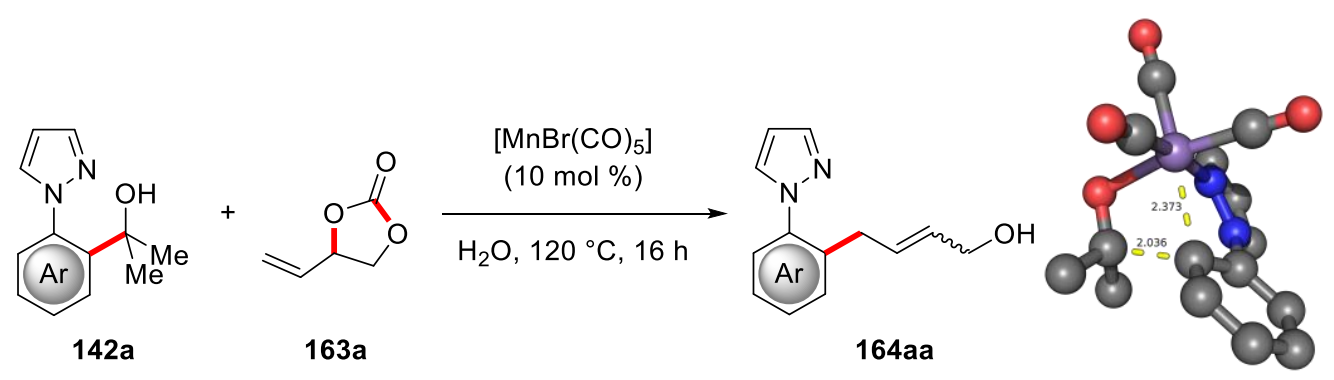

Scheme 99: Manganese catalysis for $C-C$ allylation of benzylic alcohols 142.

The obtained mechanistic insights should prove invaluable for the further development of novel $\mathrm{C}-\mathrm{C}$ activation reactions under manganese catalysis, which could enable transformations complementary to $\mathrm{C}-\mathrm{H}$ activation methods. Furthermore, a comparison between the energy profiles of $\mathrm{C}-\mathrm{C}$ activation and the corresponding $\mathrm{C}-\mathrm{H}$ activation pathways could point towards fundamental mechanistic differences, thereby allowing for rational advancements in catalyst design and the choice of systems worth exploring. 


\section{Experimental Part}

\subsection{General Remarks}

Reactions involving air- or moisture-sensitive compounds were conducted under an atmosphere of nitrogen using pre-dried glassware and standard Schlenk- or glovebox-techniques. If not otherwise noted, yields refer to isolated compounds, estimated to be $>95 \%$ pure by GC and NMR.

\section{Vacuum}

A pressure of approx. $5 \cdot 10^{-1}$ mbar was measured on the employed rotary vane pump Vacuubrand RD4.

\section{Melting points}

Melting points were measured on a Stuart Melting Point Apparatus SMP3 from Barloworld Scientific. All values are uncorrected.

\section{Liquid Chromatography}

Analytical thin layer chromatography (TLC) was performed on TLC Silica gel $60 F_{254}$ from Merck with detection at $254 \mathrm{~nm}$ or $360 \mathrm{~nm}$. Preparative chromatographic separations were carried out on Merck Geduran SI 60 (40-63 $\mu \mathrm{m}, 70-230$ mesh ASTM) silica gel.

\section{High Performance Liquid Chromatography}

Analytical high performance liquid chromatography (HPLC) was performed on an Agilent $1260 / 1290$ Infinity system equipped with a Daicel IC-3 column $(4.6 \mathrm{~mm} \times 250 \mathrm{~mm}$, $3 \mu \mathrm{m}$ particle size). Preparative HPLC purifications were performed on an Agilent 1260 Infinity system equipped with a Daicel IC-3 column ( $20 \mathrm{~mm} \times 250 \mathrm{~mm}, 5 \mu \mathrm{m}$ particle size).

\section{Gas Chromatography}

Gas chromatographic analysis (GC) was performed on an Agilent 7890A GC System or Agilent 7890B GC System equipped with an Agilent HP-5 column ( $30 \mathrm{~m}, 0.320 \mathrm{~mm}$ diameter, $0.25 \mu \mathrm{m}$ film thickness) and a flame-ionization detector (FID) using hydrogen as the carrier gas. Gas 
chromatography coupled with mass spectrometry (GC-MS) was performed on the same instrument equipped with an Agilent HP-5MS column $(30 \mathrm{~m}, 0.250 \mathrm{~mm}$ diameter, $0.25 \mu \mathrm{m}$ film thickness) and an Agilent 5875C Triple-Axis-Detector or an Agilent 5977B MSD. Mass spectra were obtained with electron-ionization (EI) at $70 \mathrm{eV}$ in positive ion mode.

\section{Gel Permeation Chromatography}

Gel permeation chromatography (GPC) was performed on a Japan Analytical Industries (JAI) LC92XX II NEXT system equipped with a JAIGEL 2.5HR or JAIGEL 2HH column. Chloroform was used as the solvent.

\section{Infrared Spectroscopy}

Infrared (IR) spectra of were measured on a Bruker Alpha-P FT-IR spectrometer with a diamond ATR probe in the range of $4000-400 \mathrm{~cm}^{-1}$. In situ IR measurements were performed with a Mettler-Toledo ReactIR 15 spectrometer equipped with a diamond ATR probe and an MCT detector. Spectra were acquired using Mettler-Toledo iC IR software version 7.0.297 in the range of $650-2200 \mathrm{~cm}^{-1}$ with a $4 \mathrm{~cm}^{-1}$ resolution. A Pearson's Correction was used as baseline correction in all measurements.

\section{Nuclear Magnetic Resonance Spectroscopy}

Nuclear magnetic resonance (NMR) spectra were recorded on Varian Mercury Plus 300, Inova 500, Inova 600 or Bruker Avance III 300, Avance III HD 300, Avance III 400, Avance III HD 400, Avance Neo 400, Avance III HD 500 spectrometer. Unless stated otherwise, all measurements were performed at $298 \mathrm{~K}$. Chemical shifts $(\delta)$ are reported relative to tetramethylsilane and are referenced using the residual proton or carbon solvent signal. ${ }^{19} \mathrm{~F}$ spectra were referenced using $\mathrm{CFCl}_{3}$ as external standard.

\begin{tabular}{c|c|c} 
Solvent & ${ }^{1} \mathrm{H}$ & ${ }^{13} \mathrm{C}$ \\
\hline $\mathrm{CDCl}_{3}{ }^{[170]}$ & $7.26 \mathrm{ppm}$ & $77.16 \mathrm{ppm}$ \\
\hline PhMe- $d_{8}{ }^{[171]}$ & $7.09,7.00,6.98,2.09 \mathrm{ppm}$ & $\begin{array}{c}137.86,129.24,128.33, \\
125.49,20.40 \mathrm{ppm}\end{array}$ \\
\hline $\mathrm{DMF}-d_{7}{ }^{[171]}$ & $8.03,2.92,2.75 \mathrm{ppm}$ & $161.15,34.89,29.76 \mathrm{ppm}$
\end{tabular}


The observed multiplicities are reported as follows: s (singlet), d (doublet), t (triplet), q (quartet), $\mathrm{m}$ (multiplet) or combinations thereof. A subscript of br indicates a broad signal. The coupling constants $J$ are given in Hertz $(\mathrm{Hz})$. All spectra were analyzed using Mestrelab Research MestReNova version 10.0.2 software.

\section{Mass Spectrometry}

Electron-ionization (EI) mass spectra were recorded on a Jeol AccuTOF instrument at $70 \mathrm{eV}$. Electrospray-ionization (ESI) mass spectra were obtained on Bruker micrOTOF and maXis instruments. All systems are equipped with time-of-flight (TOF) analyzers. The ratios of mass to charge $(m / z)$ are reported and the intensity relative to the base peak $(I=100)$ is given in parenthesis.

\section{Fluorescence Spectroscopy}

Fluorescence spectra were recorded on a Jasco FP-8500 spectrometer as $10^{-5} \mathrm{M}(\mathbf{4 5 k}, \mathbf{1 8 1})$ or $10^{-6} \mathrm{M}(\mathbf{1 5 0})$ solutions in DMSO and excitation wavelengths were selected according to the strongest signal.

\section{Optical Rotation}

Optical rotation measurements were performed on a Jasco P-2000 polarimeter at $589 \mathrm{~nm}$ in chloroform.

\section{Data Analysis and Plots}

Analysis of data was performed using OriginLab OriginPro 8.5G software, which was also employed for linear and non-linear fitting. Histograms were created with Microsoft Excel 2016.

\section{Solvents}

All solvents used for work-up and purification were distilled prior to use. Solvents used in reactions involving air- or moisture-sensitive compounds were dried and stored under an inert atmosphere of nitrogen or argon according to the following standard procedures: 
Acetonitrile was dried over $3 \AA$ molecular sieves and degassed using multiple cycles of freezepump-thaw.

tert-Butylbenzene and toluene- $d_{8}$ were dried over $4 \AA$ molecular sieves and degassed using multiple cycles of freeze-pump-thaw.

$\mathrm{N}, \mathrm{N}$-Dimethylacetamide, $\mathrm{N}, \mathrm{N}$-dimethylformamide, $\mathrm{N}$-methyl-2-pyrrolidone, dimethylsulfoxide and triethylamine were dried over $\mathrm{CaH}_{2}$ and distilled under an atmosphere of $\mathrm{N}_{2}$.

Toluene and 1,4-dioxane were dried over $\mathrm{Na}$ and distilled under an atmosphere of $\mathrm{N}_{2}$.

Water was ultra-sonicated for $4 \mathrm{~h}$ under an atmosphere of $\mathrm{N}_{2}$.

\section{Reagents}

Reagents obtained from commercial sources were used without further purification unless stated otherwise. $\mathrm{K}_{2} \mathrm{CO}_{3}$ was dried at $120^{\circ} \mathrm{C}$ and $10^{-2} \mathrm{mbar}$ for $6 \mathrm{~h}$ and stored under an atmosphere of $\mathrm{N}_{2}$. The following compounds were synthesized according to previously reported procedures:

Purines $148,{ }^{[172]}$ 2-phenylpyridines $45 d, \mathbf{i}-1, n,{ }^{[173]}$ 2-(fluorophenyl)pyridine (45e) ${ }^{[174]}$ 1-bromo-1methylcyclohexane $(\mathbf{1 0 0 c}))^{[175]}$ ketimines $11^{,[176]}\left[\mathrm{Ru}\left(\mathrm{O}_{2} \mathrm{CAd}\right)_{2}(p\right.$-cymene $\left.)\right](167),{ }^{[33]}$ and $\left[\mathrm{Ru}(\mathrm{NCMe})_{6}\right]\left[\mathrm{BF}_{4}\right]_{2}{ }^{[177]}$

The following compounds were kindly provided by the following people:

- $\quad\left[\mathrm{Ru}\left(\mathrm{O}_{2} \mathrm{CMes}\right)_{2}(p\right.$-cymene) $)(61),\left[\mathrm{RuCl}_{2}(p \text {-cymene })\right]_{2}$ : courtesy of $K$. Rauch

- 2-(3-tert-Butylphenyl)pyridine (45g): courtesy of J. Koeller

- 2-Aryl pyridine $45 \mathrm{~m},\left[\mathrm{Ru}\left(\kappa^{2}-\mathrm{PhPy}\right)\left(\mathrm{NCMe}_{4}\right]\left[\mathrm{PF}_{6}\right]\right.$ : courtesy of $K$. Korvorapun

\subsection{General Procedures}

\subsubsection{General Procedure A: Ruthenium-Catalyzed meta-Alkylation of Ketimines 151}

Under an atmosphere of $\mathrm{N}_{2}$, a Schlenk-tube was charged with ketimine $151(0.50 \mathrm{mmol}$, 1.00 equiv), [ $\mathrm{RuCl}_{2}(p \text {-cymene) }]_{2}(15.3 \mathrm{mg}, 25 \mu \mathrm{mol}, 5.0 \mathrm{~mol} \%), \mathrm{AdCO}_{2} \mathrm{H}$ (17) (27.3 mg, $0.15 \mathrm{mmol}$, $30 \mathrm{~mol} \%$ ) and $\mathrm{K}_{2} \mathrm{CO}_{3}(138 \mathrm{mg}, 1.00 \mathrm{mmol}, 2.00$ equiv). Alkyl bromide 100 ( $1.50 \mathrm{mmol}, 3.00$ equiv) and $\mathrm{PhCMe}_{3}(2.0 \mathrm{~mL})$ were added and the mixture was stirred at $120^{\circ} \mathrm{C}$ for $20 \mathrm{~h}$. After cooling to ambient temperature, aq. $\mathrm{HCl}(2 \mathrm{~N}, 3.0 \mathrm{~mL})$ was added, the mixture was stirred at ambient 
temperature for $3 \mathrm{~h}$, extracted with EtOAc $(3 \times 20 \mathrm{~mL})$, dried over $\mathrm{Na}_{2} \mathrm{SO}_{4}$ and concentrated in vacuo. Purification of the residue by column chromatography on silica gel yielded phenone 165 .

\subsubsection{General Procedure B: Ruthenium-Catalyzed Oxidative $\mathrm{C}-\mathrm{H} / \mathrm{C}-\mathrm{H}$ Activation}

Under an atmosphere of $\mathrm{N}_{2}$, a Schlenk-tube was charged with 2-phenylpyridine $45(0.50 \mathrm{mmol}$, 1.00 equiv), $\left[\mathrm{RuCl}_{2}(p \text {-cymene) }]_{2}(7.7 \mathrm{mg}, 13 \mu \mathrm{mol}, 2.5 \mathrm{~mol} \%), \mathrm{MesCO}_{2} \mathrm{H}\right.$ (58) (24.6 mg, $0.15 \mathrm{mmol}$, $30 \mathrm{~mol} \%$ ) and $\mathrm{K}_{2} \mathrm{CO}_{3}(138 \mathrm{mg}, 1.00 \mathrm{mmol}, 2.00$ equiv). Aryl bromide 46 ( $0.75 \mathrm{mmol}, 1.50$ equiv) and PhMe $(2.0 \mathrm{~mL})$ were added and the mixture was stirred at $120^{\circ} \mathrm{C}$ for $20 \mathrm{~h}$. After cooling to ambient temperature, $\mathrm{H}_{2} \mathrm{O}(25 \mathrm{~mL})$ was added, the mixture was extracted with $\mathrm{Et}_{2} \mathrm{O}(3 \times 25 \mathrm{~mL})$, washed with brine $(25 \mathrm{~mL})$, dried over $\mathrm{Na}_{2} \mathrm{SO}_{4}$ and concentrated in vacuo. Purification of the residue by column chromatography on silica gel yielded products 47 and 181 .

\subsection{Experimental Procedures and Analytical Data}

\subsubsection{Ruthenium-Catalyzed meta-Selective $\mathrm{C}-\mathrm{H}$ Bromination}

\subsubsection{Synthesis of Fluorescent-Labelled Compounds}

9-isoPropyl-6-[3-(phenylethynyl)phenyl]-9H-purine (150a)

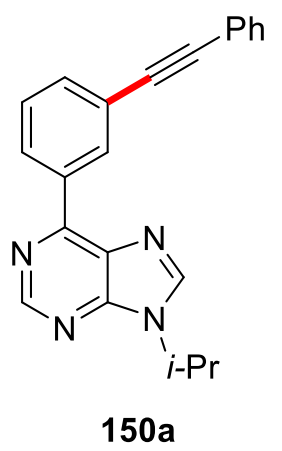

Under an atmosphere of $\mathrm{N}_{2}, 6$-(3-Bromophenyl)-9-isopropyl-9H-purine (149a) (32 mg, $0.10 \mathrm{mmol}$, 1.0 equiv.), ethynylbenzene (123a) (15 mg, $0.15 \mathrm{mmol}, 1.5$ equiv), $\left[\mathrm{Pd}\left(\mathrm{PPh}_{3}\right)_{2} \mathrm{Cl}_{2}\right]$ (3.5 mg, $5.0 \mu \mathrm{mol}, 5.0 \mathrm{~mol} \%)$, Cul ( $1.0 \mathrm{mg}, 5.0 \mu \mathrm{mol}, 5.0 \mathrm{~mol} \%$ ) and $\mathrm{NEt}_{3}(40 \mathrm{mg}, 0.40 \mathrm{mmol}, 4.0$ equiv) were dissolved in DMF $(0.5 \mathrm{~mL})$ and stirred at $70^{\circ} \mathrm{C}$ for $20 \mathrm{~h}$. After cooling to ambient temperature, $\mathrm{H}_{2} \mathrm{O}(10 \mathrm{~mL})$ was added, the mixture extracted with EtOAc $(3 \times 15 \mathrm{~mL})$, dried over $\mathrm{Na}_{2} \mathrm{SO}_{4}$ and concentrated in vacuo. Purification of the residue by column chromatography on silica gel ( $n$-hexane/EtOAc 3:1) yielded 150a (31 mg, 92\%) as a brown solid. 
${ }^{1} \mathrm{H}-\mathrm{NMR}\left(400 \mathrm{MHz}, \mathrm{CDCl}_{3}\right): \delta=9.04(\mathrm{~s}, 1 \mathrm{H}), 8.96(\mathrm{dd}, J=1.6,1.6 \mathrm{~Hz}, 1 \mathrm{H}$ ), 8.82 (ddd, $J=7.9,1.6$, $1.6 \mathrm{~Hz}, 1 \mathrm{H}), 8.21(\mathrm{~s}, 1 \mathrm{H}), 7.69$ (ddd, $J=7.7,1.6,1.6 \mathrm{~Hz}, 1 \mathrm{H}), 7.59-7.53(\mathrm{~m}, 3 \mathrm{H}), 7.39-7.32(\mathrm{~m}, 3 \mathrm{H})$, 5.00 (hept, $J=6.9 \mathrm{~Hz}, 1 \mathrm{H}), 1.69(\mathrm{~d}, J=6.9 \mathrm{~Hz}, 6 \mathrm{H}) .{ }^{13} \mathrm{C}-\mathrm{NMR}\left(100 \mathrm{MHz}, \mathrm{CDCl}_{3}\right): \delta=153.9\left(\mathrm{C}_{\mathrm{q}}\right), 152.4$ $\left(\mathrm{C}_{\mathrm{q}}\right), 152.2(\mathrm{CH}), 142.3(\mathrm{CH}), 136.2\left(\mathrm{C}_{\mathrm{q}}\right), 133.9(\mathrm{CH}), 132.8(\mathrm{CH}), 131.8(\mathrm{CH}), 131.7\left(\mathrm{C}_{\mathrm{q}}\right), 129.9(\mathrm{CH})$, $128.8(\mathrm{CH}), 128.5(\mathrm{CH}), 128.4(\mathrm{CH}), 124.0\left(\mathrm{C}_{\mathrm{q}}\right), 123.4\left(\mathrm{C}_{\mathrm{q}}\right), 89.9\left(\mathrm{C}_{\mathrm{q}}\right), 89.4\left(\mathrm{C}_{\mathrm{q}}\right), 47.5(\mathrm{CH}), 22.7\left(\mathrm{CH}_{3}\right)$. IR (ATR): $\tilde{v}=1566,1440,1324,1226,789,755,689,675,643,586 \mathrm{~cm}^{-1}$. m.p.: $119^{\circ} \mathrm{C}$. MS (ESI) m/z (relative intensity): $339(100)[\mathrm{M}+\mathrm{H}]^{+}, 361(50)[\mathrm{M}+\mathrm{Na}]^{+}, 699(40)[2 \mathrm{M}+\mathrm{Na}]^{+}$. HR-MS (ESI): $\mathrm{m} / z$ calcd for $\mathrm{C}_{22} \mathrm{H}_{19} \mathrm{~N}_{4}{ }^{+}[\mathrm{M}+\mathrm{H}]^{+}$339.1604, found 339.1605.

\section{9-isoPropyl-6-[3-(1-pyrenylethynyl)phenyl]-9H-purine (150b)}

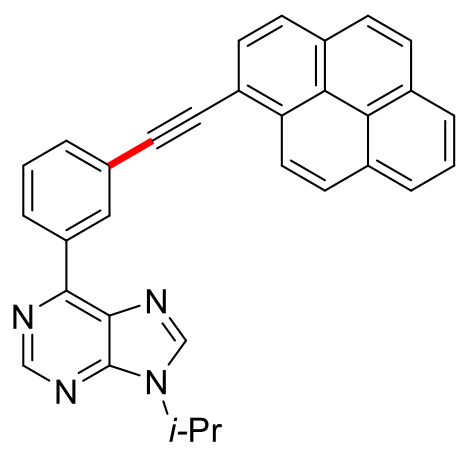

$150 \mathrm{~b}$

Under an atmosphere of $\mathrm{N}_{2}$, 6-(3-Bromophenyl)-9-isopropyl-9H-purine (149b) (32 mg, $0.10 \mathrm{mmol}$, 1.0 equiv.), 1-ethynylpyrene (123b) (34 mg, $0.15 \mathrm{mmol}, 1.5$ equiv), $\left[\mathrm{Pd}\left(\mathrm{PPh}_{3}\right)_{2} \mathrm{Cl}_{2}\right]$ (3.5 mg, $5.0 \mu \mathrm{mol}, 5.0 \mathrm{~mol} \%)$, Cul (1.0 mg, $5.0 \mu \mathrm{mol}, 5.0 \mathrm{~mol} \%$ ) and $\mathrm{NEt}_{3}(40 \mathrm{mg}, 0.40 \mathrm{mmol}, 4.0$ equiv) were dissolved in DMF $(0.5 \mathrm{~mL})$ and stirred at $70^{\circ} \mathrm{C}$ for $20 \mathrm{~h}$. After cooling to ambient temperature, $\mathrm{H}_{2} \mathrm{O}(10 \mathrm{~mL})$ was added, the mixture extracted with EtOAc $(4 \times 15 \mathrm{~mL})$, dried over $\mathrm{Na}_{2} \mathrm{SO}_{4}$ and concentrated in vacuo. Purification of the residue by column chromatography on silica gel ( $n$-hexane/EtOAc 3:1) yielded 150b (37 mg, 80\%) as a brown solid.

${ }^{1} \mathrm{H}-\mathrm{NMR}\left(400 \mathrm{MHz}, \mathrm{CDCl}_{3}\right): \delta=9.12(\mathrm{~d}, J=1.6 \mathrm{~Hz}, 1 \mathrm{H}), 9.09$ (s, $1 \mathrm{H}$ ), 8.90 (ddd, $J=7.9,1.8,1.2 \mathrm{~Hz}$, $1 \mathrm{H}), 8.74(\mathrm{~d}, J=9.1 \mathrm{~Hz}, 1 \mathrm{H}), 8.27-8.19(\mathrm{~m}, 5 \mathrm{H}), 8.15(\mathrm{~d}, J=8.0 \mathrm{~Hz}, 1 \mathrm{H}), 8.08(\mathrm{dd}, J=8.9,8.9 \mathrm{~Hz}$, $2 \mathrm{H}$ ), 8.03 (dd, $J=7.7,7.7 \mathrm{~Hz}, 1 \mathrm{H}$ ), 7.88 (ddd, $J=7.7,1.7,1.2 \mathrm{~Hz}, 1 \mathrm{H}$ ), 7.65 (ddd, $J=7.8,7.8,0.6 \mathrm{~Hz}$, $1 \mathrm{H}), 5.02$ (hept, $J=6.8 \mathrm{~Hz}, 1 \mathrm{H}), 1.70(\mathrm{~d}, J=6.8 \mathrm{~Hz}, 6 \mathrm{H}) .{ }^{13} \mathrm{C}-\mathrm{NMR}\left(100 \mathrm{MHz}, \mathrm{CDCl}_{3}\right): \delta=154.0\left(\mathrm{C}_{\mathrm{q}}\right)$, 152.4 $\left(\mathrm{C}_{\mathrm{q}}\right), 152.2(\mathrm{CH}), 142.4(\mathrm{CH}), 136.4\left(\mathrm{C}_{\mathrm{q}}\right), 134.1(\mathrm{CH}), 132.7(\mathrm{CH}), 132.1\left(\mathrm{C}_{\mathrm{q}}\right), 131.8\left(\mathrm{C}_{\mathrm{q}}\right), 131.4$ $\left(\mathrm{C}_{\mathrm{q}}\right), 131.4\left(\mathrm{C}_{\mathrm{q}}\right), 131.3\left(\mathrm{C}_{\mathrm{q}}\right), 130.1(\mathrm{CH}), 129.9(\mathrm{CH}), 129.0(\mathrm{CH}), 128.5(\mathrm{CH}), 128.3(\mathrm{CH}), 127.4(\mathrm{CH})$, $126.4(\mathrm{CH}), 125.8(\mathrm{CH}), 125.8(\mathrm{CH}), 125.7(\mathrm{CH}), 124.7(\mathrm{CH}), 124.6\left(\mathrm{C}_{\mathrm{q}}\right), 124.5\left(\mathrm{C}_{\mathrm{q}}\right), 124.3\left(\mathrm{C}_{\mathrm{q}}\right), 118.0$ $\left(\mathrm{C}_{\mathrm{q}}\right), 96.1\left(\mathrm{C}_{\mathrm{q}}\right), 89.2\left(\mathrm{C}_{\mathrm{q}}\right), 47.5(\mathrm{CH}), 22.7\left(\mathrm{CH}_{3}\right) . \mathrm{IR}(\mathrm{ATR}): \tilde{v}=1562,1322,1211,842,824,798,713$, 
700, 680, $646 \mathrm{~cm}^{-1}$. m.p.: $192{ }^{\circ} \mathrm{C}$ (decomp.). MS (EI) m/z (relative intensity): 462 (100) [M] ${ }^{+}, 420$ (28), 210 (8). HR-MS (EI): $m / z$ calcd for $\mathrm{C}_{32} \mathrm{H}_{22} \mathrm{~N}_{4}{ }^{+}[\mathrm{M}]^{+} 462.1844$, found 462.1845.

\subsubsection{Mechanistic Studies}

\section{H/D Exchange Experiment}<smiles>CC(C)n1cnc2c(-c3ccccc3)ncnc21</smiles>

$148 a$

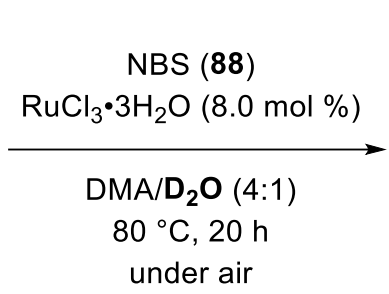

under air

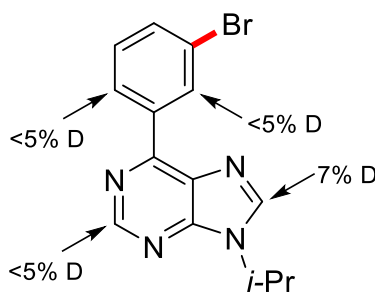

149a: $24 \%$

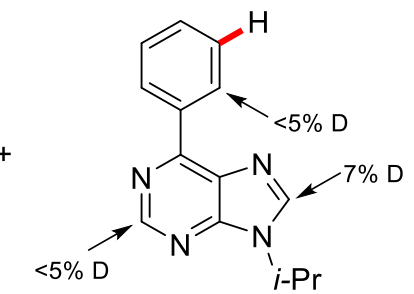

$[D]_{n}-148 a: 57 \%$

9-isoPropyl-6-phenyl-9H-purine (148a) $\quad(60 \mathrm{mg}, 0.25 \mathrm{mmol}, 1.0$ equiv), NBS (88) (89 mg, $0.50 \mathrm{mmol}, 2.0$ equiv) and $\mathrm{RuCl}_{3} \cdot 3 \mathrm{H}_{2} \mathrm{O}(5.2 \mathrm{mg}, 20 \mu \mathrm{mol}, 8.0 \mathrm{~mol} \%)$ were dissolved in a mixture of DMA $(0.4 \mathrm{~mL})$ and $\mathrm{D}_{2} \mathrm{O}(0.1 \mathrm{~mL})$ and stirred open to air at $80^{\circ} \mathrm{C}$ for $20 \mathrm{~h}$. After cooling to ambient temperature, aq. $\mathrm{HCl}(1 \mathrm{~N}, 2 \mathrm{~mL})$ and $\mathrm{CH}_{2} \mathrm{Cl}_{2}(0.5 \mathrm{~mL})$ were added. The mixture was stirred at ambient temperature for $30 \mathrm{~min}$ and afterwards sat. aq. $\mathrm{NaHCO}_{3}(10 \mathrm{~mL})$ was added. The mixture was extracted with $\mathrm{CH}_{2} \mathrm{Cl}_{2}(4 \times 10 \mathrm{~mL})$, dried over $\mathrm{Na}_{2} \mathrm{SO}_{4}$ and concentrated in vacuo. Purification of the residue by column chromatography on silica gel ( $n$-hexane/EtOAc 5:1 $\rightarrow 2: 1$ ) yielded 149a (19 mg, 24\%) as a colorless solid and $[D]_{n}-148$ a (34 mg, 57\%) was recovered. The deuterium incorporation was determined by ${ }^{1} \mathrm{H}-\mathrm{NMR}$. 


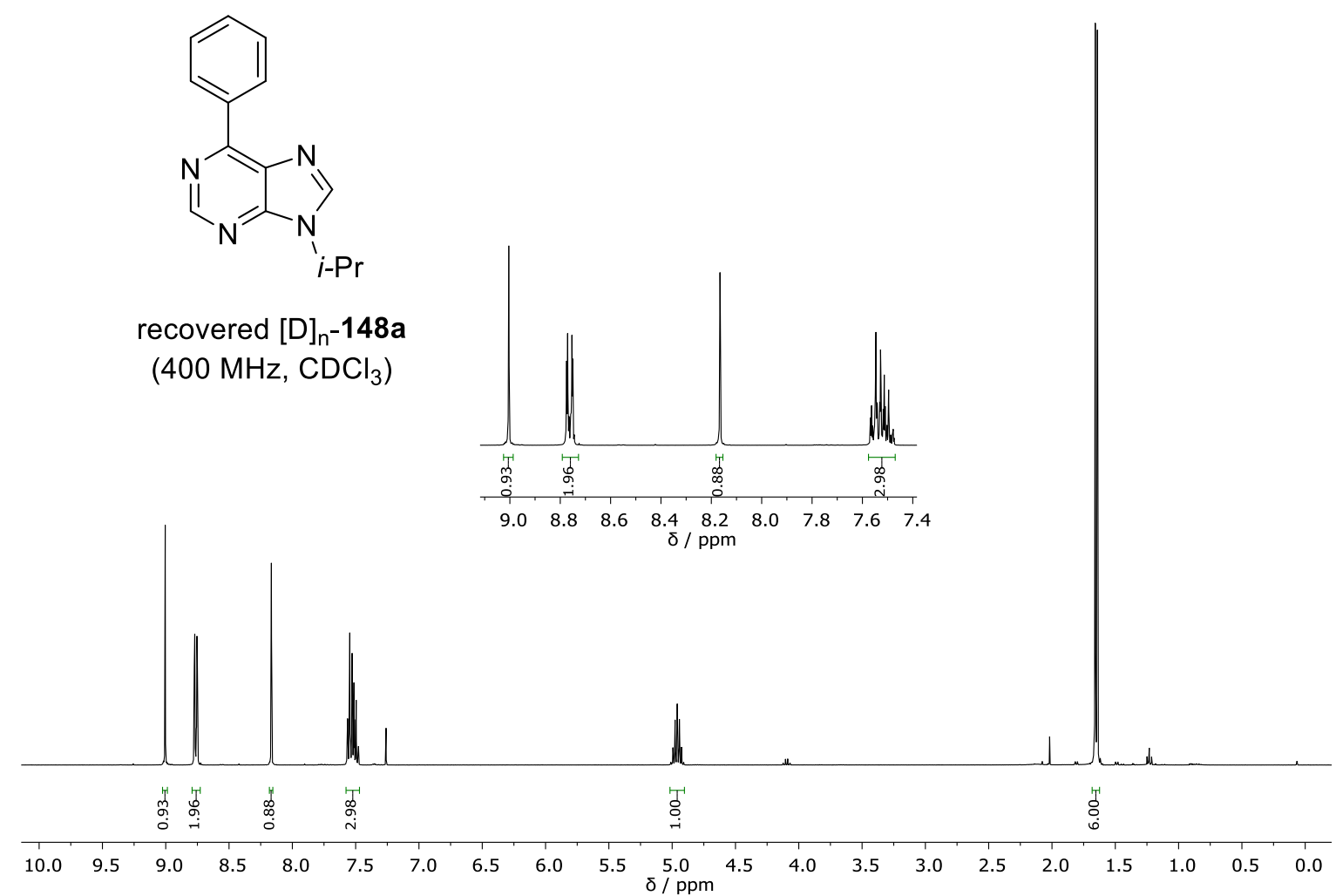<smiles>CCCn1cnc2c(-c3cccc(Br)c3)ncnc21</smiles>

$[D]_{n}-149 a$

(400 MHz, $\mathrm{CDCl}_{3}$ )

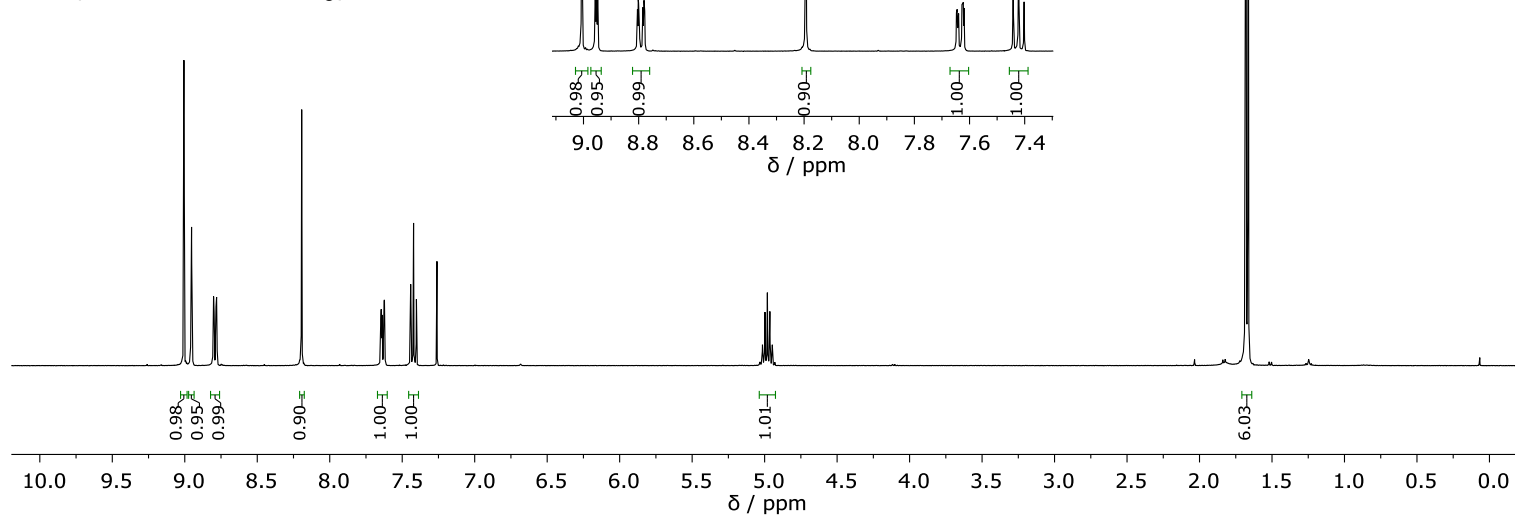




\subsubsection{Kinetic Analysis}

\section{Reaction Order with Respect to $\mathrm{RuCl}_{3}$}

The initial rate method was employed to determine the reaction order with respect to $\mathrm{RuCl}_{3} .{ }^{[178]}$ A mixture of purine 148a (179 mg, $0.75 \mathrm{mmol}, 1.00$ equiv), NBS (88) (267 mg, $1.50 \mathrm{mmol}$, 2.00 equiv), $\mathrm{RuCl}_{3} \cdot 3 \mathrm{H}_{2} \mathrm{O}(2.8,4.0,5.9,7.9,9.9,11.9 \mathrm{~mol} \%)$ and $n$-tridecane $(30 \mu \mathrm{L})$ was dissolved in DMA $(1.5 \mathrm{~mL})$ and stirred open to air at $81{ }^{\circ} \mathrm{C}$. During the first 60 min aliquots $(0.05 \mathrm{~mL})$ were removed via a syringe every $10 \mathrm{~min}$, diluted with EtOAc, filtered through a short plug of silica gel and $\mathrm{Na}_{2} \mathrm{SO}_{4}$ and analyzed by gas chromatography.

\begin{tabular}{cccc}
\hline amount $/ \mathrm{mol} \%$ & $\log \left(c / \mathrm{mol} \mathrm{L}^{-1}\right)$ & $\Delta[\mathbf{1 4 9 a}] \Delta t^{-1} / 10^{-8} \mathrm{~mol} \mathrm{~L}^{-1} \mathrm{~s}^{-1}$ & $\log \left(\Delta[149 \mathrm{a}] \Delta t^{-1} / \mathrm{mol} \mathrm{L}^{-1} \mathrm{~s}^{-1}\right)$ \\
\hline 2.8 & -1.854 & 1.625 & -7.789 \\
4.0 & -1.699 & 2.158 & -7.666 \\
5.9 & -1.523 & 3.117 & -7.506 \\
7.9 & -1.398 & 4.158 & -7.381 \\
9.9 & -1.310 & 4.442 & -7.352 \\
11.9 & -1.229 & 4.525 & -7.344 \\
\hline
\end{tabular}

\section{Reaction Order with Respect to Phenylpurine 148a}

The initial rate method was employed to determine the reaction order with respect to phenylpurine 148a ${ }^{[178]} \mathrm{A}$ mixture of phenylpurine $148 \mathrm{a}(0.45,0.56,0.60,0.75,0.94,1.13 \mathrm{mmol})$, NBS (88) $(267 \mathrm{mg}, 1.50 \mathrm{mmol}), \mathrm{RuCl}_{3} \cdot 3 \mathrm{H}_{2} \mathrm{O}(15.6 \mathrm{mg}, 60 \mu \mathrm{mol})$ and $n$-tridecane $(30 \mu \mathrm{L})$ was dissolved in DMA $(1.5 \mathrm{~mL})$ and stirred open to air at $81^{\circ} \mathrm{C}$. During the first $60 \mathrm{~min}$ aliquots $(0.05 \mathrm{~mL})$ were removed via a syringe every $10 \mathrm{~min}$, diluted with EtOAc, filtered through a short plug of silica gel and $\mathrm{Na}_{2} \mathrm{SO}_{4}$ and analyzed by gas chromatography.

\begin{tabular}{cccc}
\hline amount $/ \mathrm{mmol}$ & $\log \left(c / \mathrm{mol} \mathrm{L}^{-1}\right)$ & $\Delta[\mathbf{1 4 9 a}] \Delta t^{-1} / 10^{-8} \mathrm{~mol} \mathrm{~L}^{-1} \mathrm{~s}^{-1}$ & $\log \left(\Delta[\mathbf{1 4 9 a}] \Delta t^{-1} / \mathrm{mol} \mathrm{L}^{-1} \mathrm{~s}^{-1}\right)$ \\
\hline 0.45 & -0.523 & 7.700 & -7.114 \\
0.56 & -0.426 & $8.684^{[a]}$ & $-7.063^{[a]}$ \\
0.60 & -0.398 & 8.200 & -7.086 \\
0.75 & -0.301 & $7.813^{[a]}$ & $-7.126^{[a]}$ \\
0.94 & -0.204 & 8.367 & -7.077 \\
\hline
\end{tabular}




\begin{tabular}{llcc}
\hline 1.13 & -0.125 & 8.317 & -7.080 \\
\hline
\end{tabular}

[a] Average of two measurements.

\section{Reaction Order with Respect to 2-Phenylpyridine (45a)}

The initial rate method was employed to determine the reaction order with respect to 2phenylpyridine (45a). ${ }^{[178]} \mathrm{A}$ mixture of 2-phenylpyridine (45a) $(0.38,0.56,0.75,0.94,1.13 \mathrm{mmol})$, NBS (88) $(267 \mathrm{mg}, 1.50 \mathrm{mmol}), \mathrm{RuCl}_{3} \cdot 3 \mathrm{H}_{2} \mathrm{O}(15.6 \mathrm{mg}, 60 \mu \mathrm{mol})$ and $n$-tridecane $(30 \mu \mathrm{L})$ was dissolved in DMA $(1.5 \mathrm{~mL})$ and stirred open to air at $81^{\circ} \mathrm{C}$. During the first 60 min aliquots $(0.05 \mathrm{~mL})$ were removed via a syringe every $10 \mathrm{~min}$, diluted with EtOAc, filtered through a short plug of silica gel and $\mathrm{Na}_{2} \mathrm{SO}_{4}$ and analyzed by gas chromatography.

Each reaction was performed two times, the measured rates were averaged and the error corresponds to the standard deviation.

\begin{tabular}{ccccc}
\hline $\begin{array}{c}\text { amount } / \\
\mathrm{mmol}\end{array}$ & $\begin{array}{c}\log (\mathrm{c} / \\
\mathrm{mol} \mathrm{L}\end{array}$ & $\begin{array}{c}\Delta[\mathbf{1 1 6 a}] \Delta t^{-1} / \\
10^{-8} \mathrm{~mol} \mathrm{~L}^{-1} \mathrm{~s}^{-1}\end{array}$ & $\begin{array}{c}\log \left(\Delta[\mathbf{1 1 6 a}] \Delta t^{-1} /\right. \\
\left.\mathrm{mol} \mathrm{L}^{-1} \mathrm{~s}^{-1}\right)\end{array}$ & $\begin{array}{c}\Delta \log \left(\Delta[\mathbf{1 1 6 a}] \Delta t^{-1} /\right. \\
\left.\mathrm{mol} \mathrm{L}^{-1} \mathrm{~s}^{-1}\right)\end{array}$ \\
\hline 0.38 & -0.602 & 3.075 & -7.512 & 0.018 \\
0.56 & -0.426 & 3.167 & -7.500 & 0.034 \\
0.75 & -0.301 & 3.082 & -7.511 & 0.007 \\
0.94 & -0.204 & 3.226 & -7.492 & 0.037 \\
1.13 & -0.125 & 2.884 & -7.540 & 0.015 \\
\hline
\end{tabular}

\subsubsection{Ruthenium-Catalyzed meta-C-H Alkylation of Ketimines}

\subsubsection{Data for Alkylated Phenones 165}

\section{Cholesterol 4-acetyl-2-cycloheptylbenzoate (165aa)}

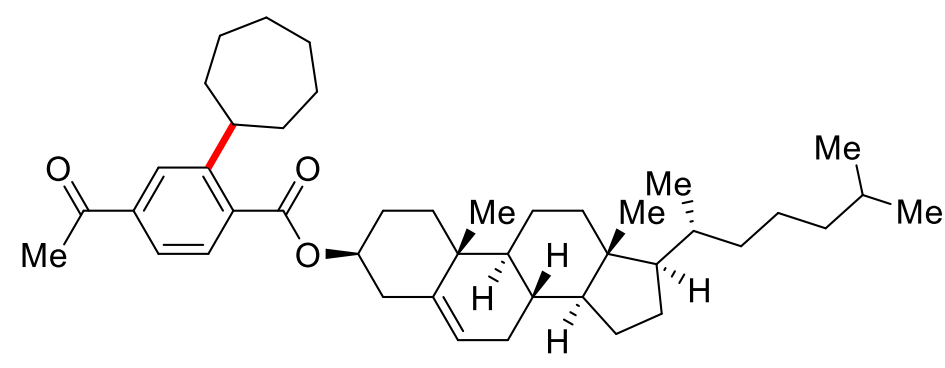

165aa 
General procedure A was followed using ketimine 151a $(175 \mathrm{mg}, 0.25 \mathrm{mmol})$ and cyclohexyl bromide (100a) (133 mg, $0.75 \mathrm{mmol}$ ). Purification by column chromatography on silica gel ( $n$ hexane/EtOAc 20:1) yielded phenone $165 \mathrm{aa}$ ( $89 \mathrm{mg}, 57 \%$ ) as a colorless solid.

${ }^{1} \mathrm{H}-\mathrm{NMR}\left(400 \mathrm{MHz}, \mathrm{CDCl}_{3}\right): \delta=7.92(\mathrm{~d}, J=1.7 \mathrm{~Hz}, 1 \mathrm{H}), 7.74(\mathrm{dd}, J=8.1,1.7 \mathrm{~Hz}, 1 \mathrm{H}), 7.68(\mathrm{dd}, J=$ 8.1, $0.4 \mathrm{~Hz}, 1 \mathrm{H}), 5.45(\mathrm{~d}, J=5.2 \mathrm{~Hz}, 1 \mathrm{H}), 4.94-4.84(\mathrm{~m}, 1 \mathrm{H}), 3.36(\mathrm{tt}, J=10.6,3.2 \mathrm{~Hz}, 1 \mathrm{H}), 2.61(\mathrm{~s}$, $3 \mathrm{H}), 2.52-2.42(\mathrm{~m}, 2 \mathrm{H}), 2.06-1.78(\mathrm{~m}, 9 \mathrm{H}), 1.76-0.95(\mathrm{~m}, 32 \mathrm{H}), 0.92(\mathrm{~d}, J=6.6 \mathrm{~Hz}, 3 \mathrm{H}), 0.87(\mathrm{dd}, J$ $=6.6,1.8 \mathrm{~Hz}, 6 \mathrm{H}), 0.69(\mathrm{~s}, 3 \mathrm{H}) .{ }^{13} \mathrm{C}-\mathrm{NMR}\left(100 \mathrm{MHz}, \mathrm{CDCl}_{3}\right): \delta=198.0\left(\mathrm{C}_{\mathrm{q}}\right), 167.8\left(\mathrm{C}_{\mathrm{q}}\right), 150.3\left(\mathrm{C}_{\mathrm{q}}\right)$, $139.6\left(\mathrm{C}_{\mathrm{q}}\right), 139.1\left(\mathrm{C}_{\mathrm{q}}\right), 134.8\left(\mathrm{C}_{\mathrm{q}}\right), 129.6(\mathrm{CH}), 127.0(\mathrm{CH}), 125.3(\mathrm{CH}), 123.2(\mathrm{CH}), 75.4(\mathrm{CH}), 56.9$ $(\mathrm{CH}), 56.3(\mathrm{CH}), 50.2(\mathrm{CH}), 42.5\left(\mathrm{C}_{q}\right), 42.3(\mathrm{CH}), 39.9\left(\mathrm{CH}_{2}\right), 39.7\left(\mathrm{CH}_{2}\right), 38.3\left(\mathrm{CH}_{2}\right), 37.2\left(\mathrm{CH}_{2}\right), 36.9$ $\left(\mathrm{CH}_{2}\right), 36.8\left(\mathrm{C}_{\mathrm{q}}\right), 36.4\left(\mathrm{CH}_{2}\right), 36.0(\mathrm{CH}), 32.1\left(\mathrm{CH}_{2}\right), 32.1(\mathrm{CH}), 28.4\left(\mathrm{CH}_{2}\right), 28.2(\mathrm{CH}), 28.0\left(\mathrm{CH}_{2}\right), 27.9$ $\left(\mathrm{CH}_{2}\right), 27.7\left(\mathrm{CH}_{2}\right), 27.0\left(\mathrm{CH}_{3}\right), 24.5\left(\mathrm{CH}_{2}\right), 24.0\left(\mathrm{CH}_{2}\right), 23.0\left(\mathrm{CH}_{3}\right), 22.7\left(\mathrm{CH}_{3}\right), 21.2\left(\mathrm{CH}_{2}\right), 19.5\left(\mathrm{CH}_{3}\right)$, $18.9\left(\mathrm{CH}_{3}\right)$. IR (ATR): $\tilde{v}=2931,2850,1718,1690,1464,1276,1234,1143,1099,1060 \mathrm{~cm}^{-1}$. m.p.: $151{ }^{\circ} \mathrm{C}$. MS (ESI) $\mathrm{m} / \mathrm{z}$ (relative intensity): 651 (100) [M+Na] $]^{+}, 1281$ (39) [2M+Na] $]^{+}$. HR-MS (ESI): $\mathrm{m} / \mathrm{z}$ calcd for $\mathrm{C}_{43} \mathrm{H}_{64} \mathrm{O}_{3} \mathrm{Na}^{+}[\mathrm{M}+\mathrm{Na}]^{+}$651.4748, found 651.4718 .

\section{4-Acetyl-2-cycloheptylphenyl 4-dimethylaminobenzoate (165ba)}<smiles>CC(=O)c1ccc(OC(=O)c2ccc(N(C)C)cc2)c(C2CCCCCC2)c1</smiles>

$165 \mathrm{ba}$

General procedure A was followed using ketimine 151b $(221 \mathrm{mg}, 0.50 \mathrm{mmol})$ and cyclohexyl bromide (100a) (266 mg, $1.50 \mathrm{mmol}$ ). Purification by column chromatography on silica gel $(n-$ hexane/EtOAc 8:1) and GPC purification yielded phenone 165ba (121 mg, 64\%) as a colorless solid.

${ }^{1} \mathrm{H}-\mathrm{NMR}\left(300 \mathrm{MHz}, \mathrm{CDCl}_{3}\right): \delta=8.08(\mathrm{~d}, J=8.8 \mathrm{~Hz}, 2 \mathrm{H}), 7.95(\mathrm{~d}, J=2.1 \mathrm{~Hz}, 1 \mathrm{H}), 7.81(\mathrm{dd}, J=8.4$, $2.1 \mathrm{~Hz}, 1 \mathrm{H}), 7.22(\mathrm{~d}, J=8.4 \mathrm{~Hz}, 1 \mathrm{H}), 6.73(\mathrm{~d}, J=8.8 \mathrm{~Hz}, 2 \mathrm{H}), 3.10(\mathrm{~s}, 6 \mathrm{H}), 2.99-2.88(\mathrm{~m}, 1 \mathrm{H}), 2.61(\mathrm{~s}$, 3H), 1.96-1.85 (m, 2H), 1.82-1.39 (m, 10H). ${ }^{13} \mathrm{C}-\mathrm{NMR}\left(125 \mathrm{MHz}, \mathrm{CDCl}_{3}\right): \delta=197.7\left(\mathrm{C}_{\mathrm{q}}\right), 165.2\left(\mathrm{C}_{\mathrm{q}}\right)$, 154.0 $\left(\mathrm{C}_{\mathrm{q}}\right), 152.4\left(\mathrm{C}_{\mathrm{q}}\right), 142.2\left(\mathrm{C}_{\mathrm{q}}\right), 134.8\left(\mathrm{C}_{\mathrm{q}}\right), 132.2(\mathrm{CH}), 127.9(\mathrm{CH}), 127.1(\mathrm{CH}), 123.1(\mathrm{CH}), 115.5$ 
$\left(\mathrm{C}_{\mathrm{q}}\right), 111.0(\mathrm{CH}), 40.4(\mathrm{CH}), 40.2\left(\mathrm{CH}_{3}\right), 35.5\left(\mathrm{CH}_{2}\right), 27.9\left(\mathrm{CH}_{2}\right), 27.6\left(\mathrm{CH}_{2}\right), 26.8\left(\mathrm{CH}_{3}\right)$. IR $(\mathrm{ATR}): \tilde{v}=$ 2917, 1706, 1687, 1600, 1276, 1235, 1161, 1074, 1056, $761 \mathrm{~cm}^{-1}$. m.p.: $110^{\circ} \mathrm{C}$. MS (ESI) $\mathrm{m} / \mathrm{z}$ (relative intensity): $402(100)[\mathrm{M}+\mathrm{Na}]^{+}, 781(76)[2 \mathrm{M}+\mathrm{Na}]^{+}, 1160(53)[3 \mathrm{M}+\mathrm{Na}]^{+}$. HR-MS (ESI): m/z calcd for $\mathrm{C}_{24} \mathrm{H}_{29} \mathrm{O}_{3} \mathrm{Na}^{+}[\mathrm{M}+\mathrm{Na}]^{+} 402.2040$, found 402.2034 .

\section{4-Acetyl-2-tert-butylphenyl 4-dimethylaminobenzoate (165bb)}<smiles>CCCCCC(C)(C)C</smiles>

General procedure A was followed using ketimine $151 \mathrm{~b}(221 \mathrm{mg}, 0.50 \mathrm{mmol})$ and tert-butyl bromide (100b) (206 mg, $1.50 \mathrm{mmol}$ ). Purification by column chromatography on silica gel ( $n$ hexane/EtOAc 8:1) and GPC purification yielded phenone $165 \mathrm{bb}$ (100 mg, 59\%) as a colorless solid.

${ }^{1} \mathrm{H}-\mathrm{NMR}\left(300 \mathrm{MHz}, \mathrm{CDCl}_{3}\right): \delta=8.12-8.04(\mathrm{~m}, 3 \mathrm{H}), 7.84$ (ddd, $\left.J=8.3,2.2,0.7 \mathrm{~Hz}, 1 \mathrm{H}\right), 7.19$ (dd, $J=$ 8.3, 0.7 Hz, 1H), 6.77-6.70 (m, 2H), $3.10(\mathrm{~s}, 6 \mathrm{H}), 2.61(\mathrm{~s}, 3 \mathrm{H}), 1.41(\mathrm{~s}, 9 \mathrm{H}) .{ }^{13} \mathrm{C}-\mathrm{NMR}(125 \mathrm{MHz}$, $\left.\mathrm{CDCl}_{3}\right): \delta=197.7\left(\mathrm{C}_{\mathrm{q}}\right), 165.3\left(\mathrm{C}_{\mathrm{q}}\right), 154.0\left(\mathrm{C}_{\mathrm{q}}\right), 154.0\left(\mathrm{C}_{\mathrm{q}}\right), 142.2\left(\mathrm{C}_{\mathrm{q}}\right), 134.2\left(\mathrm{C}_{\mathrm{q}}\right), 132.3(\mathrm{CH}), 127.7$ (CH), $127.6(\mathrm{CH}), 124.8(\mathrm{CH}), 115.7\left(\mathrm{C}_{\mathrm{q}}\right), 111.1(\mathrm{CH}), 40.2\left(\mathrm{CH}_{3}\right), 34.9\left(\mathrm{C}_{\mathrm{q}}\right), 30.3\left(\mathrm{CH}_{3}\right), 26.8\left(\mathrm{CH}_{3}\right)$. IR (ATR): $\tilde{v}=1711,1677,1599,1268,1165,1079,1048,824,760,602 \mathrm{~cm}^{-1}$. m.p.: $166^{\circ} \mathrm{C}$. MS (ESI) m/z (relative intensity): $340(24)[\mathrm{M}+\mathrm{H}]^{+}, 362(100),[\mathrm{M}+\mathrm{Na}]^{+}, 701(80),[2 \mathrm{M}+\mathrm{Na}]^{+}, 1040$ (27) $[3 \mathrm{M}+\mathrm{Na}]^{+}$. HR-MS (ESI): $\mathrm{m} / z$ calcd for $\mathrm{C}_{21} \mathrm{H}_{25} \mathrm{O}_{3} \mathrm{Na}^{+}[\mathrm{M}+\mathrm{Na}]^{+} 362.1727$, found 362.1730 . 


\section{4-Acetyl-2-cycloheptylphenyl thiophene-2-carboxylate (165ca)}<smiles>CC(=O)c1ccc(OC(=O)c2cccs2)c(C2CCCCCC2)c1</smiles>

$165 \mathrm{ca}$

General procedure A was followed using ketimine 151c $(206 \mathrm{mg}, 0.50 \mathrm{mmol})$ and cyclohexyl bromide (100a) (266 mg, $1.50 \mathrm{mmol}$ ). Purification by column chromatography on silica gel $(n-$ hexane/EtOAc 20:1) yielded phenone $165 \mathrm{ca}$ (58 mg, 34\%) as a colorless oil.

${ }^{1} \mathrm{H}-\mathrm{NMR}\left(500 \mathrm{MHz}, \mathrm{CDCl}_{3}\right): \delta=8.35(\mathrm{dd}, J=3.1,1.2 \mathrm{~Hz}, 1 \mathrm{H}), 7.96(\mathrm{~d}, J=2.2 \mathrm{~Hz}, 1 \mathrm{H}), 7.82(\mathrm{dd}, J=$ 8.4, 2.2 Hz, 1H), $7.68(\mathrm{dd}, J=5.1,1.2 \mathrm{~Hz}, 1 \mathrm{H}), 7.43(\mathrm{dd}, J=5.1,3.1 \mathrm{~Hz}, 1 \mathrm{H}), 7.22(\mathrm{~d}, J=8.4 \mathrm{~Hz}, 1 \mathrm{H}$ ), $2.91(\mathrm{tt}, J=10.6,3.4 \mathrm{~Hz}, 1 \mathrm{H}), 2.61(\mathrm{~s}, 3 \mathrm{H}), 1.94-1.86(\mathrm{~m}, 2 \mathrm{H}), 1.83-1.74(\mathrm{~m}, 2 \mathrm{H}), 1.72-1.53(\mathrm{~m}, 6 \mathrm{H})$, 1.51-1.41 (m, 2H). ${ }^{13} \mathrm{C}-\mathrm{NMR}\left(125 \mathrm{MHz}, \mathrm{CDCl}_{3}\right): \delta=197.5\left(\mathrm{C}_{\mathrm{q}}\right), 160.8\left(\mathrm{C}_{\mathrm{q}}\right), 151.5\left(\mathrm{C}_{\mathrm{q}}\right), 142.0\left(\mathrm{C}_{\mathrm{q}}\right)$, $135.3\left(\mathrm{C}_{\mathrm{q}}\right), 134.5(\mathrm{CH}), 132.5\left(\mathrm{C}_{\mathrm{q}}\right), 128.3(\mathrm{CH}), 128.1(\mathrm{CH}), 127.2(\mathrm{CH}), 126.9(\mathrm{CH}), 122.8(\mathrm{CH}), 40.4$ (CH), $35.5\left(\mathrm{CH}_{2}\right), 27.8\left(\mathrm{CH}_{2}\right), 27.6\left(\mathrm{CH}_{2}\right), 26.8\left(\mathrm{CH}_{3}\right)$. IR (ATR): $\tilde{v}=1731,1681,1235,1167,1105$, 1079, 1058, 857, $739 \mathrm{~cm}^{-1}$. MS (ESI) m/z (relative intensity): $343(100)[\mathrm{M}+\mathrm{H}]^{+}, 365(44)[\mathrm{M}+\mathrm{Na}]^{+}$, 707 (24) $[2 \mathrm{M}+\mathrm{Na}]^{+}$. HR-MS (ESI): $\mathrm{m} / z$ calcd for $\mathrm{C}_{20} \mathrm{H}_{23} \mathrm{O}_{3} \mathrm{~S}^{+}[\mathrm{M}+\mathrm{H}]^{+} 343.1362$, found 343.1358 .

\subsubsection{Additive Test}<smiles>CC(=NN)c1ccc(F)cc1</smiles>

$151 d$<smiles>BrC1CCCCCC1</smiles>

$100 \mathrm{a}$
1) $\left[\mathrm{RuCl}_{2}(p \text {-cymene })\right]_{2}(5.0 \mathrm{~mol} \%)$ $\mathrm{AdCO}_{2} \mathrm{H}(17)(30 \mathrm{~mol} \%)$

Additive (1.0 equiv)

$\mathrm{K}_{2} \mathrm{CO}_{3}$

$\mathrm{PhCMe}_{3}, 120^{\circ} \mathrm{C}, 20 \mathrm{~h}$

2) $\mathrm{HCl}(2 \mathrm{~N}), 23^{\circ} \mathrm{C}, 3 \mathrm{~h}$<smiles>CC(=O)c1ccc(F)c(C2CCCCCC2)c1</smiles>

$165 \mathrm{da}$

General procedure A was followed using ketimine $151 \mathrm{~d}$ (152 $\mathrm{mg}, 0.50 \mathrm{mmol})$, cyclohexyl bromide (100a) $(266 \mathrm{mg}, 1.50 \mathrm{mmol})$ and an additive $(0.50 \mathrm{mmol})$. After hydrolysis with aq. $\mathrm{HCl}(2 \mathrm{~N}$, $3.0 \mathrm{~mL}), n$-dodecane $(40 \mu \mathrm{L})$ was added. An aliquot $(0.2 \mathrm{~mL})$ was removed from the organic phase via a syringe, diluted with EtOAc, filtered through a short plug of silica gel and analyzed by gas chromatography. 


\begin{tabular}{|c|c|c|c|c|}
\hline Entry & Additive & $\begin{array}{l}\text { Conversion } \\
165 \mathrm{da} / \%^{\text {[a] }}\end{array}$ & $\begin{array}{c}\text { Remaining } \\
\text { Additive / \% }{ }^{[\mathrm{a}]}\end{array}$ & $\begin{array}{c}\text { Unreacted } \\
\text { Ketone / \%[a] }\end{array}$ \\
\hline 1 & none & 97 & -- & 0 \\
\hline 2 & valerophenone & 96 & 93 & 0 \\
\hline 3 & $\begin{array}{c}\mathrm{N} \text {-(tert-butyl)-2- } \\
\text { phenylacetamide } \\
(\mathbf{1 5 3 b})\end{array}$ & 52 & 45 & 0 \\
\hline 4 & $\mathrm{~N}, \mathrm{~N}$-dimethylaniline & 78 & 0 & 0 \\
\hline 5 & aniline & 64 & 0 & 0 \\
\hline 6 & 1-decene & 71 & n.d. ${ }^{[b]}$ & 0 \\
\hline 7 & methyl(phenyl)sulfane & 79 & 0 & 0 \\
\hline 8 & 1-heptanol & 41 & 77 & 22 \\
\hline 9 & nonan-5-one & 74 & 96 & 0 \\
\hline 10 & octylamine & 48 & 0 & 0 \\
\hline 11 & 1-chlorodecane & 72 & 100 & 0 \\
\hline 12 & benzaldehyde & 4 & 38 & 0 \\
\hline 13 & pyridine & 61 & n.d. ${ }^{[b]}$ & 0 \\
\hline 14 & 2-methylpyridine & 71 & 0 & 0 \\
\hline 15 & benzofuran & 96 & 91 & 0 \\
\hline 16 & $1 H$-indole & 86 & 41 & 0 \\
\hline 17 & quinoline & 81 & 0 & 0 \\
\hline 18 & 2-chloroquinoline & 10 & 0 & 0 \\
\hline 19 & benzoxazole & 2 & 10 & 48 \\
\hline 20 & 2-methylfuran & 64 & n.d..$^{[b]}$ & 0 \\
\hline 21 & 2-methylthiophene & 63 & 88 & 0 \\
\hline 22 & $N$-methylimidazole & 3 & 0 & 44 \\
\hline
\end{tabular}

[a] Determined by gas chromatography with $n$-dodecane as the internal standard. [b] Not detected due to overlap with the solvent signal. 


\subsubsection{One-pot two-fold C-H Activation}

1-[4-(1-Methyl-cyclohexyl)-5-fluoro-4'-methoxy-[1,1'-biphenyl]-2-yl]ethan-1-one (166a)<smiles>COc1ccc(-c2cc(F)c(C3(C)CCCCC3)cc2C(C)=O)cc1</smiles>

$166 a$

General procedure A was followed using ketimine 151d (152 mg, $0.50 \mathrm{mmol}$ ), 1-bromo-1methylcyclohexane $(100 \mathrm{c})(266 \mathrm{mg}, 1.50 \mathrm{mmol})$ and $\mathrm{K}_{2} \mathrm{CO}_{3}(276 \mathrm{mg}, 2.00 \mathrm{mmol})$. After $20 \mathrm{~h}$, 4-bromoanisole $(140 \mathrm{mg}, 0.75 \mathrm{mmol}$ ) was added at ambient temperature and the mixture was stirred at $120^{\circ} \mathrm{C}$ for an additional $20 \mathrm{~h}$. After cooling to ambient temperature, aq. $\mathrm{HCl}(2 \mathrm{~N}, 3.0 \mathrm{~mL})$ was added, the mixture was stirred at ambient temperature for $3 \mathrm{~h}$, extracted with EtOAc $(3 \times 20 \mathrm{~mL})$, dried over $\mathrm{Na}_{2} \mathrm{SO}_{4}$ and concentrated in vacuo. Purification of the residue by column chromatography on silica gel ( $n$-hexane/EtOAc 25:1) yielded phenone 166a (118 mg, 69\%) as a colorless solid.

${ }^{1} \mathrm{H}-\mathrm{NMR}\left(400 \mathrm{MHz}, \mathrm{CDCl}_{3}\right): \delta=7.52(\mathrm{~d}, J=8.6 \mathrm{~Hz}, 1 \mathrm{H}), 7.25(\mathrm{~d}, J=8.9 \mathrm{~Hz}, 2 \mathrm{H}), 6.99(\mathrm{~d}, J=13.3 \mathrm{~Hz}$, $1 \mathrm{H}), 6.96(\mathrm{~d}, J=8.9 \mathrm{~Hz}, 2 \mathrm{H}), 3.85(\mathrm{~s}, 3 \mathrm{H}), 2.12-2.04(\mathrm{~m}, 2 \mathrm{H}), 1.99(\mathrm{~s}, 3 \mathrm{H}), 1.73-1.65(\mathrm{~m}, 2 \mathrm{H}), 1.64-$ $1.56(\mathrm{~m}, 2 \mathrm{H}), 1.54-1.38(\mathrm{~m}, 4 \mathrm{H}), 1.32(\mathrm{~d}, J=0.8 \mathrm{~Hz}, 3 \mathrm{H}) .{ }^{13} \mathrm{C}-\mathrm{NMR}\left(100 \mathrm{MHz}, \mathrm{CDCl}_{3}\right): \delta=204.5\left(\mathrm{C}_{\mathrm{q}}\right)$, $163.1\left(d,{ }^{1} J_{C-F}=254.4 \mathrm{~Hz}, C_{q}\right), 159.9\left(C_{q}\right), 140.4\left(d,{ }^{2} J_{C-F}=9.6 \mathrm{~Hz}, C_{q}\right), 136.5\left(d,{ }^{4} J_{C-F}=2.9 \mathrm{~Hz}, C_{q}\right)$, $135.6\left(d,{ }^{3} J_{C-F}=9.6 \mathrm{~Hz}, C_{q}\right), 132.1\left(d,{ }^{4} J_{C-F}=1.7 \mathrm{~Hz}, C_{q}\right), 130.0(C H), 129.0\left(d,{ }^{3} J_{C-F}=7.5 \mathrm{~Hz}, C H\right), 118.2$ $\left(\mathrm{d},{ }^{2} J_{\mathrm{C}-\mathrm{F}}=25.9 \mathrm{~Hz}, \mathrm{CH}\right), 114.4(\mathrm{CH}), 55.5\left(\mathrm{CH}_{3}\right), 38.0\left(\mathrm{~d},{ }^{3} \mathrm{~J}_{\mathrm{C}-\mathrm{F}}=3.5 \mathrm{~Hz}, \mathrm{C}_{\mathrm{q}}\right), 37.2\left(\mathrm{~d},{ }^{4} \mathrm{~J}_{\mathrm{C}-\mathrm{F}}=3.8 \mathrm{~Hz}, \mathrm{CH}_{2}\right)$, $30.7\left(\mathrm{CH}_{3}\right), 26.6\left(\mathrm{CH}_{2}\right), 26.5\left(\mathrm{CH}_{3}\right), 22.8\left(\mathrm{CH}_{2}\right) .{ }^{19} \mathrm{~F}-\mathrm{NMR}\left(470 \mathrm{MHz}, \mathrm{CDCl}_{3}\right): \delta=-105.0(\mathrm{dd}, J=13.3$, $8.6 \mathrm{~Hz}$ ). IR (ATR): $\tilde{v}=1674,1608,1485,1467,1267,1245,1169,1031,833,532 \mathrm{~cm}^{-1}$. m.p.: $58^{\circ} \mathrm{C}$. MS (ESI) $m / z$ (relative intensity): $341[\mathrm{M}+\mathrm{H}]^{+}(75), 363[\mathrm{M}+\mathrm{Na}]^{+}(100), 703[2 \mathrm{M}+\mathrm{Na}]^{+}(90)$. HR-MS (ESI): $m / z$ calcd for $\mathrm{C}_{22} \mathrm{H}_{26} \mathrm{FO}_{2}{ }^{+}[\mathrm{M}+\mathrm{H}]^{+} 341.1911$, found 341.1908 . 


\section{1-[1-n-Hexyl-5-(1-methyl-cyclohexyl)-4-fluorophenyl]ethan-1-one (166b)}<smiles>CC(=O)c1cc(C2(C)CCCCC2)c(F)cc1[14CH3]</smiles>

$166 b$

General procedure A was followed using ketimine 151d (152 mg, $0.50 \mathrm{mmol}$ ), 1-bromo-1methylcyclohexane $(100 \mathrm{c})(266 \mathrm{mg}, 1.50 \mathrm{mmol})$ and $\mathrm{K}_{2} \mathrm{CO}_{3}(276 \mathrm{mg}, 2.00 \mathrm{mmol})$. After $20 \mathrm{~h}$, 1-bromohexane (92) (248 $\mathrm{mg}, 0.75 \mathrm{mmol})$ was added at ambient temperature and the mixture was stirred at $120^{\circ} \mathrm{C}$ for an additional $20 \mathrm{~h}$. After cooling to ambient temperature, aq. $\mathrm{HCl}(2 \mathrm{~N}$, $3.0 \mathrm{~mL}$ ) was added, the mixture was stirred at ambient temperature for $3 \mathrm{~h}$, extracted with EtOAc $\left(3 \times 20 \mathrm{~mL}\right.$ ), dried over $\mathrm{Na}_{2} \mathrm{SO}_{4}$ and concentrated in vacuo. Purification of the residue by column chromatography on silica gel ( $n$-hexane/EtOAc 30:1) and GPC purification yielded phenone 166b (89 $\mathrm{mg}, 56 \%$ ) as a colorless oil.

${ }^{1} \mathrm{H}-\mathrm{NMR}\left(400 \mathrm{MHz}, \mathrm{CDCl}_{3}\right): \delta=7.62(\mathrm{~d}, J=8.5 \mathrm{~Hz}, 1 \mathrm{H}), 6.87(\mathrm{~d}, J=13.9 \mathrm{~Hz}, 1 \mathrm{H}), 2.84-2.77(\mathrm{~m}, 2 \mathrm{H})$, $2.56(\mathrm{~s}, 3 \mathrm{H}), 2.10-1.97(\mathrm{~m}, 2 \mathrm{H}), 1.72-1.23(\mathrm{~m}, 19 \mathrm{H}), 0.91-0.84(\mathrm{~m}, 3 \mathrm{H}) .{ }^{13} \mathrm{C}-\mathrm{NMR}\left(100 \mathrm{MHz}, \mathrm{CDCl}_{3}\right)$ : $\delta=201.1\left(C_{q}\right), 163.5\left(d,{ }^{1} J_{C-F}=254.8 \mathrm{~Hz}, C_{q}\right), 144.0\left(d,{ }^{3} J_{C-F}=9.4 \mathrm{~Hz}, C_{q}\right), 133.7\left(d,{ }^{4} J_{C-F}=2.8 \mathrm{~Hz}, C_{q}\right)$, $133.5\left(d,{ }^{2} J_{C-F}=11.3 \mathrm{~Hz}, C_{q}\right), 130.2\left(d,{ }^{3} J_{C-F}=7.7 \mathrm{~Hz}, \mathrm{CH}\right), 119.1\left(d,{ }^{2} J_{C-F}=25.0 \mathrm{~Hz}, \mathrm{CH}\right), 37.7\left(\mathrm{~d},{ }^{3} J_{C-F}\right.$ $\left.=3.5 \mathrm{~Hz}, \mathrm{C}_{\mathrm{q}}\right), 37.2\left(\mathrm{~d},{ }^{4} \mathrm{~J}_{\mathrm{C}-\mathrm{F}}=4.0 \mathrm{~Hz}, \mathrm{CH}_{2}\right), 33.6\left(\mathrm{~d},{ }^{4} \mathrm{~J}_{\mathrm{C}-\mathrm{F}}=1.2 \mathrm{~Hz}, \mathrm{CH}_{2}\right), 31.8\left(\mathrm{CH}_{2}\right), 31.4\left(\mathrm{CH}_{2}\right), 30.0$ $\left(\mathrm{CH}_{3}\right), 29.5\left(\mathrm{CH}_{2}\right), 26.8\left(\mathrm{CH}_{3}\right), 26.4\left(\mathrm{CH}_{2}\right), 22.8\left(\mathrm{CH}_{2}\right), 22.7\left(\mathrm{CH}_{2}\right), 14.2\left(\mathrm{CH}_{3}\right) .{ }^{19} \mathrm{~F}-\mathrm{NMR}(282 \mathrm{MHz}$, $\left.\mathrm{CDCl}_{3}\right): \delta=-104.1$ (dd, $J=13.9,8.5 \mathrm{~Hz}$ ). IR (ATR): $\tilde{v}=2925,2856,1684,1556,1455,1389,1354$, 1247, 1141, $899 \mathrm{~cm}^{-1}$. MS (EI) m/z (relative intensity): 318 (11) [M] $]^{+}, 303$ (100) [M-Me] , 43 (46). HR-MS (EI): $m / z$ calcd for $\mathrm{C}_{21} \mathrm{H}_{31} \mathrm{FO}^{+}[\mathrm{M}]^{+} 318.2359$, found 318.2353 . 


\subsubsection{Mechanistic Studies}

\section{Reaction with chiral Bromide}

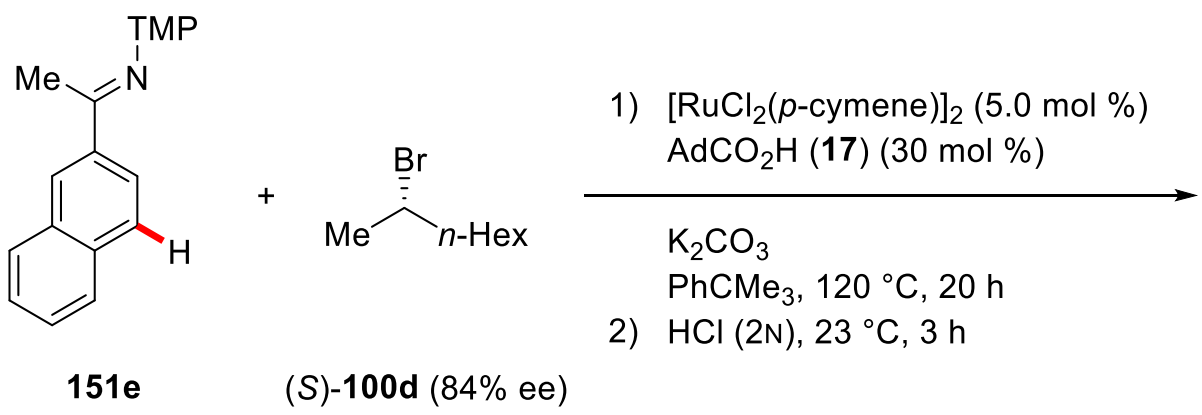<smiles>CC(=O)c1cc(C(C)P)c2ccccc2c1</smiles>

General procedure A was followed using ketimine 151e $(34 \mathrm{mg}, 0.10 \mathrm{mmol})$ and alkyl bromide (S)-100d ( $84 \%$ ee, $58 \mathrm{mg}, 0.30 \mathrm{mmol}$ ). Purification by column chromatography on silica gel $(n-$ pentane/Et ${ }_{2} \mathrm{O} 20: 1$ ) yielded phenone 165ed ( $0 \%$ ee, $23 \mathrm{mg}, 78 \%$ ) as a colorless oil. The enantiomeric excess was determined by HPLC analysis on a chiral stationary phase.

${ }^{1} \mathrm{H}-\mathrm{NMR}\left(500 \mathrm{MHz}, \mathrm{CDCl}_{3}\right): \delta=8.31(\mathrm{~s}, 1 \mathrm{H}), 8.15(\mathrm{~d}, J=8.4 \mathrm{~Hz}, 1 \mathrm{H}$ ), 7.98 (ddd, $J=8.2,0.7,0.7 \mathrm{~Hz}$, 1H), $7.97(\mathrm{~d}, J=1.8 \mathrm{~Hz}, 1 \mathrm{H}$ ), 7.63 (ddd, $J=8.5,6.8,1.4 \mathrm{~Hz}, 1 \mathrm{H}$ ), 7.54 (ddd, $J=8.1,6.8,1.2 \mathrm{~Hz}, 1 \mathrm{H}$ ), 3.58 (hept, $J=6.8 \mathrm{~Hz}, 1 \mathrm{H}), 2.73(\mathrm{~s}, 3 \mathrm{H}), 1.90-1.77(\mathrm{~m}, 1 \mathrm{H}), 1.75-1.66(\mathrm{~m}, 1 \mathrm{H}), 1.40(\mathrm{~d}, J=6.9 \mathrm{~Hz}$, 3H), $1.32-1.20(\mathrm{~m}, 8 \mathrm{H}), 0.85(\mathrm{t}, J=7.1 \mathrm{~Hz}, 3 \mathrm{H}) .{ }^{13} \mathrm{C}-\mathrm{NMR}\left(100 \mathrm{MHz}, \mathrm{CDCl}_{3}\right): \delta=198.6\left(\mathrm{C}_{\mathrm{q}}\right), 145.1$ $\left(\mathrm{C}_{\mathrm{q}}\right), 134.3\left(2 \times \mathrm{C}_{\mathrm{q}}\right), 133.3\left(\mathrm{C}_{\mathrm{q}}\right), 130.7(\mathrm{CH}), 128.9(\mathrm{CH}), 128.4(\mathrm{CH}), 126.3(\mathrm{CH}), 123.5(\mathrm{CH}), 120.4$ $(\mathrm{CH}), 37.9\left(\mathrm{CH}_{2}\right), 34.0(\mathrm{CH}), 31.9\left(\mathrm{CH}_{2}\right), 29.6\left(\mathrm{CH}_{2}\right), 27.9\left(\mathrm{CH}_{2}\right), 26.8\left(\mathrm{CH}_{3}\right), 22.8\left(\mathrm{CH}_{2}\right), 21.7\left(\mathrm{CH}_{3}\right)$, $14.2\left(\mathrm{CH}_{3}\right)$. HPLC (IC-3, $n$-hexane/ $\left.i-\operatorname{PrOH} 99: 1\right): R_{\mathrm{t} 1}=10.33 \mathrm{~min}$ (area: 49.9\%), $R_{\mathrm{t} 2}=11.97 \mathrm{~min}$ (area: $50.1 \%)$.

The analytical data are in accordance with those obtained for the racemic reaction. ${ }^{[121]}$

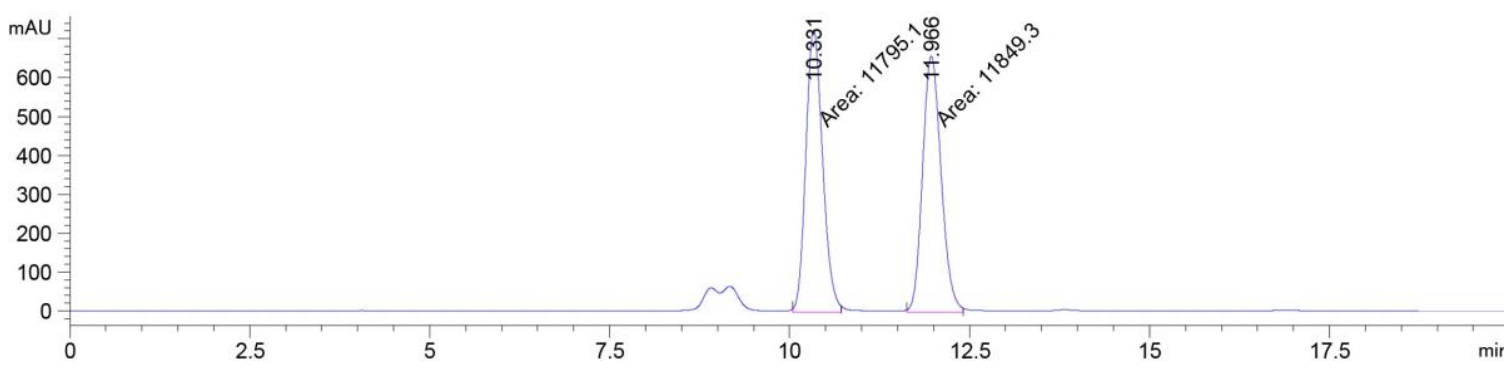

Figure 66: HPLC trace of rac-165ed. 


\subsubsection{Kinetic Analysis}

\section{Reaction Order with Respect to $\left[\mathrm{Ru}\left(\mathrm{O}_{2} \mathrm{CAd}\right)_{2}(p\right.$-cymene) $]$ (167)}

The initial rate method was employed to determine the reaction order with respect to $\left[\mathrm{Ru}\left(\mathrm{O}_{2} \mathrm{CAd}\right)_{2}\left(p\right.\right.$-cymene)] (167). ${ }^{[178]}$ Under an atmosphere of $\mathrm{N}_{2}$ inside a glovebox, a Schlenk-tube was charged with (E)-1-(4-fluorophenyl)- $N$-(3,4,5-trimethoxyphenyl)ethan-1-imine (151d) (303 mg, 1.00 mmol, 1.00 equiv), 1-bromo-1-methylcyclohexane (100c) (531 mg, 3.00 mmol, 3.00 equiv), $\mathrm{K}_{2} \mathrm{CO}_{3}$ ( $276 \mathrm{mg}, 2.00 \mathrm{mmol}, 2.00$ equiv) and 1-fluorononane ( $37 \mathrm{mg}, 0.25 \mathrm{mmol}$ ). A solution of $\left[\mathrm{Ru}\left(\mathrm{O}_{2} \mathrm{CAd}\right)_{2}(p\right.$-cymene) $](167)(2.5,3.5,7.5,10.0 \mathrm{~mol} \%)$ in $\mathrm{PhCMe}_{3}(4.0 \mathrm{~mL})$ was added and the mixture was stirred at $92{ }^{\circ} \mathrm{C}$. After $60 \mathrm{~min}$ aliquots $(0.1 \mathrm{~mL})$ were removed via a syringe every $30 \mathrm{~min}$ for $3 \mathrm{~h}$, diluted with PhMe- $d_{8}(0.25 \mathrm{~mL})$ and analyzed by ${ }^{19} \mathrm{~F}\left\{{ }^{1} \mathrm{H}\right\}$-NMR spectroscopy.

\begin{tabular}{|c|c|c|c|}
\hline amount / mol \% & $\log \left(c / \mathrm{mol} \mathrm{L}^{-1}\right)$ & $\Delta[\mathbf{1 5 2} \mathrm{dc}] \Delta t^{-1} / 10^{-8} \mathrm{~mol} \mathrm{~L}^{-1} \mathrm{~s}^{-1}$ & $\log \left(\Delta[\mathbf{1 5 2 \mathrm { dc }}] \Delta t^{-1} / \mathrm{mol} \mathrm{L}^{-1} \mathrm{~s}^{-1}\right)$ \\
\hline 2.5 & -2.204 & 0.236 & -8.627 \\
\hline 3.5 & -2.058 & 0.379 & -8.422 \\
\hline 7.5 & -1.727 & 0.844 & -8.074 \\
\hline 10.0 & -1.602 & 1.260 & -7.900 \\
\hline
\end{tabular}

\section{Reaction Order with Respect to Ketimine 151d}

The initial rate method was employed to determine the reaction order with respect to ketimine 151d. ${ }^{[178]}$ Under an atmosphere of $\mathrm{N}_{2}$ inside a glovebox, a Schlenk-tube was charged with (E)-1-(4fluorophenyl)- $N$-(3,4,5-trimethoxyphenyl)ethan-1-imine (151d) $\quad(0.50,0.75,1.00,1.50$, $2.00 \mathrm{mmol})$, 1-bromo-1-methylcyclohexane $(100 \mathrm{c})(531 \mathrm{mg}, 3.00 \mathrm{mmol}), \mathrm{K}_{2} \mathrm{CO}_{3} \quad(276 \mathrm{mg}$, $2.00 \mathrm{mmol}$ ) and 1-fluorononane (37 mg, $0.25 \mathrm{mmol})$. A solution of [ $\mathrm{Ru}\left(\mathrm{O}_{2} \mathrm{CAd}\right)_{2}(p$-cymene $\left.)\right](167)$ (44.5 mg, $75 \mu \mathrm{mol})$ in $\mathrm{PhCMe}_{3}(4.0 \mathrm{~mL})$ was added and the mixture was stirred at $92{ }^{\circ} \mathrm{C}$. After 60 min aliquots $(0.1 \mathrm{~mL})$ were removed via a syringe every $30 \min$ for $3 \mathrm{~h}$, diluted with PhMe-d 8 $(0.25 \mathrm{~mL})$ and analyzed by ${ }^{19} \mathrm{~F}\left\{{ }^{1} \mathrm{H}\right\}-\mathrm{NMR}$ spectroscopy.

\begin{tabular}{|c|c|c|c|}
\hline amount / mmol & $\log \left(c / \mathrm{mol} \mathrm{L}^{-1}\right)$ & $\Delta[\mathbf{1 5 2} \mathbf{d c}] \Delta t^{-1} / 10^{-8} \mathrm{~mol} \mathrm{~L}^{-1} \mathrm{~s}^{-1}$ & $\log \left(\Delta[\mathbf{1 5 2 \mathrm { dc }}] \Delta t^{-1} / \mathrm{mol} \mathrm{L}^{-1} \mathrm{~s}^{-1}\right)$ \\
\hline 0.50 & -0.903 & 0.471 & -8.327 \\
\hline 0.75 & -0.727 & 0.596 & -8.225 \\
\hline 1.00 & -0.602 & 0.944 & -8.025 \\
\hline 1.50 & -0.426 & 1.227 & -7.911 \\
\hline
\end{tabular}




\section{Reaction Order with Respect to Alkyl Bromide 100c}

The initial rate method was employed to determine the reaction order with respect to alkyl bromide $100 c .{ }^{[178]}$ Under an atmosphere of $\mathrm{N}_{2}$ inside a glovebox, a Schlenk-tube was charged with (E)-1-(4-fluorophenyl)- $N$-(3,4,5-trimethoxyphenyl)ethan-1-imine (151d) $(303 \mathrm{mg}, 1.00 \mathrm{mmol}$, 1.00 equiv), 1-bromo-1-methylcyclohexane (100c) $(1.00,1.50,3.00,4.50 \mathrm{mmol}), \mathrm{K}_{2} \mathrm{CO}_{3}(276 \mathrm{mg}$, $2.00 \mathrm{mmol}, 2.00$ equiv), 1-fluorononane ( $37 \mathrm{mg}, 0.25 \mathrm{mmol}$ ) and $\mathrm{MS}(4 \AA, 150 \mathrm{mg})$. A solution of $\left[\mathrm{Ru}\left(\mathrm{O}_{2} \mathrm{CAd}\right)_{2}\left(p\right.\right.$-cymene)] (167) $(44.5 \mathrm{mg}, 75 \mu \mathrm{mol}, 7.5 \mathrm{~mol} \%)$ in $\mathrm{PhCMe}_{3}(4.0 \mathrm{~mL})$ was added and the mixture was stirred at $92{ }^{\circ} \mathrm{C}$. After 60 min aliquots $(0.1 \mathrm{~mL})$ were removed via a syringe every $30 \mathrm{~min}$ for $3 \mathrm{~h}$, diluted with PhMe- $d_{8}(0.25 \mathrm{~mL})$ and analyzed by ${ }^{19} \mathrm{~F}\left\{{ }^{1} \mathrm{H}\right\}$-NMR spectroscopy.

\begin{tabular}{cccc}
\hline amount $/ \mathrm{mmol}$ & $\log \left(c / \mathrm{mol} \mathrm{L}^{-1}\right)$ & $\Delta\left[\mathbf{1 5 2 \mathrm { dc } ]} \Delta t^{-1} / 10^{-8} \mathrm{~mol} \mathrm{~L}^{-1} \mathrm{~s}^{-1}\right.$ & $\log \left(\Delta[\mathbf{1 5 2 \mathrm { dc }}] \Delta t^{-1} / \mathrm{mol} \mathrm{L}^{-1} \mathrm{~s}^{-1}\right)$ \\
\hline 1.00 & -0.602 & 0.602 & -8.220 \\
1.50 & -0.426 & 0.972 & -8.012 \\
3.00 & -0.125 & 0.844 & -8.074 \\
4.50 & 0.051 & 0.616 & -8.211 \\
\hline
\end{tabular}

\section{Determination of the Activation Energy}

An Arrhenius plot analysis was employed to determine the activation energy of the reaction with reaction rate obtained via the initial rate method. ${ }^{[178]}$ Under an atmosphere of $\mathrm{N}_{2}$ inside a glovebox, a Schlenk-tube was charged with (E)-1-(4-fluorophenyl)- $N$-(3,4,5trimethoxyphenyl)ethan-1-imine (151d) $\quad(303 \mathrm{mg}, 1.00 \mathrm{mmol}, 1.00$ equiv), 1-bromo-1methylcyclohexane (100c) $\left(561 \mathrm{mg}, 3.00 \mathrm{mmol}, 3.00\right.$ equiv), $\mathrm{K}_{2} \mathrm{CO}_{3} \quad(276 \mathrm{mg}, 2.00 \mathrm{mmol}$, 2.00 equiv) and 1-fluorononane ( $37 \mathrm{mg}, 0.25 \mathrm{mmol})$. A solution of $\left[\mathrm{Ru}\left(\mathrm{O}_{2} \mathrm{CAd}\right)_{2}(p\right.$-cymene)] (167) (44.5 mg, $75 \mu \mathrm{mol}, 7.5 \mathrm{~mol} \%$ ) in $\mathrm{PhCMe}_{3}(4.0 \mathrm{~mL}$ ) was added and the mixture was stirred at various temperatures $\left(84,92,98,103,112^{\circ} \mathrm{C}\right)$. Periodically, aliquots $(0.1 \mathrm{~mL})$ were removed via a syringe, diluted with PhMe- $d_{8}(0.25 \mathrm{~mL})$ and analyzed by ${ }^{19} \mathrm{~F}\left\{{ }^{1} \mathrm{H}\right\}$-NMR spectroscopy.

The Arrhenius plot analysis resulted in a value for the activation energy $E_{\mathrm{A}}$ of $23.6 \pm 3.0 \mathrm{kcal} \mathrm{mol}^{-1}$. Errors were calculated based on the fitting error of the linear regression as implemented in the OriginPro software. 


\begin{tabular}{ccccc}
\hline$T / \mathrm{K}$ & $\begin{array}{c}T^{-1} / 10^{-3} \\
\mathrm{~K}^{-1}\end{array}$ & $\begin{array}{c}\Delta[\mathbf{1 5 2 d c}] \Delta t^{-1} / \\
10^{-8} \mathrm{~mol} \mathrm{~L}^{-1} \mathrm{~s}^{-1}\end{array}$ & $\begin{array}{c}\ln \left(\Delta[\mathbf{1 5 2 d c}] \Delta t^{-1} /\right. \\
\left.\mathrm{mol} \mathrm{L}^{-1} \mathrm{~s}^{-1}\right)\end{array}$ & $\begin{array}{c}\ln \left(\Delta[\mathbf{1 5 2 d c}] \Delta t^{-1} T^{-1} /\right. \\
\left.\mathrm{mol} \mathrm{L}^{-1} \mathrm{~s}^{-1} \mathrm{~K}^{-1}\right)\end{array}$ \\
\hline 357.2 & 2.800 & 0.326 & -19.54 & -25.42 \\
365.2 & 2.738 & 0.944 & -18.48 & -24.38 \\
371.2 & 2.694 & 1.819 & -17.82 & -23.74 \\
376.2 & 2.658 & 2.246 & -17.61 & -23.54 \\
385.2 & 2.596 & 3.755 & -17.10 & -23.05 \\
\hline
\end{tabular}

\subsubsection{Ruthenium-Catalyzed meta-C-H Alkylation of Phenylpyridines}

\section{Reaction Order with Respect to $\left[\mathrm{Ru}\left(\mathrm{O}_{2} \mathrm{CMes}\right)_{2}(p\right.$-cymene)] (61)}

The initial rate method was employed to determine the reaction order with respect to $\left[\mathrm{Ru}\left(\mathrm{O}_{2} \mathrm{CMes}\right)_{2}\left(p\right.\right.$-cymene)] (61). ${ }^{[178]}$ Under an atmosphere of $\mathrm{N}_{2}$ inside a glovebox, a Schlenk-tube was charged with 2-phenylpyridine (45a) (155 mg, $1.00 \mathrm{mmol}, 1.00$ equiv), $\left[\mathrm{Ru}\left(\mathrm{O}_{2} \mathrm{CMes}\right)_{2}(p\right.$-cymene) $](61)(2.5,3.5,5.0,7.5,10.0,12.5 \mathrm{~mol} \%)$ and $\mathrm{K}_{2} \mathrm{CO}_{3}(276 \mathrm{mg}, 2.00 \mathrm{mmol}$, 2.00 equiv). 1-Bromo-1-methylcyclohexane (100c) (531 mg, $3.00 \mathrm{mmol}, 3.00$ equiv), $n$-dodecane $(50 \mu \mathrm{L})$ and 1,4-dioxane $(4.0 \mathrm{~mL})$ were added and the mixture was stirred at $92^{\circ} \mathrm{C}$. After $60 \mathrm{~min}$ aliquots $(0.05 \mathrm{~mL})$ were removed via a syringe every $15 \mathrm{~min}$ for $3 \mathrm{~h}$, diluted with EtOAc, filtered through a short plug of silica gel and $\mathrm{Na}_{2} \mathrm{SO}_{4}$ and analyzed by gas chromatography.

\begin{tabular}{cccc}
\hline amount $/ \mathrm{mol}_{0}$ & $\log \left(c / \mathrm{mol} \mathrm{L}^{-1}\right)$ & $\Delta[$ 104ac $] \Delta t^{-1} / 10^{-8} \mathrm{~mol} \mathrm{~L}^{-1} \mathrm{~s}^{-1}$ & $\log \left(\Delta[\mathbf{1 0 4 a c}] \Delta t^{-1} / \mathrm{mol} \mathrm{L}^{-1} \mathrm{~s}^{-1}\right)$ \\
\hline 2.5 & -2.204 & 0.417 & -8.380 \\
3.5 & -2.058 & 0.635 & -8.197 \\
5.0 & -1.903 & 0.925 & -8.034 \\
7.5 & -1.727 & 1.880 & -7.726 \\
10.0 & -1.602 & 2.201 & -7.657 \\
12.5 & -1.505 & 2.470 & -7.607 \\
\hline
\end{tabular}

\section{Determination of the Activation Energy}

An Arrhenius plot analysis was employed to determine the activation energy of the reaction with reaction rate obtained via the initial rate method. ${ }^{[178]}$ Under an atmosphere of $\mathrm{N}_{2}$ inside a 
glovebox, a Schlenk-tube was charged with 2-(4-fluorophenyl)pyridine (45c) (173 mg, $1.00 \mathrm{mmol}$, 1.00 equiv), $\left[\mathrm{Ru}\left(\mathrm{O}_{2} \mathrm{CMes}\right)_{2}\left(p\right.\right.$-cymene)] (61) $(28.1 \mathrm{mg}, 50 \mu \mathrm{mol}, 5.0 \mathrm{~mol} \%)$ and $\mathrm{K}_{2} \mathrm{CO}_{3}(276 \mathrm{mg}$, $2.00 \mathrm{mmol}, 2.00$ equiv). 1-Bromo-1-methylcyclohexane (100c) $(531 \mathrm{mg}, 3.00 \mathrm{mmol}, 3.00$ equiv), 1-fluorononane $(36.6 \mathrm{mg}, 0.25 \mathrm{mmol})$ and $\mathrm{PhCMe}_{3}(4.0 \mathrm{~mL})$ were added and the mixture was stirred at various temperatures $\left(88,92,97,100,106,110^{\circ} \mathrm{C}\right)$. Periodically, aliquots $(0.1 \mathrm{~mL})$ were removed via a syringe, diluted with PhMe- $d_{8}$ and analyzed by ${ }^{19} \mathrm{~F}\left\{{ }^{1} \mathrm{H}\right\}-\mathrm{NMR}$ spectroscopy.

The Arrhenius plot analysis resulted in a value for the activation energy $E_{\mathrm{A}}$ of $19.9 \pm 0.9 \mathrm{kcal} \mathrm{mol}^{-1}$. Errors were calculated based on the fitting error of the linear regression as implemented in the OriginPro software.

\begin{tabular}{ccccc}
\hline$T / \mathrm{K}$ & $\begin{array}{c}T^{-1} / 10^{-3} \\
\mathrm{~K}^{-1}\end{array}$ & $\begin{array}{c}\Delta\left[\mathbf{1 0 4 c c} \Delta t^{-1} /\right. \\
10^{-8} \mathrm{~mol} \mathrm{~L}^{-1} \mathrm{~s}^{-1}\end{array}$ & $\begin{array}{c}\ln \left(\Delta[\mathbf{1 0 4 c c}] \Delta t^{-1} /\right. \\
\left.\mathrm{mol} \mathrm{L}^{-1} \mathrm{~s}^{-1}\right)\end{array}$ & $\begin{array}{c}\ln \left(\Delta[\mathbf{1 0 4 c c}] \Delta t^{-1} T^{-1} /\right. \\
\left.\mathrm{mol} \mathrm{L}^{-1} \mathrm{~s}^{-1} \mathrm{~K}^{-1}\right)\end{array}$ \\
\hline 365.2 & 2.739 & 1.549 & -17.98 & -23.88 \\
370.2 & 2.702 & 2.280 & -17.60 & -23.51 \\
373.2 & 2.680 & 2.630 & -17.45 & -23.38 \\
379.2 & 2.637 & 4.042 & -17.02 & -22.96 \\
383.2 & 2.610 & 5.782 & -16.67 & -22.61 \\
\hline
\end{tabular}

\subsubsection{Ruthenium-Catalyzed Decarboxylative C-H Activation}<smiles>O=C(O)c1c(O)cccc1F</smiles>

$31 \mathrm{~b}$ or $[D]_{1}-31 b$<smiles>O=C1C=CC(=O)N1Cc1ccccc1</smiles>

$177 b$
$\left[\mathrm{Ru}\left(\mathrm{O}_{2} \mathrm{CMes}\right)_{2}(p\right.$-cymene $\left.)\right](61)$ $(10 \mathrm{~mol} \%)$

$\mathrm{PhMe}, 110^{\circ} \mathrm{C}$

$$
k_{\mathrm{H}} / k_{\mathrm{D}}=1.05
$$<smiles>O=C1CC(c2cccc(F)c2)C(=O)N1Cc1ccccc1</smiles>

$178 \mathrm{bb}$

The KIE value was determined by the comparison of initial rates of two independent reactions. Under an atmosphere of $\mathrm{N}_{2}$, a two-necked Schlenk-tube was charged with 2-fluorobenzoic acid (31b) (140 mg, $1.00 \mathrm{mmol}, 2.00$ equiv) or 6-deutero-2-fluorobenzoic acid ([D] $\left.]_{1}-31 \mathrm{~b}\right)$ (141 mg, $1.00 \mathrm{mmol}, 1.00$ equiv), 1-benzyl-1H-pyrrole-2,5-dione (177b) (94 mg, $0.50 \mathrm{mmol}, 1.00$ equiv) and [Ru( $\left.\mathrm{O}_{2} \mathrm{CMes}\right)_{2}(p$-cymene)] (61) $(28.1 \mathrm{mg}, 50 \mu \mathrm{mol}, 10.0 \mathrm{~mol} \%)$. PhMe $(3.0 \mathrm{~mL})$ was added and the mixture was stirred at $110^{\circ} \mathrm{C}$. An in situ IR spectrum was acquired every $1 \mathrm{~min}$ for the first $8 \mathrm{~h}$ and every $2 \mathrm{~min}$ for the following $16 \mathrm{~h}$. The initial rates were determined from the decrease in peak 
area of the peak at $1405 \mathrm{~cm}^{-1}$, which was assigned to the C-F stretching frequency of $\mathbf{3 1 b}$. The peak area was calculated in the range $1422-1399 \mathrm{~cm}^{-1}$ with a two-point baseline at $1422 \mathrm{~cm}^{-1}$ and $1399 \mathrm{~cm}^{-1}$. A KIE of $k_{\mathrm{H}} / k_{\mathrm{D}} \approx 1.05$ was determined by employing a linear fit for the time interval $0.5-5.0 \mathrm{~h}$.

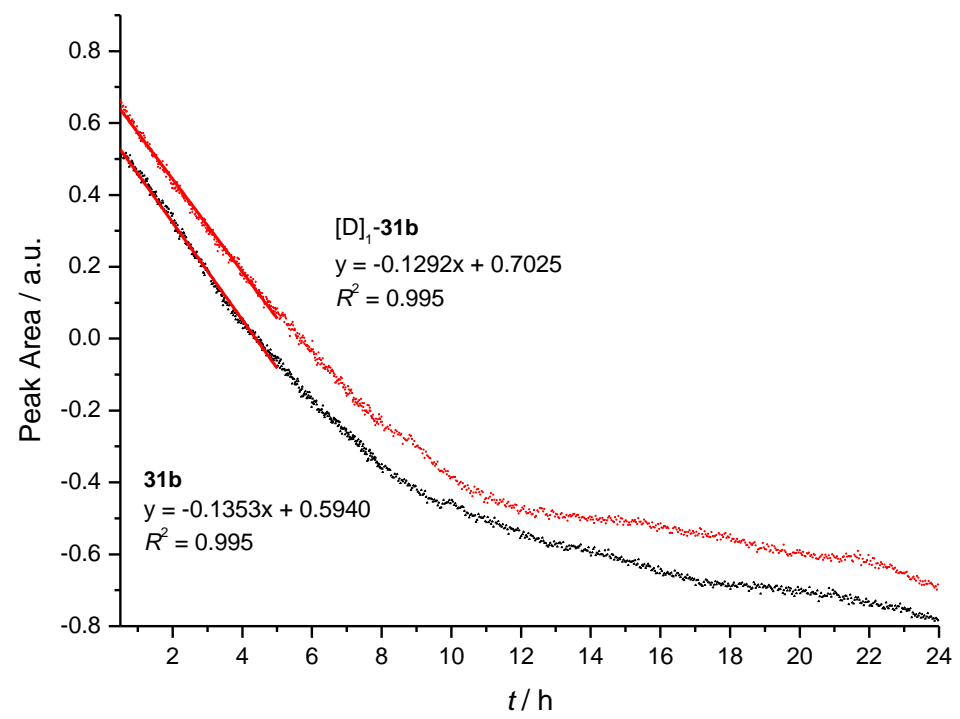

Figure 67: In situ IR measurements for the reaction of $\mathbf{3 1 b}$ and $[D]_{1}-\mathbf{3 1 b}$.

\subsubsection{Ruthenium-Catalyzed C-H Alkenylation of Aryl Acetamides}

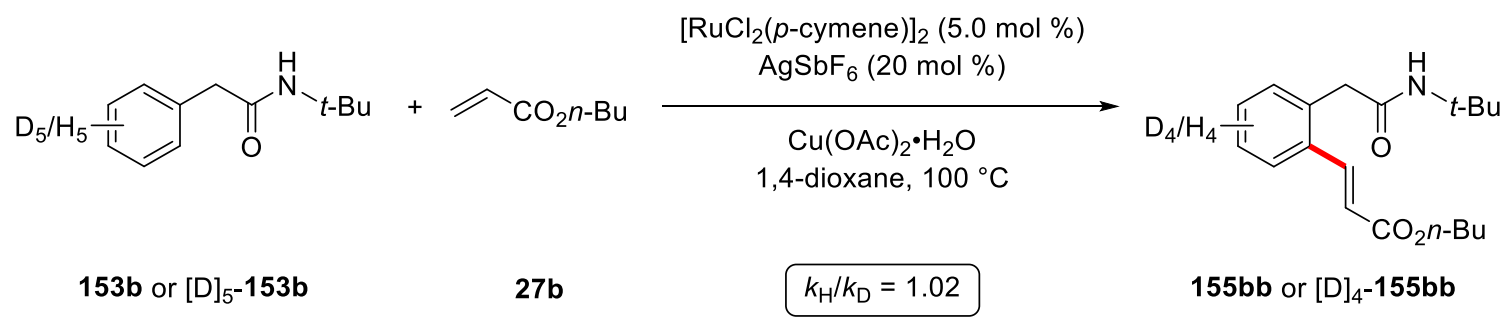

The KIE value was determined by the comparison of initial rates of two independent reactions. Under an atmosphere of $\mathrm{N}_{2}$, a two-necked Schlenk-tube was charged with $\mathrm{N}$-(tert-butyl)-2phenylacetamide (153b) (143 mg, $0.75 \mathrm{mmol}, 1.00$ equiv) or $\mathrm{N}$-(tert-butyl)-2(perdeuterophenyl)acetamide ([D $\left.]_{5}-153 b\right)\left(147 \mathrm{mg}, 0.75 \mathrm{mmol}, 1.00\right.$ equiv), $\left[\mathrm{RuCl}_{2}(p \text {-cymene) }]_{2}\right.$ (23 mg, $38 \mu \mathrm{mol}, 5.0 \mathrm{~mol} \%), \mathrm{AgSbF}_{6}(52 \mathrm{mg}, 0.15 \mathrm{mmol}, 20 \mathrm{~mol} \%)$ and $\mathrm{Cu}(\mathrm{OAc})_{2} \cdot \mathrm{H}_{2} \mathrm{O}(299 \mathrm{mg}$, $1.50 \mathrm{mmol}, 2.00$ equiv). $n$-Butylacrylate (27b) (192 mg, $1.50 \mathrm{mmol}, 2.00$ equiv) and 1,4-dioxane $(3.0 \mathrm{~mL})$ were added and the mixture was stirred at $100^{\circ} \mathrm{C}$. An in situ IR spectrum was acquired every $30 \mathrm{~s}$ for the first $2 \mathrm{~h}$, every $1 \mathrm{~min}$ for the following $4 \mathrm{~h}$ and every $2 \mathrm{~min}$ for the following $16 \mathrm{~h}$. The initial rates were determined from the increase in peak area of the peak at $1726 \mathrm{~cm}^{-1}$, which was assigned to the $\mathrm{C}=\mathrm{O}$ stretching frequency of $\mathbf{1 5 5 b \mathrm { b }}$. The peak area was calculated in the range 
$1744-1701 \mathrm{~cm}^{-1}$ with a one-point baseline at $871 \mathrm{~cm}^{-1}$. A KIE of $k_{\mathrm{H}} / k_{\mathrm{D}} \approx 1.02$ was determined by employing a linear fit for the time interval $0.4-0.9 \mathrm{~h}$ for the protonated substrate and $0.5-1.0 \mathrm{~h}$ for the deuterated substrate.

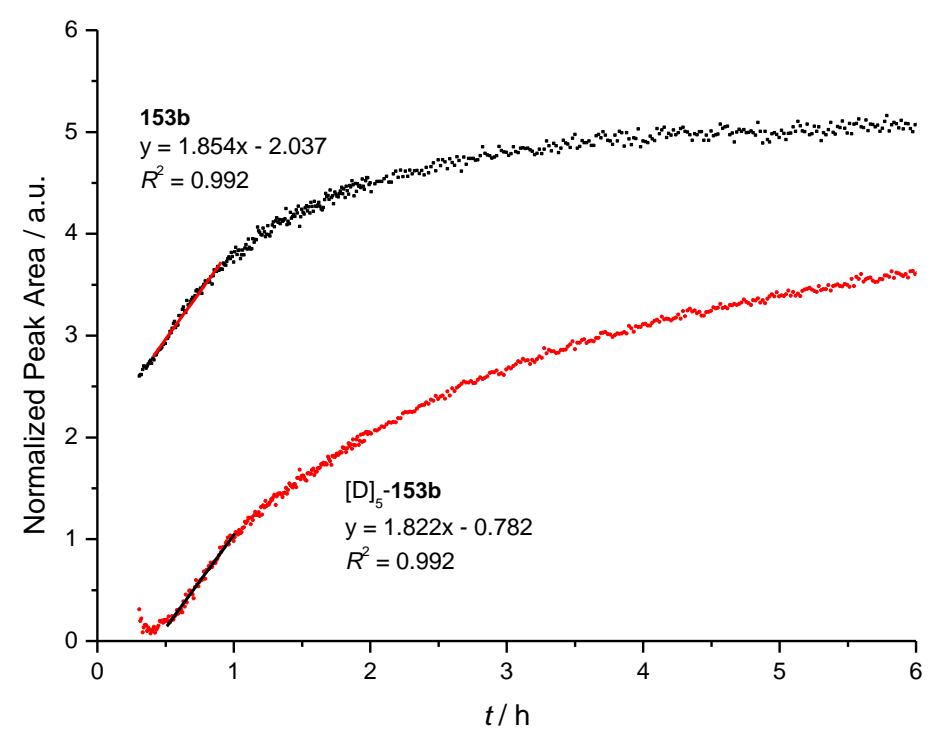

Figure 68: In situ IR measurements for the reaction of $153 b$ and $[D]_{5}-153 b$.

\subsubsection{Ruthenium-Catalyzed Oxidative $\mathrm{C}-\mathrm{H} / \mathrm{C}-\mathrm{H}$ Activation}

\subsubsection{Data for Products 47 and 181}

2,2'-(3,6'-Dimethyl-[1,1'-biphenyl]-2,2'-diyl)dipyridine (181d) and 3'-methyl-2'-(pyridin-2-yl)[1,1'-biphenyl]-2-carbonitrile (47dk)<smiles>Cc1cccc(-c2cccc(C)c2-c2ccccn2)c1-c1ccccn1</smiles><smiles>Cc1cccc(-c2ccccc2C#N)c1-c1ccccn1</smiles>

General procedure B was followed using 2-(2-methylphenyl)pyridine (45d) $(85 \mathrm{mg}, 0.50 \mathrm{mmol})$ and 2-iodobenzonitrile (54c) (172 $\mathrm{mg}, 0.75 \mathrm{mmol})$. Purification by column chromatography on silica gel ( $n$-hexane/EtOAc 2:1) yielded 181d (66 mg, 78\%) as a colorless solid and $\mathbf{4 7 d k}(12 \mathrm{mg}$, 9\%) as an off-white solid. 
Data for 181d:

${ }^{1} \mathrm{H}-\mathrm{NMR}\left(300 \mathrm{MHz}, \mathrm{CDCl}_{3}\right): \delta=8.56(\mathrm{~d}, J=4.6 \mathrm{~Hz}, 2 \mathrm{H}), 7.53$ (ddd, J = 7.8, 7.7, $\left.1.6 \mathrm{~Hz}, 2 \mathrm{H}\right), 7.31(\mathrm{~d}, J$ $=7.8 \mathrm{~Hz}, 2 \mathrm{H}), 7.11-7.00(\mathrm{~m}, 4 \mathrm{H}), 6.93(\mathrm{dd}, J=7.5,7.5 \mathrm{~Hz}, 2 \mathrm{H}), 6.77(\mathrm{~d}, J=7.4 \mathrm{~Hz}, 2 \mathrm{H}), 2.10(\mathrm{~s}, 6 \mathrm{H})$. ${ }^{13} \mathrm{C}-\mathrm{NMR}\left(75 \mathrm{MHz}, \mathrm{CDCl}_{3}\right): \delta=159.6\left(\mathrm{C}_{\mathrm{q}}\right), 148.8(\mathrm{CH}), 140.4\left(\mathrm{C}_{\mathrm{q}}\right), 139.9\left(\mathrm{C}_{\mathrm{q}}\right), 136.0\left(\mathrm{C}_{\mathrm{q}}\right), 135.6(\mathrm{CH})$, $129.0(\mathrm{CH}), 128.7(\mathrm{CH}), 126.7(\mathrm{CH}), 125.8(\mathrm{CH}), 121.3(\mathrm{CH}), 20.7\left(\mathrm{CH}_{3}\right)$. IR $(\mathrm{ATR}): \tilde{v}=1584,1562$, 1453, 1422, 1023, 783, 748, 621, 525, $399 \mathrm{~cm}^{-1}$. m.p.: $155^{\circ} \mathrm{C}$. MS (ESI) $\mathrm{m} / \mathrm{z}$ (relative intensity): 337 $[\mathrm{M}+\mathrm{H}]^{+}(100), 359[\mathrm{M}+\mathrm{Na}]^{+}(18), 695[2 \mathrm{M}+\mathrm{Na}]^{+}(9) . \mathrm{HR}-\mathrm{MS}(\mathrm{ESI}): \mathrm{m} / z$ calcd for $\mathrm{C}_{24} \mathrm{H}_{20} \mathrm{~N}_{2} \mathrm{Na}^{+}[\mathrm{M}+\mathrm{Na}]^{+}$ 359.1519 , found 359.1513 .

The analytical data are in accordance with those reported in the literature. ${ }^{[115]}$

Data for 47dk:

${ }^{1} \mathrm{H}-\mathrm{NMR}\left(300 \mathrm{MHz}, \mathrm{CDCl}_{3}\right): \delta=8.56(\mathrm{ddd}, J=4.6,1.7,1.2 \mathrm{~Hz}, 1 \mathrm{H}), 7.58(\mathrm{dd}, J=7.5,1.4 \mathrm{~Hz}, 1 \mathrm{H}), 7.50$ (ddd, J = 7.7, 7.7, 1.9 Hz, 1H), 7.46-7.37 (m, 2H), 7.34-7.27 (m, 2H), 7.23 (ddd, J = 7.7, 7.7, 1.5 Hz, 1H), 7.15-7.04 (m, 3H), $2.22(\mathrm{~s}, 3 \mathrm{H}) .{ }^{13} \mathrm{C}-\mathrm{NMR}\left(75 \mathrm{MHz}, \mathrm{CDCl}_{3}\right): \delta=158.7\left(\mathrm{C}_{\mathrm{q}}\right), 149.0(\mathrm{CH}), 145.8$ $\left(\mathrm{C}_{\mathrm{q}}\right), 139.9\left(\mathrm{C}_{\mathrm{q}}\right), 137.6\left(\mathrm{C}_{\mathrm{q}}\right), 137.0\left(\mathrm{C}_{\mathrm{q}}\right), 135.9(\mathrm{CH}), 132.6(\mathrm{CH}), 131.7(\mathrm{CH}), 131.7(\mathrm{CH}), 131.0(\mathrm{CH})$, $128.2(\mathrm{CH}), 127.6(\mathrm{CH}), 127.1(\mathrm{CH}), 125.5(\mathrm{CH}), 121.6(\mathrm{CH}), 118.6\left(\mathrm{C}_{\mathrm{q}}\right), 112.7\left(\mathrm{C}_{\mathrm{q}}\right), 20.5\left(\mathrm{CH}_{3}\right)$. IR (ATR): $\tilde{v}=1458,1419,796,772,748,618,581,558,521,422 \mathrm{~cm}^{-1}$. m.p.: $106^{\circ} \mathrm{C}$. MS (ESI) $\mathrm{m} / \mathrm{z}$ (relative intensity): $271[\mathrm{M}+\mathrm{H}]^{+}(100), 293[\mathrm{M}+\mathrm{Na}]^{+}(9)$. HR-MS (ESI): $\mathrm{m} / z$ calcd for $\mathrm{C}_{19} \mathrm{H}_{15} \mathrm{~N}_{2}{ }^{+}[\mathrm{M}+\mathrm{H}]^{+}$ 271.1230, found 271.1231 .

\section{2-[3-Methyl-4'-(trifluoromethyl)-[1,1'-biphenyl]-2-yl]pyridine (47dc)}

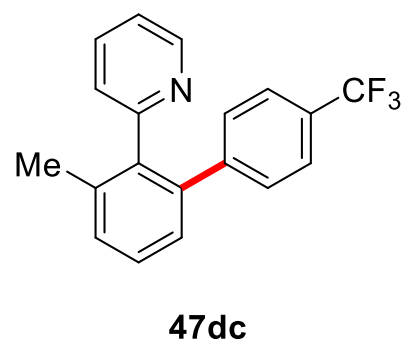

General procedure B was followed using 2-(2-methylphenyl)pyridine (45d) (85 mg, $0.50 \mathrm{mmol}$ ) and 4-bromotrifluorotoluene (46c) (169 mg, $0.75 \mathrm{mmol})$. Purification by column chromatography on silica gel ( $n$-hexane/EtOAc 5:1) yielded $47 \mathrm{dc}$ ( $137 \mathrm{mg}, 87 \%$ ) as a slightly yellow oil.

${ }^{1} \mathrm{H}-\mathrm{NMR}\left(400 \mathrm{MHz}, \mathrm{CDCl}_{3}\right): \delta=8.60$ (ddd, $J=4.9,1.8,1.0 \mathrm{~Hz}, 1 \mathrm{H}$ ), $7.44(\mathrm{ddd}, J=7.7,7.7,1.8 \mathrm{~Hz}$, $1 \mathrm{H}$ ), 7.39-7.29 (m, 4H), 7.23 (ddd, J = 7.1, 1.7, 0.7 Hz, 1H), 7.20-7.14 (m, 2H), 7.08 (ddd, J = 7.7, 
4.9, $1.2 \mathrm{~Hz}, 1 \mathrm{H}), 6.87$ (ddd, $J=7.7,1.1,1.1 \mathrm{~Hz}, 1 \mathrm{H}), 2.17(\mathrm{~s}, 3 \mathrm{H}) .{ }^{13} \mathrm{C}-\mathrm{NMR}\left(100 \mathrm{MHz}, \mathrm{CDCl}_{3}\right): \delta=$ $159.1\left(\mathrm{C}_{\mathrm{q}}\right), 149.1(\mathrm{CH}), 145.5\left(\mathrm{C}_{\mathrm{q}}\right), 139.9\left(\mathrm{C}_{\mathrm{q}}\right), 139.4\left(\mathrm{C}_{\mathrm{q}}\right), 137.1\left(\mathrm{C}_{\mathrm{q}}\right), 136.0(\mathrm{CH}), 130.2(\mathrm{CH}), 130.0$ $(\mathrm{CH}), 128.5\left(\mathrm{q},{ }^{2} \mathrm{~J}_{\mathrm{C}-\mathrm{F}}=32.3 \mathrm{~Hz}, \mathrm{C}_{\mathrm{q}}\right), 128.3(\mathrm{CH}), 127.5(\mathrm{CH}), 125.6(\mathrm{CH}), 124.6\left(\mathrm{q},{ }^{3} J_{\mathrm{C}-\mathrm{F}}=3.8 \mathrm{~Hz}, \mathrm{CH}\right)$, $124.2\left(\mathrm{q},{ }^{1} J_{\mathrm{C}-\mathrm{F}}=272.6 \mathrm{~Hz}, \mathrm{C}_{\mathrm{q}}\right), 121.7(\mathrm{CH}), 20.5\left(\mathrm{CH}_{3}\right) \cdot{ }^{19} \mathrm{~F}-\mathrm{NMR}\left(282 \mathrm{MHz}, \mathrm{CDCl}_{3}\right): \delta=-62.4(\mathrm{~s}) . \mathbf{I R}$ (ATR): $\tilde{v}=1321,1162,1107,1083,1062,1017,844,788,748,610 \mathrm{~cm}^{-1}$. MS (ESI) $\mathrm{m} / \mathrm{z}$ (relative intensity): $314[\mathrm{M}+\mathrm{H}]^{+}(100), 336[\mathrm{M}+\mathrm{Na}]^{+}$(7). HR-MS (ESI): $\mathrm{m} / \mathrm{z}$ calcd for $\mathrm{C}_{19} \mathrm{H}_{15} \mathrm{NF}_{3}{ }^{+}[\mathrm{M}+\mathrm{H}]^{+}$ 314.1151, found 314.1150.

The analytical data are in accordance with those reported in the literature. ${ }^{[161 a]}$

\section{2-[3-Methyl-3'-(trifluoromethyl)-[1,1'-biphenyl]-2-yl]pyridine (47dd)}<smiles>Cc1cccc(-c2cccc(C(F)(F)F)c2)c1-c1ccccn1</smiles>

$47 d d$

General procedure B was followed using 2-(2-methylphenyl)pyridine (45d) $(85 \mathrm{mg}, 0.50 \mathrm{mmol})$ and 3-bromotrifluorotoluene (46d) $(169 \mathrm{mg}, 0.75 \mathrm{mmol})$. Purification by column chromatography on silica gel ( $n$-hexane/EtOAc 5:1 $\rightarrow 1: 1$ ) yielded $47 \mathrm{dd}(132 \mathrm{mg}, 84 \%$ ) as a slightly yellow oil.

${ }^{1} \mathrm{H}-\mathrm{NMR}\left(400 \mathrm{MHz}, \mathrm{CDCl}_{3}\right): \delta=8.57$ (ddd, $J=4.9,1.9,1.0 \mathrm{~Hz}, 1 \mathrm{H}$ ), 7.40 (ddd, $J=7.7,7.7,1.8 \mathrm{~Hz}$, 1H), 7.36-7.15 (m, 7H), 7.04 (ddd, $J=7.7,4.9,1.1 \mathrm{~Hz}, 1 \mathrm{H}$ ), 6.84 (ddd, $J=7.7,1.1,1.0 \mathrm{~Hz}, 1 \mathrm{H}$ ), 2.15 $(\mathrm{s}, 3 \mathrm{H}) .{ }^{13} \mathrm{C}-\mathrm{NMR}\left(100 \mathrm{MHz}, \mathrm{CDCl}_{3}\right): \delta=159.1\left(\mathrm{C}_{\mathrm{q}}\right), 149.1(\mathrm{CH}), 142.2\left(\mathrm{C}_{\mathrm{q}}\right), 139.8\left(\mathrm{C}_{\mathrm{q}}\right), 139.6\left(\mathrm{C}_{\mathrm{q}}\right)$, $137.0\left(\mathrm{C}_{\mathrm{q}}\right), 135.9(\mathrm{CH}), 132.8(\mathrm{CH}), 130.1(\mathrm{CH}), 130.0\left(\mathrm{q},{ }^{2} \mathrm{~J}_{\mathrm{C}-\mathrm{F}}=32.4 \mathrm{~Hz}, \mathrm{C}_{\mathrm{q}}\right), 128.3(\mathrm{CH}), 128.1(\mathrm{CH})$, $127.4(\mathrm{CH}), 126.6\left(\mathrm{q},{ }^{3} \mathrm{~J}_{\mathrm{C}-\mathrm{F}}=3.9 \mathrm{~Hz}, \mathrm{CH}\right), 125.3(\mathrm{CH}), 126.6\left(\mathrm{q},{ }^{3} \mathrm{~J}_{\mathrm{C}-\mathrm{F}}=3.9 \mathrm{~Hz}, \mathrm{CH}\right), 124.1\left(\mathrm{q},{ }^{1} \mathrm{~J}_{\mathrm{C}-\mathrm{F}}=\right.$ $\left.273.3 \mathrm{~Hz}, \mathrm{C}_{\mathrm{q}}\right), 121.6(\mathrm{CH}), 20.4\left(\mathrm{CH}_{3}\right) .{ }^{19} \mathrm{~F}-\mathrm{NMR}\left(282 \mathrm{MHz}, \mathrm{CDCl}_{3}\right): \delta=-62.7$ (s). IR (ATR): $\tilde{v}=1334$, 1272, 1163, 1119, 1096, 1070, 784, 748, 699, $660 \mathrm{~cm}^{-1}$. MS (ESI) $\mathrm{m} / \mathrm{z}$ (relative intensity): 314 $[\mathrm{M}+\mathrm{H}]^{+}(100), 336[\mathrm{M}+\mathrm{Na}]^{+}$(7). HR-MS (ESI): $\mathrm{m} / \mathrm{z}$ calcd for $\mathrm{C}_{19} \mathrm{H}_{15} \mathrm{NF}_{3}{ }^{+}[\mathrm{M}+\mathrm{H}]^{+} 314.1151$, found 314.1150 . 
2-(3-Methyl-[1,1'-biphenyl]-2-yl)pyridine (47de)<smiles>Cc1cccc(-c2ccccc2)c1-c1ccccn1</smiles>

General procedure B was followed using 2-(2-methylphenyl)pyridine (45d) (85 mg, $0.50 \mathrm{mmol}$ ) and bromobenzene (46e) (118 $\mathrm{mg}, 0.75 \mathrm{mmol})$. Purification by column chromatography on silica gel ( $n$-hexane/EtOAc 5:1) yielded $47 \mathrm{de} \mathrm{(102} \mathrm{mg,} \mathrm{83 \% )} \mathrm{as} \mathrm{a} \mathrm{colorless} \mathrm{oil.}$

${ }^{1} \mathrm{H}-\mathrm{NMR}\left(300 \mathrm{MHz}, \mathrm{CDCl}_{3}\right.$ ): $\delta=8.64$ (ddd, $J=5.0,1.9,1.0 \mathrm{~Hz}, 1 \mathrm{H}$ ), 7.43 (ddd, $J=7.6,7.6,1.7 \mathrm{~Hz}$, $1 \mathrm{H}), 7.27-7.39(\mathrm{~m}, 3 \mathrm{H}), 7.19-7.06(\mathrm{~m}, 6 \mathrm{H}), 6.92-6.86(\mathrm{~m}, 1 \mathrm{H}), 2.22(\mathrm{~s}, 3 \mathrm{H}) .{ }^{13} \mathrm{C}-\mathrm{NMR}(75 \mathrm{MHz}$, $\left.\mathrm{CDCl}_{3}\right): \delta=159.6\left(\mathrm{C}_{\mathrm{q}}\right), 148.8(\mathrm{CH}), 141.9\left(\mathrm{C}_{\mathrm{q}}\right), 141.3\left(\mathrm{C}_{\mathrm{q}}\right), 139.4\left(\mathrm{C}_{\mathrm{q}}\right), 136.7\left(\mathrm{C}_{\mathrm{q}}\right), 135.7(\mathrm{CH}), 129.6$ (CH), $129.4(\mathrm{CH}), 128.0(\mathrm{CH}), 127.6(2 \times \mathrm{CH}), 126.2(\mathrm{CH}), 125.6(\mathrm{CH}), 121.3(\mathrm{CH}), 20.5\left(\mathrm{CH}_{3}\right) . \mathrm{IR}(\mathrm{ATR})$ : $\tilde{v}=1585,1562,1459,1418,1025,787,746,700,578,403 \mathrm{~cm}^{-1}$. MS (ESI) $\mathrm{m} / z$ (relative intensity): $246[\mathrm{M}+\mathrm{H}]^{+}(100), 268[\mathrm{M}+\mathrm{Na}]^{+}$(4). HR-MS (ESI): $m / z$ calcd for $\mathrm{C}_{18} \mathrm{H}_{16} \mathrm{~N}^{+}[\mathrm{M}+\mathrm{H}]^{+} 246.1277$, found 246.1283.

The analytical data are in accordance with those reported in the literature. ${ }^{[180]}$

\section{2-(2'-Fluoro-3-methyl-[1,1'-biphenyl]-2-yl)pyridine (47df)}<smiles>Cc1cccc(-c2ccccc2F)c1-c1ccccn1</smiles>

General procedure B was followed using 2-(2-methylphenyl)pyridine (45d) $(85 \mathrm{mg}, 0.50 \mathrm{mmol})$ and 2-bromofluorobenzene (46f) (131 $\mathrm{mg}, 0.75 \mathrm{mmol}$ ). Purification by column chromatography on silica gel ( $n$-hexane/EtOAc 7:1) yielded $\mathbf{4 7 d f}(99 \mathrm{mg}, 75 \%)$ as a yellow oil.

${ }^{1} \mathrm{H}-\mathrm{NMR}\left(400 \mathrm{MHz}, \mathrm{CDCl}_{3}\right): \delta=8.54$ (ddd, $J=4.9,1.9,1.0 \mathrm{~Hz}, 1 \mathrm{H}$ ), 7.42 (ddd, $J=7.7,7.7,1.8 \mathrm{~Hz}$, $1 \mathrm{H}), 7.36-7.29(\mathrm{~m}, 2 \mathrm{H}), 7.26-7.21(\mathrm{~m}, 1 \mathrm{H}), 7.11-7.04(\mathrm{~m}, 1 \mathrm{H}), 7.04-6.95(\mathrm{~m}, 3 \mathrm{H}), 6.90-6.83(\mathrm{~m}$, 2H), $2.19(\mathrm{~s}, 3 \mathrm{H}) .{ }^{13} \mathrm{C}-\mathrm{NMR}\left(100 \mathrm{MHz}, \mathrm{CDCl}_{3}\right): \delta=159.5\left(\mathrm{~d},{ }^{1} \mathrm{~J}_{\mathrm{C}-\mathrm{F}}=245.7 \mathrm{~Hz}, \mathrm{C}_{\mathrm{q}}\right), 159.0\left(\mathrm{C}_{\mathrm{q}}\right), 148.8$ $(\mathrm{CH}), 140.2\left(\mathrm{C}_{q}\right), 136.6\left(\mathrm{C}_{q}\right), 135.6(\mathrm{CH}), 135.1\left(\mathrm{C}_{q}\right), 132.2\left(\mathrm{~d},{ }^{4} \mathrm{~J}_{\mathrm{C}-\mathrm{F}}=3.4 \mathrm{~Hz}, \mathrm{CH}\right), 130.1(\mathrm{CH}), 129.1$ 
$\left(d,{ }^{2} J_{C-F}=16.1 \mathrm{~Hz}, C_{q}\right), 128.6\left(d,{ }^{3} J_{C-F}=8.0 \mathrm{~Hz}, \mathrm{CH}\right), 128.0\left(\mathrm{~d},{ }^{4} J_{\mathrm{C}-\mathrm{F}}=1.2 \mathrm{~Hz}, \mathrm{CH}\right), 127.8(\mathrm{CH}), 125.0$ $(\mathrm{CH}), 123.3\left(\mathrm{~d},{ }^{3} J_{\mathrm{C}-\mathrm{F}}=3.7 \mathrm{~Hz}, \mathrm{CH}\right), 121.4(\mathrm{CH}), 115.1\left(\mathrm{~d},{ }^{2} \mathrm{~J}_{\mathrm{C}-\mathrm{F}}=22.5 \mathrm{~Hz}, \mathrm{CH}\right), 20.5\left(\mathrm{CH}_{3}\right) .{ }^{19} \mathrm{~F}-\mathrm{NMR}$ (282 MHz, CDCl $): \delta=-114.7$ (s). IR (ATR): $\tilde{v}=1584,1496,1461,1420,1210,788,747,618,520$, $402 \mathrm{~cm}^{-1}$. MS (ESI) $m / z$ (relative intensity): $264[\mathrm{M}+\mathrm{H}]^{+}(100)$. HR-MS (ESI): $\mathrm{m} / z$ calcd for $\mathrm{C}_{18} \mathrm{H}_{15} \mathrm{NF}^{+}$ $[\mathrm{M}+\mathrm{H}]^{+}$264.1183, found 264.1183 .

\section{2-(2',3-Dimethyl-[1,1'-biphenyl]-2-yl)pyridine (47dg)}<smiles>Cc1ccccc1-c1cccc(C)c1-c1ccccn1</smiles>

General procedure B was followed using 2-(2-methylphenyl)pyridine (45d) $(85 \mathrm{mg}, 0.50 \mathrm{mmol})$ and 2-bromotoluene $(\mathbf{4 6 g})(128 \mathrm{mg}, 0.75 \mathrm{mmol}$ ). Purification by column chromatography on silica gel ( $n$-hexane/EtOAc 10:1 $\rightarrow 1: 1)$ and GPC purification yielded $181 \mathrm{~d}(10 \mathrm{mg}, 12 \%)$ as a colorless

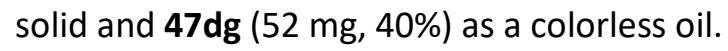

${ }^{1} \mathrm{H}-\mathrm{NMR}\left(300 \mathrm{MHz}, \mathrm{CDCl}_{3}\right): \delta=8.55(\mathrm{ddd}, J=4.9,1.9,1.1 \mathrm{~Hz}, 1 \mathrm{H}), 7.42-7.28(\mathrm{~m}, 3 \mathrm{H}), 7.17-7.11(\mathrm{~m}$, 1H), 7.09-6.94 (m, 5H), 6.87 (ddd, J = 7.8, 1.1, $1.1 \mathrm{~Hz}, 1 \mathrm{H}), 2.22(\mathrm{~s}, 3 \mathrm{H}), 2.07$ (s, 3H). ${ }^{13} \mathrm{C}-\mathrm{NMR}$ $\left(75 \mathrm{MHz}, \mathrm{CDCl}_{3}\right): \delta=159.2\left(\mathrm{C}_{\mathrm{q}}\right), 148.7(\mathrm{CH}), 141.2\left(\mathrm{C}_{\mathrm{q}}\right), 140.9\left(\mathrm{C}_{\mathrm{q}}\right), 139.8\left(\mathrm{C}_{\mathrm{q}}\right), 136.6\left(\mathrm{C}_{\mathrm{q}}\right), 136.0\left(\mathrm{C}_{\mathrm{q}}\right)$, $135.3(\mathrm{CH}), 130.5(\mathrm{CH}), 129.5(\mathrm{CH}), 129.4(\mathrm{CH}), 127.7(\mathrm{CH}), 127.5(\mathrm{CH}), 126.8(\mathrm{CH}), 125.2(\mathrm{CH}), 124.8$ (CH), $121.2(\mathrm{CH}), 20.6\left(\mathrm{CH}_{3}\right), 20.4\left(\mathrm{CH}_{3}\right)$. IR (ATR): $\tilde{v}=1584,1562,1459,1420,786,746,727,621$, $582,457 \mathrm{~cm}^{-1}$. MS (ESI) $\mathrm{m} / \mathrm{z}$ (relative intensity): $260[\mathrm{M}+\mathrm{H}]^{+}(100), 282[\mathrm{M}+\mathrm{Na}]^{+}$(4). HR-MS (ESI): $\mathrm{m} / \mathrm{z}$ calcd for $\mathrm{C}_{19} \mathrm{H}_{18} \mathrm{~N}^{+}[\mathrm{M}+\mathrm{H}]^{+} 260.1434$, found 260.1427 .

The analytical data are in accordance with those reported in the literature. ${ }^{[179]}$

\section{2-(2',6'-Difluoro-3-methyl-[1,1'-biphenyl]-2-yl)pyridine (47dh)}<smiles>Cc1cccc(-c2c(F)cccc2F)c1-c1ccccn1</smiles>

$47 \mathrm{dh}$ 
General procedure B was followed using 2-(2-methylphenyl)pyridine (45d) $(85 \mathrm{mg}, 0.50 \mathrm{mmol})$ and 1,3-difluoro-2-bromobenzene $(46 \mathrm{~h})(145 \mathrm{mg}, 0.75 \mathrm{mmol})$. Purification by column chromatography on silica gel ( $n$-hexane/EtOAc $8: 1 \rightarrow 1: 1)$ yielded $47 \mathrm{dh}(21 \mathrm{mg}, 15 \%)$ as a yellow solid.

${ }^{1} \mathrm{H}-\mathrm{NMR}\left(300 \mathrm{MHz}, \mathrm{CDCl}_{3}\right): \delta=8.53(\mathrm{~d}, J=4.9 \mathrm{~Hz}, 1 \mathrm{H}), 7.49$ (ddd, $\left.J=7.7,7.7,1.8 \mathrm{~Hz}, 1 \mathrm{H}\right), 7.43-7.33$ $(\mathrm{m}, 2 \mathrm{H}), 7.25-7.17(\mathrm{~m}, 1 \mathrm{H}), 7.15-7.06(\mathrm{~m}, 3 \mathrm{H}), 6.71(\mathrm{t}, J=8.0 \mathrm{~Hz}, 2 \mathrm{H}), 2.22(\mathrm{~s}, 3 \mathrm{H}) .{ }^{13} \mathrm{C}-\mathrm{NMR}$ $\left(75 \mathrm{MHz}, \mathrm{CDCl}_{3}\right): \delta=160.0\left(\mathrm{dd},{ }^{1,3} \mathrm{~J}_{\mathrm{C}-\mathrm{F}}=248.5,7.2 \mathrm{~Hz}, \mathrm{C}_{\mathrm{q}}\right), 158.7\left(\mathrm{C}_{\mathrm{q}}\right), 149.1(\mathrm{CH}), 141.1\left(\mathrm{C}_{\mathrm{q}}\right), 136.8$ ( $\left.\mathrm{C}_{\mathrm{q}}\right), 135.5(\mathrm{CH}), 130.9(\mathrm{CH}), 129.0\left(\mathrm{t},{ }^{3} \mathrm{~J}_{\mathrm{C}-\mathrm{F}}=10.0 \mathrm{~Hz}, \mathrm{CH}\right), 128.7\left(\mathrm{C}_{\mathrm{q}}\right), 128.3(\mathrm{CH}), 128.0(\mathrm{CH}), 124.4$ (CH), $121.6(\mathrm{CH}), 118.5\left(\mathrm{t},{ }^{2} \mathrm{~J}_{\mathrm{C}-\mathrm{F}}=21.4 \mathrm{~Hz}, \mathrm{C}_{\mathrm{q}}\right), 110.8\left(\mathrm{dd},{ }^{2,4} \mathrm{~J}_{\mathrm{C}-\mathrm{F}}=22.7,3.6 \mathrm{~Hz}, \mathrm{CH}\right), 20.5\left(\mathrm{CH}_{3}\right) .{ }^{19} \mathrm{~F}-$ NMR $\left(282 \mathrm{MHz}, \mathrm{CDCl}_{3}\right): \delta=-111.2$ (s). m.p.: $101^{\circ} \mathrm{C}$. IR (ATR): $\tilde{v}=1464,1454,996,796,783,750$, $726,511,408,396 \mathrm{~cm}^{-1}$. MS (ESI) $\mathrm{m} / \mathrm{z}$ (relative intensity): $282[\mathrm{M}+\mathrm{H}]^{+}(100), 304[\mathrm{M}+\mathrm{Na}]^{+}(10)$. HRMS (ESI): $m / z$ calcd for $\mathrm{C}_{18} \mathrm{H}_{14} \mathrm{NF}_{2}{ }^{+}[\mathrm{M}+\mathrm{H}]^{+} 282.1089$, found 282.1086 .

\section{1-[3'-Methyl-2'-(pyridin-2-yl)-[1,1'-biphenyl]-2-yl]ethan-1-one (47di)}<smiles>CC(=O)c1ccccc1-c1cccc(C)c1-c1ccccn1</smiles>

47di

General procedure B was followed using 2-(2-methylphenyl)pyridine (45d) $(85 \mathrm{mg}, 0.50 \mathrm{mmol})$ and 2'-bromoacetophenone (46i) $(149 \mathrm{mg}, 0.75 \mathrm{mmol})$. Purification by column chromatography on silica gel ( $n$-hexane/EtOAc 8:1 $\rightarrow 1: 1$ ) yielded $181 \mathrm{~d}$ (33 mg, 39\%) as a colorless solid and $\mathbf{4 7 \mathbf { d i }}$ (13 $\mathrm{mg}, 9 \%)$ as a brown oil.

${ }^{1} \mathrm{H}-\mathrm{NMR}\left(300 \mathrm{MHz}, \mathrm{CDCl}_{3}\right): \delta=8.56-8.49(\mathrm{~m}, 1 \mathrm{H}), 7.51-7.40(\mathrm{~m}, 2 \mathrm{H}), 7.35-7.29(\mathrm{~m}, 2 \mathrm{H}), 7.25-7.15$ (m, 2H), 7.12-6.97 (m, 4H), $2.19(\mathrm{~s}, 6 \mathrm{H}) .{ }^{13} \mathrm{C}-\mathrm{NMR}\left(75 \mathrm{MHz}, \mathrm{CDCl}_{3}\right): \delta=202.6\left(\mathrm{C}_{\mathrm{q}}\right), 158.9\left(\mathrm{C}_{\mathrm{q}}\right), 149.1$ $(\mathrm{CH}), 140.8\left(\mathrm{C}_{\mathrm{q}}\right), 140.5\left(\mathrm{C}_{\mathrm{q}}\right), 140.1\left(\mathrm{C}_{\mathrm{q}}\right), 139.3\left(\mathrm{C}_{\mathrm{q}}\right), 136.9\left(\mathrm{C}_{\mathrm{q}}\right), 135.7(\mathrm{CH}), 131.9(\mathrm{CH}), 130.3(\mathrm{CH})$, $130.1(\mathrm{CH}), 128.0(\mathrm{CH}), 128.0(\mathrm{CH}), 127.5(\mathrm{CH}), 126.8(\mathrm{CH}), 125.4(\mathrm{CH}), 121.5(\mathrm{CH}), 30.0\left(\mathrm{CH}_{3}\right), 20.6$ $\left(\mathrm{CH}_{3}\right)$. IR (ATR): $\tilde{v}=1681,1585,1421,1354,1268,1245,788,749,596,579 \mathrm{~cm}^{-1}$. MS (ESI) $\mathrm{m} / \mathrm{z}$ (relative intensity): $288[\mathrm{M}+\mathrm{H}]^{+}(100), 310[\mathrm{M}+\mathrm{Na}]^{+}(5)$. HR-MS (ESI): $\mathrm{m} / \mathrm{z}$ calcd for $\mathrm{C}_{20} \mathrm{H}_{18} \mathrm{NO}^{+}$ $[\mathrm{M}+\mathrm{H}]^{+}$288.1383, found 288.1385 . 


\section{2-[3-Methyl-2'-(trifluoromethyl)-[1,1'-biphenyl]-2-yl]pyridine (47dj)}<smiles>Cc1cccc(-c2ccccc2C(F)(F)F)c1-c1ccccn1</smiles>

47dj

General procedure B was followed using 2-(2-methylphenyl)pyridine (45d) $(85 \mathrm{mg}, 0.50 \mathrm{mmol})$ and 2-bromotrifluorotoluene (46j) (169 $\mathrm{mg}, 0.75 \mathrm{mmol}$ ). Purification by column chromatography on silica gel ( $n$-hexane/EtOAc 5:1 $\rightarrow 1: 1$ ) yielded $\mathbf{1 8 1 d}(43 \mathrm{mg}, 51 \%$ ) as a colorless solid and $\mathbf{4 7 d j}$ (35 mg, 22\%) as a colorless oil.

${ }^{1} \mathrm{H}-\mathrm{NMR}\left(400 \mathrm{MHz}, \mathrm{CDCl}_{3}\right): \delta=8.55(\mathrm{ddd}, J=4.9,1.8,1.0 \mathrm{~Hz}, 1 \mathrm{H}), 7.62-7.55(\mathrm{~m}, 1 \mathrm{H}), 7.41$ (ddd, $J=$ 7.7, 7.7, $1.8 \mathrm{~Hz}, 1 \mathrm{H}), 7.29-7.35(\mathrm{~m}, 2 \mathrm{H}), 7.25-7.16(\mathrm{~m}, 3 \mathrm{H}), 7.09-7.04(\mathrm{~m}, 1 \mathrm{H}), 7.01$ (ddd, J = 7.6, 4.9, $1.2 \mathrm{~Hz}, 1 \mathrm{H}), 6.94$ (ddd, $J=7.8,1.1,1.1 \mathrm{~Hz}, 1 \mathrm{H}), 2.16(\mathrm{~s}, 3 \mathrm{H}) .{ }^{13} \mathrm{C}-\mathrm{NMR}\left(100 \mathrm{MHz}, \mathrm{CDCl}_{3}\right): \delta=$ $159.1\left(\mathrm{C}_{\mathrm{q}}\right), 148.8(\mathrm{CH}), 140.0\left(\mathrm{q},{ }^{3} \mathrm{~J}_{\mathrm{C}-\mathrm{F}}=2.0 \mathrm{~Hz}, \mathrm{C}_{\mathrm{q}}\right), 139.7\left(\mathrm{C}_{\mathrm{q}}\right), 138.3\left(\mathrm{C}_{\mathrm{q}}\right), 136.5\left(\mathrm{C}_{\mathrm{q}}\right), 135.9(\mathrm{CH})$, $133.5(\mathrm{CH}), 130.4(\mathrm{CH}), 130.1(\mathrm{CH}), 128.7\left(q,{ }^{2} \mathrm{~J}_{\mathrm{C}-\mathrm{F}}=29.4 \mathrm{~Hz}, \mathrm{C}_{\mathrm{q}}\right), 127.5\left(\mathrm{q},{ }^{4} \mathrm{~J}_{\mathrm{C}-\mathrm{F}}=2.2 \mathrm{~Hz}, \mathrm{CH}\right), 127.2$ (CH), $126.9(\mathrm{CH}), 125.8\left(\mathrm{q},{ }^{3} \mathrm{~J}_{\mathrm{C}-\mathrm{F}}=5.2 \mathrm{~Hz}, \mathrm{CH}\right), 124.9(\mathrm{CH}), 124.4$ (q, $\left.{ }^{1} \mathrm{~J}_{\mathrm{C}-\mathrm{F}}=274.4 \mathrm{~Hz}, \mathrm{C}_{\mathrm{q}}\right), 121.4(\mathrm{CH})$, $20.5\left(\mathrm{CH}_{3}\right) .{ }^{19} \mathrm{~F}-\mathrm{NMR}\left(282 \mathrm{MHz}, \mathrm{CDCl}_{3}\right): \delta=-57.0$ (s). IR (ATR): $\tilde{v}=1312,1166,1109,1050,1033$, $789,748,654,579,402 \mathrm{~cm}^{-1}$. MS (ESI) $\mathrm{m} / \mathrm{z}$ (relative intensity): $314[\mathrm{M}+\mathrm{H}]^{+}(100), 336[\mathrm{M}+\mathrm{Na}]^{+}(11)$. HR-MS (ESI): $m / z$ calcd for $\mathrm{C}_{19} \mathrm{H}_{14} \mathrm{NF}_{3} \mathrm{Na}^{+}[\mathrm{M}+\mathrm{Na}]^{+} 336.0971$, found 336.0969 .

\section{2'-(Pyridin-2-yl)-[1,1':3',1"'-terphenyl]-2,2"-dicarbonitrile (47ak)}<smiles>N#Cc1ccccc1-c1cccc(-c2ccccc2N)c1-c1ccccn1</smiles>

General procedure B was followed using 2-phenylpyridine (45a) $(78 \mathrm{mg}, 0.50 \mathrm{mmol}$ ) and 2-bromobenzonitrile (46k) (137 mg, $0.75 \mathrm{mmol}$ ). Purification by column chromatography on silica gel ( $n$-hexane/EtOAc 1:1) yielded 47ak (65 mg, 48\%) as a colorless solid.

${ }^{1} \mathrm{H}-\mathrm{NMR}\left(400 \mathrm{MHz}, \mathrm{CDCl}_{3}\right): \delta=8.20(\mathrm{ddd}, J=4.9,1.9,1.0 \mathrm{~Hz}, 1 \mathrm{H}), 7.65-7.52(\mathrm{~m}, 5 \mathrm{H}), 7.33-7.20(\mathrm{~m}$, $5 \mathrm{H}), 7.17-6.87(\mathrm{~m}, 3 \mathrm{H}), 6.83$ (ddd, $J=7.6,4.9,1.2 \mathrm{~Hz}, 1 \mathrm{H}) .{ }^{13} \mathrm{C}-\mathrm{NMR}\left(100 \mathrm{MHz}, \mathrm{CDCl}_{3}\right): \delta=157.1$ 
$\left(\mathrm{C}_{\mathrm{q}}\right), 148.7(\mathrm{CH}), 145.1\left(\mathrm{C}_{\mathrm{q}}\right), 139.7\left(\mathrm{C}_{\mathrm{q}}\right), 138.5\left(\mathrm{C}_{\mathrm{q}}\right), 135.1(\mathrm{CH}), 132.8(\mathrm{CH}), 131.8(\mathrm{CH}), 131.6(\mathrm{CH})$, $130.8(\mathrm{CH}), 128.4(\mathrm{CH}), 127.3(\mathrm{CH}), 126.8(\mathrm{CH}), 121.3(\mathrm{CH}), 118.4\left(\mathrm{C}_{q}\right), 112.9\left(\mathrm{C}_{q}\right)$. m.p.: $209^{\circ} \mathrm{C} . \mathrm{IR}$ (ATR): $\tilde{v}=2226,1438,1417,791,769,751,622,552,518,405 \mathrm{~cm}^{-1}$. MS (ESI) $\mathrm{m} / \mathrm{z}$ (relative intensity): $358[\mathrm{M}+\mathrm{H}]^{+}(100), 380[\mathrm{M}+\mathrm{Na}]^{+}(48), 396[\mathrm{M}+\mathrm{K}]^{+}(6), 737[2 \mathrm{M}+\mathrm{Na}]^{+}(8) . \mathrm{HR}-\mathrm{MS}(\mathrm{ESI})$ : $\mathrm{m} / z$ calcd for $\mathrm{C}_{25} \mathrm{H}_{16} \mathrm{~N}_{3}{ }^{+}[\mathrm{M}+\mathrm{H}]^{+}$358.1339, found 358.1341.

\section{3'-Fluoro-2'-(pyridin-2-yl)-[1,1'-biphenyl]-2-carbonitrile (47ek)}<smiles>N#Cc1ccccc1-c1cccc(F)c1-c1ccccn1</smiles>

General procedure B was followed using 2-(2-fluorophenyl)pyridine (45e) $(87 \mathrm{mg}, 0.50 \mathrm{mmol}$ ) and 2-bromobenzonitrile (46k) (137 mg, $0.75 \mathrm{mmol}$ ). Purification by column chromatography on silica gel ( $n$-hexane/EtOAc 3:1 $\rightarrow$ 1:1) yielded 47ek (119 mg, 87\%) as a brown solid.

${ }^{1} \mathrm{H}-\mathrm{NMR}\left(400 \mathrm{MHz}, \mathrm{CDCl}_{3}\right): \delta=8.41$ (ddd, $J=4.8,1.8,0.9 \mathrm{~Hz}, 1 \mathrm{H}$ ), 7.57 (ddd, $J=7.8,7.8,1.9 \mathrm{~Hz}$, 1H), 7.53 (ddd, $J=7.7,1.5,0.6 \mathrm{~Hz}, 1 \mathrm{H}$ ), 7.47 (ddd, $J=8.4,7.6,5.5 \mathrm{~Hz}, 1 \mathrm{H}$ ), 7.37 (ddd, $J=7.7,7.7$, $1.4 \mathrm{~Hz}, 1 \mathrm{H}$ ), 7.32 (dddd, $J=7.8,1.7,1.1,1.1 \mathrm{~Hz}, 1 \mathrm{H}$ ), 7.29-7.22 (m, 3H), 7.20 (ddd, $J=7.8,1.3$, $0.6 \mathrm{~Hz}, 1 \mathrm{H}), 7.08$ (ddd, $J=7.6,4.9,1.2 \mathrm{~Hz}, 1 \mathrm{H}) .{ }^{13} \mathrm{C}-\mathrm{NMR}\left(100 \mathrm{MHz}, \mathrm{CDCl}_{3}\right): \delta=160.3\left(\mathrm{~d},{ }^{1} J_{\mathrm{C}-\mathrm{F}}=\right.$ $\left.248.3 \mathrm{~Hz}, \mathrm{C}_{\mathrm{q}}\right), 153.0\left(\mathrm{C}_{\mathrm{q}}\right), 149.1(\mathrm{CH}), 144.3\left(\mathrm{~d},{ }^{3} J_{\mathrm{C}-\mathrm{F}}=2.7 \mathrm{~Hz}, \mathrm{C}_{\mathrm{q}}\right), 139.9\left(\mathrm{~d},{ }^{3} J_{\mathrm{C}-\mathrm{F}}=3.1 \mathrm{~Hz}, \mathrm{C}_{\mathrm{q}}\right), 135.9$ (CH), $132.7(\mathrm{CH}), 132.0(\mathrm{CH}), 131.4(\mathrm{CH}), 129.9\left(\mathrm{~d},{ }^{3} \mathrm{~J}_{\mathrm{C}-\mathrm{F}}=9.2 \mathrm{~Hz}, \mathrm{CH}\right), 128.5\left(\mathrm{~d},{ }^{2} \mathrm{~J}_{\mathrm{C}-\mathrm{F}}=15.9 \mathrm{~Hz}, \mathrm{C}_{\mathrm{q}}\right)$, $127.5(\mathrm{CH}), 126.6\left(\mathrm{~d},{ }^{4} J_{\mathrm{C}-\mathrm{F}}=2.2 \mathrm{~Hz}, \mathrm{CH}\right), 126.2\left(\mathrm{~d},{ }^{3} J_{\mathrm{C}-\mathrm{F}}=3.5 \mathrm{~Hz}, \mathrm{CH}\right), 122.2(\mathrm{CH}), 118.2\left(\mathrm{C}_{\mathrm{q}}\right), 116.5$ $\left(\mathrm{d},{ }^{2} \mathrm{~J}_{\mathrm{C}-\mathrm{F}}=22.9 \mathrm{~Hz}, \mathrm{CH}\right), 112.6\left(\mathrm{C}_{\mathrm{q}}\right) .{ }^{19} \mathrm{~F}-\mathrm{NMR}\left(282 \mathrm{MHz}, \mathrm{CDCl}_{3}\right): \delta=(-115.7)-(-115.9)(\mathrm{m})$. m.p.: $76^{\circ} \mathrm{C}$. IR (ATR): $\tilde{v}=1586,1434,1424,1228,897,808,785,763,526,403 \mathrm{~cm}^{-1}$. MS (ESI) $\mathrm{m} / \mathrm{z}$ (relative intensity): $275[\mathrm{M}+\mathrm{H}]^{+}(100), 297[\mathrm{M}+\mathrm{Na}]^{+}(89), 571[2 \mathrm{M}+\mathrm{Na}]^{+}(21) . \mathrm{HR}-\mathrm{MS}$ (ESI): $\mathrm{m} / z$ calcd for $\mathrm{C}_{18} \mathrm{H}_{12} \mathrm{~N}_{2} \mathrm{~F}^{+}[\mathrm{M}+\mathrm{H}]^{+} 275.0979$, found 275.0980 . 


\section{4'-Methyl-2'-(pyridin-2-yl)-[1,1'-biphenyl]-2-carbonitrile (47hk)}<smiles>Cc1ccc(-c2ccccc2C#N)c(-c2ccccn2)c1</smiles>

General procedure B was followed using 2-(3-methylphenyl)pyridine (45h) $(85 \mathrm{mg}, 0.50 \mathrm{mmol})$ and 2-bromobenzonitrile (46k) (137 mg, $0.75 \mathrm{mmol}$ ). Purification by column chromatography on silica gel ( $n$-hexane/EtOAc 2:1) yielded $47 \mathrm{hk}(82 \mathrm{mg}, 61 \%$ ) as a colorless solid.

${ }^{1} \mathrm{H}-\mathrm{NMR}\left(300 \mathrm{MHz}, \mathrm{CDCl}_{3}\right): \delta=8.53(\mathrm{~d}, J=4.7 \mathrm{~Hz}, 1 \mathrm{H}), 7.62(\mathrm{~d}, J=7.7 \mathrm{~Hz}, 1 \mathrm{H}), 7.56(\mathrm{~s}, 1 \mathrm{H}), 7.49-$ $7.27(\mathrm{~m}, 5 \mathrm{H}), 7.16(\mathrm{~d}, J=7.7 \mathrm{~Hz}, 1 \mathrm{H}), 7.12-7.04(\mathrm{~m}, 1 \mathrm{H}), 6.99(\mathrm{~d}, J=7.9 \mathrm{~Hz}, 1 \mathrm{H}), 2.47(\mathrm{~s}, 3 \mathrm{H}) .{ }^{13} \mathrm{C}-$ NMR $\left(75 \mathrm{MHz}, \mathrm{CDCl}_{3}\right): \delta=158.6\left(\mathrm{C}_{\mathrm{q}}\right), 149.4(\mathrm{CH}), 145.9\left(\mathrm{C}_{\mathrm{q}}\right), 140.1\left(\mathrm{C}_{\mathrm{q}}\right), 139.2\left(\mathrm{C}_{\mathrm{q}}\right), 135.7(\mathrm{CH})$, 134.1 $\left(\mathrm{C}_{\mathrm{q}}\right), 133.0(\mathrm{CH}), 132.1(\mathrm{CH}), 131.8(\mathrm{CH}), 131.2(\mathrm{CH}), 130.7(\mathrm{CH}), 129.4(\mathrm{CH}), 127.2(\mathrm{CH}), 125.0$ (CH), $121.6(\mathrm{CH}), 118.5\left(\mathrm{C}_{\mathrm{q}}\right), 112.8\left(\mathrm{C}_{\mathrm{q}}\right), 21.4\left(\mathrm{CH}_{3}\right)$. m.p.: $125^{\circ} \mathrm{C}$. IR (ATR): $\tilde{v}=1587,1471,1426$, $828,800,753,587,548,504,403 \mathrm{~cm}^{-1}$. MS (ESI) $\mathrm{m} / z$ (relative intensity): $271[\mathrm{M}+\mathrm{H}]^{+}(100), 293$ $[\mathrm{M}+\mathrm{Na}]^{+}(6)$. HR-MS (ESI): $\mathrm{m} / z$ calcd for $\mathrm{C}_{19} \mathrm{H}_{15} \mathrm{~N}_{2}{ }^{+}[\mathrm{M}+\mathrm{H}]^{+} 271.1230$, found 271.1229.

\section{3'-(Dimethylamino)-2'-(pyridin-2-yl)-[1,1'-biphenyl]-2-carbonitrile (47ik)}<smiles>CN(C)c1cccc(-c2ccccc2C#N)c1-c1ccccn1</smiles>

General procedure B was followed using 2-(2-dimethylaminophenyl)pyridine (45i) (99 mg, $0.50 \mathrm{mmol}$ ) and 2-bromobenzonitrile (46k) $(137 \mathrm{mg}, 0.75 \mathrm{mmol})$. Purification by column chromatography on silica gel ( $n$-hexane/EtOAc $2: 1$ ) yielded $47 i k$ ( $81 \mathrm{mg}, 54 \%$ ) as a yellow, highly viscous oil.

${ }^{1} \mathrm{H}-\mathrm{NMR}\left(400 \mathrm{MHz}, \mathrm{CDCl}_{3}\right): \delta=8.36$ (ddd, $J=4.9,1.8,1.0 \mathrm{~Hz}, 1 \mathrm{H}$ ), 7.52 (ddd, $J=7.7,7.7,1.8 \mathrm{~Hz}$, 1H), 7.47 (ddd, $J=7.7,1.4,0.6 \mathrm{~Hz}, 1 \mathrm{H}$ ), 7.43-7.37 (m, 2H), 7.32 (ddd, $J=7.6,7.6,1.4 \mathrm{~Hz}, 1 \mathrm{H}$ ), 7.22$7.15(\mathrm{~m}, 3 \mathrm{H}), 7.01-6.95(\mathrm{~m}, 2 \mathrm{H}), 2.53(\mathrm{~s}, 6 \mathrm{H}) .{ }^{13} \mathrm{C}-\mathrm{NMR}\left(100 \mathrm{MHz}, \mathrm{CDCl}_{3}\right): \delta=158.3\left(\mathrm{C}_{\mathrm{q}}\right), 152.1\left(\mathrm{C}_{\mathrm{q}}\right)$, $148.8(\mathrm{CH}), 146.2\left(\mathrm{C}_{\mathrm{q}}\right), 139.4\left(\mathrm{C}_{\mathrm{q}}\right), 135.6(\mathrm{CH}), 133.4\left(\mathrm{C}_{\mathrm{q}}\right), 132.2(\mathrm{CH}), 131.5(\mathrm{CH}), 131.5(\mathrm{CH}), 128.9$ 
$(\mathrm{CH}), 127.0(\mathrm{CH}), 126.8(\mathrm{CH}), 123.4(\mathrm{CH}), 121.1(\mathrm{CH}), 118.8(\mathrm{CH}), 118.6\left(\mathrm{C}_{\mathrm{q}}\right), 112.7\left(\mathrm{C}_{\mathrm{q}}\right), 44.1\left(\mathrm{CH}_{3}\right)$. IR (ATR): $\tilde{v}=1587,1562,1476,1458,1421,956,810,786,745,558 \mathrm{~cm}^{-1}$. MS (ESI) $\mathrm{m} / z$ (relative intensity): $300[\mathrm{M}+\mathrm{H}]^{+}(100), 322[\mathrm{M}+\mathrm{Na}]^{+}(7)$. HR-MS (ESI): $\mathrm{m} / \mathrm{z}$ calcd for $\mathrm{C}_{20} \mathrm{H}_{18} \mathrm{~N}_{3}{ }^{+}[\mathrm{M}+\mathrm{H}]^{+}$ 300.1495 , found 300.1498 . yl]benzonitrile (47kk)<smiles>c1ccc(-c2c(-c3ccc4ccccc4c3-c3ccccn3)ccc3ccccc23)nc1</smiles>

$181 \mathrm{k}$<smiles>N#Cc1ccccc1-c1ccc2ccccc2c1-c1ccccn1</smiles>

$47 k k$

General procedure B was followed using 2-(1-naphthyl)pyridine (45k) (103 mg, $0.50 \mathrm{mmol})$ and 2-bromobenzonitrile (46k) (137 mg, $0.75 \mathrm{mmol}$ ). Purification by column chromatography on silica gel ( $n$-hexane/EtOAc 3:1), GPC purification and HPLC purification ( $n$-hexane/i-PrOH 80:20, $7.5 \mathrm{~mL} \mathrm{~min}{ }^{-1}$ ) yielded $\mathbf{1 8 1 k}$ (63 mg, 62\%) as a colorless solid and $\mathbf{4 7 k k}(12 \mathrm{mg}, 8 \%$ ) as a light brown solid.

Data for 181k:

${ }^{1} \mathrm{H}-\mathrm{NMR}\left(400 \mathrm{MHz}, \mathrm{DMF}-d_{7}, 353 \mathrm{~K}\right.$ ): $\delta=8.64$ (ddd, $J=4.9,1.4,1.4 \mathrm{~Hz}, 2 \mathrm{H}$ ), 7.90 (dd, $J=7.6,2.0 \mathrm{~Hz}$, 2H), $7.72(\mathrm{~d}, J=8.5 \mathrm{~Hz}, 2 \mathrm{H}$ ), 7.68 (ddd, $J=6.4,6.4,1.7 \mathrm{~Hz}, 4 \mathrm{H}$ ), 7.50 (ddd, $J=7.8,7.8,1.4 \mathrm{~Hz}, 4 \mathrm{H}$ ), 7.48-7.39 (m, 2H), 7.31-7.23 (m, 4H). ${ }^{13} \mathrm{C}-\mathrm{NMR}\left(100 \mathrm{MHz}, \mathrm{DMF}-d_{7}, 353 \mathrm{~K}\right): \delta=159.5\left(\mathrm{C}_{\mathrm{q}}\right), 150.1$ $(\mathrm{CH}), 139.4\left(\mathrm{C}_{q}\right), 138.8\left(\mathrm{C}_{\mathrm{q}}\right), 136.8(\mathrm{CH}), 133.8\left(\mathrm{C}_{\mathrm{q}}\right), 133.5\left(\mathrm{C}_{\mathrm{q}}\right), 130.4(\mathrm{CH}), 129.0(\mathrm{CH}), 128.0(\mathrm{CH})$, $127.9(\mathrm{CH}), 127.3(\mathrm{CH}), 127.2(\mathrm{CH}), 126.9(\mathrm{CH}), 123.0(\mathrm{CH})$. m.p.: $259^{\circ} \mathrm{C}$. IR (ATR): $\tilde{v}=819,747$, $563,498,454,419,408,398,388,380 \mathrm{~cm}^{-1}$. MS (ESI) $\mathrm{m} / z$ (relative intensity): $409[\mathrm{M}+\mathrm{H}]^{+}(100)$, $431[\mathrm{M}+\mathrm{Na}]^{+}(10), 839[2 \mathrm{M}+\mathrm{Na}]^{+}(3)$. HR-MS (ESI): $\mathrm{m} / z$ calcd for $\mathrm{C}_{30} \mathrm{H}_{21} \mathrm{~N}_{2}{ }^{+}[\mathrm{M}+\mathrm{H}]^{+} 409.1699$, found 409.1697.

Data for 47kk:

${ }^{1} \mathrm{H}-\mathrm{NMR}\left(400 \mathrm{MHz}, \mathrm{CDCl}_{3}\right): \delta=8.65(\mathrm{~d}, J=4.7 \mathrm{~Hz}, 1 \mathrm{H}), 8.01(\mathrm{~d}, J=8.5 \mathrm{~Hz}, 1 \mathrm{H}), 7.95(\mathrm{~d}, J=8.1 \mathrm{~Hz}$, $1 \mathrm{H}$ ), 7.62 (dd, $J=7.7,1.4 \mathrm{~Hz}, 1 \mathrm{H}$ ), 7.59-7.50 (m, 4H), 7.45 (ddd, $J=8.3,6.8,1.3 \mathrm{~Hz}, 1 \mathrm{H}$ ), 7.32 (ddd, $J=7.6,7.6,1.5 \mathrm{~Hz}, 1 \mathrm{H}), 7.29-7.23(\mathrm{~m}, 1 \mathrm{H}), 7.22-7.13(\mathrm{~m}, 3 \mathrm{H}) .{ }^{13} \mathrm{C}-\mathrm{NMR}\left(100 \mathrm{MHz}, \mathrm{CDCl}_{3}\right): \delta=157.8$ 
$\left(\mathrm{C}_{\mathrm{q}}\right), 149.2(\mathrm{CH}), 145.7\left(\mathrm{C}_{\mathrm{q}}\right), 137.7\left(\mathrm{C}_{\mathrm{q}}\right), 136.1(\mathrm{CH}), 135.1\left(\mathrm{C}_{\mathrm{q}}\right), 133.7\left(\mathrm{C}_{\mathrm{q}}\right), 132.7(\mathrm{CH}), 132.2\left(\mathrm{C}_{\mathrm{q}}\right)$, 132.1 (CH), $131.8(\mathrm{CH}), 128.8(\mathrm{CH}), 128.3(\mathrm{CH}), 127.3(\mathrm{CH}), 127.2(\mathrm{CH}), 127.1(\mathrm{CH}), 126.6(\mathrm{CH}), 126.6$ (CH), $126.4(\mathrm{CH}), 122.0(\mathrm{CH}), 118.6\left(\mathrm{C}_{\mathrm{q}}\right), 112.9\left(\mathrm{C}_{\mathrm{q}}\right)$. m.p.: $111^{\circ} \mathrm{C}$. IR (ATR): $\tilde{v}=1584,832,800,774$, $749,606,584,550,530,401 \mathrm{~cm}^{-1}$. MS (ESI) $\mathrm{m} / \mathrm{z}$ (relative intensity): $307[\mathrm{M}+\mathrm{H}]^{+}(100), 329[\mathrm{M}+\mathrm{Na}]^{+}$ (33). HR-MS (ESI): $m / z$ calcd for $\mathrm{C}_{22} \mathrm{H}_{14} \mathrm{~N}_{2} \mathrm{Na}^{+}[\mathrm{M}+\mathrm{Na}]^{+} 329.1049$, found 329.1050.

2,2'-(3,3'-Diisopropyl-[1,1'-biphenyl]-2,2'-diyl)dipyridine (181l) and 3'-isopropyl-2'-(pyridin-2yl)-[1,1'-biphenyl]-2-carbonitrile (47lk)<smiles>CC(C)c1cccc(-c2ccccc2-c2ccccn2)c1-c1ccccn1</smiles>

1811<smiles>CC(C)c1cccc(-c2ccccc2-c2ccccn2)c1C#N</smiles>

47lk

General procedure B was followed using 2-(2-isopropylphenyl)pyridine (45I) $(99 \mathrm{mg}, 0.50 \mathrm{mmol})$ and 2-bromobenzonitrile (46k) (137 mg, $0.75 \mathrm{mmol})$. Purification by column chromatography on silica gel ( $n$-hexane/EtOAc 7:1 $\rightarrow 2: 1$ ) yielded $181 \mathrm{l}(70 \mathrm{mg}, 71 \%)$ as a colorless solid and $47 \mathrm{lk}$ (12 $\mathrm{mg}, 8 \%$ ) as a dark brown oil.

Data for 181I:

${ }^{1} \mathrm{H}-\mathrm{NMR}\left(400 \mathrm{MHz}\right.$, PhMe- $\left.d_{8}, 343 \mathrm{~K}\right): \delta=8.39(\mathrm{~d}, J=4.1 \mathrm{~Hz}, 2 \mathrm{H}), 7.45(\mathrm{sbr}, 2 \mathrm{H}), 6.97(\mathrm{t}, J=1.0 \mathrm{~Hz}$, 4H), $6.91(\mathrm{t}, J=7.6 \mathrm{~Hz}, 2 \mathrm{H}), 6.86(\mathrm{dd}, J=7.6,1.6 \mathrm{~Hz}, 2 \mathrm{H}), 6.57$ (ddd, $J=7.6,4.9,1.2 \mathrm{~Hz}, 2 \mathrm{H}$ ), 2.93 (hept, $J=6.9 \mathrm{~Hz}, 2 \mathrm{H}), 1.23(\mathrm{~d}, J=6.9 \mathrm{~Hz}, 6 \mathrm{H}), 0.99(\mathrm{~d}, J=6.9 \mathrm{~Hz}, 6 \mathrm{H}) .{ }^{13} \mathrm{C}-\mathrm{NMR}\left(100 \mathrm{MHz}\right.$, PhMe- $d_{8}$, $343 \mathrm{~K}): \delta=160.5\left(\mathrm{C}_{\mathrm{q}}\right), 148.8(\mathrm{CH}), 147.1\left(\mathrm{C}_{\mathrm{q}}\right), 141.5\left(\mathrm{C}_{\mathrm{q}}\right), 140.1\left(\mathrm{C}_{\mathrm{q}}\right), 134.7(\mathrm{CH}), 129.2(\mathrm{CH}), 127.2$ (CH), $126.6(\mathrm{CH}), 123.9(\mathrm{CH}), 121.1(\mathrm{CH}), 30.5(\mathrm{CH}), 24.4\left(\mathrm{CH}_{3}\right), 24.1\left(\mathrm{CH}_{3}\right)$. m.p.: $162^{\circ} \mathrm{C}$. IR (ATR): $\tilde{v}$ $=2963,1582,1422,1021,804,794,777,756,620,402 \mathrm{~cm}^{-1}$. MS (ESI) $\mathrm{m} / \mathrm{z}$ (relative intensity): 393 $[\mathrm{M}+\mathrm{H}]^{+}(100), 415[\mathrm{M}+\mathrm{Na}]^{+}(8)$. HR-MS (ESI): $\mathrm{m} / z$ calcd for $\mathrm{C}_{28} \mathrm{H}_{29} \mathrm{~N}_{2}{ }^{+}[\mathrm{M}+\mathrm{H}]^{+} 393.2325$, found 393.2327.

Data for 47lk:

${ }^{1} \mathrm{H}-\mathrm{NMR}\left(400 \mathrm{MHz}, \mathrm{CDCl}_{3}\right): \delta=8.49(\mathrm{~d}, J=4.8 \mathrm{~Hz}, 1 \mathrm{H}), 7.54-7.41(\mathrm{~m}, 4 \mathrm{H}), 7.26-7.21(\mathrm{~m}, 2 \mathrm{H}), 7.16$ (dddd, $J=7.6,7.6,1.4,1.4 \mathrm{~Hz}, 1 \mathrm{H}$ ), 7.13-7.05 (m, 2H), 7.02 (ddd, $J=7.6,4.8,1.2 \mathrm{~Hz}, 1 \mathrm{H}$ ), 2.79 (hept, $J=6.8 \mathrm{~Hz}, 1 \mathrm{H}), 1.21\left(\mathrm{~s}_{\mathrm{br}}, 3 \mathrm{H}\right), 1.09(\mathrm{sbr}, 3 \mathrm{H}) .{ }^{13} \mathrm{C}-\mathrm{NMR}\left(100 \mathrm{MHz}, \mathrm{CDCl}_{3}\right): \delta=158.6\left(\mathrm{C}_{q}\right), 148.8$ 
$(\mathrm{CH}), 147.5\left(\mathrm{C}_{q}\right), 145.9\left(\mathrm{C}_{\mathrm{q}}\right), 139.0\left(\mathrm{C}_{\mathrm{q}}\right), 137.6\left(\mathrm{C}_{\mathrm{q}}\right), 135.7(\mathrm{CH}), 132.5(\mathrm{CH}), 131.9(\mathrm{CH}), 131.5(\mathrm{CH})$, $128.5(\mathrm{CH}), 127.2(\mathrm{CH}), 127.0(\mathrm{CH}), 126.2(\mathrm{CH}), 125.8(\mathrm{CH}), 121.6(\mathrm{CH}), 118.7\left(\mathrm{C}_{\mathrm{q}}\right), 112.6\left(\mathrm{C}_{\mathrm{q}}\right), 30.1$ (CH), $24.2\left(\mathrm{CH}_{3}\right), 23.9\left(\mathrm{CH}_{3}\right)$. IR (ATR): $\tilde{v}=1584,1563,1467,1440,1422,788,751,731,620$, $556 \mathrm{~cm}^{-1}$. MS (ESI) $\mathrm{m} / z$ (relative intensity): $299[\mathrm{M}+\mathrm{H}]^{+}(100), 321[\mathrm{M}+\mathrm{Na}]^{+}(16)$. HR-MS (ESI): $\mathrm{m} / z$ calcd for $\mathrm{C}_{21} \mathrm{H}_{19} \mathrm{~N}_{2}{ }^{+}[\mathrm{M}+\mathrm{H}]^{+}$299.1543, found 299.1544.

2,2'-[3,3'-Bis(4-fluorobenzyl)-[1,1'-biphenyl]-2,2'-diyl]dipyridine (181m) and 3'-(4-fluorobenzyl)2'-(pyridin-2-yl)-[1,1'-biphenyl]-2-carbonitrile (47mk)<smiles>Fc1ccc(Cc2cccc(-c3cccc(Cc4ccc(F)cc4)c3-c3ccccn3)c2-c2ccccn2)cc1</smiles>

$181 \mathrm{~m}$<smiles>N#Cc1ccccc1-c1cccc(Cc2ccc(F)cc2)c1-c1ccccn1</smiles>

$47 \mathrm{mk}$

General procedure B was followed using 2-[2-(4-fluorobenzyl)phenyl]pyridine (45m) (132 mg, $0.50 \mathrm{mmol}$ ) and 2-bromobenzonitrile (46k) $(137 \mathrm{mg}, 0.75 \mathrm{mmol})$. Purification by column chromatography on silica gel ( $n$-hexane/EtOAc 7:1 $\rightarrow 2: 1$ ) and GPC purification yielded $181 \mathrm{~m}$ (99 mg, 75\%) as a colorless solid and $\mathbf{4 7} \mathrm{mk}$ (11 mg, approx. 90\% purity, 5\%) as a colorless oil.

Data for $181 \mathrm{~m}$ :

${ }^{1} \mathrm{H}-\mathrm{NMR}\left(400 \mathrm{MHz}, \mathrm{CDCl}_{3}\right): \delta=8.49(\mathrm{~d}, J=4.8 \mathrm{~Hz}, 2 \mathrm{H}), 7.37(\mathrm{dd}, J=7.7,7.7 \mathrm{~Hz}, 2 \mathrm{H}), 7.13\left(\mathrm{~s}_{\mathrm{br}}, 2 \mathrm{H}\right)$, 7.02 (ddd, $J=7.6,4.9,1.2 \mathrm{~Hz}, 2 \mathrm{H}), 7.00-6.95(\mathrm{~m}, 4 \mathrm{H}), 6.85-6.74(\mathrm{~m}, 10 \mathrm{H}), 3.86(\mathrm{~d}, J=15.6 \mathrm{~Hz}, 2 \mathrm{H})$, $3.75(\mathrm{~d}, J=15.6 \mathrm{~Hz}, 2 \mathrm{H}) .{ }^{13} \mathrm{C}-\mathrm{NMR}\left(100 \mathrm{MHz}, \mathrm{CDCl}_{3}\right): \delta=161.2\left(\mathrm{~d},{ }^{1} J_{\mathrm{C}-\mathrm{F}}=243.5 \mathrm{~Hz}, \mathrm{C}_{\mathrm{q}}\right), 158.9\left(\mathrm{C}_{\mathrm{q}}\right)$, $148.6(\mathrm{CH}), 140.8\left(\mathrm{C}_{\mathrm{q}}\right), 140.1\left(\mathrm{C}_{\mathrm{q}}\right), 138.9\left(\mathrm{C}_{\mathrm{q}}\right), 137.1\left(\mathrm{~d},{ }^{4} \mathrm{~J}_{\mathrm{C}-\mathrm{F}}=3.2 \mathrm{~Hz}, \mathrm{C}_{\mathrm{q}}\right), 135.2(\mathrm{CH}), 130.1\left(\mathrm{~d},{ }^{3} \mathrm{~J}_{\mathrm{C}-\mathrm{F}}\right.$ $=7.8 \mathrm{~Hz}, \mathrm{CH}), 129.3(\mathrm{CH}), 128.9(\mathrm{CH}), 127.0(\mathrm{CH}), 126.3(\mathrm{CH}), 121.4(\mathrm{CH}), 114.8\left(\mathrm{~d},{ }^{2} \mathrm{~J}_{\mathrm{C}-\mathrm{F}}=21.1 \mathrm{~Hz}\right.$, $\mathrm{CH}), 38.7\left(\mathrm{CH}_{2}\right) .{ }^{19} \mathrm{~F}-\mathrm{NMR}\left(376 \mathrm{MHz}, \mathrm{CDCl}_{3}\right): \delta=-117.9$ (s). m.p.: $64{ }^{\circ} \mathrm{C}$. IR (ATR): $\tilde{v}=1587,1505$, $1420,1217,1156,803,787,747,509,486 \mathrm{~cm}^{-1}$. MS (ESI) $\mathrm{m} / \mathrm{z}$ (relative intensity): $525[\mathrm{M}+\mathrm{H}]^{+}(100)$, $547[\mathrm{M}+\mathrm{Na}]^{+}$(27). HR-MS (ESI): $\mathrm{m} / z$ calcd for $\mathrm{C}_{36} \mathrm{H}_{27} \mathrm{~N}_{2} \mathrm{~F}_{2}{ }^{+}[\mathrm{M}+\mathrm{H}]^{+} 525.2137$, found 525.2134.

Data for 47mk:

${ }^{1} \mathrm{H}-\mathrm{NMR}\left(400 \mathrm{MHz}, \mathrm{CDCl}_{3}\right): \delta=8.54$ (ddd, $J=4.9,1.8,1.0 \mathrm{~Hz}, 1 \mathrm{H}$ ), 7.56 (ddd, $J=7.6,1.5,0.6 \mathrm{~Hz}$, $1 \mathrm{H}), 7.44$ (dd, $J=7.7,7.7 \mathrm{~Hz}, 1 \mathrm{H}), 7.36-7.28(\mathrm{~m}, 3 \mathrm{H}), 7.26$ (dd, $J=7.6,1.6 \mathrm{~Hz}, 1 \mathrm{H}), 7.10$ (ddd, $J=$ 7.8, 1.4, 0.6 Hz, 1H), 7.02 (ddd, $J=7.6,4.9,1.2 \mathrm{~Hz}, 1 \mathrm{H}), 6.92-6.74(\mathrm{~m}, 6 \mathrm{H}), 3.90(\mathrm{~s}, 2 \mathrm{H}) .{ }^{13} \mathrm{C}-\mathrm{NMR}$ 
$\left(100 \mathrm{MHz}, \mathrm{CDCl}_{3}\right): \delta=161.4\left(\mathrm{~d},{ }^{1} J_{\mathrm{C}-\mathrm{F}}=244.0 \mathrm{~Hz}, \mathrm{C}_{\mathrm{q}}\right), 158.1\left(\mathrm{C}_{\mathrm{q}}\right), 148.9(\mathrm{CH}), 145.5\left(\mathrm{C}_{\mathrm{q}}\right), 139.9\left(\mathrm{C}_{\mathrm{q}}\right)$, $139.9\left(\mathrm{C}_{\mathrm{q}}\right), 138.1\left(\mathrm{C}_{\mathrm{q}}\right), 136.3\left(\mathrm{~d},{ }^{4} \mathrm{~J}_{\mathrm{C}-\mathrm{F}}=3.2 \mathrm{~Hz}, \mathrm{C}_{\mathrm{q}}\right), 135.8(\mathrm{CH}), 132.6(\mathrm{CH}), 131.7(\mathrm{CH}), 131.7(\mathrm{CH})$, $130.8(\mathrm{CH}), 130.4\left(\mathrm{~d},{ }^{3} J_{\mathrm{C}-\mathrm{F}}=7.8 \mathrm{~Hz}, \mathrm{CH}\right), 128.4\left(\mathrm{~d},{ }^{2} J_{\mathrm{C}-\mathrm{F}}=18.8 \mathrm{~Hz}, \mathrm{CH}\right), 127.2(\mathrm{CH}), 125.9(\mathrm{CH}), 121.8$ $(\mathrm{CH}), 118.5\left(\mathrm{C}_{\mathrm{q}}\right), 115.2(\mathrm{CH}), 115.0(\mathrm{CH}), 112.7\left(\mathrm{C}_{\mathrm{q}}\right), 38.7\left(\mathrm{CH}_{2}\right) .{ }^{19} \mathrm{~F}-\mathrm{NMR}\left(376 \mathrm{MHz}, \mathrm{CDCl}_{3}\right): \delta=$ $(-117.5)-(-117.6)$ (m). IR (ATR): $\tilde{v}=1507,1422,1218,1157,809,789,750,620,511,494 \mathrm{~cm}^{-1}$. MS (ESI) $m / z$ (relative intensity): $365[\mathrm{M}+\mathrm{H}]^{+}(100), 387[\mathrm{M}+\mathrm{Na}]^{+}(26)$. HR-MS (ESI): $m / z$ calcd for $\mathrm{C}_{25} \mathrm{H}_{18} \mathrm{~N}_{2} \mathrm{~F}^{+}[\mathrm{M}+\mathrm{H}]^{+}$365.1449, found 365.1451.

\subsubsection{Mechanistic Studies}

Synthesis of 2-(2-methyl-6-deuterophenyl)pyridine ([D $\left.]_{1}-45 d\right)$<smiles>[2H]c1cccc(OC)c1-c1ccccn1</smiles>

$[D]_{1}-45 d$

Under an atmosphere of $\mathrm{N}_{2}$, a Schlenk-tube was charged with 2-(2-methylphenyl)pyridine (45d) (338 mg, $2.00 \mathrm{mmol}, 1.00$ equiv), $\left[\mathrm{RuCl}_{2}(p \text {-cymene) }]_{2}\right.$ (31 mg, $50 \mu \mathrm{mol}, 2.5 \mathrm{~mol} \%$ ), $\mathrm{MesCO}_{2} \mathrm{H}$ (58) (99 mg, $0.60 \mathrm{mmol}, 30 \mathrm{~mol} \%$ ) and $\mathrm{K}_{2} \mathrm{CO}_{3}\left(553 \mathrm{mg}, 4.00 \mathrm{mmol}, 2.00\right.$ equiv). $\mathrm{D}_{2} \mathrm{O}$ (5.0 mL) was added and the mixture was stirred at $100^{\circ} \mathrm{C}$ for $24 \mathrm{~h}$. After cooling to ambient temperature, $\mathrm{H}_{2} \mathrm{O}$ $(10 \mathrm{~mL})$ was added, the mixture was extracted with EtOAc $(3 \times 30 \mathrm{~mL})$, dried over $\mathrm{Na}_{2} \mathrm{SO}_{4}$ and concentrated in vacuo. Purification of the residue by column chromatography on silica gel ( $n$-hexane/EtOAc 7:1) yielded [D $]_{1}-\mathbf{4 5 d}(232 \mathrm{mg}, 68 \%)$ as a light yellow oil. The deuterium incorporation was found to be $94 \%$ in the ortho-position as determined by ${ }^{1} \mathrm{H}-\mathrm{NMR}$ spectroscopy. ${ }^{1} \mathrm{H}-\mathrm{NMR}\left(300 \mathrm{MHz}, \mathrm{CDCl}_{3}\right): \delta=8.70$ (ddd, $\left.J=4.9,1.9,0.9 \mathrm{~Hz}, 0.69 \mathrm{H}\right), 7.74$ (ddd, $J=7.7,7.7,1.5 \mathrm{~Hz}$, $1 \mathrm{H}), 7.44-7.37(\mathrm{~m}, 1.06 \mathrm{H}), 7.35-7.27(\mathrm{~m}, 3 \mathrm{H}), 7.26-7.21(\mathrm{~m}, 1 \mathrm{H}), 2.37(\mathrm{~s}, 3 \mathrm{H})$. 


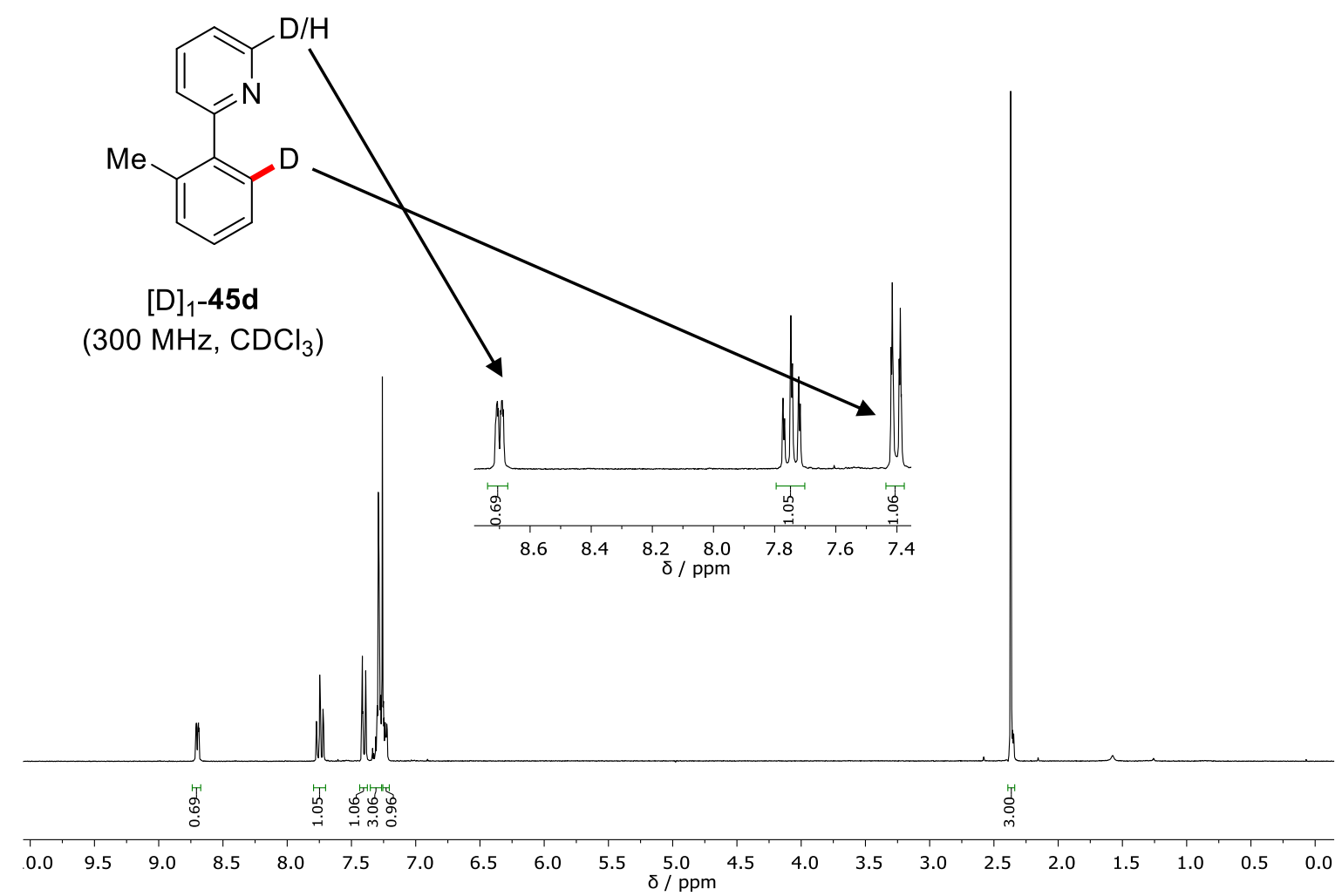

\section{H/D Exchange Studies}

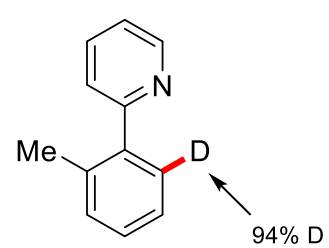

$[D]_{1}-45 d$

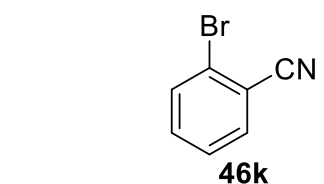

$\left[\mathrm{RuCl}_{2}(p \text {-cymene })\right]_{2}(2.5 \mathrm{~mol} \%)$ $\mathrm{MesCO}_{2} \mathrm{H}(58)(30 \mathrm{~mol} \%)$

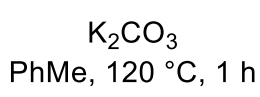

PhMe, $120^{\circ} \mathrm{C}, 1 \mathrm{~h}$

$[D]_{n}-181 d: 19 \%$<smiles></smiles>

$[D]_{n}-45 d: 33 \%$

Under an atmosphere of $\mathrm{N}_{2}$, a Schlenk-tube was charged with 2-(2-methyl-6deuterophenyl)pyridine ([D $\left.]_{1}-\mathbf{4 5 d}\right)(43 \mathrm{mg}, 0.25 \mathrm{mmol}, 1.00$ equiv), 2-bromobenzonitrile (46k) (68 mg, $0.38 \mathrm{mmol}, 1.50$ equiv), $\left[\mathrm{RuCl}_{2}(p \text {-cymene) }]_{2}(3.8 \mathrm{mg}, 6.2 \mu \mathrm{mol}, 2.5 \mathrm{~mol} \%), \mathrm{MesCO}_{2} \mathrm{H}(58)\right.$ (12.3 mg, $0.08 \mathrm{mmol}, 30 \mathrm{~mol} \%$ ) and $\mathrm{K}_{2} \mathrm{CO}_{3}(69 \mathrm{mg}, 0.50 \mathrm{mmol}, 2.00$ equiv). PhMe (1.0 mL) was added and the mixture was stirred at $120^{\circ} \mathrm{C}$ for $1 \mathrm{~h}$. After cooling to ambient temperature, $\mathrm{H}_{2} \mathrm{O}$ $(12 \mathrm{~mL})$ was added, the mixture was extracted with $\mathrm{Et}_{2} \mathrm{O}(3 \times 12 \mathrm{~mL})$, washed with brine $(12 \mathrm{~mL})$, dried over $\mathrm{Na}_{2} \mathrm{SO}_{4}$ and concentrated in vacuo. Purification of the residue by column chromatography on silica gel ( $n$-hexane/EtOAc 7:1 $\rightarrow 1: 1)$ yielded $181 \mathrm{~d}(8 \mathrm{mg}, 19 \%)$ and recovered 45d (14 mg, 33\%). The deuterium incorporation was determined by ${ }^{1} \mathrm{H}-\mathrm{NMR}$ spectroscopy. 


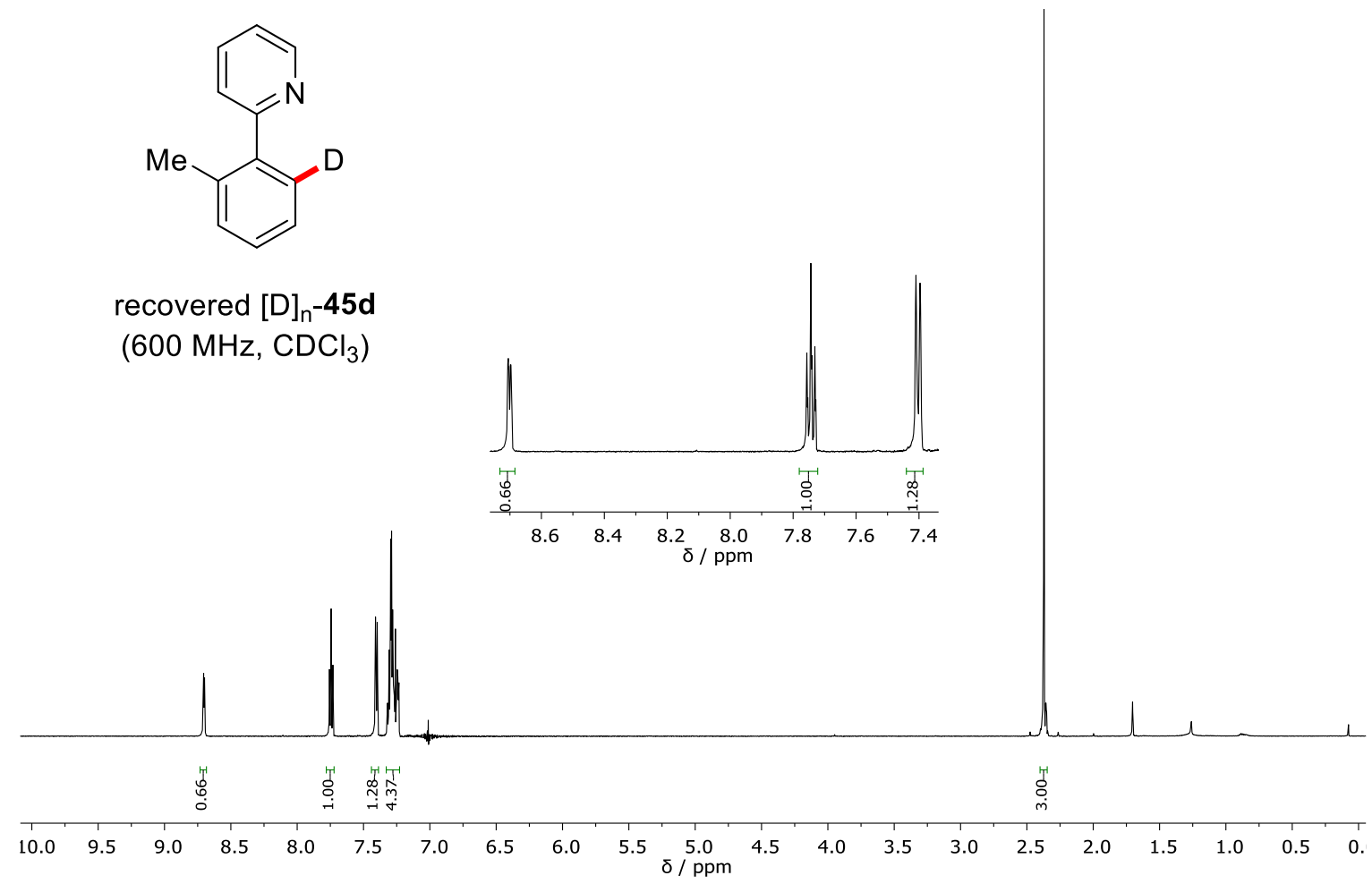<smiles>Cc1cccc(-c2cccc(C)c2-c2ccccn2)c1-c1ccccn1</smiles>

$[D]_{n}-181 d$ (600 MHz, $\mathrm{CDCl}_{3}$ )
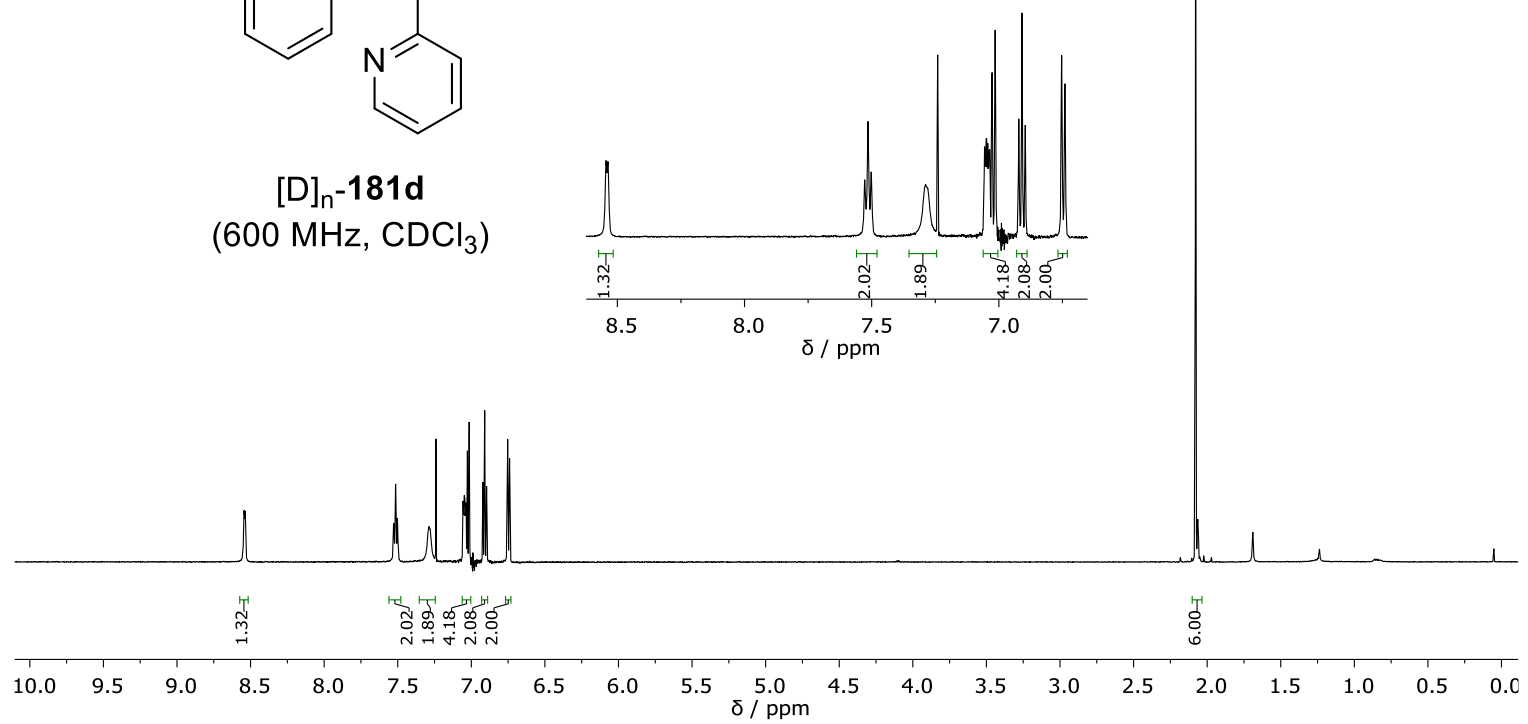


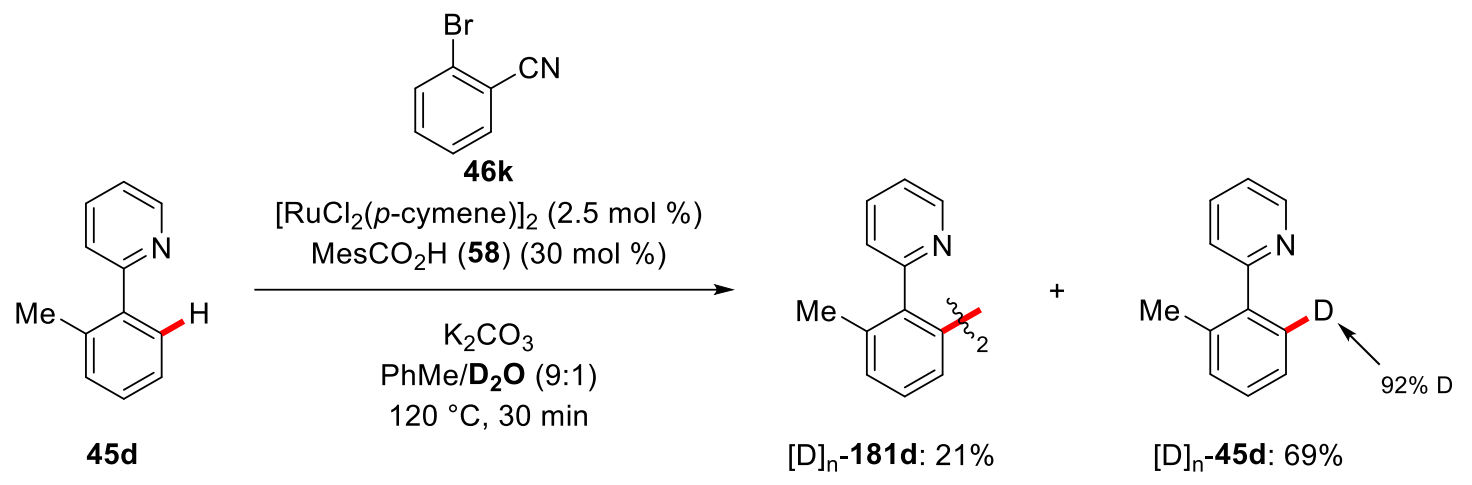

Under an atmosphere of $\mathrm{N}_{2}$, a Schlenk-tube was charged with 2-(2-methylphenyl)pyridine (45d) ( $85 \mathrm{mg}, 0.50 \mathrm{mmol}, 1.00$ equiv), 2-bromobenzonitrile (46k) (137 mg, $0.75 \mathrm{mmol}, 1.50$ equiv), $\left[\mathrm{RuCl}_{2}(p \text {-cymene) }]_{2}(7.7 \mathrm{mg}, 12.5 \mu \mathrm{mol}, 2.5 \mathrm{~mol} \%), \mathrm{MesCO}_{2} \mathrm{H}\right.$ (58) (24.6 mg, $\left.0.15 \mathrm{mmol}, 30 \mathrm{~mol} \%\right)$ and $\mathrm{K}_{2} \mathrm{CO}_{3}\left(138 \mathrm{mg}, 1.00 \mathrm{mmol}, 2.00\right.$ equiv). PhMe $(1.8 \mathrm{~mL})$ and $\mathrm{D}_{2} \mathrm{O}(0.2 \mathrm{~mL})$ were added and the mixture was stirred at $120^{\circ} \mathrm{C}$ for $30 \mathrm{~min}$. After cooling to ambient temperature, $\mathrm{H}_{2} \mathrm{O}(25 \mathrm{~mL})$ was added, the mixture was extracted with $\mathrm{Et}_{2} \mathrm{O}(3 \times 25 \mathrm{~mL})$, washed with brine $(25 \mathrm{~mL})$, dried over $\mathrm{Na}_{2} \mathrm{SO}_{4}$ and concentrated in vacuo. Purification of the residue by column chromatography on silica gel ( $n$-hexane/EtOAc 7:1 $\rightarrow 1: 1$ ) yielded 181d (18 mg, 21\%) and recovered 45d (57 mg, 69\%). The deuterium incorporation was determined by ${ }^{1} \mathrm{H}-\mathrm{NMR}$ spectroscopy.<smiles>[2H]c1cccc(C)c1-c1ccccn1</smiles>

recovered $[D]_{n}-45 d$ $\left(600 \mathrm{MHz}, \mathrm{CDCl}_{3}\right)$
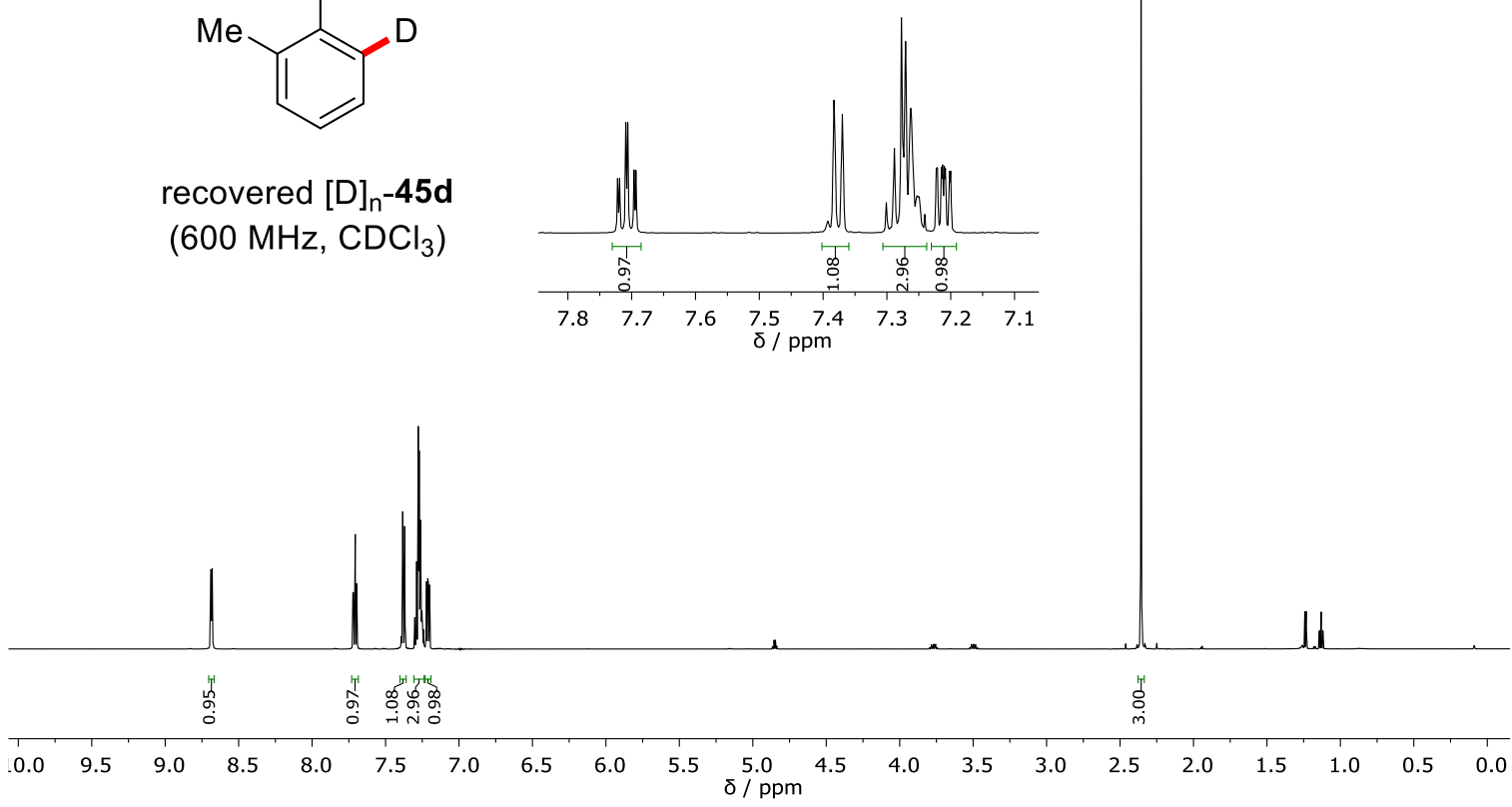
<smiles>Cc1cccc(-c2cccc(C)c2-c2ccccn2)c1-c1ccccn1</smiles>

$[D]_{n}-181 d$ $\left(300 \mathrm{MHz}, \mathrm{CDCl}_{3}\right)$
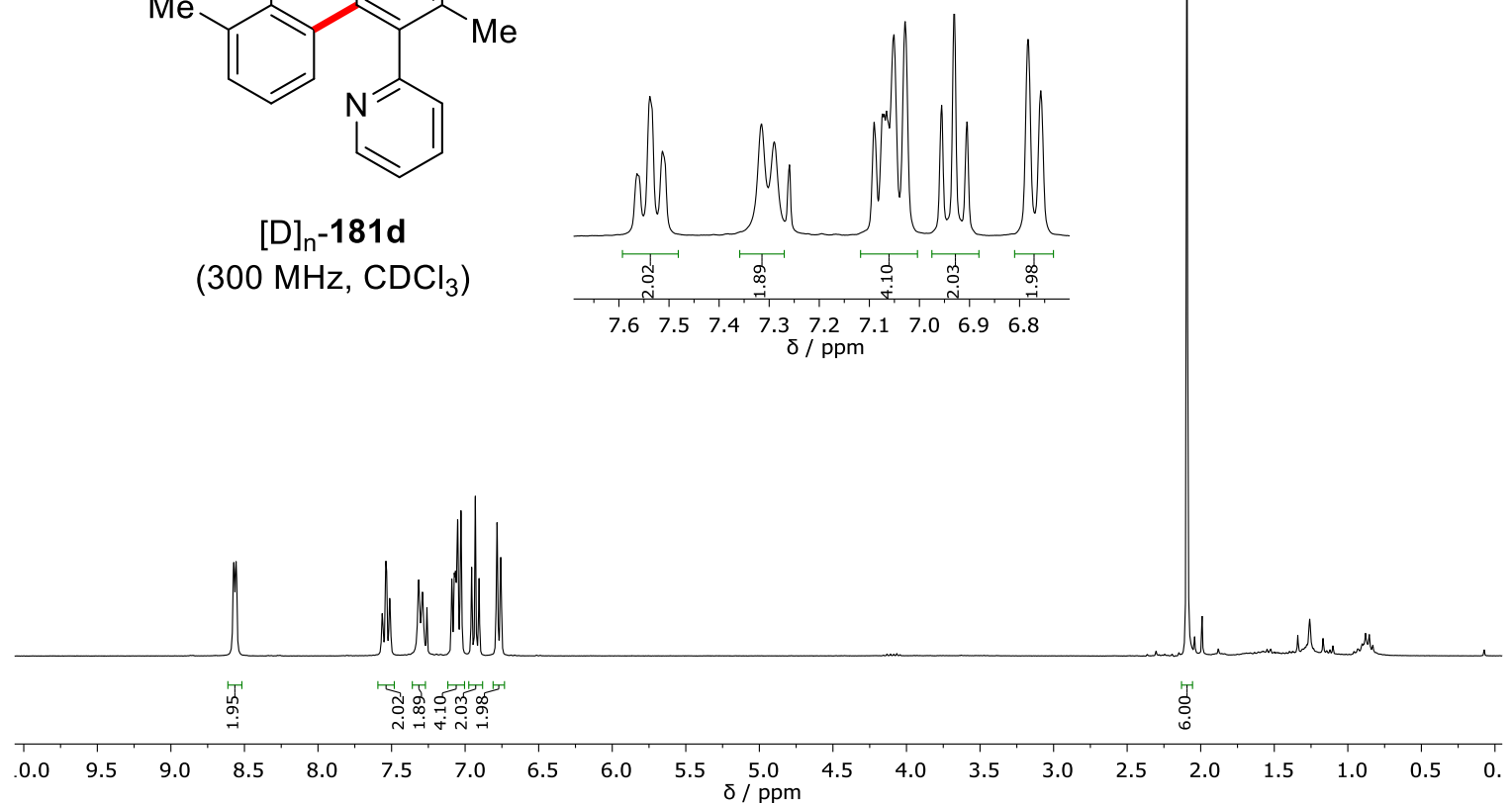

Kinetic Isotope Effect (KIE) Studies<smiles>Cc1cccc(O)c1-c1ccccn1</smiles>

$45 d$ or $[D]_{1}-45 d$<smiles>FC(F)(F)c1ccccc1Br</smiles>

46j
$\left[\mathrm{Ru}\left(\mathrm{O}_{2} \mathrm{CMes}\right)_{2}(\right.$-cymene $\left.)\right](\mathbf{6 1})$ $(5.0 \mathrm{~mol} \%)$

$$
\mathrm{K}_{2} \mathrm{CO}_{3}
$$

PhMe, $102{ }^{\circ} \mathrm{C}$

$k_{\mathrm{H}} / k_{\mathrm{D}}=1.76$<smiles>Cc1cccc(C)c1-c1ccccn1</smiles>

$181 \mathrm{~d}$ or $[D]_{n}-181 d$

The kinetic isotope effect (KIE) was determined by measuring the initial rates of two independent reactions. Under an atmosphere of $\mathrm{N}_{2}$ inside a glovebox, a Schlenk-tube was charged with 2-(2methylphenyl)pyridine (45d) $\quad(85 \mathrm{mg}, \quad 0.50 \mathrm{mmol}, \quad 1.00$ equiv) or $\quad 2$-(2-methyl-6deuterophenyl)pyridine ([D] $\left.{ }_{1}-45 \mathrm{~d}\right)(85 \mathrm{mg}, 0.50 \mathrm{mmol}, 1.00$ equiv), 2-bromotrifluorotoluene (46j) (169 mg, $0.75 \mathrm{mmol}, 1.50$ equiv), [Ru( $\left.\mathrm{O}_{2} \mathrm{CMes}\right)_{2}($-cymene)] (61) (14.1 mg, $25 \mu \mathrm{mol}, 5.0 \mathrm{~mol} \%$ ), $\mathrm{K}_{2} \mathrm{CO}_{3}$ (138 mg, $1.00 \mathrm{mmol}, 2.00$ equiv) and $n$-dodecane $(40 \mu \mathrm{L})$. PhMe $(2.0 \mathrm{~mL})$ was added and the mixture was stirred at $102{ }^{\circ} \mathrm{C}$. During the course of the reaction aliquots $(0.05 \mathrm{~mL})$ were removed via a syringe every $15 \mathrm{~min}$ for $60 \mathrm{~min}$, every $20 \mathrm{~min}$ for the following $60 \mathrm{~min}$ and after the following $30 \mathrm{~min}$, diluted with EtOAc, filtered through a short plug of silica gel and analyzed by gas chromatography. 
A linear fit was employed for the time 80-150 min and the obtained slopes were used to calculate the KIE value.

Table 4: Conversion versus time for $45 \mathrm{~d}$ and $[D]_{1}-\mathbf{4 5 d}$.

\begin{tabular}{|c|c|c|}
\hline$t / \min$ & {$[\mathbf{1 8 1 d}] / \mathrm{mmol} \mathrm{L}^{-1}$} & conversion / \% \\
\hline \multicolumn{3}{|c|}{ Measurement for $\mathbf{4 5 d :}$} \\
\hline 15 & 1.31 & 1.05 \\
\hline 30 & 1.99 & 1.59 \\
\hline 45 & 3.20 & 2.56 \\
\hline 60 & 4.65 & 3.72 \\
\hline 80 & 7.20 & 5.76 \\
\hline 100 & 10.25 & 8.20 \\
\hline 120 & 14.84 & 11.87 \\
\hline 150 & 19.87 & 15.90 \\
\hline \multicolumn{3}{|c|}{ Measurement for $[D]_{1}-\mathbf{4 5 d}$ : } \\
\hline 15 & 1.68 & 1.35 \\
\hline 30 & 2.11 & 1.69 \\
\hline 45 & 2.87 & 2.30 \\
\hline 60 & 3.70 & 2.96 \\
\hline 80 & 5.40 & 4.32 \\
\hline 100 & 7.02 & 5.61 \\
\hline 120 & 9.32 & 7.45 \\
\hline 150 & 12.62 & 10.10 \\
\hline
\end{tabular}




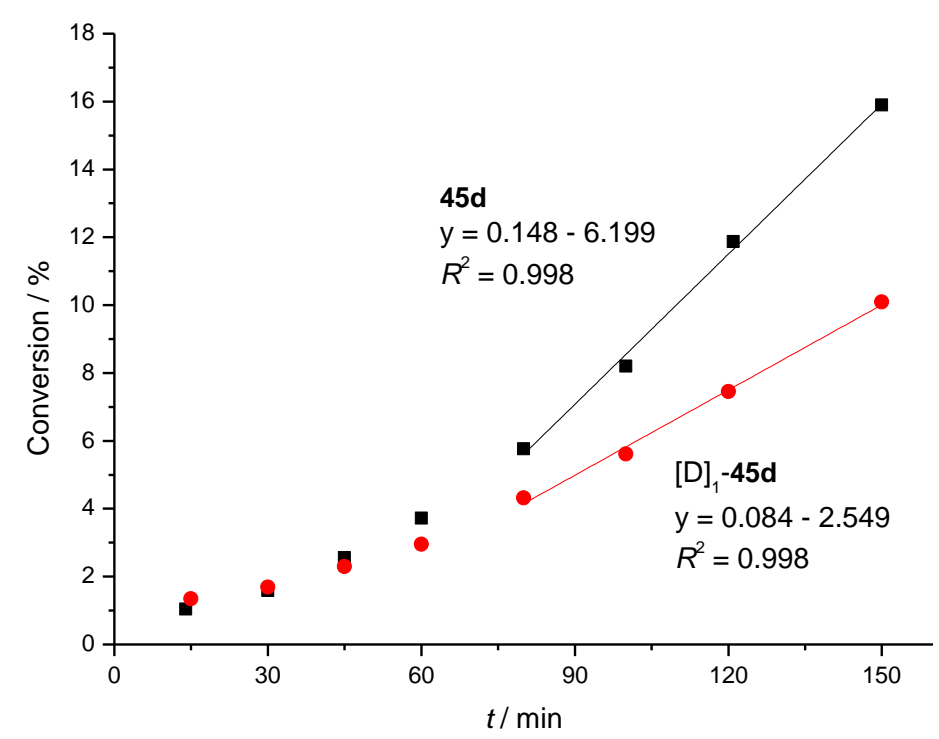

Figure 69: Initial rate measurement for the reaction of $45 d$ and $[D]_{n}-45 d$.<smiles>Cc1cccc(O)c1-c1ccccn1</smiles>

$45 d$ or $[D]_{1}-45 d$<smiles>N#Cc1ccccc1Br</smiles>

46k
$\left[\mathrm{Ru}\left(\mathrm{O}_{2} \mathrm{CMes}\right)_{2}(p\right.$-cymene $\left.)\right](\mathbf{6 1})$

$(5.0 \mathrm{~mol} \%)$

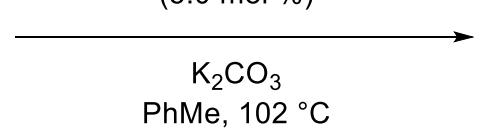

$k_{\mathrm{H}} / k_{\mathrm{D}}=2.17 \pm 0.18$<smiles>Cc1cccc(C)c1-c1ccccn1</smiles>

$181 d$ or $[D]_{n}-181 d$

The kinetic isotope effect (KIE) was determined by measuring the initial rates of two independent reactions. Under an atmosphere of $\mathrm{N}_{2}$ inside a glovebox, a Schlenk-tube was charged with 2-(2methylphenyl)pyridine (45d) $\quad(85 \mathrm{mg}, \quad 0.50 \mathrm{mmol}, \quad 1.00$ equiv) or 2-(2-methyl-6deuterophenyl)pyridine ([D] $\left.]_{1}-45 \mathrm{~d}\right)(85 \mathrm{mg}, 0.50 \mathrm{mmol}, 1.00$ equiv), 2-bromobenzonitrile (46k) (137 mg, $0.75 \mathrm{mmol}, 1.50$ equiv), [Ru( $\left.\mathrm{O}_{2} \mathrm{CMes}\right)_{2}(p$-cymene)] (61) (14.1 mg, $25 \mu \mathrm{mol}, 5.0 \mathrm{~mol} \%)$, $\mathrm{K}_{2} \mathrm{CO}_{3}$ (138 mg, $1.00 \mathrm{mmol}, 2.00$ equiv) and $n$-dodecane $(40 \mu \mathrm{L})$. PhMe $(2.0 \mathrm{~mL})$ was added and the mixture was stirred at $102{ }^{\circ} \mathrm{C}$. During the course of the reaction aliquots $(0.05 \mathrm{~mL})$ were removed via a syringe every $3 \mathrm{~min}$ for $15 \mathrm{~min}$ and every $5 \mathrm{~min}$ for the following $15 \mathrm{~min}$, diluted with EtOAc, filtered through a short plug of silica gel and analyzed by gas chromatography.

Each reaction was performed two times, the measured conversions were averaged and the error corresponds to the standard deviation. A linear fit with instrumentally weighted errors was employed for the time 3-15 min and the obtained errors of the slope were employed in a variance formula error propagation to determine the error of the KIE value. 
Table 5: Conversion versus time for $\mathbf{4 5 d}$ and $[D]_{1}-\mathbf{4 5 d}$.

\begin{tabular}{|c|c|c|c|c|c|}
\hline$t / \min$ & $\begin{array}{c}{[\mathbf{1 8 1 d}]_{\text {run1 }} /} \\
\mathrm{mmol} \mathrm{L}^{-1}\end{array}$ & $\begin{array}{c}{[\mathbf{1 8 1 d}]_{\text {run2 }} /} \\
\mathrm{mmol} \mathrm{L}^{-1}\end{array}$ & $\begin{array}{c}{[\mathbf{1 8 1 d}]_{\text {average }} /} \\
\mathrm{mmol} \mathrm{L}^{-1}\end{array}$ & $\begin{array}{c}\text { conversion }_{\text {average }} \\
/ \%\end{array}$ & $\begin{array}{c}\Delta \text { conversion } \\
/ \%\end{array}$ \\
\hline \multicolumn{6}{|c|}{ Measurement for $\mathbf{4 5 d :}$} \\
\hline 3 & 1.96 & 2.02 & 1.99 & 1.59 & 0.04 \\
\hline 6 & 5.04 & 5.46 & 5.25 & 4.20 & 0.24 \\
\hline 9 & 8.62 & 9.05 & 8.84 & 7.07 & 0.24 \\
\hline 12 & 11.76 & 13.53 & 12.65 & 10.12 & 1.00 \\
\hline 15 & 15.19 & 16.34 & 15.77 & 12.61 & 0.65 \\
\hline 20 & 16.84 & 21.18 & 19.01 & 15.21 & 2.45 \\
\hline 25 & 21.76 & 25.95 & 23.86 & 19.08 & 2.37 \\
\hline 30 & 24.05 & 27.24 & 25.65 & 20.51 & 1.80 \\
\hline \multicolumn{6}{|c|}{ Measurement for $[D]_{1}-\mathbf{4 5 d}$ : } \\
\hline 3.08 & 1.47 & 1.80 & 1.64 & 1.31 & 0.19 \\
\hline 6.08 & 2.62 & 3.11 & 2.87 & 2.29 & 0.28 \\
\hline 9.50 & 4.44 & 5.64 & 5.04 & 4.03 & 0.68 \\
\hline 12.08 & 5.91 & 7.53 & 6.72 & 5.37 & 0.92 \\
\hline 15.09 & 7.23 & 9.49 & 8.36 & 6.69 & 1.28 \\
\hline 20.10 & 9.18 & 12.26 & 10.72 & 8.58 & 1.74 \\
\hline 25.08 & 11.73 & 13.93 & 12.83 & 10.27 & 1.25 \\
\hline 30.10 & 14.33 & 17.56 & 15.95 & 12.76 & 1.83 \\
\hline
\end{tabular}




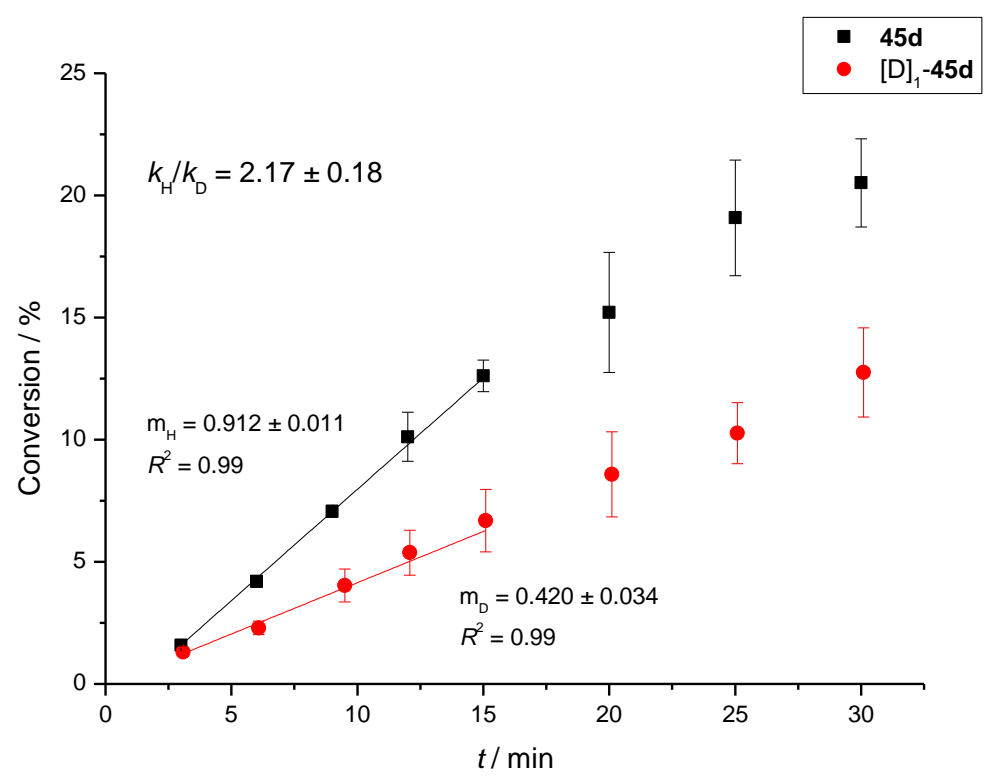

Figure 70: Initial rate measurement for the reaction of $45 d$ and $[D]_{1}-45 d$.

\section{Detection of Byproducts}<smiles>Cc1ccccc1-c1ccccn1</smiles>

45d<smiles>FC(F)(F)c1ccccc1Br</smiles>

46j

$\left[\mathrm{RuCl}_{2}(p \text {-cymene })\right]_{2}(2.5 \mathrm{~mol} \%)$ MesCO ${ }_{2} \mathrm{H}(58)(30 \mathrm{~mol} \%)$

$$
\mathrm{K}_{2} \mathrm{CO}_{3}
$$

PhMe, $120^{\circ} \mathrm{C}, 20 \mathrm{~h}$<smiles>Cc1cccc(-c2ccccc2C(F)(F)F)c1-c1ccccn1</smiles>

47dj: $21 \%$<smiles>Cc1cccc(C)c1-c1ccccn1</smiles>

181d: $41 \%$<smiles>FC(F)(F)c1ccccc1</smiles>

182: $74 \%$

Under an atmosphere of $\mathrm{N}_{2}$, a Schlenk-tube was charged with 2-(2-methylphenyl)pyridine (45d) (42 mg, $0.25 \mathrm{mmol}, 1.00$ equiv), 2-bromotrifluorotoluene (46j) (84 mg, $0.38 \mathrm{mmol}, 1.50$ equiv), $\left[\mathrm{RuCl}_{2}(p\right.$-cymene)] 2 (3.8 mg, $6.2 \mu \mathrm{mol}, 2.5 \mathrm{~mol} \%), \mathrm{MesCO}_{2} \mathrm{H}(58)(12.3 \mathrm{mg}, 0.08 \mathrm{mmol}, 30 \mathrm{~mol} \%)$ and $\mathrm{K}_{2} \mathrm{CO}_{3}(69 \mathrm{mg}, 0.50 \mathrm{mmol}, 2.00$ equiv). $\mathrm{PhMe}(2.0 \mathrm{~mL})$ was added and the mixture was stirred at $120^{\circ} \mathrm{C}$ for $20 \mathrm{~h}$. After cooling to ambient temperature, $n$-dodecane $(40 \mu \mathrm{L})$ and EtOAc $(3 \mathrm{~mL})$ were added. A portion of the mixture (approx. $0.7 \mathrm{~mL}$ ) was removed via a syringe, diluted with EtOAc, filtered through a short plug of silica gel and analyzed by gas chromatography. The conversion was determined by gas chromatography and the structure of $\mathbf{1 8 2}$ was confirmed by GC-MS and by comparison with commercially obtained 182 . 


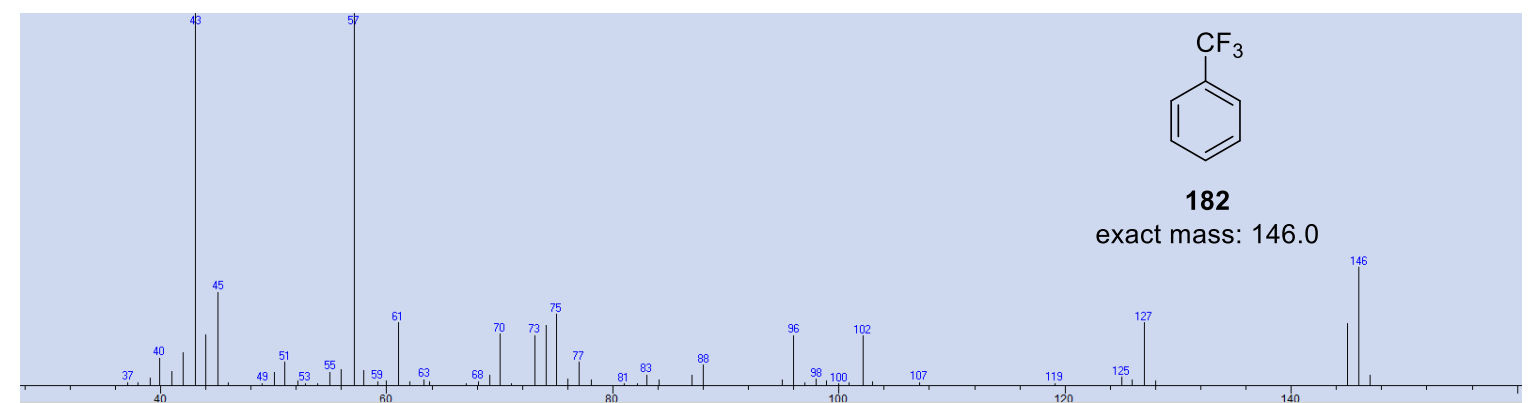<smiles>COc1cccc(O)c1-c1ccccn1</smiles>

$[\mathrm{D}]_{1}-45 \mathrm{~d}$<smiles>N#Cc1ccccc1Br</smiles>

$46 k$

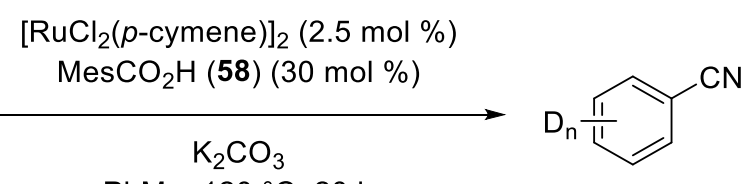

$\mathrm{PhMe}, 120^{\circ} \mathrm{C}, 20 \mathrm{~h}$

$$
\begin{gathered}
{[\mathrm{D}]_{\mathrm{n}}-\mathbf{1 8 3}} \\
\text { (detected by GC-MS) }
\end{gathered}
$$

Under an atmosphere of $\mathrm{N}_{2}$, a Schlenk-tube was charged with 2-(2-methyl-6deuterophenyl)pyridine (45d) (85 mg, $0.50 \mathrm{mmol}, 1.00$ equiv), 2-bromobenzonitrile (46k) (137 mg, $0.75 \mathrm{mmol}, 1.50$ equiv), $\left[\mathrm{RuCl}_{2}(p \text {-cymene) }]_{2}(7.7 \mathrm{mg}, 12.5 \mu \mathrm{mol}, 2.5 \mathrm{~mol} \%), \mathrm{MesCO}_{2} \mathrm{H}\right.$ (58) (25 mg, $0.15 \mathrm{mmol}, 30 \mathrm{~mol} \%)$ and $\mathrm{K}_{2} \mathrm{CO}_{3}(138 \mathrm{mg}, 1.00 \mathrm{mmol}, 2.00$ equiv). PhMe (2.0 mL) was added and the mixture was stirred at $120^{\circ} \mathrm{C}$ for $20 \mathrm{~h}$. After cooling to ambient temperature, EtOAc $(3 \mathrm{~mL}$ ) was added. A portion of the mixture (approx. $0.7 \mathrm{~mL}$ ) was removed via a syringe, diluted with EtOAc, filtered through a short plug of silica gel and analyzed by gas chromatography. The structure of 183 was confirmed by GC-MS and by comparison with commercially obtained 183 .

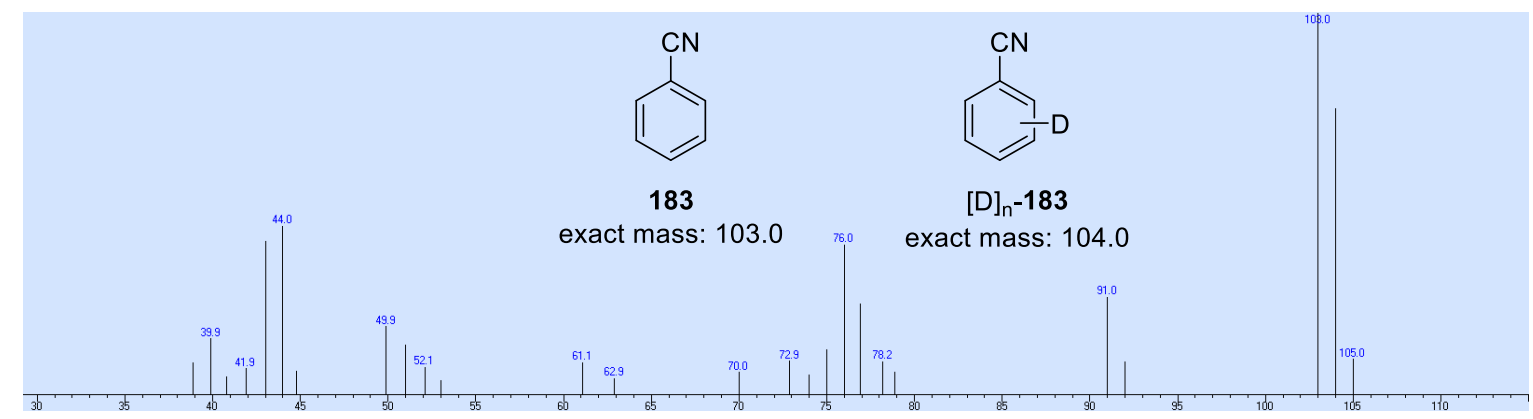




\section{Effect of Additional Nitrile}<smiles>Cc1ccccc1-c1ccccn1</smiles>

45d<smiles>FC(F)(F)c1ccccc1Br</smiles>

46j
$\left[\mathrm{Ru}\left(\mathrm{O}_{2} \mathrm{CMes}\right)_{2}(p\right.$-cymene $\left.)\right]$ (61)

$(5.0 \mathrm{~mol} \%)$

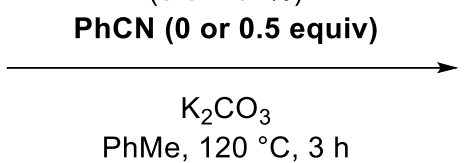

PhMe, $120^{\circ} \mathrm{C}, 3 \mathrm{~h}$<smiles>Cc1cccc(-c2ccccc2C(F)(F)F)c1-c1ccccn1</smiles>

47dj

Under an atmosphere of $\mathrm{N}_{2}$, a Schlenk-tube was charged with 2-(2-methylphenyl)pyridine (45d) (85 mg, 0.50 mmol, 1.00 equiv), 2-bromotrifluorotoluene (46j) (169 mg, $0.75 \mathrm{mmol}, 1.50$ equiv), $\left[\mathrm{Ru}\left(\mathrm{O}_{2} \mathrm{CMes}\right)_{2}(p\right.$-cymene) $(61)(14.1 \mathrm{mg}, 25.0 \mu \mathrm{mol}, 5.0 \mathrm{~mol} \%)$, benzonitrile (26 mg, $0.25 \mathrm{mmol}$, 0.50 equiv or 0 equiv) and $\mathrm{K}_{2} \mathrm{CO}_{3}(138 \mathrm{mg}, 1.00 \mathrm{mmol}, 2.00$ equiv). PhMe $(2.0 \mathrm{~mL})$ was added and the mixture was stirred at $120^{\circ} \mathrm{C}$ for $3 \mathrm{~h}$. After cooling to ambient temperature, EtOAc ( $\left.3 \mathrm{~mL}\right)$ and $n$-dodecane $(40 \mu \mathrm{L}$ ) were added. A portion of the mixture (approx. $0.7 \mathrm{~mL}$ ) was removed via a syringe, diluted with EtOAc, filtered through a short plug of silica gel and analyzed by gas chromatography.

Table 6: Effect of benzonitrile addition.

\begin{tabular}{ccc}
\hline PhCN & conversion 181d $/ \%^{[\mathrm{a}]}$ & conversion 47dj $/ \%^{[\mathrm{a}]}$ \\
\hline e equiv & 23 & 9 \\
0.5 equiv & 75 & 2
\end{tabular}

[a] Determined by GC analysis with $n$-dodecane as the internal standard.

\section{Detection of free $p$-Cymene}<smiles>Cc1ccccc1-c1ccccn1</smiles>

45d<smiles>N#Cc1ccccc1Br</smiles>

46k

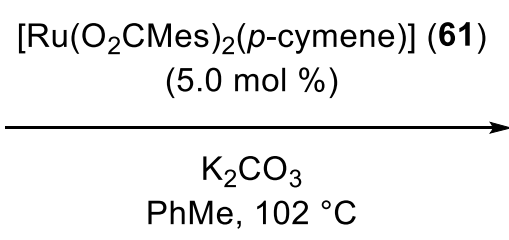

$\mathrm{PhMe}, 102{ }^{\circ} \mathrm{C}$

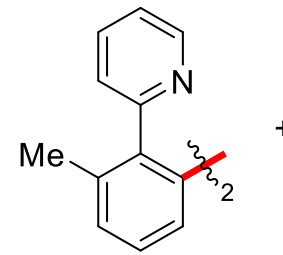

$181 d$<smiles>Cc1ccc(Br)cc1</smiles>

184

Under an atmosphere of $\mathrm{N}_{2}$ inside a glovebox, a Schlenk-tube was charged with 2-(2methylphenyl)pyridine (45d) (85 mg, $0.50 \mathrm{mmol}, 1.00$ equiv), 2-bromobenzonitrile (46k) (137 mg, $0.75 \mathrm{mmol}, 1.50$ equiv), [Ru(O $\left.{ }_{2} \mathrm{CMes}\right)_{2}(p$-cymene)] (61) (14.1 mg, $25 \mu \mathrm{mol}, 5.0 \mathrm{~mol} \%), \mathrm{K}_{2} \mathrm{CO}_{3}$ (138 mg, $1.00 \mathrm{mmol}, 2.00$ equiv) and $n$-dodecane $(40 \mu \mathrm{L})$. PhMe $(2.0 \mathrm{~mL})$ was added and the mixture was stirred at $102{ }^{\circ} \mathrm{C}$. During the course of the reaction aliquots $(0.15 \mathrm{~mL})$ were removed 
via a syringe after $3 \mathrm{~min}, 15 \mathrm{~min}, 60 \mathrm{~min}$ and $180 \mathrm{~min}$, diluted with EtOAc, filtered through a short plug of silica gel and analyzed by gas chromatography.

\begin{tabular}{ccc}
\hline$t / \min$ & {$[\mathbf{1 8 1} \mathbf{d}] / \mathrm{mmol} \mathrm{L}^{-1}$} & {$[\mathbf{1 8 4}] / \mathrm{mmol} \mathrm{L}^{-1}$} \\
\hline 3 & 2.84 & 3.28 \\
15 & 15.8 & 6.80 \\
30 & 22.6 & 7.21 \\
60 & 49.1 & 7.86 \\
180 & 93.8 & 9.16 \\
\hline
\end{tabular}<smiles>Cc1ccc(C(C)(C)C)cc1</smiles>

Under an atmosphere of $\mathrm{N}_{2}$ inside a glovebox, a Schlenk-tube was charged with 2-(2methylphenyl)pyridine (45d) $(85 \mathrm{mg}, 0.50 \mathrm{mmol}, 1.00$ equiv), 2-bromotrifluorotoluene (46j) (169 mg, $0.75 \mathrm{mmol}, 1.50$ equiv), [Ru( $\left(\mathrm{O}_{2} \mathrm{CMes}\right)_{2}(p$-cymene)] (61) (14.1 mg, $25 \mu \mathrm{mol}, 5.0 \mathrm{~mol} \%)$, $\mathrm{K}_{2} \mathrm{CO}_{3}$ (138 mg, $1.00 \mathrm{mmol}, 2.00$ equiv) and $n$-dodecane $(40 \mu \mathrm{L})$. PhMe $(2.0 \mathrm{~mL})$ was added and the mixture was stirred at $102^{\circ} \mathrm{C}$. During the course of the reaction aliquots $(0.15 \mathrm{~mL})$ were removed via a syringe after $3 \mathrm{~min}, 15 \mathrm{~min}, 60 \mathrm{~min}$ and $180 \mathrm{~min}$, diluted with EtOAc, filtered through a short plug of silica gel and analyzed by gas chromatography.

\begin{tabular}{cccc}
\hline$t / \mathrm{min}$ & {$[\mathbf{1 8 1} \mathrm{d}] / \mathrm{mmol} \mathrm{L}^{-1}$} & {$[\mathbf{4 7} \mathbf{d j}] / \mathrm{mmol} \mathrm{L}^{-1}$} & {$[\mathbf{1 8 4}] / \mathrm{mmol} \mathrm{L}^{-1}$} \\
\hline 3 & 1.27 & 1.15 & 0.29 \\
15 & 1.82 & 1.52 & 0.84 \\
30 & 2.86 & 2.34 & 1.50 \\
60 & 6.37 & 4.97 & 2.46 \\
180 & 28.3 & 22.5 & 5.02 \\
\hline
\end{tabular}


<smiles>Fc1ccccc1-c1ccccn1</smiles>

$45 e$<smiles>N#Cc1ccccc1Br</smiles>

46k

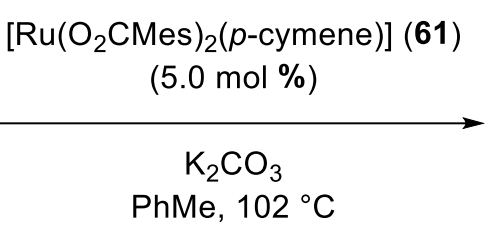

PhMe, $102{ }^{\circ} \mathrm{C}$

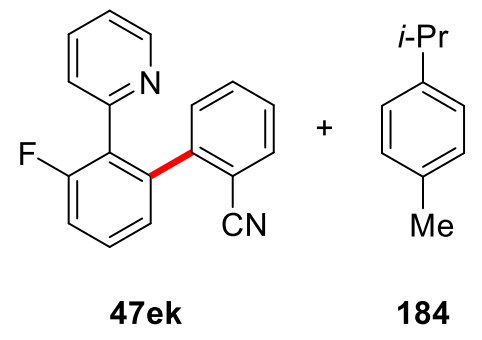

Under an atmosphere of $\mathrm{N}_{2}$ inside a glovebox, a Schlenk-tube was charged with 2-(2fluorophenyl)pyridine (45e) (87 mg, $0.50 \mathrm{mmol}, 1.00$ equiv), 2-bromobenzonitrile (46k) (137 mg, $0.75 \mathrm{mmol}, 1.50$ equiv), [Ru(O) $\left.{ }_{2} \mathrm{CMes}\right)_{2}\left(p\right.$-cymene)] (61) $(14.1 \mathrm{mg}, 25 \mu \mathrm{mol}, 5.0 \mathrm{~mol} \%), \mathrm{K}_{2} \mathrm{CO}_{3}$ (138 mg, $1.00 \mathrm{mmol}, 2.00$ equiv) and $n$-dodecane $(40 \mu \mathrm{L})$. PhMe $(2.0 \mathrm{~mL})$ was added and the mixture was stirred at $102{ }^{\circ} \mathrm{C}$. During the course of the reaction aliquots $(0.15 \mathrm{~mL})$ were removed via a syringe after $3 \mathrm{~min}, 15 \mathrm{~min}, 60 \mathrm{~min}$ and $180 \mathrm{~min}$, diluted with EtOAc, filtered through a short plug of silica gel and analyzed by gas chromatography.

\begin{tabular}{ccc}
\hline$t / \min$ & {$[\mathbf{4 7 e k}] / \mathrm{mmol} \mathrm{L}^{-1}$} & {$[\mathbf{1 8 4}] / \mathrm{mmol} \mathrm{L}^{-1}$} \\
\hline 3 & 2.32 & 0.37 \\
15 & 7.77 & 0.81 \\
30 & 20.1 & 1.27 \\
60 & 51.2 & 2.10 \\
180 & 193 & 4.94 \\
\hline
\end{tabular}<smiles>Fc1ccccc1-c1ccccn1</smiles>

$45 e$<smiles>N#Cc1ccccc1Br</smiles>

46k
$\left[\mathrm{Ru}\left(\mathrm{O}_{2} \mathrm{CMes}\right)_{2}(p\right.$-cymene $\left.)\right](\mathbf{6 1})$ $(2.5 \mathrm{~mol} \%)$

$\mathrm{K}_{2} \mathrm{CO}_{3}$
PhMe, $102{ }^{\circ} \mathrm{C}$<smiles>CCCc1ccc(C)cc1</smiles>

47ek

Under an atmosphere of $\mathrm{N}_{2}$ inside a glovebox, a Schlenk-tube was charged with 2-(2fluorophenyl)pyridine (45e) (87 mg, $0.50 \mathrm{mmol}, 1.00$ equiv), 2-bromobenzonitrile (46k) (137 mg, $0.75 \mathrm{mmol}, 1.50$ equiv), $\left[\mathrm{Ru}\left(\mathrm{O}_{2} \mathrm{CMes}\right)_{2}(p\right.$-cymene $\left.)\right]$ (61) $(7.0 \mathrm{mg}, 13 \mu \mathrm{mol}, 2.5 \mathrm{~mol} \%), \mathrm{K}_{2} \mathrm{CO}_{3}$ (138 mg, $1.00 \mathrm{mmol}, 2.00$ equiv) and $n$-dodecane $(40 \mu \mathrm{L})$. PhMe $(2.0 \mathrm{~mL})$ was added and the mixture was stirred at $102{ }^{\circ} \mathrm{C}$. During the course of the reaction aliquots $(0.15 \mathrm{~mL})$ were removed via a syringe after $3 \mathrm{~min}, 15 \mathrm{~min}, 60 \mathrm{~min}$ and $180 \mathrm{~min}$, diluted with EtOAc, filtered through a short plug of silica gel and analyzed by gas chromatography. 


\begin{tabular}{ccc}
\hline$t / \min$ & {$[\mathbf{4 7 e k}] / \mathrm{mmol} \mathrm{L}^{-1}$} & {$[\mathbf{1 8 4}] / \mathrm{mmol} \mathrm{L}^{-1}$} \\
\hline 3 & 2.25 & 0.28 \\
15 & 5.53 & 0.62 \\
30 & 13.4 & 0.89 \\
60 & 33.6 & 1.36 \\
180 & 139 & 2.83 \\
\hline
\end{tabular}

To determine the background decoordination of $p$-cymene (184), an experiment was conducted as follows:

Under an atmosphere of $\mathrm{N}_{2}$, a Schlenk-tube was charged with $\left[\mathrm{Ru}\left(\mathrm{O}_{2} \mathrm{CMes}\right)_{2}(p\right.$-cymene)] (61) $(14.1 \mathrm{mg}, 25 \mu \mathrm{mol})$ and $\mathrm{K}_{2} \mathrm{CO}_{3}(138 \mathrm{mg}, 1.00 \mathrm{mmol})$. PhMe $(2.0 \mathrm{~mL})$ was added and the mixture was stirred at $102{ }^{\circ} \mathrm{C}$ for $180 \mathrm{~min}$. Afterwards, the reaction mixture was quickly cooled to ambient temperature and $n$-dodecane $(40 \mu \mathrm{L})$ was added. An aliquot $(0.15 \mathrm{~mL})$ were removed via a syringe, filtered through a short plug of silica gel and analyzed by gas chromatography. A concentration of $0.41 \mathrm{mmol} \mathrm{L}^{-1}$ of $p$-cymene (184) was determined, which corresponds to $3.3 \%$ of the maximum possible amount.

\subsubsection{Kinetic Analysis}

\subsection{Reaction Order Determination with 2-Bromotrifluorotoluene (46j)}

\section{Reaction Order with Respect to Phenylpyridine 45d}

The initial rate method was employed to determine the reaction order with respect to phenylpyridine $45 \mathrm{~d} .{ }^{[178]}$ Under an atmosphere of $\mathrm{N}_{2}$ inside a glovebox, a Schlenk-tube was charged with 2-(2-methylphenyl)pyridine $\quad(45 \mathrm{~d}) \quad(0.30, \quad 0.38, \quad 0.50, \quad 0.63, \quad 0.75 \mathrm{mmol}), \quad 2-$ bromotrifluorotoluene (46j) (169 mg, $0.75 \mathrm{mmol}$ ), $\mathrm{MesCO}_{2} \mathrm{H}$ (58) $(25 \mathrm{mg}, 0.15 \mathrm{mmol}), \mathrm{K}_{2} \mathrm{CO}_{3}$ $(138 \mathrm{mg}, 1.00 \mathrm{mmol})$ and $n$-dodecane $(40 \mu \mathrm{L})$. A solution of $\left[\mathrm{RuCl}_{2}(p \text {-cymene })\right]_{2}(7.7 \mathrm{mg}$, $12.5 \mu \mathrm{mol})$ in PhMe $(2.0 \mathrm{~mL})$ was added and the mixture was stirred at $102^{\circ} \mathrm{C}$. Aliquots $(0.05 \mathrm{~mL})$ were removed via a syringe after 15, 30, 45, 60, 80, 100, 120 and 150 min, diluted with EtOAc $(1.0 \mathrm{~mL})$, filtered through a short plug of silica gel and analyzed by gas chromatography. 


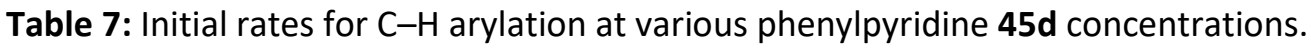

\begin{tabular}{cccc}
\hline amount $/ \mathrm{mmol}$ & $\log \left(c / \mathrm{mol} \mathrm{L}^{-1}\right)$ & $\Delta[47 \mathrm{dj}] \Delta t^{-1} / 10^{-6} \mathrm{~mol} \mathrm{~L}^{-1} \mathrm{~s}^{-1}$ & $\log \left(\Delta[47 \mathrm{dj}] \Delta t^{-1} / \mathrm{mol} \mathrm{L}^{-1} \mathrm{~s}^{-1}\right)$ \\
\hline 0.30 & -0.824 & 1.660 & -5.780 \\
0.38 & -0.727 & 2.108 & -5.676 \\
0.50 & -0.602 & 2.990 & -5.524 \\
0.63 & -0.505 & 3.756 & -5.425 \\
0.75 & -0.426 & 4.737 & -5.325 \\
\hline
\end{tabular}

Table 8: Initial rates for $\mathrm{C}-\mathrm{H} / \mathrm{C}-\mathrm{H}$ activation at various phenylpyridine $\mathbf{4 5} \mathrm{d}$ concentrations.

\begin{tabular}{cccc}
\hline amount $/ \mathrm{mmol}$ & $\log \left(c / \mathrm{mol} \mathrm{L}^{-1}\right)$ & $\Delta\left[\mathbf{1 8 1 \mathrm { d } ]} \Delta t^{-1} / 10^{-6} \mathrm{~mol} \mathrm{~L}^{-1} \mathrm{~s}^{-1}\right.$ & $\log \left(\Delta[\mathbf{1 8 1 \mathrm { d }}] \Delta t^{-1} / \mathrm{mol} \mathrm{L}^{-1} \mathrm{~s}^{-1}\right)$ \\
\hline 0.30 & -0.824 & 1.987 & -5.702 \\
0.38 & -0.727 & 2.794 & -5.554 \\
0.50 & -0.602 & 3.506 & -5.455 \\
0.63 & -0.505 & 3.817 & -5.418 \\
0.75 & -0.426 & 6.190 & -5.208 \\
\hline
\end{tabular}

\section{Reaction Order with Respect to $\left[\mathrm{RuCl}_{2}(p \text {-cymene })\right]_{2}$}

The initial rate method was employed to determine the reaction order with respect to $\left[\mathrm{RuCl}_{2}(p \text {-cymene })\right]_{2 \cdot}{ }^{[178]}$ Under an atmosphere of $\mathrm{N}_{2}$ inside a glovebox, a Schlenk-tube was charged with 2-(2-methylphenyl)pyridine (45d) $(85 \mathrm{mg}, 0.50 \mathrm{mmol}, 1.00$ equiv), 2-bromotrifluorotoluene (46j) (169 mg, $0.75 \mathrm{mmol}, 1.50$ equiv), $\mathrm{MesCO}{ }_{2} \mathrm{H}$ (58) $(25 \mathrm{mg}, 0.15 \mathrm{mmol}, 30 \mathrm{~mol} \%), \mathrm{K}_{2} \mathrm{CO}_{3}$ (138 mg, $1.00 \mathrm{mmol}, 2.00$ equiv) and $n$-dodecane $(40 \mu \mathrm{L})$. A solution of $\left[\mathrm{RuCl}_{2}(p \text {-cymene) }]_{2}(1.5\right.$, 2.5, 3.5, $5.0 \mathrm{~mol} \%)$ in PhMe $(2.0 \mathrm{~mL})$ was added and the mixture was stirred at $102{ }^{\circ} \mathrm{C}$. Aliquots $(0.05 \mathrm{~mL})$ were removed via a syringe after $15,30,45,60,80,100,120$ and $150 \mathrm{~min}$, diluted with EtOAc $(1.0 \mathrm{~mL})$, filtered through a short plug of silica gel and analyzed by gas chromatography. 
Table 9: Initial rates for $\mathrm{C}-\mathrm{H}$ arylation at various $\left[\mathrm{RuCl}_{2}(p \text {-cymene })\right]_{2}$ concentrations.

\begin{tabular}{|c|c|c|c|}
\hline amount / mol \% & $\log \left(c / \mathrm{mol} \mathrm{L}^{-1}\right)$ & $\Delta[47 \mathrm{dj}] \Delta t^{-1} / 10^{-6} \mathrm{~mol} \mathrm{~L}^{-1} \mathrm{~s}^{-1}$ & $\log \left(\Delta[47 \mathrm{dj}] \Delta t^{-1} / \mathrm{mol} \mathrm{L}^{-1} \mathrm{~s}^{-1}\right)$ \\
\hline 1.5 & -2.426 & 1.910 & -5.719 \\
\hline 2.5 & -2.204 & 2.990 & -5.524 \\
\hline 3.5 & -2.058 & 3.714 & -5.430 \\
\hline 5.0 & -1.903 & 4.550 & -5.342 \\
\hline
\end{tabular}

Table 10: Initial rates for $\mathrm{C}-\mathrm{H} / \mathrm{C}-\mathrm{H}$ activation at various $\left[\mathrm{RuCl}_{2}(p \text {-cymene })\right]_{2}$ concentrations.

\begin{tabular}{cccc}
\hline amount $/ \mathrm{mol} \%$ & $\log \left(\mathrm{c} / \mathrm{mol} \mathrm{L}^{-1}\right)$ & $\Delta[\mathbf{1 8 1} \mathrm{d}] \Delta t^{-1} / 10^{-6} \mathrm{~mol} \mathrm{~L}^{-1} \mathrm{~s}^{-1}$ & $\log \left(\Delta[\mathbf{1 8 1} \mathrm{d}] \Delta t^{-1} / \mathrm{mol} \mathrm{L}^{-1} \mathrm{~s}^{-1}\right)$ \\
\hline 1.5 & -2.426 & 2.563 & -5.591 \\
2.5 & -2.204 & 3.507 & -5.455 \\
3.5 & -2.058 & 4.433 & -5.353 \\
5.0 & -1.903 & 6.813 & -5.166 \\
\hline
\end{tabular}

\section{Reaction Order with Respect to 2-Bromotrilfuorotoluene (46j)}

The initial rate method was employed to determine the reaction order with respect to aryl halide 46j. ${ }^{[178]}$ Under an atmosphere of $\mathrm{N}_{2}$ inside a glovebox, a Schlenk-tube was charged with 2-(2methylphenyl)pyridine (45d) ( $85 \mathrm{mg}, 0.50 \mathrm{mmol}, 1.00$ equiv), 2-bromotrifluorotoluene (46j) (0.38, $0.50,0.63,0.75,0.88 \mathrm{mmol}), \mathrm{MesCO}_{2} \mathrm{H}$ (58) $(25 \mathrm{mg}, 0.15 \mathrm{mmol}, 30 \mathrm{~mol} \%), \mathrm{K}_{2} \mathrm{CO}_{3}(138 \mathrm{mg}$, $1.00 \mathrm{mmol}, 2.00$ equiv) and $n$-dodecane $(40 \mu \mathrm{L})$. A solution of $\left[\mathrm{RuCl}_{2}(p \text {-cymene })\right]_{2}(7.7 \mathrm{mg}$, $12.5 \mu \mathrm{mol}, 2.5 \mathrm{~mol} \%)$ in PhMe $(2.0 \mathrm{~mL})$ was added and the mixture was stirred at $102^{\circ} \mathrm{C}$. Aliquots $(0.05 \mathrm{~mL})$ were removed via a syringe after $15,30,45,60,80,100,120$ and $150 \mathrm{~min}$, diluted with EtOAc $(1.0 \mathrm{~mL})$, filtered through a short plug of silica gel and analyzed by gas chromatography.

Table 11: Initial rates for $\mathrm{C}-\mathrm{H}$ arylation at various 2-bromotrifluorotoluene (46j) concentrations.

\begin{tabular}{|c|c|c|c|}
\hline amount / mmol & $\log \left(c / \mathrm{mol} \mathrm{L}^{-1}\right)$ & $\Delta[47 \mathrm{dj}] \Delta t^{-1} / 10^{-6} \mathrm{~mol} \mathrm{~L}^{-1} \mathrm{~s}^{-1}$ & $\log \left(\Delta[47 \mathrm{dj}] \Delta t^{-1} / \mathrm{mol} \mathrm{L}^{-1} \mathrm{~s}^{-1}\right)$ \\
\hline 0.38 & -0.727 & 2.479 & -5.606 \\
\hline 0.50 & -0.602 & 2.528 & -5.597 \\
\hline
\end{tabular}




\begin{tabular}{llll}
\hline 0.63 & -0.505 & 2.942 & -5.531 \\
0.75 & -0.426 & 2.990 & -5.524 \\
0.88 & -0.359 & 2.528 & -5.597 \\
\hline
\end{tabular}

Table 12: Initial rates for $\mathrm{C}-\mathrm{H} / \mathrm{C}-\mathrm{H}$ activation at various 2-bromotrifluorotoluene (46j) concentrations.

\begin{tabular}{cccc}
\hline amount $/ \mathrm{mmol}$ & $\log \left(c / \mathrm{mol} \mathrm{L}^{-1}\right)$ & $\Delta[\mathbf{1 8 1 \mathrm { d }}] \Delta t^{-1} / 10^{-6} \mathrm{~mol} \mathrm{~L}^{-1} \mathrm{~s}^{-1}$ & $\log \left(\Delta[\mathbf{1 8 1 \mathrm { d }}] \Delta t^{-1} / \mathrm{mol} \mathrm{L}^{-1} \mathrm{~s}^{-1}\right)$ \\
\hline 0.38 & -0.727 & 3.159 & -5.501 \\
0.50 & -0.602 & 2.062 & -5.686 \\
0.63 & -0.505 & 3.075 & -5.512 \\
0.75 & -0.426 & 2.990 & -5.524 \\
0.88 & -0.359 & 2.509 & -5.600 \\
\hline
\end{tabular}

\section{Reaction Order with Respect to $\left[\mathrm{Ru}\left(\mathrm{O}_{2} \mathrm{CMes}\right)_{2}(p\right.$-cymene)] (61)}

The initial rate method was employed to determine the reaction order with respect to $\left[\mathrm{Ru}\left(\mathrm{O}_{2} \mathrm{CMes}\right)_{2}(p\right.$-cymene) $](61) .{ }^{[178]}$ Under an atmosphere of $\mathrm{N}_{2}$ inside a glovebox, a Schlenk-tube was charged with 2-(2-methylphenyl)pyridine (45d) $(85 \mathrm{mg}, 0.50 \mathrm{mmol}, 1.00$ equiv), 2-bromotrifluorotoluene (46j) (169 mg, $0.75 \mathrm{mmol}, 1.50$ equiv), $\mathrm{K}_{2} \mathrm{CO}_{3}(138 \mathrm{mg}, 1.00 \mathrm{mmol}$, 2.00 equiv) and $n$-dodecane $(40 \mu \mathrm{L})$. A solution of $\left[\mathrm{Ru}\left(\mathrm{O}_{2} \mathrm{CMes}\right)_{2}(p\right.$-cymene $\left.)\right](61)(5.0,6.5,7.5$, $10.0 \mathrm{~mol} \%)$ in PhMe $(2.0 \mathrm{~mL})$ was added and the mixture was stirred at $102{ }^{\circ} \mathrm{C}$. Aliquots $(0.05 \mathrm{~mL})$ were removed via a syringe after 15, 30, 45, 60, 80, 100, 120 and 150 min, diluted with EtOAc $(1.0 \mathrm{~mL})$, filtered through a short plug of silica gel and analyzed by gas chromatography.

Table 13: Initial rates for $\mathrm{C}-\mathrm{H} / \mathrm{C}-\mathrm{H}$ activation at various $\left[\mathrm{Ru}\left(\mathrm{O}_{2} \mathrm{CMes}\right)_{2}(p\right.$-cymene $\left.)\right](61)$ concentrations.

\begin{tabular}{cccc}
\hline amount $/ \mathrm{mol} \%$ & $\log \left(c / \mathrm{mol} \mathrm{L}^{-1}\right)$ & $\Delta[\mathbf{1 8 1} \mathrm{d}] \Delta t^{-1} / 10^{-6} \mathrm{~mol} \mathrm{~L}^{-1} \mathrm{~s}^{-1}$ & $\log \left(\Delta[\mathbf{1 8 1} \mathrm{d}] \Delta t^{-1} / \mathrm{mol} \mathrm{L}^{-1} \mathrm{~s}^{-1}\right)$ \\
\hline 5.0 & -1.903 & 3.073 & -5.512 \\
6.5 & -1.790 & 3.684 & -5.434 \\
7.5 & -1.727 & 3.707 & -5.431 \\
\hline
\end{tabular}




\begin{tabular}{llcc}
\hline 10.0 & -1.602 & 4.493 & -5.348 \\
\hline
\end{tabular}

\subsection{Reaction Order Determination with 2-Bromobenzonitrile (46k)}

\section{Reaction Order with Respect to Phenylpyridine 45d}

The initial rate method was employed to determine the reaction order with respect to phenylpyridine $45 \mathrm{~d}^{[178]}$ Under an atmosphere of $\mathrm{N}_{2}$ inside a glovebox, a Schlenk-tube was charged with 2-(2-methylphenyl)pyridine (45d) $(0.30,0.35,0.40,0.50,0.60 \mathrm{mmol})$, 2-bromobenzonitrile (46k) $(137 \mathrm{mg}, 0.75 \mathrm{mmol}), \mathrm{K}_{2} \mathrm{CO}_{3}(138 \mathrm{mg}, 1.00 \mathrm{mmol})$ and $n$-dodecane $(40 \mu \mathrm{L})$. A solution of $\left[\mathrm{Ru}\left(\mathrm{O}_{2} \mathrm{CMes}\right)_{2}(p\right.$-cymene $\left.)\right](61)(14.1 \mathrm{mg}, 25.0 \mu \mathrm{mol})$ in $\mathrm{PhMe}(2.0 \mathrm{~mL})$ was added and the mixture was stirred at $102^{\circ} \mathrm{C}$. Aliquots $(0.05 \mathrm{~mL})$ were removed via a syringe after $3,6,9,12,15,20,25$ and $30 \mathrm{~min}$, diluted with EtOAc $(1.0 \mathrm{~mL})$, filtered through a short plug of silica gel and analyzed by gas chromatography.

Each reaction was performed two times, the logarithmic values of the measured rates were averaged and the error corresponds to the standard deviation.

Table 14: Initial rates for $\mathrm{C}-\mathrm{H} / \mathrm{C}-\mathrm{H}$ activation at various phenylpyridine $\mathbf{4 5 d}$ concentrations.

\begin{tabular}{|c|c|c|c|c|}
\hline $\begin{array}{c}\text { amount / } \\
\text { mmol }\end{array}$ & $\begin{array}{l}\log (c / \\
\left.\mathrm{mol} \mathrm{L}^{-1}\right)\end{array}$ & $\begin{array}{c}\Delta[\mathbf{1 8 1 d}] \Delta t^{-1} / \\
10^{-5} \mathrm{~mol} \mathrm{~L}^{-1} \mathrm{~s}^{-1}\end{array}$ & $\begin{array}{c}\log \text { average }\left(\Delta[\mathbf{1 8 1} \mathrm{d}] \Delta t^{-1} /\right. \\
\left.\mathrm{mol} \mathrm{L}^{-1} \mathrm{~s}^{-1}\right)\end{array}$ & $\begin{array}{c}\Delta \log _{\text {average }}(\Delta[\mathbf{1 8 1 \mathrm { d }}] \\
\left.\Delta t^{-1} / \mathrm{mol} \mathrm{L}^{-1} \mathrm{~s}^{-1}\right)\end{array}$ \\
\hline 0.30 & -0.824 & $\begin{array}{l}2.050 \\
1.387\end{array}$ & -4.773 & 0.120 \\
\hline 0.35 & -0.757 & $\begin{array}{l}1.462 \\
1.657\end{array}$ & -4.808 & 0.039 \\
\hline 0.40 & -0.699 & $\begin{array}{l}2.933 \\
2.333\end{array}$ & -4.582 & 0.070 \\
\hline 0.50 & -0.602 & $\begin{array}{l}1.850 \\
2.039\end{array}$ & -4.712 & 0.030 \\
\hline 0.60 & -0.523 & $\begin{array}{l}1.883 \\
2.619\end{array}$ & -4.653 & 0.101 \\
\hline
\end{tabular}




\section{Reaction Order with Respect to $\left[\mathrm{Ru}\left(\mathrm{O}_{2} \mathrm{CMes}\right)_{2}(p\right.$-cymene) $)$ (61)}

The initial rate method was employed to determine the reaction order with respect to $\left[\mathrm{Ru}\left(\mathrm{O}_{2} \mathrm{CMes}\right)_{2}(p\right.$-cymene) $](61) .{ }^{[178]}$ Under an atmosphere of $\mathrm{N}_{2}$ inside a glovebox, a Schlenk-tube was charged with 2-(2-methylphenyl)pyridine (45d) $(85 \mathrm{mg}, 0.50 \mathrm{mmol}, 1.00$ equiv), 2-bromobenzonitrile (46k) (137 mg, $0.75 \mathrm{mmol}, 1.50$ equiv), $\mathrm{K}_{2} \mathrm{CO}_{3} \quad(138 \mathrm{mg}, 1.00 \mathrm{mmol}$, 2.00 equiv) and $n$-dodecane $(40 \mu \mathrm{L})$. A solution of $\left[\mathrm{Ru}\left(\mathrm{O}_{2} \mathrm{CMes}\right)_{2}(p\right.$-cymene $\left.)\right](61)(2.5,3.5,5.0,7.5$, $10.0 \mathrm{~mol} \%)$ in PhMe $(2.0 \mathrm{~mL})$ was added and the mixture was stirred at $102{ }^{\circ} \mathrm{C}$. Aliquots $(0.05 \mathrm{~mL})$ were removed via a syringe after 3, 6, 9, 12, 15, 20, 25 and 30 min, diluted with EtOAc (1.0 mL), filtered through a short plug of silica gel and analyzed by gas chromatography.

Each reaction was performed two times, the logarithmic values of the measured rates were averaged and the error corresponds to the standard deviation.

Table 15: Initial rates for $\mathrm{C}-\mathrm{H} / \mathrm{C}-\mathrm{H}$ activation at various $\left[\mathrm{Ru}\left(\mathrm{O}_{2} \mathrm{CMes}\right)_{2}(p\right.$-cymene $\left.)\right](61)$ concentrations.

\begin{tabular}{|c|c|c|c|c|}
\hline $\begin{array}{c}\text { amount / } \\
\text { mol \% }\end{array}$ & $\begin{array}{l}\log (c / \\
\left.\mathrm{mol} \mathrm{L}^{-1}\right)\end{array}$ & $\begin{array}{c}\Delta[\mathbf{1 8 1 \mathrm { d }}] \Delta t^{-1} / \\
10^{-5} \mathrm{~mol} \mathrm{~L}^{-1} \mathrm{~s}^{-1}\end{array}$ & $\begin{array}{c}\log _{\text {average }}\left(\Delta[\mathbf{1 8 1} \mathrm{d}] \Delta t^{-1} /\right. \\
\left.\mathrm{mol} \mathrm{L}^{-1} \mathrm{~s}^{-1}\right)\end{array}$ & $\begin{array}{c}\Delta \log _{\text {average }}(\Delta[\mathbf{1 8 1 \mathrm { d }}] \\
\left.\Delta t^{-1} / \mathrm{mol} \mathrm{L}^{-1} \mathrm{~s}^{-1}\right)\end{array}$ \\
\hline 2.5 & -2.204 & $\begin{array}{l}1.505 \\
1.504\end{array}$ & -4.823 & $1.9 \cdot 10^{-4}$ \\
\hline 3.5 & -2.058 & $\begin{array}{l}1.595 \\
2.198\end{array}$ & -4.728 & 0.099 \\
\hline 5.0 & -1.903 & $\begin{array}{l}1.854 \\
2.039\end{array}$ & -4.711 & 0.029 \\
\hline 7.5 & -1.727 & $\begin{array}{l}2.410 \\
3.177\end{array}$ & -4.558 & 0.085 \\
\hline 10.0 & -1.602 & $\begin{array}{l}3.721 \\
3.720\end{array}$ & -4.429 & $0.5 \cdot 10^{-4}$ \\
\hline
\end{tabular}

\section{Reaction Order with Respect to 2-Bromobenzonitrile (46k)}

The initial rate method was employed to determine the reaction order with respect to 2-bromobenzonitrile (46k). ${ }^{[178]}$ Under an atmosphere of $\mathrm{N}_{2}$ inside a glovebox, a Schlenk-tube was charged with 2-(2-methylphenyl)pyridine (45d) $\quad(85 \mathrm{mg}, \quad 0.50 \mathrm{mmol}, \quad 1.00$ equiv), 2-bromobenzonitrile (46k) $(0.50,0.63,0.75,0.88,1.00 \mathrm{mmol}), \mathrm{K}_{2} \mathrm{CO}_{3}(138 \mathrm{mg}, 1.00 \mathrm{mmol}$, 
2.00 equiv) and $n$-dodecane $(40 \mu \mathrm{L})$. A solution of $\left[\mathrm{Ru}\left(\mathrm{O}_{2} \mathrm{CMes}\right)_{2}(p\right.$-cymene $\left.)\right](61)(14.1 \mathrm{mg}$, $25.0 \mu \mathrm{mol}, 5.0 \mathrm{~mol} \%)$ in $\mathrm{PhMe}(2.0 \mathrm{~mL})$ was added and the mixture was stirred at $102^{\circ} \mathrm{C}$. Aliquots $(0.05 \mathrm{~mL})$ were removed via a syringe after $3,6,9,12,15,20,25$ and $30 \mathrm{~min}$, diluted with EtOAc $(1.0 \mathrm{~mL})$, filtered through a short plug of silica gel and analyzed by gas chromatography.

Each reaction was performed two times, the logarithmic values of the measured rates were averaged and the error corresponds to the standard deviation.

Table 16: Initial rates for $\mathrm{C}-\mathrm{H} / \mathrm{C}-\mathrm{H}$ activation at various 2-bromobenzonitrile (46k) concentrations.

\begin{tabular}{|c|c|c|c|c|}
\hline $\begin{array}{l}\text { amount / } \\
\text { mmol }\end{array}$ & $\begin{array}{l}\log (c / \\
\left.\mathrm{mol} \mathrm{L}^{-1}\right)\end{array}$ & $\begin{array}{c}\Delta[\mathbf{1 8 1 d}] \Delta t^{-1} / \\
10^{-5} \mathrm{~mol} \mathrm{~L}^{-1} \mathrm{~s}^{-1}\end{array}$ & $\begin{array}{c}\log \text { average }\left(\Delta[\mathbf{1 8 1} \mathbf{d}] \Delta t^{-1} /\right. \\
\left.\mathrm{mol} \mathrm{L}^{-1} \mathrm{~s}^{-1}\right)\end{array}$ & $\begin{array}{c}\Delta \log _{\text {average }}(\Delta[\mathbf{1 8 1 \mathrm { d }}] \\
\left.\Delta t^{-1} / \mathrm{mol} \mathrm{L}^{-1} \mathrm{~s}^{-1}\right)\end{array}$ \\
\hline 0.50 & -0.602 & $\begin{array}{l}1.623 \\
1.284\end{array}$ & -4.841 & 0.072 \\
\hline 0.63 & -0.505 & $\begin{array}{l}1.855 \\
1.972\end{array}$ & -4.718 & 0.019 \\
\hline 0.75 & -0.426 & $\begin{array}{l}1.854 \\
2.039\end{array}$ & -4.711 & 0.029 \\
\hline 0.88 & -0.359 & $\begin{array}{l}2.003 \\
2.076\end{array}$ & -4.691 & 0.011 \\
\hline 1.00 & -0.301 & $\begin{array}{l}2.776 \\
2.181\end{array}$ & -4.609 & 0.074 \\
\hline
\end{tabular}

\subsubsection{X-Ray Crystallography}

Single crystals of $\mathrm{C}_{30} \mathrm{H}_{20} \mathrm{~N}_{2}$ (181k) were grown by slow evaporation from a saturated solution in PhMe- $d_{8}$. A suitable crystal was selected and the crystal was mounted on a MITIGEN holder in NVH oil on a Bruker D8 Venture diffractometer. The crystal was kept at $100.02 \mathrm{~K}$ during data collection. Using Olex2, ${ }^{[181]}$ the structure was solved with the XT structure solution program ${ }^{[182]}$ using Intrinsic Phasing and refined with the $X L$ refinement package ${ }^{[183]}$ using Least Squares minimization.

Crystal Data for $\mathrm{C}_{30} \mathrm{H}_{20} \mathrm{~N}_{2}(M=408.48 \mathrm{~g} / \mathrm{mol})$ : monoclinic, space group $\mathrm{P} 2_{1} / \mathrm{c}$ (no. 14), $a=$ 10.3579(10) $\AA, b=16.1134(16) \AA, c=13.4520(10) \AA, b=111.680(3)^{\circ}, V=2086.3(3) \AA^{3}, Z=4, T=$ $100.02 \mathrm{~K}, \mu($ MoK $\alpha)=0.076 \mathrm{~mm}^{-1}$, Dcalc $=1.300 \mathrm{~g} / \mathrm{cm}^{3}, 34183$ reflections measured $\left(4.93^{\circ} \leq 2 \Theta \leq\right.$ 
$\left.61.07^{\circ}\right), 6252$ unique $\left(R_{\text {int }}=0.0266, R_{\text {sigma }}=0.0200\right)$ which were used in all calculations. The final $R_{1}$ was $0.0429(\mathrm{I}>2 \sigma(\mathrm{I}))$ and $w R_{2}$ was 0.1148 (all data).

The X-Ray crystallographic data for compound $\mathbf{1 8 1} \mathbf{k}$ was deposited at the Cambridge Crystallographic Data Centre (CCDC) under deposition number 1942734.

Table 17: Crystal data and structure refinement for $\mathbf{1 8 1 k}$.

\begin{tabular}{|c|c|}
\hline Empirical formula & $\mathrm{C}_{30} \mathrm{H}_{20} \mathrm{~N}_{2}$ \\
\hline Formula weight & 408.48 \\
\hline Temperature/K & 100.02 \\
\hline Crystal system & monoclinic \\
\hline Space group & $\mathrm{P} 2{ }_{1} / \mathrm{c}$ \\
\hline $\mathrm{a} / \AA$ & $10.3579(10)$ \\
\hline $\mathrm{b} / \AA ̊$ & $16.1134(16)$ \\
\hline$c / \AA$ & $13.4520(10)$ \\
\hline$\alpha /^{\circ}$ & 90 \\
\hline$\beta /^{\circ}$ & $111.680(3)$ \\
\hline$\gamma /{ }^{\circ}$ & 90 \\
\hline Volume $/ \AA^{3}$ & $2086.3(3)$ \\
\hline Z & 4 \\
\hline$\rho_{\text {calc }} g / \mathrm{cm}^{3}$ & 1.3 \\
\hline$\mu / \mathrm{mm}^{-1}$ & 0.076 \\
\hline$F(000)$ & 856 \\
\hline Crystal size $/ \mathrm{mm}^{3}$ & $0.446 \times 0.439 \times 0.228$ \\
\hline Radiation & $\operatorname{MoK} \alpha(\lambda=0.71073)$ \\
\hline $2 \Theta$ range for data collection $/^{\circ}$ & 4.93 to 61.07 \\
\hline Index ranges & $-14 \leq h \leq 14,-22 \leq k \leq 22,-19 \leq \mathrm{I} \leq 17$ \\
\hline Reflections collected & 34183 \\
\hline Independent reflections & $6252\left[R_{\text {int }}=0.0266, R_{\text {sigma }}=0.0200\right]$ \\
\hline Data/restraints/parameters & $6252 / 0 / 289$ \\
\hline Goodness-of-fit on $F^{2}$ & 1.058 \\
\hline Final $R$ indexes $[I>=2 \sigma(I)]$ & $\mathrm{R}_{1}=0.0429, \mathrm{wR}_{2}=0.1102$ \\
\hline Final R indexes [all data] & $\mathrm{R}_{1}=0.0477, \mathrm{wR}_{2}=0.1148$ \\
\hline
\end{tabular}


Table 18: Bond lengths.

\begin{tabular}{lll|lll}
\hline Atom & Atom & Length $/ \AA$ & Atom & Atom & Length $/ \AA$ \\
\hline N1 & C1 & $1.3427(13)$ & C12 & C22 & $1.4192(13)$ \\
N1 & C5 & $1.3448(12)$ & C13 & C14 & $1.4952(13)$ \\
N2 & C14 & $1.3458(12)$ & C13 & C19 & $1.4364(12)$ \\
N2 & C18 & $1.3405(13)$ & C14 & C15 & $1.3945(13)$ \\
C1 & C2 & $1.3887(15)$ & C15 & C16 & $1.3890(14)$ \\
C2 & C3 & $1.3890(15)$ & C16 & C17 & $1.3881(16)$ \\
C3 & C4 & $1.3894(13)$ & C17 & C18 & $1.3878(16)$ \\
C4 & C5 & $1.3923(13)$ & C19 & C20 & $1.4242(13)$ \\
C5 & C6 & $1.4928(12)$ & C19 & C26 & $1.4219(13)$ \\
C6 & C7 & $1.4256(12)$ & C20 & C21 & $1.4147(14)$ \\
C6 & C11 & $1.3845(12)$ & C20 & C23 & $1.4195(13)$ \\
C7 & C8 & $1.4245(13)$ & C21 & C22 & $1.3669(14)$ \\
C7 & C30 & $1.4222(13)$ & C23 & C24 & $1.3665(16)$ \\
C8 & C9 & $1.4203(13)$ & C24 & C25 & $1.4124(16)$ \\
C8 & C27 & $1.4205(13)$ & C25 & C26 & $1.3762(14)$ \\
C9 & C10 & $1.3680(13)$ & C27 & C28 & $1.3713(14)$ \\
C10 & C11 & $1.4203(13)$ & C28 & C29 & $1.4126(14)$ \\
C11 & C12 & $1.4935(13)$ & C29 & C30 & $1.3728(13)$ \\
C12 & C13 & $1.3858(13)$ & & & \\
\hline
\end{tabular}

Table 19: Bond angles.

\begin{tabular}{cccc|cccc}
\hline Atom & Atom & Atom & Angle $^{\circ}$ & Atom & Atom & Atom & Angle $^{\circ}$ \\
\hline C1 & N1 & C5 & $116.90(9)$ & C12 & C13 & C14 & $119.47(8)$ \\
C18 & N2 & C14 & $117.26(9)$ & C12 & C13 & C19 & $119.80(8)$ \\
N1 & C1 & C2 & $124.00(9)$ & C19 & C13 & C14 & $120.69(8)$ \\
C1 & C2 & C3 & $118.33(9)$ & N2 & C14 & C13 & $116.13(8)$ \\
C2 & C3 & C4 & $118.65(9)$ & N2 & C14 & C15 & $122.66(9)$ \\
C3 & C4 & C5 & $118.90(9)$ & C15 & C14 & C13 & $121.16(8)$ \\
N1 & C5 & C4 & $123.16(9)$ & C16 & C15 & C14 & $119.08(9)$ \\
\hline
\end{tabular}




\begin{tabular}{llll|llll}
\hline N1 & C5 & C6 & $116.93(8)$ & C17 & C16 & C15 & $118.70(10)$ \\
C4 & C5 & C6 & $119.91(8)$ & C18 & C17 & C16 & $118.27(10)$ \\
C7 & C6 & C5 & $119.23(8)$ & N2 & C18 & C17 & $124.00(10)$ \\
C11 & C6 & C5 & $120.18(8)$ & C20 & C19 & C13 & $118.96(8)$ \\
C11 & C6 & C7 & $120.53(8)$ & C26 & C19 & C13 & $122.96(9)$ \\
C8 & C7 & C6 & $119.33(8)$ & C26 & C19 & C20 & $118.02(8)$ \\
C30 & C7 & C6 & $122.09(8)$ & C21 & C20 & C19 & $119.67(9)$ \\
C30 & C7 & C8 & $118.55(8)$ & C21 & C20 & C23 & $120.65(9)$ \\
C9 & C8 & C7 & $118.78(8)$ & C23 & C20 & C19 & $119.65(9)$ \\
C9 & C8 & C27 & $122.05(9)$ & C22 & C21 & C20 & $120.36(9)$ \\
C27 & C8 & C7 & $119.15(9)$ & C21 & C22 & C12 & $121.10(9)$ \\
C10 & C9 & C8 & $120.76(9)$ & C24 & C23 & C20 & $120.87(10)$ \\
C9 & C10 & C11 & $121.09(9)$ & C23 & C24 & C25 & $119.90(9)$ \\
C6 & C11 & C10 & $119.42(8)$ & C26 & C25 & C24 & $120.62(10)$ \\
C6 & C11 & C12 & $120.75(8)$ & C25 & C26 & C19 & $120.91(9)$ \\
C10 & C11 & C12 & $119.80(8)$ & C28 & C27 & C8 & $120.86(9)$ \\
C13 & C12 & C11 & $122.05(8)$ & C27 & C28 & C29 & $120.08(9)$ \\
\hline
\end{tabular}




\section{Computational Details}

\subsection{General Remarks}

Calculations were performed using Gaussian 09, ${ }^{[184]}$ Gaussian 16, ${ }^{[185]}$ Orca version 3.0.3 ${ }^{[186]}$ or Orca version $4.0^{[187]}$ software packages on the high performance computing (HPC) system of the research group of Prof. Dr. Lutz Ackermann, the HPC cluster of the Gesellschaft für wissenschaftliche Datenverarbeitung Göttingen GmbH (GWDG) and the HPC cluster of the Institute Charles Gerhardt, Université de Montpellier.

Images of 3D structures were created using PyMOL version 1.8.x. ${ }^{[188]}$

Cartesian coordinates of all calculated structures are stored on the attached DVD disc as xyz-files and can be obtained from the author upon reasonable request.

\subsection{Selectivity Prediction for meta-C-H Functionalization}

\subsubsection{Computational Methods}

All calculations were performed with the Orca version 3.0.3 package. ${ }^{[186]}$ Geometry optimizations were performed at the TPSS level of theory ${ }^{[125]}$ including D3 dispersion correction ${ }^{[126]}$ with BeckeJohnson damping scheme. Ruthenium was described with a def2-TZVP basis set ${ }^{[127]}$ in combination with Stuttgart-Dresden (SDD) pseudopotential, ${ }^{[189]}$ while all other atoms were described with a def2-TZVP basis set. Numerical frequency calculations were performed at the same level of theory to characterize all stationary points as intermediates (no imaginary frequencies). RIJCOSX approximation was used in all calculations together with def2-TZVP/J auxiliary basis set. ${ }^{[190]}$ In all calculations the GRID4, TightSCF, SlowConv keywords and in the geometry optimizations additionally TightOPT keyword was used.

NBO charges were obtained through single point calculations on the optimized structures at the B3LYP level of theory ${ }^{[128]}$ including D3(BJ) correction. Ruthenium was described with a def2-TZVP basis set in combination with Stuttgart-Dresden (SDD) pseudopotential, while all other atoms were described with a def2-TZVP basis set. The single point calculations were performed with the Gaussian 09, Revision D.01 package employing the implemented NBO version. ${ }^{[184]}$ 


\subsubsection{Fukui Indices}

Fukui indice ${ }^{[191]}$ were calculated based on atomic charges values obtained from NBO calculations. Radical Fukui indices $f_{\mathrm{A}}{ }^{0}$ were calculated according to equation (1), where $\delta_{\mathrm{N}+1}$ corresponds to the atomic charges of the anionic species, $\delta_{\mathrm{N}-1}$ to the cationic species and $N$ to the number of electrons.

$$
f_{A}^{0}=\frac{1}{2}\left(\delta_{N+1}-\delta_{N-1}\right)
$$

Nucleophilicity Fukui indices $f_{\mathrm{A}}^{-}$were calculated according to equation (2), where $\delta_{\mathrm{N}}$ corresponds to the atomic charges of the neutral species, $\delta_{\mathrm{N}-1}$ to the cationic species and $N$ to the number of electrons.

$$
f_{A}^{-}=\delta_{N}-\delta_{N-1}
$$

\subsubsection{Oxazoline as Directing Group}

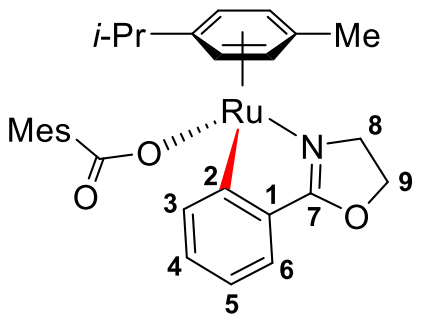

4.A

\begin{tabular}{cccccccc}
\hline Atom & $\delta_{\mathrm{N}}$ & $\delta_{\mathrm{N}-1}$ & $\delta_{\mathrm{N}+1}$ & $f_{\mathrm{A}}{ }^{-}$ & $f_{\mathrm{A}^{-}}$(norm.) & $f_{\mathrm{A}}{ }^{0}$ & $f_{\mathrm{A}}{ }^{0}$ (norm.) \\
\hline C1 & 6.1916 & 6.1700 & 6.2160 & 0.0216 & 0.41 & 0.0230 & 0.34 \\
$\mathrm{C} 2$ & 5.9223 & 5.8967 & 5.9644 & 0.0256 & 0.49 & 0.0338 & 0.50 \\
$\mathrm{C} 3$ & 6.2514 & 6.2385 & 6.2607 & 0.0129 & 0.25 & 0.0111 & 0.16 \\
$\mathrm{C} 4$ & 6.1727 & 6.1527 & 6.2887 & 0.0200 & 0.38 & $\mathbf{0 . 0 6 8 0}$ & $\mathbf{1 . 0 0}$ \\
$\mathrm{C} 5$ & 6.2365 & 6.1844 & 6.2434 & $\mathbf{0 . 0 5 2 1}$ & $\mathbf{1 . 0 0}$ & 0.0295 & 0.43 \\
C6 & 6.1581 & 6.1477 & 6.2256 & 0.0104 & 0.20 & 0.0389 & 0.57 \\
$\mathrm{C} 7$ & 5.4149 & 5.3986 & 5.5207 & 0.0163 & 0.31 & 0.0610 & 0.90 \\
C8 & 6.2546 & 6.2575 & 6.2480 & -0.0029 & -0.06 & -0.0048 & -0.07 \\
C9 & 6.0854 & 6.0858 & 6.0827 & -0.0003 & -0.01 & -0.0015 & -0.02 \\
\hline
\end{tabular}




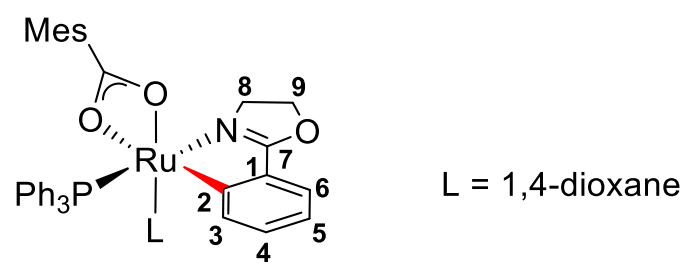

4.B

\begin{tabular}{cccccccc}
\hline Atom & $\delta_{\mathrm{N}}$ & $\delta_{\mathrm{N}-1}$ & $\delta_{\mathrm{N}+1}$ & $f_{\mathrm{A}}^{-}$ & $f_{\mathrm{A}}^{-}$(norm.) & $f_{\mathrm{A}}{ }^{0}$ & $f_{\mathrm{A}}{ }^{0}$ (norm.) \\
\hline C1 & 6.2147 & 6.1616 & 6.2256 & 0.0531 & 0.69 & 0.0320 & 0.72 \\
C2 & 5.9864 & 6.0237 & 6.0170 & -0.0373 & -0.49 & -0.0034 & -0.08 \\
C3 & 6.2605 & 6.2151 & 6.2667 & 0.0454 & 0.59 & 0.0258 & 0.58 \\
C4 & 6.1735 & 6.1670 & 6.2564 & 0.0064 & 0.08 & $\mathbf{0 . 0 4 4 7}$ & 1.00 \\
C5 & 6.2557 & 6.1792 & 6.2578 & $\mathbf{0 . 0 7 6 5}$ & $\mathbf{1 . 0 0}$ & 0.0393 & 0.88 \\
C6 & 6.1616 & 6.1570 & 6.2165 & 0.0046 & 0.06 & 0.0298 & 0.67 \\
C7 & 5.4192 & 5.4122 & 5.4932 & 0.0069 & 0.09 & 0.0405 & 0.91 \\
C8 & 6.2416 & 6.2450 & 6.2345 & -0.0034 & -0.04 & -0.0052 & -0.12 \\
C9 & 6.0888 & 6.0892 & 6.0867 & -0.0004 & 0.00 & -0.0013 & -0.03 \\
\hline
\end{tabular}

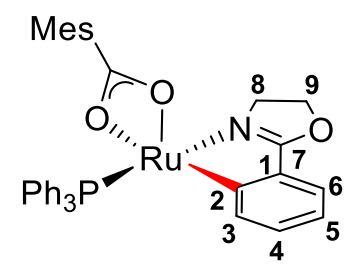

4.C

\begin{tabular}{cccccccc}
\hline Atom & $\delta_{\mathrm{N}}$ & $\delta_{\mathrm{N}-1}$ & $\delta_{\mathrm{N}+1}$ & $f_{\mathrm{A}^{-}}$ & $f_{\mathrm{A}^{-}}$(norm.) & $f_{\mathrm{A}}{ }^{0}$ & $f_{\mathrm{A}}{ }^{0}$ (norm.) \\
\hline C1 & 6.1994 & 6.1503 & 6.2060 & 0.0491 & 0.64 & 0.0279 & 0.47 \\
C2 & 6.0259 & 6.0583 & 6.0142 & -0.0324 & -0.42 & -0.0220 & -0.37 \\
C3 & 6.2440 & 6.1977 & 6.2503 & 0.0463 & 0.60 & 0.0263 & 0.44 \\
C4 & 6.1743 & 6.1673 & 6.2114 & 0.0070 & 0.09 & 0.0221 & 0.37 \\
C5 & 6.2458 & 6.1688 & 6.2874 & $\mathbf{0 . 0 7 7 0}$ & $\mathbf{1 . 0 0}$ & $\mathbf{0 . 0 5 9 3}$ & $\mathbf{1 . 0 0}$ \\
C6 & 6.1620 & 6.1542 & 6.1788 & 0.0078 & 0.10 & 0.0123 & 0.21 \\
C7 & 5.4149 & 5.4034 & 5.4668 & 0.0115 & 0.15 & 0.0317 & 0.53 \\
C8 & 6.2437 & 6.2480 & 6.2405 & -0.0043 & -0.06 & -0.0037 & -0.06 \\
\hline
\end{tabular}




$\begin{array}{llllllll}\text { C9 } & 6.0885 & 6.0893 & 6.0871 & -0.0008 & -0.01 & -0.0011 & -0.02\end{array}$

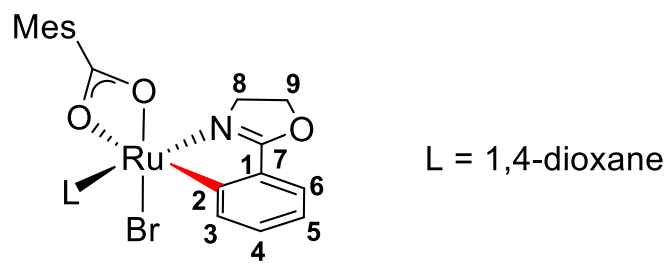

4.D

\begin{tabular}{cccccccc}
\hline Atom & $\delta_{\mathrm{N}}$ & $\delta_{\mathrm{N}-1}$ & $\delta_{\mathrm{N}+1}$ & $f_{\mathrm{A}}{ }^{-}$ & $f_{\mathrm{A}^{-}}$(norm.) & $f_{\mathrm{A}}{ }^{0}$ & $f_{\mathrm{A}}{ }^{0}$ (norm.) \\
\hline C1 & 6.1726 & 6.1205 & 6.1967 & 0.0521 & 0.58 & 0.0381 & 0.51 \\
$\mathrm{C} 2$ & 5.9648 & 5.9505 & 5.9506 & 0.0143 & 0.16 & 0.0001 & 0.00 \\
$\mathrm{C} 3$ & 6.2407 & 6.1970 & 6.2600 & 0.0437 & 0.49 & 0.0315 & 0.42 \\
C4 & 6.1722 & 6.1571 & 6.2007 & 0.0151 & 0.17 & 0.0218 & 0.29 \\
C5 & 6.2266 & 6.1375 & 6.2875 & $\mathbf{0 . 0 8 9 2}$ & $\mathbf{1 . 0 0}$ & $\mathbf{0 . 0 7 5 0}$ & $\mathbf{1 . 0 0}$ \\
C6 & 6.1570 & 6.1527 & 6.1725 & 0.0042 & 0.05 & 0.0099 & 0.13 \\
C7 & 5.4196 & 5.4126 & 5.4615 & 0.0070 & 0.08 & 0.0244 & 0.33 \\
C8 & 6.2486 & 6.2543 & 6.2472 & -0.0057 & -0.06 & -0.0035 & -0.05 \\
C9 & 6.0855 & 6.0871 & 6.0858 & -0.0016 & -0.02 & -0.0006 & -0.01 \\
\hline
\end{tabular}

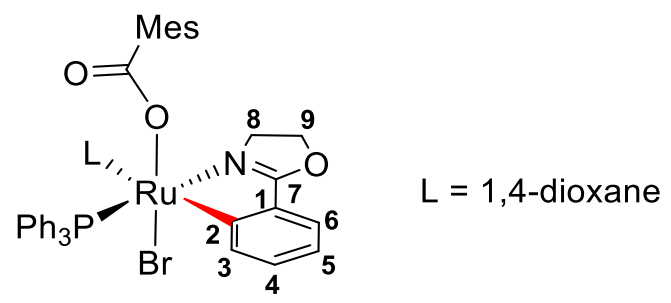

4.E

\begin{tabular}{cccccccc}
\hline Atom & $\delta_{\mathrm{N}}$ & $\delta_{\mathrm{N}-1}$ & $\delta_{\mathrm{N}+1}$ & $f_{\mathrm{A}}^{-}$ & $f_{\mathrm{A}}^{-}$(norm.) & $f_{\mathrm{A}}{ }^{0}$ & $f_{\mathrm{A}}{ }^{0}$ (norm.) \\
\hline C1 & 6.1786 & 6.1514 & 6.2104 & 0.0272 & 0.46 & 0.0295 & 0.52 \\
C2 & 5.9519 & 5.9336 & 5.9218 & 0.0184 & 0.31 & -0.0059 & -0.10 \\
C3 & 6.2363 & 6.2099 & 6.2569 & 0.0263 & 0.44 & 0.0235 & 0.41 \\
C4 & 6.1735 & 6.1661 & 6.1871 & 0.0074 & 0.13 & 0.0105 & 0.18 \\
C5 & 6.2155 & 6.1563 & 6.2698 & $\mathbf{0 . 0 5 9 2}$ & $\mathbf{1 . 0 0}$ & $\mathbf{0 . 0 5 6 8}$ & $\mathbf{1 . 0 0}$ \\
\hline
\end{tabular}




\begin{tabular}{llllllll}
\hline C6 & 6.1614 & 6.1532 & 6.1697 & 0.0081 & 0.14 & 0.0082 & 0.15 \\
C7 & 5.4069 & 5.4036 & 5.4197 & 0.0033 & 0.06 & 0.0080 & 0.14 \\
C8 & 6.2465 & 6.2497 & 6.2456 & -0.0032 & -0.05 & -0.0021 & -0.04 \\
C9 & 6.0866 & 6.0876 & 6.0867 & -0.0010 & -0.02 & -0.0005 & -0.01 \\
\hline
\end{tabular}

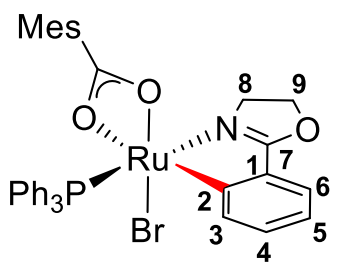

4.F

\begin{tabular}{cccccccc}
\hline Atom & $\delta_{\mathrm{N}}$ & $\delta_{\mathrm{N}-1}$ & $\delta_{\mathrm{N}+1}$ & $f_{\mathrm{A}}^{-}$ & $f_{\mathrm{A}}^{-}$(norm.) & $f_{\mathrm{A}}{ }^{0}$ & $f_{\mathrm{A}}{ }^{0}$ (norm.) \\
\hline C1 & 6.1577 & 6.1113 & 6.1976 & 0.0464 & 0.56 & 0.0431 & 0.57 \\
C2 & 5.9517 & 5.9285 & 5.9209 & 0.0232 & 0.28 & -0.0038 & -0.05 \\
C3 & 6.2264 & 6.1791 & 6.2567 & 0.0473 & 0.57 & 0.0388 & 0.52 \\
C4 & 6.1781 & 6.1741 & 6.1920 & 0.0039 & 0.05 & 0.0089 & 0.12 \\
C5 & 6.2137 & 6.1302 & 6.2804 & $\mathbf{0 . 0 8 3 5}$ & $\mathbf{1 . 0 0}$ & $\mathbf{0 . 0 7 5 1}$ & $\mathbf{1 . 0 0}$ \\
C6 & 6.1630 & 6.1575 & 6.1697 & 0.0055 & 0.07 & 0.0061 & 0.08 \\
C7 & 5.4187 & 5.4190 & 5.4315 & -0.0003 & 0.00 & 0.0062 & 0.08 \\
C8 & 6.2472 & 6.2501 & 6.2460 & -0.0028 & -0.03 & -0.0020 & -0.03 \\
C9 & 6.0866 & 6.0873 & 6.0867 & -0.0007 & -0.01 & -0.0003 & 0.00 \\
\hline
\end{tabular}

6.2.2.2 Purine as Directing Group

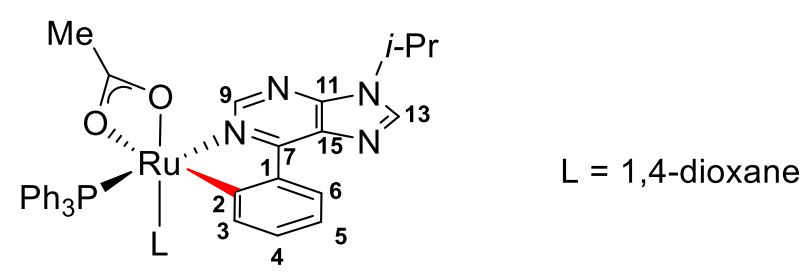

4.G

\begin{tabular}{cccccccc}
\hline Atom & $\delta_{\mathrm{N}}$ & $\delta_{\mathrm{N}-1}$ & $\delta_{\mathrm{N}+1}$ & $f_{\mathrm{A}}^{-}$ & $f_{\mathrm{A}}^{-}$(norm.) & $f_{\mathrm{A}}{ }^{0}$ & $f_{\mathrm{A}}{ }^{0}$ (norm.) \\
\hline $\mathrm{C} 1$ & 6.1830 & 6.1179 & 6.1427 & 0.0651 & 0.77 & 0.0124 & 0.17 \\
\hline
\end{tabular}




\begin{tabular}{llllllll}
\hline C2 & 5.9771 & 6.0224 & 6.0335 & -0.0453 & -0.54 & 0.0056 & 0.08 \\
C3 & 6.2632 & 6.2082 & 6.2721 & 0.0550 & 0.65 & 0.0320 & 0.44 \\
C4 & 6.1694 & 6.1719 & 6.2598 & -0.0025 & -0.03 & 0.0439 & 0.60 \\
C5 & 6.2551 & 6.1710 & 6.2519 & 0.0841 & 1.00 & 0.0405 & 0.56 \\
C6 & 6.1625 & 6.1648 & 6.2264 & -0.0023 & -0.03 & 0.0308 & 0.42 \\
C7 & 5.7391 & 5.7538 & 5.8991 & -0.0147 & -0.17 & 0.0726 & 1.00 \\
N8 & 7.4216 & 7.4343 & 7.4370 & -0.0127 & -0.15 & 0.0014 & 0.02 \\
C9 & 5.7381 & 5.7402 & 5.7564 & -0.0021 & -0.02 & 0.0081 & 0.11 \\
N10 & 7.4775 & 7.4346 & 7.5756 & 0.0429 & 0.51 & 0.0705 & 0.97 \\
C11 & 5.6769 & 5.6624 & 5.7066 & 0.0145 & 0.17 & 0.0221 & 0.30 \\
N12 & 7.3399 & 7.3290 & 7.3485 & 0.0109 & 0.13 & 0.0097 & 0.13 \\
C13 & 5.7871 & 5.7542 & 5.8783 & 0.0329 & 0.39 & 0.0620 & 0.85 \\
N14 & 7.4412 & 7.4430 & 7.4679 & -0.0019 & -0.02 & 0.0124 & 0.17 \\
C15 & 5.9843 & 5.9663 & 5.9786 & 0.0180 & 0.21 & 0.0061 & 0.08 \\
\hline
\end{tabular}

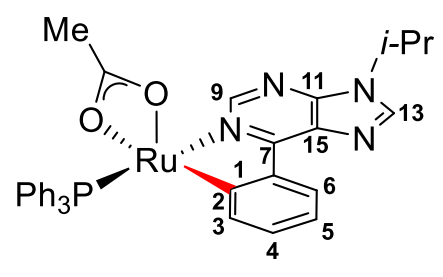

4.H

\begin{tabular}{cccccccc}
\hline Atom & $\delta_{\mathrm{N}}$ & $\delta_{\mathrm{N}-1}$ & $\delta_{\mathrm{N}+1}$ & $f_{\mathrm{A}^{-}}$ & $f_{\mathrm{A}}^{-}$(norm.) & $f_{\mathrm{A}}{ }^{0}$ & $f_{\mathrm{A}}{ }^{0}$ (norm.) \\
\hline C1 & 6.1637 & 6.0948 & 6.1549 & 0.0689 & 0.76 & 0.0301 & 0.50 \\
C2 & 6.0232 & 6.0581 & 6.0308 & -0.0348 & -0.38 & -0.0137 & -0.23 \\
C3 & 6.2441 & 6.1856 & 6.2474 & 0.0585 & 0.64 & 0.0309 & 0.51 \\
C4 & 6.1726 & 6.1765 & 6.2196 & -0.0038 & -0.04 & 0.0216 & 0.36 \\
C5 & 6.2421 & 6.1511 & 6.2721 & 0.0910 & 1.00 & 0.0605 & 1.00 \\
C6 & 6.1629 & 6.1656 & 6.1836 & -0.0027 & -0.03 & 0.0090 & 0.15 \\
C7 & 5.7385 & 5.7581 & 5.8166 & -0.0196 & -0.21 & 0.0292 & 0.48 \\
N8 & 7.4368 & 7.4568 & 7.4301 & -0.0200 & -0.22 & -0.0133 & -0.22 \\
C9 & 5.7310 & 5.7313 & 5.7294 & -0.0004 & 0.00 & -0.0009 & -0.02 \\
\hline
\end{tabular}




\begin{tabular}{llllllll}
\hline N10 & 7.4731 & 7.4294 & 7.5287 & 0.0437 & 0.48 & 0.0497 & 0.82 \\
C11 & 5.6707 & 5.6553 & 5.7080 & 0.0154 & 0.17 & 0.0263 & 0.44 \\
N12 & 7.3398 & 7.3278 & 7.3472 & 0.0120 & 0.13 & 0.0097 & 0.16 \\
C13 & 5.7838 & 5.7497 & 5.8387 & 0.0341 & 0.37 & 0.0445 & 0.74 \\
N14 & 7.4391 & 7.4410 & 7.4550 & -0.0019 & -0.02 & 0.0070 & 0.12 \\
C15 & 5.9824 & 5.9612 & 5.9752 & 0.0212 & 0.23 & 0.0070 & 0.12 \\
\hline
\end{tabular}

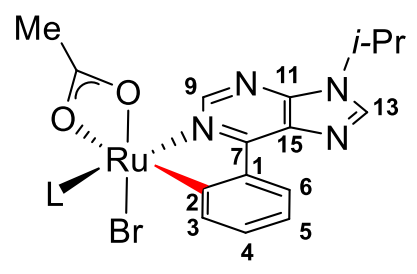

\section{1}

\begin{tabular}{cccccccc}
\hline Atom & $\delta_{\mathrm{N}}$ & $\delta_{\mathrm{N}-1}$ & $\delta_{\mathrm{N}+1}$ & $f_{\mathrm{A}}^{-}$ & $f_{\mathrm{A}}^{-}$(norm.) & $f_{\mathrm{A}}{ }^{0}$ & $f_{\mathrm{A}}{ }^{0}$ (norm.) \\
\hline C1 & 6.1279 & 6.0540 & 6.1656 & 0.0739 & 0.72 & 0.0558 & 0.66 \\
C2 & 5.9729 & 5.9563 & 5.9469 & 0.0166 & 0.16 & -0.0047 & -0.06 \\
C3 & 6.2304 & 6.1747 & 6.2549 & 0.0557 & 0.54 & 0.0401 & 0.47 \\
C4 & 6.1731 & 6.1703 & 6.1946 & 0.0028 & 0.03 & 0.0121 & 0.14 \\
C5 & 6.2163 & 6.1131 & 6.2828 & 0.1032 & 1.00 & 0.0849 & 1.00 \\
C6 & 6.1594 & 6.1654 & 6.1662 & -0.0059 & -0.06 & 0.0004 & 0.01 \\
C7 & 5.7453 & 5.7674 & 5.7645 & -0.0221 & -0.21 & -0.0014 & -0.02 \\
N8 & 7.3346 & 7.3318 & 7.3248 & 0.0028 & 0.03 & -0.0035 & -0.04 \\
C9 & 5.7253 & 5.7301 & 5.7315 & -0.0048 & -0.05 & 0.0007 & 0.01 \\
N10 & 7.4555 & 7.4069 & 7.5029 & 0.0486 & 0.47 & 0.0480 & 0.57 \\
C11 & 5.6742 & 5.6579 & 5.6987 & 0.0162 & 0.16 & 0.0204 & 0.24 \\
N12 & 7.3363 & 7.3233 & 7.3477 & 0.0130 & 0.13 & 0.0122 & 0.14 \\
C13 & 5.7801 & 5.7411 & 5.8196 & 0.0390 & 0.38 & 0.0392 & 0.46 \\
N14 & 7.4382 & 7.4369 & 7.4440 & 0.0013 & 0.01 & 0.0036 & 0.04 \\
C15 & 5.9711 & 5.9457 & 5.9809 & 0.0254 & 0.25 & 0.0176 & 0.21 \\
\hline & & & & & & &
\end{tabular}




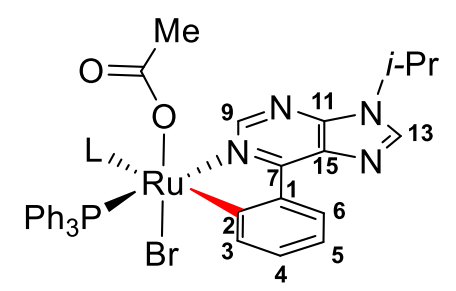

$L=1,4$-dioxane

4.J

\begin{tabular}{cccccccc}
\hline Atom & $\delta_{\mathrm{N}}$ & $\delta_{\mathrm{N}-1}$ & $\delta_{\mathrm{N}+1}$ & $f_{\mathrm{A}}^{-}$ & $f_{\mathrm{A}}^{-}$(norm.) & $f_{\mathrm{A}}{ }^{0}$ & $f_{\mathrm{A}}{ }^{0}$ (norm.) \\
\hline C1 & 6.1406 & 6.0898 & 6.1743 & 0.0508 & 0.67 & 0.0423 & 0.65 \\
C2 & 5.9632 & 5.9482 & 5.9302 & 0.0150 & 0.20 & -0.0090 & -0.14 \\
C3 & 6.2408 & 6.2036 & 6.2624 & 0.0372 & 0.49 & 0.0294 & 0.45 \\
C4 & 6.1807 & 6.1775 & 6.1919 & 0.0032 & 0.04 & 0.0072 & 0.11 \\
C5 & 6.2172 & 6.1415 & 6.2723 & 0.0757 & 1.00 & 0.0654 & 1.00 \\
C6 & 6.1631 & 6.1666 & 6.1665 & -0.0035 & -0.05 & -0.0001 & 0.00 \\
C7 & 5.7339 & 5.7563 & 5.7338 & -0.0224 & -0.30 & -0.0113 & -0.17 \\
N8 & 7.3894 & 7.4013 & 7.3713 & -0.0119 & -0.16 & -0.0150 & -0.23 \\
C9 & 5.6967 & 5.7059 & 5.6922 & -0.0092 & -0.12 & -0.0069 & -0.10 \\
N10 & 7.4548 & 7.4160 & 7.4922 & 0.0388 & 0.51 & 0.0381 & 0.58 \\
C11 & 5.6655 & 5.6555 & 5.6799 & 0.0099 & 0.13 & 0.0122 & 0.19 \\
N12 & 7.3367 & 7.3257 & 7.3458 & 0.0110 & 0.15 & 0.0101 & 0.15 \\
C13 & 5.7786 & 5.7476 & 5.8101 & 0.0310 & 0.41 & 0.0313 & 0.48 \\
N14 & 7.4417 & 7.4421 & 7.4418 & -0.0004 & -0.01 & -0.0002 & 0.00 \\
C15 & 5.9703 & 5.9515 & 5.9803 & 0.0188 & 0.25 & 0.0144 & 0.22 \\
\hline
\end{tabular}

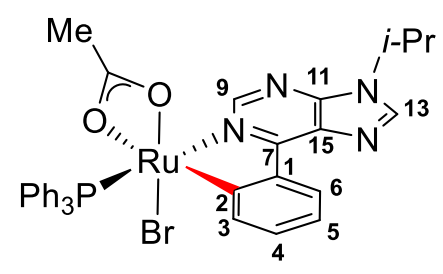

4.K

\begin{tabular}{cccccccc}
\hline Atom & $\delta_{\mathrm{N}}$ & $\delta_{\mathrm{N}-1}$ & $\delta_{\mathrm{N}+1}$ & $f_{\mathrm{A}}{ }^{-}$ & $f_{\mathrm{A}}{ }^{-}$(norm.) & $f_{\mathrm{A}}{ }^{0}$ & $f_{\mathrm{A}}{ }^{0}$ (norm.) \\
\hline $\mathrm{C} 1$ & 6.1226 & 6.0592 & 6.1650 & 0.0634 & 0.68 & 0.0529 & 0.66 \\
$\mathrm{C} 2$ & 5.9555 & 5.9326 & 5.9179 & 0.0229 & 0.25 & -0.0074 & -0.09 \\
\hline
\end{tabular}




\begin{tabular}{llllllll}
\hline C3 & 6.2258 & 6.1728 & 6.2579 & 0.0530 & 0.57 & 0.0426 & 0.53 \\
C4 & 6.1767 & 6.1800 & 6.1882 & -0.0033 & -0.04 & 0.0041 & 0.05 \\
C5 & 6.2095 & 6.1163 & 6.2760 & $\mathbf{0 . 0 9 3 2}$ & $\mathbf{1 . 0 0}$ & $\mathbf{0 . 0 7 9 8}$ & $\mathbf{1 . 0 0}$ \\
C6 & 6.1634 & 6.1684 & 6.1663 & -0.0050 & -0.05 & -0.0011 & -0.01 \\
C7 & 5.7356 & 5.7633 & 5.7399 & -0.0277 & -0.30 & -0.0117 & -0.15 \\
N8 & 7.3752 & 7.3864 & 7.3622 & -0.0112 & -0.12 & -0.0121 & -0.15 \\
C9 & 5.7173 & 5.7228 & 5.7153 & -0.0054 & -0.06 & -0.0037 & -0.05 \\
N10 & 7.4584 & 7.4179 & 7.5021 & 0.0405 & 0.43 & 0.0421 & 0.53 \\
C11 & 5.6688 & 5.6565 & 5.6856 & 0.0123 & 0.13 & 0.0146 & 0.18 \\
N12 & 7.3382 & 7.3274 & 7.3476 & 0.0108 & 0.12 & 0.0101 & 0.13 \\
C13 & 5.7783 & 5.7434 & 5.8141 & 0.0348 & 0.37 & 0.0353 & 0.44 \\
N14 & 7.4411 & 7.4434 & 7.4412 & -0.0023 & -0.02 & -0.0011 & -0.01 \\
C15 & 5.9722 & 5.9465 & 5.9845 & 0.0257 & 0.28 & 0.0190 & 0.24 \\
\hline
\end{tabular}

\subsection{Ruthenium-Catalyzed Decarboxylative $\mathrm{C}-\mathrm{H}$ Activation}

\subsubsection{Computational Methods}

All calculations were performed with the Gaussian 09, Revision D.01 package. ${ }^{[184]}$ Geometry optimizations were performed at the PBEO level of theory. ${ }^{[134]}$ Ruthenium was described with a def2-SVP basis set ${ }^{[127]}$ in combination with SDD pseudopotential, ${ }^{[189]}$ while all other atoms were described with a def2-SVP basis set. Analytical frequency calculations were performed at the same level of theory to characterize all stationary points as either intermediates (no imaginary frequencies) or transition states (exactly one imaginary frequency). The connection of transition states to intermediates was confirmed by IRC calculations. The electronic energy was refined through single point calculations at the PBEO level of theory ${ }^{[134]}$ including D3 dispersion correction $^{[126]}$ with Becke-Johnson damping scheme. Ruthenium was described with a def2-QZVP basis set $^{[127]}$ in combination with SDD pseudopotential, hydrogen was described with def2QZVP(-f) basis set and all other atoms were described with def2-QZVP(-g) basis set. This basis set is denoted as def2-QZVP*. In the single point calculations solvent effects were taken into consideration through the use of the SMD continuum solvation model ${ }^{[135]}$ as implemented in Gaussian. Unless stated otherwise, all energies are Gibbs free energies in $\mathrm{kcal} \mathrm{mol}^{-1}$, which were 
calculated by addition of the gas-phase Gibbs free energy contribution at $383 \mathrm{~K}$ and $1 \mathrm{~atm}$ (denoted as $\Delta \Delta G(383)$ ) to the single point energies (denoted as $E$ ).

\subsubsection{Relative Energies in Various Solvents}

The energies for the reaction of benzoic acid (31a) with alkyne 35a were calculated with DCE $(\varepsilon=$ 10.125), PhMe $(\varepsilon=2.3741)$, TFE $(\varepsilon=26.726)$, and water $(\varepsilon=78.3553)$ as solvent.

Table 20: Gibbs free energies in $\mathrm{kcal} \mathrm{mol}^{-1}$ for the reaction of 31a with 35a relative to $\mathbf{5 . A}$.

\begin{tabular}{|c|c|c|c|c|}
\hline Structure & $\Delta G_{383}(D C E)$ & $\Delta \mathrm{G}_{383}(\mathrm{PhMe})$ & $\Delta G_{383}(T F E)$ & $\Delta \mathrm{G}_{383}$ (Water \\
\hline $5 . A$ & 0.0 & 0.0 & 0.0 & 0.0 \\
\hline TS5.1 & 16.6 & 19.6 & 12.5 & 10.5 \\
\hline 5.B & 14.5 & 17.6 & 12.4 & 10.5 \\
\hline TS5.2 & 19.3 & 21.9 & 19.2 & 17.3 \\
\hline $5 . C$ & 10.8 & 12.4 & 11.3 & 9.7 \\
\hline 5.D & 3.7 & 6.6 & 3.9 & 0.5 \\
\hline TS5.3 & 19.9 & 22.8 & 19.5 & 15.8 \\
\hline 5.E & -5.4 & -3.3 & -4.8 & -8.5 \\
\hline TS5.4 & 13.9 & 14.5 & 16.9 & 13.6 \\
\hline $5 . F$ & 2.3 & 2.3 & 6.1 & 2.9 \\
\hline 5.6 & -9.0 & -10.8 & -2.3 & -6.0 \\
\hline TS5.5 & -1.8 & -3.4 & 4.5 & 0.9 \\
\hline $5 . \mathrm{H}$ & -6.6 & -7.6 & -2.5 & -6.2 \\
\hline TS5.6 & -3.8 & -4.5 & -1.5 & -5.3 \\
\hline 5.1 & -12.2 & -12.9 & -7.8 & -11.5 \\
\hline 5.J & -1.5 & -3.5 & 2.0 & -1.2 \\
\hline TS5.7 & 17.2 & 15.5 & 19.6 & 16.5 \\
\hline $5 . K$ & -19.0 & -20.6 & -17.8 & -20.2 \\
\hline TS5.8 & 17.1 & 19.5 & 17.1 & 13.7 \\
\hline 5.L & -18.1 & -17.4 & -15.4 & -19.3 \\
\hline
\end{tabular}


The energies for the reaction of benzoic acid (31a) with malimide 177a were calculated with DCE $(\varepsilon=10.125)$, PhMe $(\varepsilon=2.3741), \operatorname{TFE}(\varepsilon=26.726)$, and water $(\varepsilon=78.3553)$ as solvent.

Table 21: Gibbs free energies in $\mathrm{kcal} \mathrm{mol}^{-1}$ for the reaction of 31a with 177a relative to 5.A.

\begin{tabular}{|c|c|c|c|c|}
\hline Structure & $\Delta \mathrm{G}_{383}(\mathrm{DCE})$ & $\Delta \mathrm{G}_{383}(\mathrm{PhMe})$ & $\Delta \mathrm{G}_{383}(\mathrm{TFE})$ & $\Delta \mathrm{G}_{383}$ (Water) \\
\hline 5. $D^{\prime}$ & 3.7 & 9.1 & 2.2 & -0.9 \\
\hline 5. $D^{\prime \prime}$ & 1.1 & 4.2 & 0.8 & -1.8 \\
\hline TS5.3' & 19.3 & 23.4 & 18.2 & 15.3 \\
\hline TS5.3" & 22.2 & 24.7 & 21.1 & 18.6 \\
\hline 5. $E^{\prime}$ & -0.6 & 2.7 & -1.9 & -4.6 \\
\hline 5.E" & 0.3 & 2.2 & -0.1 & -2.7 \\
\hline TS5.4' & 16.2 & 17.2 & 17.5 & 15.2 \\
\hline $5 . \mathrm{F}^{\prime}$ & 6.6 & 6.6 & 7.3 & 5.3 \\
\hline 5.G' & -3.9 & -5.7 & 0.2 & -2.4 \\
\hline TS5.5' & 3.4 & 2.8 & 6.9 & 3.9 \\
\hline 5. $\mathrm{H}^{\prime}$ & -3.2 & -3.1 & -1.8 & -4.9 \\
\hline TS5.6' & 0.2 & 1.3 & 0.5 & -2.6 \\
\hline $5.1^{\prime}$ & -6.8 & -7.9 & -5.1 & -6.8 \\
\hline 5.J' & 15.0 & 13.0 & 14.8 & 13.7 \\
\hline TS5.7' & 21.0 & 19.9 & 20.2 & 19.0 \\
\hline 5. $\mathrm{K}^{\prime}$ & -13.7 & -15.2 & -13.0 & -14.2 \\
\hline TS5.8' & 69.0 & 71.1 & 70.5 & 67.7 \\
\hline 5..' $L^{\prime}$ & 24.6 & 26.7 & 25.3 & 22.3 \\
\hline
\end{tabular}

\subsubsection{Calculated KIE Values}

The Gaussian freqchk utility was used to rerun thermochemical calculations on the optimized structures for 2-D-PhCO 2 D. KIE values were then calculated using the following equation (3):

$$
\mathrm{KIE}=\frac{k_{\mathrm{H}}}{k_{\mathrm{D}}}=\exp \left[\frac{\Delta G_{\mathrm{D}}^{\ddagger}-\Delta G_{\mathrm{H}}^{\ddagger}}{k_{B} T}\right]
$$


Table 22: Calculated KIE values.

\begin{tabular}{cccc}
\hline Elemental Step & $\Delta \mathrm{G}_{H^{\ddagger}}$ & $\Delta \mathrm{G}^{\ddagger}$ & $\mathrm{KIE}$ \\
\hline $\mathbf{5 . A} \rightarrow$ TS5.1 & 16.58 & 16.64 & 1.082 \\
$\mathbf{5 . B} \rightarrow$ TS5.2 & 4.76 & 5.60 & 2.991 \\
$\mathbf{5 . \mathbf { D } ^ { \prime }} \rightarrow$ TS5.3' & 15.62 & 15.62 & 0.993 \\
$\mathbf{5 . E ^ { \prime }} \rightarrow$ TS5.4' & 16.88 & 16.90 & 1.027 \\
$\mathbf{5 . G ^ { \prime }} \rightarrow$ TS5.5' & 7.34 & 8.39 & 3.973 \\
$\mathbf{5 . H ^ { \prime }} \rightarrow$ TS5.6' & 3.34 & 3.25 & 0.897 \\
$\mathbf{5 . J ^ { \prime }} \rightarrow$ TS5.7' & 5.99 & 6.81 & 2.928 \\
\hline
\end{tabular}

\subsubsection{Electronic Energies and Correction Values}

Table 23: Electronic energies and correction values in Hartree.

\begin{tabular}{cccccc}
\hline Structure & $E(D C E)$ & $E(P h M e)$ & $E(T F E)$ & $E($ Water $)$ & $\Delta \Delta G(383)$ \\
\hline 5.A & -1324.140250 & -1324.135296 & -1324.139198 & -1324.129988 & 0.340471 \\
TS5.1 & -1324.114823 & -1324.105113 & -1324.120302 & -1324.114174 & 0.341459 \\
5.B & -1324.116815 & -1324.107039 & -1324.119224 & -1324.113020 & 0.340197 \\
TS5.2 & -1324.107754 & -1324.098615 & -1324.106825 & -1324.100653 & 0.338725 \\
5.C & -1324.124550 & -1324.117055 & -1324.122744 & -1324.116030 & 0.341961 \\
5.D & -1442.648623 & -1442.639053 & -1442.644637 & -1442.632468 & 0.412898 \\
TS5.3 & -1442.622817 & -1442.613298 & -1442.619725 & -1442.608047 & 0.412900 \\
5.E & -1442.664224 & -1442.655966 & -1442.659661 & -1442.647912 & 0.414031 \\
TS5.4 & -1442.631915 & -1442.626019 & -1442.623527 & -1442.611116 & 0.412463 \\
$\mathbf{5 . F}$ & -1442.647465 & -1442.642568 & -1442.637690 & -1442.625244 & 0.409485 \\
$\mathbf{5 . G}$ & -1674.756695 & -1674.751208 & -1674.747548 & -1674.730188 & 0.507052 \\
TS5.5 & -1674.740739 & -1674.734992 & -1674.732286 & -1674.714689 & 0.502638 \\
$\mathbf{5 . H}$ & -1674.750890 & -1674.744126 & -1674.745785 & -1675.728433 & 0.505028 \\
TS5.6 & -1674.747796 & -1674.740651 & -1674.745520 & -1674.728351 & 0.506390 \\
$\mathbf{5 . I}$ & -1674.760316 & -1674.753270 & -1674.754900 & -1674.737395 & 0.505620 \\
$\mathbf{5 . J}$ & -2095.327323 & -2095.320150 & -2095.319671 & -2095.301198 & 0.604973 \\
\hline
\end{tabular}




\begin{tabular}{|c|c|c|c|c|c|}
\hline TS5.7 & -2095.298031 & -2095.290354 & -2095.292166 & -2095.273482 & 0.605471 \\
\hline $5 . K$ & -2095.348376 & -2095.340505 & -2095.344211 & -2095.324632 & 0.598040 \\
\hline TS5.8 & -1442.628996 & -1442.620157 & -1442.625172 & -1442.612982 & 0.414509 \\
\hline 5.L & -1442.691440 & -1442.685374 & -1442.683440 & -1442.671923 & 0.420906 \\
\hline 5. $\mathrm{D}^{\prime}$ & -1302.085811 & -1302.072513 & -1302.084742 & -1302.083204 & 0.330949 \\
\hline 5.D" & -1302.084298 & -1302.074574 & -1302.081250 & -1302.078942 & 0.325249 \\
\hline TS5.3' & -1302.058491 & -1302.047284 & -1302.056715 & -1302.055013 & 0.328527 \\
\hline TS5.3" & -1302.055653 & -1302.046859 & -1302.053802 & -1302.051448 & 0.330231 \\
\hline $5 . \mathrm{E}^{\prime}$ & -1302.091204 & -1302.081233 & -1302.089713 & -1302.087636 & 0.329443 \\
\hline 5.E" & -1302.090172 & -1302.082397 & -1302.087168 & -1302.084965 & 0.329856 \\
\hline TS5.4' & -1302.061867 & -1302.055623 & -1302.056302 & -1302.053551 & 0.327006 \\
\hline 5. $F^{\prime}$ & -1302.073012 & -1302.068258 & -1302.068425 & -1302.065180 & 0.322776 \\
\hline 5.G' & -1534.180911 & -1534.175730 & -1534.176130 & -1534.168128 & 0.420308 \\
\hline TS5.5' & -1534.164766 & -1534.157819 & -1534.160980 & -1534.153567 & 0.415859 \\
\hline $5 . \mathrm{H}^{\prime}$ & -1534.177402 & -1534.169329 & -1534.176961 & -1534.169738 & 0.417963 \\
\hline TS5.6' & -1534.173070 & -1534.163163 & -1534.174138 & -1534.167054 & 0.418946 \\
\hline $5.1^{\prime}$ & -1534.185851 & -1534.179509 & -1534.184753 & -1534.175440 & 0.420628 \\
\hline 5.J' & -1954.739077 & -1954.732241 & -1954.737515 & -1954.726956 & 0.523945 \\
\hline TS5.7' & -1954.718383 & -1954.710064 & -1954.717674 & -1954.707390 & 0.512801 \\
\hline 5. $\mathrm{K}^{\prime}$ & -1954.775556 & -1954.767932 & -1954.772565 & -195 & 0.514664 \\
\hline TS5.8' & -1301.976474 & -1301.968321 & -1301.970488 & -1301.968626 & 0.325617 \\
\hline 5. $L^{\prime}$ & -1302.049391 & -1302.041377 & -1302.044862 & -1302.043171 & 0.327922 \\
\hline $\mathrm{CO}_{2}$ & -188.475352 & -188.476577 & -188.466471 & -188.471946 & -0.015755 \\
\hline Acetate & -228.467437 & -228.434781 & -228.484031 & -228.491139 & 0.011227 \\
\hline HOAC & -228.957205 & -228.955049 & -228.955291 & -228.957869 & 0.025500 \\
\hline Alkyne 35a & -539.066228 & -539.064129 & -539.059897 & -539.051295 & 0.139615 \\
\hline Alkene 177a & -398.499250 & -398.497411 & -398.493110 & -398.495725 & 0.053558 \\
\hline Benzoate & -420.073662 & -420.043122 & -420.085704 & -420.089967 & 0.059398 \\
\hline $\mathrm{PhCO}_{2} \mathrm{H}(31 \mathrm{a})$ & -420.557916 & -420.555806 & -420.554241 & -420.554049 & 0.073175 \\
\hline
\end{tabular}


Table 24: Electronic energies in Hartree without D3(BJ) correction in DCE as solvent.

\begin{tabular}{|c|c|}
\hline Structure & $E(D C E)$ \\
\hline $5 . \mathrm{A}$ & -1324.075031 \\
\hline TS5.1 & -1324.042681 \\
\hline 5.B & -1324.044735 \\
\hline TS5.2 & -1324.035395 \\
\hline $5 . C$ & -1324.052405 \\
\hline 5.D & -1442.553339 \\
\hline TS5.3 & -1442.528313 \\
\hline 5.E & -1442.569376 \\
\hline TS5.4 & -1442.537732 \\
\hline $5 . F$ & -1442.552364 \\
\hline $5 . G$ & -1674.643165 \\
\hline TS5.5 & -1674.628079 \\
\hline 5.H & -1674.638489 \\
\hline TS5.6 & -1674.634657 \\
\hline 5.1 & -1674.648406 \\
\hline 5.J & -2095.186463 \\
\hline TS5.7 & -2095.156420 \\
\hline $5 . K$ & -2095.223212 \\
\hline TS5.8 & -1442.535726 \\
\hline $5 . \mathrm{L}$ & -1442.593517 \\
\hline 5. $D^{\prime}$ & -1302.009228 \\
\hline TS5.3' & -1301.982447 \\
\hline 5. $\mathrm{E}^{\prime}$ & -1302.015551 \\
\hline TS5.4' & -1301.986660 \\
\hline $5 . \mathrm{F}^{\prime}$ & -1301.997605 \\
\hline $5 . G^{\prime}$ & -1534.087169 \\
\hline TS5.5' & -1534.070892 \\
\hline $5 . \mathrm{H}^{\prime}$ & -1534.084453 \\
\hline
\end{tabular}




\begin{tabular}{cc}
\hline TS5.6' & -1534.081498 \\
$\mathbf{5 . \mathbf { I } ^ { \prime }}$ & -1534.093462 \\
$\mathbf{5 . J ^ { \prime }}$ & -1954.617153 \\
$\mathbf{T S 5 . 7 ^ { \prime }}$ & -1954.602613 \\
$\mathbf{5 . \mathbf { K } ^ { \prime }}$ & -1954.669018 \\
$\mathbf{T S 5 . 8 ^ { \prime }}$ & -1301.903319 \\
$\mathbf{5 . L ^ { \prime }}$ & -1301.976594 \\
CO & -188.474581 \\
Acetate & -228.464423 \\
HOAc & -228.953759 \\
Alkyne 35a & -539.042204 \\
Alkene 177a & -398.488839 \\
Benzoate & -420.060916 \\
PhCO ${ }_{2} \mathrm{H}$ (31a) & -420.544653 \\
\hline
\end{tabular}

\subsection{Ruthenium-Catalyzed C-H Alkenylation of Aryl Acetamides}

\subsubsection{Computational Methods}

All calculations were performed with the Orca version 3.0.3 package. ${ }^{[186]}$ Geometry optimizations were performed at the TPSS level of theory ${ }^{[125]}$ including D3 dispersion correction ${ }^{[126]}$ with BeckeJohnson damping scheme. Ruthenium was described with a def2-TZVP basis set ${ }^{[127]}$ in combination with Stuttgart-Dresden (SDD) pseudopotential, ${ }^{[189]}$ while all other atoms were described with a def2-TZVP basis set. Numerical frequency calculations were performed the same level of theory to characterize all stationary points as either intermediates (no imaginary frequencies) or transition states (exactly one imaginary frequency). The electronic energy was refined through single point calculations at the B3LYP ${ }^{[128]}, \mathrm{PW} 6 \mathrm{~B}^{[145]}{ }^{\left[14 \mathrm{PBEO}^{[134]}\right.}$ level of theory including D3(BJ) correction. Ruthenium was described with a def2-TZVP basis set in combination with SDD pseudopotential and all other atoms were described with def2-TZVP basis set. In the single point calculations solvent effects were taken into consideration through the use of the COSMO continuum solvation model ${ }^{[142]}$ with a dielectric constant of $\varepsilon=2.2099$, which corresponds to 1,4 dioxane. RIJCOSX approximation was used in all calculations together with def2-TZVP/J auxiliary basis set. ${ }^{[190]}$ In all calculations the GRID4, TightSCF, SlowConv keywords and in the geometry 
optimizations additionally TightOPT keyword was used. Unless stated otherwise, all energies are Gibbs free energies in $\mathrm{kcal} \mathrm{mol}^{-1}$, which were calculated by addition of the gas-phase thermal and non-thermal correction at $298 \mathrm{~K}$ and $1 \mathrm{~atm}$ (denoted as $\Delta \Delta \mathrm{H}(298)$ ) and entropy contribution at $298 \mathrm{~K}$ and $1 \mathrm{~atm}$ (denoted as $\mathrm{S}(298)$ ) to the single point energies (denoted as $\mathrm{E}$ ).

Bond orders correspond to Mayer bond orders at the TPSS-D3(BJ)/def2-TZVP level of theory as implemented in Orca.

\subsubsection{Electronic Energies and Correction Values}

Table 25: Electronic energies and correction values in Hartree for calculations at the B3LYP level of theory.

\begin{tabular}{ccccc}
\hline Structure & $\mathrm{E}(1,4-$ dioxane $)$ & $\Delta \Delta \mathrm{H}(298)$ & $\mathrm{S}(298)$ & Dispersion \\
\hline 6.A & -1192.220650 & 0.471210 & 0.079505 & -0.126830 \\
TS6.1 & -1192.198748 & 0.471948 & 0.083377 & -0.132817 \\
6.B & -1192.202723 & 0.473625 & 0.086341 & -0.136157 \\
TS6.2 & -1192.182713 & 0.466945 & 0.082182 & -0.133205 \\
6.C & -1192.204000 & 0.471347 & 0.080652 & -0.132806 \\
6.D & -1269.566300 & 0.507600 & 0.084158 & -0.147457 \\
6.D' & -1269.565137 & 0.509431 & 0.087951 & -0.149437 \\
TS6.3 & -1269.537908 & 0.507730 & 0.083027 & -0.148115 \\
TS6.3' & -1269.544278 & 0.508041 & 0.086803 & -0.149002 \\
6.E & -1269.575208 & 0.509161 & 0.085560 & -0.150630 \\
6.E' & -1269.576493 & 0.509264 & 0.084764 & -0.152011 \\
6.F & -1269.594740 & 0.507067 & 0.083282 & -0.139476 \\
6.F' & -1269.549865 & 0.507043 & 0.083792 & -0.140617 \\
TS6.4 & -1269.560022 & 0.504154 & 0.082883 & -0.139860 \\
TS6.4' & -1269.545720 & 0.504288 & 0.083186 & -0.140883 \\
6.G & -1269.565777 & 0.506833 & 0.086054 & -0.140634 \\
6.G' & -1269.553465 & 0.506350 & 0.086405 & -0.141610 \\
6.A & -1152.911091 & 0.442482 & 0.079138 & -0.117837 \\
6.B & -1152.886421 & 0.440792 & 0.079425 & -0.122848 \\
\hline & & & & \\
\hline
\end{tabular}




\begin{tabular}{ccccc}
\hline TS6.2 $^{5}$ & -1152.881243 & 0.435628 & 0.074262 & -0.123297 \\
$6 . C^{5}$ & -1152.904701 & 0.441906 & 0.078963 & -0.122790 \\
HOAC & -229.081963 & 0.064232 & 0.030836 & -0.006990 \\
Acrylate 27a & -306.445470 & 0.100263 & 0.038215 & -0.013845 \\
\hline
\end{tabular}

Table 26: Electronic energies and correction values in Hartree for calculations at the PW6B95 level of theory.

\begin{tabular}{ccccc}
\hline Structure & $\mathrm{E}(1,4-$ dioxane $)$ & $\Delta \Delta \mathrm{H}(298)$ & $\mathrm{S}(298)$ & Dispersion \\
\hline 6.A & -1194.269411 & 0.471210 & 0.079505 & -0.043620 \\
TS6.1 & -1194.245634 & 0.471948 & 0.083377 & -0.045956 \\
6.B & -1194.251280 & 0.473625 & 0.086341 & -0.047042 \\
TS6.2 & -1294.228733 & 0.466945 & 0.082182 & -0.045920 \\
6.C & -1194.250519 & 0.471347 & 0.080652 & -0.045675 \\
6.D & -1271.761212 & 0.507600 & 0.084158 & -0.050852 \\
TS6.3 & -1271.735498 & 0.507730 & 0.083027 & -0.051367 \\
6.E & -1271.773879 & 0.509161 & 0.085560 & -0.052427 \\
6.F & -1271.759862 & 0.507067 & 0.083282 & -0.047582 \\
TS6.4 & -1271.754530 & 0.504154 & 0.082883 & -0.047735 \\
6.G & -1271.758157 & 0.506833 & 0.086054 & -0.047995 \\
6.A & -1154.886322 & 0.442482 & 0.079138 & -0.040235 \\
6.B & -1154.858117 & 0.440792 & 0.079425 & -0.042239 \\
TS6.2 & -1154.852438 & 0.435628 & 0.074262 & -0.042334 \\
6.C & -1154.876830 & 0.441906 & 0.078963 & -0.042089 \\
HOAc & -229.454407 & 0.064232 & 0.030836 & -0.001767 \\
Acrylate 27a & -306.963192 & 0.100263 & 0.038215 & -0.003774 \\
\hline & & & &
\end{tabular}


Table 27: Electronic energies and correction values in Hartree for calculations at the PBEO level of theory.

\begin{tabular}{ccccc}
\hline Structure & $\mathrm{E}(1,4$-dioxane $)$ & $\Delta \Delta \mathrm{H}(298)$ & $\mathrm{S}(298)$ & Dispersion \\
\hline 6.A & -1191.572517 & 0.471210 & 0.079505 & -0.068722 \\
TS6.1 & -1191.548034 & 0.471948 & 0.083377 & -0.071964 \\
6.B & -1191.553489 & 0.473625 & 0.086341 & -0.073651 \\
TS6.2 & -1191.538332 & 0.466945 & 0.082182 & -0.071991 \\
6.C & -1191.558868 & 0.471347 & 0.080652 & -0.071637 \\
6.D & -1268.872575 & 0.507600 & 0.084158 & -0.079749 \\
TS6.3 & -1268.848760 & 0.507730 & 0.083027 & -0.080398 \\
6.E & -1268.886796 & 0.509161 & 0.085560 & -0.081835 \\
6.F & -1268.876587 & 0.507067 & 0.083282 & -0.075150 \\
TS6.4 & -1268.871682 & 0.504154 & 0.082883 & -0.075351 \\
6.G & -1268.874343 & 0.506833 & 0.086054 & -0.075737 \\
6.A & -1152.285999 & 0.442482 & 0.079138 & -0.063340 \\
6.8 & -1152.262555 & 0.440792 & 0.083377 & -0.066137 \\
TS6.2 & -1152.259888 & 0.435628 & 0.086341 & -0.066320 \\
6.C & -1152.282994 & 0.441906 & 0.082182 & -0.065963 \\
HOAc & -228.938403 & 0.064232 & 0.080652 & -0.003433 \\
Acrylate 27a & -306.249209 & 0.471210 & 0.084158 & -0.006941 \\
\hline
\end{tabular}

\subsection{Ruthenium-Catalyzed Thiocarbonyl-Directed Ferrocene C-H Arylation}

\subsubsection{Computational Methods}

All calculations were performed with the Orca version 3.0.3 package. ${ }^{[186]}$ Geometry optimizations were performed at the TPSS level of theory ${ }^{[125]}$ including D3 dispersion correction ${ }^{[126]}$ with BeckeJohnson damping scheme. Ruthenium was described with a def2-TZVP basis set ${ }^{[127]}$ in combination with Stuttgart-Dresden (SDD) pseudopotential, ${ }^{[189]}$ while all other atoms were described with a def2-TZVP basis set. Numerical frequency calculations were performed at the same level of theory to characterize all stationary points as either intermediates (no imaginary frequencies) or transition states (exactly one imaginary frequency). The electronic energy was refined through single point calculations at the PW6B95 level of theory ${ }^{[145]}$ including D3(BJ). Ruthenium was 
described with a def2-TZVP basis set in combination with SDD pseudopotential and all other atoms were described with def2-TZVP basis set. In the single point calculations solvent effects were taken into consideration through the use of the COSMO continuum solvation model ${ }^{[142]}$ with a dielectric constant of $\varepsilon=2.3741$, which corresponds to toluene. RIJCOSX approximation was used in all calculations together with def2-TZVP/J auxiliary basis set. ${ }^{[190]}$ In all calculations the GRID4, TightSCF, SlowConv keywords and in the geometry optimizations additionally TightOPT keyword was used. Unless stated otherwise, all energies are Gibbs free energies in $\mathrm{kcal} \mathrm{mol}^{-1}$, which were calculated by addition of the gas-phase thermal and non-thermal correction at $298 \mathrm{~K}$ and $1 \mathrm{~atm}$ (denoted as $\Delta \Delta \mathrm{H}(298)$ ) and entropy contribution at $298 \mathrm{~K}$ and $1 \mathrm{~atm}$ (denoted as $\mathrm{S}(298)$ ) to the single point energies (denoted as $\mathrm{E}$ ).

The prefix O-, S- and Se- corresponds to ketone, thioketone and selenoketone as directing group, respectively.

\subsubsection{Influence of Dispersion}

Table 28: Comparison of energies with and without dispersion correction relative to S-7.A in $\mathrm{kcal} \mathrm{mol}{ }^{-1}$.

\begin{tabular}{ccc}
\hline Structure & $\Delta \mathrm{G}_{298} \mathrm{~W} / \mathrm{D} 3(\mathrm{BJ})$ & $\Delta \mathrm{G}_{298} \mathrm{~W} / \mathrm{O} \mathrm{D} 3(\mathrm{BJ})$ \\
O-7.A & 8.6 & 7.8 \\
O-TS7.1 & 21.6 & 21.8 \\
O-7.B & 19.9 & 20.5 \\
O-TS7.2 & 27.8 & 28.6 \\
O-7.C & 17.5 & 18.3 \\
S-7.A & 0.0 & 0.0 \\
S-TS7.1 & 10.9 & 11.8 \\
S-7.B & 8.9 & 10.3 \\
S-TS7.2 & 14.8 & 16.3 \\
S-7.C & 5.6 & 6.7 \\
Se-7.A & -3.1 & -2.9 \\
Se-TS7.1 & 9.5 & 10.8 \\
Se-7.B & 8.7 & 10.5 \\
\hline
\end{tabular}


Se-TS7.2

Se-7.C
12.7

4.3
14.5

5.8

\subsubsection{Selected Bond Distances}

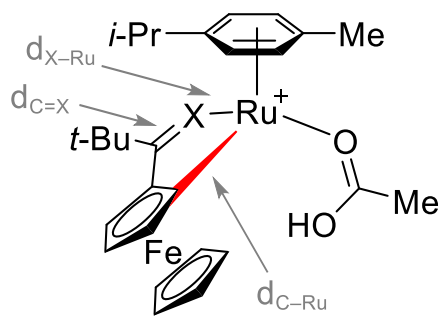

Table 29: Selected bond distances for ketone as directing group in $\AA$.

\begin{tabular}{cccc}
\hline Structure & $\mathrm{d}_{\mathrm{O}-\mathrm{Ru}}$ & $\mathrm{d}_{\mathrm{C}=\mathrm{O}}$ & $\mathrm{d}_{\mathrm{C}-\mathrm{Ru}}$ \\
\hline O-7.A & 2.069 & 1.263 & 3.461 \\
O-TS7.1 & 2.104 & 1.263 & 2.632 \\
O-7.B & 2.101 & 1.262 & 2.356 \\
O-TS7.2 & 2.102 & 1.267 & 2.187 \\
O-7.C & 2.097 & 1.273 & 2.061 \\
\hline
\end{tabular}

Table 30: Selected bond distances for thioketone as directing group in $\AA$.

\begin{tabular}{cccc}
\hline Structure & $\mathrm{d}_{\text {S-Ru }}$ & $\mathrm{d}_{\mathrm{c}=\mathrm{S}}$ & $\mathrm{d}_{\mathrm{C}-\mathrm{Ru}}$ \\
\hline S-7.A & 2.368 & 1.685 & 3.398 \\
S-TS7.1 & 2.373 & 1.676 & 2.644 \\
S-7.B & 2.347 & 1.673 & 2.331 \\
S-TS7.2 & 2.350 & 1.682 & 2.197 \\
S-7.C & 2.343 & 1.688 & 2.067 \\
\hline
\end{tabular}

Table 31: Selected bond distances for selenoketone as directing group in $\AA$.

\begin{tabular}{cccc}
\hline Structure & $\mathrm{d}_{\mathrm{Se}-\mathrm{Ru}}$ & $\mathrm{d}_{\mathrm{C}=\mathrm{Se}}$ & $\mathrm{d}_{\mathrm{C}-\mathrm{Ru}}$ \\
\hline Se-7.A & 2.498 & 1.844 & 3.433 \\
Se-TS7.1 & 2.497 & 1.831 & 2.646 \\
Se-7.B & 2.484 & 1.831 & 2.334 \\
\hline
\end{tabular}




\begin{tabular}{cccc}
\hline Se-TS7.2 & 2.474 & 1.837 & 2.198 \\
Se-7.C & 2.468 & 1.841 & 2.077 \\
\hline
\end{tabular}

\subsubsection{Distortion-Interaction Analysis}

Transition state TS7.1 was analyzed with distortion-interaction analysis at the PW6B95D3(BJ)/def2-TZVP+COSMO(toluene)//TPSS-D3(BJ)/def2-TZVP level of theory. ${ }^{[151]}$ The structure of TS7.1 was separated in two fragments: a $[\mathrm{Ru}(\mathrm{OAc})(p \text {-cymene })]^{+}$fragment and a substrate fragment, for which frequency and single point calculations were performed. The obtained energies were compared to freely optimized $[\mathrm{Ru}(\mathrm{OAc})(p \text {-cymene })]^{+}$and substrates.

Table 32: Distortion and interaction energies in $\mathrm{kcal} \mathrm{mol}^{-1}$ relative to corresponding complex

7.A.

\begin{tabular}{ccccc}
\hline $\mathrm{X}$ & $\mathrm{E}_{\text {dist }}($ metal $)$ & $\mathrm{E}_{\text {dist }}($ substrate $)$ & $\mathrm{E}_{\text {interaction }}$ & $\Delta \mathrm{E}^{\ddagger}$ \\
\hline $\mathrm{O}$ & 22.4 & 5.8 & -15.2 & 13.0 \\
$\mathrm{~S}$ & 22.8 & 6.3 & -18.3 & 10.9 \\
$\mathrm{Se}$ & 22.9 & 6.2 & -16.5 & 12.6 \\
\hline
\end{tabular}

\subsubsection{Electronic Energies and Correction Values}

Table 33: Electronic energies and correction values in Hartree.

\begin{tabular}{ccccc}
\hline Structure & $\mathrm{E}(\mathrm{PhMe})$ & $\Delta \Delta \mathrm{H}(298)$ & $\mathrm{S}(298)$ & Dispersion \\
\hline O-7.A & -2637.134608 & 0.582353 & 0.090453 & -0.058787 \\
O-TS7.1 & -2637.111758 & 0.581552 & 0.091871 & -0.060434 \\
O-7.B & -2637.112667 & 0.583518 & 0.095505 & -0.060895 \\
O-TS7.2 & -2637.099559 & 0.576325 & 0.088907 & -0.061275 \\
O-7.C & -2637.119678 & 0.582806 & 0.091680 & -0.061319 \\
S-7.A & -2960.323367 & 0.581919 & 0.092748 & -0.063026 \\
S-TS7.1 & -2960.302065 & 0.580467 & 0.095281 & -0.064517 \\
S-7.B & -2960.305691 & 0.579813 & 0.094134 & -0.065181 \\
S-TS7.2 & -2960.293760 & 0.575171 & 0.091999 & -0.065362 \\
\hline
\end{tabular}




\begin{tabular}{ccccc}
\hline S-7.C & -2960.313171 & 0.580870 & 0.092939 & -0.064815 \\
Se-7.A & -4964.433931 & 0.580703 & 0.094660 & -0.064328 \\
Se-TS7.1 & -4964.411729 & 0.580310 & 0.096397 & -0.065996 \\
Se-7.B & -4964.412920 & 0.578872 & 0.094963 & -0.066830 \\
Se-TS7.2 & -4964.403734 & 0.575903 & 0.094899 & -0.066866 \\
Se-7.C & -4964.422284 & 0.580154 & 0.093911 & -0.066243 \\
O-156a & -1923.247239 & 0.303270 & 0.059776 & -0.025596 \\
S-156a & -2246.421598 & 0.301153 & 0.061083 & -0.028595 \\
Se-156a & -4250.530244 & 0.299663 & 0.059680 & -0.029530 \\
\hline
\end{tabular}

Table 34: Electronic energies and correction values in Hartree for distortion-interaction analysis.

\begin{tabular}{ccccc}
\hline Structure & $\mathrm{E}(\mathrm{PhMe})$ & $\Delta \Delta \mathrm{H}(298)$ & $\mathrm{S}(298)$ & Dispersion \\
\hline Complex & -713.832500 & 0.277321 & 0.058485 & -0.020992 \\
Ketone metal & -713.795859 & 0.276007 & 0.058198 & -0.021445 \\
Ketone substrate & -1923.236776 & 0.302633 & 0.060397 & -0.025540 \\
Thioketone metal & -713.794586 & 0.275915 & 0.058676 & -0.021296 \\
Thioketone substrate & -2246.412928 & 0.300075 & 0.058581 & -0.028326 \\
Selenoketone metal & -713.794200 & 0.275895 & 0.058884 & -0.021265 \\
Selenoketone substrate & -4250.521553 & 0.299959 & 0.058788 & -0.029200 \\
\hline
\end{tabular}

\subsection{Ruthenium-Catalyzed C-H Alkylation on Peptides}

\subsubsection{Computational Methods}

All calculations were performed with the Gaussian 16, Revision A.03 package. ${ }^{[185]}$ Geometry optimizations were performed at the PBEO level of theory ${ }^{[134]}$ including D3 dispersion correction $^{[126]}$ with Becke-Johnson damping scheme or at the $\mathrm{M06}^{[157]}$ level of theory including D3 correction. Ruthenium was described with a def2-SVP basis set ${ }^{[127]}$ in combination with SDD pseudopotential, ${ }^{[189]}$ while all other atoms were described with a def2-SVP basis set. Analytical frequency calculations were performed at the same level of theory to characterize all stationary points as either intermediates (no imaginary frequencies) or transition states (exactly one imaginary frequency). The connection of transition states to intermediates was confirmed by IRC 
calculations. The electronic energy was refined through single point calculations at the PBEO or PW6B95 ${ }^{[145]}$ level of theory including D3(BJ) dispersion correction. Ruthenium was described with a def2-QZVP basis set ${ }^{[127]}$ in combination with SDD pseudopotential, hydrogen was described with def2-QZVP(-f) basis set and all other atoms were described with def2-QZVP(-g) basis set. This basis set is denoted as def2-QZVP*. In the single point calculations solvent effects were taken into consideration through the use of the SMD continuum solvation model ${ }^{[135]}$ with acetic acid $(\varepsilon=$ 6.2528) as implemented in Gaussian. Unless stated otherwise, all energies are Gibbs free energies in $\mathrm{kcal} \mathrm{mol}^{-1}$, which were calculated by addition of the gas-phase Gibbs free energy contribution at $353 \mathrm{~K}$ and $1 \mathrm{~atm}$ (denoted as $\Delta \Delta \mathrm{G}(353)$ ) to the single point energies (denoted as $\mathrm{E}$ ).

Superscripts correspond to the arene-ligand. If no superscript is given, $p$-cymene is implied as the arene-ligand.

Wiberg bond order analysis was performed at the PW6B95-D3(BJ)/def2-TZVP//M06-D3/def2-SVP level of theory employing NBO 6 software. ${ }^{[192]}$

\subsubsection{Wiberg Bond Order Analysis}

Table 35: Wiberg bond order analysis for $\mathrm{C}-\mathrm{H}$ ruthenation with unsubstituted, methylsubstituted and trifluoromethyl-substituted pyridyl indole 125a.

\begin{tabular}{ccc}
\hline Structure & $\mathrm{C}-\mathrm{H}$ bond order & Ru-C bond order \\
\hline 8.A & 0.9047 & 0.0041 \\
TS8.1 & 0.8728 & 0.1273 \\
8.B & 0.8653 & 0.2494 \\
TS8.2 & 0.5086 & 0.4231 \\
8.C & 0.0344 & 0.6986 \\
8.B $(\mathrm{Me})$ & 0.8640 & 0.2567 \\
TS8.2 $(\mathrm{Me})$ & 0.5061 & 0.4295 \\
8.C $(\mathrm{Me})$ & 0.0335 & 0.6996 \\
8.B $\left(\mathrm{CF}_{3}\right)$ & 0.8689 & 0.2310 \\
TS8.2 $\left(\mathrm{CF}_{3}\right)$ & 0.5137 & 0.4079 \\
8.C $\left(\mathrm{CF}_{3}\right)$ & 0.0330 & 0.6970 \\
\hline
\end{tabular}




\subsubsection{Electronic Energies and Correction Values}

Table 36: Electronic energies and correction values in Hartree at the PBEO-D3(BJ)/def2QZVP*+SMD(HOAC)//PBE0-D3(BJ)/def2-SVP level of theory.

\begin{tabular}{|c|c|c|}
\hline Structure & $\mathrm{E}(\mathrm{HOAC})$ & $\Delta \Delta \mathrm{G}(353)$ \\
\hline 8.A & -1322.919154 & 0.396571 \\
\hline TS8.1 & -1322.898926 & 0.393381 \\
\hline 8.B & -1322.902812 & 0.394631 \\
\hline 8.C & -1322.921971 & 0.395220 \\
\hline 8.D & -1400.244897 & 0.428333 \\
\hline TS8.3 & -1400.225382 & 0.429702 \\
\hline 8.E & -1400.248995 & 0.432568 \\
\hline $8 . F$ & -1629.209186 & 0.487612 \\
\hline TS8.4 & -1629.183552 & 0.483402 \\
\hline 8.G & -1629.201819 & 0.485205 \\
\hline 8.H & -1629.232680 & 0.484414 \\
\hline 8. $A^{\text {benzene }}$ & -1165.763414 & 0.293233 \\
\hline TS8.1 $1^{\text {benzene }}$ & -1165.743738 & 0.291709 \\
\hline 8. $\mathrm{B}^{\text {benzene }}$ & -1165.748628 & 0.291483 \\
\hline 8. $C^{\text {benzene }}$ & -1165.767420 & 0.291483 \\
\hline 8. $D^{\text {benzene }}$ & -1243.089690 & 0.325409 \\
\hline TS8.3 $3^{\text {benzene }}$ & -1243.071195 & 0.327083 \\
\hline 8. $E^{\text {benzene }}$ & -1243.095101 & 0.329739 \\
\hline 8. $F^{\text {benzene }}$ & -1472.052792 & 0.384520 \\
\hline TS8.4 & -1472.030998 & 0.379853 \\
\hline 8.G $G^{\text {benzene }}$ & -1472.048548 & 0.382223 \\
\hline 8. $\mathrm{H}^{\text {benzene }}$ & -1472.077144 & 0.381587 \\
\hline 8. $A^{t-\text { Bubenzene }}$ & -1322.908834 & 0.398323 \\
\hline TS8.1 ${ }^{t \text {-Bubenzene }}$ & -1322.888185 & 0.397227 \\
\hline 8. $\mathrm{B}^{t-\text { Bubenzene }}$ & -1322.893220 & 0.395954 \\
\hline 8. $C^{t-\text { Bubenzene }}$ & -1322.912188 & 0.397145 \\
\hline
\end{tabular}




\begin{tabular}{|c|c|c|}
\hline 8. $D^{t-\text { Bubenzene }}$ & -1400.235611 & 0.430170 \\
\hline TS8.3 $3^{t-\text { Bubenzene }}$ & -1400.216070 & 0.428204 \\
\hline 8. $E^{t-B u b e n z e n e ~}$ & -1400.238856 & 0.434368 \\
\hline 8. $\mathrm{F}^{t \text {-Bubenzene }}$ & -1629.196825 & 0.489014 \\
\hline TS8.4 ${ }^{t-\text { Bubenzene }}$ & -1629.175555 & 0.484630 \\
\hline 8. $\mathbf{G}^{t \text {-Bubenzene }}$ & -1629.194335 & 0.486437 \\
\hline 8. $\mathrm{H}^{t \text {-Bubenzene }}$ & -1629.222437 & 0.486591 \\
\hline HOAC & -228.952262 & 0.029151 \\
\hline Acetate & -228.467675 & 0.014592 \\
\hline Acrylate $27 a$ & -306.263685 & 0.058388 \\
\hline$p$-Cymene & -389.215198 & 0.166011 \\
\hline Benzene & -232.072172 & 0.067643 \\
\hline$t$-Bubenzene & -389.210794 & 0.170727 \\
\hline Indole 125a & -610.478575 & 0.154933 \\
\hline$\left[\mathrm{Ru}(\mathrm{OAc})_{2}(p\right.$-cymene $\left.)\right](\mathbf{7 9})$ & -940.928367 & 0.254300 \\
\hline
\end{tabular}

Table 37: Electronic energies and correction values in Hartree at the PW6B95-D3(BJ)/def2QZVP*+SMD(HOAC)//M06-D3/def2-SVP level of theory.

\begin{tabular}{ccc}
\hline Structure & $E(\mathrm{HOAc})$ & $\Delta \Delta \mathrm{G}(353)$ \\
\hline 8.A & -1325.968745 & 0.389382 \\
TS8.1 & -1325.948371 & 0.389554 \\
8.B & -1325.951899 & 0.388463 \\
TS8.2 & -1325.941160 & 0.385173 \\
8.C & -1325.963398 & 0.385144 \\
8.D & -1403.482404 & 0.423396 \\
TS8.3 & -1403.462204 & 0.423437 \\
8.E & -1403.486541 & 0.426426 \\
8.F & -1632.962863 & 0.480600 \\
TS8.4 & -1632.936304 & 0.475273 \\
8.G & -1632.965014 & 0.479009 \\
\hline
\end{tabular}




\begin{tabular}{ccc}
\hline $\mathbf{8 . H}$ & -1632.988615 & 0.478226 \\
HOAc & -229.469374 & 0.028749 \\
Acrylate 27a & -306.978933 & 0.057218 \\
\hline
\end{tabular}

\subsection{Ruthenium-Catalyzed Oxidative $\mathrm{C}-\mathrm{H} / \mathrm{C}-\mathrm{H}$ Activation}

\subsubsection{Computational Methods}

All calculations were performed with the Orca version 4.0.1 package. ${ }^{[187]}$ Geometry optimizations were performed at the TPSS ${ }^{[125]}$ level of theory including D3 dispersion correction ${ }^{[126]}$ with BeckeJohnson damping scheme. Ruthenium was described with a def2-TZVP basis set ${ }^{[127]}$ in combination with Stuttgart-Dresden (SDD) pseudopotential, ${ }^{[189]}$ while all other atoms were described with a def2-TZVP basis set. Numerical frequency calculations were performed at the same level of theory to characterize all stationary points as either intermediates (no imaginary frequencies) or transition states (exactly one imaginary frequency). The electronic energy was refined through single point calculations at the PBEO ${ }^{[134]}$ level of theory including D3(BJ). Ruthenium was described with a def2-TZVP basis set ${ }^{[127]}$ in combination with SDD pseudopotential and all other atoms were described with def2-TZVP basis set. In the single point calculations solvent effects were taken into consideration through the use of the SMD solvation model[135] for MeCN as implemented in Orca. RIJCOSX approximation was used in all calculations together with def2-TZVP/J auxiliary basis set. ${ }^{[190]}$ In all calculations the GRID4, TightSCF, SlowConv keywords and in the geometry optimizations additionally TightOPT keyword was used. Unless stated otherwise, all energies are Gibbs free energies in $\mathrm{kcal} \mathrm{mol}^{-1}$, which were calculated by addition of the gas-phase thermal and non-thermal correction at $298 \mathrm{~K}$ and $1 \mathrm{~atm}$ (denoted as $\Delta \Delta \mathrm{H}(298)$ ) and entropy contribution at $298 \mathrm{~K}$ and $1 \mathrm{~atm}$ (denoted as $\mathrm{S}(298)$ ) to the single point energies (denoted as $\mathrm{E}$ ).

Bond order analysis was performed with NBO 5.9 software using Wiberg bond orders in the NAO basis employing electron densities generated with Orca at the PBEO-D3(BJ)/def2-TZVP level of theory. ${ }^{[193]}$

Superscripts correspond to the spin state of the structure ( $1=$ singlet; $3=$ triplet; 5 = quintet). If no superscript is given, a singlet spin state is implied. 
<smiles>CN(C)[P+](c1ccccc1-c1ccccn1)(N(C)C)N1CC=CC=C1c1ccccc1-c1ccccn1</smiles>

9. $\mathrm{E}^{*}{ }_{1}$

$0.0 \mathrm{kcal} / \mathrm{mol}$

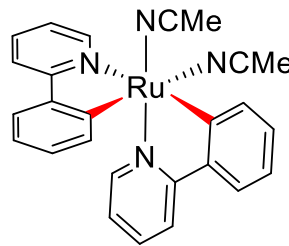

$9 . \mathrm{E}^{*}{ }_{2}$ $1.3 \mathrm{kcal} / \mathrm{mol}$

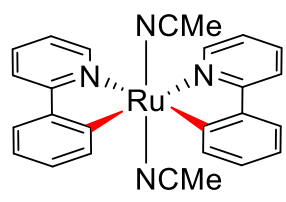

9. $\mathrm{E}^{*}{ }_{3}$

$17.3 \mathrm{kcal} / \mathrm{mol}$

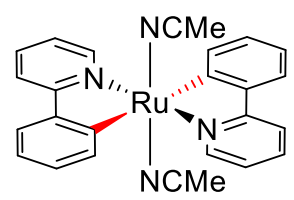

9. $\mathrm{E}^{*}{ }_{4}$

$11.1 \mathrm{kcal} / \mathrm{mol}$

Scheme 100: Comparison of biscyclometalated complexes 9.E*.

\subsubsection{Comparison of Spin States}

Table 38: Gibbs free energies in $\mathrm{kcal} \mathrm{mol}^{-1}$ for different spin states relative to $9 . \mathbf{A}^{\mathbf{1}}$.

\begin{tabular}{|c|c|c|c|}
\hline Structure & $\Delta \mathrm{G}_{298}$ (singlet) & $\Delta \mathrm{G}_{298}$ (triplet) & $\Delta G_{298}$ (quintet) \\
\hline 9.A & 0.0 & 8.1 & 37.5 \\
\hline 9. $\mathbf{A}_{\text {cis }}$ & 0.5 & -- & -- \\
\hline 9.E" & -7.6 & 31.2 & 44.8 \\
\hline 9. $\mathrm{F}^{\prime}$ & -2.0 & 31.7 & $--[a]$ \\
\hline 9.G & 4.1 & 30.0 & 64.6 \\
\hline 9.H & -16.4 & 3.6 & 44.7 \\
\hline 9.1 & -25.9 & -5.3 & 27.9 \\
\hline 9.1' & -34.0 & -15.4 & 21.1 \\
\hline 9.J & -34.5 & -19.6 & 17.2 \\
\hline 9.J' & -39.3 & -18.2 & 12.1 \\
\hline $9 . \mathrm{K}$ & 36.3 & $--^{[a]}$ & 54.3 \\
\hline
\end{tabular}

[a] No convergence was achieved employing this spin state.

\subsubsection{Influence of Dispersion}

Table 39: Comparison of relative Gibbs free energies in $\mathrm{kcal} \mathrm{mol}^{-1}$ with and without dispersion correction. All energies are relative to intermediate 9.A.

\begin{tabular}{ccc}
\hline Structure & $\Delta \mathrm{G}_{298} \mathrm{~W} / \mathrm{D} 3(\mathrm{BJ})$ & $\Delta \mathrm{G}_{298} \mathrm{~W} / \mathrm{o} \mathrm{D3(BJ)}$ \\
\hline 9.A & 0.0 & 0.0 \\
TS9.1 & 10.4 & 10.4 \\
\hline
\end{tabular}




\begin{tabular}{|c|c|c|}
\hline 9.B & 4.3 & 4.1 \\
\hline TS9.2 & 10.1 & 10.4 \\
\hline 9.C & 6.5 & 7.3 \\
\hline 9. $C^{\prime}$ & -4.5 & -5.1 \\
\hline TS9.3 & 16.9 & 18.9 \\
\hline TS9.3' & 4.3 & 4.8 \\
\hline 9.D & 3.5 & 4.8 \\
\hline 9. $D^{\prime}$ & -4.6 & -5.0 \\
\hline TS9.4 & 4.7 & 5.9 \\
\hline TS9.4' & -1.0 & -1.4 \\
\hline 9.E & -0.6 & 0.1 \\
\hline 9. $E^{\prime}$ & -4.8 & -5.8 \\
\hline 9.F & 1.6 & 9.3 \\
\hline 9. $F^{\prime}$ & -2.0 & 3.8 \\
\hline 9.G & 4.1 & 6.8 \\
\hline 9.G' & 1.1 & 5.3 \\
\hline TS9.5 & 19.8 & 22.3 \\
\hline TS9.5' & 16.0 & 20.7 \\
\hline 9.H & -16.4 & -14.7 \\
\hline 9. $\mathrm{H}^{\prime}$ & -16.7 & -12.9 \\
\hline TS9.6 & -5.8 & -3.4 \\
\hline TS9.6' & -11.4 & -7.2 \\
\hline 9.1 & -25.9 & -21.9 \\
\hline 9.1' & -34.0 & -28.3 \\
\hline TS9.7 & -9.7 & -7.8 \\
\hline TS9.7' & -5.7 & -1.4 \\
\hline 9.J & -34.5 & -30.1 \\
\hline 9.J' & -39.3 & -33.8 \\
\hline TS9.8 & 41.2 & 40.1 \\
\hline 9.K & 36.3 & 38.7 \\
\hline
\end{tabular}




\subsubsection{Wiberg Bond Order Analysis}

Table 40: Wiberg bond order analysis for $\mathrm{C}-\mathrm{H}$ ruthenation steps.

\begin{tabular}{cccc}
\hline Structure & C-H bond order & Ru-C bond order & O-H bond order \\
\hline 9.A & $0.9100,0.9051^{[\mathrm{a}]}$ & $0.0028,0.0049^{[\mathrm{a}]}$ & $0.0019,0.0028^{[\mathrm{a}]}$ \\
TS9.1 & 0.8590 & 0.0673 & 0.0107 \\
9.B & 0.6150 & 0.3947 & 0.0456 \\
TS9.2 & 0.2861 & 0.6310 & 0.3406 \\
9.C & $0.8875,0.0451^{[\mathrm{aj}]}$ & $0.0040,0.8544^{[\mathrm{a}]}$ & $0.0112,0.6250^{[\mathrm{a}]}$ \\
TS9.3 & 0.8452 & 0.0523 & 0.0201 \\
9.D & 0.5708 & 0.3958 & 0.0668 \\
TS9.4 & 0.3347 & 0.5524 & 0.2610 \\
9.E & 0.0522 & 0.7449 & 0.6196 \\
\hline
\end{tabular}

[a] Values correspond to the bond order for both coordinated phenylpyridines.

\subsubsection{Electronic Energies and Correction Values}

Table 41: Electronic energies and correction values in Hartree.

\begin{tabular}{ccccc}
\hline Structure & $\mathrm{E}(\mathrm{MeCN})$ & $\Delta \Delta \mathrm{H}(298)$ & $\mathrm{S}(298)$ & Dispersion \\
\hline 9.A & -1588.218616 & 0.527699 & 0.096206 & -0.094209 \\
9.A & -1588.201636 & 0.527505 & 0.100046 & -0.097622 \\
9.A & -1588.151503 & 0.525865 & 0.101783 & -0.098207 \\
9.A cis & -1588.219358 & 0.528226 & 0.095170 & -0.094210 \\
TS9.1 & -1588.203283 & 0.526794 & 0.094118 & -0.094280 \\
9.B & -1588.211608 & 0.526594 & 0.095186 & -0.093732 \\
TS9.2 & -1588.199588 & 0.522062 & 0.093560 & -0.094813 \\
9.C & -1588.209294 & 0.527143 & 0.094660 & -0.095464 \\
9.C' & -1491.935965 & 0.511054 & 0.093305 & -0.092134 \\
TS9.3 & -1588.192601 & 0.525589 & 0.093242 & -0.097417 \\
TS9.3' & -1491.921833 & 0.509757 & 0.092110 & -0.093820 \\
9.D & -1588.213037 & 0.525381 & 0.093895 & -0.096201 \\
\hline
\end{tabular}




\begin{tabular}{|c|c|c|c|c|}
\hline 9. $D^{\prime}$ & -1491.934866 & 0.509518 & 0.093098 & -0.092478 \\
\hline TS9.4 & -1588.207307 & 0.521071 & 0.093401 & -0.096106 \\
\hline TS9.4' & -1491.925437 & 0.504574 & 0.091728 & -0.092434 \\
\hline 9.E & -1588.220165 & 0.526647 & 0.094548 & -0.095246 \\
\hline 9. $E^{\prime}$ & -1491.935224 & 0.509729 & 0.093289 & -0.091521 \\
\hline 9.E”' & -1395.648796 & 0.493807 & 0.092126 & -0.087128 \\
\hline $9 . E^{\prime \prime 3}$ & -1395.581008 & 0.490759 & 0.094995 & -0.087175 \\
\hline $9 . E^{\prime \prime} 5$ & -1395.557514 & 0.490508 & 0.096556 & -0.090463 \\
\hline 9. $E_{1}{ }_{1}$ & -1317.092070 & 0.435078 & 0.086548 & -0.078643 \\
\hline $9 . \mathrm{E}_{2}$ & -1317.090279 & 0.435151 & 0.086357 & -0.078385 \\
\hline $9 . \mathrm{E}_{3}{ }_{3}$ & -1317.065071 & 0.435561 & 0.086517 & -0.077586 \\
\hline $9 . \mathrm{E}_{4}{ }_{4}$ & -1317.074268 & 0.435474 & 0.086995 & -0.077288 \\
\hline 9.F & -4164.599618 & 0.556395 & 0.098787 & -0.114715 \\
\hline 9. $\mathrm{F}^{\prime}$ & -4068.314736 & 0.540339 & 0.097257 & -0.110544 \\
\hline $9 . F^{3}$ & -4068.256026 & 0.538010 & 0.099903 & -0.109692 \\
\hline 9.G & -3935.630368 & 0.489209 & 0.086979 & -0.103336 \\
\hline $9 . G^{3}$ & -3935.585951 & 0.487860 & 0.088700 & -0.103694 \\
\hline $9 . G^{5}$ & -3935.527206 & 0.486438 & 0.090995 & -0.100703 \\
\hline 9.G' & -4027.804899 & 0.489517 & 0.090405 & -0.108676 \\
\hline TS9.5 & -3935.605218 & 0.487705 & 0.085529 & -0.102956 \\
\hline TS9.5' & -4027.781124 & 0.487992 & 0.088843 & -0.109373 \\
\hline 9.H & -3935.664269 & 0.489902 & 0.086357 & -0.101731 \\
\hline $9 . \mathrm{H}^{3}$ & -3935.628620 & 0.488962 & 0.089321 & -0.099376 \\
\hline $9 . \mathrm{H}^{5}$ & -3935.559560 & 0.488377 & 0.092190 & -0.099357 \\
\hline $9 . \mathrm{H}^{\prime}$ & -4027.835916 & 0.490865 & 0.089050 & -0.107972 \\
\hline TS9.6 & -3935.648268 & 0.488348 & 0.084015 & -0.102905 \\
\hline TS9.6' & -4027.827156 & 0.488803 & 0.087361 & -0.108668 \\
\hline 9.1 & -3935.679119 & 0.489664 & 0.086405 & -0.105373 \\
\hline $9.1^{3}$ & -3935.643063 & 0.488695 & 0.088732 & -0.103780 \\
\hline $9.1^{5}$ & -3935.587087 & 0.487428 & 0.090501 & -0.108368 \\
\hline
\end{tabular}




\begin{tabular}{|c|c|c|c|c|}
\hline $9.1^{\prime}$ & -4027.862125 & 0.490172 & 0.089799 & -0.111075 \\
\hline $9.1^{3}$ & -4027.828189 & 0.489574 & 0.093401 & -0.109524 \\
\hline $9.1^{5}$ & -4027.763665 & 0.487824 & 0.093210 & -0.108420 \\
\hline TS9.7 & -3935.654172 & 0.488528 & 0.084525 & -0.102144 \\
\hline TS9.7' & -4027.818709 & 0.489648 & 0.087584 & -0.108772 \\
\hline 9.J & -3935.693517 & 0.490154 & 0.086198 & -0.105959 \\
\hline $9 . J^{3}$ & -3935.668053 & 0.490584 & 0.088397 & -0.107345 \\
\hline $9 . J^{5}$ & -3935.604375 & 0.488114 & 0.090947 & -0.107512 \\
\hline 9.J' & -4027.870238 & 0.490265 & 0.090134 & -0.110614 \\
\hline $9 . J^{3}$ & -4027.832820 & 0.489744 & 0.093401 & -0.106839 \\
\hline $9 . J^{5}$ & -4027.782206 & 0.488448 & 0.094485 & -0.112568 \\
\hline TS9.8 & -1395.569659 & 0.490915 & 0.090596 & -0.090170 \\
\hline $9 . \mathrm{K}$ & -1395.579997 & 0.493294 & 0.090469 & -0.095850 \\
\hline $9 . K^{5}$ & -1395.544096 & 0.488615 & 0.093003 & -0.095754 \\
\hline $\mathrm{MeCN}$ & -132.654365 & 0.048221 & 0.028637 & -0.002319 \\
\hline HOAC & -228.943471 & 0.065121 & 0.032509 & -0.003437 \\
\hline $\mathrm{PhBr}(46 \mathrm{e})$ & -2805.325865 & 0.094683 & 0.037115 & -0.011683 \\
\hline $2-\mathrm{CN}-\mathrm{C}_{6} \mathrm{H}_{4} \mathrm{Br}(46 \mathrm{k})$ & -2897.493981 & 0.094894 & 0.042087 & -0.014632 \\
\hline
\end{tabular}

\subsection{Manganese-Catalyzed C-H Allylation on Peptides}

\subsubsection{Computational Methods}

All calculations were performed with the Orca version 3.0.3 package. ${ }^{[186]}$ Geometry optimizations were performed at the TPSS ${ }^{[125]}$ level of theory including D3 dispersion correction ${ }^{[126]}$ with BeckeJohnson damping scheme. Manganese was described with a def2-TZVP basis set $^{[127]}$ in combination with Stuttgart-Dresden (SDD) pseudopotential, ${ }^{[189]}$ while all other atoms were described with a def2-TZVP basis set. Numerical frequency calculations were performed at the same level of theory to characterize all stationary points as either intermediates (no imaginary frequencies) or transition states (exactly one imaginary frequency). The electronic energy was refined through single point calculations at the PW6B95 ${ }^{[145]}$ level of theory including D3(BJ). All atoms were described with a def2-QZVP basis set. ${ }^{[127]}$ In the single point calculations solvent effects were taken into consideration through the use of the COSMO continuum solvation 
mode ${ }^{[142]}$ with a dielectric constant of $\varepsilon=2.2099$, which corresponds to 1,4-dioxane. RIJCOSX approximation was used in all calculations together with def2-TZVP/J or def2-QZVP/J auxiliary basis set. ${ }^{[190]}$ In all calculations the GRID4, TightSCF, SlowConv keywords and in the geometry optimizations additionally TightOPT keyword was used. Unless stated otherwise, all energies are Gibbs free energies in $\mathrm{kcal} \mathrm{mol}^{-1}$, which were calculated by addition of the gas-phase thermal and non-thermal correction at $298 \mathrm{~K}$ and $1 \mathrm{~atm}$ (denoted as $\Delta \Delta \mathrm{H}(298)$ ) and entropy contribution at $298 \mathrm{~K}$ and $1 \mathrm{~atm}$ (denoted as $\mathrm{S}(298)$ ) to the single point energies (denoted as $\mathrm{E}$ ).

\subsubsection{Electronic Energies and Correction Values}

Table 42: Electronic energies and correction values in Hartree.

\begin{tabular}{ccccc}
\hline Structure & $\mathrm{E}(1,4$-dioxane $)$ & $\Delta \Delta \mathrm{H}(298)$ & $\mathrm{S}(298)$ & Dispersion \\
\hline 10.A & -2871.829322 & 0.498143 & 0.095489 & -0.055376 \\
TS10.1 & -2871.815161 & 0.497346 & 0.094357 & -0.054894 \\
10.B & -2871.842524 & 0.499360 & 0.097465 & -0.056811 \\
10.C & -2871.847688 & 0.501311 & 0.098134 & -0.060350 \\
TS10.2 & -2871.826529 & 0.497088 & 0.096429 & -0.061325 \\
10.D & -2871.853554 & 0.499092 & 0.098166 & -0.060475 \\
10.E & -2678.361683 & 0.407793 & 0.090899 & -0.052414 \\
HOAC & -229.470747 & 0.065125 & 0.032254 & -0.001769 \\
HOCO $t-B u$ & -422.967631 & 0.157755 & 0.043218 & -0.007221 \\
\hline
\end{tabular}

\subsection{Manganese-Catalyzed C-C Allylation}

\subsubsection{Computational Methods}

All calculations were performed with the Gaussian 09, Revision D.01 package. ${ }^{[184]}$ Geometry optimizations were performed at the $\mathrm{PBEO}^{[134]}$ level of theory including $\mathrm{D} 3$ dispersion correction $^{[126]}$ with Becke-Johnson damping scheme. Manganese was described with a def2-SVP basis set ${ }^{[127]}$ in combination with SDD pseudopotential, ${ }^{[189]}$ while all other atoms were described with a def2-SVP basis set. Analytical frequency calculations were performed at the same level of theory to characterize all stationary points as either intermediates (no imaginary frequencies) or transition states (exactly one imaginary frequency). The connection of transition states to 
intermediates was confirmed by IRC calculations. The electronic energy was refined through single point calculations at the PBEO level of theory including D3(BJ) dispersion correction. Manganese was described with a def2-QZVP basis set, ${ }^{[127]}$ while hydrogen was described with def2-QZVP(-f) basis set and a def2-QZVP(-g) basis set was used for all other atoms. In all calculations solvent effects were taken into consideration through the use of the SMD continuum solvation model ${ }^{[135]}$ with water $(\varepsilon=78.3553)$ as implemented in Gaussian. Unless stated otherwise, all energies are Gibbs free energies in $\mathrm{kcal} \mathrm{mol}^{-1}$, which were calculated by addition of the gas-phase Gibbs free energy contribution at $393 \mathrm{~K}$ and $1 \mathrm{~atm}$ (denoted as $\Delta \Delta \mathrm{G}(393)$ ) to the single point energies (denoted as E). Previously reported structures were employed as initial geometries for the optimization of $\left(\mathrm{H}_{2} \mathrm{O}\right)_{5}{ }^{[194]}$ and $\mathrm{HBr} \cdot\left(\mathrm{H}_{2} \mathrm{O}\right)_{5}$ cluster. ${ }^{[165]}$

Superscripts correspond to the spin state of the structure ( $1=\operatorname{singlet;} 3=$ triplet; 5 = quintet). If no superscript is given, a singlet spin state is implied.

\subsubsection{Comparison of Spin States}

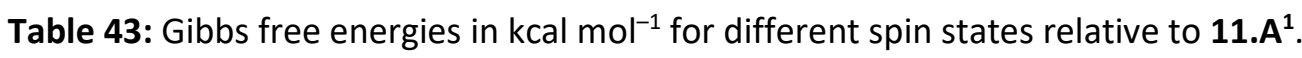

\begin{tabular}{cccc}
\hline Structure & $\Delta \mathrm{G}_{393}$ (singlet) & $\Delta \mathrm{G}_{393}$ (triplet) & $\Delta \mathrm{G}_{393}$ (quintet) \\
\hline 11.A & 0.0 & 26.3 & - [a] $^{\text {[a }}$ \\
11.B & 5.9 & 17.8 & 17.0 \\
TS11.1 & 25.5 & 48.9 & $--^{[\mathrm{a}]}$ \\
11.C & -1.0 & 17.5 & 30.3 \\
11.D & -1.7 & 15.8 & 29.3 \\
TS11.2 & 12.3 & 45.0 & 54.2 \\
11.E & -4.5 & 3.8 & 11.8 \\
11.F & 10.5 & 6.0 & 11.7 \\
TS11.3 & 15.3 & 19.7 & 13.8 \\
11.G & -15.5 & -6.8 & -16.3 \\
11.H & -12.6 & -4.6 & -15.6 \\
11.I & -10.1 & 2.1 & -8.7 \\
\hline
\end{tabular}

[a] Structure could not be located with a quintet spin state. 
6.9.3 Electronic Energies and Correction Values

Table 44: Electronic energies and correction values in Hartree.

\begin{tabular}{|c|c|c|}
\hline Structure & $\mathrm{E}$ (Water) & $\Delta \Delta \mathrm{G}(393)$ \\
\hline 11.A & -2253.284060 & 0.190844 \\
\hline $11 . A^{3}$ & -2253.230136 & 0.179862 \\
\hline 11. B & -2140.020217 & 0.185627 \\
\hline $11 . \mathrm{B}^{3}$ & -2139.994038 & 0.179538 \\
\hline $11 . \mathrm{B}^{5}$ & -2139.984952 & 0.169204 \\
\hline TS11.1 & -2139.991768 & 0.188401 \\
\hline TS11. $1^{3}$ & -2139.939079 & 0.174160 \\
\hline 11.C & -2140.023726 & 0.178087 \\
\hline $11 . C^{3}$ & -2139.984015 & 0.168997 \\
\hline $11 . C^{5}$ & -2139.954001 & 0.159374 \\
\hline 11.D & -2366.546883 & 0.203054 \\
\hline 11. $D^{3}$ & -2366.500882 & 0.186023 \\
\hline $11 . D^{5}$ & -2366.474591 & 0.181227 \\
\hline TS11.2 & -2366.526776 & 0.205190 \\
\hline $\mathrm{TS} 11.2^{3}$ & -2366.459891 & 0.191472 \\
\hline TS11. $2^{5}$ & -2366.437271 & 0.183628 \\
\hline 11.E & -2366.551899 & 0.203560 \\
\hline $11 . \mathrm{E}^{3}$ & -2366.534132 & 0.200132 \\
\hline $11 . \mathrm{E}^{5}$ & -2366.509585 & 0.188305 \\
\hline 11.F & -2366.530278 & 0.205763 \\
\hline $11 . \mathrm{F}^{3}$ & -2366.529009 & 0.198401 \\
\hline $11 . \mathrm{F}^{5}$ & -2366.507104 & 0.185717 \\
\hline TS11.3 & -2366.520966 & 0.204125 \\
\hline $\mathrm{TS} 11.3^{3}$ & -2366.505098 & 0.196393 \\
\hline TS11. $3^{5}$ & -2366.502393 & 0.184227 \\
\hline $11 . G$ & -2366.570800 & 0.204968 \\
\hline $11 . G^{3}$ & -2366.547295 & 0.196372 \\
\hline
\end{tabular}




\begin{tabular}{ccc}
\hline $11 . G^{5}$ & -2366.553561 & 0.187533 \\
$\mathbf{1 1 . H}$ & -2366.562047 & 0.200881 \\
$\mathbf{1 1 . H ^ { 3 }}$ & -2366.541586 & 0.194150 \\
$\mathbf{1 1 . \mathbf { H } ^ { 5 }}$ & -2366.549775 & 0.184862 \\
$\mathbf{1 1 . I}$ & -2178.060347 & 0.191866 \\
$\mathbf{1 1 . I ^ { 3 }}$ & -2178.031224 & 0.183199 \\
$\mathbf{1 1 . I ^ { 5 }}$ & -2178.040029 & 0.174893 \\
$\mathrm{CO}$ & -113.227997 & -0.021251 \\
$\mathrm{Acetone}$ & -193.027356 & 0.044006 \\
$\mathbf{1 4 2 a}$ & -649.964819 & 0.184960 \\
$\mathrm{Carbonate} 163 \mathrm{a}$ & -419.544482 & 0.063934 \\
$\mathrm{CO}{ }_{2}$ & -188.471938 & -0.016861 \\
{$\left[\mathrm{MnBr}(\mathrm{CO})_{5}\right]$} & -4291.132370 & -0.015749 \\
$\mathrm{HBr}$ & -2574.512774 & -0.020466 \\
$\mathrm{HBr} \cdot\left(\mathrm{H}_{2} \mathrm{O}\right)_{5}$ & -2956.568422 & 0.075871 \\
$\left(\mathrm{H}_{2} \mathrm{O}\right)_{5}$ & -382.019841 & 0.072041 \\
\hline
\end{tabular}

Table 45: Electronic energies and correction values in Hartree w/o SMD model in the optimizations.

\begin{tabular}{cccc}
\hline Structure & $E($ Water $)$ & $E(D C E)$ & $\Delta \Delta G(393)$ \\
\hline 11.A & -2253.282382 & -2253.297944 & 0.190245 \\
11.A $^{3}$ & -2253.227919 & -- & 0.178893 \\
11.A & -2253.211784 & -- & 0.166386 \\
11.B & -2140.018235 & -2140.029970 & 0.183553 \\
11.B $^{\mathbf{3}}$ & -2139.992170 & -- & 0.178089 \\
11.B $^{5}$ & -2139.981798 & -- & 0.167714 \\
TS11.1 $^{5}$ & -2139.990519 & -2140.004684 & 0.188252 \\
TS11.1 $^{3}$ & -2139.933537 & -- & 0.174293 \\
TS11.1 $^{5}$ & -2139.928479 & -- & 0.163027 \\
11.C $^{\text {11.C }}$ & -2140.022531 & -2140.040512 & 0.180853 \\
\hline
\end{tabular}




\begin{tabular}{|c|c|c|c|}
\hline $11 . c^{3}$ & -2139.977717 & -- & 0.167004 \\
\hline $11 . c^{5}$ & -2139.944362 & -- & 0.156045 \\
\hline 11.D & -2366.544867 & -2366.559636 & 0.204038 \\
\hline $11 . D^{3}$ & -2366.497844 & -- & 0.186393 \\
\hline 11. $D^{5}$ & -2366.464943 & -- & 0.174325 \\
\hline TS11.2 & -2366.524040 & -2366.538504 & 0.204755 \\
\hline TS11. $2^{3}$ & -2366.457672 & -- & 0.191281 \\
\hline TS11. $2^{5}$ & -2366.431715 & -- & 0.179364 \\
\hline 11.E & -2366.549183 & -2366.563818 & 0.203767 \\
\hline $11 . \mathrm{E}^{3}$ & -2366.530314 & -- & 0.199354 \\
\hline $11 . \mathrm{E}^{5}$ & -2366.506394 & -- & 0.188628 \\
\hline 11.F & -2366.528587 & -2366.543745 & 0.205569 \\
\hline $11 . \mathrm{F}^{3}$ & -2366.526659 & -- & 0.197121 \\
\hline $11 . \mathrm{F}^{5}$ & -2366.505115 & -- & 0.187232 \\
\hline TS11.3 & -2366.519548 & -2366.532664 & 0.204276 \\
\hline TS11.3 $3^{3}$ & -2366.500849 & -- & 0.196097 \\
\hline TS11. $3^{5}$ & -2366.486594 & -- & 0.185373 \\
\hline $11 . \mathrm{G}$ & -2366.566180 & -2366.575253 & 0.205513 \\
\hline $11 . G^{3}$ & -2366.542789 & -- & 0.194733 \\
\hline $11 . G^{5}$ & -2366.545270 & -- & 0.183950 \\
\hline 11. $\mathrm{H}$ & -2366.551149 & -2366.562264 & 0.201041 \\
\hline $11 . \mathrm{H}^{3}$ & -2366.533064 & -- & 0.189846 \\
\hline $11 . H^{5}$ & -2366.543783 & -- & 0.184266 \\
\hline TS11.4 & -2366.538969 & -2366.554971 & 0.198142 \\
\hline TS11. $4^{3}$ & -2366.512995 & -- & 0.187615 \\
\hline $\mathrm{TS} 11.4^{5}$ & -2366.519518 & -- & 0.179225 \\
\hline 11.I' & -2366.537994 & -2366.554372 & 0.194598 \\
\hline $11.1^{33}$ & -2366.513729 & -- & 0.184045 \\
\hline $11.1^{15}$ & -2366.517842 & -- & 0.175333 \\
\hline 11.1 & -2178.057804 & -2178.069431 & 0.192056 \\
\hline
\end{tabular}




\begin{tabular}{cccc}
\hline CO & -113.227991 & -113.231316 & -0.021226 \\
Acetone & -193.026822 & -193.028946 & 0.043844 \\
142a & -649.964138 & -649.971816 & 0.184774 \\
Carbonate 163a & -419.543171 & -419.545496 & 0.063906 \\
$\mathrm{CO}_{2}$ & -188.471946 & -188.475353 & -0.016608 \\
{$\left[\mathrm{MnBr}(\mathrm{CO})_{5}\right]$} & -4291.130985 & -4291.142604 & -0.014531 \\
\hline
\end{tabular}




\section{References}

[1] a) P. T. Anastas, M. M. Kirchhoff, Acc. Chem. Res. 2002, 35, 686-694; b) P. T. Anastas, J. C. Warner, Green Chemistry: Theory and Practice, Oxford University Press, New York, 1998.

[2] a) Modern Heterocyclic Chemistry (Eds.: J. Alvarez-Builla, J. J. Vaquero, J. Barluenga), Wiley-VCH, Weinheim, 2011; b) A. P. Taylor, R. P. Robinson, Y. M. Fobian, D. C. Blakemore, L. H. Jones, O. Fadeyi, Org. Biomol. Chem. 2016, 14, 6611-6637; c) N. A. McGrath, M. Brichacek, J. T. Njardarson, J. Chem. Educ. 2010, 87, 1348-1349.

[3] a) K. Tamao, K. Sumitani, M. Kumada, J. Am. Chem. Soc. 1972, 94, 4374-4376; b) R. J. P. Corriu, J. P. Masse, J. Chem. Soc., Chem. Commun. 1972, 144.

[4] a) E.-i. Negishi, A. O. King, N. Okukado, J. Org. Chem. 1977, 42, 1821-1823; b) A. O. King, N. Okukado, E.-i. Negishi, J. Chem. Soc., Chem. Commun. 1977, 683-684.

[5] a) J. K. Stille, Angew. Chem. 1986, 98, 504-519; b) D. Milstein, J. K. Stille, J. Am. Chem. Soc. 1979, 101, 4992-4998; c) D. Milstein, J. K. Stille, J. Am. Chem. Soc. 1978, 100, 3636-3638.

[6] a) N. Miyaura, A. Suzuki, Chem. Rev. 1995, 95, 2457-2483; b) N. Miyaura, K. Yamada, A. Suzuki, Tetrahedron Lett. 1979, 20, 3437-3440; c) N. Miyaura, A. Suzuki, J. Chem. Soc., Chem. Commun. 1979, 866-867.

[7] a) K.-i. Gouda, E. Hagiwara, Y. Hatanaka, T. Hiyama, J. Org. Chem. 1996, 61, 7232-7233; b) Y. Hatanaka, T. Hiyama, J. Org. Chem. 1988, 53, 918-920.

[8] a) R. F. Heck, Org. React. 1982, 27, 345-390; b) R. F. Heck, J. P. Nolley, J. Org. Chem. 1972, 37, 2320-2322; c) M. Tsutomu, M. Kunio, O. Atsumu, Bull. Chem. Soc. Jpn. 1971, 44, 581581.

[9] a) K. Sonogashira, J. Organomet. Chem. 2002, 653, 46-49; b) K. Sonogashira, Y. Tohda, N. Hagihara, Tetrahedron Lett. 1975, 16, 4467-4470.

[10] For selected reviews, see: a) C. C. C. Johansson Seechurn, M. O. Kitching, T. J. Colacot, V. Snieckus, Angew. Chem. Int. Ed. 2012, 51, 5062-5085; b) J.-P. Corbet, G. Mignani, Chem. Rev. 2006, 106, 2651-2710; c) A. O. King, N. Yasuda, Top. Organomet. Chem. 2004, 6, 205245.

[11] The Nobel Prize in Chemistry 2010, NobelPrize.org. Nobel Media AB, accessed on 25.07.2019, https://www.nobelprize.org/prizes/chemistry/2010/summary/.

[12] For selected reviews, see: a) S. M. Khake, N. Chatani, Trends Chem. 2019, 1, 524-539; b) P. Gandeepan, T. Müller, D. Zell, G. Cera, S. Warratz, L. Ackermann, Chem. Rev. 2019, 119, 2192-2452; c) C. S. Wang, P. H. Dixneuf, J. F. Soule, Chem. Rev. 2018, 118, 7532-7585; d) J. C. K. Chu, T. Rovis, Angew. Chem. Int. Ed. 2018, 57, 62-101; e) K. Murakami, S. Yamada, 
T. Kaneda, K. Itami, Chem. Rev. 2017, 117, 9302-9332; f) Y. Park, Y. Kim, S. Chang, Chem. Rev. 2017, 117, 9247-9301; g) J. He, M. Wasa, K. S. L. Chan, Q. Shao, J.-Q. Yu, Chem. Rev. 2017, 117, 8754-8786.

[13] a) R. A. Sheldon, Pure Appl. Chem. 2000, 72, 1233-1246; b) B. M. Trost, Angew. Chem. Int. Ed. 1995, 34, 259-281.

[14] A review: H. Yi, G. Zhang, H. Wang, Z. Huang, J. Wang, A. K. Singh, A. Lei, Chem. Rev. 2017, 117, 9016-9085.

[15] For selected reviews, see: a) L. Ackermann, Chem. Rev. 2011, 111, 1315-1345; b) D. Balcells, E. Clot, O. Eisenstein, Chem. Rev. 2010, 110, 749-823; c) Y. Boutadla, D. L. Davies, S. A. Macgregor, A. I. Poblador-Bahamonde, Dalton Trans. 2009, 5820-5831; d) J. A. Labinger, J. E. Bercaw, Nature 2002, 417, 507-514.

[16] For pioneering contributions in stoichiometric base-assisted $\mathrm{C}-\mathrm{H}$ metalations, see: a) J. C. Gaunt, B. L. Shaw, J. Organomet. Chem. 1975, 102, 511-516; b) J. M. Duff, B. E. Mann, B. L. Shaw, B. Turtle, J. Chem. Soc., Dalton Trans. 1974, 139-145; c) J. M. Duff, B. L. Shaw, J. Chem. Soc., Dalton Trans. 1972, 2219-2225.

[17] For an early computational study on carboxylate-assisted undirected $\mathrm{C}-\mathrm{H}$ activations, see: B. Biswas, M. Sugimoto, S. Sakaki, Organometallics 2000, 19, 3895-3908.

[18] a) L. David, F. Keith, Chem. Lett. 2010, 39, 1118-1126; b) S. I. Gorelsky, D. Lapointe, K. Fagnou, J. Am. Chem. Soc. 2008, 130, 10848-10849.

[19] Y. Boutadla, D. L. Davies, S. A. Macgregor, A. I. Poblador-Bahamonde, Dalton Trans. 2009, 5887-5893.

[20] a) D. Zell, M. Bursch, V. Müller, S. Grimme, L. Ackermann, Angew. Chem. Int. Ed. 2017, 56, 10378-10382; b) W. Ma, R. Mei, G. Tenti, L. Ackermann, Chem. Eur. J. 2014, 20, 1524815251.

[21] J. F. Hartwig, M. A. Larsen, ACS Cent. Sci. 2016, 2, 281-292.

[22] K. Shen, Y. Fu, J.-N. Li, L. Liu, Q.-X. Guo, Tetrahedron 2007, 63, 1568-1576.

[23] For selected reviews, see: a) C. Sambiagio, D. Schonbauer, R. Blieck, T. Dao-Huy, G. Pototschnig, P. Schaaf, T. Wiesinger, M. F. Zia, J. Wencel-Delord, T. Besset, B. U. W. Maes, M. Schnürch, Chem. Soc. Rev. 2018, 47, 6603-6743; b) M. Zhang, Y. Zhang, X. Jie, H. Zhao, G. Li, W. Su, Org. Chem. Front. 2014, 1, 843-895; c) L. Ackermann, Top. Organomet. Chem. 2007, 24, 35-60.

[24] A review: W. Ma, P. Gandeepan, J. Li, L. Ackermann, Org. Chem. Front. 2017, 4, 14351467. 
[25] For selected reviews, see: a) P. Gandeepan, L. Ackermann, Chem 2018, 4, 199-222; b) F. Zhang, D. R. Spring, Chem. Soc. Rev. 2014, 43, 6906-6919.

[26] On July 30,2019 , the prices of platinum, rhodium, iridium, palladium and ruthenium were $871,3515,1480,1540$ and 253 US\$ per troy oz, respectively. See: http://www.platinum.matthey.com/prices/price-charts.

[27] For selected reviews, see: a) P. Nareddy, F. Jordan, M. Szostak, ACS Catal. 2017, 7, 57215745; b) C. Bruneau, P. H. Dixneuf, Top. Organomet. Chem. 2015, 55, 137-188; c) L. Ackermann, Acc. Chem. Res. 2014, 47, 281-295; d) B. Li, P. H. Dixneuf, Chem. Soc. Rev. 2013, 42, 5744-5767; e) P. B. Arockiam, C. Bruneau, P. H. Dixneuf, Chem. Rev. 2012, 112, 5879-5918; f) N. Chatani, S. Inoue, K. Yokota, H. Tatamidani, Y. Fukumoto, Pure Appl. Chem. 2010, 82, 1443-1451; g) L. Ackermann, R. Vicente, Top. Curr. Chem. 2010, 292, 211229.

[28] J. Chatt, J. M. Davidson, J. Chem. Soc. 1965, 843-855.

[29] L. N. Lewis, J. F. Smith, J. Am. Chem. Soc. 1986, 108, 2728-2735.

[30] S. Murai, F. Kakiuchi, S. Sekine, Y. Tanaka, A. Kamatani, M. Sonoda, N. Chatani, Nature 1993, 366, 529-531.

[31] M. Lail, B. N. Arrowood, T. B. Gunnoe, J. Am. Chem. Soc. 2003, 125, 7506-7507.

[32] K. A. Pittard, J. P. Lee, T. R. Cundari, T. B. Gunnoe, J. L. Petersen, Organometallics 2004, $23,5514-5523$.

[33] L. Ackermann, P. Novák, R. Vicente, N. Hofmann, Angew. Chem. Int. Ed. 2009, 48, 60456048.

[34] L. Ackermann, N. Hofmann, R. Vicente, Org. Lett. 2011, 13, 1875-1877.

[35] M. Schinkel, L. Wang, K. Bielefeld, L. Ackermann, Org. Lett. 2014, 16, 1876-1879.

[36] H. Weissman, X. Song, D. Milstein, J. Am. Chem. Soc. 2001, 123, 337-338.

[37] T. Ueyama, S. Mochida, T. Fukutani, K. Hirano, T. Satoh, M. Miura, Org. Lett. 2011, 13, 706-708.

[38] A. Maehara, H. Tsurugi, T. Satoh, M. Miura, Org. Lett. 2008, 10, 1159-1162.

[39] L. Ackermann, J. Pospech, Org. Lett. 2011, 13, 4153-4155.

[40] A. Bechtoldt, C. Tirler, K. Raghuvanshi, S. Warratz, C. Kornhaaß, L. Ackermann, Angew. Chem. Int. Ed. 2016, 55, 264-267.

[41] A. Bechtoldt, M. E. Baumert, L. Vaccaro, L. Ackermann, Green Chem. 2018, 20, 398-402.

[42] L. Ackermann, A. V. Lygin, N. Hofmann, Angew. Chem. Int. Ed. 2011, 50, 6379-6382.

[43] L. Ackermann, J. Pospech, K. Graczyk, K. Rauch, Org. Lett. 2012, 14, 930-933.

[44] R. K. Chinnagolla, M. Jeganmohan, Chem. Commun. 2012, 48, 2030-2032. 
[45] a) L. Ackermann, L. Wang, R. Wolfram, A. V. Lygin, Org. Lett. 2012, 14, 728-731; b) J. Li, C. Kornhaaß, L. Ackermann, Chem. Commun. 2012, 48, 11343-11345.

[46] B. Li, J. Ma, Y. Liang, N. Wang, S. Xu, H. Song, B. Wang, Eur. J. Org. Chem. 2013, 1950-1962.

[47] M. C. Reddy, M. Jeganmohan, Eur. J. Org. Chem. 2013, 1150-1157.

[48] S. Oi, S. Fukita, N. Hirata, N. Watanuki, S. Miyano, Y. Inoue, Org. Lett. 2001, 3, 2579-2581.

[49] S. G. Ouellet, A. Roy, C. Molinaro, R. Angelaud, J.-F. Marcoux, P. D. O'Shea, I. W. Davies, J. Org. Chem. 2011, 76, 1436-1439.

[50] L. Ackermann, A. Althammer, R. Born, Synlett 2007, 2833-2836.

[51] L. Ackermann, R. Vicente, A. Althammer, Org. Lett. 2008, 10, 2299-2302.

[52] L. Ackermann, R. Vicente, H. K. Potukuchi, V. Pirovano, Org. Lett. 2010, 12, 5032-5035.

[53] S. Oi, H. Sato, S. Sugawara, Y. Inoue, Org. Lett. 2008, 10, 1823-1826.

[54] M. Simonetti, G. J. Perry, X. C. Cambeiro, F. Julia-Hernandez, J. N. Arokianathar, I. Larrosa, J. Am. Chem. Soc. 2016, 138, 3596-3606.

[55] M. Simonetti, D. M. Cannas, X. Just-Baringo, I. J. Vitorica-Yrezabal, I. Larrosa, Nat. Chem. 2018, 10, 724-731.

[56] For selected recent reviews, see: a) Y. Wei, P. Hu, M. Zhang, W. Su, Chem. Rev. 2017, 117, 8864-8907; b) M. Font, J. M. Quibell, G. J. P. Perry, I. Larrosa, Chem. Commun. 2017, 53, $5584-5597$.

[57] X.-Y. Shi, X.-F. Dong, J. Fan, K.-Y. Liu, J.-F. Wei, C.-J. Li, Sci. China Chem. 2015, 58, 12861291.

[58] H. Tan, H. Li, J. Wang, L. Wang, Chem. Eur. J. 2015, 21, 1904-1907.

[59] N. Y. P. Kumar, A. Bechtoldt, K. Raghuvanshi, L. Ackermann, Angew. Chem. Int. Ed. 2016, $55,6929-6932$.

[60] a) A. Biafora, B. A. Khan, J. Bahri, J. M. Hewer, L. J. Gooßen, Org. Lett. 2017, 19, 1232 1235; b) L. Huang, A. Biafora, G. Zhang, V. Bragoni, L. J. Gooßen, Angew. Chem. Int. Ed. 2016, 55, 6933-6937.

[61] J. Zhang, R. Shrestha, J. F. Hartwig, P. Zhao, Nat. Chem. 2016, 8, 1144-1151.

[62] X.-Y. Jin, L.-J. Xie, H.-P. Cheng, A.-D. Liu, X.-D. Li, D. Wang, L. Cheng, L. Liu, J. Org. Chem. $2018,83,7514-7522$.

[63] For selected reviews, see: a) M. T. Mihai, G. R. Genov, R. J. Phipps, Chem. Soc. Rev. 2018, 47, 149-171; b) J. Li, S. De Sarkar, L. Ackermann, Top. Organomet. Chem. 2016, 55, 217257; c) L. Ackermann, J. Li, Nat. Chem. 2015, 7, 686-687; d) J. Yang, Org. Biomol. Chem. 2015, 13, 1930-1941; e) J. Schranck, A. Tlili, M. Beller, Angew. Chem. Int. Ed. 2014, 53, 
9426-9428; f) F. Julia-Hernandez, M. Simonetti, I. Larrosa, Angew. Chem. Int. Ed. 2013, 52, 11458-11460.

[64] a) D. W. Robbins, J. F. Hartwig, Angew. Chem. 2013, 125, 967-971; b) J.-Y. Cho, M. K. Tse, D. Holmes, R. E. Maleczka, M. R. Smith, Science 2002, 295, 305-308.

[65] In an earlier study, Breslow, and Crabtree/Brudvig reported a molecular recognition approach for remote C-H functionalizations. See: a) S. Das, C. D. Incarvito, R. H. Crabtree, G. W. Brudvig, Science 2006, 312, 1941-1943; b) R. Breslow, X. Zhang, Y. Huang, J. Am. Chem. Soc. 1997, 119, 4535-4536.

[66] D. Leow, G. Li, T.-S. Mei, J.-Q. Yu, Nature 2012, 486, 518-522.

[67] Y. Kuninobu, H. Ida, M. Nishi, M. Kanai, Nat. Chem. 2015, 7, 712-717.

[68] a) M. Catellani, E. Motti, N. Della Ca', Acc. Chem. Res. 2008, 41, 1512-1522; b) M. Catellani, F. Frignani, A. Rangoni, Angew. Chem. Int. Ed. 1997, 36, 119-122.

[69] For selected references, see: a) J. Wang, G. Dong, Chem. Rev. 2019, 119, 7478-7528; b) N. Della Ca', M. Fontana, E. Motti, M. Catellani, Acc. Chem. Res. 2016, 49, 1389-1400; c) P. Wang, M. E. Farmer, X. Huo, P. Jain, P.-X. Shen, M. Ishoey, J. E. Bradner, S. R. Wisniewski, M. D. Eastgate, J.-Q. Yu, J. Am. Chem. Soc. 2016, 138, 9269-9276; d) Z. Dong, J. Wang, G. Dong, J. Am. Chem. Soc. 2015, 137, 5887-5890; e) P.-X. Shen, X.-C. Wang, P. Wang, R.-Y. Zhu, J.-Q. Yu, J. Am. Chem. Soc. 2015, 137, 11574-11577; f) X.-C. Wang, W. Gong, L.-Z. Fang, R.-Y. Zhu, S. Li, K. M. Engle, J.-Q. Yu, Nature 2015, 519, 334-338.

[70] M. Gagliardo, D. J. Snelders, P. A. Chase, R. J. Klein Gebbink, G. P. van Klink, G. van Koten, Angew. Chem. Int. Ed. 2007, 46, 8558-8573.

[71] For a recent review, see: J. A. Leitch, C. G. Frost, Chem. Soc. Rev. 2017, 46, 7145-7153, and references cited therein.

[72] It should be mentioned, that a remote $\mathrm{C}-\mathrm{H}$ functionalization for arenes without directing group was observed by Roper/Wright. See: G. R. Clark, C. E. L. Headford, W. R. Roper, L. J. Wright, V. P. D. Yap, Inorg. Chim. Acta 1994, 220, 261-272.

[73] J.-P. Sutter, D. M. Grove, M. Beley, J.-P. Collin, N. Veldman, A. L. Spek, J.-P. Sauvage, G. van Koten, Angew. Chem. Int. Ed. 1994, 33, 1282-1285.

[74] C. Coudret, S. Fraysse, Chem. Commun. 1998, 663-664.

[75] a) A. M. Clark, C. E. F. Rickard, W. R. Roper, L. J. Wright, J. Organomet. Chem. 2000, 598, 262-275; b) A. M. Clark, C. E. F. Rickard, W. R. Roper, L. J. Wright, Organometallics 1999, 18, 2813-2820.

[76] O. Saidi, J. Marafie, A. E. W. Ledger, P. M. Liu, M. F. Mahon, G. Kociok-Köhn, M. K. Whittlesey, C. G. Frost, J. Am. Chem. Soc. 2011, 133, 19298-19301. 
[77] N. Hofmann, L. Ackermann, J. Am. Chem. Soc. 2013, 135, 5877-5884.

[78] J. Li, S. Warratz, D. Zell, S. De Sarkar, E. E. Ishikawa, L. Ackermann, J. Am. Chem. Soc. 2015, $137,13894-13901$.

[79] A. J. Paterson, S. St John-Campbell, M. F. Mahon, N. J. Press, C. G. Frost, Chem. Commun. 2015, 51, 12807-12810.

[80] G. Li, X. Ma, C. Jia, Q. Han, Y. Wang, J. Wang, L. Yu, S. Yang, Chem. Commun. 2017, 53, $1261-1264$.

[81] G. Li, P. Gao, X. Lv, C. Qu, Q. Yan, Y. Wang, S. Yang, J. Wang, Org. Lett. 2017, 19, 26822685.

[82] P. Gandeepan, J. Koeller, K. Korvorapun, J. Mohr, L. Ackermann, Angew. Chem. Int. Ed. 2019, 58, 9820-9825.

[83] M. Greaney, A. Sagadevan, Angew. Chem. Int. Ed. 2019, 58, 9826-9830.

[84] C. J. Teskey, A. Y. W. Lui, M. F. Greaney, Angew. Chem. Int. Ed. 2015, 54, 11677-11680.

[85] Q. Yu, L. Hu, Y. Wang, S. Zheng, J. Huang, Angew. Chem. Int. Ed. 2015, 54, 15284-15288.

[86] http://mineralprices.com/, http://www.infomine.com/investment/metal-prices/, https://www.metalary.com/ and https://www.metal.com/, accessed on August 05, 2019.

[87] a) K. S. Egorova, V. P. Ananikov, Organometallics 2017, 36, 4071-4090; b) K. S. Egorova, V. P. Ananikov, Angew. Chem. Int. Ed. 2016, 55, 12150-12162.

[88] J. Emsley, Nature's Building Blocks: An A-Z Guide to the Elements, Oxford University Press, Oxford, 2001.

[89] For selected reviews, see: a) R. Cano, K. Mackey, G. P. McGlacken, Catal. Sci. Technol. 2018, 8, 1251-1266; b) Y. Hu, B. Zhou, C. Wang, Acc. Chem. Res. 2018, 51, 816-827; c) W. Liu, L. Ackermann, ACS Catal. 2016, 6, 3743-3752.

[90] M. I. Bruce, M. Z. Iqbal, F. G. A. Stone, J. Chem. Soc. A 1970, 3204-3209.

[91] a) G. J. Depree, L. Main, B. K. Nicholson, J. Organomet. Chem. 1998, 551, 281-291; b) R. C. Cambie, M. R. Metzler, P. S. Rutledge, P. D. Woodgate, J. Organomet. Chem. 1992, 429, 41-57; c) L. S. Liebeskind, J. R. Gasdaska, J. S. McCallum, S. J. Tremont, J. Org. Chem. 1989, $54,669-677$.

[92] Y. Kuninobu, Y. Nishina, T. Takeuchi, K. Takai, Angew. Chem. Int. Ed. 2007, 46, 6518-6520.

[93] B. Zhou, H. Chen, C. Wang, J. Am. Chem. Soc. 2013, 135, 1264-1267.

[94] S. Tang, O. Eisenstein, Y. Nakao, S. Sakaki, Organometallics 2017, 36, 2761-2771.

[95] Z. Ruan, N. Sauermann, E. Manoni, L. Ackermann, Angew. Chem. Int. Ed. 2017, 56, 31723176. 
[96] For selected reviews, see: a) Z. Nairoukh, M. Cormier, I. Marek, Nat. Rev. Chem. 2017, 1, 0035; b) G. Fumagalli, S. Stanton, J. F. Bower, Chem. Rev. 2017, 117, 9404-9432; c) P.-h. Chen, B. A. Billett, T. Tsukamoto, G. Dong, ACS Catal. 2017, 7, 1340-1360; d) M. Murakami, N. Ishida, J. Am. Chem. Soc. 2016, 138, 13759-13769; e) L. Souillart, N. Cramer, Chem. Rev. 2015, 115, 9410-9464; f) F. Chen, T. Wang, N. Jiao, Chem. Rev. 2014, 114, 8613-8661; g) M. Murakami, T. Matsuda, Chem. Commun. 2011, 47, 1100-1105.

[97] S. J. Blanksby, G. B. Ellison, Acc. Chem. Res. 2003, 36, 255-263.

[98] a) P. E. M. Siegbahn, J. Phys. Chem. 1995, 99, 12723-12729; b) J. A. M. Simoes, J. L. Beauchamp, Chem. Rev. 1990, 90, 629-688.

[99] C. F. H. Tipper, J. Chem. Soc. 1955, 2045-2046.

[100] Although Tipper reported $\mathrm{PtCl}_{2}$ to be the active complex, subsequent studies by Chatt, and Bailey revealed $\mathrm{H}_{2} \mathrm{PtCl}_{6}$ to be the actual complex. See: a) N. A. Bailey, R. D. Gillard, M. Keeton, R. Mason, D. R. Russell, Chem. Commun. 1966, 396-398; b) D. M. Adams, J. Chatt, R. G. Guy, N. Sheppard, J. Chem. Soc. 1961, 738-742.

[101] C. Aïssa, A. Fürstner, J. Am. Chem. Soc. 2007, 129, 14836-14837.

[102] L. Ackermann, S. I. Kozhushkov, D. S. Yufit, Chem. Eur. J. 2012, 18, 12068-12077.

[103] S. I. Kozhushkov, D. S. Yufit, L. Ackermann, Org. Lett. 2008, 10, 3409-3412.

[104] J.-Q. Wu, Z.-P. Qiu, S.-S. Zhang, J.-G. Liu, Y.-X. Lao, L.-Q. Gu, Z.-S. Huang, J. Li, H. Wang, Chem. Commun. 2015, 51, 77-80.

[105] D. Zell, Q. Bu, M. Feldt, L. Ackermann, Angew. Chem. Int. Ed. 2016, 55, 7408-7412.

[106] T. H. Meyer, W. Liu, M. Feldt, A. Wuttke, R. A. Mata, L. Ackermann, Chem. Eur. J. 2017, 23, 5443-5447.

[107] Y. Terao, H. Wakui, T. Satoh, M. Miura, M. Nomura, J. Am. Chem. Soc. 2001, 123, 1040710408.

[108] H. Li, Y. Li, X.-S. Zhang, K. Chen, X. Wang, Z.-J. Shi, J. Am. Chem. Soc. 2011, 133, 1524415247.

[109] E. Ozkal, B. Cacherat, B. Morandi, ACS Catal. 2015, 5, 6458-6462.

[110] a) G. Li, L. Wan, G. Zhang, D. Leow, J. Spangler, J.-Q. Yu, J. Am. Chem. Soc. 2015, 137, 43914397; b) X.-C. Wang, Y. Hu, S. Bonacorsi, Y. Hong, R. Burrell, J.-Q. Yu, J. Am. Chem. Soc. 2013, 135, 10326-10329; c) M. Wasa, J.-Q. Yu, J. Am. Chem. Soc. 2008, 130, 14058-14059.

[111] a) Y. Jaiswal, Y. Kumar, R. Thakur, J. Pal, R. Subramanian, A. Kumar, J. Org. Chem. 2016, 81, 12499-12505; b) A. Deb, S. Bag, R. Kancherla, D. Maiti, J. Am. Chem. Soc. 2014, 136, 13602-13605; c) J. Park, M. Kim, S. Sharma, E. Park, A. Kim, S. H. Lee, J. H. Kwak, Y. H. Jung, 
I. S. Kim, Chem. Commun. 2013, 49, 1654-1656; d) C. S. Yeung, X. Zhao, N. Borduas, V. M. Dong, Chem. Sci. 2010, 1, 331-336.

[112] a) J.-C. Zhu, D.-X. Cui, Y.-D. Li, R. Jiang, W.-P. Chen, P.-A. Wang, ChemCatChem 2018, 10, 907-919; b) F. A. Larik, A. Saeed, T. A. Fattah, U. Muqadar, P. A. Channar, Appl. Organomet. Chem. 2017, 31, e3664; c) R. Gómez Arrayás, J. Adrio, J. C. Carretero, Angew. Chem. Int. Ed. 2006, 45, 7674-7715; d) R. C. J. Atkinson, V. C. Gibson, N. J. Long, Chem. Soc. Rev. 2004, 33, 313-328; e) L.-X. Dai, T. Tu, S.-L. You, W.-P. Deng, X.-L. Hou, Acc. Chem. Res. 2003, 36, 659-667.

[113] a) A. Kondratskyi, K. Kondratska, F. Vanden Abeele, D. Gordienko, C. Dubois, R.-A. Toillon, C. Slomianny, S. Lemière, P. Delcourt, E. Dewailly, R. Skryma, C. Biot, N. Prevarskaya, Sci. Rep. 2017, 7, 15896; b) A. J. Corry, Á. Mooney, D. O’Sullivan, P. T. M. Kenny, Inorg. Chim. Acta 2009, 362, 2957-2961; c) W. Daher, C. Biot, T. Fandeur, H. Jouin, L. Pelinski, E. Viscogliosi, L. Fraisse, B. Pradines, J. Brocard, J. Khalife, D. Dive, Malar J. 2006, 5, 11.

[114] For selected references, see: a) W. Wang, M. M. Lorion, J. Shah, A. R. Kapdi, L. Ackermann, Angew. Chem. Int. Ed. 2018, 57, 14700-14717; b) X. Zhang, G. Lu, M. Sun, M. Mahankali, Y. Ma, M. Zhang, W. Hua, Y. Hu, Q. Wang, J. Chen, G. He, X. Qi, W. Shen, P. Liu, G. Chen, Nat. Chem. 2018, 10, 540-548; c) B.-B. Zhan, Y. Li, J.-W. Xu, X.-L. Nie, J. Fan, L. Jin, B.-F. Shi, Angew. Chem. Int. Ed. 2018, 57, 5858-5862; d) W. Wang, M. M. Lorion, O. Martinazzoli, L. Ackermann, Angew. Chem. Int. Ed. 2018, 57, 10554-10558; e) M. Bauer, W. Wang, M. M. Lorion, C. Dong, L. Ackermann, Angew. Chem. Int. Ed. 2018, 57, 203-207; f) L. MendiveTapia, S. Preciado, J. García, R. Ramón, N. Kielland, F. Albericio, R. Lavilla, Nat. Commun. $2015,6,7160$.

[115] L. Ackermann, P. Novák, R. Vicente, V. Pirovano, H. K. Potukuchi, Synthesis 2010, 22452253.

[116] For selected reviews, see: a) V. Gayakhe, Y. S. Sanghvi, I. J. Fairlamb, A. R. Kapdi, Chem. Commun. 2015, 51, 11944-11960; b) L. P. Jordheim, D. Durantel, F. Zoulim, C. Dumontet, Nat. Rev. Drug Discovery 2013, 12, 447-464; c) S. Knapp, Chem. Rev. 1995, 95, 1859-1876.

[117] S. Warratz, D. J. Burns, C. Zhu, K. Korvorapun, T. Rogge, J. Scholz, C. Jooss, D. Gelman, L. Ackermann, Angew. Chem. Int. Ed. 2017, 56, 1557-1560.

[118] G. P. Drummen, Molecules 2012, 17, 14067-14090.

[119] a) D. A. Colby, R. G. Bergman, J. A. Ellman, J. Am. Chem. Soc. 2008, 130, 3645-3651; b) Y.Q. Wang, J. Song, R. Hong, H. Li, L. Deng, J. Am. Chem. Soc. 2006, 128, 8156-8157; c) M. Rueping, E. Sugiono, C. Azap, T. Theissmann, M. Bolte, Org. Lett. 2005, 7, 3781-3783; d) R. W. Layer, Chem. Rev. 1963, 63, 489-510. 
[120] a) C. G. Bologa, C. M. Revankar, S. M. Young, B. S. Edwards, J. B. Arterburn, A. S. Kiselyov, M. A. Parker, S. E. Tkachenko, N. P. Savchuck, L. A. Sklar, T. I. Oprea, E. R. Prossnitz, Nat. Chem. Biol. 2006, 2, 207-212; b) T. G. Kantor, Pharmacotherapy 1986, 6, 93-102.

[121] J. Li, K. Korvorapun, S. De Sarkar, T. Rogge, D. J. Burns, S. Warratz, L. Ackermann, Nat. Commun. 2017, 8, 15430.

[122] G. B. Boursalian, W. S. Ham, A. R. Mazzotti, T. Ritter, Nat. Chem. 2016, 8, 810-815.

[123] a) A. J. Paterson, C. J. Heron, C. L. McMullin, M. F. Mahon, N. J. Press, C. G. Frost, Org. Biomol. Chem. 2017, 15, 5993-6000; b) J. A. Leitch, C. L. McMullin, M. F. Mahon, Y. Bhonoah, C. G. Frost, ACS Catal. 2017, 7, 2616-2623.

[124] K. Korvorapun, N. Kaplaneris, T. Rogge, S. Warratz, A. C. Stückl, L. Ackermann, ACS Catal. 2018, 8, 886-892.

[125] J. Tao, J. P. Perdew, V. N. Staroverov, G. E. Scuseria, Phys. Rev. Lett. 2003, 91, 146401.

[126] a) S. Grimme, S. Ehrlich, L. Goerigk, J. Comput. Chem. 2011, 32, 1456-1465; b) S. Grimme, J. Antony, S. Ehrlich, H. Krieg, J. Chem. Phys. 2010, 132, 154104.

[127] F. Weigend, R. Ahlrichs, Phys. Chem. Chem. Phys. 2005, 7, 3297-3305.

[128] a) P. J. Stephens, F. J. Devlin, C. F. Chabalowski, M. J. Frisch, J. Phys. Chem. 1994, 98, 11623-11627; b) A. D. Becke, J. Chem. Phys. 1993, 98, 5648-5652.

[129] F. Fumagalli, S. Warratz, S. K. Zhang, T. Rogge, C. Zhu, A. C. Stuckl, L. Ackermann, Chem. Eur. J. 2018, 24, 3984-3988.

[130] J.-L. Yu, S.-Q. Zhang, X. Hong, J. Am. Chem. Soc. 2017, 139, 7224-7243.

[131] N. Y. P. Kumar, PhD thesis, Geog-August-Universität (Göttingen), 2016.

[132] N. Y. P. Kumar, T. Rogge, S. R. Yetra, A. Bechtoldt, E. Clot, L. Ackermann, Chem. Eur. J. 2017, 23, 17449-17453.

[133] a) S. H. Han, S. Kim, U. De, N. K. Mishra, J. Park, S. Sharma, J. H. Kwak, S. Han, H. S. Kim, I. S. Kim, J. Org. Chem. 2016, 81, 12416-12425; b) J. Obniska, M. Kopytko, A. Zagórska, I. Chlebek, K. Kamiński, Arch. Pharm. 2010, 343, 333-341.

[134] C. Adamo, V. Barone, J. Chem. Phys. 1999, 110, 6158-6170.

[135] A. V. Marenich, C. J. Cramer, D. G. Truhlar, J. Phys. Chem. B 2009, 113, 6378-6396.

[136] a) L. Goerigk, A. Hansen, C. Bauer, S. Ehrlich, A. Najibi, S. Grimme, Phys. Chem. Chem. Phys. 2017, 19, 32184-32215; b) M. Steinmetz, S. Grimme, ChemistryOpen 2013, 2, 115-124.

[137] B. Cordero, V. Gómez, A. E. Platero-Prats, M. Revés, J. Echeverría, E. Cremades, F. Barragán, S. Alvarez, Dalton Trans. 2008, 2832-2838. 
[138] a) G. Subramanian, M. G. Paterlini, D. L. Larson, P. S. Portoghese, D. M. Ferguson, J. Med. Chem. 1998, 41, 4777-4789; b) J. Szmuszkovicz, P. F. Von Voigtlander, J. Med. Chem. 1982, 25, 1125-1126.

[139] a) Y.-M. Tao, Q.-L. Li, C.-F. Zhang, X.-J. Xu, J. Chen, Y.-W. Ju, Z.-Q. Chi, Y.-Q. Long, J.-G. Liu, Eur. J. Pharmacol. 2008, 584, 306-311; b) M. Kunihara, M. Ohyama, M. Nakano, S. Hayashi, Life Sci. 1989, 45, 1191-1198.

[140] V. Martínez, M. I. Maguregui, R. M. Jiménez, R. M. Alonso, J. Pharm. Biomed. Anal. 2000, $23,459-468$.

[141] Q. Bu, T. Rogge, V. Kotek, L. Ackermann, Angew. Chem. Int. Ed. 2018, 57, 765-768.

[142] a) S. Sinnecker, A. Rajendran, A. Klamt, M. Diedenhofen, F. Neese, J. Phys. Chem. A 2006, 110, 2235-2245; b) A. Klamt, G. Schüürmann, J. Chem. Soc., Perkin Trans. 1993, 2, 799805.

[143] For selected reviews, see: a) I. M. Riddlestone, A. Kraft, J. Schaefer, I. Krossing, Angew. Chem. Int. Ed. 2018, 57, 13982-14024; b) I. Krossing, I. Raabe, Angew. Chem. Int. Ed. 2004, 43, 2066-2090.

[144] J. A. Leitch, P. B. Wilson, C. L. McMullin, M. F. Mahon, Y. Bhonoah, I. H. Williams, C. G. Frost, ACS Catal. 2016, 6, 5520-5529.

[145] Y. Zhao, D. G. Truhlar, J. Phys. Chem. A 2005, 109, 5656-5667.

[146] A. Karton, S. Daon, J. M. L. Martin, Chem. Phys. Lett. 2011, 510, 165-178.

[147] For selected reviews on sustainable solvents, see: a) P. Gandeepan, N. Kaplaneris, S. Santoro, L. Vaccaro, L. Ackermann, ACS Sustain. Chem. Eng. 2019, 7, 8023-8040; b) S. Santoro, A. Marrocchi, D. Lanari, L. Ackermann, L. Vaccaro, Chem. Eur. J. 2018, 24, 1338313390.

[148] S. R. Yetra, T. Rogge, S. Warratz, J. Struwe, W. Peng, P. Vana, L. Ackermann, Angew. Chem. Int. Ed. 2019, 58, 7490-7494.

[149] a) S. Coriani, A. Haaland, T. Helgaker, P. Jørgensen, ChemPhysChem 2006, 7, 245-249; b)

R. K. Bohn, A. Haaland, J. Organomet. Chem. 1966, 5, 470-476.

[150] A. Bondi, J. Phys. Chem. 1964, 68, 441-451.

[151] A review: F. M. Bickelhaupt, K. N. Houk, Angew. Chem. Int. Ed. 2017, 56, 10070-10086.

[152] P. Schwerdtfeger, J. K. Nagle, Mol. Phys. 2018, 117, 1200-1225.

[153] a) A. F. B. Räder, M. Weinmüller, F. Reichart, A. Schumacher-Klinger, S. Merzbach, C. Gilon, A. Hoffman, H. Kessler, Angew. Chem. Int. Ed. 2018, 57, 14414-14438; b) M. A. T. Blaskovich, J. Med. Chem. 2016, 59, 10807-10836; c) K. Fosgerau, T. Hoffmann, Drug Discovery Today 2015, 20, 122-128. 
[154] For selected references, see: a) C. Bottecchia, T. Noël, Chem. Eur. J. 2019, 25, 26-42; b) K. Kubota, P. Dai, B. L. Pentelute, S. L. Buchwald, J. Am. Chem. Soc. 2018, 140, 3128-3133; c) E. V. Vinogradova, C. Zhang, A. M. Spokoyny, B. L. Pentelute, S. L. Buchwald, Nature 2015, 526, 687-691; d) K. Maruoka, T. Ooi, Chem. Rev. 2003, 103, 3013-3028.

[155] L. Palego, L. Betti, A. Rossi, G. Giannaccini, J. Amino Acids 2016, 8952520.

[156] A. Schischko, N. Kaplaneris, T. Rogge, G. Sirvinskaite, J. Son, L. Ackermann, Nat. Commun. 2019, 10, 3553.

[157] Y. Zhao, D. G. Truhlar, Theor. Chem. Acc. 2008, 120, 215-241.

[158] For selected examples, see: a) S. Dana, D. Chowdhury, A. Mandal, F. A. S. Chipem, M. Baidya, ACS Catal. 2018, 8, 10173-10179; b) D. Srimani, Y. Ben-David, D. Milstein, Angew. Chem. Int. Ed. 2013, 52, 4012-4015; c) J. Dong, Z. Long, F. Song, N. Wu, Q. Guo, J. Lan, J. You, Angew. Chem. Int. Ed. 2013, 52, 580-584; d) G. Deng, L. Zhao, C.-J. Li, Angew. Chem. Int. Ed. 2008, 47, 6278-6282.

[159] a) J. McIntyre, I. Mayoral-Soler, P. Salvador, A. Poater, D. J. Nelson, Catal. Sci. Technol. 2018, 8, 3174-3182; b) P. Marcé, A. J. Paterson, M. F. Mahon, C. G. Frost, Catal. Sci. Technol. 2016, 6, 7068-7076.

[160] a) W. P. Jencks, Chem. Rev. 1972, 72, 705-718; b) R. A. More O'Ferrall, J. Chem. Soc. B $1970,274-277$.

[161] a) J. Kim, K. Shin, S. Jin, D. Kim, S. Chang, J. Am. Chem. Soc. 2019, 141, 4137-4146; b) K. Shin, Y. Park, M.-H. Baik, S. Chang, Nat. Chem. 2017, 10, 218-224.

[162] N. Kaplaneris, T. Rogge, R. Yin, H. Wang, G. Sirvinskaite, L. Ackermann, Angew. Chem. Int. Ed. 2019, 58, 3476-3480.

[163] N. Kaplaneris, H. Wang, L. Ackermann, unpublished results.

[164] H. Wang, I. Choi, T. Rogge, N. Kaplaneris, L. Ackermann, Nat. Catal. 2018, 1, 993-1001.

[165] C. Conley, F.-M. Tao, Chem. Phys. Lett. 1999, 301, 29-36.

[166] K. Szalewicz, WIREs Comput. Mol. Sci. 2012, 2, 254-272.

[167] F. Neese, A. Hansen, D. G. Liakos, J. Chem. Phys. 2009, 131, 064103.

[168] T. Rogge, L. Ackermann, Angew. Chem. Int. Ed. 2019, doi: 10.1002/anie.201909457.

[169] S. Wold, C. Albano, W. J. Dunn, U. Edlund, K. Esbensen, P. Geladi, S. Hellberg, E. Johansson, W. Lindberg, M. Sjöström, Multivariate Data Analysis in Chemistry, in Chemometrics (Ed.: B. R. Kowalski), Springer Netherlands, Dordrecht, 1984, pp. 17-95.

[170] H. E. Gottlieb, V. Kotlyar, A. Nudelman, J. Org. Chem. 1997, 62, 7512-7515.

[171] M. J. O. N. S. Budavari, A. Smith, P. E. Heckelmann, The Merck Index, an Encyclopedia of Chemicals, Drugs, and Biologicals, 11th ed., Merck Co., Inc., Rahway, NJ, 1989. 
[172] a) L.-L. Gundersen, A. Kristin Bakkestuen, A. Jørgen Aasen, H. Øverås, F. Rise, Tetrahedron 1994, 50, 9743-9756; b) M. Havelková, D. Dvořak, M. Hocek, Synthesis 2001, 1704-1710.

[173] V. P. W. Böhm, T. Weskamp, C. W. K. Gstöttmayr, W. A. Herrmann, Angew. Chem. Int. Ed. 2000, 39, 1602-1604.

[174] L. Huang, F. Rominger, M. Rudolph, A. S. K. Hashmi, Chem. Commun. 2016, 52, 6435-6438.

[175] H. Masada, Y. Murotani, Bull. Chem. Soc. Jpn. 1980, 53, 1181-1182.

[176] M. Periasamy, G. Srinivas, P. Bharathi, J. Org. Chem. 1999, 64, 4204-4205.

[177] C. C. Underwood, B. S. Stadelman, M. L. Sleeper, J. L. Brumaghim, Inorg. Chim. Acta 2013, 405, 470-476.

[178] J. H. Espenson, Chemical Kinetics and Reaction Mechanisms, 2nd ed., McGraw-Hill, New York, 1995.

[179] H. Aiso, T. Kochi, H. Mutsutani, T. Tanabe, S. Nishiyama, F. Kakiuchi, J. Org. Chem. 2012, $77,7718-7724$.

[180] P. Nareddy, F. Jordan, M. Szostak, Org. Biomol. Chem. 2017, 15, 4783-4788.

[181] O. V. Dolomanov, L. J. Bourhis, R. J. Gildea, J. A. K. Howard, H. Puschmann, J. Appl. Cryst. 2009, 42, 339-341.

[182] G. Sheldrick, Acta Cryst. A 2015, 71, 3-8.

[183] G. Sheldrick, Acta Cryst. A 2008, 64, 112-122.

[184] G. W. T. M. J. Frisch, H. B. Schlegel, G. E. Scuseria, M. A. Robb, J. R. Cheeseman, G. Scalmani, V. Barone, G. A. Petersson, H. Nakatsuji, X. Li, M. Caricato, A. Marenich, J. Bloino, B. G. Janesko, R. Gomperts, B. Mennucci, H. P. Hratchian, J. V. Ortiz, A. F. Izmaylov, J. L. Sonnenberg, D. Williams-Young, F. Ding, F. Lipparini, F. Egidi, J. Goings, B. Peng, A. Petrone, T. Henderson, D. Ranasinghe, V. G. Zakrzewski, J. Gao, N. Rega, G. Zheng, W. Liang, M. Hada, M. Ehara, K. Toyota, R. Fukuda, J. Hasegawa, M. Ishida, T. Nakajima, Y. Honda, O. Kitao, H. Nakai, T. Vreven, K. Throssell, J. A. Montgomery, Jr., J. E. Peralta, F. Ogliaro, M. Bearpark, J. J. Heyd, E. Brothers, K. N. Kudin, V. N. Staroverov, T. Keith, R. Kobayashi, J. Normand, K. Raghavachari, A. Rendell, J. C. Burant, S. S. Iyengar, J. Tomasi, M. Cossi, J. M. Millam, M. Klene, C. Adamo, R. Cammi, J. W. Ochterski, R. L. Martin, K. Morokuma, O. Farkas, J. B. Foresman, D. J. Fox, Gaussian 09, Revision D.01, Gaussian, Inc., Wallingford CT, 2013.

[185] M. J. Frisch, G. W. Trucks, H. B. Schlegel, G. E. Scuseria, M. A. Robb, J. R. Cheeseman, G. Scalmani, V. Barone, G. A. Petersson, H. Nakatsuji, X. Li, M. Caricato, A. V. Marenich, J. Bloino, B. G. Janesko, R. Gomperts, B. Mennucci, H. P. Hratchian, J. V. Ortiz, A. F. Izmaylov, J. L. Sonnenberg, Williams, F. Ding, F. Lipparini, F. Egidi, J. Goings, B. Peng, A. Petrone, T. 
Henderson, D. Ranasinghe, V. G. Zakrzewski, J. Gao, N. Rega, G. Zheng, W. Liang, M. Hada, M. Ehara, K. Toyota, R. Fukuda, J. Hasegawa, M. Ishida, T. Nakajima, Y. Honda, O. Kitao, H. Nakai, T. Vreven, K. Throssell, J. A. Montgomery Jr., J. E. Peralta, F. Ogliaro, M. J. Bearpark, J. J. Heyd, E. N. Brothers, K. N. Kudin, V. N. Staroverov, T. A. Keith, R. Kobayashi, J. Normand, K. Raghavachari, A. P. Rendell, J. C. Burant, S. S. Iyengar, J. Tomasi, M. Cossi, J. M. Millam, M. Klene, C. Adamo, R. Cammi, J. W. Ochterski, R. L. Martin, K. Morokuma, O. Farkas, J. B. Foresman, D. J. Fox, Gaussian 16, Rev. A.03, Gaussian, Inc., Wallingford, CT, 2016.

[186] F. Neese, WIREs Comput. Mol. Sci. 2012, 2, 73-78.

[187] F. Neese, WIREs Comput. Mol. Sci. 2018, 8, e1327.

[188] The PyMOL Molecular Graphics System, Version 1.8.x, Schrödinger, LLC.

[189] D. Andrae, U. Häußermann, M. Dolg, H. Stoll, H. Preuß, Theor. Chim. Acta 1990, 77, $123-$ 141.

[190] F. Weigend, Phys. Chem. Chem. Phys. 2006, 8, 1057-1065.

[191] a) R. Balawender, L. Komorowski, J. Chem. Phys. 1998, 109, 5203-5211; b) R. G. Parr, W. Yang, J. Am. Chem. Soc. 1984, 106, 4049-4050.

[192] E. D. Glendening, J. K. Badenhoop, A. E. Reed, J. E. Carpenter, J. A. Bohmann, C. M. Morales, C. R. Landis, F. Weinhold, NBO 6.0, Theoretical Chemistry Institute, University of Wisconsin, Madison, 2013.

[193] E. D. Glendening, J. K. Badenhoop, A. E. Reed, J. E. Carpenter, J. A. Bohmann, C. M. Morales, F. Weinhold, NBO 5.9, Theoretical Chemistry Institute, University of Wisconsin, Madison, WI, 2009.

[194] a) M. Boda, G. Naresh Patwari, Phys. Chem. Chem. Phys. 2017, 19, 7461-7464; b) E. Miliordos, E. Aprà, S. S. Xantheas, J. Chem. Phys. 2013, 139, 114302. 


\section{Appendix: NMR Spectra}
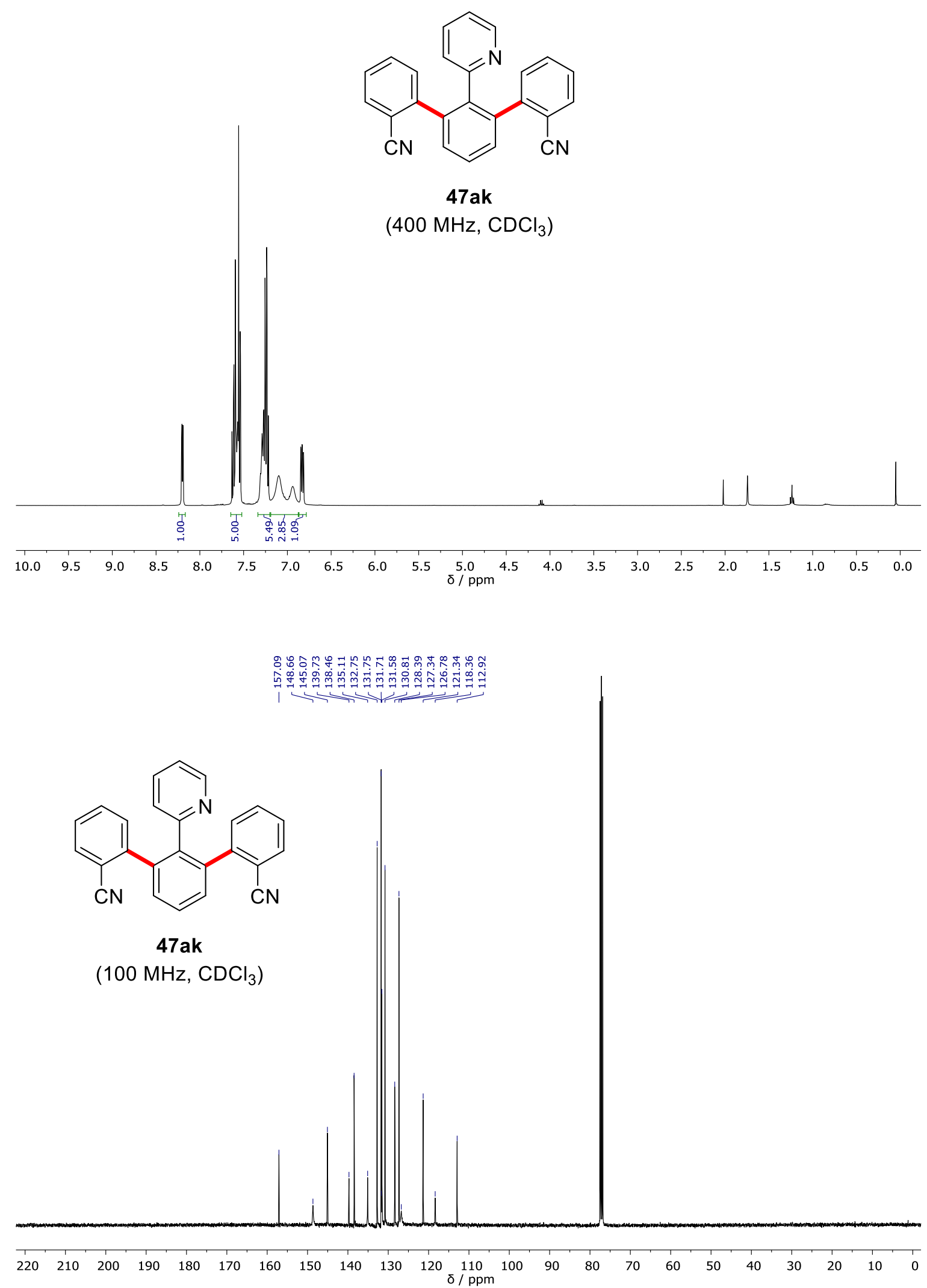
<smiles>Cc1cccc(-c2ccc(C(F)(F)F)cc2)c1-c1ccccn1</smiles>

$47 \mathrm{dc}$

(400 MHz, $\mathrm{CDCl}_{3}$ )

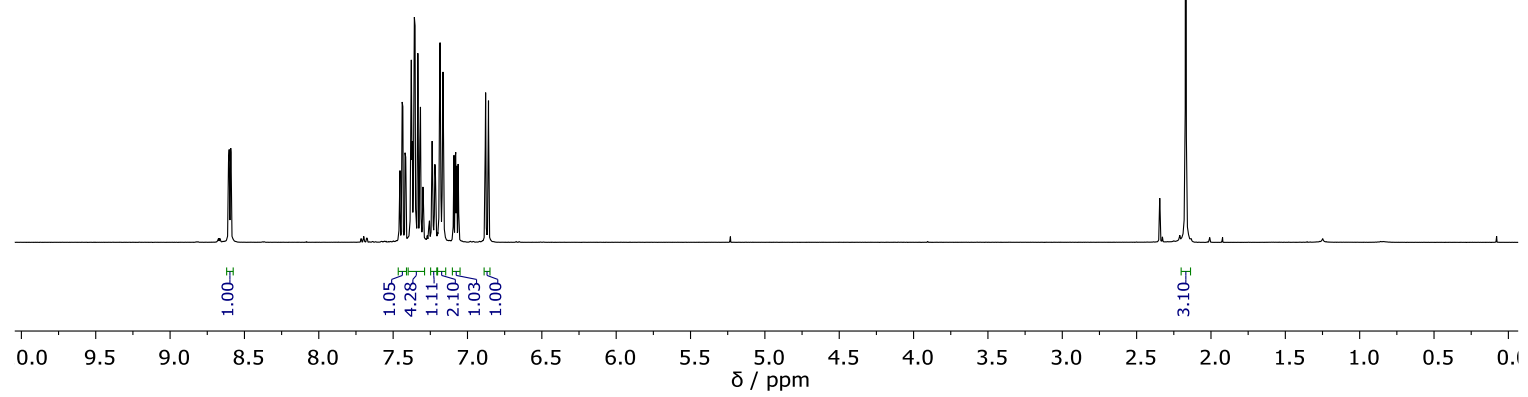<smiles>Cc1cccc(-c2ccc(C(F)(F)F)cc2)c1-c1ccccn1</smiles>

47dc

(100 MHz, $\mathrm{CDCl}_{3}$ )

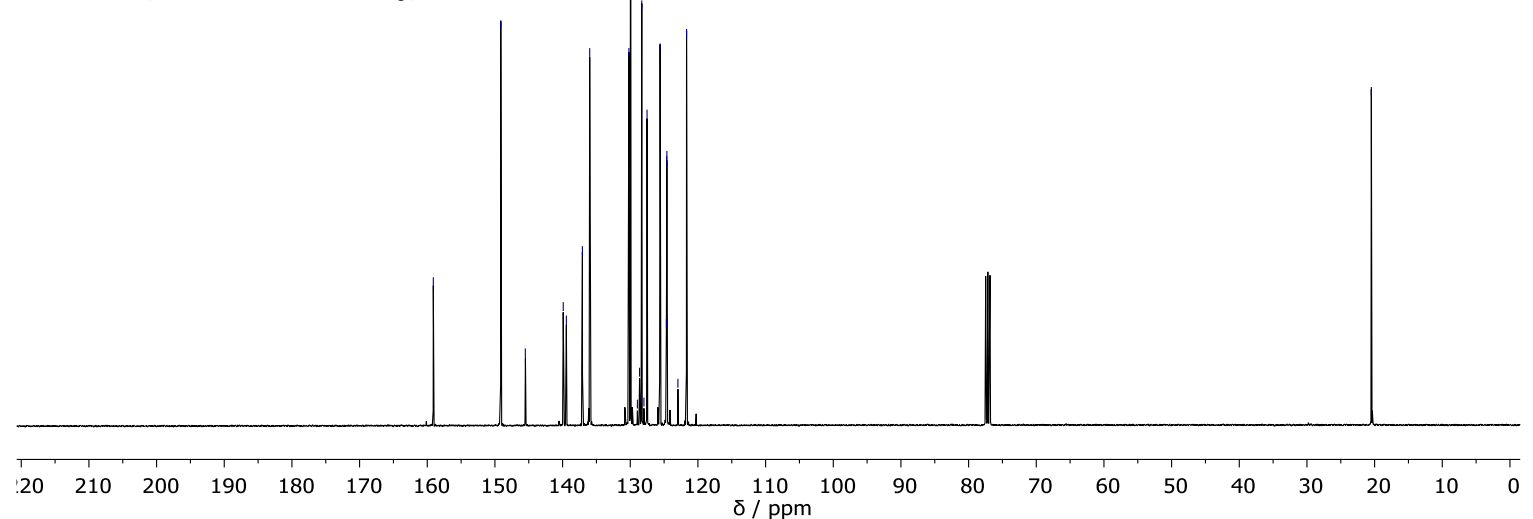




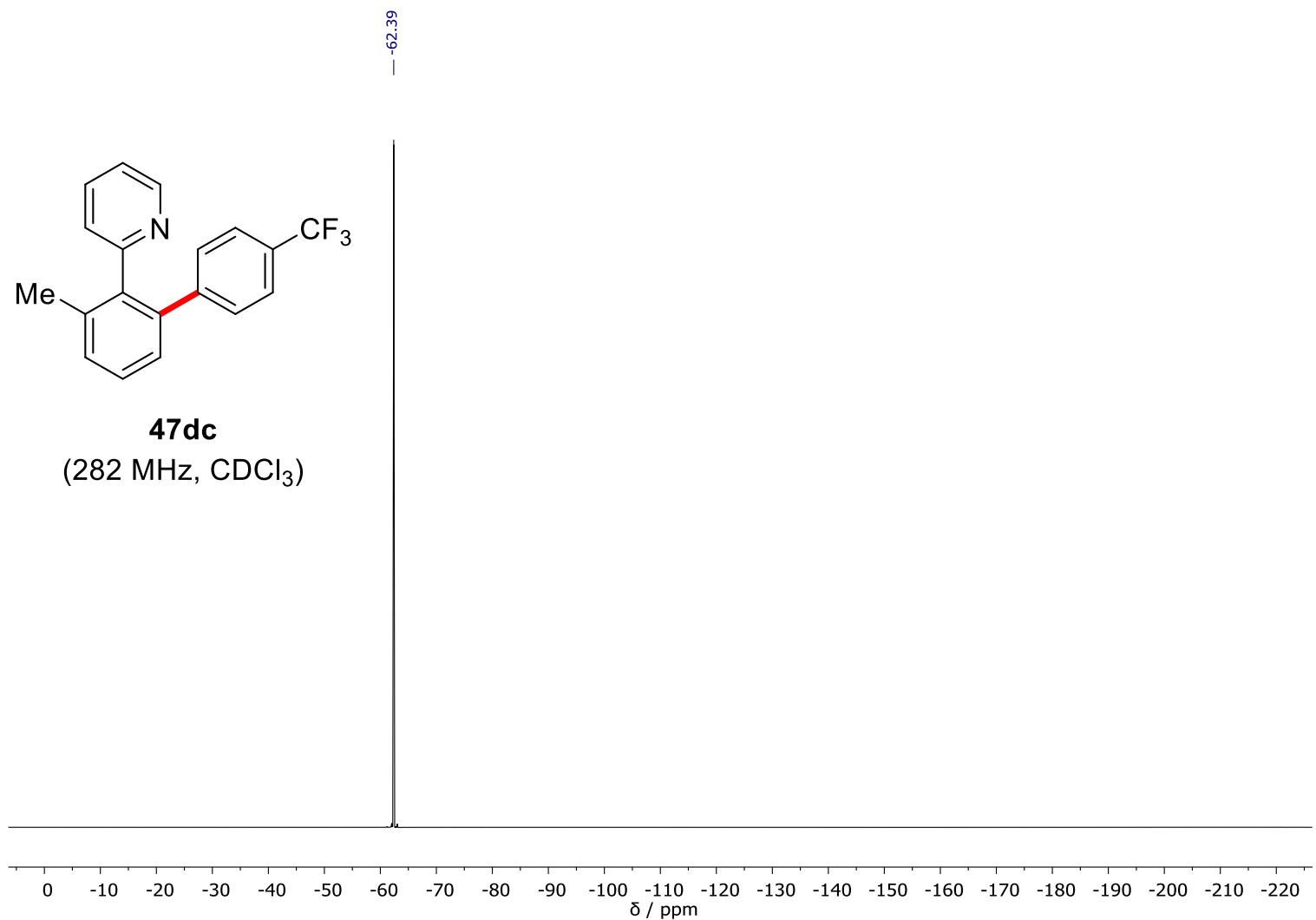<smiles>Cc1cccc(-c2cccc(C(F)(F)F)c2)c1-c1ccccn1</smiles>

47dd

(400 MHz, $\mathrm{CDCl}_{3}$ )

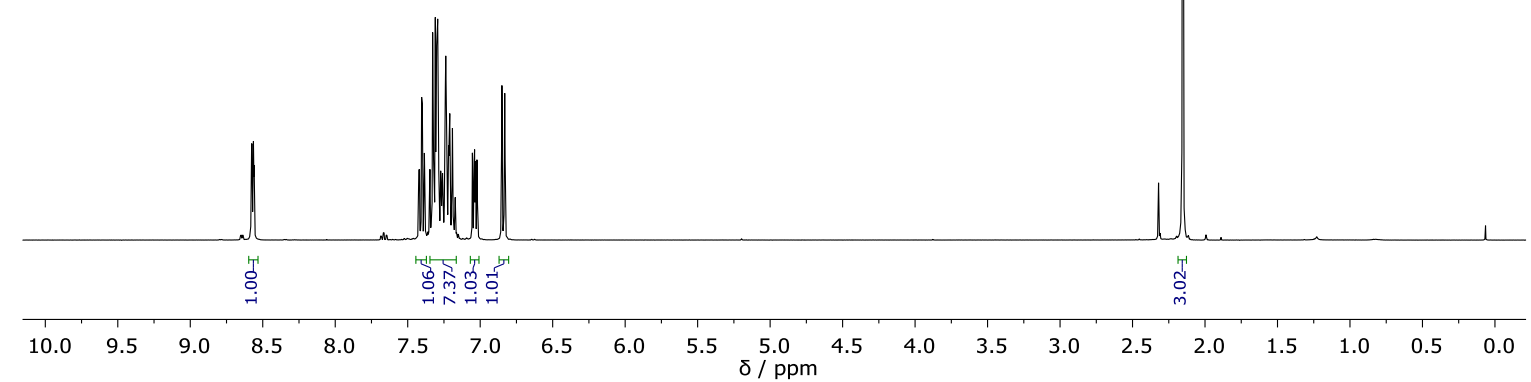



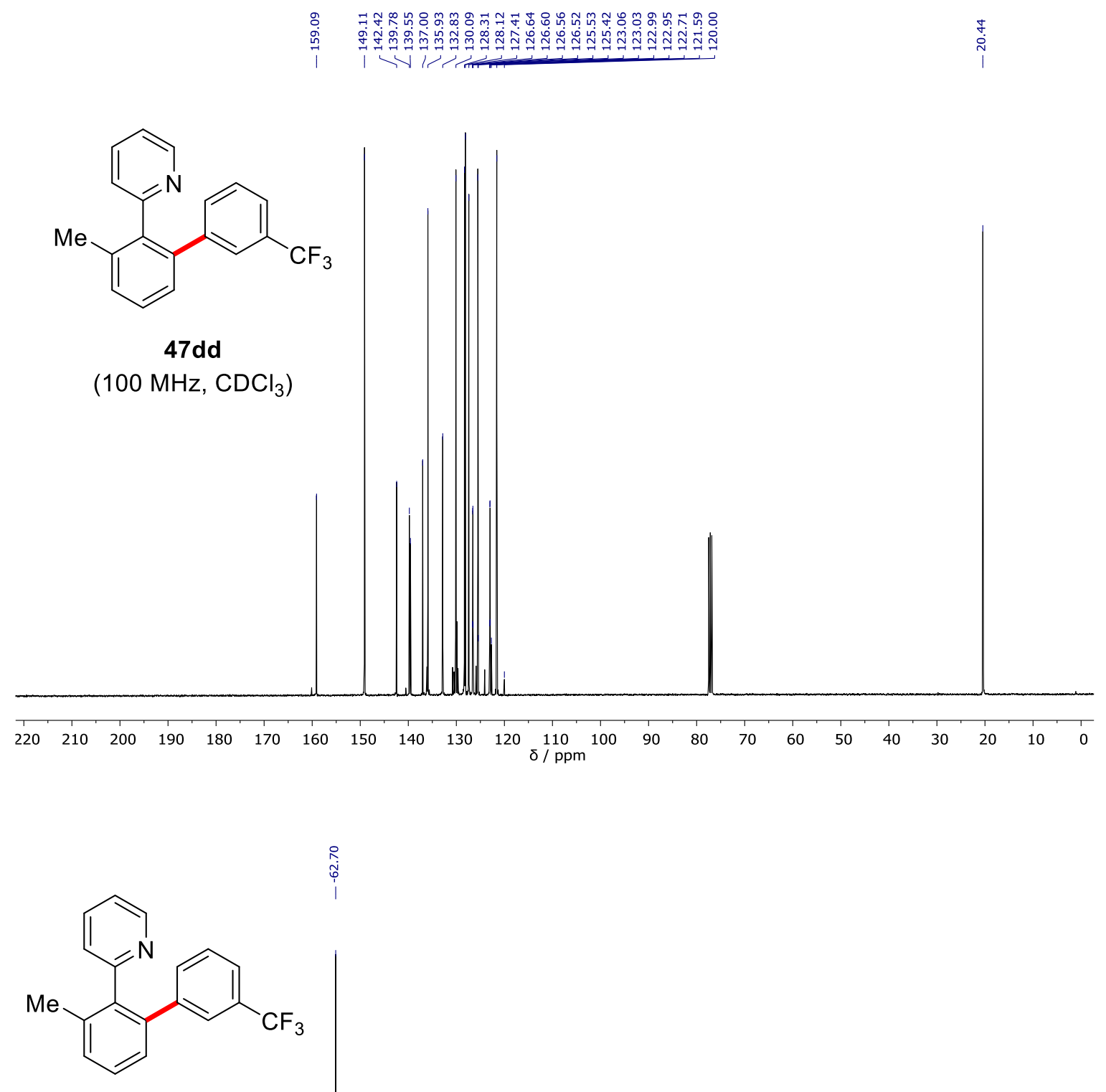

$47 d d$

$\left(282 \mathrm{MHz} \mathrm{CDCl}_{3}\right)$

$\begin{array}{llllllllllllllllllllllllllllll}0 & -10 & -20 & -30 & -40 & -50 & -60 & -70 & -80 & -90 & -100 & -110 & -120 & -130 & -140 & -150 & -160 & -170 & -180 & -190 & -200 & -210 & -220\end{array}$ 
<smiles>Cc1cccc(-c2ccccc2)c1-c1ccccn1</smiles>

47de

$\left(300 \mathrm{MHz}, \mathrm{CDCl}_{3}\right.$ )
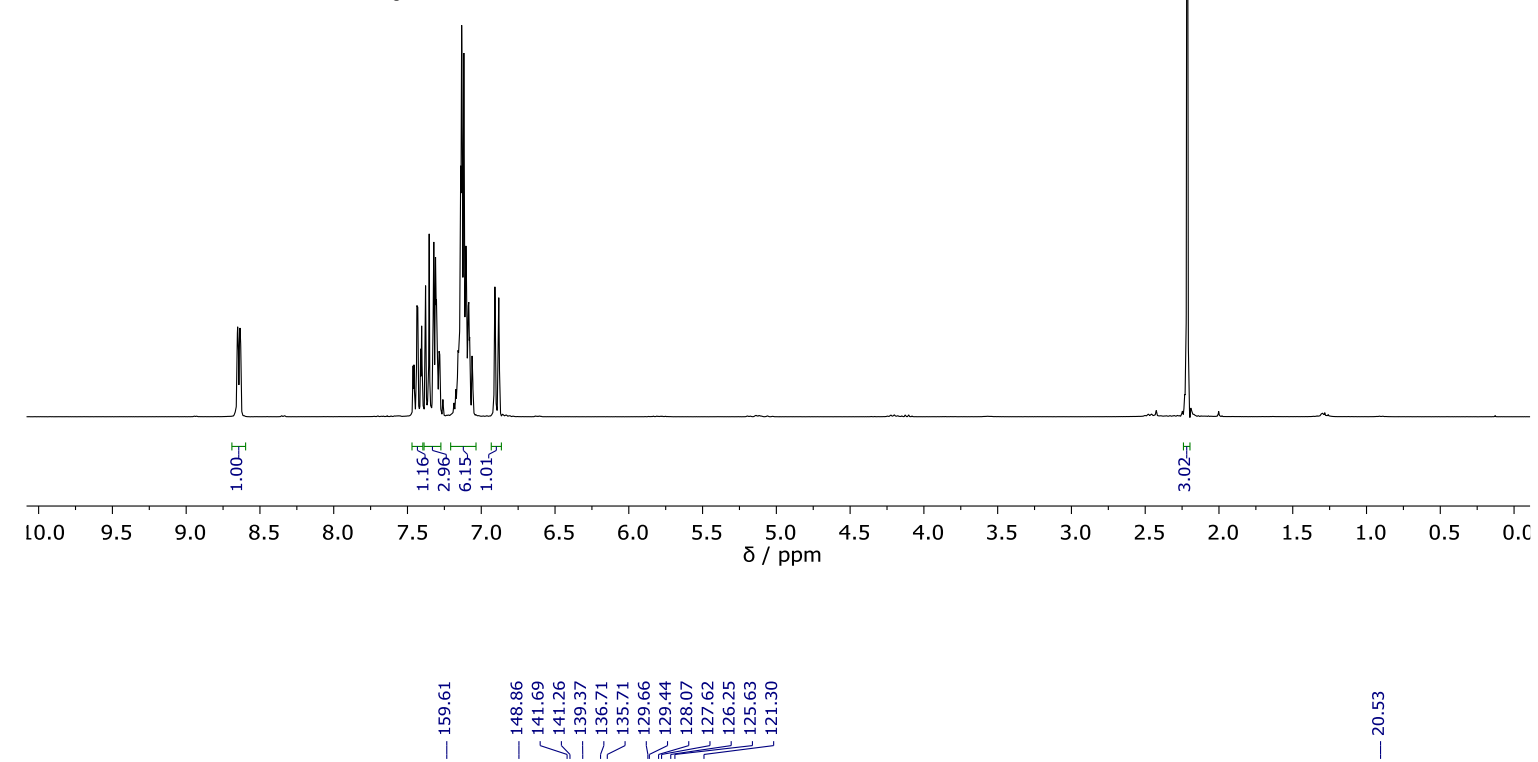<smiles>COc1cccc(-c2ccccc2)c1-c1ccccn1</smiles>

47de

(75 MHz, $\mathrm{CDCl}_{3}$ )

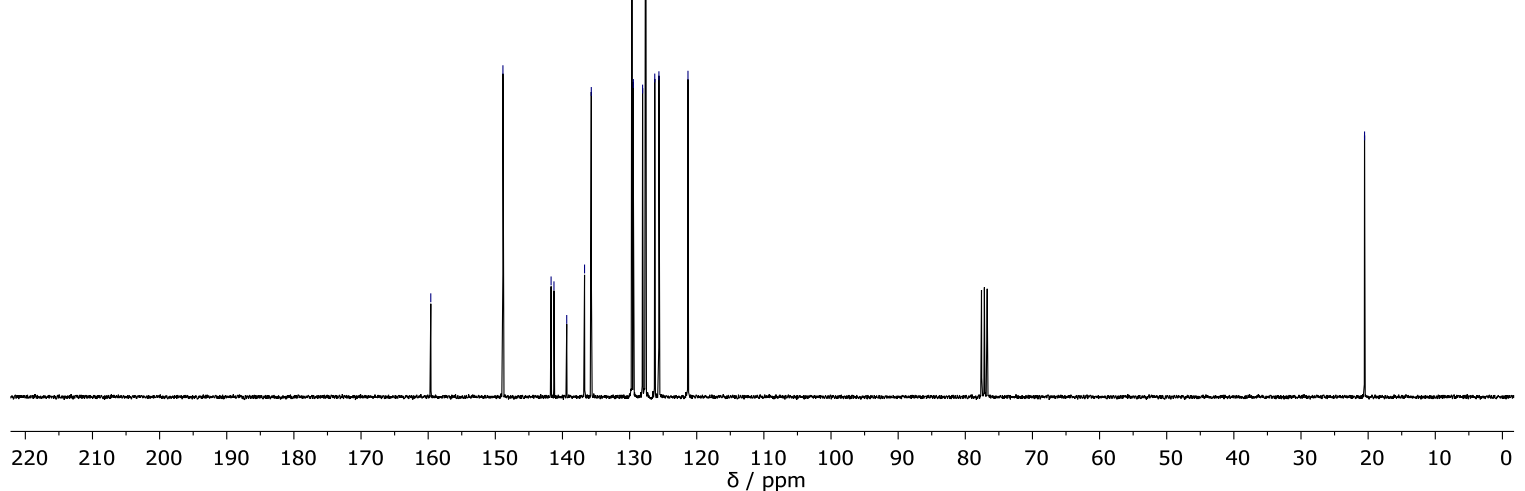


<smiles>Cc1cccc(-c2ccccc2F)c1-c1ccccn1</smiles>

$47 \mathrm{df}$

(400 MHz, $\mathrm{CDCl}_{3}$ )

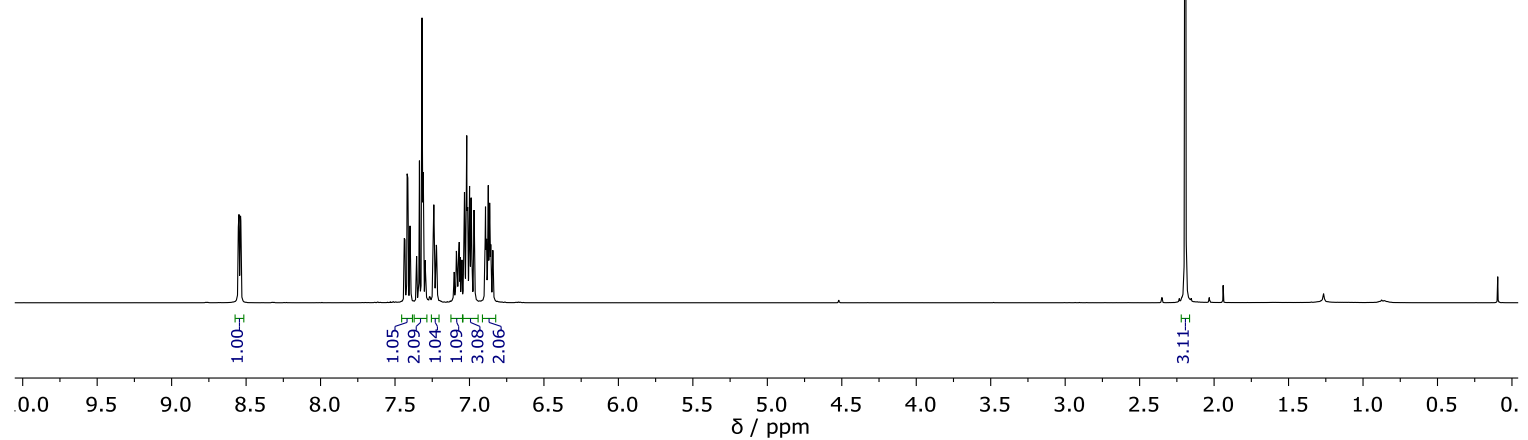

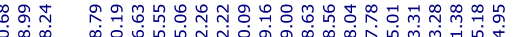

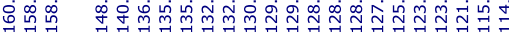

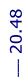<smiles>Cc1cccc(-c2ccccc2F)c1-c1ccccn1</smiles>

$\left(100 \mathrm{MHz}, \mathrm{CDCl}_{3}\right)$

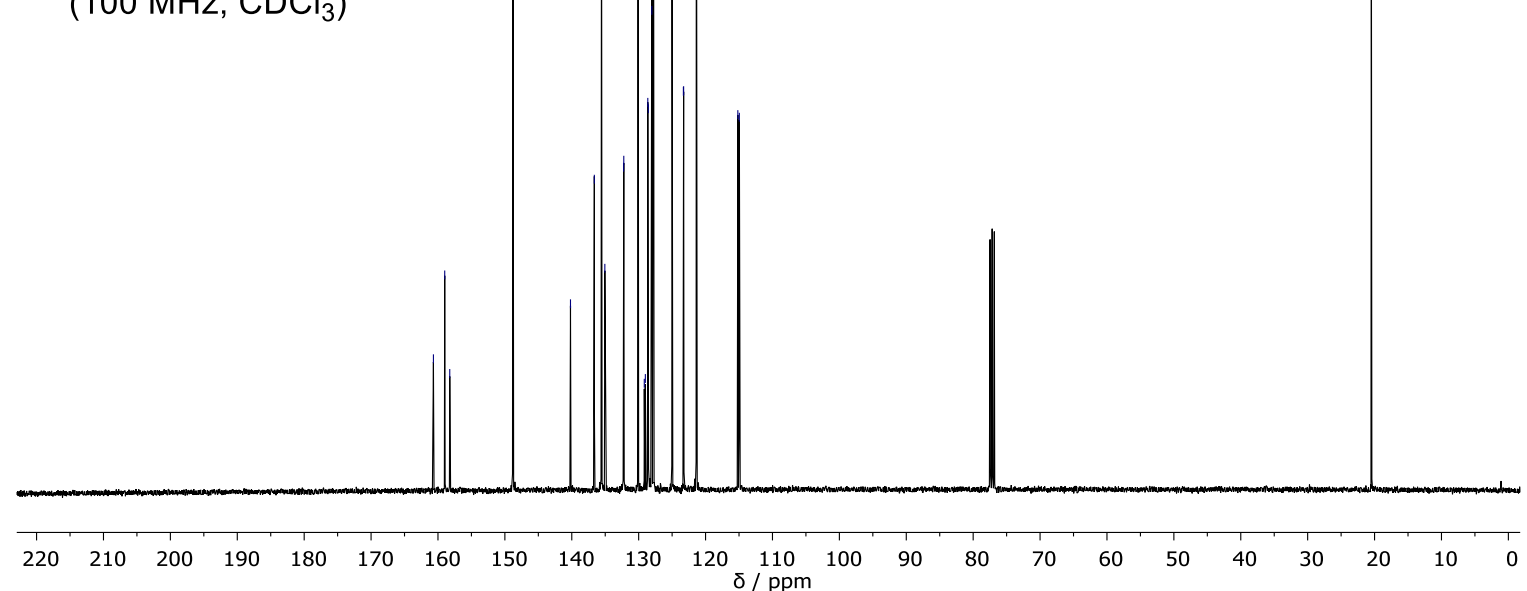




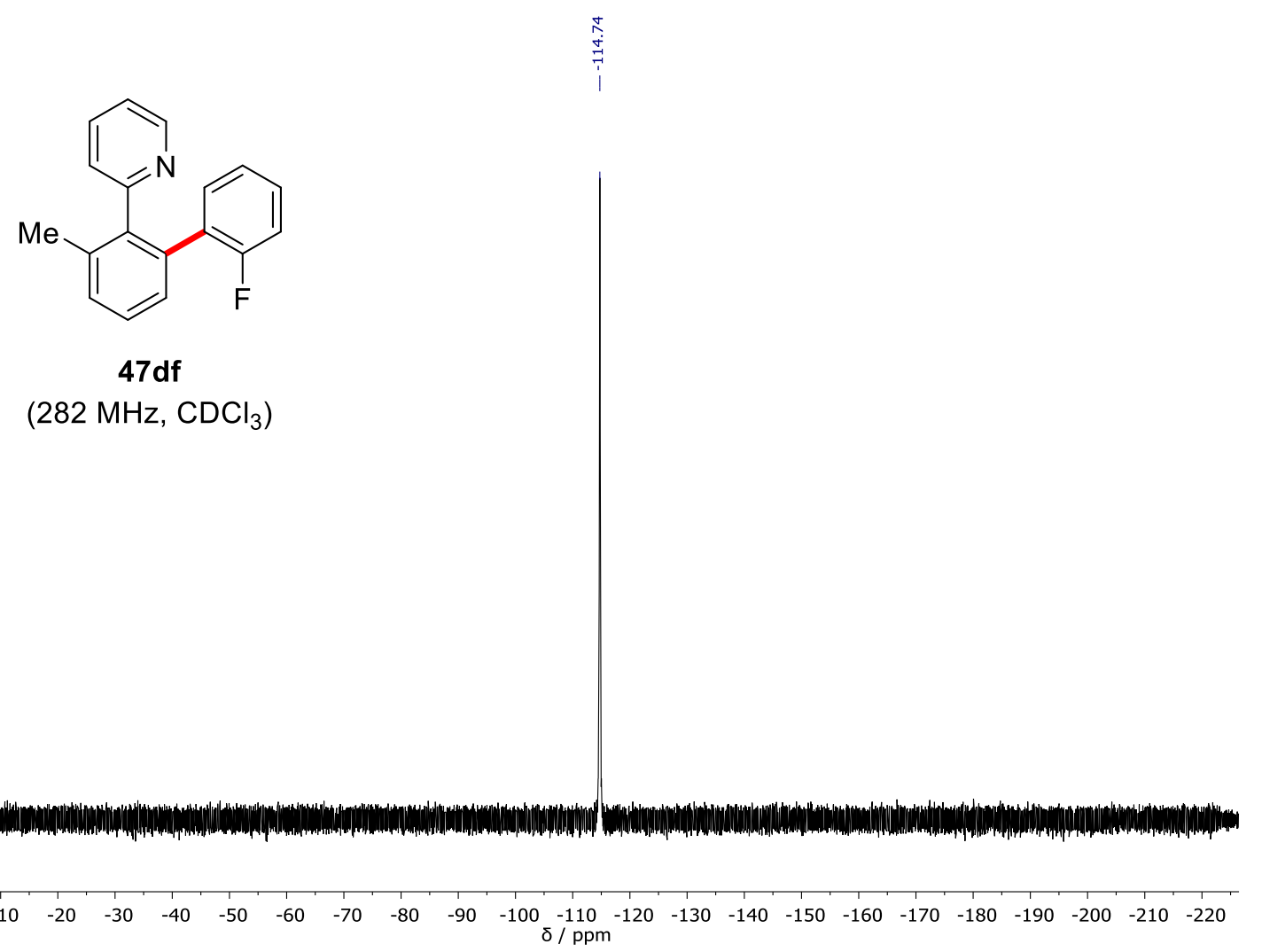<smiles>Cc1ccccc1-c1cccc(C)c1-c1ccccn1</smiles>

$47 \mathrm{dg}$

(300 MHz, $\mathrm{CDCl}_{3}$ )

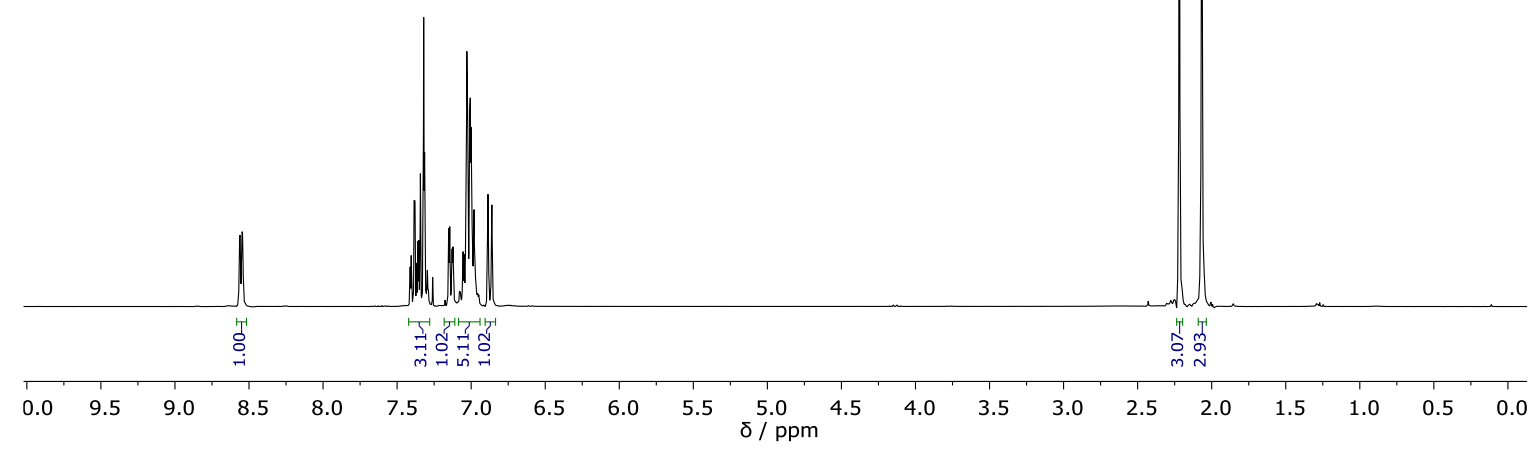



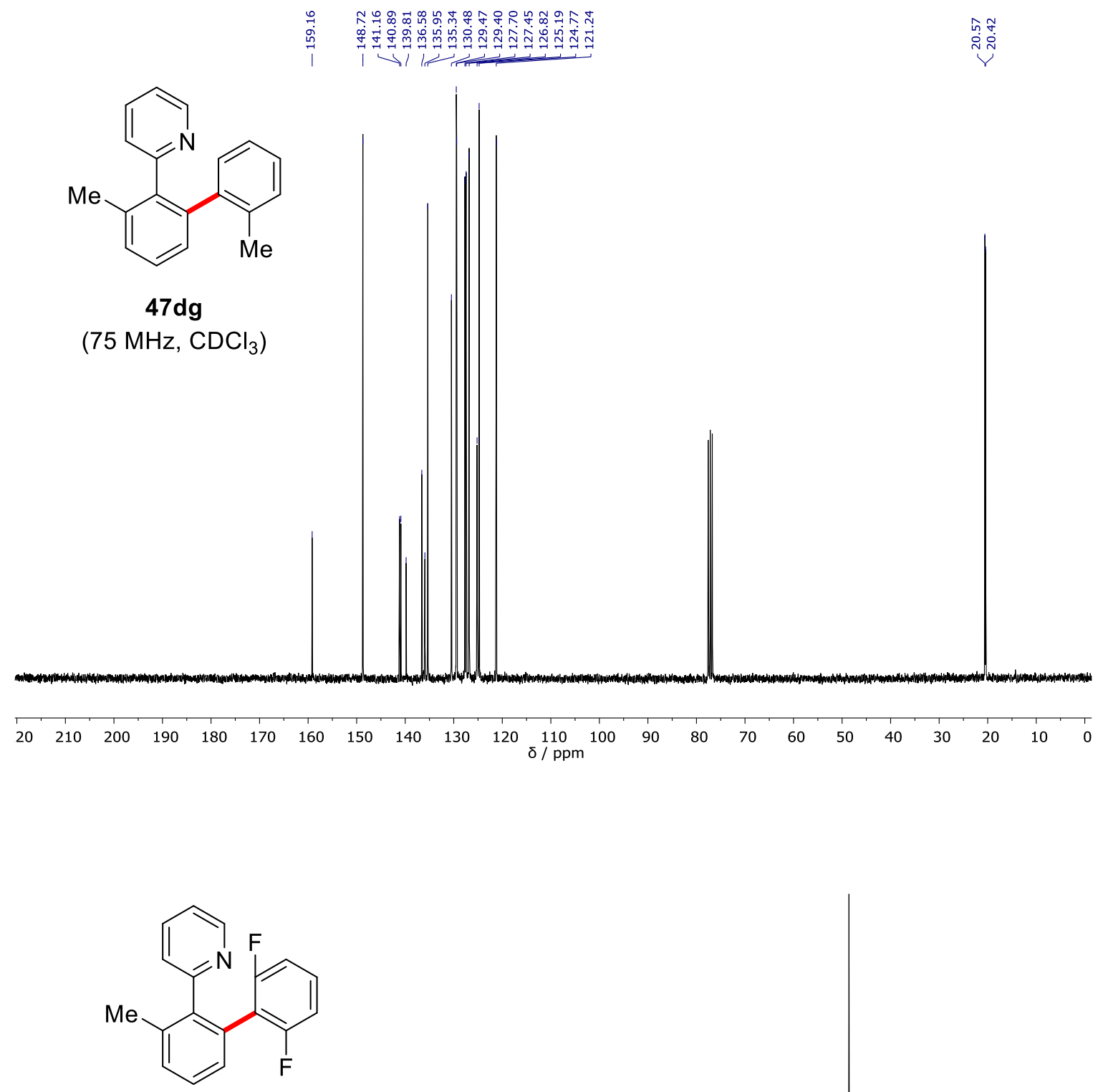

47dh

(300 MHz, $\mathrm{CDCl}_{3}$ )

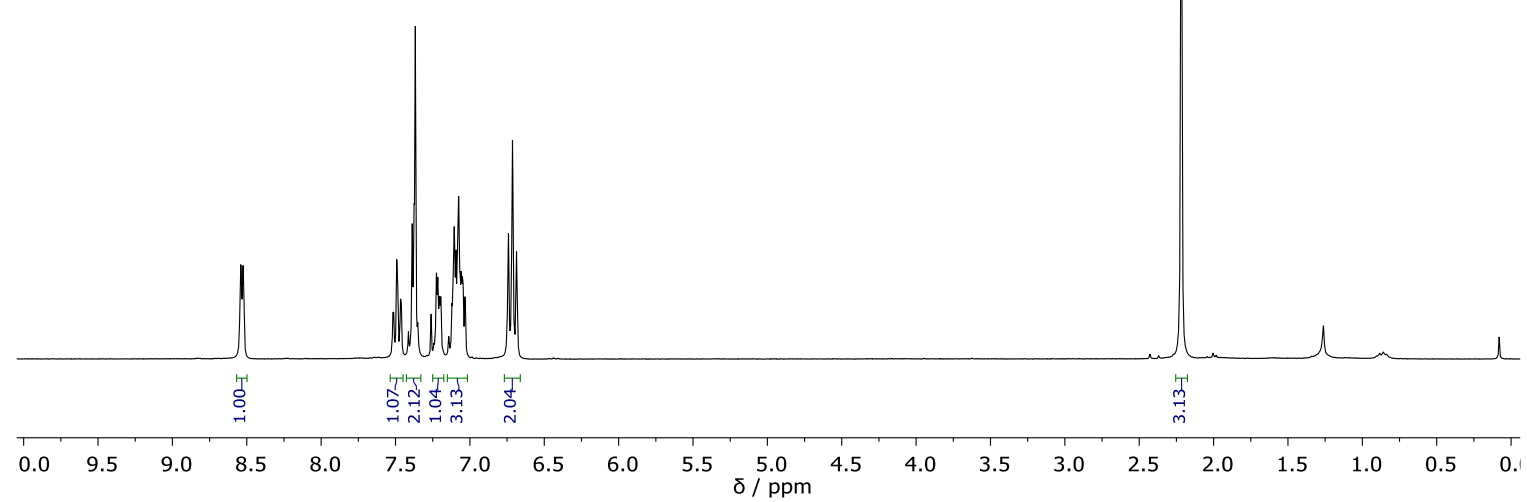


<smiles>Cc1cccc(-c2c(F)cccc2F)c1-c1ccccn1</smiles>

$47 \mathrm{dh}$

(75 MHz, $\mathrm{CDCl}_{3}$ )

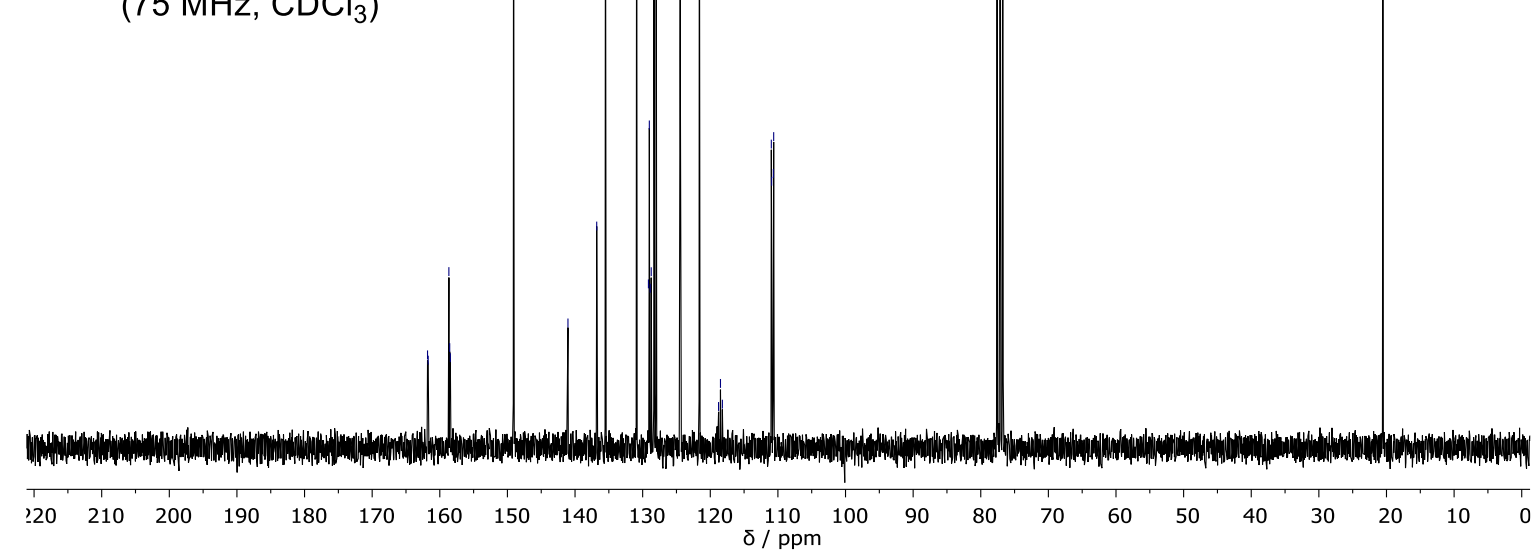<smiles>Cc1cccc(-c2c(F)cccc2F)c1-c1ccccn1</smiles>

$47 \mathrm{dh}$

(282 MHz, $\mathrm{CDCl}_{3}$ ) 
<smiles>CC(=O)c1ccccc1-c1cccc(C)c1-c1ccccn1</smiles>

47di

(300 MHz, $\mathrm{CDCl}_{3}$ )

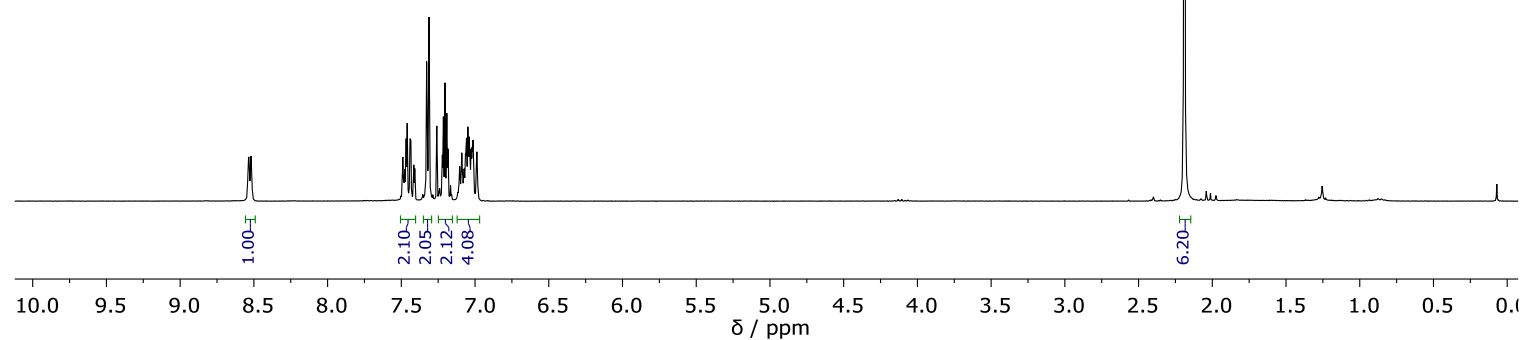<smiles>CC(=O)c1ccccc1-c1cccc(C)c1-c1ccccn1</smiles>

47di

(75 MHz, $\mathrm{CDCl}_{3}$ )

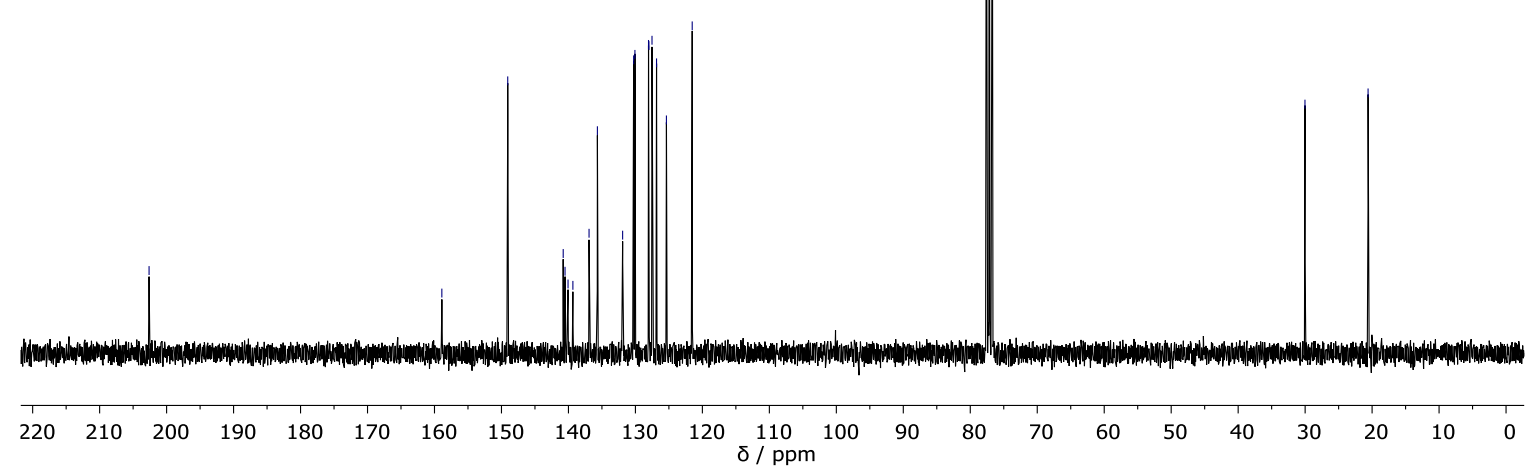


<smiles>Cc1cccc(-c2ccccc2C(F)(F)F)c1-c1ccccn1</smiles>

47dj

$\left(400 \mathrm{MHz}, \mathrm{CDCl}_{3}\right.$ )

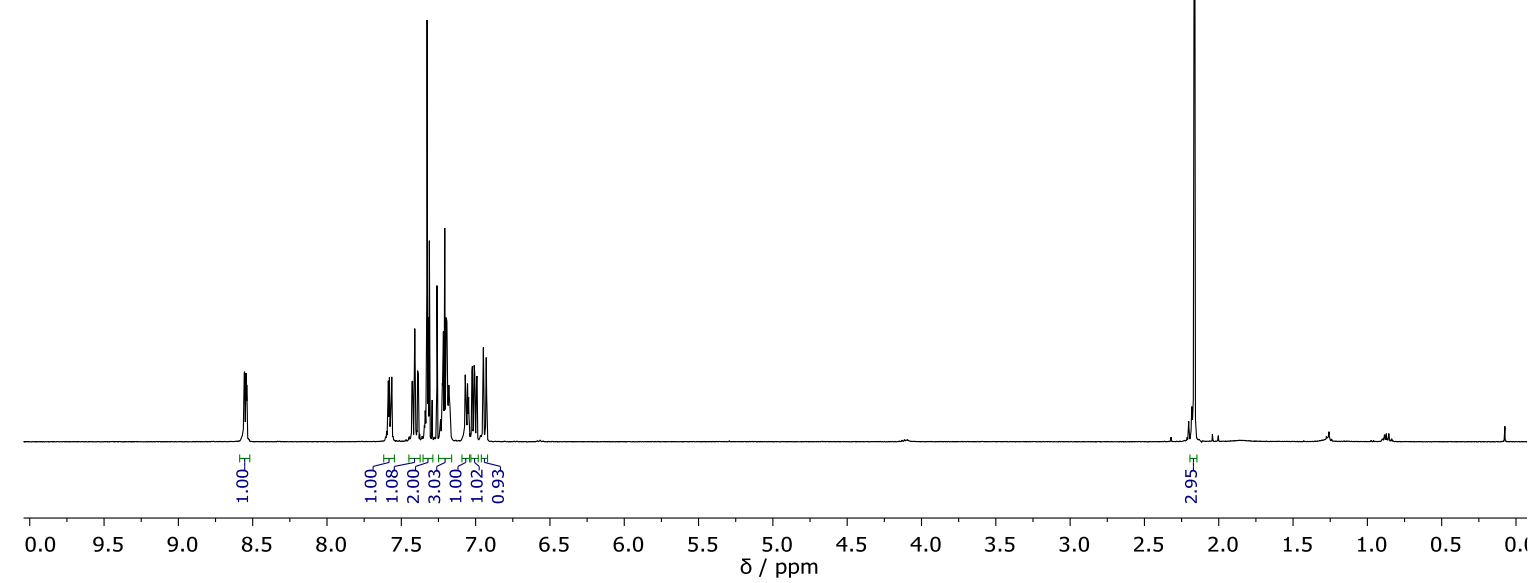

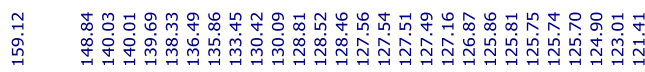<smiles>Cc1cccc(-c2ccccc2C(F)(F)F)c1-c1ccccn1</smiles>

47dj

$\left(100 \mathrm{MHz}, \mathrm{CDCl}_{3}\right.$ )

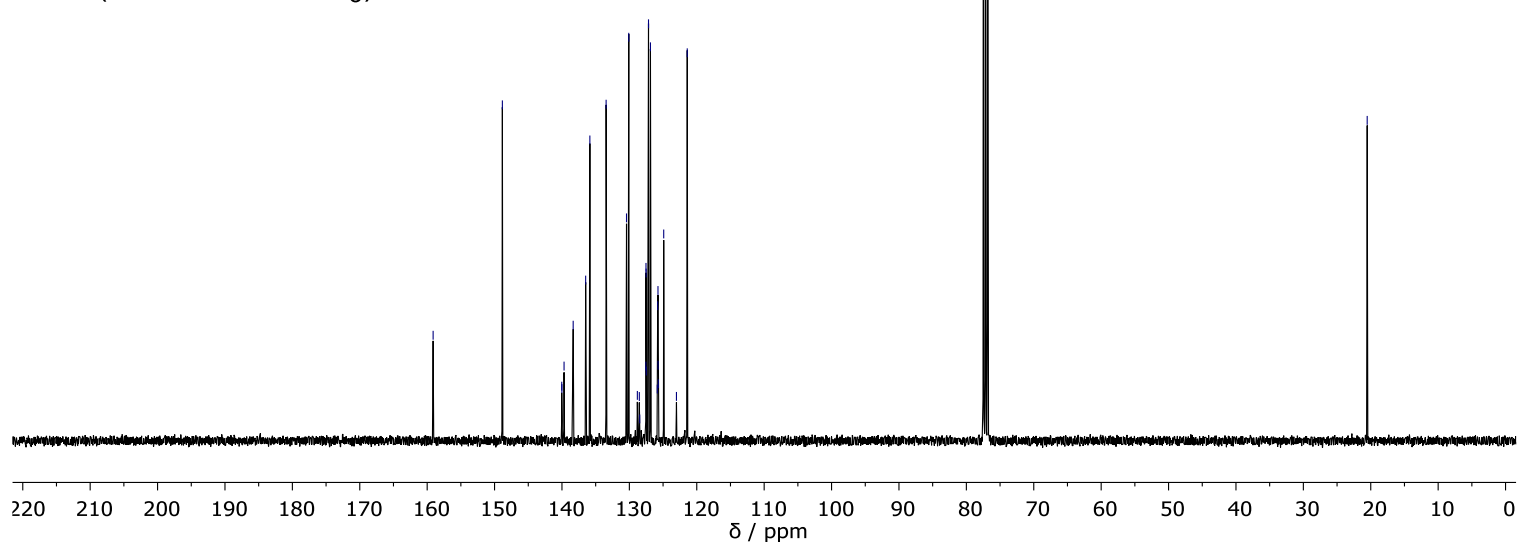




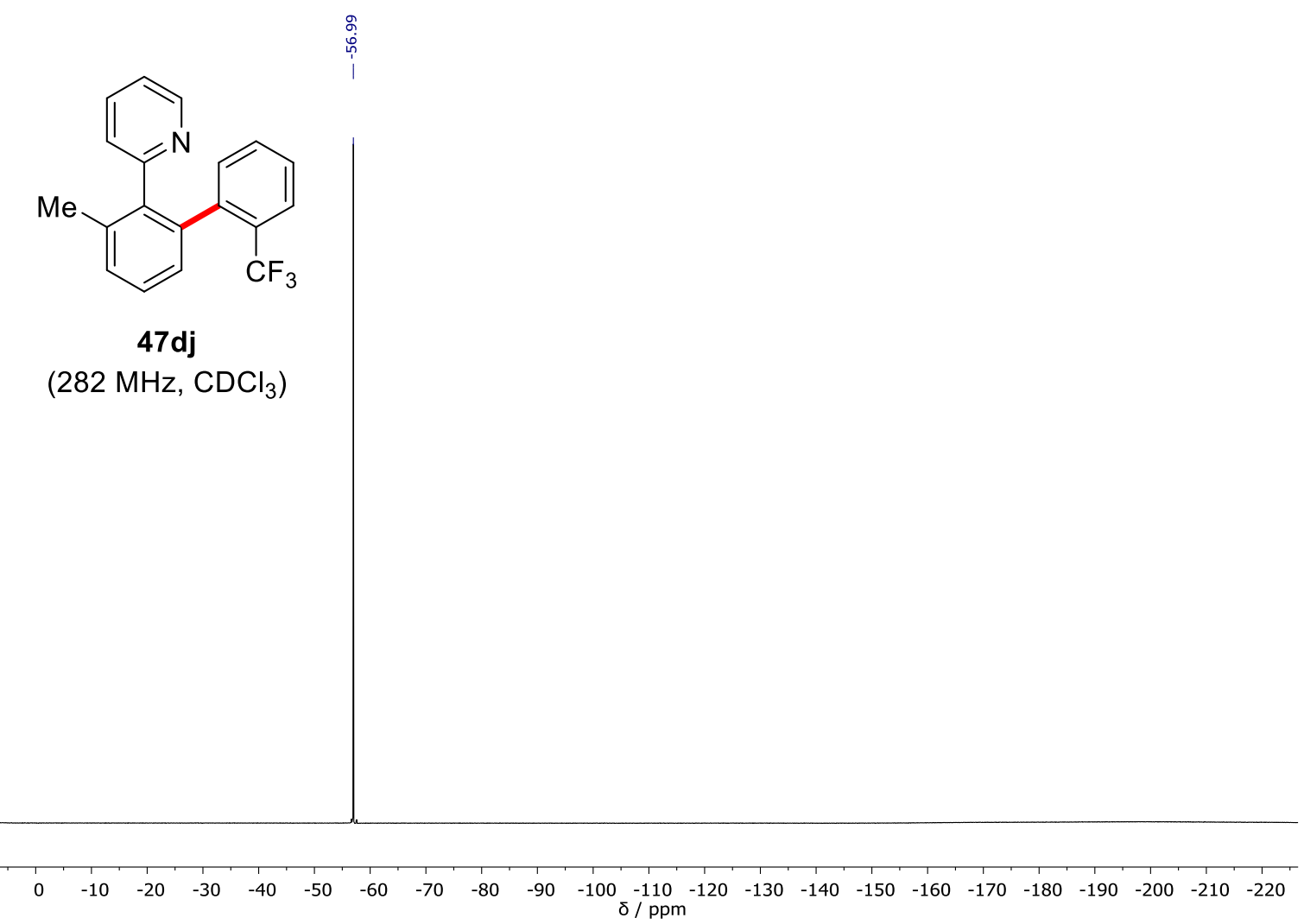<smiles>Cc1cccc(-c2ccccc2C#N)c1-c1ccccn1</smiles>

47dk

(300 MHz, $\mathrm{CDCl}_{3}$ )

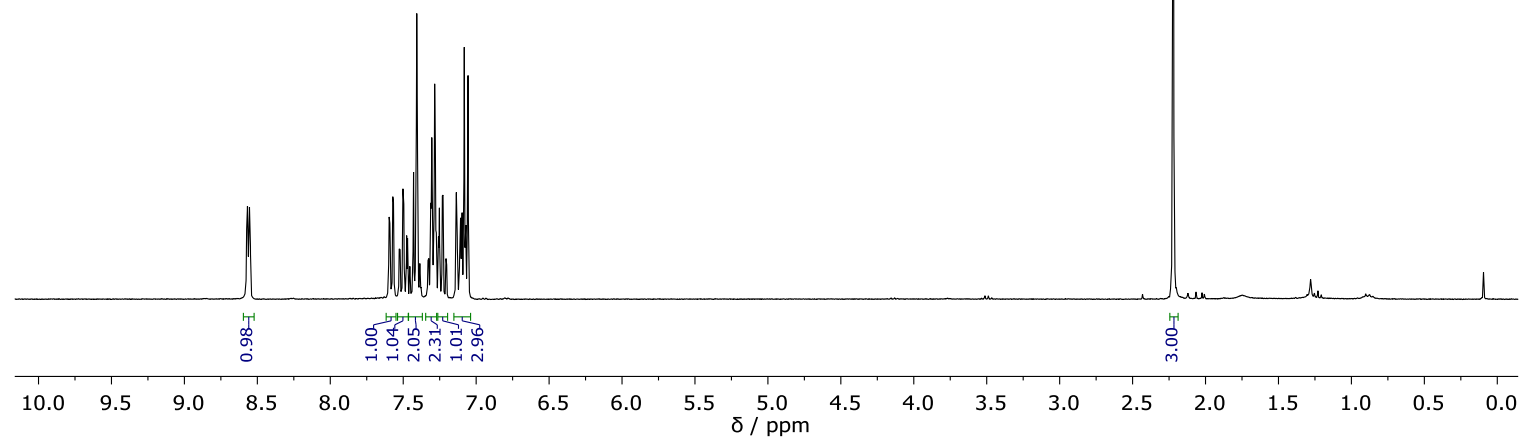


<smiles>Cc1cccc(-c2ccccc2C#N)c1-c1ccccn1</smiles>

47dk

$\left(75 \mathrm{MHz}, \mathrm{CDCl}_{3}\right.$ )
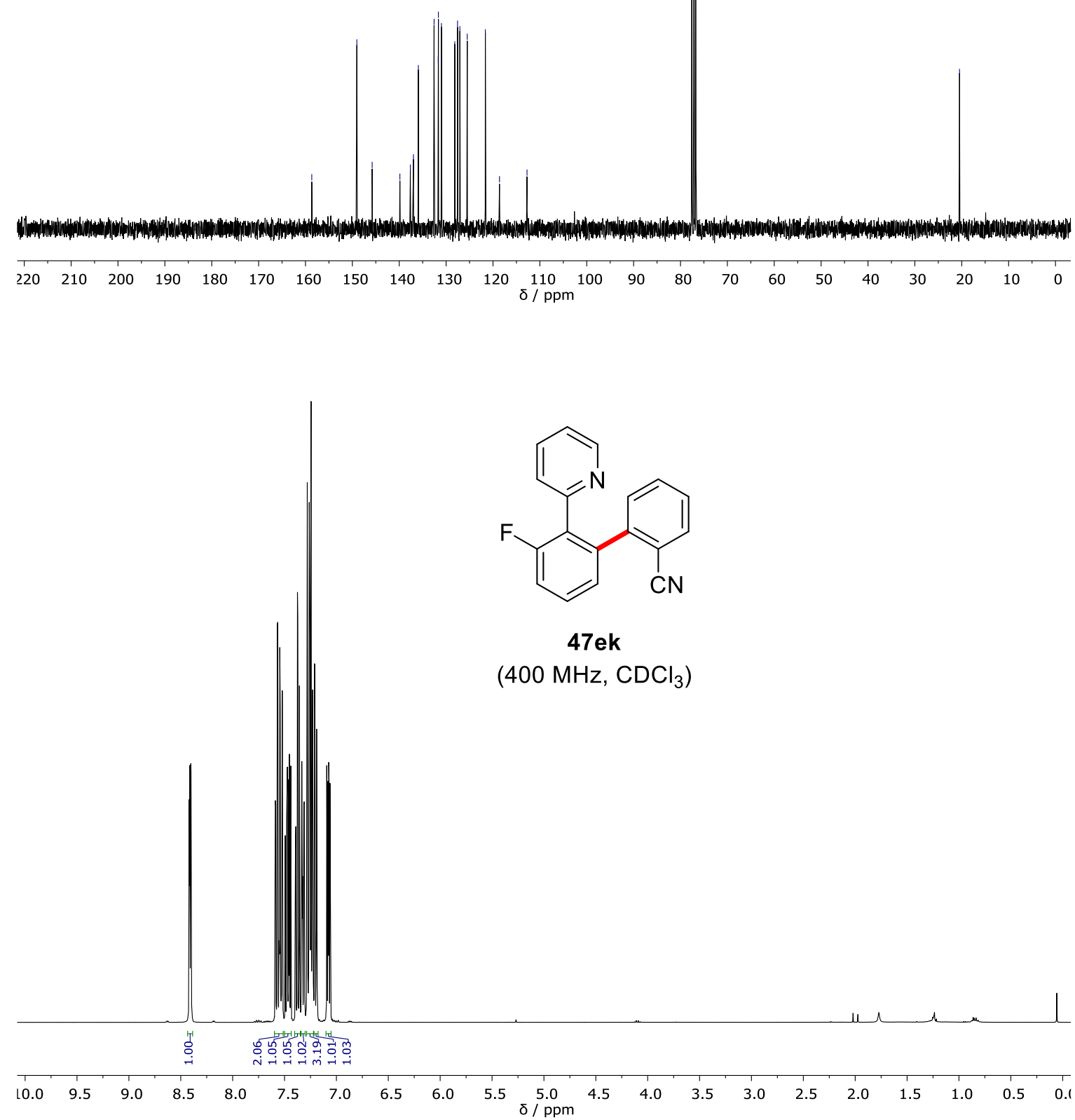


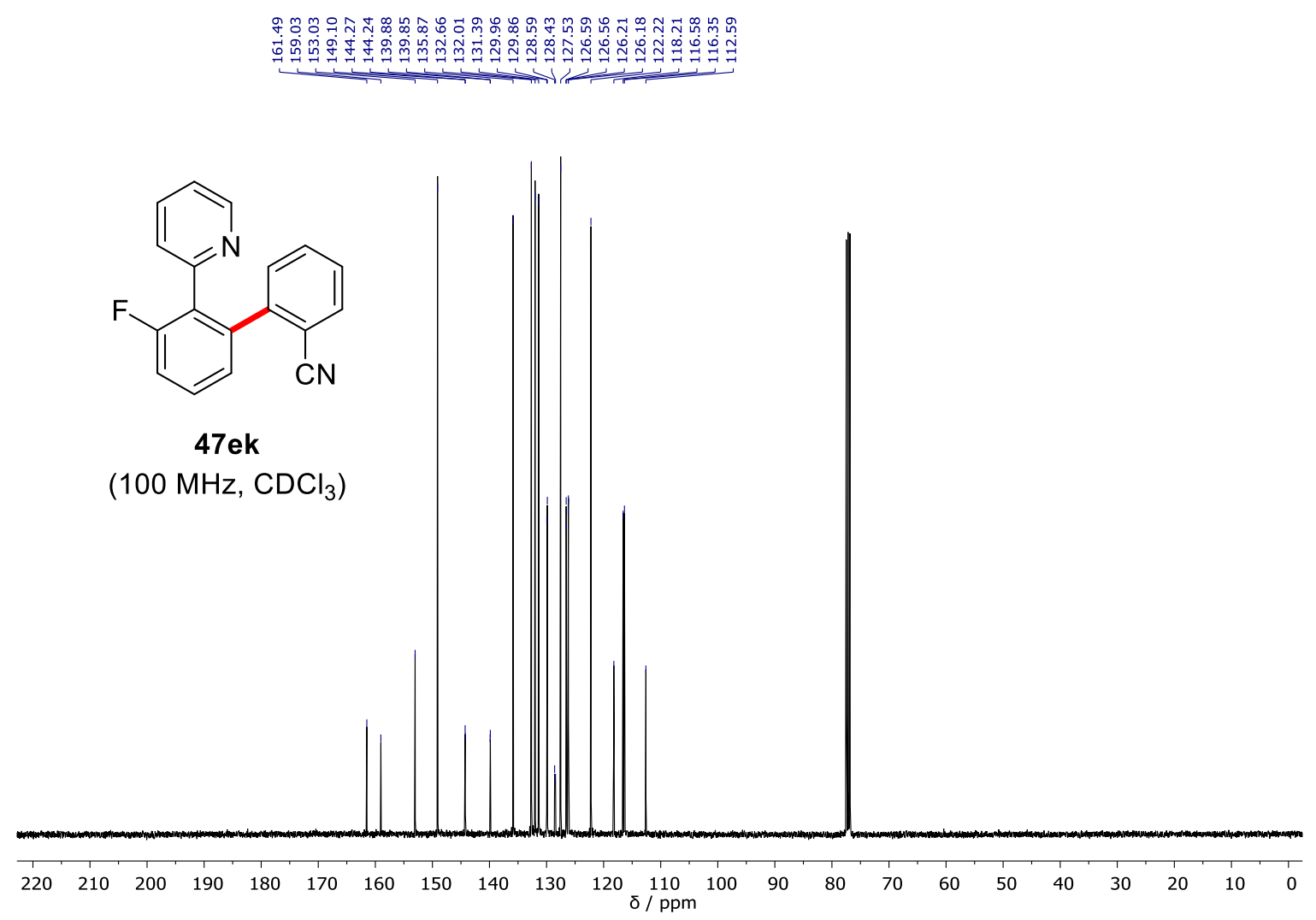<smiles>N#Cc1ccccc1-c1cccc(F)c1-c1ccccn1</smiles>

47ek

(282 $\mathrm{MHz}, \mathrm{CDCl}_{3}$ )

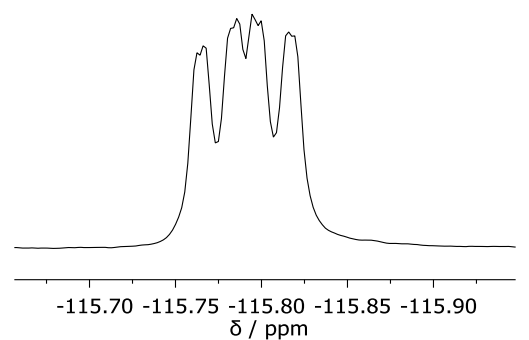

$\begin{array}{lllllllllllllllllllllll}0 & -10 & -20 & -30 & -40 & -50 & -60 & -70 & -80 & -90 & -100 & -110 & -120 & -130 & -140 & -150 & -160 & -170 & -180 & -190 & -200 & -210 & -220\end{array}$ 
<smiles>Cc1ccc(-c2ccccc2C#N)c(-c2ccccn2)c1</smiles>

47hk

(300 MHz, $\mathrm{CDCl}_{3}$ )

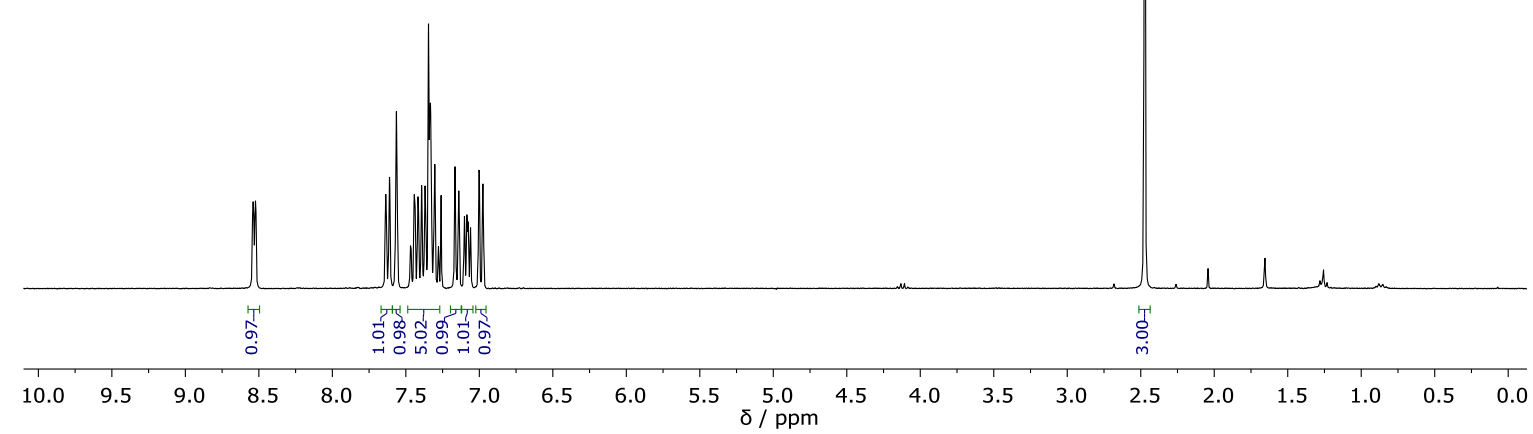

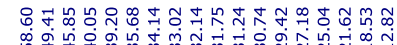

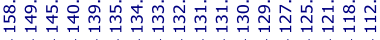<smiles>Cc1ccc(-c2ccccc2C#N)c(-c2ccccn2)c1</smiles>

(75 $\mathrm{MHz}, \mathrm{CDCl}_{3}$ )

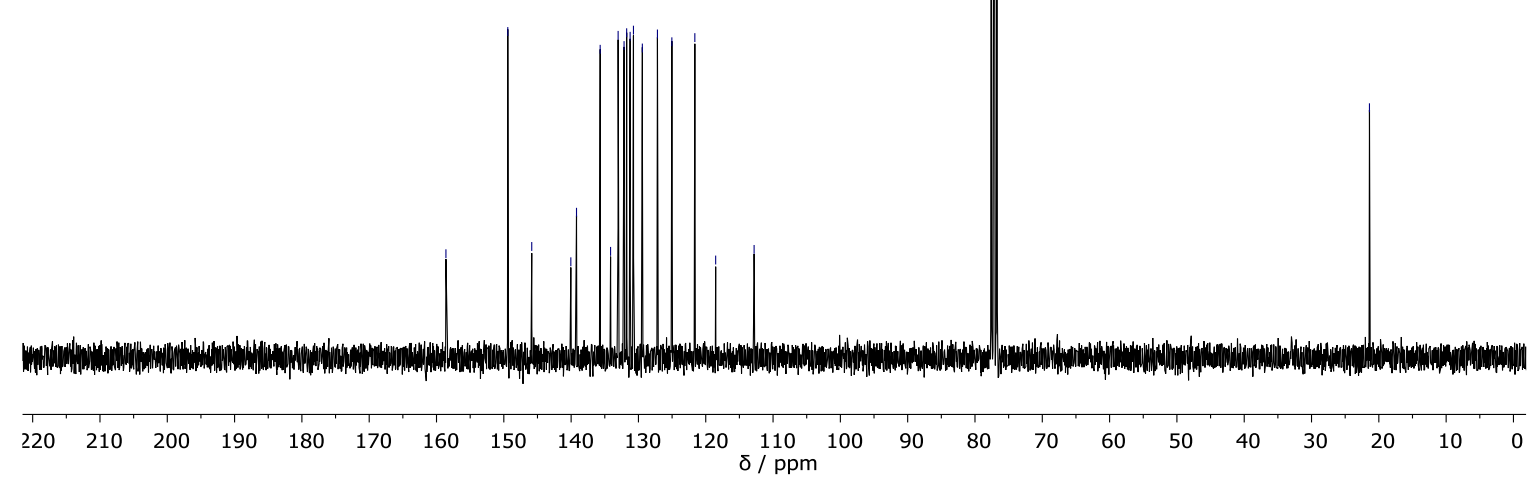


<smiles>CN(C)c1cccc(-c2ccccc2C#N)c1-c1ccccn1</smiles>

\section{7ik}

(400 MHz, $\mathrm{CDCl}_{3}$ )

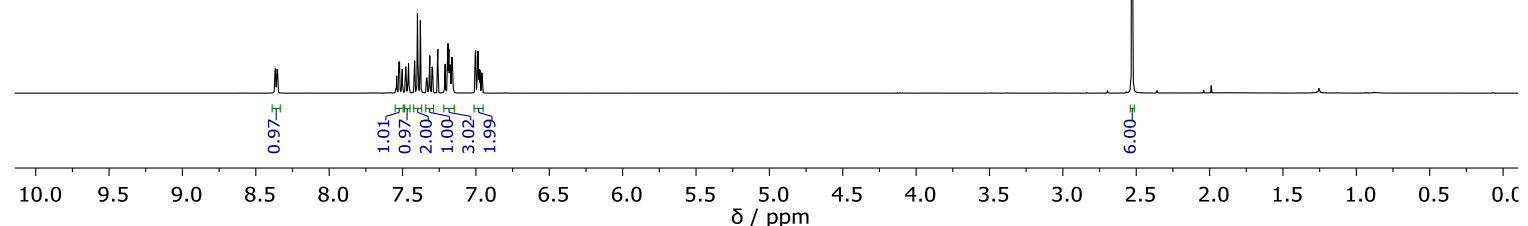

จุ๊

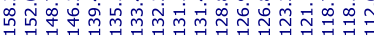<smiles>CN(C)c1cccc(-c2ccccc2C#N)c1-c1ccccn1</smiles>

47ik

(100 MHz, $\mathrm{CDCl}_{3}$ )

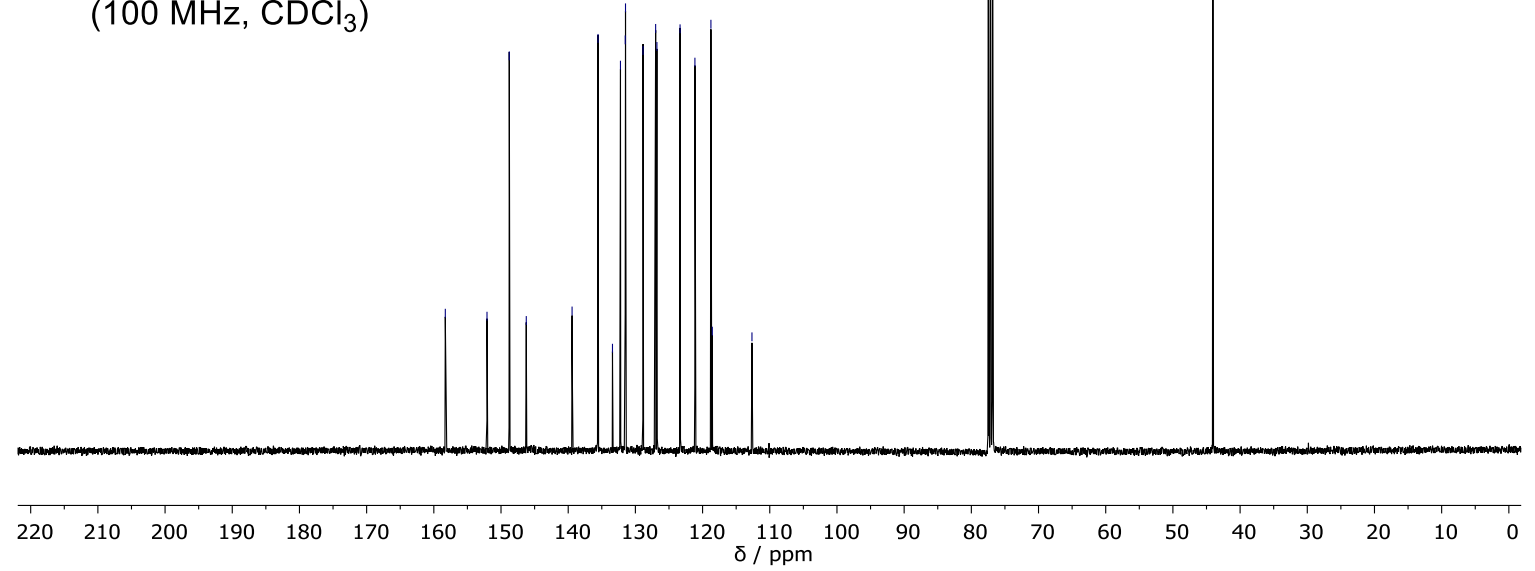



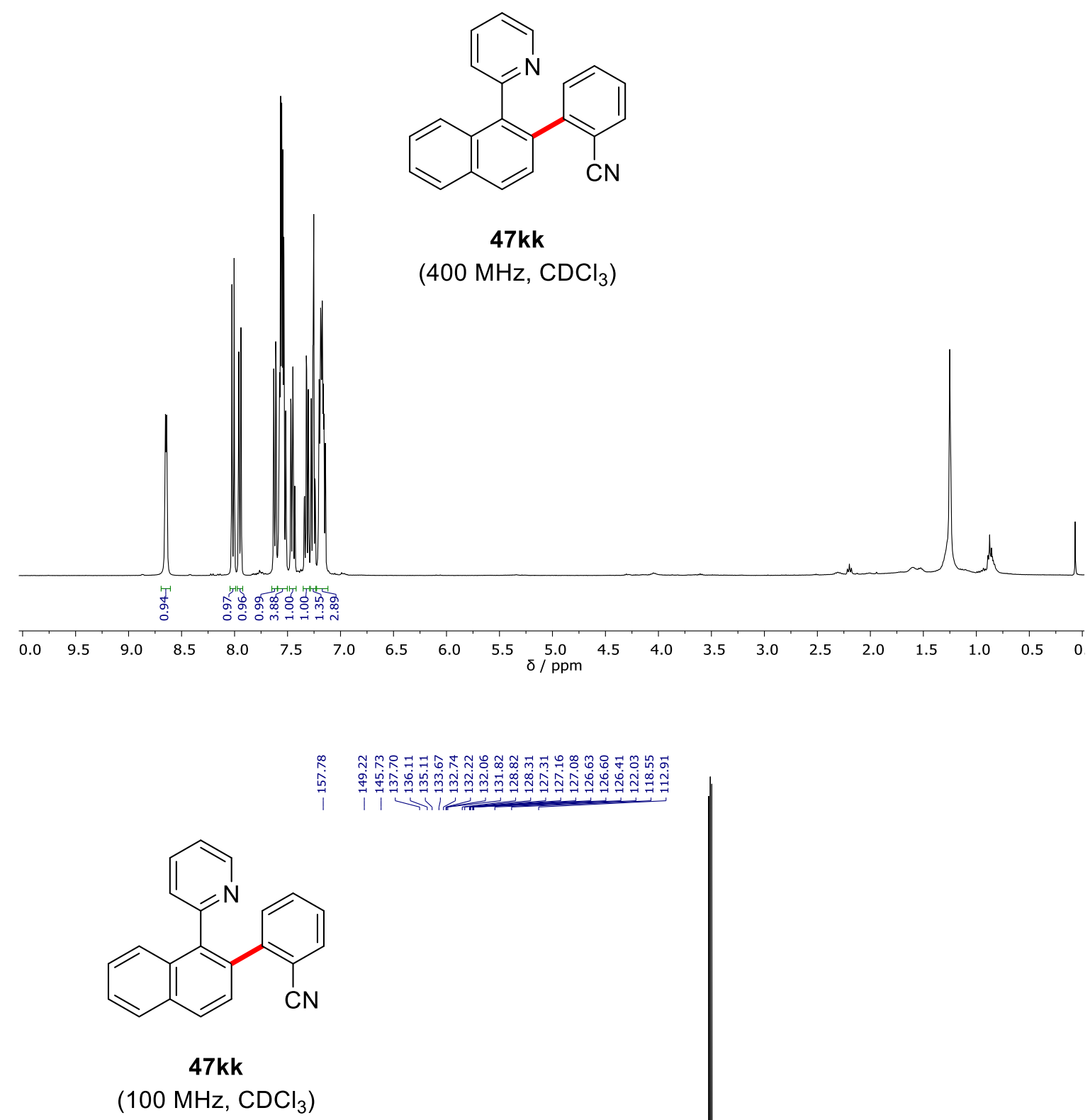

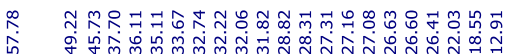

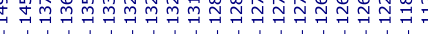

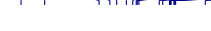




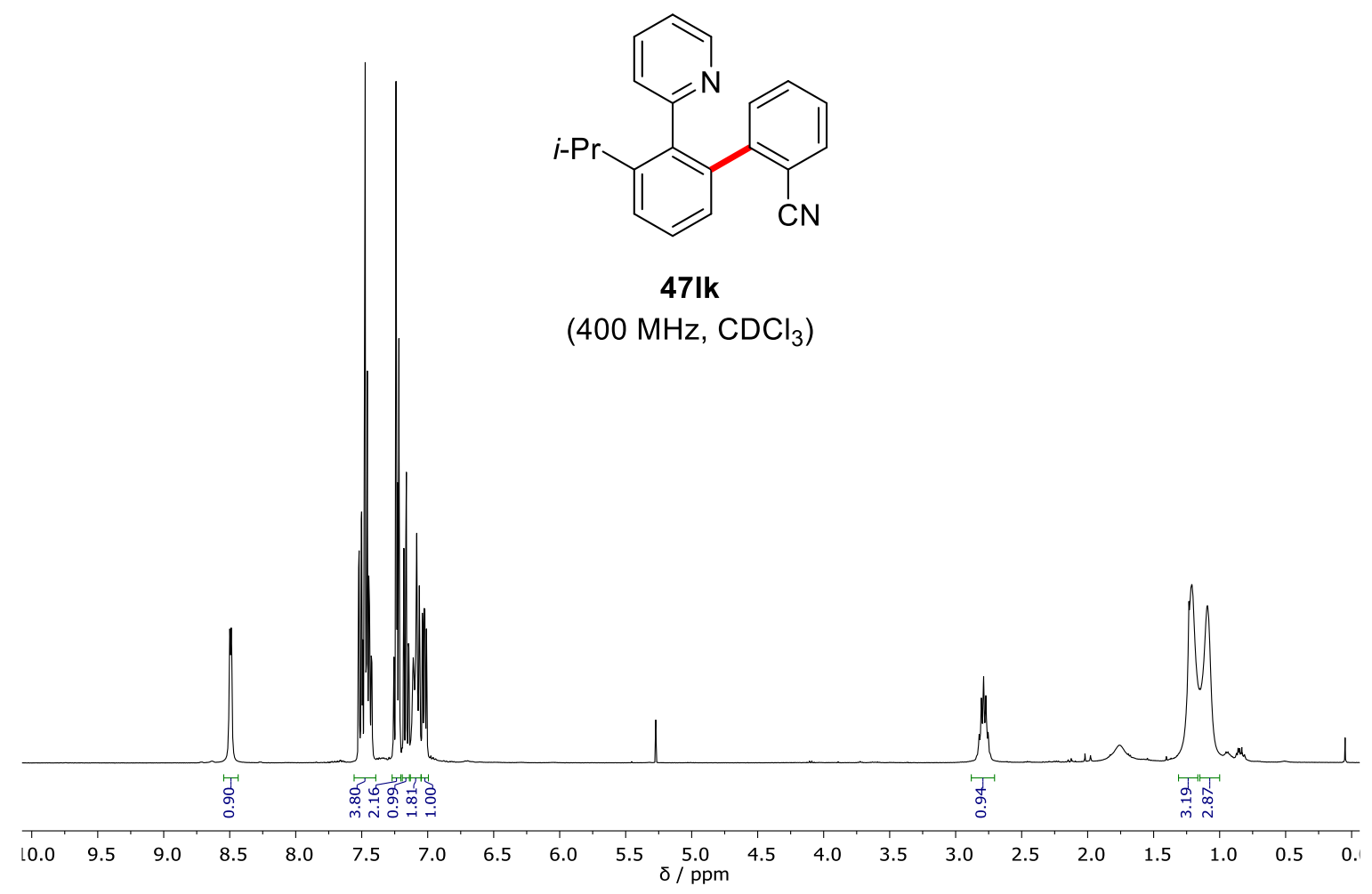<smiles>CC(C)c1cccc(-c2ccccc2C#N)c1-c1ccccn1</smiles>

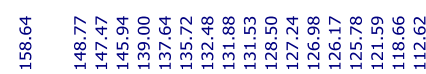

:

47lk

(100 MHz, $\mathrm{CDCl}_{3}$ )

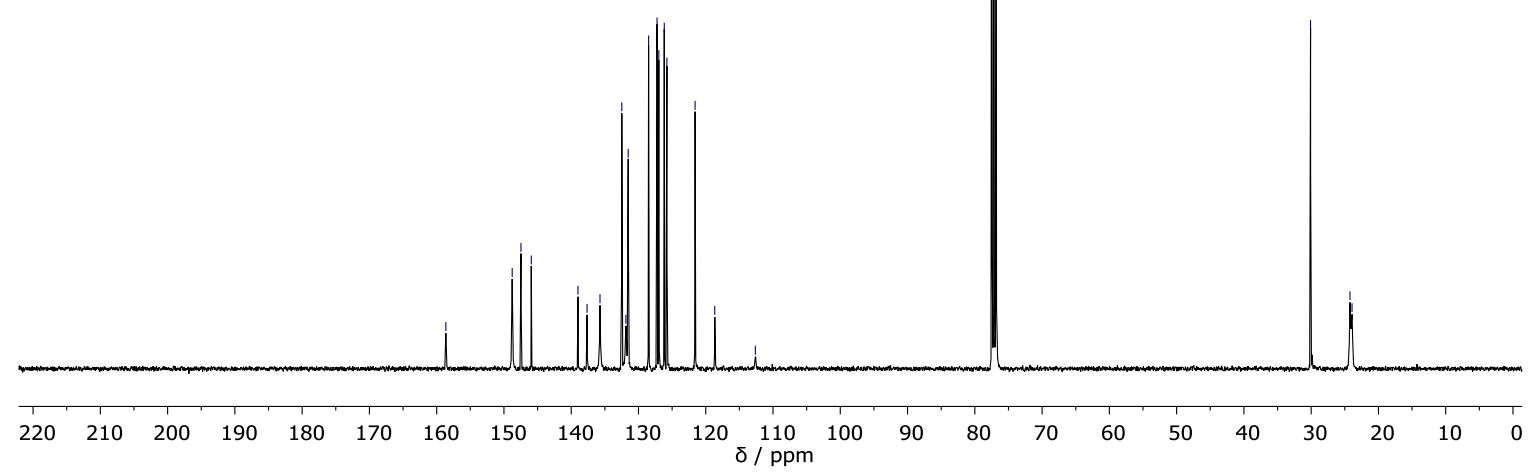




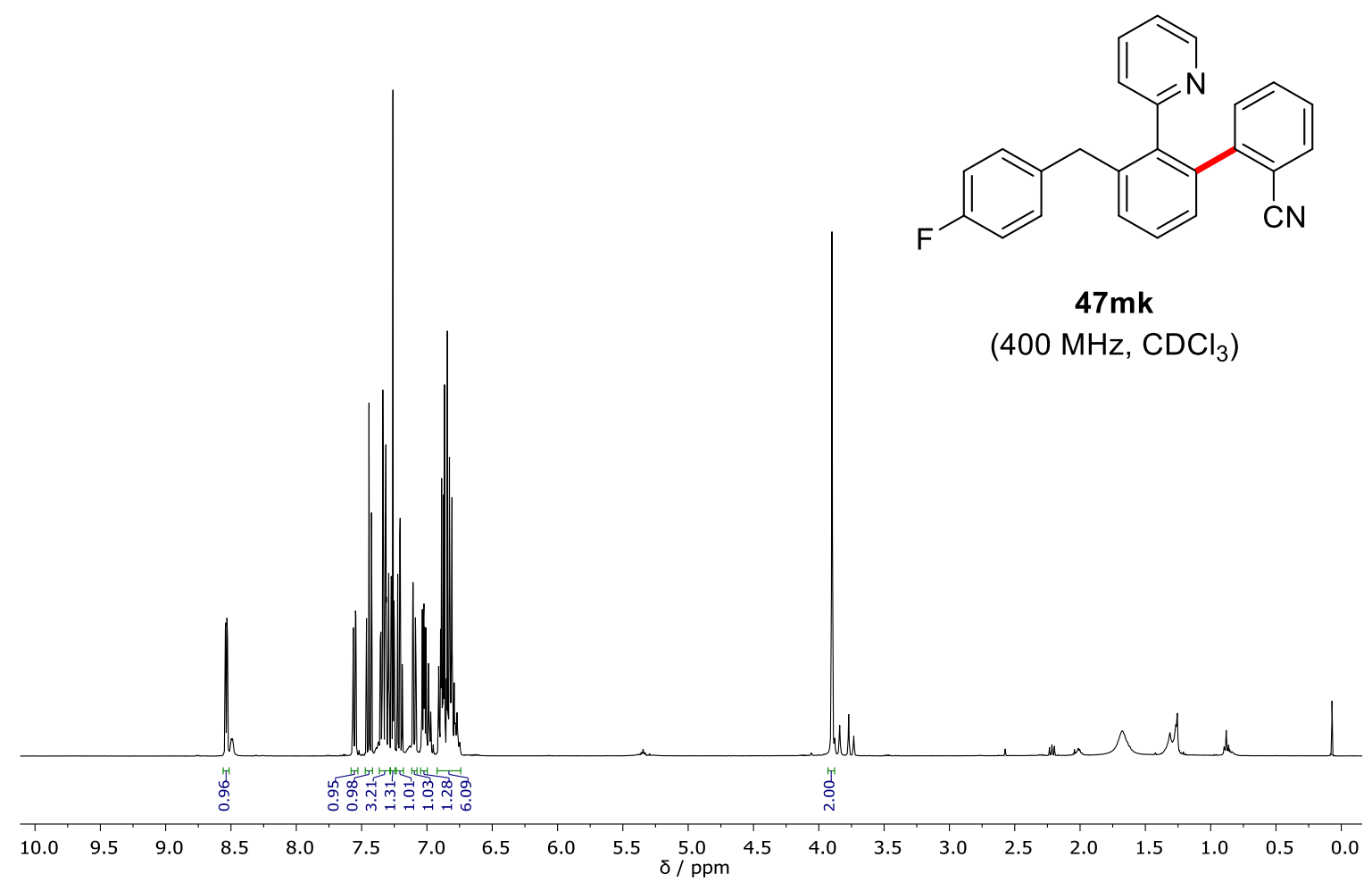<smiles>N#Cc1ccccc1-c1cccc(Cc2ccc(F)cc2)c1-c1ccccn1</smiles>

47mk

$\left(100 \mathrm{MHz}, \mathrm{CDCl}_{3}\right)$

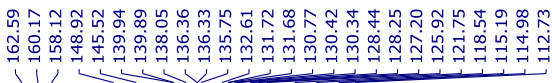

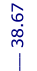

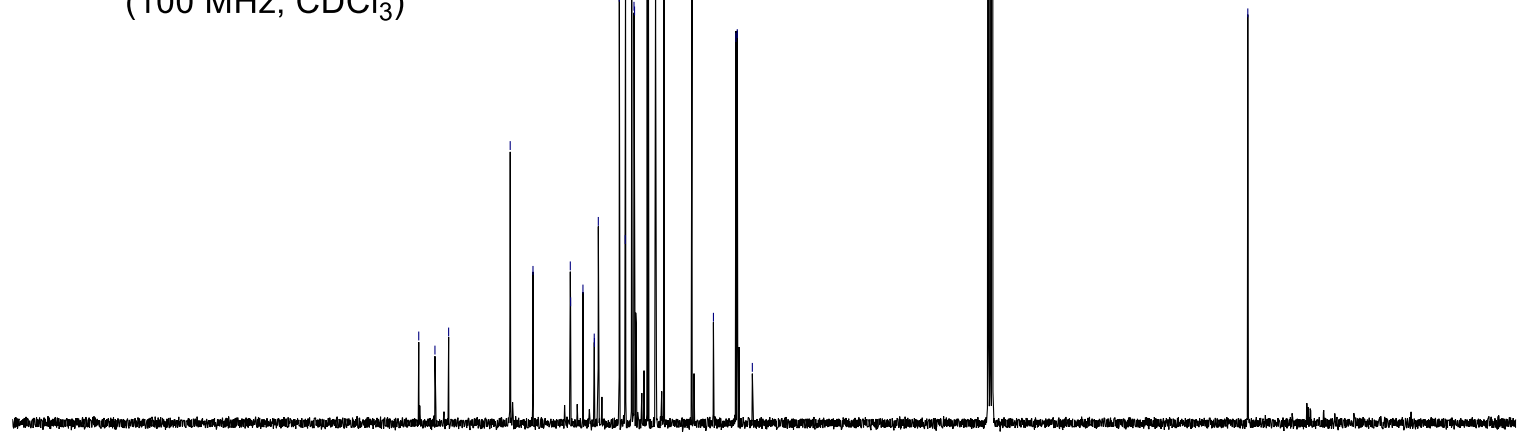

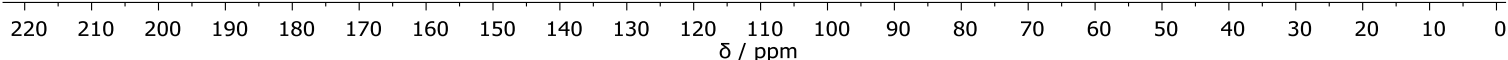



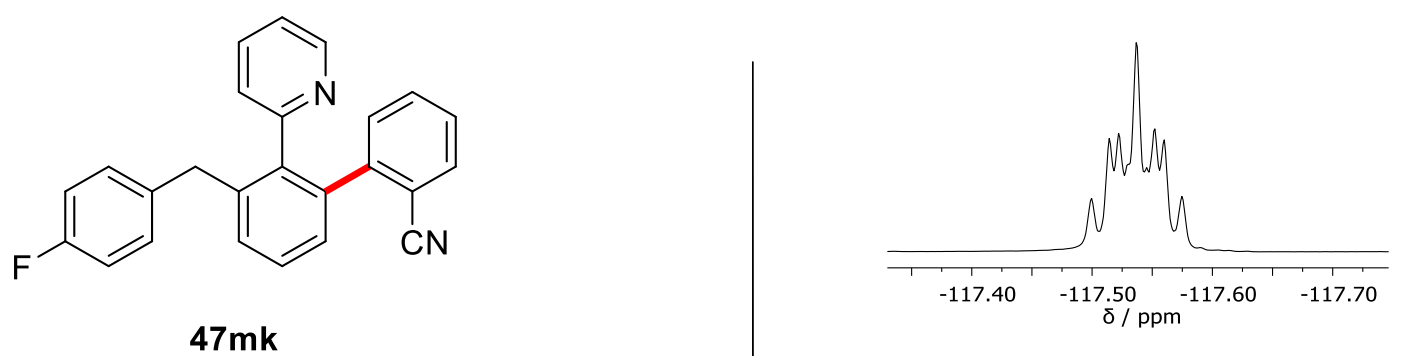

(376 MHz, $\mathrm{CDCl}_{3}$ )

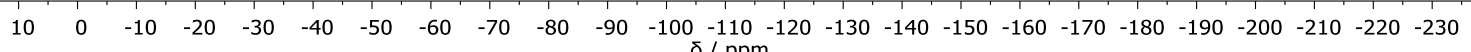

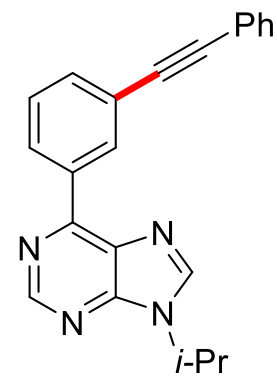

$150 a$

$\left(400 \mathrm{MHz}, \mathrm{CDCl}_{3}\right)$

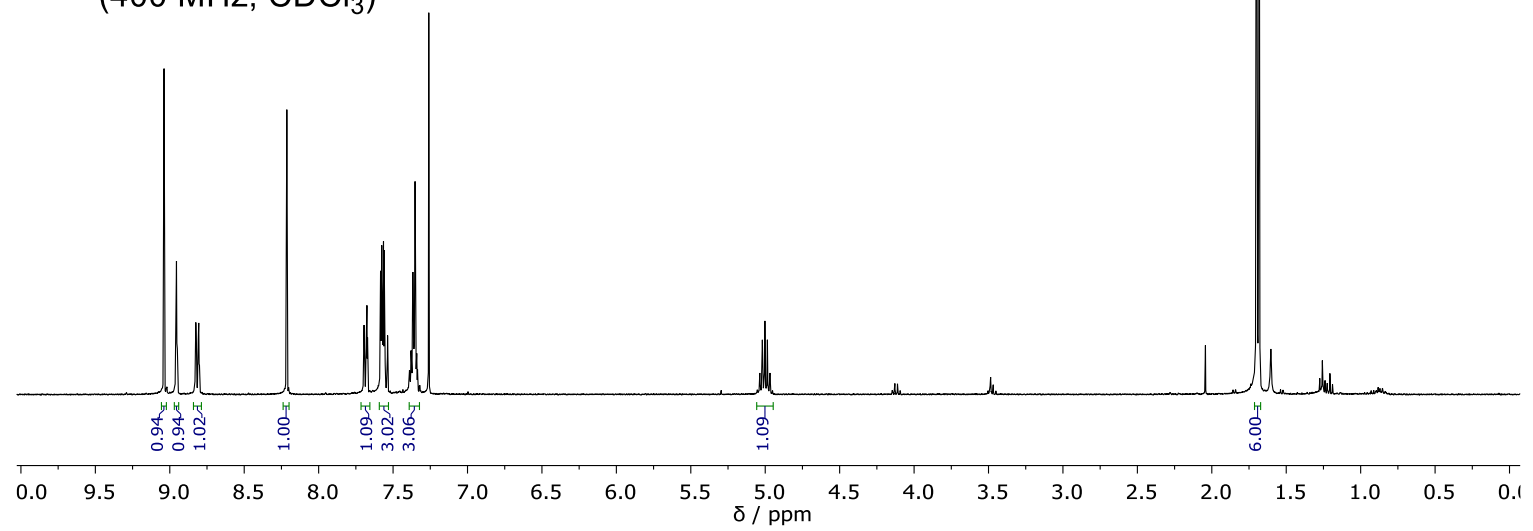



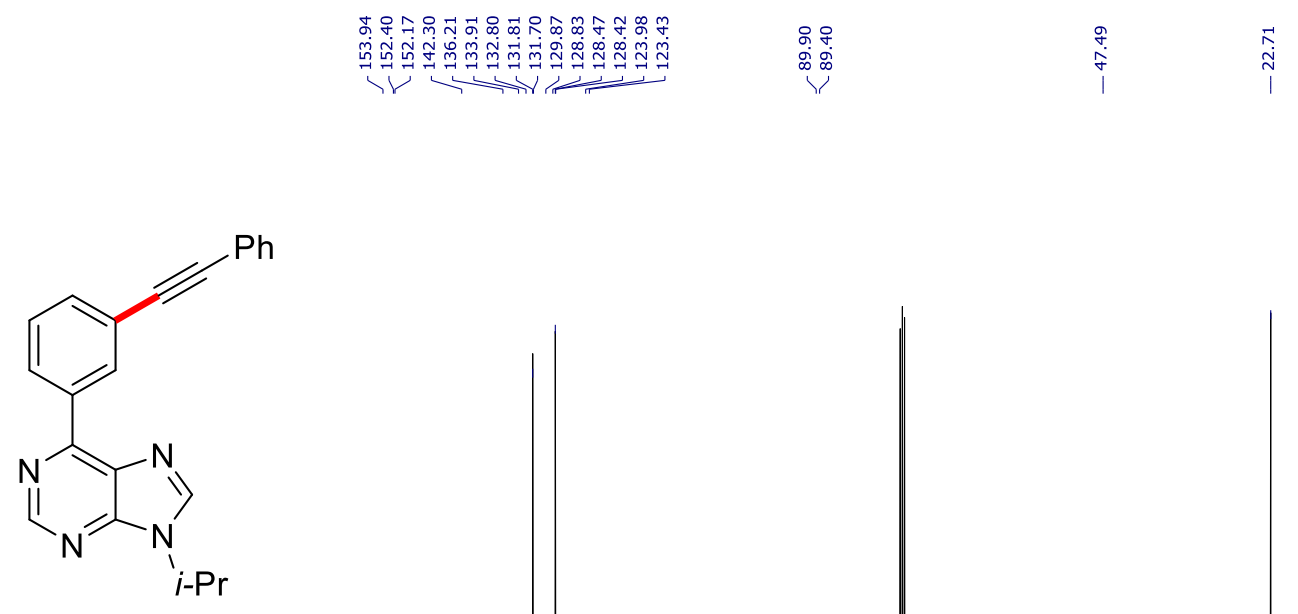

$150 a$

(100 MHz, CDCl $\mathrm{CD}_{3}$ )
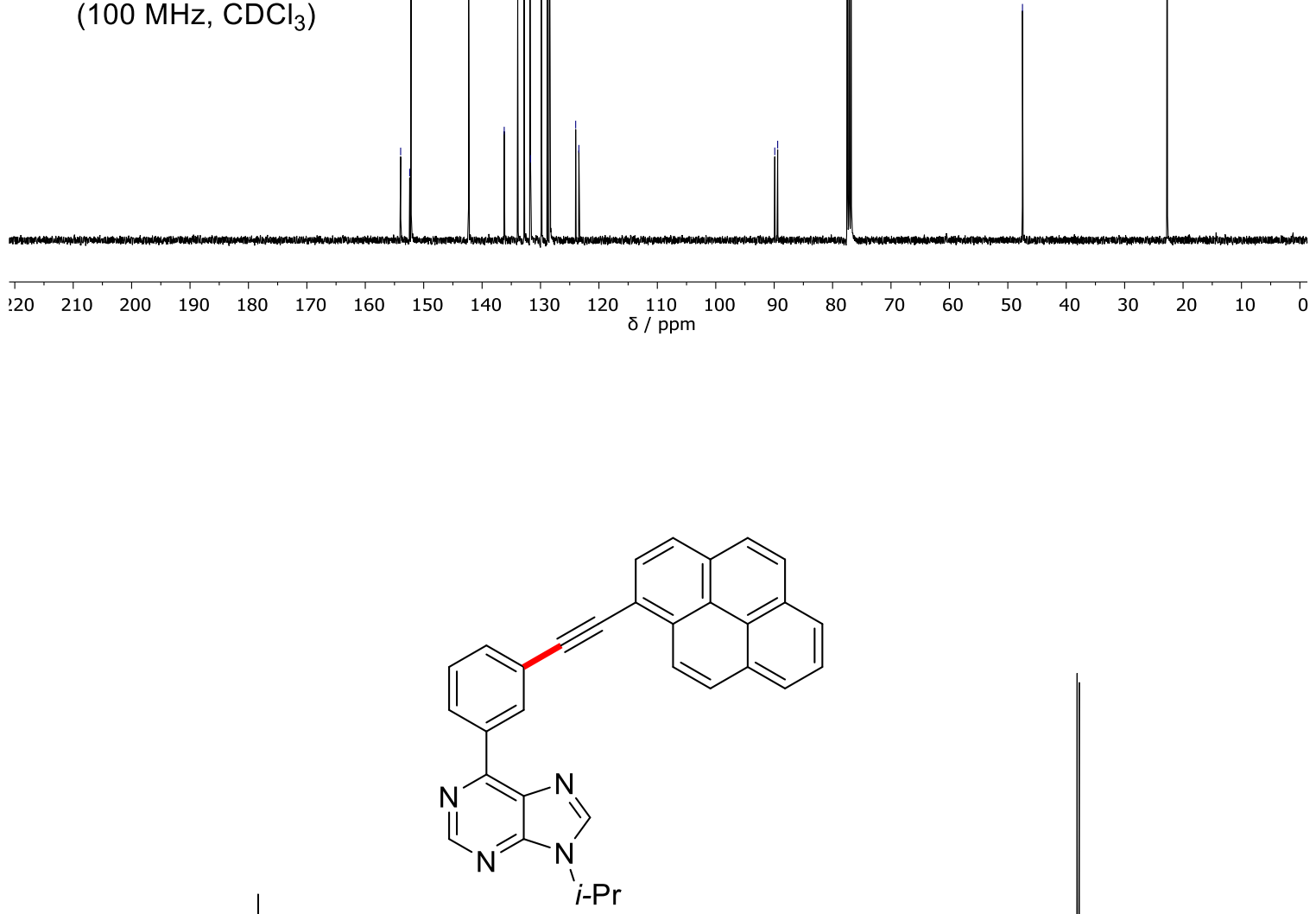

$150 \mathrm{~b}$

(400 MHz, $\mathrm{CDCl}_{3}$ )

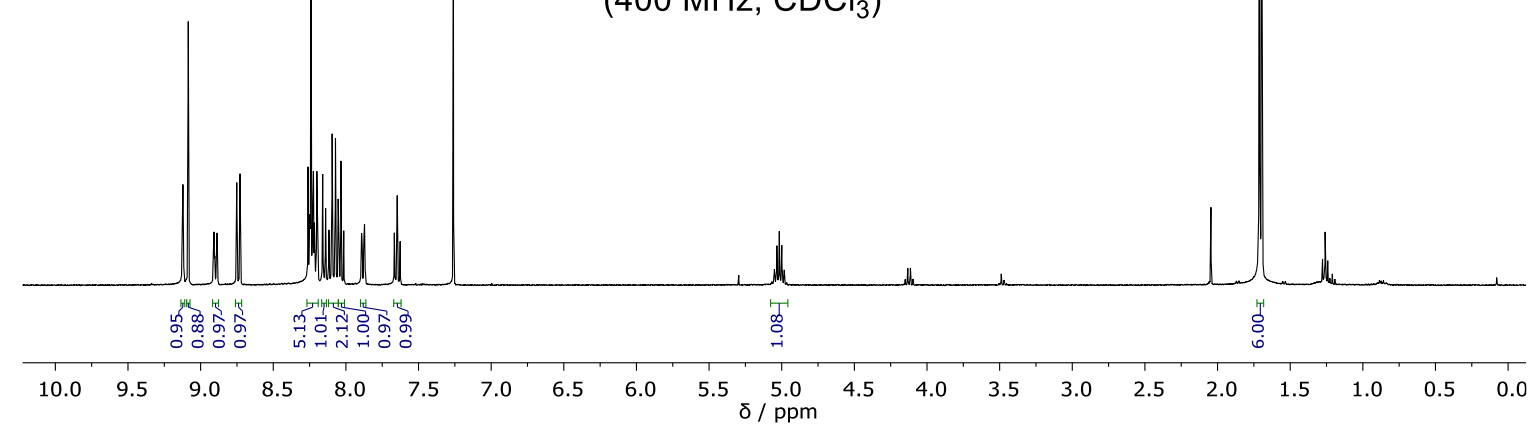




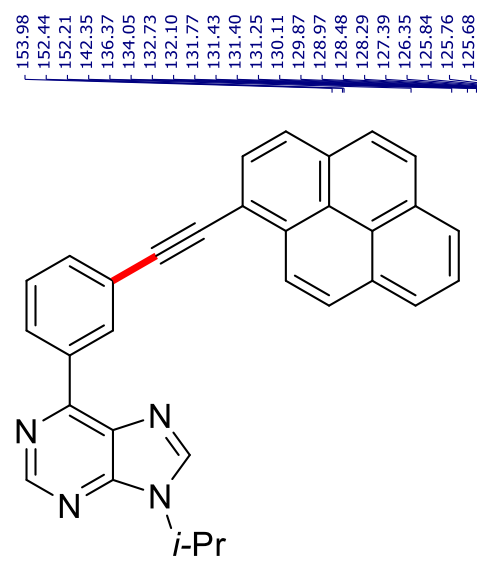

$150 b$

(100 MHz, $\mathrm{CDCl}_{3}$ )
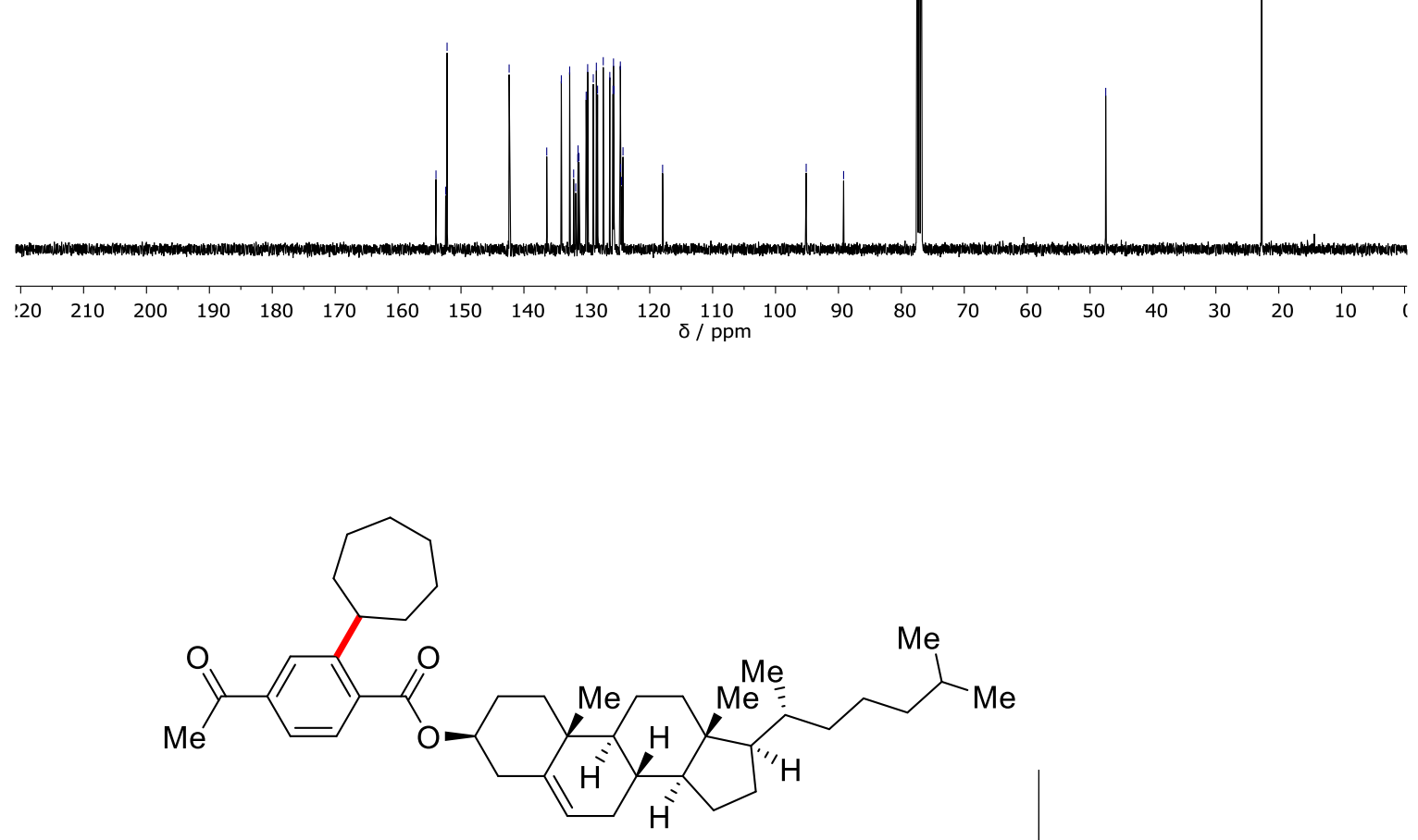

165aa

(400 MHz, $\mathrm{CDCl}_{3}$ )

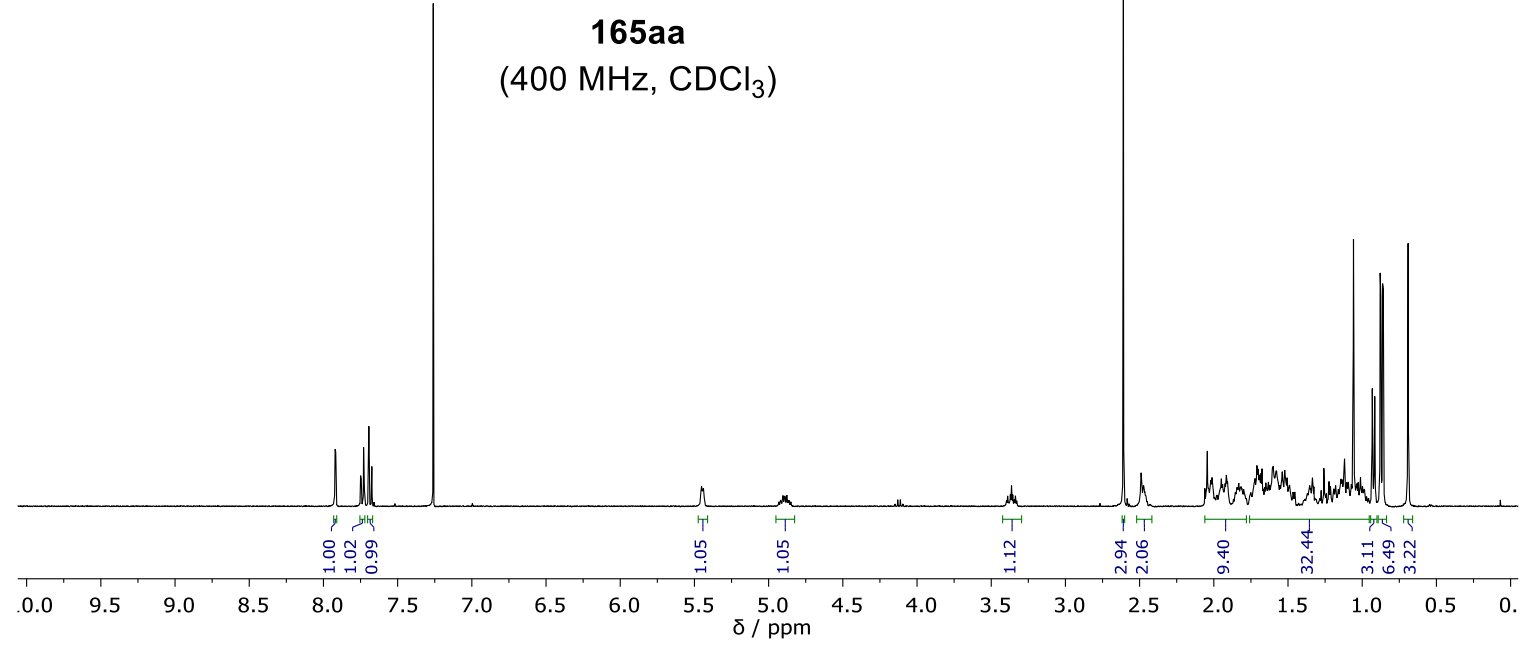



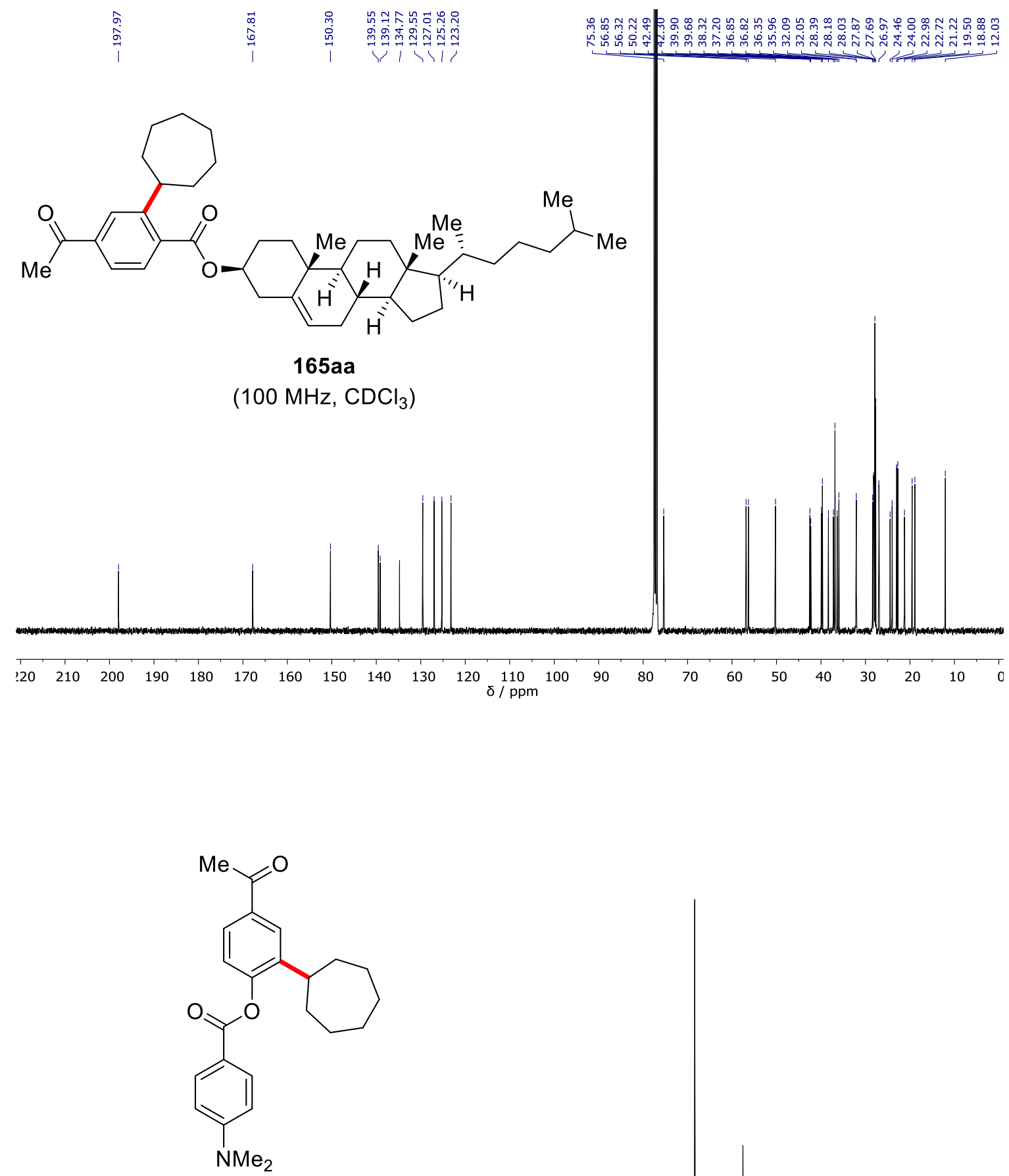

165ba

(300 MHz, $\mathrm{CDCl}_{3}$ )

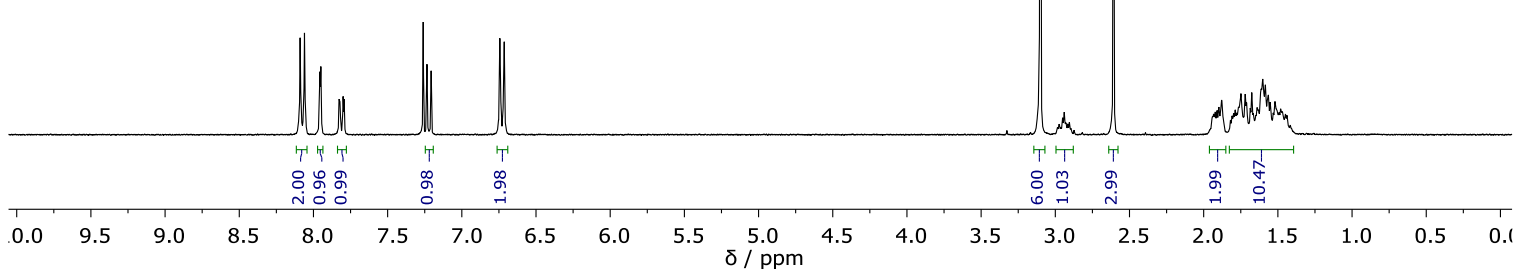




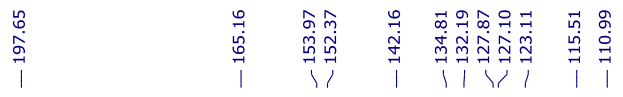

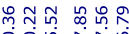

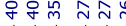<smiles>CC(=O)c1ccc(OC(=O)c2ccc([N+](=O)[O-])cc2)c(C2CCCCCC2)c1</smiles>

$165 \mathrm{ba}$

(125 MHz, $\mathrm{CDCl}_{3}$ )

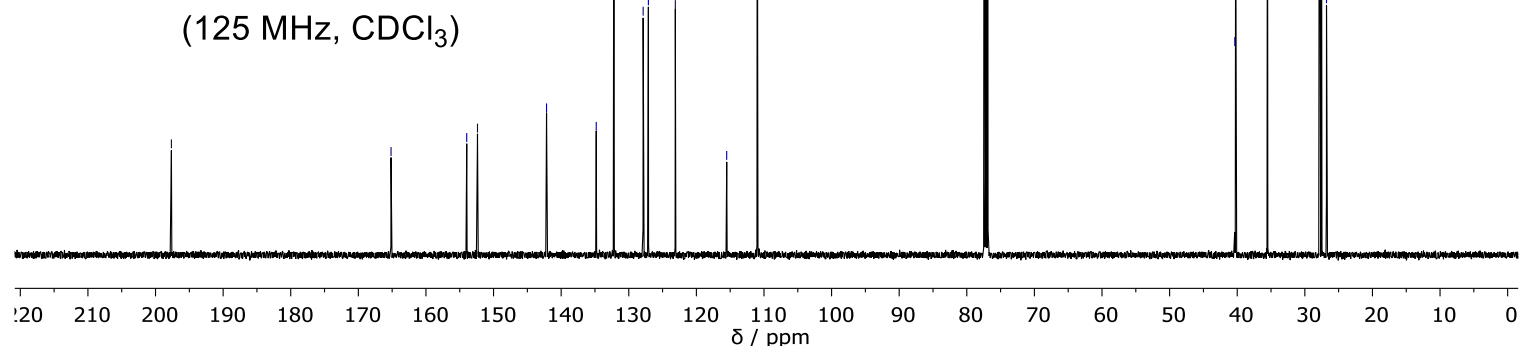<smiles>CC(=O)c1ccc(OC(=O)c2ccc(C)cc2)c(C(C)(C)C)c1</smiles>

$165 \mathrm{bb}$

(300 MHz, $\mathrm{CDCl}_{3}$ )

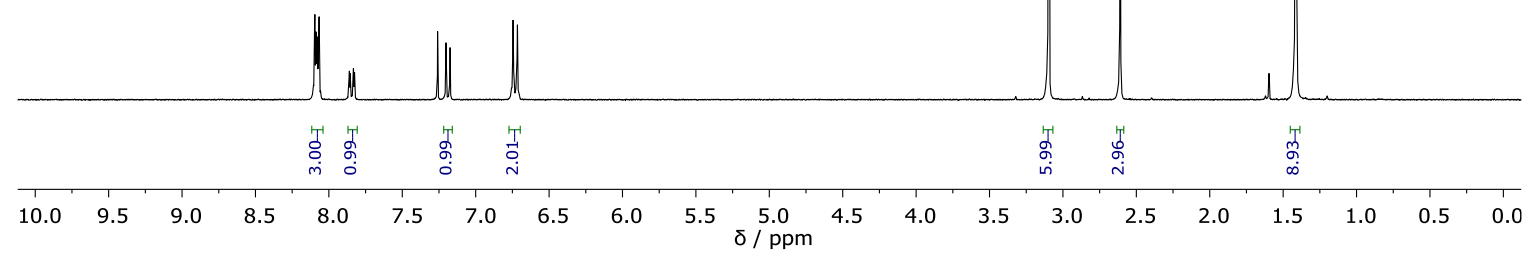




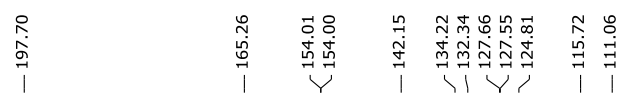

กิ๊

긱<smiles>CC(=O)c1ccc(OC(=O)c2ccc(N(C)C)cc2)c(C(C)(C)C)c1</smiles>

$165 \mathrm{bb}$

(125 MHz, $\mathrm{CDCl}_{3}$ )

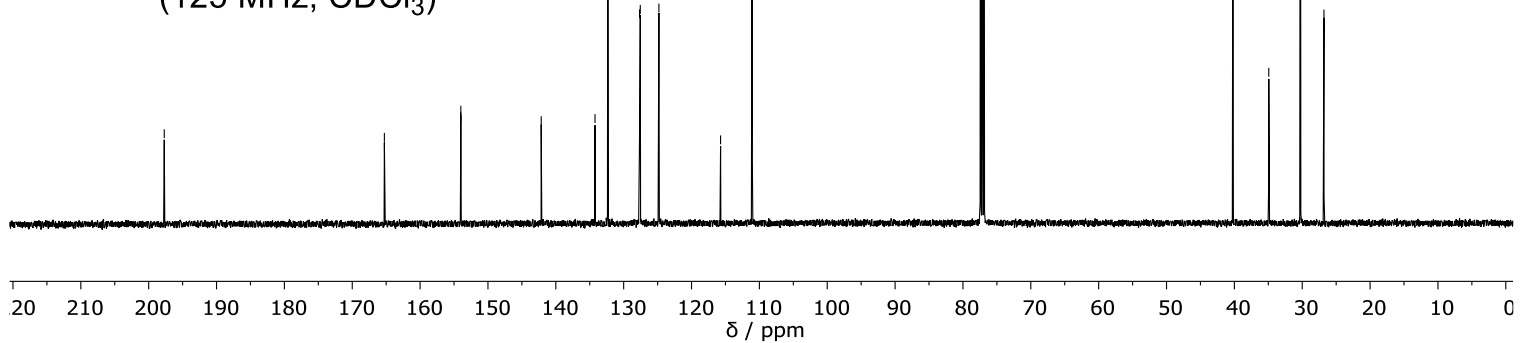<smiles>CC(=O)c1ccc(OC(=O)c2cccs2)c(C2CCCCCC2)c1</smiles>

$165 \mathrm{ca}$

(500 MHz, $\mathrm{CDCl}_{3}$ )

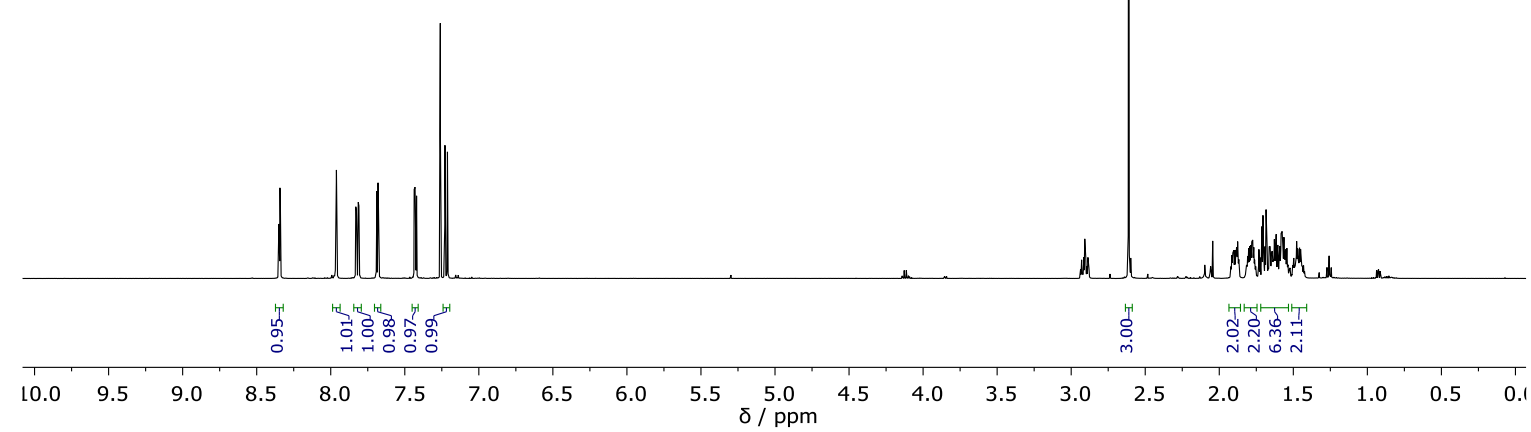



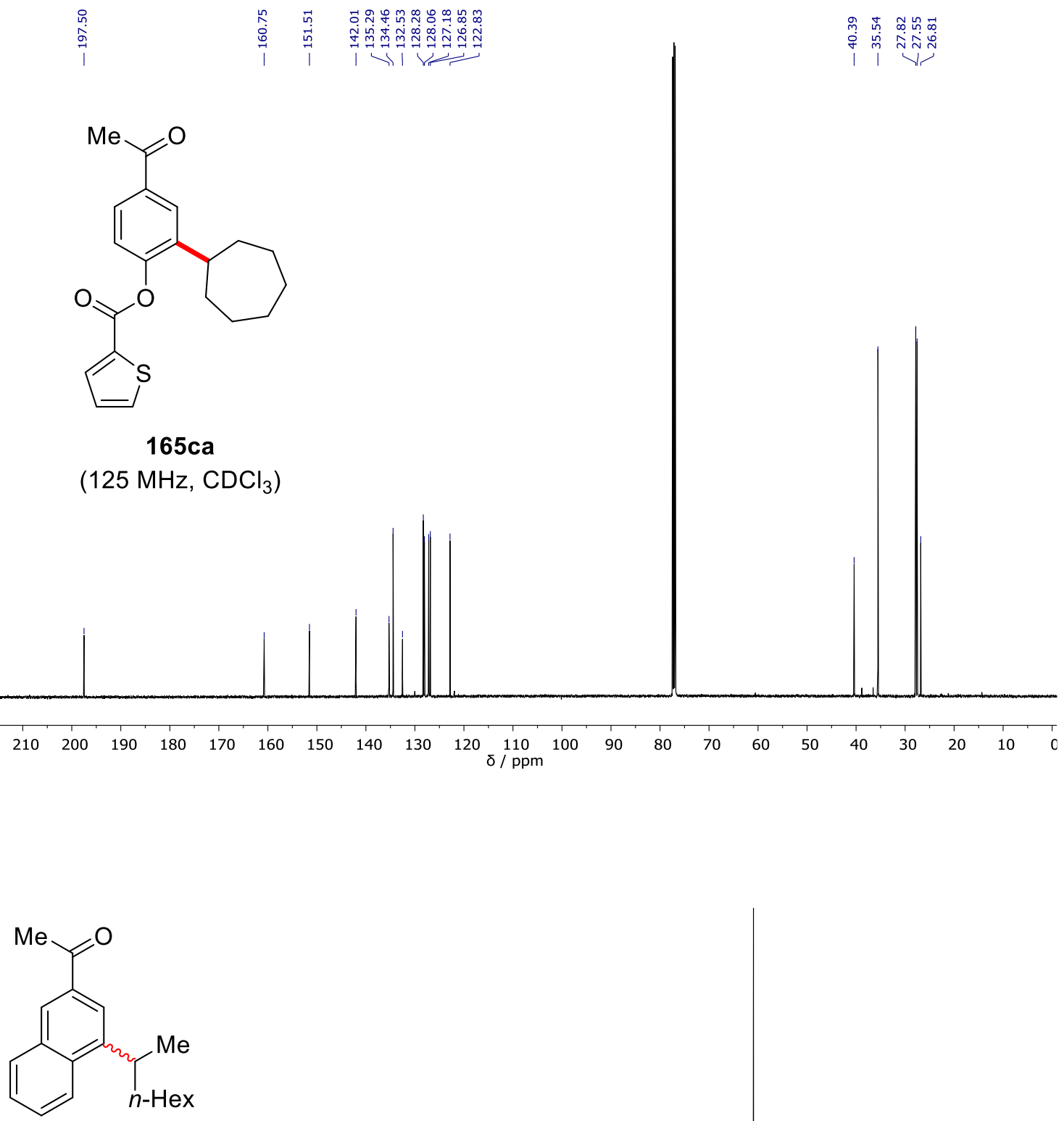

rac-165ed

$\left(500 \mathrm{MHz}, \mathrm{CDCl}_{3}\right)$

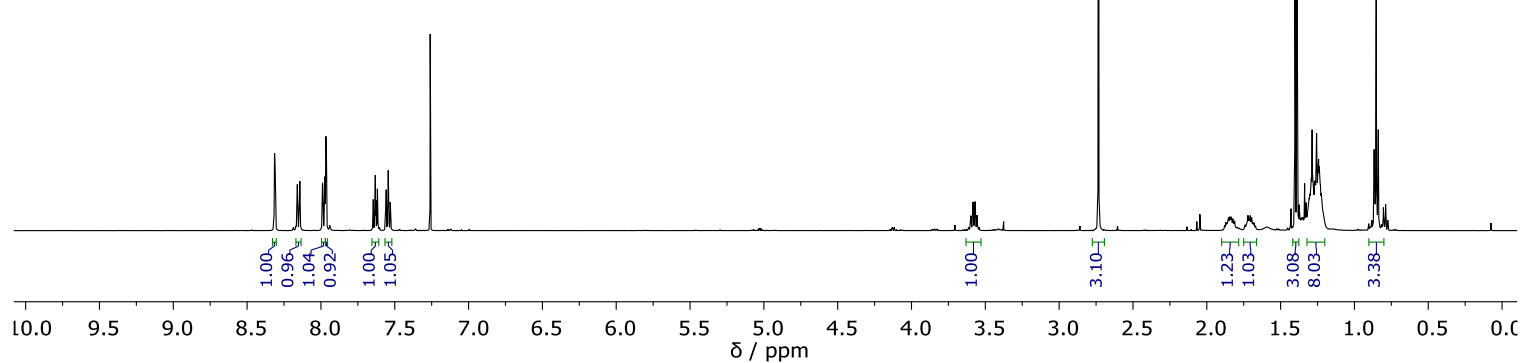




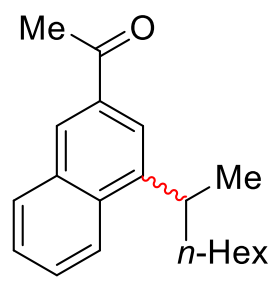

rac-165ed

(125 MHz, $\mathrm{CDCl}_{3}$ )

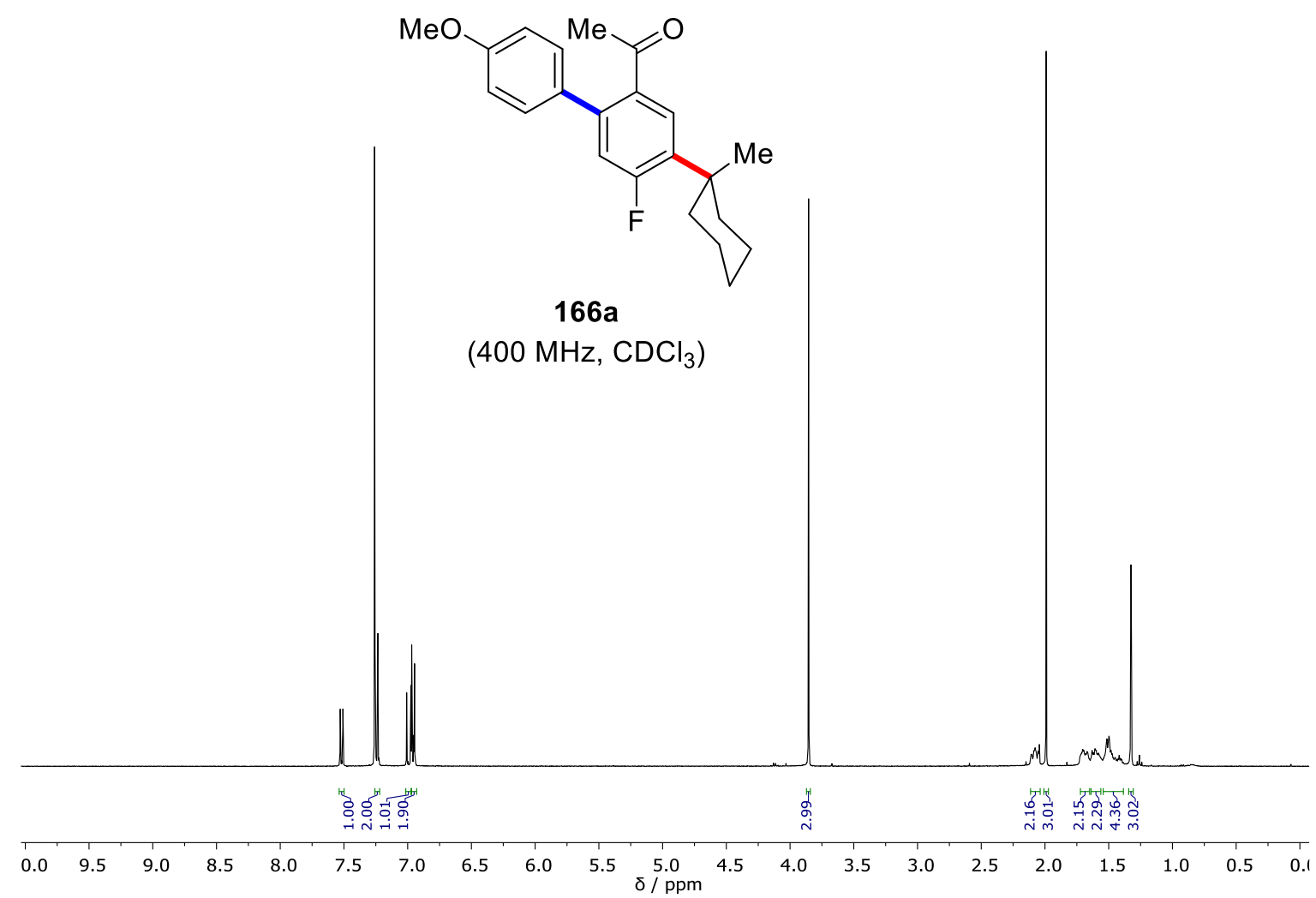



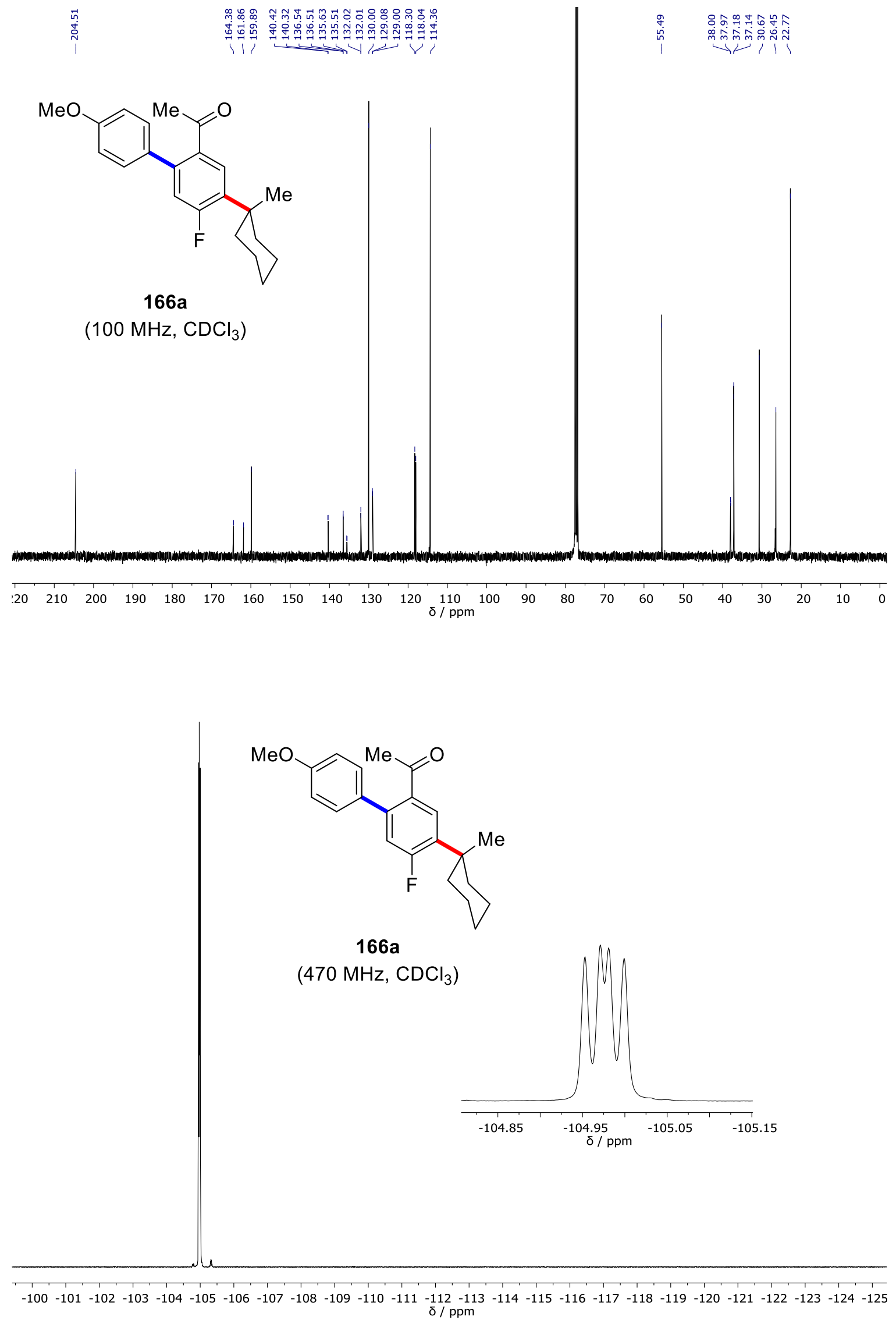


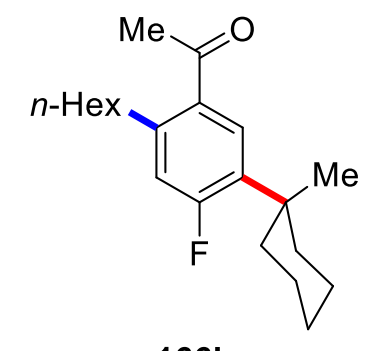

166b

(400 MHz, $\mathrm{CDCl}_{3}$ )

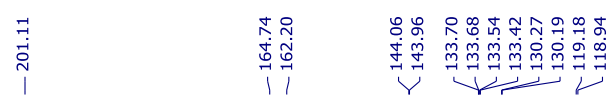

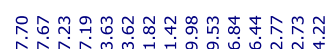

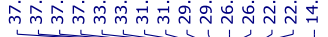<smiles>CCCCCCCCOc1cc(F)c(C2(C)CCCC2)cc1C(C)=O</smiles>

166b

$\left(100 \mathrm{MHz}, \mathrm{CDCl}_{3}\right.$ )

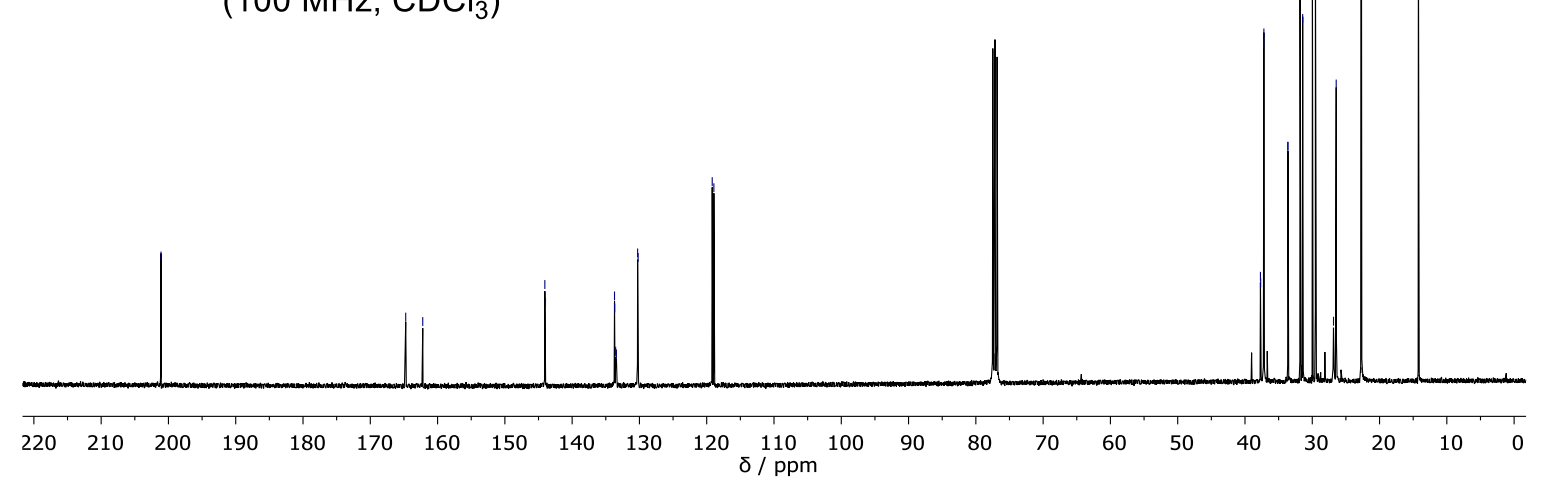




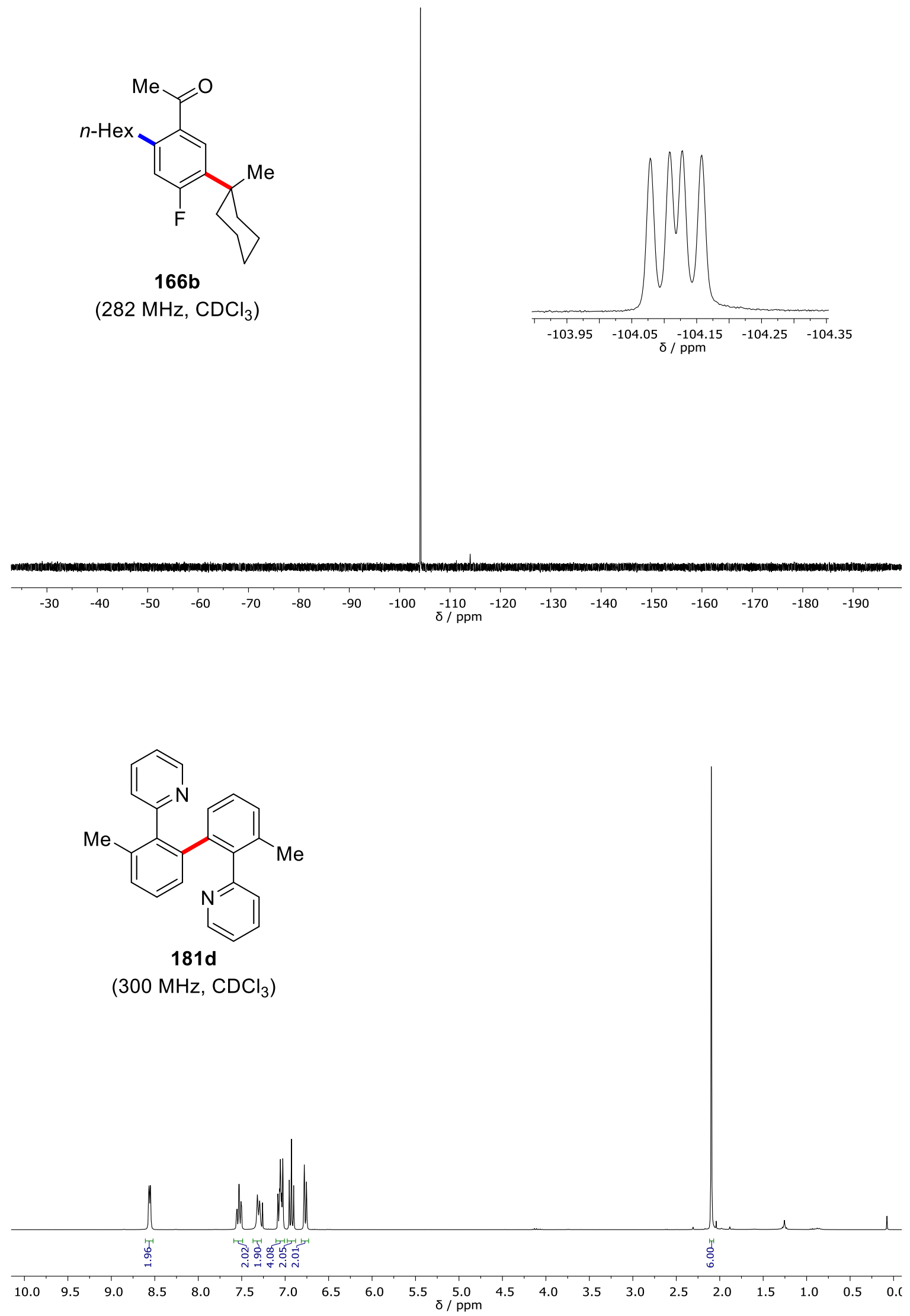




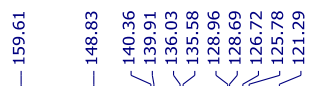<smiles>Cc1cccc(-c2cccc(C)c2-c2ccccn2)c1-c1ccccn1</smiles>

181d

(75 MHz, $\mathrm{CDCl}_{3}$ )

$\begin{array}{lllllll}20 & 210 & 200 & 190 & 180 & 170 & 160\end{array}$ $120 \begin{gathered}110 \\ \delta / \mathrm{ppm}\end{gathered}$
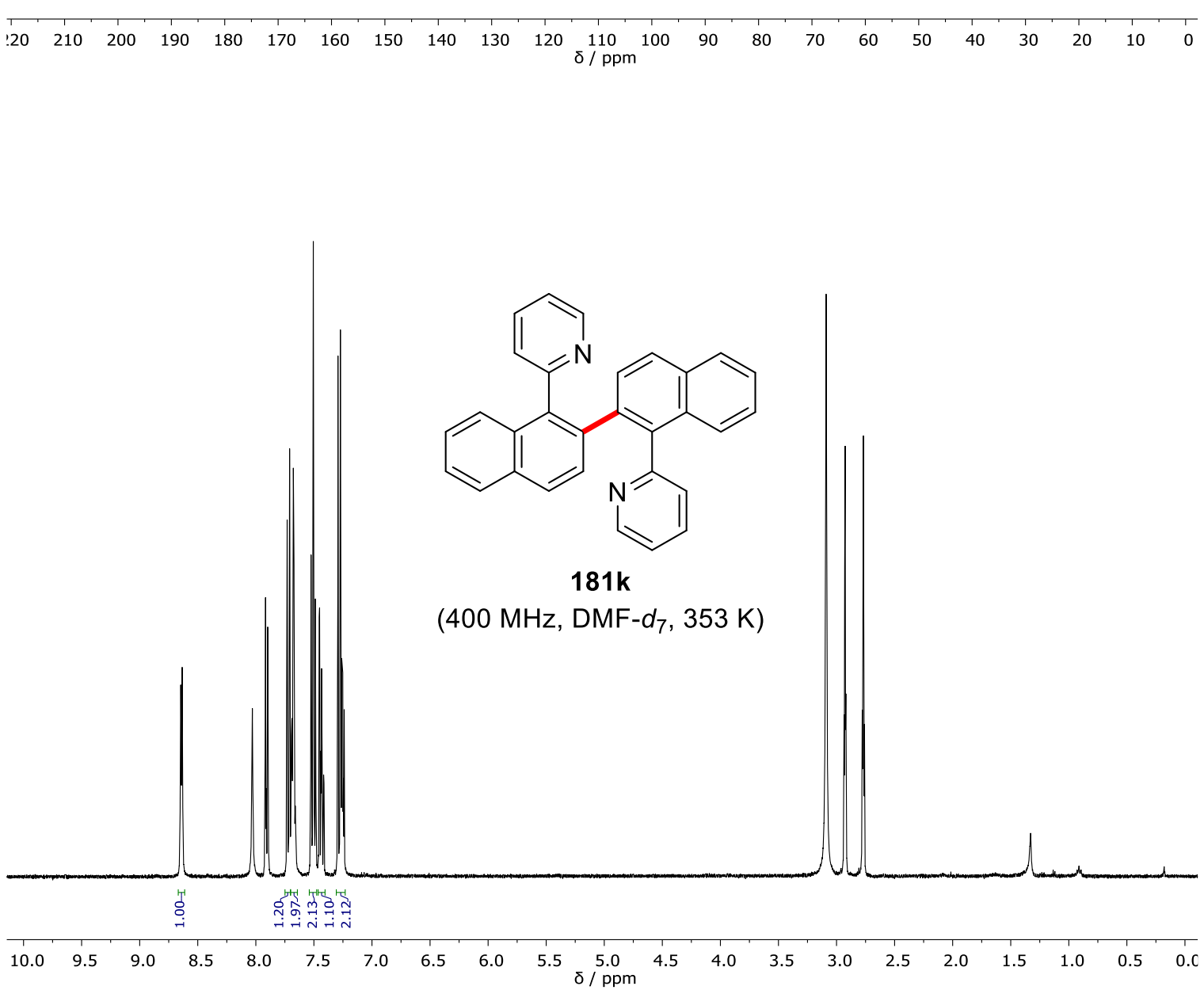


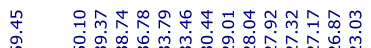

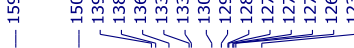
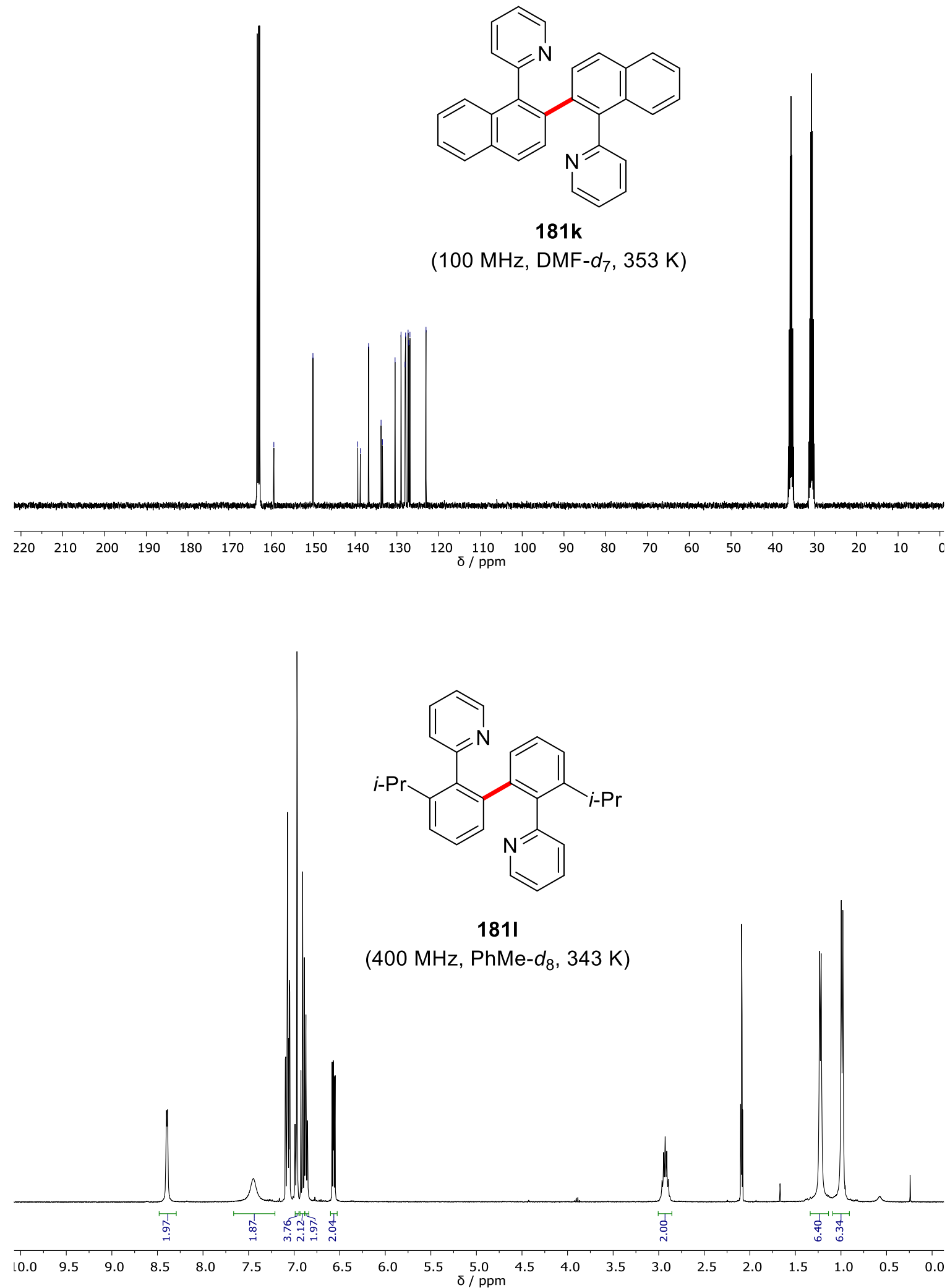
<smiles>CCCc1cccc(-c2cccc(C(C)C)c2-c2ccccn2)c1-c1ccccn1</smiles>

1811

(100 MHz, PhMe-d $8,343 \mathrm{~K}$ )
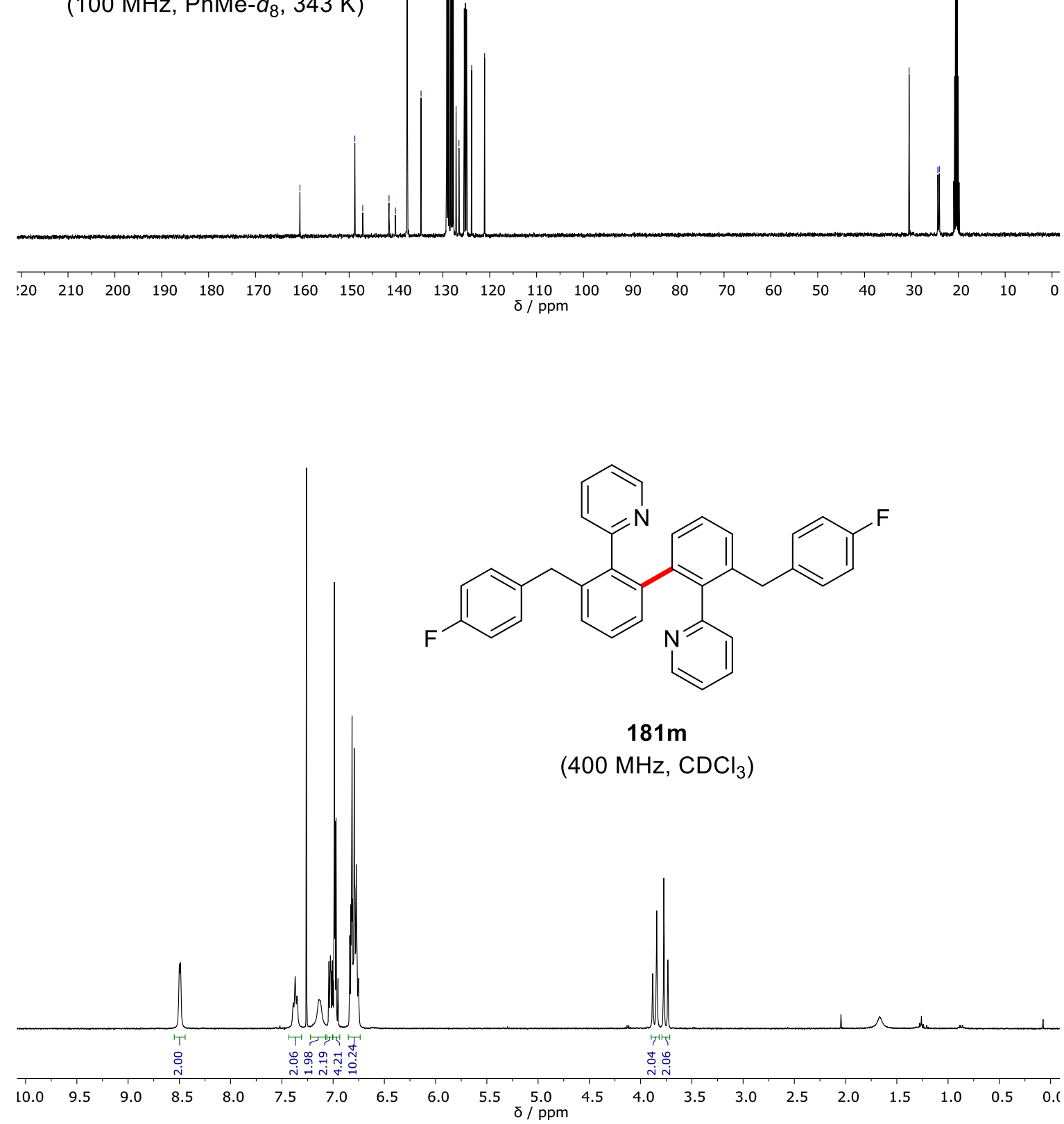


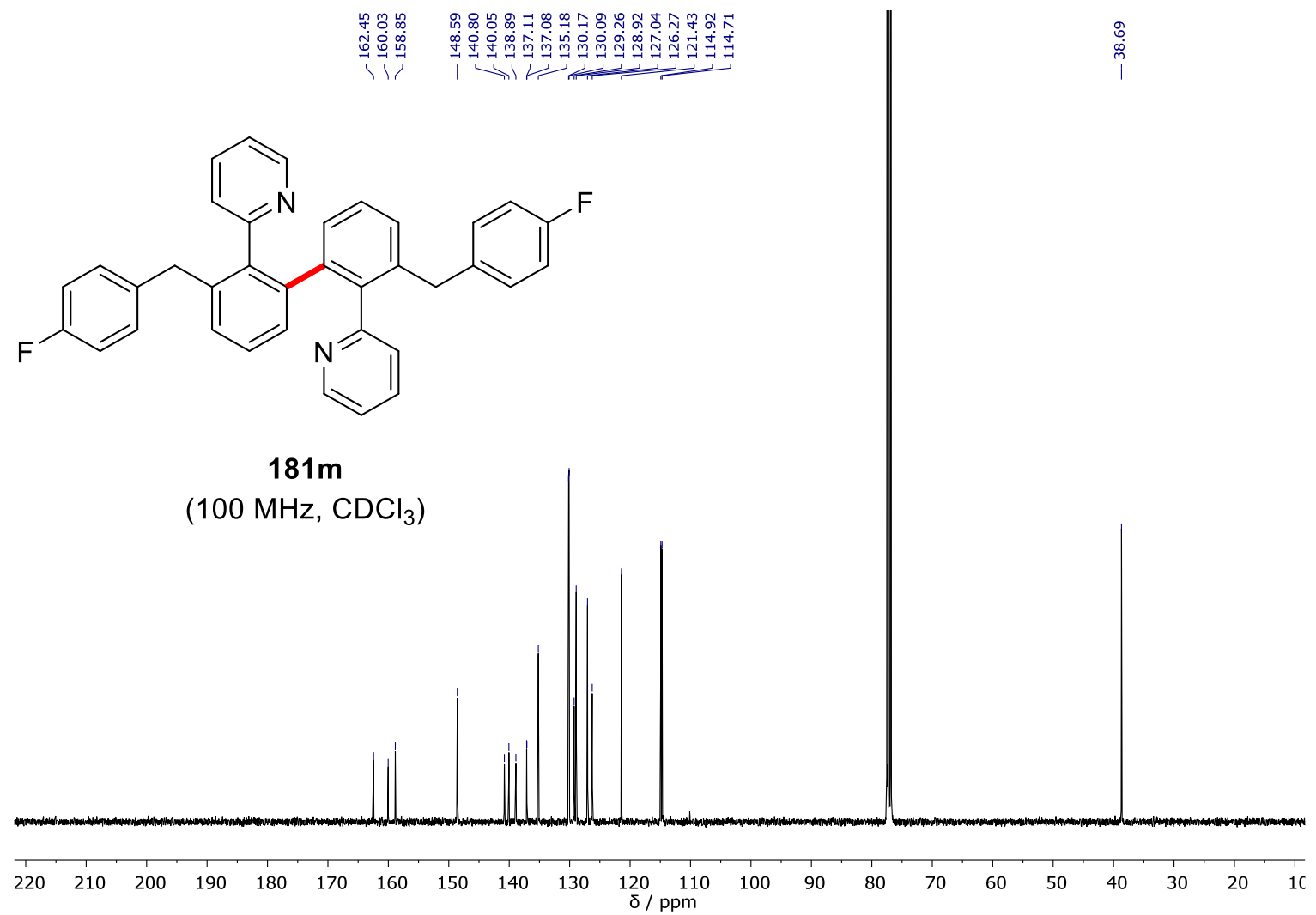<smiles>Fc1ccc(Cc2cccc(-c3cccc(Cc4ccc(F)cc4)c3-c3ccccn3)c2-c2ccccc2)cc1</smiles>

$181 \mathrm{~m}$

$\left(376 \mathrm{MHz}, \mathrm{CDCl}_{3}\right)$ 


\section{Curriculum Vitae}

\section{TORBEN ROGGE}

Date and place of birth: October 12, 1990 in Holzminden (Germany)

Nationality: German

\section{SCIENTIFIC EdUCATION}

11/2015 - present Dissertation under the supervision of Prof. Dr. Lutz Ackermann

Georg-August-Universität Göttingen (Germany)

Thesis: "Experimental and Computational Studies on Ruthenium- and

Manganese-Catalyzed C-H and C-C Activation"

01/2017-03/2017 Research Stay in the group of Dr. Eric Clot

Institute Charles Gerhardt, Université de Montpellier (France)

COST Grant for "DFT Studies on Ruthenium(II)-catalyzed C-H

Functionalization"

September 16, 2015 Master of Science (Final grade: good, 1.7)

03/2015 - 09/2015 Master Thesis under the supervision of Prof. Dr. Lutz Ackermann Georg-August-Universität Göttingen (Germany)

Thesis: "Secondary Phosphine Oxide Preligands in Ruthenium-Catalyzed

C-H Bond Functionalization" (excellent, 1.3)

July 01, $2013 \quad$ Bachelor of Science (Final grade: good, 1.9)

04/2013 - 07/2013 Bachelor Thesis under the supervision of Prof. Dr. Lutz Ackermann Georg-August-Universität Göttingen (Germany) Thesis: "Ruthenium-Catalyzed C-H Bond Functionalizations" (excellent, 1.3)

10/2010 - 09/2015 Chemistry Studies

Georg-August-Universität Göttingen (Germany) 


\section{SCHOOL EDUCATION}

2001-2010 Paul-Gerhardt Schule Dassel (Germany), Abitur Grade: 1.8

A-Levels: Chemistry, Mathematics, Physics

1997-2001 Grundschule Stadtoldendorf (Germany)

\section{TEACHING EXPERIENCE}

07/2019-08/2019 Assistant for the practical course "Chemistry for Medicine Students"

10/2018-03/2019 Assistant for the practical course "Methods of Modern Organic

Chemistry"

04/2018-09/2018 Assistant for the practical course "Organic Chemistry: Basic practical course"

10/2017-03/2018 Assistant for the practical course "Methods of Modern Organic Chemistry"

10/2017-03/2018 Assistant within the FoLL Program (Research-Oriented Teaching and Learning)

04/2017 - 09/2017 Assistant for the practical course "Organic Chemistry: Basic practical course"

10/2016-03/2017 Assistant within the FoLL Program (Research-Oriented Teaching and Learning)

10/2016 - 03/2017 Teaching assistant for the course "Heterocyclic Chemistry"

10/2016-03/2017 Assistant for the practical course "Advanced Organic Synthesis"

04/2016 - 09/2016 Assistant for the practical course "Organic Chemistry: Basic practical course"

10/2014-03/2015 Teaching assistant for the course "Structure Elucidation Methods in Chemistry l" 
10/2013 - 03/2014 Teaching assistant for the course "Structure Elucidation Methods in Chemistry l"

\section{MEMBERSHIPS}

Since 2016

Gesellschaft Deutscher Chemiker (GDCh, German Chemical Society)

\section{Publications}

17) T. Rogge, L. Ackermann, "Arene-Free Ruthenium(II/IV)-Catalyzed Bifurcated Arylation for Oxidative C-H/C-H Functionalizations" Angew. Chem. Int. Ed. 2019, 58, 15640-15645.

16) A. Schischko, N. Kaplaneris, T. Rogge, G. Sirvinskaite, J. Son, L. Ackermann, "Late-stage peptide $\mathrm{C}-\mathrm{H}$ alkylation for biorthogonal $\mathrm{C}-\mathrm{H}$ activation featuring solid phase peptide synthesis" Nat. Commun. 2019, 10, 3553.

15) S. R. Yetra, T. Rogge, S. Warratz, J. Struwe, W. Peng, P. Vana, L. Ackermann, "Micellar Catalysis for Ruthenium(II)-Catalyzed $\mathrm{C}-\mathrm{H}$ Arylation: Weak-Coordination-Enabled $\mathrm{C}-\mathrm{H}$ Activation in H2O" Angew. Chem. Int. Ed. 2019, 58, 7490-7494.

14) N. Kaplaneris, T. Rogge, R. Yin, H. Wang, G. Sirvinskaite, L. Ackermann, "Late-Stage Diversification by Manganese-Catalyzed C-H Activation: Access to Acyclic, Hybrid and Stapled Peptides" Angew. Chem. Int. Ed. 2019, 58, 3476-3480.

13) H. Wang, I. Choi, T. Rogge, N. Kaplaneris, L. Ackermann, "Versatile and Robust C-C Activation by Chelation-Assisted Manganese-Catalysis" Nat. Catal. 2018, 1, 993-1001.

12) G. G. Dias, T. Rogge, R. Kuniyil, C. Jacob, R. F. S. Menna-Barreto, E. N. da Silva Júnior, L. Ackermann, "Ruthenium-catalyzed $\mathrm{C}-\mathrm{H}$ oxygenation of quinones by weak O-coordination for potent trypanocidal agents" Chem. Commun. 2018, 54, 12840-12843.

11) Y.-F. Liang,' L. Yang,' $\underline{T}$. Rogge,' L. Ackermann, 'Ruthenium(IV) Intermediates in $\mathrm{C}-\mathrm{H}$ Activation/Annulation by Weak O-Coordination" Chem. Eur. J. 2018, 24, 16548-16552. 'equal contribution

10) Y. Fang, T. Rogge, L. Ackermann, S.-Y. Wang, S.-J. Yi, "Nickel-catalyzed reductive thiolation and selenylation of unactivated alkyl bromides" Nat. Commun. 2018, 9, 2240.

9) Y. Qiu, W.-J. Kong, J. Struwe, N. Sauermann, T. Rogge, A. Scheremetjew, L. Ackermann, "Electrooxidative Rhodium-Catalyzed $\mathrm{C}-\mathrm{H} / \mathrm{C}-\mathrm{H}$ Activation: Electricity as Oxidant for CrossDehydrogenative Alkenylation" Angew. Chem. Int. Ed. 2018, 57, 5828-5832.

8) Y. Qiu, C. Tian, L. Massignan, T. Rogge, L. Ackermann, "Electrooxidative RutheniumCatalyzed C-H/O-H Annulation by Weak O-Coordination" Angew. Chem. Int. Ed. 2018, 57, 5818-5822. 
7) F. Fumagalli, S. Warratz, S.-K. Zhang, T. Rogge, C. Zhu, A. C. Stückl, L. Ackermann, "AreneLigand-free Ruthenium(II/III) Manifold for meta-C-H Alkylation: Remote Purine Diversification" Chem. Eur. J. 2018, 24, 3984-3988.

6) K. Korvorapun, N. Kaplaneris, T. Rogge, S. Warratz, A. C. Stückl, L. Ackermann, "Sequential meta-/ortho-C-H Functionalizations by One-Pot Ruthenium(II/III) Catalysis" ACS Catal. 2018, 8, 886-892.

5) W. Ma, Z. Weng, T. Rogge, L. Gu, J. Lin, A. Peng, X. Luo, X. Gou, L. Ackermann, "Ruthenium(II)Catalyzed C-H Chalcogenation of Anilides" Adv. Synth. Catal. 2018, 360, 704-710.

4) Q. Bu,' T. Rogge,' V. Kotek, L. Ackermann, "Distal Weak Coordination of Acetamides in Ruthenium(II)-catalyzed C-H Activation Processes" Angew. Chem. Int. Ed. 2018, 57, 765768. 'equal contribution

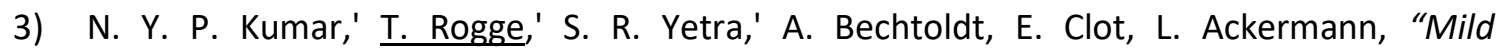
Decarboxylative C-H Alkylation: Computational Insights for Solvent-Robust Ruthenium(II) Domino Manifold" Chem. Eur. J. 2017, 23, 17449-17453. 'equal contribution

2) J. Li, K. Korvorapun, S. De Sarkar, T. Rogge, D. J. Burns, S. Warratz, L. Ackermann, "Ruthenium(II)-catalysed remote $\mathrm{C}-\mathrm{H}$ alkylations as a versatile platform to meta-decorated arenes" Nat. Commun. 2017, 8, 15430.

1) S. Warratz, D. J. Burns, C. Zhu, K. Korvorapun, T. Rogge, J. Scholz, C. Jooss, D. Gelman, L. Ackermann, "meta-C-H Bromination on Purine Bases by Heterogeneous Ruthenium Catalysis" Angew. Chem. Int. Ed. 2017, 56, 1557-1560.

\section{Oral Presentations}

3) T. Rogge, L. Ackermann, "Experimental and Computational Studies on Ruthenium-Catalyzed $\mathrm{C}-\mathrm{H}$ Activation", Control of London dispersion interactions in molecular chemistry, $4^{\text {th }}$ SPP1807 Summer School, Paderborn (Germany), July 16-19, 2019.

2) T. Rogge, L. Ackermann, "Ruthenium(II)-Catalyzed Alkenylations and Alkylations: Experiment and Computations", Control of London dispersion interactions in molecular chemistry, $3^{\text {rd }}$ SPP1807 Summer School, Hamburg (Germany), July 22-25, 2018.

1) T. Rogge, L. Ackermann, "Influence of Dispersion in Catalyzed C-H Bond Activation", Control of London dispersion interactions in molecular chemistry, $2^{\text {nd }}$ SPP1807 Summer School, Rostock (Germany), July 09-12, 2017.

\section{Poster Presentations}

5) T. Rogge, J. Loup, L. Ackermann, "Dispersion Interactions in Catalyzed C-H Activation", Control of London dispersion interactions in molecular chemistry, $3^{\text {rd }}$ SPP1807 Workshop, Erlangen (Germany), February 25-26, 2019. 
4) T. Rogge, N. Y. P. Kumar, S. R. Yetra, L. Ackermann, "Computational Studies on RutheniumCatalyzed C-H Activation", ORCHEM 2018, Berlin (Germany), September 10-12, 2018.

3) T. Rogge, J. Li, K. Korvorapun, S. De Sarkar, D. J. Burns, S. Warratz, L. Ackermann, "Ruthenium(II)-Catalyzed Remote meta-C-H Alkylations", GDCh Wissenschaftsforum 2017, Berlin (Germany), September 10-14, 2017.

2) T. Rogge, J. Li, K. Korvorapun, S. De Sarkar, D. J. Burns, S. Warratz, L. Ackermann, "Ruthenium(II)-Catalyzed Remote meta-C-H Alkylations", Jungchemikerforum 2017, Göttingen (Germany), June 22, 2017.

1) A. Bechtoldt, N. Y. P. Kumar, T. Rogge, K. Raghuvanshi, C. Kornhaaß, L. Ackermann, "Ruthenium(II)-Catalyzed C-H Functionalizations of Benzoic Acids", ORCHEM 2016, Weimar (Germany), September 05-07, 2016. 


\section{Erklärung}

Hiermit versichere ich, dass ich die vorliegende Dissertation im Zeitraum von November 2015 bis Oktober 2019 am Institut für Organische und Biomolekulare Chemie der Georg-August-

Universität Göttingen auf Anregung und unter Anleitung von

Herrn Prof. Dr. Lutz Ackermann

selbstständig durchgeführt und keine anderen als die angegeben Hilfsmittel und Quellen verwendet habe.

Göttingen, den 27.09.2019 